\title{
Regeln für den Schlagwortkatalog
}

RSWK

3., überarbeitete und erweiterte Auflage auf dem Stand der

5. Ergänzungslieferung April 2009

Stand: April 2009 
Grundwerk (1998), 1. Ergänzungslieferung (2000): Erarbeitet von der Expertengruppe RSWK des Deutschen Bibliotheksinstituts. Herausgegeben von der Konferenz für

Regelwerksfragen beim Deutschen Bibliotheksinstitut. Redaktionelle Bearbeitung: Dr. Hans-Jürgen Schubert (München).

2. Ergänzungslieferung (2002), 3. Ergänzungslieferung (2005), 4. Ergänzungslieferung (2007), 5. Ergänzungslieferung (2009): Erarbeitet von der Expertengruppe RSWK/SWD sowie der Expertengruppe Sacherschließung im Auftrag des

Standardisierungsausschusses.

Herausgegeben von der Arbeitsstelle für Standardisierung.

Redaktionelle Bearbeitung: Esther Scheven, Martin Kunz, Sigrid Bellgardt.

Deutsche Nationalbibliothek (Leipzig, Frankfurt am Main, Berlin) 2009

ISBN 978-3-941113-08-4

<urn:nbn:de:101-2009051809> 


\section{Elektronische Ausgabe der Regeln für den Schlagwortkatalog (RSWK)}

Die 1998 erschienene 3. Auflage der Regeln für den Schlagwortkatalog (RSWK) vollzieht noch wesentlich stärker als ihre Vorgänger die Orientierung an den Bedürfnissen der Online-Kataloge. Die Ergänzungslieferungen (2000, 2002, 2005, 2007, 2009), deren fünfte im Mai dieses Jahres erschienen ist, haben diesem Prinzip weiter Rechnung getragen und orientieren sich an dem Leitmotiv, die Regeln zu vereinfachen und sie so auch über den traditionellen bibliothekarischen Bereich hinaus nutzbar zu machen.

Eine besondere Rolle nimmt dabei die Schlagwortnormdatei (SWD) ein. Die über die Jahre erfolgten Änderungen der RSWK haben die SWD aus ihrer ursprünglichen Umgebung gelöst und sie zu einer Dokumentationssprache geformt, die als Universalthesaurus nun auch außerhalb der bibliothekarischen Welt genutzt wird.

Die Weiterentwicklung sowohl der RSWK als auch der SWD konnte nur dank der Unterstützung durch die Bibliotheksverbünde und der Mitwirkung zahlreicher Kolleginnen und Kollegen aus den Bibliotheken, Museen und Archiven des deutschsprachigen Raums verwirklicht werden.

In den vergangenen Jahren wurde von der bibliothekarischen Öffentlichkeit wiederholt der Wunsch nach einer elektronischen Ausgabe der RSWK vorgetragen. Die Deutsche Nationalbibliothek stellt diese nunmehr kostenfrei auf ihren Webseiten zur Verfügung. Die elektronische Ausgabe befindet sich auf dem Stand der 3. Auflage 1998 einschließlich der 5. Ergänzungslieferung 2009. Das Beispielregister wurde wie schon zur 3. Ergänzungslieferung unverändert gelassen; es entspricht somit dem Stand nach der 2.

Ergänzungslieferung. Damit ist die elektronische Ausgabe der RSWK in allen Teilen inhaltsgleich mit der aktuellen Printausgabe.

Mit der elektronischen Ausgabe verbinden wir die Erwartung einer einheitlichen Nutzung der RSWK und der SWD in einer heterogenen Informationslandschaft.

Frankfurt am Main, den 15. Mai 2009

Berndt Dugall

Vorsitzender des Standardisierungsausschusses 



\section{Vorwort}

Ein Plädoyer für Arbeitsteilung und Kooperation stand am Anfang des Vorworts der ersten Auflage der RSWK. Mittlerweile ist dies zu einer Selbstverständlichkeit geworden. Die RSWK haben sich weitgehend durchgesetzt, wo eine verbale Erschließung von den Bibliotheken angeboten wird. Dies gilt nicht nur für Deutschland, sondern auch für Österreich und seit kurzem für deutschsprachige Bibliotheken der Schweiz und Südtirols. Ein wesentlicher Faktor für diese Verbreitung war die Schaffung der Schlagwortnormdatei (SWD). Diese Rolle als Regelwerk für den gesamten deutschsprachigen Raum hat eine effektive Übernahme von Fremddaten möglich gemacht.

Trotzdem gab es mehrere Gründe, eine Neuauflage anzustreben, die alle Bestimmungen auf den Prüfstand stellen und eine durchgehende Revision erbringen sollte. Die Gesichtspunkte lassen sich insgesamt unter den Anforderungen des Online-Katalogs zusammenfassen. Technische Möglichkeiten haben in der Sacherschließung zentralen Einfluss auf das Erschließungsverfahren. Die RSWK waren daher in der ersten Auflage sehr stark vom damals vorherrschenden Listenkatalog geprägt. Die Entscheidung der Expertengruppe RSWK, dem Gesichtspunkt des Online-Katalogs den Vorrang zu geben und Bestimmungen für Listenkataloge nur noch als fakultative Bestimmungen aufzunehmen, hatte für das Regelwerk wesentliche Auswirkungen. Wesentlich ist insbesondere die klarere Abgrenzung von Schlagwort und Schlagwortkette. Die SWD, die in der Praxis von Anfang an großes Gewicht hatte, steht jetzt im Mittelpunkt des Regelwerks. Trotzdem hat die Schlagwortkette als deskriptives Element in der Aufbereitung von Retrievalergebnissen weiterhin Bedeutung. Postkoordinierende Suche steht nicht im Gegensatz zur Bildung von Schlagwortketten.

Unter dem Gesichtspunkt des Online-Kataloges ist auch die Annäherung an die RAK zu sehen, vor allem im Bereich der Personennamen. Die Ausrichtung beider Regelwerke aufeinander wirft jedoch auch Probleme auf, da der jeweilige Entwicklungsstand sehr unterschiedlich ist. So mussten z. B. Änderungen im Bereich der Körperschaften fast ganz zurückgestellt werden, da dieses Thema in RAK zur Zeit nicht entscheidungsreif ist.

Neben inhaltlichen Änderungen war mit der 3. Auflage auch eine durchgehend redaktionelle Überarbeitung notwendig. Dies betrifft zum einen die Übernahme von Bestimmungen mit Regelwerkscharakter aus den Praxisregeln, dem Datenformat, den Regelungen der SWD und der Beispielsammlung. Zum anderen sind, soweit irgend möglich, Ausnahmebestimmungen abgeschafft worden, um die Anwendung zu vereinfachen. Außerdem wurden sprachliche Vereinfachungen und eine bessere Präsentation des Regelwerks angestrebt.

Für die intensive Arbeit an der Neuauflage, die neben der täglichen Arbeit geleistet werden musste, ist zahlreichen Kolleginnen und Kollegen zu danken: den Mitgliedern der Expertengruppe RSWK, HansDieter Gebauer, Friedrich Geißelmann, Barbara Kelm, Ute Scharmann und Hans-Jürgen Schubert; hinzu kamen Vertreter aus den Verbundsystemen und DDB: Ingrid Ankenbrand, Walther Bossart, Christine Eichhorn, Christina Hengel-Dittrich, Ulrike Junger, Martin Kunz, Michael Mücke, Armin Müller-Dreier, Gisela Schmitt, Roswitha Schwan-Michels, Gerhard Stumpf, Annelore UntereggerVaerst, Sabine Wefers, Hans-Peter Wessel. Federführend an der Bearbeitung einzelner Teile des Regelwerks waren beteiligt: Herr Geißelmann, Frau Wiechmann, Frau Hengel-Dittrich, Herr Stumpf, Herr Schubert, Herr Mücke, Herr Gebauer, Frau Zoller-Philips, Frau Bernhard, Frau Heiner-Freiling 
und Frau Kelm. Die Überarbeitung des Sachregisters hatte Herr Nöther übernommen, das Beispielregister wurde von Herrn Stumpf zusammengestellt. Der Betreuer im DBI war Dieter Höchsmann, der Redakteur Hans-Jürgen Schubert. Die intensive Mitarbeit so vieler Kolleginnen und Kollegen zeigt die breite Akzeptanz und die Praxisnähe des Regelwerks.

Friedrich Geißelmann 


\section{Inhalt}

Abkürzungen

Einleitung

\section{Grundregeln}

Aufgabe der Regeln für den Schlagwortkatalog

1

Grundbegriffe

1

Zu erschließende Dokumente

Inhaltsanalyse

Erschließung mit Formschlagwörtern und Gattungsbegriffen

Grundprinzipien der Schlagwortkatalogisierung

Verhältnis von Schlagwort und Schlagwortkette

Formen des Schlagworts

Ansetzung des Schlagworts

Homonymenzusatz

Schlagwortkategorien, Indikatoren

Verweisungen

Schlagwortkette

Darstellung von Beziehungen in der Schlagwortkette

Reihenfolge in der Schlagwortkette, Permutationen

Rechtschreibung, Zeichenvorrat

Zahlen und sonstige Zeichen

Codierungen in Schlagwortsätzen

Bemerkungen in Schlagwortsätzen

Gestaltung der Schlagwort-Recherche im Online-Katalog

Personenschlagwörter

Definition und Verwendung

Definition

Verwendung

Ansetzung

Grundregeln 
Notnamen und Monogrammisten

Vornamen und Namensbestandteile, die in der Ordnungsgruppe der Vornamen angesetzt werden

Homonyme Personennamen

Familien und Geschwister

Personen des Altertums und des europäischen Mittelalters sowie biblische Personen, Fürsten und geistliche Würdenträger

Moderne Personennamen aus Sprachen mit griechischer und kyrillischer Schrift

Personennamen aus Sprachen mit sonstigen nichtlateinischen Schriften

Literarische und mythologische Gestalten

Personennamen als Bestandteil präkombinierter Schlagwörter

Datensatz für Personenschlagwörter

Verknüpfung und Permutation

Das Personenschlagwort in der Grundkette

Verknüpfung mehrerer Personenschlagwörter

Verknüpfung eines Personenschlagworts mit Schlagwörtern anderer Kategorien

Permutation

$\begin{array}{lr}\text { Paragraph } & \text { Seite } \\ 104 & 5 \\ 105 & 54 \\ 106 & 55 \\ 107 & 56 \\ & \\ 108 & 57 \\ 109 & 62 \\ & \\ 110 & 62 \\ 110 a & 64 \\ 111 & 64 \\ 111 a & 64 \\ & 66 \\ 115 & 66 \\ 115 a & 66 \\ 116 & 66 \\ 117 & 68\end{array}$

Geographische/ethnographische Schlagwörter

Geographische Schlagwörter

Definition und Verwendung

71

Definition

201

Verwendung

201a

73

75

Ansetzung

202

75

Geographische Namen mit Präfixen, einleitenden Bezeichnungen und präpositionalen Wendungen innerhalb des Namens

Erläuternde Bestandteile des Ortsnamens

$202 b$

80

Homonyme geographische Namen

203

82

Mit geomorphologischen Gattungsbezeichnungen gebildete Namen

204

90

Die Umgebung geographischer Einheiten

204a

92

Namen von Teileinheiten

205

92

Historische Geographika

206

94

Namensänderungen

Namen von Ortsteilen 
Namen von naturräumlichen Einheiten, von bio-, paläobio- und paläogeographischen Regionen sowie von räumlich begrenzten geologischen bzw. stofflich-räumlichen stratigraphischen Einheiten

Namen von Wegen, Grenzen, Linien

Namen von Ländergruppen

Ethnographische Schlagwörter

Definition und Verwendung

Definition

Verwendung

Ansetzung

Geographische/ethnographische Namen als Bestandteil präkombinierter Schlagwörter

SWD-Datensatz

Verknüpfung und Permutation

Das geographische/ethnographische Schlagwort in der Grundkette

Verknüpfung eines geographischen/ethnographischen Schlagworts

\section{Sachschlagwörter}

Definition und Verwendung

Definition

Ansetzung

Rechtschreibung

Singular oder Plural

Weibliche Form des Sachschlagworts

Wiedergabe von Allgemeinbegriffen durch Sachschlagwörter

Lexikalische Form

Homonyme

Individualnamen

Deutsche oder fremdsprachige Bezeichnung 


$\begin{array}{lcr} & \text { Paragraph } & \text { Seite } \\ \text { Formeln, naturwissenschaftliche und technische Zeichen und Symbole } & 314 & 143 \\ \text { Quasisynonyme } & 315 & 145 \\ \text { Verwandte Begriffe: Allgemeines } & 316 & 147 \\ \text { Verwandte Begriffe: Gleicher Sachverhalt - verschiedene } & & \\ \text { Begriffskategorien } & 317 & 148 \\ \text { SWD-Datensatz } & 318 & 150 \\ \text { Verknüpfung und Permutation } & & 151 \\ \text { Das Sachschlagwort in der Grundkette } & 321 & 151 \\ \text { Verküpfung mehrerer Sachschlagwörter } & 322 & 151 \\ \text { Pleonasmus in der Schlagwortkette } & 324 & 153 \\ \text { Permutation } & 325 & 155\end{array}$

Zeitschlagwörter und andere Zeitaspekte

Zeitschlagwörter

Definition und Verwendung 157

$\begin{array}{lll}\text { Definition } & 401 & 157\end{array}$

$\begin{array}{lll}\text { Verwendung } & 401 \mathrm{a} & 157\end{array}$

Ansetzung 159

$\begin{array}{lll}\text { Grundregeln } & 402 & 159\end{array}$

Zeitangaben $\quad 403 \quad 159$

'Geschichte', 'Prognose’ und Komposita mit '-geschichte’ als

Sachschlagwort $\quad 405 \quad 161$

SWD-Datensatz $\quad$ 405a 161

Verknüpfung und Permutation 162

Verknüpfung und Permutation $\quad 406 \quad 162$

Epochenbezeichnungen $\quad 163$

Definition und Verwendung 163

$\begin{array}{llll}\text { Definition } & 408 & 463\end{array}$

$\begin{array}{lll}\text { Verwendung } & 408 \mathrm{a} & 163\end{array}$

Ansetzung 166

$\begin{array}{lll}\text { Ansetzung } & 409 & 166\end{array}$

Verknüpfung und Permutation 167

$\begin{array}{lll}\text { Verknüpfung und Permutation } & 410 & 167\end{array}$

Historische Einzelereignisse 168

$\begin{array}{lll}\text { Definition } & 415 & 168\end{array}$

$\begin{array}{lll}\text { Ansetzung } & 415 \mathrm{a} & 169\end{array}$

$\begin{array}{lll}\text { Verknüpfung und Permutation } & 416 & 170\end{array}$ 


\section{Formschlagwörter}

Definition

Ansetzung

Zeitangaben

503

176

SWD-Datensatz

503a

177

Verknüpfung

504

178

Formschlagwort als erstes Schlagwort in der Schlagwortkette

505

179

Permutation

\section{Sonderregeln}

\section{Körperschaftsnamen}

Definition und Verwendung

Definition

601

181

Verwendung

$601 \mathrm{a}$

182

Ansetzung

Grundregeln

Deutsche oder fremdsprachige Form des Körperschaftsnamens

Körperschaften mit offiziellen Namen in mehreren Sprachen

Ortsbindung von Körperschaften

Nicht ortsgebundene Körperschaften

Veranstaltungen

Selbständige oder unselbständige Ansetzung bei Unterordnung unter eine Körperschaft

Selbständige oder unselbständige Ansetzung bei Unterordnung unter mehrere Körperschaften

Namensänderungen von Körperschaften

Homonyme Körperschaftsnamen

Gebietskörperschaften 
Regionale, lokale und personelle Einheiten einer Religions-

$\begin{array}{ll}\text { gemeinschaft } & 618\end{array}$

Organe einer Religionsgemeinschaft

$619 \quad 205$

Körperschaftsnamen als Bestandteil präkombinierter Schlagwörter

$620 \quad 206$

SWD-Datensatz

$620 \mathrm{a} \quad 207$

Verknüpfung und Permutation

208

Verknüpfung und Permutation

622

Weitere Sonderregeln

Sprache, Wörterbücher, Literatur

209

Sprache

209

Wörterbücher

701

213

Literatur

702

215

Sprachbezeichnung oder Geographikum bei Verknüpfung mit

Sachschlagwörtern

703

Motive

704

218

Verknüpfung von Sprachbezeichnungen

219

705

223

Werke

Definition

224

Grundregeln

224

Einheitssachtitel oder deutscher gebräuchlicher Titel

Homonymenzusatz

228

Teile von Werken und Werkgruppen

229

Werke des Altertums, des Mittelalters und der frühen Neuzeit

230

Die Bibel und Teile der Bibel

232

Psychologische Tests

233

Rechtsmaterien

233

Rechtsnormen (Gesetze u. ä.)

233

Verträge zwischen Staaten und Gliedstaaten

236

Verfassungen

237

Schriftdenkmäler

Schriftdenkmäler ohne Schriften rechtlichen, wirtschaftlichen u. ä. Inhalts

Schriften rechtlichen, wirtschaftlichen u. ä. Inhalts

Quellenausgaben von Schriftdenkmälern

Werke der bildenden Kunst und Bauwerke

Definition und Verwendung

Ansetzung der Künstlernamen, Aufbewahrungs- und Herkunftsorte 
Ansetzung der Werktitel

Paragraph

Nicht ortsgebundene Kunstwerke

Ansetzung von Werken der Wand- und Deckenmalerei, Mosaiken u. a.

beweglichen Ausstattungsgegenständen von Bauwerken

Kunsthandwerkliche Produkte von Firmen

Ortsgebundene Kunstwerke (ausgenommen Kirchenbauten)

Kirchenbauten

Filme, Hörfunk- und Fernsehsendungen

Dokumente zu einem Film, einer Hörfunk- oder Fernsehsendung

Dokumente zu mehreren Filmen, Hörfunk- oder Fernsehsendungen

Ausstellungen

Ausstellungen

Sammlungen

Sammlungen

Audiovisuelle Materialien

Audiovisuelle Materialien

Elektronische Publikationen

Elektronische Publikationen

Musikalische Werke

Grundregeln

Originalsachtitel

Konventionalsachtitel

Formalsachtitel

Zitiertitel

Komponist, Textdichter, Interpret

Einheitssachtitel für Teile musikalischer Werke

Musikdrucke, Musiktonträger und Musikvideos

\section{Schöne Literatur}

Aufnahmeprinzipien für den Schlagwortkatalog

Schlagwortformen und Schlagwortkategorien

Einzelne Schlagwortkategorien

Kinder- und Jugendliteratur

Aufnahmeprinzipien für den Schlagwortkatalog

Schlagwortformen und Schlagwortkategorien

Einzelne Schlagwortkategorien

Verwendung mehrerer Formschlagwörter in einer Schlagwortkette

Schul- und Berufsschulbücher

Aufnahmeprinzipien für den Schlagwortkatalog

Unterrichtsfächer, Schularten und Schulstufen

Geographische Aspekte bei Schul- und Berufsschulbüchern
725

727 
Formschlagwörter

Schulbücher und Materialien für die Berufsausbildung

Materialien zur Prüfungsvorbereitung

Übungslektüre und Lesebücher

Ordnungsregeln

Ordnung der Eintragungen bei Listenfunktionen

801

291

\section{Anlagen}

1. Ansetzung der geistlichen Reichsfürsten 1500-1803

2. Nicht aussagekräftige Sachschlagwörter nach Personenschlagwörtern und Sachschlagwörter, die in Verknüpfung mit Personennamen entfallen

3. entfällt

4. Bundesstaaten der USA und ihre Abkürzungen in Homonymenzusätzen

5. Sach- und Zeitschlagwörter, die nicht permutiert werden

6. Liste der Formschlagwörter

7. entfällt

8. entfällt

9. UDK-Zeitcode

10. Konkordanz zu den Gattungsbegriffen des VD 17 


\section{Abkürzungen}

\begin{tabular}{|c|c|}
\hline * & Bemerkungen zu Verweisungsformen \\
\hline$\neg$ & Nichtsortierzeichen \\
\hline $\mathrm{BF}$ & Benutzt für \\
\hline BS & Benutze Synonym \\
\hline c & Indikator für Körperschaften, deren Name mit einem Geographikum beginnt \\
\hline CF früher & Frühere Namensform \\
\hline CF später & Spätere Namensform \\
\hline $\mathrm{D}$ & Definition \\
\hline $\mathrm{f}$ & Indikator für Formschlagwort \\
\hline g & $\begin{array}{l}\text { Indikator für geographisches/ethnographisches Schlagwort, Sprachbezeich- } \\
\text { nung }\end{array}$ \\
\hline ggf. & gegebenenfalls \\
\hline GKD & $\begin{array}{l}\text { Gemeinsame Körperschaftsdatei; in Beispielsätzen; Verweisung von der An- } \\
\text { setzungsform der GKD }\end{array}$ \\
\hline $\mathrm{H}$ & Verwendungshinweis \\
\hline $\mathrm{HZ}$ & Homonymenzusatz \\
\hline i.d.R. & in der Regel \\
\hline $\mathrm{k}$ & Indikator für Körperschaften (soweit nicht c) \\
\hline LC & Ländercode \\
\hline MAB & Maschinelles Austauschformat für Bibliotheken \\
\hline MO & Mehrgliedriger Oberbegriff \\
\hline MU & Unterbegriff zu Mehrgliedrigem Oberbegriff \\
\hline OB & Oberbegriff \\
\hline ÖB & Alternativansetzung für öffentliche Bibliotheken \\
\hline $\mathrm{p}$ & Indikator für Personenschlagwort \\
\hline PND & Personennamendatei \\
\hline Pvw & Pauschalverweisung \\
\hline Q & Quelle \\
\hline $\mathrm{R}$ & Redaktionelle Bemerkung \\
\hline s & Indikator für Sachschlagwort \\
\hline SC & Sprachencode \\
\hline SW & Schlagwort \\
\hline
\end{tabular}


SWW

SWD

SYS

$\mathrm{t}$

UB

v.a.

VB

Vw

Z

ZC
Schlagwörter, Schlagwortkette

Schlagwortnormdatei

SWD-Notation

Indikator für Titel von Werken

Unterbegriff

vor allem

Verwandter Begriff

Verweisung

Indikator für Zeitschlagwort

Zeitcode 


\section{Einleitung}

\section{Allgemeines}

Seit dem Erscheinen der 2. Auflage im Oktober 1991 befasste sich eine Expertengruppe des DBI mit der Pflege und Weiterentwicklung der RSWK. Die Ergebnisse fanden u. a. ihren Niederschlag in den "RSWK-Mitteilungen" 3 - $10^{1}$ und den "Praxisregeln"2.

Nachdem die Expertengruppe Online-Kataloge in ihrem Abschlussbericht ${ }^{3}$ Vorgaben für eine Anpassung der RSWK an die Bedürfnisse von OPACs formuliert hatte, begann im April 1995 die Arbeit an der 3. Auflage. Dabei wurde die Expertengruppe RSWK von Vertretern der Bibliotheksverbünde tatkräftig unterstützt, die regelmäßig als Gäste an den Arbeitssitzungen teilnahmen.

Um Veränderungen in Zukunft leichter vornehmen zu können, die sich u. U. aus der geplanten Revision der RAK ergeben, erscheint die 3. Auflage in Loseblattform.

Text und Beispiele richten sich nach der reformierten Rechtschreibung (Stand: Mai 1998).

Nach über zehnjähriger Anwendung der RSWK in vielen Bibliotheken und dem Aufbau der SWD musste bei der Überarbeitung die Konsistenz der Kataloge und der Normdatei ein wichtiges Anliegen sein. Deshalb sollten Regelwerksänderungen nicht zu Lasten eines einheitlichen Retrievals gehen und sind nur dort vorgenommen worden, wo spürbare Verbesserungen für den Benutzer, besonders für das Online-Retrieval, zu erreichen waren.

Die Struktur und die grundlegenden Bestimmungen der Regeln, wie sie in der Einleitung zur 2. Auflage erläutert und begründet wurden 4 , bleiben erhalten. Das gilt auch, mit Ausnahme der Grundregeln, für die bisherige Paragrapheneinteilung, wobei zusätzliche Paragraphen (kenntlich an den Kleinbuchstaben) soweit erforderlich eingefügt und entbehrlich gewordene gestrichen sind. Bei den Anlagen entfallen Nr. 3 (Geographische Problemfälle) und 7 (Ansetzungsformen Biblischer Bücher), die in die SWD eingearbeitet sind, sowie Nr. 8 (Ansetzung von Körperschaften), die in den Text des Regelwerks integriert ist. Neu aufgenommen sind Nr. 9 (UDK-Zeitcode) und 10 (Konkordanz zu den Gattungsbegriffen des VD 17).

Um ein gezieltes Auffinden einzelner Sachverhalte zu erleichtern, erhält jeder Paragraph eine seinen Inhalt charakterisierende Überschrift. Die in den Vorauflagen eingeführte Dezimalgliederung entfällt, da sie als zusätzliches Ordnungselement nicht notwendig erscheint.

1 Nr. 3 in: Bibliotheksdienst 26 (1992) S. 1047-1053

Nr. 4-6 in: Bibliotheksdienst 27 (1993) H.12, Beilage

Nr. 7 in: Bibliotheksdienst 28 (1994) S. 1258-1261

Nr. 8 in: Bibliotheksdienst 29 (1995) H.1, Beilage, in Kraft gesetzt mit einer Änderung, Bibliotheksdienst 29 (1995) S. 1644

Nr. 9 in: Bibliotheksdienst 29 (1995) S. 1645-1647

Nr. 10 in: Bibliotheksdienst 31 (1997) S. 224-229, in Kraft gesetzt Bibliotheksdienst 31 (1997) S. 1096-1097

2 Praxisregeln zu den Regeln für den Schlagwortkatalog (RSWK) und der Schlagwortnormdatei (SWD). - 2. überarb. und erw. Aufl. - 1995 - Losebl.-Ausg.

3 Sacherschließung in Online-Katalogen. [Hrsg. von Friedrich Geißelmann]. - Berlin 1994

4 Regeln für den Schlagwortkatalog : RSWK. - 2., erw. Aufl. - Berlin 1991, S. XII - XXXII. Dort ist auch die ältere Literatur verzeichnet. Zu neueren Publikationen vgl. die Verzeichnisse bei den Tätigkeitsberichten der DBIKommission für Erschließung und Katalogmanagement. In: Bibliotheksdienst, 25 (1991) 747; 26 (1992) 731-732; 27 (1993) 749-750; 28 (1994) 706-707; 29 (1995) 708-709; 30 (1996) 884-885; 31 (1997) 887-889 
Die Hauptteile des Regelwerks gliedern sich eindeutiger als bisher in die Abschnitte Definition, Verwendung, Ansetzung mit Verweisungen und Verknüpfung mit Permutation, da diese Reihenfolge dem praktischen Vorgehen bei der Indexierung am besten entsprechen dürfte.

Sachverhalte, die an verschiedenen Stellen der RSWK stehen könnten, werden an der Stelle geregelt, an der sie inhaltlich am besten passen.

Eine Reihe wichtiger Neuerungen wird im Text begründet, um sie für den Anwender besser nachvollziehbar zu machen.

Um den Text zu entlasten, sind verstärkt typographisch abgesetzte Anmerkungen eingefügt.

Auch die 3. Auflage bemüht sich um eine verständliche und gestraffte Darstellung. Diese Reduktion und Vereinfachung der RSWK wirken sich auf den Umfang nicht aus, weil dafür Bestimmungen aus den "Praxisregeln" und für eine Reihe von Dokumenttypen hinzukommen, Präzisierungen nötig sind (vgl. etwa Anl. 6), mehr Beispiele erläuternd wirken sollen und ein Beispielregister neu enthalten ist (vgl. unten).

Terminologisch ist eine Reihe von Begriffen und Formulierungen, die in den Grundregeln erläutert werden, stärker den einschlägigen DIN-Normen (besonders DIN 1463) und der Praxis der SWD angeglichen.

Die Beispiele, deren Zahl vermehrt wurde, dienen der Charakterisierung und Veranschaulichung von Regelwerksaussagen, denen sie konsequenter als bisher zugeordnet sind. Dabei bezeichnet die einleitende Wendung "Titel” die Kurztitelaufnahme eines existierenden Dokuments, während "Inhalt" einen Sachverhalt ausdrückt, für den keine konkrete Publikation zu ermitteln war. Teilweise finden sich noch ergänzende Erläuterungen zum besseren Verständnis des Beispiels in kursiver Schrift. Beim einzelnen Schlagwort erscheinen die Indikatoren der SWD dort, wo die Kategorisierung thematisiert oder zum besseren Verständnis nötig ist.

Da Permutationen nur noch fakultativ sind, werden sie i. d. R. lediglich bei den Verknüpfungsregeln angegeben.

Die Bedeutung der Beispiele wird auch durch das erstmals beigegebene Beispielregister unterstrichen, das alle vorkommenden Schlagwörter mit Belegstellen verzeichnet.

\section{Neuerungen der 3. Auflage}

Mehrere Entwicklungen der letzten Jahre machten eine umfassende Revision der RSWK notwendig, ohne dabei die grundlegenden Bestimmungen anzutasten.

Nachdem Online-Kataloge in den Bibliotheken nunmehr allgemein verbreitet sind, stellen sich auch die RSWK auf die veränderten Anforderungen ein und beziehen sich jetzt primär auf den OPAC. Folgende Neuerungen tragen dem u.a. Rechnung:

- Zwar wird an der Schlagwortkette als der am besten geeigneten Form zur Wiedergabe eines spezifischen Dokumentinhalts festgehalten, doch ist der Pleonasmus in der Kette weitgehend abgeschafft (vgl. § 324), d. h. der Kontext der jeweiligen Kette soll die Wahl des Einzelbegriffs nicht beeinflussen. Dies fördert konsistente Ergebnisse beim punktuellen Sucheinstieg im Online-Katalog.

- Die Zahl der Sucheinstiege ist deutlich erhöht (vgl. z.B. §§ 3,3; 5,3-5; 5,7; 6,1; 13,1; 13,4).

- Für die Gestaltung des Schlagwortretrievals im OPAC liegen erstmals Vorschläge vor (vgl. § 20). 
- Die Abschnitte für die Verknüpfung und Permutation sind vereinfacht und verkürzt worden, der Schwerpunkt verschiebt sich noch deutlicher auf die Ansetzungsregeln (vgl. z. B. §§ 115ff; 217ff; 321ff.).

- Die Ordnungsregeln entfallen unter Hinweis auf entsprechende Bestimmungen bei den RAK (vgl. § 801).

Personen und Körperschaften sollten gerade in Online-Katalogen sowohl bei formaler als auch bei sachlicher Suche mit der gleichen Namensform recherchiert werden können. Soweit es das Prinzip der Deutschsprachigkeit erlaubte, werden deshalb weitere Angleichungen an die RAK vorgenommen bzw. die Nutzung der darauf aufbauenden Normdateien (PND, GKD) berücksichtigt.

- Römische Personen und altgriechische Autoren werden nun nach RAK angesetzt (vgl. § 108,4).

- Ebenso wird bei orientalischen Namen verfahren, sobald für die einzelnen Sprachen verbindliche Umschrifttabellen vorliegen (vgl. § 110).

- Die Personennamen der SWD werden als Teil der PND geführt (vgl. § 111a).

- Durch die Erfassung der GKD-Nummer im SWD-Datensatz wird eine datentechnische Verknüpfung beider Normdateien möglich (vgl. §§ 202,2; 602).

Da die SWD zum wichtigsten Instrument für die tägliche Indexierungsarbeit geworden ist, muss auch das Regelwerk einen engeren Bezug zu dieser Normdatei herstellen.

- Normierungen im Vokabular der SWD treten stärker als bisher neben das Prinzip der Gebräuchlichkeit (vgl. § 9,3), das gilt vor allem für die präkombinierten Bezeichnungen bzw. deren Zerlegung (vgl. §§ 8,5; 304).

- Die Indikatoren der SWD sollen verstärkt als Elemente der Selektion bei der Recherche genutzt werden.

- In den Hauptteilen der RSWK sind deshalb Mustersätze aus SWD bzw. PND beschrieben (vgl. $\S \S 7,4 ; 18 ; 19 ; 111 a ; 213 a ; 318 ; 405 a ;$ 503a; 620a).

Um das Regelwerk zu straffen und anwendungsfreundlicher zu machen, ist die Zahl der Ausnahmeregelungen deutlich reduziert worden (vgl. z.B. §§ 110a; 204,1; 210,3; 306; 408a,3,a; 616,1; $715,2 ; 715,10)$.

Seit ca. 1990 entstanden aus der praktischen Arbeit der für die SWD tätigen Redaktionen Ergänzungen, Präzisierungen und in wenigen Fällen auch Änderungen der RSWK, die als "Praxisregeln” verabschiedet und erstmals 1992, zuletzt 19955 publiziert wurden. Soweit diese Festlegungen allgemein interessieren, sind sie in die vorliegende Auflage eingearbeitet, die in anderen Fällen, insbesondere bei Listen, auf die ”Praxisregeln” Bezug nimmt, für die eine Neuausgabe vorgesehen ist.

Der Zunahme sachlicher Suchen in Online-Katalogen trägt die vorliegende Ausgabe auch dadurch Rechnung, als sie eine möglichst umfassende und konsistente Indexierung aller Bibliotheksmaterialien anstrebt.

- Die Beschlagwortung von AV-Materialien wird präzisiert (vgl. § 737).

- Neu sind die ausführlichen Bestimmungen für elektronische Publikationen auf Datenträgern oder Online (vgl. § 737a).

- Erstmals aufgenommen sind die Regeln zur Indexierung von schöner Literatur (vgl. §§ 760762), Kinder- und Jugendliteratur (vgl. §§ 763-766) sowie Schul- und Berufsschulbüchern (vgl. §§ 767-773).

5 vgl. Anm. 2 
- Auch das System der nichtverbalen Erschließungselemente wird erweitert. Neben den bereits erwähnten Schlagwortindikatoren (vgl. § 11,2), der Systematik (vgl. § 18,1) und dem Ländercode (vgl. § 18,2) sind ein Sprachencode (vgl. § 18,3) und ein Zeitcode (vgl. §§ 18,4; 418; Anl. 9) vorgesehen, um zusätzliche Suchmöglichkeiten zu eröffnen.

RSWK und SWD sind im Wesentlichen auf die überregionale kooperative Sacherschließung im deutschsprachigen Raum ausgerichtet. Die vorliegende Ausgabe geht aber verstärkt auch auf lokale, regionale und fächerspezifische Bedürfnisse ein, die meist als "lokale Anwendung” bezeichnet sind.

- So werden mit Blick auf die öffentlichen Bibliotheken die RAK-ÖB-Alternativen bei bestimmten Gruppen von Personennamen (vgl. §§ 108,4; 109; 110) und Werktiteln (vgl. §§ 709,3; 733,2; 740,2) beibehalten.

- Für schöne Literatur, Kinder- und Jugendliteratur, Musikdrucke, AV-Materialien und elektronische Publikationen ist eine Erschließung nach mehr formalen Kriterien (Entstehungsgebiet, Sprache, Gattung, Zeit) (vgl. § 5,3) oder mit Form- und Gattungsbegriffen (vgl. § 5,4 und 5) zugelassen.

- Für die Erschließung von Altbeständen sind Regelungen für die Indexierung älterer Literatur (vgl. §§ 4,5; 5,7; Anl. 10) aufgenommen.

- Bei mehrbändigen begrenzten Werken wird die Beschlagwortung des Einzelbandes zugelassen (vgl. § 3,3).

- Für die detaillierte Erschließung von Dokumenten zu Sammelschwerpunkten einer Bibliothek ist die Berücksichtigung zusätzlicher Einzelaspekte neben dem Gesamtinhalt vorgesehen (vgl. $\S 6,1)$.

- Bei unterschiedlichem Sprachgebrauch in den verschiedenen deutschsprachigen Staaten wird bei Fachausdrücken des Rechts, der Verwaltung und des Schulwesens die jeweils gebräuchliche Terminologie verwendet (vgl. § 311,2). 


\section{Übersicht über die wichtigeren Neuerungen der 3. Auflage}

Zur besseren Orientierung folgt hier eine Übersicht der wichtigsten Veränderungen geordnet nach den Paragraphen der 3. Auflage.

\section{Grundregeln}

Die Grundregeln sind völlig neu formuliert und gegliedert, da sie stärker als bisher die Kernbestimmungen der RSWK zusammenfassen, auf die in den anderen Abschnitten immer wieder Bezug genommen wird.

2 Die Grundbegriffe sind stärker am Gebrauch der SWD und einschlägiger DINNormen orientiert.

3,3 Bei mehrbändigen begrenzten Werken können Einzelbände mit klar abgegrenzten Themen zusätzlich erschlossen werden.

4,5 Bestimmungen für die Beschlagwortung älterer Literatur

5,3 Schöne Literatur, Kinder- und Jugendliteratur, Musik, Kunstwerke und AV-Materialien sowie elektronische Publikationen können zusätzlich durch Schlagwörter für Entstehungsgebiet, Sprache, Gattung, Zeit sowie Formschlagwort erschlossen werden.

5,4 u. 5 Schöne Literatur, Kinder- und Jugendliteratur und AV-Materialien können daneben auch mit Form- und Gattungsbegriffen indexiert werden.

5,7 Auch ältere Literatur kann mit Gattungsbegriffen indexiert werden, wenn eine inhaltliche Erschließung ( vgl. § 4,5) nicht möglich ist.

6,1 Um besondere Sammelschwerpunkte und Spezialbestände tiefer zu erschließen, können zusätzlich Teilaspekte eines Dokumenteninhalts berücksichtigt werden.

7,4 Beschreibung eines SWD-Datensatzes (vgl. auch §§ 18; 19)

7,5 Neben Schlagwörtern werden in die SWD auch Schlagwortketten in Form von Hinweissätzen aufgenommen.

8,5 Betonung der Zerlegungskontrolle bei der Ansetzung neuer Schlagwörter

9,3 Normierungen im Vokabular der SWD treten stärker als bisher neben das Prinzip der Gebräuchlichkeit.

11,2 Die Indikatoren der SWD als Element zur Selektion bei der Recherche und zur Steuerung der Permutation

12,4 Einführung des mehrgliedrigen Oberbegriffs als Sonderform der hierarchischen Verweisung

13,1 In bestimmten Fällen kann die Zahl der Glieder einer Schlagwortkette bis zu zehn betragen.

13,2 Sind mehrere Schlagwortreihenfolgen in der Grundkette gleich sinnvoll, so kann alphabetisch geordnet werden.

13,4 Je Dokument sollen nicht mehr als zehn Schlagwortketten gebildet werden.

15,1 Permutationen für Listenfunktionen sind fakultativ; jedes Schlagwort erhält dabei i. d. R. nur eine Eintragung. 
Zusätzlich zu den bisherigen Codierungen der Schlagwortsätze in der SWD (Notation, Ländercode in neuer Form) werden ein Sprachencode $(\S 18,3)$ und ein Zeitcode ( $\S \S 18,4 ; 418)$ eingeführt.

\section{Personenschlagwörter}

101 Personenschlagwörter werden jetzt originär in der PND gehalten als Datensätze mit einem besonderen Satzartkennzeichen, das ihre Nutzung in allen SWD-Datendiensten ermöglicht.

101a Zusammenfassung der Verwendungsbestimmungen

106 Die nach RAK vorgesehenen Namenszusätze werden für die PND von den nur nach RSWK zur Individualisierung erforderlichen Homonymenzusätzen unterschieden. Für die Praxis der Beschlagwortung hat dies keine Konsequenzen.

108,4 Römische Personen und altgriechische Autoren werden nach RAK angesetzt.

108,5 Als Personen des europäischen Mittelalters gelten solche mit Todesjahr 501-1500 (wie in RAK).

110 Personennamen aus Sprachen in arabischer, hebräischer, chinesischer und japanischer Schrift werden nach RAK angesetzt. Alle übrigen Personennamen in nichtlateinischen Schriften sollen nach RAK angesetzt werden, sobald dort dafür verbindliche Ansetzungsregeln vorliegen.

110a Namen literarischer und mythologischer Gestalten sind stets selbständig anzusetzen.

111a Datensatz für Personenschlagwörter

116,2,d Einzelne Abschnitte des Lebens oder Werkes einer Person werden durch Verknüpfung mit 'Geschichte' und Jahreszahlen ausgedrückt.

\section{Geographische/ethnographische Schlagwörter}

201a Zusammenfassung der Verwendungsbestimmungen

202,2 Datentechnische Verknüpfung mit der GKD durch Erfassen der GKD-Nummer für Gebietskörperschaften, ohne die Ansetzungsform anzugleichen

202,4 Die fremdsprachige Namensform von Geographika in Ostmitteleuropa, Ost- und Südosteuropa wird bei der Ansetzung stärker berücksichtigt.

202a,1 Artikel am Anfang geographischer Namen aus germanischen Sprachen werden nur in Ausnahmefällen zum Namen gezogen.

202b/203 Es wird unterschieden zwischen Ortsnamen mit erläuternden Bestandteilen und ‘echten' homonymen Ortsnamen. Bei fremdsprachigen Ortsnamen wird der erläuternde Zusatz als Wortfolge, nicht als Homonymenzusatz angesetzt.

203,3,a Bei der Vergabe von Homonymenzusätzen für Orte Australiens, Indiens, Japans und Kanadas wird nach RAK verfahren.

204,1 Die Ausnahme für Bucht, Golf, Isthmus ist gestrichen.

204a Ansetzung der Umgebung geographischer Einheiten (neu)

205,3 Überschneidungsgebiete (neu) 
209,4 Kleinräumige Geographika innerhalb eines Ortes (neu)

209a Namen von naturräumlichen Einheiten von bio-, paläobio- und paläogeographischen Regionen usw. (neu)

210,3 Gibt es für Wegstrecken keinen Individualnamen, so werden die Bezeichnungen für die Streckenendpunkte mit dem einschlägigen Gattungsbegriff für den Weg usw. verknüpft (anstelle der für das Online-Retrieval ungünstigen Bindestrichformen).

212a Zusammenfassung der Verwendungsbestimmungen

213a SWD-Datensatz für geographische/ethnographische Schlagwörter

\section{Sachschlagwörter}

304,1,c u. d Die Zulässigkeit präkombinierter Bezeichnungen regelt im Zweifelsfall die SWD auch für ganze Begriffskomplexe.

304,2 Das Vorgehen bei der Auswahl der Schlagwörter für neue Begriffsinhalte wird präzisiert.

304,3 u. 4 Begriffszerlegung und ihre Grenzen (teilweise neu)

304,5 Bei präkombinierten Bezeichnungen wird durchgängig eine Synonymie-Verweisung von der äquivalenten, semantisch zerlegten Form gemacht.

305,1,c Buchstaben, Morpheme und Wörter als Gegenstand linguistischer Untersuchungen (teilweise neu)

305,2,d-g Präkombinierte Bezeichnungen mit Personennamen, Geographika/Ethnographika, Körperschaften, Formschlagwörtern (teilweise neu)

306 Homonyme und Polyseme werden gleich behandelt und häufiger als bisher durch Homonymenzusatz unterschieden.

306a Zusammenfassung der Ansetzungsregeln für Individualnamen (z.B. Produktbezeichnungen, Preise, Wettbewerbe, Projekte, Verkehrsmittel, Tier- und Pflanzennamen usw.)

311,2 Bei Fachausdrücken des Rechts, der Verwaltung und des Schulwesens wird die im jeweiligen deutschsprachigen Staat gebräuchliche Terminologie verwendet. (neu)

$318 \quad$ SWD-Datensatz für Sachschlagwörter

322 Die Regelung der Reihenfolge mehrerer Sachschlagwörter aufgrund ihrer syntaktischen Beziehungen bei der Bildung der Grundkette bewährte sich in der Praxis nicht und wird deshalb aufgegeben.

324 Bei der Verknüpfung mehrerer Sachschlagwörter können bei präkombinierten Bezeichnungen Bestandteile auftreten, die im Zusammenhang der Kette pleonastisch sind. Grundsätzlich wird für jeden Begriff der spezifische Sucheinstieg gewählt. Das gilt auch für den Fall, dass Allgemeinbegriffe mit Individualnamen (Geographika, Körperschaftsnamen, Produktbezeichnungen usw.) verknüpft werden.

\section{Zeitschlagwörter und andere Zeitaspekte}

401a Zusammenfassung der Verwendungsbestimmungen

405a SWD-Datensatz für Zeitschlagwörter

408a,2,b Als Epochenbezeichnungen politischen Ursprungs sind auch die chinesischen Herrscherdynastien zugelassen. (neu) 
408a,3,a 'Altertum', 'Antike' und 'Spätantike' werden prinzipiell wie andere Epochenbezeichnungen verwendet, d.h. auch bei sachlicher Einschränkung.

408a,5 Als permutierende Sachschlagwörter sind Stile und Richtungen zu behandeln, die nicht eine ganze Epoche bestimmen, sowie einzelne Schulen und Künstlervereinigungen.

418 Um historische Sachverhalte einheitlich und einfach recherchieren zu können, wird ein in einem eigenen Feld zu erfassender Zeitcode eingeführt (vgl. auch § 18; Anl. 10). (neu)

\section{Formschlagwörter}

Formschlagwörter sollen in der SWD künftig als eigene Schlagwortkategorie kenntlich sein.

Bei gleichlautendem Form- und Sachschlagwort wird es zwei getrennte Datensätze geben.

503a SWD-Datensatz für Formschlagwörter

504,1 Es können mehrere Formschlagwörter verknüpft werden.

\section{Körperschaftsnamen}

602,2 Erfassung der GKD-Nummer zur datentechnischen Verknüpfung beider Normdateien, ohne die Ansetzungsform anzugleichen

605,3 Orte und Ortsteile am Beginn und Ende von Namen ortsgebundener Körperschaften werden mit angesetzt.

605,4 Ansetzung von Universitäten außerhalb des deutschen Sprachraums (teilweise neu)

606,1,b Rundfunk- und Fernsehanstalten sowie öffentliche Dienstleistungs- und Versorgungsbetriebe werden nicht ortsgebunden angesetzt.

611 Die Kriterien für gesplittete Ansetzungsformen bei der Namensänderung einer Körperschaft sind teilweise neu gefasst.

612,2 Bei Homonymie eines Körperschaftsnamens zu Schlagwörtern anderer Kategorien werden verschiedene Homonymenzusätze zugelassen.

614,2 Die Ausnahmeregelung für historische zentrale Organe entfällt.

614,2 Behandlung von Botschaften, Gesandtschaften, Konsulaten usw. (neu)

616,1 Die Gesamtstreitkräfte eines Staates sowie die obersten Waffengattungen werden wie Sachschlagwörter verknüpft.

616,3 Militärischen Körperschaften unterstellte Körperschaften mit ortsfester Einrichtung werden selbständig und ortsgebunden angesetzt. (neu)

618,2 Normierte Ansetzung von 'Stadtteilpfarreien’ der katholischen Kirche

618,3 Normierte Ansetzung von Klöstern und Stiften

619,2 Bestimmte Spitzenorgane von Religionsgemeinschaften werden wie Sachschlagwörter behandelt.

620a SWD-Datensatz für Körperschaftsnamen

\section{Sprache, Wörterbücher, Literatur}

703,2,b Die Sprachbezeichnung kann pleonastisch sein bei Staaten sowie i.d.R. bei den Sprachen deutsch, englisch, französisch und spanisch. Bei Bedarf werden entsprechende Ketten in die SWD aufgenommen. 
705,7 Bildet eine Begriffsrelation, die durch zwei oder mehr Schlagwörter ausgedrückt wird, das Motiv, erhalten beide bzw. alle Schlagwörter den Zusatz $<$ Motiv $>$.

\section{Werke}

708,10 Fortlaufende Sammelwerke erhalten einen mehrgliedrigen Oberbegriff. (neu)

712,6 Anonyme Werke der Literatur und Fachliteratur erhalten einen mehrgliedrigen Oberbegriff. (neu)

713,3 Beschlagwortung von Perikopen (neu)

\section{Rechtsmaterien}

715,1 Fehlt ein amtlicher Kurztitel oder gebräuchlicher Zitiertitel, wird der volle Titel der Rechtsnorm angesetzt.

715,1 u. 5 Deutsch- und fremdsprachige Rechtsnormen werden mit der Gebietskörperschaft und dem Kurz- bzw. Zitiertitel angesetzt. Der Titel der Rechtsnorm mit der Gebietskörperschaft als zweiter Teil wird als Synonym erfasst.

715,2 'Deutschland' und 'Deutschland <Bundesrepublik>' entfallen bei der Ansetzung nicht als pleonastisch.

715,10 Historische Rechtsnormen werden gemäß 715,1 und 5 angesetzt.

715,11 Rechtsnormen internationaler Zusammenschlüsse (neu)

715,12 Rechtsnormen von Kirchen (neu)

\section{Werke der bildenden Kunst und Bauwerke}

Titel von Werken der bildenden Kunst werden (anders als bei der Belletristik) sowohl für die Indexierung von Originalen bzw. Reproduktionen als auch der zugehörigen Sekundärliteratur verwendet.

725 Oberbegriffe werden für Werke der Plastik und des Kunsthandwerks sowie für Bauwerke erfasst. (neu)

730,1,b Bei Sakralbauten, Adelshäusern, 'Rathaus' und 'Hafen' wird ein mehrgliedriges Schlagwort angesetzt, in allen übrigen Fällen wird verknüpft.

730,1,c u. d Bauwerke von Körperschaften (neu)

731 Die Ansetzung von Kirchenbauten ist präziser geregelt.

\section{Filme, Hörfunk- und Fernsehsendungen}

Die Bestimmungen gelten auch für Hörfunksendungen.

\section{Audiovisuelle Materialien}

Die Bestimmungen sind wesentlich detaillierter gefasst.

\section{Elektronische Publikationen}

737a Die Indexierung elektronischer Publikationen ist erstmals geregelt. 


\section{Musikalische Werke}

740a Konventionalsachtitel (neu)

743 Bestimmungen für Interpreten und Komponisten von Film-, Ballett- und Tanztheatermusik (neu)

743a Einheitssachtitel für Teile musikalischer Werke (teilweise neu)

744 Erschließung von Musikdrucken, Musiktonträgern und Musikvideos (neu)

\section{Schöne Literatur}

760-762 Regeln für die Erschließung sind erstmals aufgenommen.

\section{Kinder- und Jugendliteratur}

763-766 Regeln für die Erschließung sind erstmals aufgenommen.

\section{Schul- und Berufsschulbücher}

767-773 Regeln für die Erschließung sind erstmals aufgenommen.

\section{Ordnungsregeln}

801

Für Listenfunktionen gelten künftig die Ordnungsregeln von RAK.

\section{Anlage 1}

Auf die Auflistung der geistlichen Reichsfürstentümer (1500-1803) folgt eine Zusammenstellung der nicht dem Reichsfürstenrat angehörigen Erzdiözesen und Diözesen.

\section{Anlage 3}

Die Liste der geographischen Problemfälle entfällt, da sie in die SWD eingearbeitet ist.

\section{Anlage 5}

Die Liste der nicht permutierenden Sach- und Zeitschlagwörter mit ausführlichen Verwendungshinweisen ist aktualisiert.

\section{Anlage 6}

Die Zahl der Formschlagwörter ist nur wenig gestiegen. Die meisten neu hinzugekommenen Begriffe dienen der Kennzeichnung spezieller Materialtypen. Definitionen, Verwendungshinweise und Verweisungen sind erheblich ausgebaut. Die Begriffsrelationen gelten nur zwischen Formschlagwörtern.

\section{Anlage 7}

Die Ansetzungsformen biblischer Bücher sind in der SWD nachgewiesen.

\section{Anlage 8}

Der Sachverhalt wurde in die Ansetzungsregeln für Körperschaften eingearbeitet. 


\section{Anlage 9}

Der Zeitcode der UDK soll künftig der besseren Erschließung historisch ausgerichteter Literatur dienen (vgl. §§ 18,4; 418).

\section{Anlage 10}

Konkordanz zu den Gattungsbegriffen des VD 17 (neu)

\section{Beispielregister}

Dieses erschien notwendig, da Beispiele oft als Einstieg für einzelne Regelwerksbestimmungen dienen, die nun leichter auffindbar sind. 



\section{Grundregeln}

\section{§ 1 Aufgabe der Regeln für den Schlagwortkatalog}

1. Die RSWK regeln die Inhaltserschließung von Bibliotheksbeständen durch die Schlagwortkatalogisierung. Ausgangspunkt ist die Praxis Der Deutschen Bibliothek und der Bibliotheksverbünde, die ihre Bestände unter Nutzung der Schlagwortnormdatei (SWD) erschließen. Das Regelwerk kann jedoch in gleicher Weise lokal wie außerhalb der Bibliotheken auf andere Dokumente angewandt werden. Hierfür können Sonderbestimmungen geschaffen werden, insbesondere beim Umfang der Verweisungen.

2. Die Schlagwortkatalogisierung kann nicht alle Beziehungen zwischen Begriffen und Gegenständen darstellen. Daher sollten die Dokumente daneben auch klassifiziert werden.

3. Die Schlagwortkatalogisierung kann durch maschinelle Indexierung ergänzt werden, insbesondere bei speziellen Gattungen von Dokumenten, wie retrokonvertierten Altbeständen, Zeitschriftenaufsätzen oder elektronischen Publikationen. Hier hat die maschinelle Indexierung in erster Linie die Funktion, Sucheinstiege zu vermehren, falls der Aufwand für eine intellektuelle Schlagwortvergabe unvertretbar hoch erscheint. Soweit durch maschinelles Indexieren keine rasch les- und interpretierbaren Inhaltsbeschreibungen im Sinn von § 13 erzeugt werden, ist eine Trennung beider Datenschichten für das Retrieval sinnvoll.

4. Die RSWK haben Bezüge zu den „Regeln für die Alphabetische Katalogisierung“ (RAK). Die Erfassung der Daten nach beiden Regelwerken wird aufeinander abgestimmt.

5. Die RSWK berücksichtigen vorrangig die Bedürfnisse von Online-Katalogen. Für Listenoder Zettelkataloge können sie analog angewandt werden. Spezielle Bedingungen dieser Katalogformen sowie von Bibliographien und Kettenlisten in Online-Katalogen werden als fakultative Bestimmungen aufgeführt.

\section{$\S 2$ Grundbegriffe}

Anm.: Die folgenden Definitionen dienen nur dem leichteren Überblick über die verwendete Terminologie. Herangezogen wurden u.a. die einschlägigen DIN-Normen 1463 Erstellung und Weiterentwicklung von Thesauri, 2330 Begriffe und Benennungen, 31623 Indexierung zur inhaltlichen Erschließung von Dokumenten, 31631 Kategorienkatalog für Dokumente. Die Terminologie der RSWK richtet sich jedoch teilweise nach dem abweichenden bibliothekarischen Sprachgebrauch.

\section{Inhaltserschließung (Sacherschließung)}

Inhaltserschließung ist die Gesamtheit der Methoden und Verfahren zur inhaltlichen Beschreibung von Dokumenten. Dabei sind zu unterscheiden:

a) Verbale Inhaltserschließung (Indexierung), die dem Dokument natürlich-sprachliche Bezeichnungen zuordnet, sie suchfähig macht, anzeigt und soweit erforderlich alphabetisch sortiert. Zu unterscheiden sind:

- intellektuell vergebene Schlagwörter (Schlagwortkatalogisierung),

- Stichwörter aus dem Hauptsachtitel oder anderen Titeln sowie 
- maschinelle Indexierung, die Wörter aus den Titeln oder weiteren Elementen des Dokuments wie Abstract, Inhaltsverzeichnis, Register u.a. verwendet.

Anm.: Indexierung wird überwiegend im obigen Sinn verwendet, daneben aber auch für den Aufbau von Indizes aus Datenelementen der SWD und der Titelaufnahmen.

b) Klassifikatorische Inhaltserschließung, die mit Hilfe von Notationen Inhalte wiedergibt, anzeigt, nach sachlichen Kriterien ordnet und suchfähig macht. Die Ordnung ist vorwiegend hierarchisch, auch wenn die Notation dies (etwa bei der Verwendung als Aufstellungssystematik) nicht immer ausdrückt.

\section{Schlagwortkatalogisierung, Schlagwortnormdatei (SWD), Schlagwortkette}

Die Schlagwortkatalogisierung basiert auf der natürlichen Sprache. Sie folgt festgelegten Regeln für die Ansetzung der Schlagwörter (vgl. § 9) sowie für deren Verwendung zur Wiedergabe eines Dokumenteninhalts. Die Schlagwörter werden in der SWD geführt.

Anm: Hierbei handelt es sich um eine bei Der Deutschen Bibliothek nach den Vorschriften dieses Regelwerks geführte, kooperativ bearbeitete Normdatei. Bei lokaler Anwendung sollte von einer Schlagwortdatei gesprochen werden.

Die SWD bzw. die Schlagwortdatei besteht aus Schlagwortsätzen. Diese enthalten Felder für Ansetzungs- und Verweisungsformen sowie ergänzend Codierungen (einschließlich der Notation einer nationalen oder lokalen Klassifikation), Bemerkungen und Verwaltungsinformationen (vgl. § 7,4).

Bei der Zuordnung der Schlagwörter zu den Dokumenten sind grundsätzlich zwei strukturell unterschiedliche Verfahren möglich:

a) Die Verwendung einzelner nicht verknüpfter Schlagwörter, die unabhängig von dokumentspezifischen Beziehungen gleichrangig nebeneinander gestellt werden (gleichordnende Indexierung).

b) Die Verknüpfung einzelner Schlagwörter zu Schlagwortketten, die den dokumentspezifischen Zusammenhängen entsprechen (syntaktische Indexierung).

Das vorliegende Regelwerk sieht Schlagwortketten (vgl. § 13) vor. Die Reihenfolge der Schlagwörter in der Schlagwortkette wird primär durch Schlagwortkategorien (vgl. § 15) und ergänzend durch inhaltliche Kriterien bestimmt.

\section{Dokument (Vorlage)}

Als Dokument wird die vorliegende, im Schlagwortkatalog nachzuweisende Ausgabe eines Werks bezeichnet. Je nach der Erscheinungsform sind bibliographisch selbständige Dokumente und bibliographisch unselbständige Dokumente zu unterscheiden (vgl. § 3).

\section{Gegenstand des Dokuments}

Als Gegenstand wird ein in einem Dokument behandeltes Thema (Sachverhalt) bezeichnet. Ein solcher Gegenstand wird durch einen oder mehrere Begriffe, die in einer sachlichen Beziehung zueinander stehen, repräsentiert (vgl. §§ 7,1; 13,4). Der Dokumenteninhalt besteht aus einem oder mehreren Gegenständen.

\section{Begriff}

Ein Begriff ist das Ergebnis einer Abstraktion. In Allgemeinbegriffen (abstrakten Begriffen) sind gemeinsame Merkmale einer Menge individueller Gegenstände materieller oder immaterieller Art zusammengefasst. 
Zu den Begriffen zählen auch Individualbegriffe, die durch Anschauung entstehen und konkreten individuellen Gegenständen im Denken entsprechen. Sie werden i.d.R. durch einen Individualnamen wiedergegeben, z.B. durch die Namen von Personen, Geographika oder Körperschaften. Gibt es keinen Individualnamen oder ist er sehr entlegen, so werden Individualbegriffe durch Bezeichnungen für die entsprechenden Allgemeinbegriffe in Kombination mit individualisierenden Angaben wiedergegeben (vgl. § 8,3).

\section{Bezeichnung (Benennung)}

Eine Bezeichnung ist ein sprachlicher Ausdruck für einen Allgemeinbegriff oder einen Individualbegriff.

\section{Schlagwort (Deskriptor, Vorzugsbezeichnung, Ansetzungsform)}

Ein Schlagwort ist eine terminologisch kontrollierte Bezeichnung, die in Indexierung und Retrieval für einen Begriff aus einem Dokumenteninhalt verwendet wird (vgl. §§ 8; 9).

\section{Schlagwortkategorie, Indikator}

Grundlegende inhaltliche Kategorien von Begriffen werden als Schlagwortkategorien unterschieden. Sie gliedern das Gesamtrepertoire der Schlagwörter, bestimmen die Rangfolge in der Schlagwortkette und werden, ebenso wie weitere Begriffskategorien, durch Indikatoren gekennzeichnet (vgl. § 11).

\section{Ansetzung, Terminologische Kontrolle}

Terminologische Kontrolle ist die Gesamtheit der Maßnahmen, die dazu dienen, Begriffe und Bezeichnungen eindeutig aufeinander zu beziehen (Beseitigung von Mehrdeutigkeiten, Disambiguierung). Der wichtigste Schritt ist die Ansetzung des Schlagworts (vgl. § 9), indem

- für jeden Begriff eine Ansetzungsform (Vorzugsbezeichnung) festgelegt wird, die den Begriff eindeutig vertritt (Festlegungskontrolle),

- Synonyme (nicht gewählte Ansetzungsformen) möglichst vollständig erfasst werden (Synonymiekontrolle, vgl. § 12,2),

- Homonyme und Polyseme besonders gekennzeichnet werden (Homonymiekontrolle, vgl. $\S 10)$,

- geprüft wird, ob ein komplexer Begriff in mehrere Schlagwörter zerlegt werden soll (Zerlegungskontrolle, vgl. §§ 8,5; 304,3 und 4).

Weitere Hilfsmittel sind

- die Bestimmung der hierarchischen Relationen bzw. der hierarchischen Verweisungen,

- die Bestimmung der begriffsinhaltlichen Überschneidungen bzw. der assoziativen und chronologischen Verweisungen,

- Definitionen und Verwendungshinweise.

\section{Relation (Beziehung)}

Eine Relation ist die Beziehung zwischen mehreren Bezeichnungen, die denselben Begriff repräsentieren (Äquivalenzrelation), oder die Beziehung zwischen verschiedenen Begriffen aufgrund ihrer gemeinsamen Merkmale (Begriffsbeziehung: hierarchische und assoziative Relation).

\section{Verweisung}

Eine Verweisung ist die Darstellung der Relation zwischen Bezeichnungen bzw. Begriffen mit Hilfe einer abgekürzten Verweisungsformel (z.B. den Symbolen BS, BF usw.). Verweisungen dienen zur Führung des Benutzers, vor allem von nicht zugelassenen auf die zugelas- 
sene Bezeichnung (Vorzugsbezeichnung) oder auf hierarchisch übergeordnete, untergeordnete oder auf verwandte Begriffe (vgl. § 12).

\section{Schlagwortkatalog}

Der Schlagwortkatalog ist die Gesamtheit der mit der Schlagwortkatalogisierung geschaffenen Zugriffsmöglichkeiten auf Titelaufnahmen: das verwendete Vokabular und die Schlagwortketten (Schlagwortkettenregister) einschließlich der zugehörigen Titelaufnahmen.

\section{Listenfunktion, Eintragung, Permutation}

Listenfunktion meint die Reihung von alphabetisch sortierten Schlagwortketten in einem Kettenregister im OPAC, im Listen- oder Zettelkatalog oder in gedruckten Bibliographien.

Die Eintragung ist bei Listenfunktionen diejenige Stelle, unter der ein Gegenstand im Schlagwortkatalog durch die Schlagwortkette mit ihren Permutationsformen nachgewiesen ist.

Zu den Eintragungen zählen auch Verweisungen.

Unter Permutation wird jede Veränderung der Reihenfolge der Glieder der Schlagwortkette verstanden (z.B. Transposition: der Austausch jeweils zweier Kettenglieder, vgl. §§ 13; 15).

\section{§ 3 Zu erschließende Dokumente}

1. In den Schlagwortkatalog können grundsätzlich alle in einer Bibliothek vorhandenen selbständig erschienenen Dokumente aufgenommen werden.

2. Im jeweiligen Verbund oder in der jeweiligen Bibliothek wird festgelegt,

a) ob darüber hinaus unselbständig erschienene Dokumente, wie Aufsätze in Zeitschriften, Sammelwerken und Festschriften, die eine Titelaufnahme nach RAK-UW erhalten, erschlossen werden,

b) ob minder wichtige Literatur, zumal bei geringem Umfang oder Literaturgattungen, die vor allem unter formalen Gesichtspunkten gesammelt werden (wie Auktionskataloge, Telefonbücher, Vorlesungsverzeichnisse), von der Erschließung auszunehmen sind,

c) ob vor einem bestimmten Erscheinungsjahr erschienene Dokumente ausgenommen werden. Für Reprints und Neuauflagen ist dabei das Erscheinungsjahr des Nachdrucks maßgebend. (Zur Schlagwortvergabe bei älterer Literatur vgl. §§ 4,5; 5,7; 401a,2,c; Anl. 10),

d) ob schöne Literatur, Musikdrucke, Musiktonträger, Musikvideos, Abbildungen von Kunstwerken und vergleichbare audiovisuelle sowie elektronische Materialien durch Schlagwörter für Entstehungsgebiet, Sprache, Gattung, Zeit und Form erschlossen werden (vgl. § 5,3),

e) in welchem Umfang in wissenschaftlichen Bibliotheken schöne Literatur sowie Kinderund Jugendliteratur erschlossen werden (vgl. § 4,6),

f) ob schöne Literatur, Kinder- und Jugendliteratur und audiovisuelle sowie elektronische Materialien vergleichbaren Inhalts durch Schlagwörter für die Gattung oder Strömungen sowie ein Formschlagwort erschlossen werden (vgl. § 5,4 und 5),

g) ob Musikdrucke, Musiktonträger und Musikvideos nach thematisch erschließbaren Inhalten (Motiv, Anlass), Form und Gattung, Besetzung, Provenienz, Zeit, Präsentation und Realisation erschlossen werden (vgl. § 5,6),

h) ob Altbestände durch Gattungsbegriffe und ein Formschlagwort erschlossen werden (vgl. $\S 5,7)$. 
Anm.: Der jeweilige Umfang der Beschlagwortung Der Deutschen Bibliothek ist in den „Praxisregeln“ festgelegt.

3. Bei mehrbändigen begrenzten Werken ist i.d.R. das Gesamtwerk zu erschließen. Es wird jedoch zusätzlich der Einzelband erschlossen, wenn er ein im Verhältnis zum Gesamttitel klar abgegrenztes und sachlich eingeschränktes Thema behandelt. Dies gilt insbesondere, wenn zur Erschließung andere Schlagwörter zu verwenden sind als für das Gesamtwerk oder wenn der Titel des Gesamtwerks nur eine lose Klammer für die Einzelbände bildet, z.B. bei Einzelbänden, die in zahlreichen, unterschiedlichen Auflagen erschienen sind. Auf die Erschließung des Gesamtwerks kann verzichtet werden, wenn es sich um sehr allgemeine Themen handelt, z.B. bei Handbüchern ganzer Wissenschaften.

Anm. 1: Dies gilt unabhängig von der Form der Titelaufnahme des Einzelbandes als Stücktitel (nach MAB hSatz) oder mit bloßer Bandaufführung (nach MAB u-Satz). Auch Abteilungen eines Gesamtwerks (nach MAB y-Satz) können, wo sinnvoll, erschlossen werden.

Anm. 2: Ist ein Gesamtwerk nicht vollständig vorhanden oder noch nicht vollständig erschienen, so richtet sich (insbesondere in Verbundsystemen) die Erschließung dennoch nach dem geplanten Umfang der Publikation.

Anm. 3: Der jeweilige Umfang der Beschlagwortung Der Deutschen Bibliothek ist in den „Praxisregeln“ festgelegt.

Titel: $\quad \neg$ Der $\neg$ deutsche Roman / hrsg. von Benno von Wiese. - 1965

Bd. 1 Vom Barock bis zur späten Romantik

Bd. 2 Vom Realismus bis zur Gegenwart

Erschlossen wird nur das Gesamtwerk. Einzelbände, die sich nur durch die zeitliche Gliederung unterscheiden, sollten nicht getrennt erschlossen werden.

Titel: $\quad \neg$ Die $\neg$ Kunst im Heiligen Römischen Reich Deutscher Nation / Wolfgang Braunfels.

- 1979-1989

Bd. 1-3 Die Räume

1. $\neg$ Die $\neg$ weltlichen Fürstentümer

2. $\neg$ Die $\neg$ geistlichen Fürstentümer

3. Reichsstädte, Grafschaften, Reichsklöster

Bd. 4-5 Die Grenzen

4. Grenzstaaten in Westen und Süden. Deutsche und romanische Kultur

5. Grenzstaaten in Osten und Norden. Deutsche und slawische Kultur

Bd. 6 Die Zeiten

6. $\neg$ Das $\neg$ Werk der Kaiser, Bischöfe, Äbte und ihrer Künstler: 750-1250

(Bd. 7 und 8, 1250-1870 nicht erschienen)

Erschlossen wird nur das Gesamtwerk, da das Werk auf einer individuellen Gesamtkonzeption beruht, die Einzelbände nicht in sich abgeschlossene Einheiten darstellen und ihre Gliederung für eine Erschließung wenig geeignet ist.

Titel: $\quad$ Fouilles de Delphes / École Française d'Athènes

Bd 2 Topographie et architecture

Bd 2,1,3 $\neg$ Le $\neg$ trésor des Atheniens / par Jean Audiat. - 1933

Die Einzelbände werden nicht erschlossen, da der wichtigste Suchbegriff ('Delphi') identisch wäre. In einer Spezialbibliothek kann dies auch anders gehandhabt werden.

Titel: $\quad$ Grundlagen der Betriebswirtschaftslehre / Erich Gutenberg. - 1965-1970

Bd. $1 \neg$ Die $\neg$ Produktion

Bd. $2 \neg$ Der $\neg$ Absatz

Bd. $3 \neg$ Die $\neg$ Finanzen

Da Einzelbände in zahlreichen Auflagen erschienen sind, liegt es nahe, sowohl das Gesamtwerk als auch die Einzelbände zu erschließen. 
Titel: $\quad$ Grundriß zur deutschen Verwaltungsgeschichte : 1815-1945. Bd. 1-22.

Bd. 1 Ost- und Westpreußen. - 1975

Erschlossen wird sowohl das mehrbändige Werk wie der Einzelband, da es sich um klar abgegrenzte Themen handelt.

Titel: Handbuch der Altertumswissenschaft

Abt. 1 Einleitende und Hilfsdisziplinen

Abt. 2 Griechische Grammatik, lateinische Grammatik, Rhetorik

Abt. ...

Gesamtwerk bzw. Abteilungen umfassen jeweils zahlreiche Bände, die nur lose zusammenhängen. Erschlossen werden daher nur die Einzelbände

Titel: Handbuch der Orientalistik

5. Abt. Japan. - 1988 -

Bd. 1,2 Sprache und Schrift Japans / Bruno Lewin. - 1989

Erschlossen werden die Abteilung und die Einzelbände. Das Gesamtwerk hat nur einen losen Zusammenhang.

Titel: $\quad \neg$ Der $\neg$ Duden : in 12 Bänden

Bd. 1 Duden, Rechtschreibung der deutschen Sprache. - 1991

Erschlossen wird nur der Einzelband, da der Inhalt des Gesamtwerks zu unspezifisch ist.

Titel: $\quad$ Gesammelte Werke / Jean-Paul Sartre

$<$ Abt. $>$ Schriften zur Literatur

5. Der Idiot der Familie ; Bd. 1. - 1986

6. Der Idiot der Familie ; Bd. 2. - 1986

7. Der Idiot der Familie ; Bd. 3. - 1986

Das Gesamtwerk wird nicht erschlossen, da es sich um ein Dokument vermischten Inhalts handelt (vgl. § 4,4). Einzelbände einer Werkausgabe können erschlossen werden, wenn es sich um ein klar abgegrenztes Einzelwerk handelt.

Titel: Monumenta Egrana : Denkmäler des Egerlandes als Quelle für dessen Geschichte / hrsg. von H. Gradl. Bd. 1 (1886) [mehr nicht erschienen]

Erschlossen wird der tatsächlich erschienene Inhalt (Geschichte 805-1322).

Titel: $\quad \neg$ The $\neg$ international who’s who [Erscheint 1935-] 1996/1997

Bei Werken, die in regelmäßiger Neuauflage erscheinen, wird nur das Gesamtwerk erschlossen.

4. Bei Schriftenreihen wird i.d.R. nur der Stücktitel erschlossen. Die Schriftenreihe kann zusätzlich erschlossen werden, wenn es sich um ein spezielles Thema handelt, das durch die Erschließung der Stücktitel nicht abgedeckt wird.

Titel: $\quad$ Schriften zum öffentlichen Recht

Schriftenreihe mit mehreren hundert Titeln. Erschlossen werden nur die Einzelbände.

Titel: $\quad$ Materialien zur Fremdenverkehrsgeographie

Schriftenreihe, deren Einzelbände speziellere Themen behandeln. z.B.

Bd.14. Städtetourismus als Teil der kommunalen Imageplanung / Mechthild May. - 1986

Bd. 16. Gemeinnützige Familienferienstätten / Burkhard Schmidt. - 1988

Erschlossen werden sowohl die Serie wie die Einzelbände.

5. Bei Zeitschriften, Zeitungen und zeitschriftenartigen Reihen mit einzelnen Stücktiteln werden i.d.R. sowohl das Gesamtwerk wie die Stücktitel erschlossen. 


\section{§ 4 Inhaltsanalyse}

1. Die Schlagwortkatalogisierung umfasst die Analyse des begrifflichen Inhalts eines vorliegenden Dokuments und dessen Umsetzung in Schlagwörter, deren Ansetzung sowie die Bildung von Schlagwortketten.

Die Inhaltsanalyse umfasst die einzelnen Schritte bei der intellektuellen Erfassung eines Dokumenteninhalts zum Zwecke einer möglichst präzisen und spezifischen Inhaltserschließung. Ihre Grundprinzipien sind unabhängig von dem jeweiligen Erschließungsverfahren. Neben allgemeinen Normen sind fachspezifische Aspekte sowie folgende Grundsätze bzw. Phasen zu berücksichtigen:

- Feststellen des Inhalts bzw. der inhaltlichen Schwerpunkte eines vorliegenden Dokuments, also der darin behandelten Gegenstände. Maßgebend für die Wahl der Schlagwörter ist der Inhalt, nicht die jeweilige Titelfassung mit den sich daraus ergebenden Stichwörtern.

- Gewichtung und Auswahl der zu erschließenden inhaltlichen Aspekte unter Berücksichtigung der Aufnahmeprinzipien für den Schlagwortkatalog (vgl. § 3) und der Grundprinzipien der Schlagwortkatalogisierung (vgl. § 6).

- Ermittlung eines oder mehrerer Begriffe, die den wesentlichen Inhaltskomponenten eines Dokuments entsprechen.

- Umsetzung der ausgewählten Begriffe in prägnante Bezeichnungen zum Zweck der möglichen Ansetzung einzelner Schlagwörter (vgl. § 9).

- Spezifizierung der Beziehungen zwischen den ermittelten Begriffen bzw. der Anzahl der im Dokument behandelten Gegenstände im Hinblick auf die vorgegebenen Regeln zur Bildung von Schlagwortketten (vgl. §§ 7; 13; 14).

Anm.: Als Indexierungsnormen für die Inhaltsanalyse sind zu nennen ISO/DIS 5963 Methods for examining documents, determining their subjects and selecting indexing terms und DIN 31623 Indexierung zur inhaltlichen Erschließung von Dokumenten.

2. Der Standpunkt oder eine Weltanschauung des Verfassers wird im Allgemeinen nicht berücksichtigt. Er wird aber durch ein Schlagwort ausgedrückt, wenn er sich auf Methode und Thematik der vorliegenden Darstellung deutlich auswirkt. Die Sicht von Kirchen, Parteien und ähnlichen Körperschaften wird berücksichtigt, wenn es sich um eine Stellungnahme mit offiziellem bzw. repräsentativem Charakter handelt.

Titel: $\quad$ Gesellschaft - Staat - Recht : zur Kritik der bürgerlichen Ideologie über die Entstehung von Gesellschaft, Staat und Recht / Werner Sellnow. - 1975

Der Autor geht zwar vom marxistischen Standpunkt aus, unterscheidet sich jedoch von „,bürgerlichen " Darstellungen nur in der Bewertung.

SWW Sozialphilosophie ; Geschichte 1750-1880

Titel: $\quad$ Scientology: eine neue Sicht des Lebens / L. Ron Hubbard. - 1983

SW Scientology

Titel: $\quad$ Verführung statt Erleuchtung : Sekten, Scientology, Esoterik / hrsg. von Hans Michael Baumgartner. - 1994

SWW Scientology; Aufsatzsammlung

Beim ersten Dokument handelt es sich um eine Schrift des Begründers der Scientology, beim zweiten um eine Kritik aus katholischer Sicht. 
Titel: $\quad \neg$ Der $\neg$ erzwungene Krieg : die Ursachen und Urheber des Zweiten Weltkriegs / David L. Hoggan. - 1997

SWW Weltkrieg <1939-1945> ; Kriegsschuldfrage

Nicht berücksichtigt wird, dass die Thesen Hoggans der Geschichtswissenschaft völlig widersprechen.

Aber:

Titel: $\quad \neg$ The $\urcorner$ arena of capital / Michael Dunford ... - 1983

Das Werk ist stark methodisch orientiert. Es untersucht den Wert der marxistischen Wirtschaftstheorie zur Analyse der Industrialisierung Großbritanniens im Vergleich mit anderen Ansätzen. Marxismus stellt hier mehr als einen weltanschaulichen Standpunkt dar.

SWW Großbritannien ; Industrialisierung ; Marxismus ; Wirtschaftstheorie

Titel: $\quad$ Schwangerschaftsabbruch und Bewahrung des Lebens : eine Arbeitshilfe / hrsg. vom Diakonischen Werk Bayerns. - 1986

SWW Schwangerschaftsabbruch ; Evangelische Kirche ; Aufsatzsammlung Es handelt sich um eine offizielle Stellungnahme der evangelischen Kirche.

Titel: $\quad$ Selbstanalyse : ein leicht verständliches Handbuch mit Tests und Übungen zur Selbsthilfe ... / L. Ron Hubbard. - 1983

Die Anleitung ist spezifisch auf Verfahren und Zweck der Scientology zugeschnitten.

SWW Selbstanalyse ; Dianetik

3. Die Zielgruppe des Autors wird bei der Erschließung des Dokuments i.d.R. nur berücksichtigt, wenn dies einen wesentlichen Einfluss auf den Inhalt hat. Das Niveau der Darstellung wird nur angegeben, wo dies im Regelwerk ausdrücklich vorgesehen ist, z.B. mit den Formschlagwörtern 'Einführung', 'Schulbuch', 'Jugendsachbuch', 'Lehrbuch' sowie bei der Beschlagwortung von Materialien für die Berufsausbildung (vgl. § 771).

Titel: $\quad$ Physik, Strahlenkunde und Chemie : eine Einführung ... für Angehörige der Heilberufe und Krankenpflegeschulen / von O. K. Linde ... - 1986

Der Inhalt ist nicht eng auf die genannten Berufe zugeschnitten; die Zielgruppe hat jedoch Auswirkungen auf das Niveau der Darstellung. Dieses wird durch ein Formschlagwort bezeichnet.

SWW Physik; Einführung

SWW Medizinische Radiologie ; Einführung

SWW Chemie ; Einführung

Aber:

Titel: $\quad$ Gesetzeskunde für Apotheker / Rudolf Schiedermair. - 1982

Die Zielgruppe bedingt hier eine inhaltliche Einengung des Themas.

SW Apothekenrecht

SW Arzneimittelrecht

Inhalt: Hygiene : ein Arbeitsbuch für Pflegeberufe

Der Inhalt beschränkt sich weitgehend auf Hygienemaßnahmen, die bei der Krankenpflege zu treffen sind.

SWW Hygiene; Krankenpflege

4. Nicht erschlossen werden Dokumente sehr allgemeinen oder vermischten Inhalts und solche, die keinen bestimmten Gegenstand behandeln:

Titel: $\quad$ Gesammelte Werke / Michail Bakunin. - Nachdr. - 1975

kein Schlagwort (auch nicht z.B.: Anarchismus ; Quelle)

Titel: Forschung : Mitteilungen der DFG. - 1979-

Enthält Berichte aus allen Wissenschaftsgebieten; deshalb kein Schlagwort. 
Dazu können insbesondere Erbauungsliteratur, Gebetbücher, Gesangbücher, Kalender und Almanache allgemeiner Art, meditative Literatur, Sammlungen von Lebensweisheiten, Streitschriften ohne klar erkennbaren Inhalt u.ä. zählen.

Anm.: Zur Erschließung mit Gattungsbegriffen vgl. jedoch § 5.

Titel: Auf dem Weg zur Meisterschaft des Lebens : Erkenntnisse und Begegnungen, die das Leben schenkt / Rosmarie Stüssi. - 1995

kein Schlagwort

Titel: $\quad$ Wir bleiben das Volk / Horst Eckert. - 1994

Der Autor behandelt zahlreiche Themen der deutschen und internationalen Politik aus rechtsradikaler Sicht in kursorischer Weise; kein Schlagwort.

5. Ältere Literatur und klassische Texte können nach den Bestimmungen dieses Regelwerks erschlossen werden. Eine Beschlagwortung erfolgt aus heutiger Sicht, d.h. für den heutigen Leser mit heutiger Terminologie, die allerdings rezipierte historische Begriffe einschließt.

Der Inhalt solcher Werke (unabhängig davon, ob es sich um die Originalausgabe, einen Reprint oder eine nicht überarbeitete Neuauflage handelt) ist gegenüber der Entstehungszeit unverändert. Es besteht jedoch vielfach ein verändertes Interesse, aus dem heraus das Werk heute gelesen wird: Es gibt Literatur, die heute unverändert relevant ist; andere Literatur ist veraltet und wird deswegen in den Schlagwortkatalog nicht aufgenommen, oder sie wird heute unter veränderten Aspekten gelesen: als Quelle für einen bestimmten Stand der Sache oder der Forschung (vgl. Anl. 10).

a) Beschlagwortung wie ein neues Werk

Titel: $\quad$ Abriß der Geologie von Bayern rechts des Rheins : in 6 Abteilungen - 1923-1929 noch heute brauchbare, umfassende Darstellung

SWW Bayern; Geologie

Titel: Zur Soziologie des Parteiwesens in der modernen Demokratie / Robert Michels. - 4. erg. Aufl. - 1989. Inhaltlich unveränderter Nachdruck der 2. Aufl. 1925.

Es handelt sich um ein klassisches Werk der Parteienforschung von 1911, dessen Thesen heute nicht mehr akzeptiert werden. Im Hinblick auf die heute noch notwendige Auseinandersetzung mit diesem Werk ist jedoch eine Beschlagwortung auf die gleiche Weise wie bei einem neuen Werk sinnvoll.

SWW Partei ; Soziologie

Titel: $\quad$ Allgemeine Theorie der Beschäftigung, des Zinses und des Geldes / John Maynard Keynes. - 1983

Klassisches Werk von 1936, das für die aktuelle wissenschaftliche Diskussion noch heute wesentlich ist.

SW Geldtheorie

$S W \quad$ Konjunkturtheorie

SW Keynessche Theorie

Titel: $\quad \neg \mathrm{A} \neg$ letter concerning toleration / John Locke. - 1690-1692

SWW Religiöse Toleranz; Philosophie

Im Hinblick auf die spezielle Thematik ist eine Erschließung im Schlagwortkatalog sinnvoll. Unveränderte Relevanz kann man vor allem bei spezielleren Themen annehmen.

Titel: Vite de’ pittori, scultori ed architetti genovesi / Raffaello Soprani e Carlo G. Ratti. [Nachdr. der Ausg.] 1768-1797

Bei biographischen Nachschlagewerken sind oft auch ältere Werke heute noch relevant, da sie vielfach für weniger bedeutende Personen den einzigen Nachweis bringen.

SWW Genua ; Künstler ; Geschichte Anfänge-1740 ; Biographie 
Titel: $\quad \neg U n\urcorner$ manuel de construction des galères / éd. annot. par Jan Fennis. - Repr. - 1985 Bei diesem Gegenstand ist es nur von geringer Bedeutung, ob es sich um ein älteres oder um ein modernes Werk handelt.

SWW Galeere ; Schiffbau

b) Keine Beschlagwortung

Titel: De arte poetica / Aristoteles. - 1968

Titel: $\quad$ Kritik der reinen Vernunft / Immanuel Kant. - 1984

Hier handelt es sich um klassische Werke, die vor allem historisch relevant sind. Ein Erschließen im Schlagwortkatalog ist jedoch entbehrlich.

c) Beschlagwortung aus heutiger Sicht

Für die Beschlagwortung heute überholter Literatur gelten die Gesichtspunkte, unter denen das Werk heute von Interesse ist. Der zeitliche Aspekt wird mit Geschichte und Jahreszahl oder durch ein anderes Zeitschlagwort ausgedrückt; i.d.R. wird das Formschlagwort 'Quelle' hinzugefügt. Dies geschieht insbesondere, wenn ohne Zeit- und Formschlagwort ein unzutreffender Eindruck über den Inhalt des Werks entstünde. Im Zweifelsfall wird nach $\S 4,5$,a beschlagwortet.

Titel: Publication der Röm. Kays. Mayestät ... Augsburg. - 1583

Es handelt sich um eine Quelle zur Einführung des Gregorianischen Kalenders in Augsburg.

SWW Augsburg; Gregorianischer Kalender ; Geschichte 1583; Quelle

Titel: Dictionnaire des richesses de la langue française / Pons-Augustin Alletz. - 1968

Nachdruck eines Wörterbuchs von 1770

SWW Französisch ; Wortschatz ; Geschichte 1770 ; Wörterbuch

Titel: Sozialismus und Krieg / Vladimir I. Lenin. - 1915

SWW Kommunismus ; Weltkrieg <1914-1918> ; Quelle

Titel: $\quad$ Five early guides to Rome and Florence. - 1972

Enthält einen Nachdruck von 5 Kunstführern. Ist nicht mehr als Reiseführer, sonders als Quelle für den damaligen Zustand der Kunstdenkmäler relevant.

SWW Rom ; Kunst ; Geschichte 1480-1554 ; Quelle

SWW Florenz ; Kunst ; Geschichte 1510 ; Quelle

d) Auf eine Beschlagwortung klassischer Werke der Belletristik nach Abs. 5,c wird jedoch verzichtet.

Anm.: Vgl. jedoch die Erschließung nach § 5,3 und 4 sowie die Erschließung der Themen nach § 4,6.

Titel: $\quad$ Dramen / Friedrich Schiller. - 1984

keine Beschlagwortung

6. Die Aufnahme von schöner Literatur, von Kinder- und Jugendliteratur beschränkt sich i.d.R. auf Dokumente, die einen bestimmten, als Problem, Ereignis oder mit einem Namen benennbaren Gegenstand behandeln. Zur Kennzeichnung dieser Dokumentgruppen tritt ein Formschlagwort hinzu (vgl. §§ 3,2,e; 760; 763)

Anm.: Zur Erschließung mit Gattungsbegriffen vgl. jedoch § 5,3 und 4.

Titel: Hölderlin : ein Roman / Peter Härtling. - 1989

SWW Hölderlin, Friedrich ; Belletristische Darstellung

SWW Dinosaurier; Kinderbuch 
7. Für audiovisuelle Materialien und elektronische Publikationen gelten die gleichen Regeln wie für anderes Bibliotheksmaterial, doch wird die Art des Datenträgers durch ein Formschlagwort gekennzeichnet, ggf. zusätzlich zur Form der Darstellung (vgl. § 737; 737a).

Anm.: Zur Erschließung mit Gattungsbegriffen vgl. § 5,5

SWW Einzeller; Film $16 \mathrm{~mm}$

SWW Psychologie ; Bibliographie ; CD-ROM

\section{§ $5 \quad$ Erschließung mit Formschlagwörtern und Gattungsbegriffen}

Neben Schlagwörtern für den begrifflichen Inhalt eines Werks sind auch Schlagwörter für Form oder Gattung des Dokuments möglich. Eine solche Erschließung ist teils obligatorisch (Abs. 1 und 2), teils fakultativ (Abs. 3-7). Bei den Regeln für Ansetzung, Verknüpfung und für die Präsentation im OPAC ist auf Eindeutigkeit und Verständlichkeit im Retrieval Rücksicht zu nehmen.

1. Formschlagwörter für die Erscheinungsweise, die Art der Darstellung, die physische Form eines Dokuments (Dokumenttyp) sowie in Einzelfällen für das Niveau der Darstellung bilden zusammen mit den Schlagwörtern für den begrifflichen Inhalt eine Schlagwortkette (vgl. $\S \S 501-506)$.

$\begin{array}{lll}S W W & \text { p Kleist, Heinrich } \neg \text { von } \neg \text {; f Zeitschrift } & \text { (Erscheinungsweise) } \\ S W W & \text { s Wirtschaftswachstum ; f Statistik } & \text { (Art der Darstellung) } \\ S W W & \text { s Junges Deutschland ; s Essay ; f Anthologie } & \text { (Art der Darstellung) } \\ S W W & \text { g Griechenland ; s Landeskunde ; f Tonbildreihe } & \text { (physische Form) } \\ \text { SWW } & \text { g Greifswald ; f Belletristische Darstellung } & \text { (Niveau der Darstellung) }\end{array}$

2. Schulbücher und Lehrmittel für den Unterricht werden neben eventuellen Schlagwörtern für den Inhalt mit solchen für die Zweckbestimmung (Unterrichtsfach, Schulart, Schulstufe, Schuljahr, Ausbildungsberuf, Geltungsbereich) sowie mit einem Formschlagwort erschlossen (vgl. §§ 767-773).

SWW s Optik; s Physikunterricht ; f Schulbuch

3. Schöne Literatur, Kinder- und Jugendliteratur, Musikdrucke, Musiktonträger, Musikvideos, Kunstwerke und deren Reproduktionen, sowie audiovisuelle Materialien und elektronische Publikationen vergleichbaren Inhalts (z.B. Spielfilme) können bei einer lokalen Anwendung dieses Regelwerks durch Schlagwörter für Entstehungsgebiet, Sprache, Gattung, Zeit (i.d.R. das Jahr der ersten Veröffentlichung) sowie ein Formschlagwort erschlossen werden. Werden diese Gattungsbezeichnungen für das Retrieval gemeinsam mit Schlagwortketten, die nach $\S 4$ gebildet sind, angezeigt, so tritt ein Formschlagwort hinzu.

Titel: Umthate uzala umlotha / I. S. Kubheka. - 1993

SWW g Südafrika <Staat> ; g Zulu-Sprache ; s Roman ; z Geschichte 1993 ; f Text

Für einen vorliegenden Roman. Das Geographikum wird bei dieser Erschließung nicht als pleonastisch behandelt, obwohl die Zulu-Sprache nur in Südafrika gesprochen wird.

Inhalt: Bach, Johann Sebastian: Der Herr ist mein getreuer Hirt: BWV 112

SWW g Deutschland; s Kantate ; z Geschichte 1731 ; f CD

Für eine Audio-CD. Jahreszahl nach Bach-Werke-Verzeichnis (Entstehungsjahr) 
Titel: $\quad \neg$ Die $\neg$ Apokalypse von Angers / Pierre-Marie Auzas. - 1985 [Bildband]

SWW g Frankreich ; s Bildteppich ; z Geschichte 1380 ; f Bildband.

Entstehungsland und Jahr sind nach dem Stand der Forschung angegeben. Daneben nach der Grundregel \& 4 und \& 723 obligatorisch

SW Apokalypse von Angers ; Bildband

Titel: $\quad$ Schrei wenn Du kannst [Bildtonträger] / Regie: Claude Chabrol. - 1959

SWW g Frankreich ; s Film ; z Geschichte 1959 ; f Film 35 mm

4. Schöne Literatur, Kinder- und Jugendliteratur kann bei einer lokalen Anwendung dieses Regelwerks durch Schlagwörter für die literarische Gattung oder für literarische Strömungen erschlossen werden. Bei der Erschließung kann auf sehr spezielle Schlagwörter verzichtet werden, indem die Literatur unter Oberbegriffen zusammengefasst wird. Auf den Nachweis unter sehr häufig vorkommenden Begriffen kann verzichtet werden. Werden diese Gattungsbezeichnungen für das Retrieval gemeinsam mit Schlagwortketten, die nach § 4 gebildet sind, angezeigt, so tritt das Formschlagwort 'Text' hinzu.

Anm. 1: Anthologien werden jedoch nach $\S 5,1$ beschlagwortet.

Anm. 2: Zur Erschließung des sachlichen Inhalts vgl. § 4,5

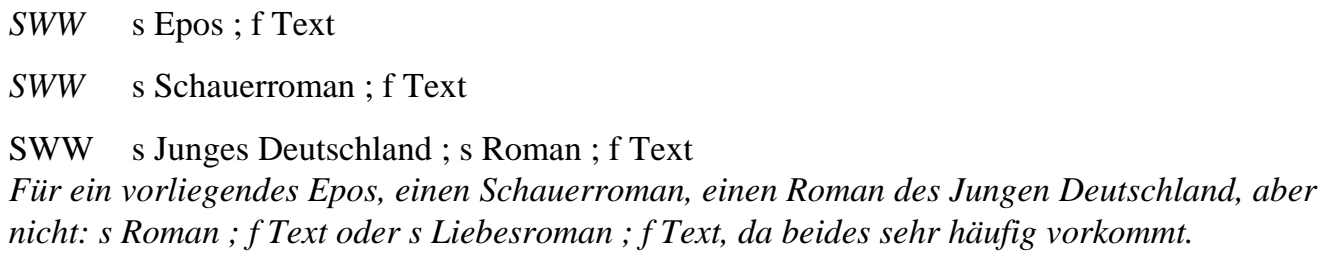

5. Filme, Videos, Hörfunk- und Fernsehsendungen können bei lokaler Anwendung analog zu Abs. 4 mit Form- und Gattungsbegriffen oder mit Bezeichnungen für künstlerische Strömungen erschlossen werden. Werden diese Gattungsbezeichnungen für das Retrieval gemeinsam mit Schlagwortketten, die nach $\S 4$ gebildet sind, angezeigt, so tritt ein Formschlagwort für das physische Material hinzu.

Anm.: Zur Erschließung des sachlichen Inhalts vgl. § 4,7.

Titel: $\quad \neg$ Der $\neg$ Förster vom Silberwald [Bildtonträger] : österreichischer Spielfilm von 1954

SWW s Heimatfilm; f Videokassette

Titel: $\quad$ Schrei wenn Du kannst [Bildtonträger] / Regie: Claude Chabrol. - 1959

SWW s Nouvelle vague ; f Film 35 mm

6. Musikdrucke, Wiedergaben musikalischer Werke auf Tonträgern und Musikvideos können bei einer lokalen Anwendung des Regelwerks nach thematisch erschließbaren Inhalten (Motiv, Anlass), Form und Gattung, Besetzung, Provenienz, Zeit, Präsentation und Realisation erschlossen werden. Vgl. „Regeln für den Schlagwortkatalog (RSWK) / Musikalien und Musiktonträger. - Entwurf. - Berlin: Deutsches Bibliotheksinstitut, 1991“ (sowie § 744).

Titel: $\quad$ Toccata D-Dur : für 2 Tromp. u. Org. bearb. ... / Alessandro Scarlatti. - 1978

SWW s Tokkata ; s Trio, Trompete 1,2 Orgel ; f Musikdruck

7. Für die Katalogisierung von Altbeständen (z.B. Erscheinungsjahr vor 1800 wie in RAK), die nicht nach § 4,5 erschlossen werden, können bei einer lokalen Anwendung nicht nur schöne Literatur, Kinder- und Jugendliteratur, sondern auch Bücher, die einer anderen literarischen Gattung zuzuordnen sind, mit Gattungsbegriffen erschlossen werden (vgl. Anl. 10). Entsprechend Abs. 4 tritt das Formschlagwort 'Text' hinzu (vgl. Anl. 10).

SWW s Pflanzenbuch; f Text

für ein vorliegendes Pflanzenbuch 


\title{
§ 6 Grundprinzipien der Schlagwortkatalogisierung
}

1. Die Schlagwortkatalogisierung erschließt das Dokument als Ganzes, nicht einzelne Teile oder besonders relevante Aspekte. (Wenn mehrere Gegenstände behandelt werden vgl. § 13,4.) Einschränkungen ergeben sich nur dort, wo eine zusammenfassende Bezeichnung wesentlich weniger bekannt ist als ihre Unterbegriffe (vgl. § 13,5). Daneben ist im Einzelfall auch zusätzlich die Berücksichtigung einzelner Teilaspekte möglich, um besondere Sammelschwerpunkte und Spezialbestände tiefer zu erschließen.

Titel: $\quad$ Deutsche Kaisergeschichte in der Zeit der Salier und Staufer / Karl Hampe. - 1985

Trotz der Gliederung in zwei große Kapitel handelt es sich um eine fortlaufende Darstellung.

SWW Deutschland; Geschichte 1024-1250

Titel: $\quad$ Von Wyhl nach Gorleben / Dieter Rucht. - 1980

SWW Deutschland < Bundesrepublik> ; Antikernkraftbewegung ; Geschichte

Inhalt: Politische Systeme der baltischen Staaten

Das Dokument enthält eine zusammenfassende, vergleichende Darstellung. Wäre die

Darstellung nach Staaten gegliedert, so wären die einzelnen Staaten zu beschlagworten.

Baltikum kann nicht nur im geographischen Sinn verwendet werden, sondern für alle

Sachgebiete.

SWW Baltikum; Politisches System

nicht: Litauen ; Politisches System usw.

2. Das Dokument wird möglichst spezifisch, präzise erschlossen, d. h. je nach Sachverhalt werden speziellere oder allgemeinere Schlagwörter verwendet. Einschränkungen ergeben sich dort, wo eine Differenzierung mit verbalen Mitteln nur sehr schwer möglich ist (vgl. u. a. Quasisynonyme § 315, Namen chemischer Verbindungen § 315,4) und bei der Darstellung von Beziehungen (vgl. § 14,1) sowie bei der Beschlagwortung von Belletristik, Kinder- und Jugendliteratur (vgl. §§ 762, 765 sowie 5,3).

\author{
Inhalt: Der Aminosäuregehalt einiger Mutanten und Rekombinanten von Phaseolus coccineus \\ SWW Feuerbohne; Aminosäuren \\ nicht: Bohne ; Aminosäuren \\ Titel: Chapbooks : zur Literaturgeschichte des einfachen Lesers ; englische Konsumliteratur \\ 1680-1840 / Rainer Schöwerling. - 1980 \\ SWW Chapbook; Leser \\ nicht: Großbritannien ; Leser ; Geschichte 1680-1840 \\ oder: Englisch ; Unterhaltungsliteratur ; Geschichte 1680-1840 \\ Inhalt: Geschichte der ETA \\ SWW ETA; Geschichte \\ nicht: Baskenland ; Unabhängigkeitsbewegung ; Geschichte
}

3. Der Dokumenteninhalt und die Gesamtheit der vergebenen Schlagwörter sollen deckungsgleich sein. Es werden keine über den Dokumenteninhalt hinausgehenden Schlagwörter verwendet, z. B. keine Oberbegriffe (oder keine zusätzlichen allgemeineren Schlagwörter) zusätzlich zu den für den Dokumenteninhalt erforderlichen Schlagwörtern. Der sachliche Kontext des im Dokument behandelten Gegenstands wird i. d. R. nur durch Verweisungen auf der begrifflichen Ebene in der SWD bzw. durch eine Klassifikation abgedeckt (vgl. § 12 und § 13,4). 
$\begin{array}{lc}\text { SW } & \text { HP LaserJet IV } \\ \text { OB } & \text { Laserdrucker } \\ \text { nicht: } & \text { Laserdrucker / HP LaserJet IV }\end{array}$

Titel: Informieren, unterhalten, bilden : Medien zwischen Wirkung und Nutzen / Joachim Paschen. - 1994

SWW Medienkonsum ; Massenmedien ; Wirkung ; Politischer Unterricht ; Lehrmittel nicht zusätzlich: Medienpädagogik. Medienpädagogik ist nicht Oberbegriff zu einem der verwendeten Begriffe, sondern das weitere Sachgebiet, zu dem die vorliegenden Spezialabhandlung gehört. Es handelt sich auch nicht um einen zweiten Gegenstand (vgl. \& 13,4). Ein solcher sachlicher Bezug kann nur durch eine Klassifikation abgedeckt werden.

4. Gleiche Gegenstände werden gleich erschlossen. Dies gilt insbesondere für verschiedene Ausgaben desselben Werks (vgl. auch § 9,2).

\section{§ $7 \quad$ Verhältnis von Schlagwort und Schlagwortkette}

1. Bei der Schlagwortkatalogisierung sind drei Ebenen zu unterscheiden:

- der Begriff: Er wird durch das Schlagwort repräsentiert.

- der Gegenstand: Er wird durch die Schlagwortkette repräsentiert.

- der Dokumenteninhalt: Er wird durch die Gesamtheit der für ein Dokument vergegebenen Schlagwortketten repräsentiert.

Ein Dokumenteninhalt kann aus nur einem Gegenstand, ein Gegenstand aus nur einem Begriff bestehen.

2. Die wichtigste Ebene für Erschließung und Retrieval ist das Schlagwort. Es muss einerseits so spezifisch sein, dass es einen eindeutig festgelegten Begriffsumfang hat (Differenzierung von Homonymen). Andererseits kann die Verwendung in unterschiedlichen Zusammenhängen nicht immer auf der Begriffsebene dargestellt werden, v. a. bei Allgemeinbegriffen. Hier erfolgt die Differenzierung durch die Bildung von Schlagwortketten. Auch die Zerlegungskontrolle bei komplexen Begriffen kann zur Verwendung von Schlagwortketten führen (vgl. $\S \S 8,5 ; 304,3)$.

SW $\quad$ Einstellung $<$ Arbeitsrecht $>$

SW Einstellung $<$ Prozessrecht $>$

nicht: Einstellung ; Arbeitnehmer

oder: Einstellung; Prozess

Etymologisch gesehen haben beide Begriffe zwar den gleichen Ursprung, wegen ihrer semantischen Unterschiede werden sie jedoch als Homonyme behandelt.

SW Strafe

Beispiele für Schlagwortketten:

SWW Strafe ; Lernpsychologie

SWW Strafe; Rechtstheorie

Der Begriff 'Strafe' wird in Philosophie, Pädagogik und Recht benutzt. Es handelt sich dabei um ein Polysem mit jeweils gleicher Grundbedeutung. Da es zusammenfassende Darstellungen gibt, ist die Trennung durch Homonymenzusätze nicht möglich. Die spezifische Bedeutung wird daher durch die Schlagwortketten ausgedrückt.

SWW Eisenlegierung; Amorpher Zustand

nicht: Amorphe Eisenlegierung 


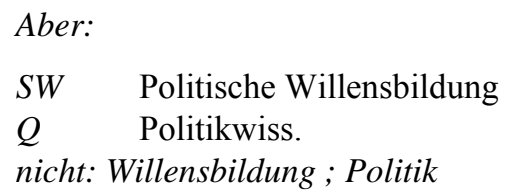

3. Ist in einer Schlagwortkette die Verwendung mehrerer hierarchisch übergeordneter Begriffe denkbar, so soll der jeweils spezifischste Begriff verwendet werden (zum Pleonasmus in der Schlagwortkette vgl. § 324).
SWW Schulleistung; Leistungsmessung
nicht: Schulleistung ; Messung
oder: Schule ; Leistungsmessung

4. Die Schlagwörter werden in der SWD geführt.

Anm.1: Personenschlagwörter werden gemeinsam mit den für die Formalerschließung benötigten Personennamen in der Personennamendatei (PND) geführt. Soweit in vorliegendem Regelwerk von der SWD die Rede ist, sind damit i. d. R. auch die als Schlagwörter genutzten Datensätze der PND gemeint.

Anm. 2: Die im Folgenden verwendeten Symbole können im OPAC oder in Listenfunktionen anders wiedergegeben werden, z. B. durch s. bzw. s. a., durch die Bezeichnung der Verweisung (z. B. 'Oberbegriff') oder auf andere Weise.

Überblick über die wichtigsten in Schlagwortsätzen enthaltenen Informationen (vgl. auch $\S \S 111 \mathrm{a} ; 213 \mathrm{a} ; 318 ; 405 \mathrm{a} ; 503 \mathrm{a} ; 620 \mathrm{a})$.

Verbale Elemente:

- Ansetzungsform (ggf. mehrgliedrig) (vgl. §§ 8-10)

- Alternative Ansetzungsform für öffentliche Bibliotheken (wird für wissenschaftliche Bibliotheken in eine Verweisungsform umgesetzt; analog wird dann bei öffentlichen Bibliotheken mit der Ansetzungsform verfahren) (Symbol ÖB)

- Synonyme (Symbol BS / BF) (zu Verweisungen vgl. § 12)

- Oberbegriffe (Symbol OB)

- Unterbegriffe (Symbol UB)

- Mehrgliedrige Oberbegriffe (Symbol MO)

- Unterbegriffe zu den mehrgliedrigen Oberbegriffen (Symbol MU)

- Verwandte Begriffe (Symbol VB)

- Chronologische verwandte Begriffe (Symbole CF früher, CF später)

Codierungen

- Indikator (vgl. § 11)

- Notation einer oder mehrerer Klassifikationen (Symbol SYS) (vgl. § 18,1)

- Ländercode (Symbol LC) (vgl. § 18,2)

- Sprachencode (Symbol SC) (vgl. § 18,3)

- Zeitcode (Symbol ZC) (vgl. §§ 18,4; 418)

Bemerkungen

- Quelle für die Ansetzungsform (Symbol Q) (vgl. § 19,1)

- Definition des Begriffs (Symbol D) (vgl. § 19,2)

- Verwendungshinweis (Symbol H) (vgl. § 19,3)

- Redaktionelle Bemerkung (Symbol R) (vgl. § 19,4) 
Verwaltungsinformationen

- Status

- Daten der Bearbeitung

- Geschichte des Satzes

- Kennzeichnung nicht mehr verwendeter Sätze

- Verknüpfung mit der GKD (Symbol GKD) (vgl. §§ 202,2; 602,2).

5. Neben den Schlagwörtern werden in die SWD auch Hinweissätze aufgenommen, soweit eine Verweisung auf die Verknüpfung mehrerer Schlagwörter erforderlich ist. Der Ausgangspunkt der Verweisung wird mit dem Symbol BF (Benutzt für) dargestellt. Beim jeweiligen Titel wird nicht der Hinweissatz verwendet, sondern die im Hinweissatz angeführten Schlagwörter.

\author{
BF Betonkorrosion \\ Hinweissatz, gekennzeichnet in MAB Feld 067 \\ SWW Beton; Korrosion \\ Titel: $\quad$ Betonkorrosion / Red. Bearb.: Friedrich Breckner. - 1993 \\ SWW Beton; Korrosion \\ Beim Titel werden die Schlagwortsätze ‘Beton' und 'Korrosion' verwendet. \\ $B F \quad$ Trier $<$ Diözese $>/$ Kloster / Handschrift / Sammlung \\ Hinweissatz, gekennzeichnet in MAB Feld 067 \\ SWW Koblenz / Landeshauptarchiv Koblenz ; Handschrift ; Geschichte 816-1945
}

\title{
§ 8 Formen des Schlagworts
}

1. Ein Schlagwort kann aus einem oder aus mehreren Wörtern oder einer Verbindung von Wörtern bzw. Buchstaben mit Ziffern (sowie ggf. Sonderzeichen) bestehen und durch einen Homonymenzusatz (vgl. § 10) ergänzt werden, z. B. einfaches Substantiv, Kompositum, Adjektiv-Substantiv-Verbindung, Wortfolge (vgl. § 305), mehrgliedriges Schlagwort (§ 8,4), Familien- und Vorname (vgl. § 101), Individualname von geographischen/ethnographischen Einheiten (vgl. §§ 201; 212) und Körperschaften (vgl. § 601), Werktitel (vgl. §§ 707; 708) sowie Zeitangaben mit Jahreszahlen (vgl. § 401) und Formeln (vgl. § 314). 
Anm.: Kompositum, Adjektiv-Substantiv-Verbindung, Schlagwörter mit Homonymenzusatz, Wortfolge und mehrgliedriges Schlagwort werden unter dem Begriff 'Präkombinierte Bezeichnung' bzw. 'Präkombiniertes Schlagwort' zusammengefasst.

2. Bei den Schlagwörtern werden Individualnamen (Bezeichnungen für Individualbegriffe) und Bezeichnungen für Allgemeinbegriffe (abstrakte Begriffe) unterschieden. Einschlägige Allgemeinbegriffe werden entsprechend der jeweiligen Regeln als Oberbegriffe zu Individualbegriffen berücksichtigt.

Die Verwendung von Individualnamen ist im Regelwerk in den Paragraphen § 101a; § 201a,1-2 u. 4; § 306a ; § 415a; § 601a einschließlich weiterer Sonderregelungen in §§ 701ff festgelegt.

Auf die Verwendung von Individualnamen wird verzichtet, wenn

- im vorliegenden Dokument der Individualbegriff nicht substanziell, sondern eher stellvertretend für andere ähnliche Gegenstände behandelt wird, oder

- wenn die umschreibende Beschlagwortung (oder auch ein Oberbegriff) eine einheitlichere Erschließung und damit zugleich eine bessere Voraussehbarkeit und bessere Retrievalergebnisse bringt, z. B. bei entlegenen Gegenständen, Namen von Produkten, Projekten, Programmen, Methoden oder Verfahren ohne Nachweis in den Nachschlagewerken (vgl. u. a. § 306a,10).

Anm.: Bibliotheken mit regionalem oder fachlichem Schwerpunkt können darüber hinaus zusätzliche Ketten mit Individualnamen bilden.

Beispiel für Oberbegriffe:

$S W \quad$ HAWIK

$O B \quad$ Intelligenztest

Beispiele für Individualbegriffe, die nicht substanziell behandelt werden:

Titel: $\quad \neg$ Die $\neg$ Frauen von Isabey / Magda Taroni. - 1986

SWW Türkei ; Frau ; Ländlicher Raum ; Bildband

Es handelt sich um einen Bildband, der die geachtete Stellung der Frau im türkischen Dorf darlegen möchte. Das Dorf Isabey wird nicht substanziell behandelt.

Titel: Mathematik in den Jahrgangsstufen 3 und 4 des Sonderpädagogischen Förderzentrums / Staatsinstitut für Schulpädagogik und Bildungsforschung München. - 1996

SWW Mathematikunterricht ; Diagnose- und Förderklasse ; Schuljahr 3-4

Das Sonderpädagogische Förderzentrum, an dem sich die Diagnose- und Förderklasse befindet, wird nicht substanziell behandelt; das Retrieval erfolgt über die einschlägigen Sachschlagwörter. 
Beispiele für umschreibende Beschlagwortung:

Ausweichen auf einen Oberbegriff:

Inhalt: 2,7 (Bis-dimethylamino)-9,9-dimethylanthracen

SW Anthracenderivate

vgl. § 306a,8 und die Praxisregeln: Die präzise chemische Bezeichnung ist zur Erschließung nicht geeignet.

Sachverhalt wird durch mehrere Allgemeinbegriffe wiedergegeben:

Titel: $\quad$ Das schulische Enrichment-Modell SEM / Joseph S. Renzulli; Sally M. Reis ; Ulrike Stedtnitz. - 2001

SWW Schweiz; Begabtenförderung; Projekt

Anstelle des Projektnamens erleichtert die Beschlagwortung mit vorhandenen Schlagwörtern das Wiederauffinden des Titels.

Titel: Bescheidenliche Tortur : der ehrbare Rat der Stadt Nördlingen im Hexenprozeß 1593/94 gegen die Kronenwirtin Maria Holl / Gloria Eschbaumer. - 1983

SWW Nördlingen ; Hexenprozess ; Geschichte 1593-1594

Es werden sowohl der spezielle Hexenprozess wie auch der Gegenstand Hexenprozess in Nördlingen behandelt. Der Name der Maria Holl könnte von einer Bibliothek mit regionalem oder fachlichem Schwerpunkt in einer weiteren Kette berücksichtigt werden.

3. Einzelne konkrete Gegenstände, die keinen Individualnamen haben, werden durch Bezeichnungen für einschlägige Allgemeinbegriffe in Kombination mit anderen individualisierenden Angaben (z. B. dem Individualnamen eines Orts) wiedergegeben und i. d. R. nicht in die SWD aufgenommen (vgl. z. B. § 730,3). (Zur Ansetzung als mehrgliedriges Schlagwort vgl. jedoch Abs. 4, zur Aufnahme von Schlagwortketten als Hinweissätze in die SWD vgl. § 7,5.)

Titel: $\quad \neg$ Die $\neg$ Schnabelkanne vom Dürrnberg / Fritz Moosleitner. - 1985

SWW Dürrnberg < Hallein> ; Schnabelkanne

Es handelt sich um einen einzelnen Gegenstand; wenn weitere Schnabelkannen am Dürrnberg gefunden würden, würden diese gleich beschlagwortet, also nicht differenziert.

4. Kann ein Individualbegriff nicht durch ein einzelnes Wort, ein Kompositum, eine AdjektivSubstantiv-Verbindung oder eine Wortfolge ausgedrückt werden, so wird er als mehrgliedriges Schlagwort wiedergegeben und in die SWD aufgenommen.

Mehrgliedrige Schlagwörter werden vor allem gebildet, wenn alle Teile aus Individualnamen bestehen. In folgenden Fällen können mehrgliedrige Schlagwörter gebildet werden, die aus einem Individualnamen und einem Schlagwort für einen Allgemeinbegriff bestehen: bei historischen Einzelereignissen (vgl. § 415a,2), Körperschaften (vgl. § 605,2), Werken (vgl. § 708,3), Titeln von Rechtsnormen (vgl. § 715), Bauwerken (vgl. §§ 724; 730; 731) und musikalischen Werken (vgl. § 739,2). Mehrgliedrige Schlagwörter zur Wiedergabe von zwei Allgemeinbegriffen sind nicht zugelassen (vgl. § 304,1,b).

In der Darstellung werden die Teile von mehrgliedrigen Schlagwörtern durch Spatium Schrägstrich Spatium getrennt und nicht permutiert. 
Anm.: Auch Hinweissätze, die nach § 7,5 in die SWD aufgenommen sind, werden dort derzeit noch mit Spatium Schrägstrich Spatium dargestellt.

$\begin{array}{ll}\text { SW } & \text { Düppeler Schanzen / Erstürmung } \\ \text { SW } & \text { Kolin / Schlacht } \\ \text { SW } & \text { Metten / Kloster } \\ \text { SW } & \text { Kant, Immanuel / Kritik der reinen Vernunft } \\ \text { SW } & \text { Beethoven, Ludwig } \neg \text { van } / \text { Messe op. } 123 \\ \text { SW } & \text { Österreich / Einkommensteuergesetz } \\ \text { SW } & \text { Nibelungenlied / Handschrift C } \\ \text { SW } & \text { Jean < Berry, Herzog, II. > / Belles heures } \\ \text { SW } & \text { Dürer, Albrecht / Friedrich der Weise } \\ \text { SW } & \text { Straßburg / Münster / Engelspfeiler } \\ \text { SW } & \text { Nürnberg / Burg }\end{array}$

5. Bevor für einen Begriff (Individual- bzw. Allgemeinbegriff) ein neues Schlagwort eingeführt wird, ist zu prüfen, ob er durch eine gebräuchliche Bezeichnung wiedergegeben oder durch zwei oder mehr Schlagwörter dargestellt werden soll (vgl. § 304,3, Zerlegungskontrolle bei Allgemeinbegriffen).

Sowohl Allgemein- als auch Individualbegriffe können durch mehrere Schlagwörter wiedergegeben werden. Für die Gebräuchlichkeit sind die Nachschlagewerke in der festgelegten Reihenfolge, der Sprachgebrauch und die Verwendung analoger Begriffe in der SWD heranzuziehen.

Präkombinierte Sachschlagwörter, die mit Personennamen (vgl. §§ 111; 305,2,d), geographischen/ethnographischen Bezeichnungen (vgl. §§ 213; 305,2,e), Formschlagwörtern (vgl. §§ 305,2,g; 502) oder Körperschaftsnamen (vgl. §§ 305,2,f; 620) gebildet werden, sind nur in geringem Umfang zugelassen.

Auf die Ansetzung von Schlagwörtern wird verzichtet, wenn sie nicht in die vorhandene Terminologie einzupassen, oder aus anderem Grund nicht praktikabel sind; etwa wenn sie unzureichende Retrievalergebnisse erwarten lassen. Voraussetzung für eine Wiedergabe eines Begriffs durch mehrere Schlagwörter ist, dass die dafür benötigten, hinlänglich prägnanten Schlagwörter in der SWD vorhanden sind und dass ihre Verknüpfung dem Begriffsinhalt semantisch entspricht (vgl. § 304,2,b). 
Wird eine gebräuchliche präkombinierte Bezeichnung nicht als Schlagwort angesetzt, so kann mit einem Hinweissatz auf die zu verwendenden Schlagwörter verwiesen werden (vgl. $\S 7,5)$.

Beispiele für eine Wiedergabe durch mehrere Schlagwörter:

SWW Musikinstrument ; Restaurierung

nicht: Musikinstrumentenrestaurierung

SWW Italien ; Wein

nicht: Italienischer Wein

Beispiele für Hinweissätze:

SWW Beton ; Korrosion

Hinweissatz, gekennzeichnet in MAB Feld 067

BF Betonkorrosion

SWW Hauslabjoch; Gletscherleiche

Hinweissatz, gekennzeichnet in MAB Feld 067

$B F \quad$ Ötzi

SWW Geometrie ; Mathematikunterricht

Hinweissatz, gekennzeichnet in MAB Feld 067

$B F \quad$ Geometrieunterricht

"Geometrieunterricht" lässt sich nicht in die vorhandene Terminologie einpassen, weil es kein Schulfach ist. Es ist Teil des „Mathematikunterrichts“ und wird deshalb, wie im Hinweissatz angegeben, verknüpft.

SWW Lehrer; Schüler

Hinweissatz, gekennzeichnet in MAB Feld 067

$B F \quad$ Lehrer-Schüler-Beziehung

$B F \quad$ Lehrer-Schüler-Verhältnis

"Lehrer-Schüler-Beziehung" ist zwar durchaus gebräuchlich, aber als Schlagwort nicht praktikabel. Die Verknüpfung führt zu besseren Retrievalergebnissen, da in gleicher Weise auch Unterbegriffe zu Lehrer (z. B. Sportlehrer) oder Schüler (z. B. Hauptschüler) miteinander verknüpft werden 


\section{§ 9 Ansetzung des Schlagworts}

1. Die Ansetzung des Schlagworts umfasst

- die Festlegung der Ansetzungsform (Vorzugsbezeichnung), die den Begriff eindeutig vertritt,

- die Erfassung von Synonymen und Quasisynonymen (vgl. § 12)

- die Kennzeichnung von Homonymen und Polysemen (vgl. § 10)

- die Zerlegungskontrolle (vgl. § 8,5)

- die Festlegung einer eindeutigen Definition, soweit begriffliche Unklarheiten vorliegen $(\S 19,2)$.

Verweisungen (§ 12), Notationen (§ 18,1) und Quellenangaben (§ 19,1) dienen in gewissem Umfang der Definition. Bei der Verweisung von Quasisynonymen werden aber Unschärfen hingenommen.

Wird ein Begriff erstmals benutzt und ist seine Definition oder sprachliche Formulierung unklar, so wird das Schlagwort mit 'Vorläufige Ansetzung' gekennzeichnet (vgl. § 19,4).

2. Gleiche Begriffe müssen immer durch das gleiche Schlagwort bezeichnet werden (vgl. auch $\S 6,4)$.

3. Das Grundprinzip der Ansetzung ist die Gebräuchlichkeit, d. h. von mehreren Bezeichnungen wird die gebräuchlichste gewählt. Das Vokabular des Schlagwortkatalogs basiert auf der natürlichen Sprache (Allgemeinsprache und Fachsprachen). Es soll der zu erwartenden Suchsprache von Benutzern entsprechen, muss aber in der SWD einheitlich sein, auch wenn die Suchsprache verschiedener Benutzer an verschiedenen Bibliotheken und Retrievalsystemen Unterschiede aufweist. Normierungen sind daher für die Konsistenz der Erschließung notwendig. In diesem Punkt ist ggf. ein Abweichen von der natürlichen Sprache, auch den Fachsprachen, erforderlich.

Die Möglichkeit, Schlagwortketten zu bilden (syntaktische Indexierung), und die Einbettung des Prinzips der Gebräuchlichkeit in die Umgebung von Online-Katalogen mit postkoordinierender Suche (vgl. § 20,2) bedingen, dass die verwendete Terminologie das rechte Maß zwischen extremer Ausführlichkeit und extremer Verknappung sowie zwischen extremer Präkombination (z. B. komplexe Komposita, ganze Sätze oder Phrasen) und extremer Begriffszerlegung einhalten muss (Zerlegungskontrolle vgl. § 8,5).

Schlagwörter sind i. d. R. Wörter der deutschen Sprache, jedoch können auch Bezeichnungen aus anderen Sprachen gewählt werden, wenn es keine gleichwertige, gebräuchliche deutsche Bezeichnung gibt bzw. eine fremdsprachige Bezeichnung in der Fachsprache üblicher ist. Zur Feststellung der Gebräuchlichkeit sind die jeweils neueste deutschsprachige Allgemein- 
enzyklopädie einschließlich ihrer Nachträge, danach andere allgemeine und fachliche Nachschlagewerke einschließlich der Fachthesauri heranzuziehen. Wenn es keinen Nachweis gibt und auch die korrekte Wiedergabe des Begriffs durch mehrere verknüpfte Schlagwörter nicht möglich ist, so wird eine treffende Bezeichnung dem vorliegenden Dokument entnommen bzw. analog zu vorhandenen Schlagwörtern gemäß den Regeln und der in der SWD vorhandenen Terminologie modifiziert.

Eine Zusammenstellung von Nachschlagewerken enthält die „Liste der fachlichen Nachschlagewerke zu den Normdateien (SWD, GKD, PND). - Leipzig, Frankfurt am Main, Berlin: Dt. Nationalbibliothek“ (im Folgenden zitiert als „Liste der Nachschlagewerke“). Diese Liste gibt auch die Rangfolge an, in der die Nachschlagewerke zu benutzen sind.

4. Pleonastische Begriffe oder Begriffsteile, d. h. Begriffe bzw. Wortteile, die eine Häufung sinngleicher oder ähnlicher Elemente bringen, aber den Begriffsinhalt nicht wesentlich verändern, sollen vermieden werden (vgl. § 312).

$\begin{array}{ll}\text { SW } & \text { Partei } \\ \text { BF } & \text { Politische Partei } \\ \text { SW } & \text { Krise } \\ \text { nicht: } & \text { Krisensituation } \\ \text { SW } & \text { Bibliothek } \\ \text { BF } & \text { Bibliothekswesen }\end{array}$

\section{§ 10 Homonymenzusatz}

1. Gleich lautende Schlagwörter (Homonyme) können sowohl Wörter verschiedenen Ursprungs sein als auch Wörter mit ursprünglich gleichem Bedeutungsinhalt, die in verschiedenen Sachgebieten unterschiedliche Bedeutungskomponenten entwickelt haben (Polyseme) (vgl. $\S$ 306). Sie werden im Allgemeinen durch Zusätze (Homonymenzusätze) unterschieden. Der Homonymenzusatz dient nicht dazu, Erläuterungen zu geben.

Anm. 1: Ausnahmen bilden u. a. die differenzierenden Zusätze <Motiv> (vgl. § 705), < für Kinder > bei Formschlagwörtern (vgl. Anl. 6), die Unterscheidung von Himmelsrichtungen bei Geographika (vgl. § 205) sowie die Homonymenzusätze bei Orten Australiens, Kanadas und der USA (vgl. § 203,3,a).

Anm. 2: Zur Behandlung von Polysemen beim Sachschlagwort vgl. § 306.

Der Homonymenzusatz ist i. d. R. in deutscher Sprache anzusetzen und auszuschreiben. Er steht in Winkelklammern und ist Bestandteil der Ansetzungsform des Schlagworts. Bei einer Sortierung bildet er mit dem Schlagwort zusammen einen Ordnungsblock.

(Homonymenzusätze für gleichnamige Personen vgl. § 106, für gleichnamige geographische Bezeichnungen vgl. § 203, für gleichnamige Ethnographika vgl. § 212b,3, für gleichnamige Sachbezeichnungen vgl. § 306, für gleichnamige historische Einzelereignisse vgl. § 415a,1,a; für gleichnamige Körperschaften vgl. § 612 , für gleichnamige Werktitel vgl. § 710.)

2. Repräsentiert eines der Homonyme die Grundbedeutung bzw. ist es sehr viel gebräuchlicher als die anderen oder ist wesentlich mehr Literatur zu diesem Thema zu erwarten, so kann hier der Homonymenzusatz entfallen. 
SW Brücke

Für das Bauwerk; es handelt sich um die Grundbedeutung.

$S W \quad$ Brücke $<$ Graphentheorie $>$

$S W \quad$ Brücke $<$ Künstlervereinigung $>$

SW $\quad$ Brücke $<$ Teppich $>$

$S W \quad$ Brücke $<$ Zahnmedizin $>$

SW München

Für die Stadt in Bayern; sie ist sehr viel bekannter.

SW $\quad$ München $<$ Berka, Weimar $>$

SW Absatz

Für den Absatz von Waren; es ist sehr viel mehr Literatur zu erwarten.

SW Absatz $<$ Text $>$

SW Schuhabsatz

BF $\quad$ Absatz $<$ Schuh $>$

3. Homonymenzusätze sind im Allgemeinen in der Ansetzungsform der SWD zu verwenden, sofern es sich nicht um Namensbestandteile handelt (vgl. §§ 106,2; 202b; 203,2). Dabei entfällt i.d. R. eine dem als Homonymenzusatz verwendeten Begriff hinzugefügte unterscheidende Angabe, sofern die Eindeutigkeit nicht verlorengeht.

$S W \quad$ Mare Australe $<$ Mars $>$

daneben:

$S W \quad$ Mars $<$ Planet $>$

SW $\quad$ Zell $<$ Luzern $>$

daneben:

$S W \quad$ Luzern $<$ Kanton $>$

$S W \quad$ Alexander $<$ Makedonien, König, III. $>$

daneben:

$S W \quad$ Makedonien $<$ Altertum $>$

Aber:

SW $\quad$ Bergen $<$ Limburg, Niederlande $>$

Der Name Limburg wird für mehrere geographische Einheiten verwendet.

In mehrgliedrigen Schlagwörtern entfällt i. d. R. der Homonymenzusatz beim Sachschlagwort.

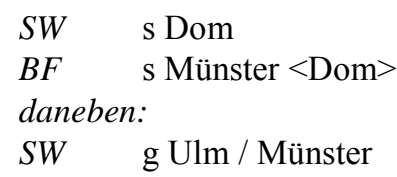

4. Mehrere Homonymenzusätze folgen innerhalb der Klammer aufeinander und werden durch Komma mit folgendem Spatium getrennt.

SW $\quad$ Otto $<$ Römisch-Deutsches Reich, Kaiser, I. $>$

$S W \quad$ Münster $<$ Westfalen, Diözese $>$

SW Weltkrieg $<1939-1945$, Motiv $>$

5. Ziffern, die lediglich der Zählung gleichartiger Schlagwörter (z. B. Sachschlagwörter, Körperschaftsschlagwörter) dienen, werden nicht als Homonymenzusatz behandelt (vgl. § 17,2,d und 305,1,b).

Anm.: Ausnahme: Zählung bei Altersstufen, z. B. Kind $<3$ Jahre>, und Körperschaften (vgl. § 602,5). 


\section{§ 11 Schlagwortkategorien, Indikatoren}

1. Fünf grundlegende inhaltliche Kategorien von Begriffen werden als Schlagwortkategorien unterschieden. Sie gliedern das Gesamtrepertoire der Schlagwörter und bestimmen die Reihenfolge in der Schlagwortkette (vgl. § 15).
a) Personenschlagwörter
b) Geographische/ethnographische Schlagwörter einschließlich Sprachbezeichnungen
c) Sachschlagwörter
d) Zeitschlagwörter
e) Formschlagwörter

2. Alle Schlagwortkategorien und weitere Begriffskategorien werden mit Indikatoren bezeichnet. Diese können zur Selektion bei der Recherche und zur Steuerung der Permutation von Schlagwortketten dienen:

Übersicht:

c Körperschaft, deren Ansetzungsform mit einem Geographikum beginnt

f Formschlagwort

g Geographisches/ethnographisches Schlagwort, Sprachbezeichnung

k Körperschaft (soweit nicht c)

$\mathrm{p}$ Personenschlagwort (in der PND durch die Satzart tp ersetzt)

s Sachschlagwort

$\mathrm{t}$ Titel eines Werkes

z Zeitschlagwort

Erläuterung zu einzelnen Kategorien:

Als Zeitschlagwörter gelten 'Geschichte' einschließlich seiner Komposita und 'Prognose', ggf. mit folgenden Jahreszahlen (Indikator z) (vgl. § 401).

Epochenbezeichnungen werden in der Schlagwortkette wie Sachschlagwörter behandelt (Indikator s) (zur Umsetzung in Jahreszahlen vgl. § 408a,1).

Historische Einzelereignisse werden in der Schlagwortkette behandelt (vgl. § 415):

- wie Personenschlagwörter, wenn ihre Ansetzungsform mit einem Personennamen beginnt (Indikator p),

- wie geographische/ethnographische Schlagwörter, wenn ihre Ansetzungsform mit einem Geographikum beginnt (Indikator g oder c),

- wie Sachschlagwörter (Indikator s).

Körperschaften werden in der Schlagwortkette behandelt (vgl. § 601,3):

- wie geographische Schlagwörter, wenn ihre Ansetzungsform mit einem Geographikum beginnt (Indikator c),

- wie Sachschlagwörter (Indikator k).

Titel von Werken werden in der Schlagwortkette behandelt (vgl. § 708):

- Verfasserwerke als mehrgliedriges Schlagwort wie Personenschlagwörter (Indikatoren $p$ und $\mathrm{t}$ ).

- Sachtitelwerke wie Sachschlagwörter (Indikator t).

- Urheberwerke wie Sachschlagwörter (Indikatoren $k$ und t) bzw. wie geographische Schlagwörter (Indikatoren $\mathrm{c}$ und $\mathrm{t}$ bzw. $\mathrm{g}$ und $\mathrm{t}$ ). 
3. Indikatoren werden bei der Ansetzungsform und bei den Verweisungsformen erfasst. Bei Synonymen wird unabhängig von der Ansetzungsform derjenige Indikator gewählt, dem der betreffende Begriff bzw. das erste Glied der mehrgliedrigen Verweisungsform zuzuordnen ist.

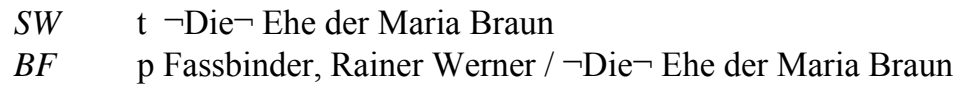

\section{$\S 12$ Verweisungen}

1. Definition

Eine Verweisung ist die Darstellung der Relation zwischen Bezeichnungen bzw. Begriffen. Sie besteht aus der Bezeichnung dessen, wovon verwiesen wird, und der Bezeichnung dessen, worauf verwiesen wird. Beide Bezeichnungen werden durch eine abgekürzte Verweisungsformel verbunden (vgl. § 7,4). Verweisungen werden reziprok dargestellt.

2. Synonymie-Verweisungen

a) Synonymie-Verweisungen dienen der Wiedergabe von Äquivalenzrelationen, d. h. der Beziehung zwischen mehreren Bezeichnungen, die bedeutungsgleiche oder quasisynonyme Begriffe repräsentieren. Sie führen den Benutzer von einer nicht als Schlagwort zugelassenen auf eine zugelassene Bezeichnung (Ansetzungsform). Symbole: BS (Benutze Synonym) und BF (Benutzt für).

Anm.: Unter Synonym wird in den RSWK eine nicht als Ansetzungsform gewählte Bezeichnung (auch eine Kette aus mehreren Bezeichnungen) verstanden, die als Verweisungsform erfasst wird.

SW Novalis

$B F \quad$ Hardenberg, Friedrich Leopold $\neg$ von $\neg$

$V w \quad$ Hardenberg, Friedrich Leopold $\neg$ von $\neg B S$ Novalis

b) $\mathrm{Zu}$ solchen Verweisungen zählen insbesondere:

- Verweisungen auf den aktuellen Sprachgebrauch

SW Köln

BF Colonia Agrippinensis

- Verweisungen von einer abgekürzten auf eine ausgeschriebene Form (oder umgekehrt)

SW Deutsche Demokratische Partei

BF DDP

- Verweisungen von unterschiedlichen sprachlichen Darstellungsformen oder Schreibvarianten, um möglichst viele Sucheinstiege anzubieten, insbesondere Verweisungen von der semantisch zerlegten Darstellung auf Komposita. Ausgeschlossen sind bei Adjektiv-Substantiv-Verbindungen Verweisungen von der invertierten Form.

$\begin{array}{ll}S W & \text { Altenarbeit } \\ B F & \text { Alter/Sozialarbeit } \\ & \text { Altenbetreuung } \\ & \text { Altensozialarbeit } \\ & \text { Seniorenarbeit }\end{array}$


- Verweisungen zwischen Quasisynonymen, d.h. zwischen bedeutungsähnlichen Bezeichnungen, die für Indexierung und Retrieval als Synonyme behandelt werden (vgl. § 315).
SW Psychische Belastung
$B F \quad$ Psychische Beanspruchung

- Verweisung vom deutschen Übersetzungstitel auf den Originaltitel (vgl. §§ 709; 733,1; 740).

- Einen Sonderfall bildet die Verweisung von einer nicht gewählten präkombinierten Wiedergabe eines Begriffs auf die $\mathrm{zu}$ seiner Darstellung $\mathrm{zu}$ verknüpfenden Schlagwörter (vgl. § 7,5).

c) Synonymie-Verweisungen werden in den Fällen wiederholt, in denen die angesetzte Bezeichnung Teil eines mehrgliedrigen Kompositums oder präkombinierten Schlagworts ist, wenn dies zur Führung des Benutzers notwendig ist.
$S W \quad$ Bauchspeicheldrüse
BF Pankreas
daneben:
$\begin{array}{ll}S W & \text { Bauchspeicheldrüsenkrebs } \\ B F & \text { Pankreascarcinom }\end{array}$

Pankreascarcinom ist fachsprachlich geläufig.

Aber:

$S W \quad$ Ljubljana

$B F \quad$ Laibach

$S W \quad$ Ljubljana / Naturkundemuseum

Ohne BF Laibach / Naturkundemuseum; die Wiederholung der Verweisung bei allen ortsgebundenen Körperschaften wäre sehr aufwendig.

d) Ist bei Synonymie-Verweisungen die nicht gewählte Form mit einer gleich lautenden Ansetzungsform oder gleich lautenden Verweisungsformen anderer Schlagwörter identisch, so wird sie durch einen Homonymenzusatz von dieser unterschieden. Ausnahmen bilden die Verweisungen mehrerer gleich lautender Abkürzungen auf die Vollform (vgl. § 602,4) und von gleich lautenden Personennamen (vgl. § 106,4).

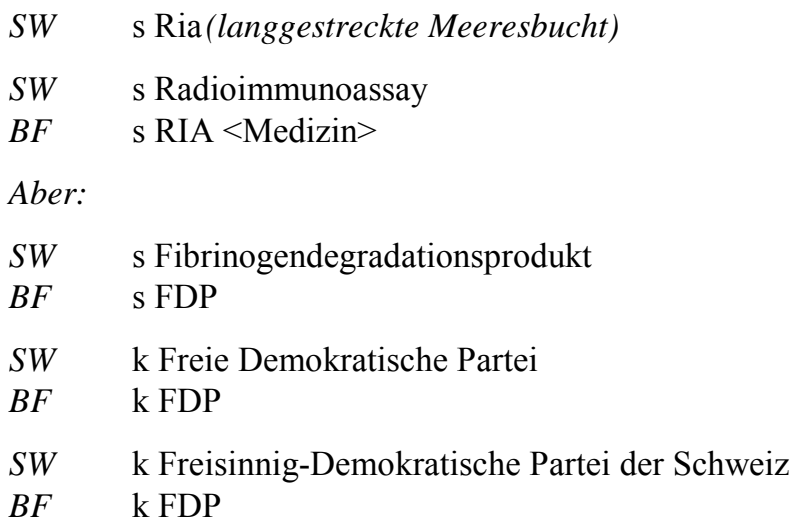


3. Hierarchische Verweisungen

a) Hierarchische Verweisungen stellen die hierarchische Relation zwischen verschiedenen Begriffen auf Grund gemeinsamer Merkmale dar, d. h. die Beziehung zwischen Unterund Oberbegriffen. Symbole: UB (Unterbegriff) und OB (Oberbegriff). Die hierarchischen Verweisungen strukturieren das Vokabular der SWD, indem sie eine zielgerichtete Recherche vom Allgemeinen zum Spezifischen und umgekehrt erlauben.

$\begin{array}{ll}S W & \text { Altenarbeit } \\ O B & \text { Sozialarbeit } \\ \text { SW } & \text { Sozialarbeit } \\ \text { UB } & \text { Altenarbeit }\end{array}$

b) Bei den hierarchischen Relationen gibt es zwei Formen, die jedoch in der SWD formal nicht unterschieden werden:

Abstraktionsrelation (logische Beziehung, generische Beziehung):

In der Abstraktionsrelation schließt der Begriffsinhalt des untergeordneten Begriffs den Begriffsinhalt des Oberbegriffs ein, wobei sich der Unterbegriff in mindestens einem zusätzlichen Merkmal, das in der betreffenden Merkmalart des Oberbegriffs nicht spezifiziert wurde, vom Oberbegriff unterscheidet. Der Begriffsumfang (Extension) des Oberbegriffs umfasst alle Unterbegriffe mit den Merkmalen des Oberbegriffs.

SW Psychotherapie

UB Gruppentherapie

Gruppentherapie hat alle Merkmale des OB Psychotherapie sowie ein zusätzliches Merkmal, welches die Art der Durchführung in Gruppen bestimmt.

Partitive Relation (Bestandsrelation, Ganzes-Teil-Beziehung):

In der partitiven Relation steht der einem Ganzen entsprechende übergeordnete Begriff mit den Unterbegriffen in einer Beziehung, die sich durch gedankliche Zerlegung des Ganzen in seine Teile ergibt. Derartige Beziehungen bestehen i.d.R. zwischen Begriffen des materiell-gegenständlichen Bereichs.

SW Bein

UB Oberschenkel

c) Im Hinblick auf die Navigation in der SWD ist anzustreben, dass Sachschlagwörter durchgängig und Individualnamen in dem vom Regelwerk definierten Umfang relationiert sind. Hierarchieleitern sollen vollständig vom speziellen bis zum allgemeinen Schlagwort wiedergegeben werden.

$\begin{array}{ll}\text { SW } & \text { Test } \\ \text { UB } & \text { Persönlichkeitstest } \\ \text { SW } & \text { Persönlichkeitstest } \\ U B & \text { Wahlverfahren <Psychologie> } \\ O B & \text { Test } \\ \text { SW } & \text { Wahlverfahren <Psychologie> } \\ U B & \text { Farbentest } \\ O B & \text { Persönlichkeitstest } \\ \text { SW } & \text { Farbentest } \\ U B & \text { Farbpyramidentest } \\ O B & \text { Wahlverfahren }<\text { Psychologie }>\end{array}$


SW Farbpyramidentest

$O B$ Farbentest

Die hierarchische Verweisung erfolgt i.d.R. nur zwischen unmittelbar über- und untergeordneten Begriffen.

$\begin{array}{ll}\text { SW } & \text { Artikulationsstörung } \\ O B & \text { Sprachstörung } \\ \text { SW } & \text { Stammeln } \\ \text { OB } & \text { Artikulationsstörung } \\ \text { nicht: } & \text { OB Sprachstörung }\end{array}$

d) Sind mehrere Begriffe auf gleicher Stufe übergeordnet (Polyhierarchie) oder untergeordenet (Polydimensionalität), so wird mehrfach verwiesen.

Im Falle der Polyhierarchie können einem Begriff mehrere Oberbegriffe auf gleicher hierarchischer Stufe als Folge unterschiedlicher Ordnungskriterien zugeteilt werden (vgl. auch § 316,4). Polyhierarchien liegen vor, wenn ein Begriff z.B. zu mehr als einer Systemstelle bzw. Begriffsklasse gehört.

$\begin{array}{lll}S W & \text { Herzmuskel } & \\ O B & \text { Herz } & \begin{array}{l}\text { (Ganzes-Teil-Beziehung) } \\ \text { (Abstraktionsbeziehung) }\end{array} \\ O B & \text { Muskel } & \\ \text { SW } & \text { Baumtest } & \text { (getestetes Merkmal) } \\ O B & \text { Entwicklungstest } & \text { (getestetes Merkmal) } \\ O B & \text { Persönlichkeitstest } & \text { (Testverfahren) }\end{array}$

In diesem Falle befindet sich der Unterbegriff in einer Abstraktionsrelation zu allen Oberbegriffen (er enthält jeweils alle Merkmale des jeweiligen Oberbegriffes). Diese Oberbegriffe wiederum wären in einer psychologischen Klassifikation unterschiedlichen Systemstellen zuzuordnen, wie etwa Entwicklungspsychologie, Persönlickeitspsychologie und Testpsychologie.

Im Falle der Polydimensionalität können einem Begriff mehrere Unterbegriffe auf gleicher hierarchischer Ebene zugewiesen werden. Unterbegriffe mit einem gemeinsamen nächsthöheren Oberbegriff haben entweder miteinander gemeinsam die Merkmale ihres Oberbegriffs (Abstraktionsbeziehung) oder sie sind gemeinsam Bestandteil des durch den Oberbegriff wiedergegebenen Ganzen (Ganzes-Teil-Beziehung).

SW $\quad$ Verbrennungsmotor
SW $\quad$ Dieselmotor
OB $\quad$ Verbrennungsmotor
Abstraktionsrelation, Unterscheidung nach Art des verbrannten Kraftstoffs
SW $\quad$ Ottomotor
OB $\quad$ Verbrennungsmotor
Abstraktionsrelation, Unterscheidung nach Art des verbrannten Kraftstoffs
SW $\quad$ Viertaktmotor
OB $\quad$ Verbrennungsmotor
Abstraktionsrelation, Unterscheidung nach dem Funktionsprinzip
SW $\quad$ Zweitaktmotor
OB $\quad$ Verbrennungsmotor
Abstraktionsrelation, Unterscheidung nach dem Funktionsprinzip




$\begin{array}{ll}\text { SW } & \text { Krankenhaus } \\ \text { SW } & \text { Intensivstation } \\ \text { OB } & \text { Krankenhaus } \\ \text { Ganzes-Teil-Beziehung } \\ \text { SW } & \text { Rheumaklinik } \\ \text { OB } & \text { Krankenhaus } \\ \text { Abstraktionsbeziehung }\end{array}$

e) Um in einem universellen Begriffsnachweissystem hierarchische Bezüge möglichst lückenlos erstellen zu können, ist es u. U. erforderlich, einen Oberbegriff nachzuweisen, der für sich allein in eingeschränkter Bedeutung verwendet wird. Derartige Oberbegriffe sind üblicherweise stark polysem, jedoch im Hinblick auf die Eindeutigkeit einer Dokumentationssprache in der SWD in ihrem Begriffsinhalt eng definiert. Sie können bei generisch aufsteigender Suche nur in dem definierten Begriffsinhalt zu relevanten Treffern führen, für alle anderen möglichen Bedeutungen ist die Treffermenge leer. Es ist dann erforderlich, in der SWD sowohl die genaue begriffsinhaltliche Bestimmung des Oberbegriffs in seiner Verwendung als Schlagwort, als auch seine polyseme Funktion zu verdeutlichen.

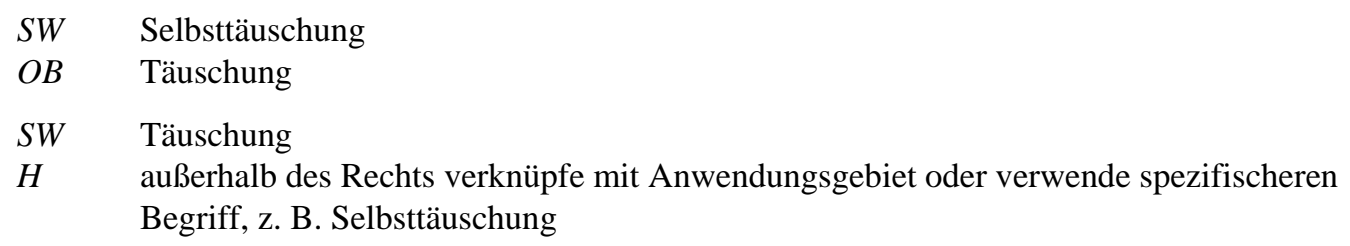

f) Hierarchische Verweisungen werden in den Datensätzen wiederholt, in denen der Unterbegriff Teil eines Kompositums oder einer adjektivischen Wendung ist, wenn dies zur Führung des Benutzers notwendig ist.

$\begin{array}{ll}S W & \text { Steinobst } \\ O B & \text { Obst } \\ S W & \text { Steinobstanbau } \\ O B & \text { Obstbau }\end{array}$

4. Hierarchische Verweisungen mit mehrgliedrigem Oberbegriff

a) Eine Sonderform der hierarchischen Relation ist die Verweisung zwischen einem mehrgliedrigen Oberbegriff und einem Unterbegriff; Symbole: MO (Mehrgliedriger Oberbegriff) und MU (Unterbegriff zu mehrgliedrigem Oberbegriff). Diese Art der Verweisung wird v. a. für Individualnamen verwendet.

Anm. 1: Zu Individualnamen des Sachschlagworts vgl. § 306a, zu historischen Einzelereignissen vgl. $\S 415 a$, zu Körperschaften vgl. § 602,9, zu Sachtiteln von Werken vgl. §§ 712,6; 722,5, zu Filmen vgl. § 733,5, zu Nationalparks, Naturparks und Naturschutzgebieten vgl. § 209a,3. Bei Personenschlagwörtern werden keine mehrgliedrigen Oberbegriffe gebildet.

Anm. 2: Zur Aufnahme von Schlagwortketten als Hinweissätze in die SWD vgl. § 7,5.

Für den Oberbegriff wird eine Schlagwortkette gebildet, die der Beschlagwortung des Gegenstands ohne Verwendung des Individualnamens entsprechen würde. Gegebenenfalls wird auch die permutierte Form der Schlagwortkette als mehrgliedriger Oberbegriff erfasst. 


$\begin{array}{ll}\text { SW } & \text { Mathe-Master } \\ \text { MO } & \text { Mathematikunterricht ; Autorensystem } \\ & \text { Autorensystem ; Mathematikunterricht } \\ \text { SW } & \text { Mathematikunterricht ; Autorensystem } \\ M U & \text { Mathe-Master } \\ \text { SW } & \text { Autorensystem ; Mathematikunterricht } \\ \text { MU } & \text { Mathe-Master } \\ \text { SW } & \text { Deutsche Demokratische Partei } \\ M O & \text { Deutschland ; Partei } \\ & \text { Partei ; Deutschland }\end{array}$

Kann anstelle des mehrgliedrigen Oberbegriffs ein einzelnes hinlänglich genaues Schlagwort verwendet werden, so wird dieses als Oberbegriff erfasst.

$\begin{array}{ll}S W & \text { Georg-Büchner-Preis } \\ O B & \text { Literaturpreis }\end{array}$

Preise werden mit ihren Individualnamen angesetzt. Der einschlägige Allgemeinbegriff wird Oberbegriff. Ein mehrgliedriger Oberbegriff ist nicht erforderlich, da die Preise oft nicht geographisch oder sprachlich gebunden sind und die Zahl solcher Ansetzungen nicht sehr groß ist.

SW Parcevals saga

$O B \quad$ Saga

Zum mehrgliedrigen Oberbegriff von anonymen Werken vgl. \& 712,6.

SW Flamenco

OB Volkstanz

nicht: MO Spanien ; Volkstanz

Gattungsbegriffe erhalten i. d. R. keinen mehrgliedrigen Oberbegriff, vgl. jedoch § 306a,7.

b) Ein mehrgliedriger Oberbegriff kann auch bei einem Allgemeinbegriff erfasst werden, wenn der Oberbegriff auf Grund der Zerlegungskontrolle (vgl. § 8,5) durch eine Verknüpfung wiedergegeben wird.
SW Analytische Hermeneutik
MO Hermeneutik; Philosophie

5. Assoziative Verweisung

a) Verwandte Begriffe (Begriffe in assoziativer Relation) sind Begriffe,

- die sich in ihrem Begriffsinhalt teilweise überschneiden,

- die nicht als Synonyme oder Quasisynonyme anzusehen sind,

- die nicht in einer hierarchischen Beziehung stehen,

- auf deren gegenseitige Beziehung der Benutzer bei der Suche hingewiesen werden muss, weil möglicherweise ein Teil der mit dem einen Suchbegriff gesuchten Dokumente mit dem anderen Schlagwort erschlossen ist.

Assoziationsrelationen sind sequentielle (symmetrische) Relationen (vgl. DIN 2330 und 2331).
SW Zeus
$V B \quad$ Jupiter

Die griechischen und römischen Götter entsprechen sich, sie sind aber nicht identisch. 
b) Verwandte Begriffe lassen sich, soweit es sich um Allgemeinbegriffe handelt, vielfach einem definierten Typ zuordnen, z. B.:

Ursache und Wirkung,

SW Kondition

$V B \quad$ Fitness

Kondition ist die Ursache der Fitness

SW Endothia parasitica

$V B \quad$ Rindenkrebs

Der Erreger ist die Ursache der Krankheit; eine solche Verweisung wird nur bei eindeutiger kausaler Relation erfasst.

Gegensatzpaare (Gegenstände, deren Darstellung i. d. R. auch das Gegenteil mit umfasst, die aber nicht als Quasisynonyme im Sinn von $\S 315,2$, a gelten),

SW Kommunismus

VB Antikommunismus

Mittel und Zweck,

SW Lerntechnik

$V B \quad$ Lernen

Lerntechnik ist Mittel/Methode des Lernens.

Wissenschaftsdisziplin und ihr Gegenstand (vgl. § 317,2,b),

SW Sportwissenschaft

$V B \quad$ Sport

Sachgebiet und zugehörige Personengruppe (vgl. § 317,2,a),

SW Innenarchitektur

$V B \quad$ Innenarchitekt

SW Christentum

VB Christ

Komplementärbeziehung,

SW Psychotherapie

$V B \quad$ Psychologische Beratung

Beide Begriffe überschneiden sich, ohne dass es einen gemeinsamen Oberbegriff gibt.

SW Arbeiterin

$V B \quad$ Arbeiter

männliche und weibliche Form eines Schlagworts, vgl. § 303a,3

Folge bzw. Nachfolge,

SW Lateinschule

$V B \quad$ Humanistisches Gymnasium

Die Lateinschule ist Vorgängerin des Humanistischen Gymnasiums.

SW Lehrling

$V B \quad$ Auszubildender

ältere und moderne Bezeichnung mit Bedeutungsverschiebung, vgl. § 310,2

c) entfällt. 
d) Ein Gegenstand soll i. d. R. nicht durch zwei verwandte Begriffe erschlossen werden. Innerhalb einer Schlagwortkette dürfen zwei verwandte Begriffe nur verwendet werden, wenn ihr Verhältnis zueinander ausdrücklich thematisiert ist (vgl. § 324,2).

e) Bei Sachschlagwörtern und Körperschaftsnamen, die in einer inhaltlichen Beziehung zu Personen stehen, kann das Personenschlagwort als verwandter Begriff erfasst werden, sofern dies für Indexierung und Retrieval erforderlich ist (vgl. $\S \S 305,2, \mathrm{~d} ; 602,8$ und "Praxisregeln").

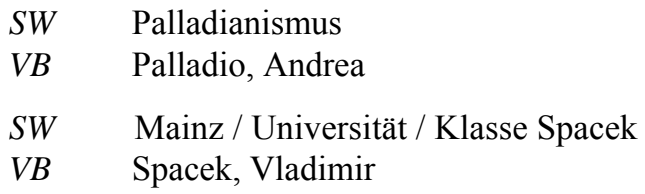

6. Verzicht auf eine assoziative Verweisung

Folgende Beziehungen werden i. d. R. nicht als assoziative Verweisungen dargestellt:

a) Gleichordnung: Die Begriffe haben einen gemeinsamen Oberbegriff und sind einander nebengeordnet, sie schließen sich also gegenseitig aus.

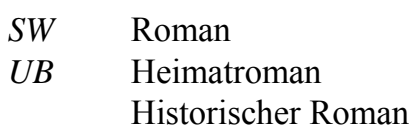

keine assoziative Verweisung zwischen 'Heimatroman' und 'Historischer Roman'

SW Gehirn

UB Zwischenhirn

Vorderhirn

keine assoziative Verweisung zwischen 'Zwischenhirn' und 'Vorderhirn'

Ausnahmen sind möglich, wenn eine assoziative Verweisung wegen unscharfer Begriffsverwendung zur Benutzerführung geboten erscheint.
SW Unterrichtsfilm
$O B \quad$ Film
$V B \quad$ Lehrfilm
Wissenschaftlicher Film

b) Vermeintliche Ähnlichkeit: Die Begriffe werden im alltäglichen Sprachgebrauch als ähnliche Begriffe angesehen, ihre Begriffsinhalte schließen sich jedoch gegenseitig aus. Zur Vermeidung von Missverständnissen sollte beim einen Schlagwort die missverständliche Bezeichnung definiert sowie beim anderen Schlagwort als Synonym mit einem Homonymenzusatz, ggf. in Form der Ansetzungsform, erfasst werden.

$\begin{array}{ll}\text { SW } & \text { Proband } \\ D & \text { Zur Bewährung entlassener Strafgefangener } \\ \text { SW } & \text { Versuchsperson } \\ \text { BF } & \text { Proband }<\text { Versuchsperson }>\end{array}$




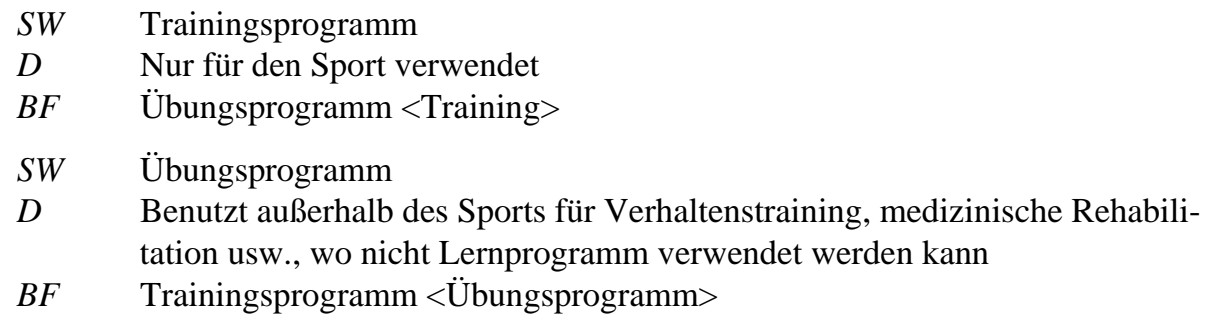

7. Chronologische Verweisungen

Chronologische Verweisungen sind eine Sonderform der assoziativen Verweisung; Symbole: CF früher (Chronologische Form; früher) und CF später (Chronologische Form; später). Sie werden bei geographischen Schlagwörtern (Namensänderungen vgl. § 207) sowie bei Körperschaften (Namensänderung mit grundlegender Veränderung der Natur der Körperschaft vgl. § 611,2) verwendet.

\section{8. entfällt}

\section{§ 13 Schlagwortkette}

1. Sind zur Beschreibung eines Gegenstandes mehrere Begriffe erforderlich, so wird aus den in der SWD enthaltenen Schlagwörtern eine Schlagwortkette (Verknüpfungskette) gebildet.

Schlagwortketten dienen dazu, im OPAC und im Listenkatalog Kurz-Abstracts des Dokumenteninhalts anzuzeigen und dem Benutzer damit eine Hilfe zur Einschätzung der Relevanz und zur Selektion, insbesondere bei größeren Titelmengen, zu geben.

Die Zahl der Schlagwörter soll im Hinblick auf die Verständlichkeit sechs nicht überschreiten. In bestimmten Fällen, z.B. bei mehreren Zeit- oder Formschlagwörtern können bis zu 10 Schlagwörter verknüpft werden. Weitere Aspekte werden wie weitere Gegenstände behandelt, d.h. in zusätzlichen Schlagwortketten berücksichtigt (vgl. § 13,4 und 6).

Anm: Bei Permutationsmustern werden derzeit aus datentechnischen Gründen mehrgliedrige Schlagwörter als mehrere Kettenglieder gezählt.

SWW Darwin, Charles ; Evolutionstheorie

SWW Goethe, Johann Wolfgang ᄀvon $\neg$ / Faust ; Textgeschichte ; Bibliographie Hier handelt es sich um drei Schlagwörter (bzw. vier Kettenglieder).

Inhalt: Studien zur nordischen Rezeption der deutschen Barockliteratur Aufsatzsammlung

SWW Barock ; Literatur ; Deutsch ; Rezeption ; Nordische Staaten ; Geschichte 1600-1800 ; Aufsatzsammlung

SWW Deutsch ; Literatur ; Geschichte 1600-1720 ; Rezeption ; Nordische Staaten ; Geschichte 1600-1800 ; Aufsatzsammlung 
2. Die Reihenfolge in der Schlagwortkette folgt zunächst den Schlagwortkategorien (Personen-, geographisches, Sach-, Zeit- und Formschlagwort vgl. § 15). Bei Zusammentreffen mehrerer Schlagwörter derselben Kategorie soll eine sinnvolle Reihenfolge gewählt werden. (Nähere Bestimmungen für sich gegenseitig einschränkende geographische Schlagwörter vgl. $\S \S$ 202,5; 205,3, für Sachschlagwörter vgl. § 322, für Formschlagwörter vgl. § 504,1, für Sprachbezeichnungen vgl. § 701,1,e.) Sind mehrere Reihenfolgen gleich sinnvoll, so kann alphabetisch geordnet werden. Die so gewählte Reihenfolge wird als Grundkette bezeichnet.

Für Listenfunktionen werden Schlagwortketten sortiert. Für diesen Zweck können die Schlagwörter der Schlagwortkette permutiert werden (vgl. § 15).

3. Das geographische/ethnographische Schlagwort oder die Sprachbezeichnung entfallen in der Kette als pleonastisch, wenn es sich um einen Sachverhalt handelt, der nur in einer bestimmten geographischen Einheit oder Sprache auftritt (vgl. §§ 201a,3; 701,5,b; 703,1,b).

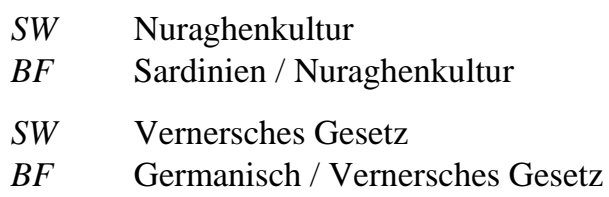

Das geographische Schlagwort 'Europa' entfällt bei Gegenständen, bei denen es als pleonatisch vorausgesetzt werden kann (vgl. § 201a,6).

Das geographische Schlagwort 'Deutschland' kann bei lokaler Anwendung in Listenfunktionen als Sucheinstieg entfallen (vgl. § 201a,5).

Treffen Schlagwörter für Allgemeinbegriffe mit Individualnamen zusammen, werden grundsätzlich die spezifischen Sachschlagwörter verwendet. Schlagwörter für Allgemeinbegriffe entfallen jedoch in der Kette, wenn ihre semantischen Merkmale in Individualnamen vollständig enthalten sind. Ein geographischer, ethnographischer oder sprachlicher Bezug kann aber auch dann ausgedrückt werden, wenn er bereits in einem Individualnamen enthalten ist, aber in Verknüpfung mit einem anderen Schlagwort der Kette recherchierbar sein soll (vgl. § 324,3).

SWW Daimler-Benz-Aktiengesellschaft ; Beschäftigungspolitik

nicht: Daimler-Benz-Aktiengesellschaft ; Betriebliche Beschäftigungspolitik

oder: Daimler-Benz-Aktiengesellschaft ; Unternehmen ; Beschäftigungspolitik

Betriebliche Beschäftigungspolitik ist auf Unternehmen ; Beschäftigungspolitik verwiesen.

SWW Eichendorff, Joseph $\neg$ von $\neg$; Lyrik

nicht: Eichendorff, Joseph ᄀvon $\neg$; Deutsch ; Lyrik

Aber (vgl. 4c):

SWW Frankreich ; Schulpolitik ; Kommunistische Partei Frankreichs

4. a) Werden in einem Dokument mehrere Gegenstände behandelt, so sind mehrere Schlagwortketten zu bilden (vgl. § 7,1). Je Dokument sollten nicht mehr als zehn Schlagwortketten gebildet werden.

Titel: $\quad$ Rires et sourires littéraires. - 1994

SWW Lachen ; Literatur

SWW Humor; Literatur

Titel: $\quad$ Musica privata : die Rolle der Musik im privaten Leben ; Festschrift ... - 1991

SWW Salmen, Walter ; Bibliographie

SWW Hausmusik; Geschichte ; Aufsatzsammlung 
Titel: $\quad$ Lexikon des gesamten Buchwesens / hrsg. von Severin Corsten. - 1987 -

SWW Buch; Wörterbuch

SWW Bibliothek; Wörterbuch

Titel: Adelsfamilien im Umkreis der frühen Karolinger : die Verwandtschaft Irminas von Oeren und Adelas von Pfalzel / Matthias Werner. - 1982

SWW Maas-Mosel-Gebiet ; Adel ; Geschichte 600-800

SWW Karolinger; Genealogie

$S W W \quad$ Irmina $<$ von Oeren $>$; Genealogie

SWW Adela $<$ von Pfalzel $>$; Genealogie

b) $\mathrm{Ob}$ es sich um mehrere Gegenstände oder um einen sehr komplexen einzelnen Gegenstand handelt, hängt davon ab, ob die einzelnen Begriffe in einer Beziehung zueinander stehen, sich gegenseitig einschränken. Vergleich und Gegenüberstellung zweier Sachverhalte gelten als ein einheitlicher Gegenstand. Im Zweifelsfall wird angenommen, dass mehrere Gegenstände behandelt werden.

Inhalt: Schweiz und Libanon : Vergleich zweier politischer Systeme

SWW Schweiz ; Politisches System ; Libanon

Titel: $\quad$ Salesman in Beijing / Arthur Miller. - 1984

SWW Miller, Arthur / Death of a salesman ; Inszenierung ; Peking / Volkstheater ; Geschichte 1984

Bei gleichgeordneten Begriffen werden mehrere Gegenstände angenommen.

Titel: Insekten und Spinnentiere am Mittelmeer / Joachim und Hiroko Haupt. - 1993

SWW Mittelmeerraum; Insekten ; Bestimmungsbuch

SWW Mittelmeerraum; Spinnentiere ; Bestimmungsbuch

nicht: Mittelmeerraum ; Insekten ; Spinnentiere ; Bestimmungsbuch

Titel: $\quad$ Lehrstücke in der Praxis : zwei Versuche mit Bertolt Brechts: Die Ausnahme und die Regel, Die Horatier und die Kuriatier / hrsg. von Joachim Lucchesi. - 1979

SWW Brecht, Bertolt / $\neg$ Die $\neg$ Ausnahme und die Regel ; Aufführung

SWW Brecht, Bertolt / $\neg$ Die $\neg$ Horatier und die Kuriatier ; Aufführung nicht: Brecht, Bertolt ; Lehrstück; Aufführung.

zur Bevorzugung des Individualbegriffs vgl. \& 8,2

c) Verschiedene Aspekte desselben Themas, die eng zusammenhängen, können je als eigene Gegenstände behandelt werden, wenn es verschiedene gleichwertige Ausdrucksmöglichkeiten gibt, die sich nicht unter einem Oberbegriff zusammenfassen lassen.

Titel: $\quad$ Wahrnehmung von Lehrer-Kollegen in Merkmalen des zwischenmenschlichen Geschehens sowie deren Förderung durch personenzentrierte Gesprächsgruppen / Ursula Behrens-Tönnies. - 1983

SWW Lehrerkollegium; Interaktion

SWW Lehrer ; Kollege ; Interpersonale Wahrnehmung

SWW Lehrerkollegium ; Interaktion ; Nichtdirektive Gesprächsführung ; Gruppenarbeit

Inhalt: Arbeiterbewegung und Literatur in Schweden

SWW Schwedisch ; Literatur ; Arbeiterbewegung

SWW Schweden; Arbeiterbewegung; Literatur

SWW Schwedisch; Arbeiterliteratur

Inhalt: Das Alltagsleben im Dreißigjährigen Krieg

SWW Dreißigjähriger Krieg ; Alltag

SWW Deutschland ; Alltag ; Geschichte 1618-1648 
Titel: $\quad \neg$ Die $\neg$ Ostverträge / Benno Zündorf. - 1979

SWW Ostverträge ; Geschichte

SWW Deutschland <Bundesrepublik> ; Außenpolitik ; Ostblock ; Geschichte 1970-1974

Dargestellt werden nicht nur die Verträge, sondern auch die Einbindung in die Ostpolitik.

d) Als zwei Gegenstände kann die Darstellung eines Themas und die Verknüpfung desselben Themas mit einem Formschlagwort behandelt werden, wenn der Formaspekt beim vorliegenden Dokument sehr gewichtig ist (vgl. § 504,1).

Titel: $\quad$ Türkei / Klaus Liebe ; Gerhard P. Müller. - 1985

geschichtlich-landeskundliche Darstellung mit zahlreichen Illustrationen

SWW Türkei ; Landeskunde

SWW Türkei ; Bildband

Inhalt: Luther und Lutherforschung im 20. Jahrhundert

SWW Luther, Martin ; Aufsatzsammlung

SWW Luther, Martin ; Literaturbericht 1900-1985

SWW Luther, Martin ; Bibliographie 1900-1985

e) Ausnahmsweise können auch ein weiterer und ein engerer Gegenstand bzw. verwandter Gegenstand als zwei unterschiedliche Gegenstände angesehen werden, sofern beide gleichgewichtig als Thema auftreten.

Titel: Die öffentliche Meinung in der Staatsphilosophie von Thomas Hobbes : auf dem Hintergrund der Begriffsgeschichte und der Phänomengenesis der öffentlichen Meinung von der Antike bis zur neuen Zeit / Heinz Flieger. - 1975

Die Darstellung der Theorie beansprucht ca. ein Drittel des Umfangs.

SWW Hobbes, Thomas ; Öffentliche Meinung

SWW Öffentliche Meinung ; Theorie ; Geschichte Anfänge-1800

Titel: Friedrich Hölderlin in the context of Württemberg pietism / Priscilla A. HaydenRoy. - 1988

Der erste Gegenstand wird auf 135 Seiten, der zweite auf 133 Seiten behandelt.

SWW Württemberg ; Pietismus ; Geschichte 1700-1800

SWW Hölderlin, Friedrich ; Pietismus

Titel: Revolutionary women : gender and the socialist revolutionary role / Marie Marmo Mullaney. - 1983

Die 5 Personen werden jeweils eigens, beispielhaft für das Thema, in einem Kapitel von ca. 50 Seiten behandelt. Das Schlusskapitel versucht, daraus eine allgemeine Theorie abzuleiten.

SWW Revolutionärin ; Sozialismus

SWW Marx-Aveling, Eleanor

SWW Kollontaj, Aleksandra M.

SWW Luxemburg, Rosa

SWW Balabanoff, Angelica

SWW Ibárruri, Dolores Gómez

5. Die Bildung mehrerer Schlagwortketten sollte jedoch immer dann vermieden werden, wenn ein passender Oberbegriff verwendet werden kann (vgl. § 6,1). Dies hängt davon ab, wie weit der Oberbegriff den Inhalt des Dokuments vollständig und angemessen wiedergibt und wie weit er für die Erschließung geeignet ist. 
Inhalt: Politische Systeme Westeuropas

Es werden Großbitannien, Frankreich, Bundesrepublik Deutschland, Schweiz, Österreich, Norwegen behandelt.

SWW Westeuropa ; Politisches System

Der zusammenfassende Begriff wird gewählt, da die abgehandelten Systeme beispielhaft behandelt werden und der vergleichende Aspekt im Vordergrund steht. Anders wäre zu verfahren, wenn das Gewicht auf den einzelnen Staaten liegen würde.

Aber:

Titel: Im Namen des Papstes : die verschwiegenen Truppen des Vatikan / Gordon Urquhart. - 1995

SW Fokolar-Bewegung

SW Comunione e Liberazione

SW Neocatechumenate

Als zusammenfassende Beschlagwortung wäre allenfalls Fundamentalismus ; Katholische Kirche denkbar, was aber über den Inhalt weit hinausgeht. Da die Unterbegriffe weit spezifischer sind, ist dies nicht sinnvoll.

6. Ist ein Gegenstand so komplex, dass er in einer Schlagwortkette nicht mehr verständlich darzustellen ist, so soll er nach Möglichkeit durch mehrere Ketten wiedergegeben werden. Das kann z.B. beim Zusammentreffen von mehr als drei Sachschlagwörtern der Fall sein.

Titel: Elektrodynamische Eigenschaften von Hochtemperatur-Supraleitern im THz-Bereich

/ Rainer Buhleier. - 1994

SWW Yttriumverbindungen ; Bariumverbindungen ; Praseodymverbindungen ; Cuprate ; Hochtemperatursupraleiter

SWW Hochtemperatursupraleiter ; Optische Eigenschaft ; Terahertzbereich

\section{§ 14 Darstellung von Beziehungen in der Schlagwortkette}

1. Die in einer Schlagwortkette verknüpften Schlagwörter stehen untereinander in einer sachlichen Beziehung. Dabei sind vielfach nicht nur die vorliegenden, sondern auch weitere Beziehungen denkbar. Da in der Schlagwortkette keine Rollenoperatoren verwendet werden, kann die Art der Beziehung nicht dargestellt werden. Die Darstellung eines Gegenstands in der Schlagwortkette ist daher nicht immer eindeutig.

SWW USA ; Geographieunterricht

Dies kann sowohl den Geographieunterricht in den USA wie die Behandlung der USA im Geographieunterricht meinen.

2. Die Richtung von Beziehungen in einer Schlagwortkette wird nicht dargestellt. Werden Permutationen gemacht, so erhalten Ausgangs- und Zielpunkt je eine Eintragung.

Titel: $\quad \neg$ An $\neg$ English-Arabic lexicon / George P. Badger. - 1980

SWW Arabisch; Wörterbuch; Englisch

(321)

ebenso für ein arabisch-englisches Wörterbuch und für ein Wörterbuch in beide Richtungen

Titel: $\quad \neg$ La $\neg$ déportation sous le premier Empire : les Espagnols en France (1808-1814) /

Jean-René Aymes. - 1983

SWW Frankreich ; Deportation ; Spanier ; Geschichte 1808-1814

(2314) (3214) 
3. Unklarheiten in der Beziehung können durch eine präzise Beschlagwortung vielfach vermieden werden. Es werden aber keine präkombinierten Schlagwörter angesetzt, nur um Unklarheiten in der Schlagwortkette zu vermeiden.

Titel: $\quad \neg$ Der $\neg$ gute und der schlechte Sportlehrer aus Schülersicht / Manfred Messing. - 1988

SWW Sportlehrer; Schülerurteil

nicht: Sportlehrer ; Schüler

Inhalt: Die Beurteilung der Schüler im Sportunterricht

SWW Sportunterricht; Schülerbeurteilung

nicht: Sportlehrer; Schüler

4. Wenig aussagekräftige Schlagwörter wie 'Beeinflussung', 'Beziehung', 'Darstellung', 'Kritik', 'Thema', 'Verhältnis' werden nicht verwendet, wenn sie nur dazu dienen würden, die Beziehung der Schlagwörter in der Schlagwortkette zu verdeutlichen.

Titel: $\quad$ Staatsgrenzen und ihr Einfluss auf Raumstrukturen und Verhaltensmuster / hrsg. von J. Maier. - 1983

SWW Staatsgrenze ; Regionalstruktur

ohne Schlagwort 'Einfluss'

Inhalt: Die französische Revolution in der Geschichtsschreibung des 19. Jahrhunderts

SWW Französische Revolution; Geschichtsschreibung ; Geschichte 1815-1900 ohne Schlagwort 'Darstellung'

Aber:

Titel: $\quad \neg$ Die $\neg$ Volksschule des Obrigkeitsstaates und ihre Kritiker / hrsg. von Ludwig Fertig. $-1979$

SWW Deutschland ; Volksschule ; Kritik ; Geschichte 1777-1888 ; Quelle

Titel: $\quad$ Hölderlin und die deutsche Nation / Werner Bantscher. - 1942

SWW Hölderlin, Friedrich ; Rezeption ; Deutschland

Inhalt: Lehrer und Schulräte : ein strukturell gestörtes Verhältnis

SWW Lehrer; Einstellung; Schulaufsicht

\section{§ 15 Reihenfolge in der Schlagwortkette, Permutationen}

1. Die Reihenfolge der Schlagwörter in der Schlagwortkette richtet sich zunächst nach den Schlagwortkategorien (vgl. §§ 11 und 13,2):

a) Personenschlagwörter

b) Geographische/ethnographische Schlagwörter einschließlich Sprachbezeichnungen

c) Sachschlagwörter

d) Zeitschlagwörter

e) Formschlagwörter

Für Listenfunktionen können die Schlagwörter permutiert werden. Dabei erhält jedes Schlagwort i.d.R. nicht mehr als eine Eintragung.

2. Treffen Schlagwörter derselben Schlagwortkategorie zusammen, so wird die Grundkette nach § 13,2 gebildet (sinnvolle Reihenfolge bzw. im Zweifelsfall alphabetische Ordnung).

Wenn die Glieder der Schlagwortkette permutiert werden, so erhält i.d.R. jedes Schlagwort nicht mehr als eine Eintragung. Auf die Eintragung unter Sachschlagwörtern, denen im vor- 
liegenden Zusammenhang kein selbständiges Gewicht zukommt, kann verzichtet werden (vgl. §§ 322,3; 325).

In der Permutation wird für einzelne Schlagwörter eine sinnvolle Reihenfolge gewählt. Gibt es mehrere sinnvolle Reihenfolgen, so wird die Transposition gewählt, bei der jeweils zwei Kettenglieder ausgetauscht werden.

Sache 1 ; Sache 2 ; Sache 3 ; Sache 4

s 2 ; s 1 ; s 3 ; 44

$\mathrm{s} 3$; 2 ; s 1 ; 4

s 4 ; s 2 ; s 3 ; s 1

Analog wird beim Zusammentreffen mehrerer Schlagwörter derselben Kategorie mit einem Schlagwort einer anderen Kategorie verfahren.

3. Personenschlagwörter gehen in der Grundkette den geographischen/ethnographischen, Sach-, Zeit- und Formschlagwörtern voran (vgl. §§ 116ff.). Bei der Permutation für Listenfunktionen wird i.d.R. mit den geographischen/ethnographischen Schlagwörtern und den Sachschlagwörtern je eine Eintragung gemacht. (Ausnahmen vgl. § 117,4; Anl. 2).

4. Geographische/ethnographische Schlagwörter gehen in der Grundkette den Sach-, Zeit-, und Formschlagwörtern voran. (Ausnahmen vgl. §§ 504,2 und 3; 702; 770). Bei der Permutation für Listenfunktionen wird i.d.R. mit den Sachschlagwörtern je eine Eintragung gemacht. (Ausnahmen vgl. § 220,4; Anl. 5).

5. Treffen mehrere Personen- oder geographische/ethnographische Schlagwörter mit mehreren Sachschlagwörtern zusammen, so hat in der Grundkette die Darstellung der Beziehung Personenschlagwort - Sachschlagwort bzw. geographisches/ethnographisches Schlagwort Sachschlagwort Vorrang vor der Beziehung zwischen den Personenschlagwörtern bzw. den geographischen/ethnographischen Schlagwörtern. Sach- und gegebenenfalls Zeitschlagwörter werden dabei demjenigen Schlagwort zugeordnet, zu dem sie gehören. Sachbegriffe, die zu beiden Personen- oder geographischen/ethnographischen Schlagwörtern gehören, werden nur dem ersten Schlagwort zugeordnet (vgl. §§ 115a,2; 218,2, zu vergleichenden Darstellungen vgl. aber § 15,9).

6. Sachschlagwörter gehen in der Grundkette den Zeit- und Formschlagwörtern voran.

7. Das Zeitschlagwort steht in der Grundkette an letzter Stelle vor dem Formschlagwort. Es wird i.d.R. nicht als erstes oder einziges Schlagwort in der Schlagwortkette verwendet (Ausnahme vgl. § 406,3). Nach dem Zeitschlagwort können jedoch noch weitere Schlagwörter folgen, für die die zeitliche Eingrenzung des Zeitschlagworts nicht gilt (vgl. § 406,4), z.B. bei der Behandlung einer Epoche in einer anderen literarischen oder sachlichen Form, bei der Eingrenzung durch einen Sachbegriff, der nur der Erläuterung dient und wenn 'Geschichte' als Sachbegriff gemeint ist (vgl. § 405).

8. Formschlagwörter stehen grundsätzlich an letzter Stelle in der Grundkette (vgl. § 504,1). (Ausnahmen vgl. § 504,2 und 3; 505; 702; Anl. 6).

9. Bei Vergleichen und der Darstellung gegenseitiger Beeinflussung kann sich die Reihenfolge der Schlagwortkategorien innerhalb einer Schlagwortkette wiederholen (vgl. §§ 115a,2; 219,2; 406,3). 
10. Schemata zur Reihenfolge und Permutation der Schlagwortkategorien:

Die Grundkette ist jeweils in Vollform, die fakultativ zu bildenden weiteren Eintragungen sind verkürzt dargestellt. Zur Reihenfolge bei mehreren Schlagwörtern der gleichen Kategorie vgl. Abs. 2.

a) Formschlagwort

Nur am Ende einer Schlagwortkette (Ausnahmen vgl. § 15,8)

b) Zeitschlagwort

Zeit ; Form

Als erstes Schlagwort in der Schlagwortkette nur bei Komposita mit Geschichte (vgl. $\S 406,3)$

c) Sachschlagwort

1. Sache ; Form

2. Sache ; Zeit ; Form

3. Sache 1 ; Sache 2 s 2 ; s 1

4. Sache 1 ; Sache 2 ; Zeit ; Form s 2 ; 1 ; z ; f

5. Sache 1 ; Sache 2 ; Sache 3 s 2 ; s 1 ; s 3 (oder eine andere sinnvolle Reihenfolge) s 3 ; s 2 ; s 1

6. Sache 1 ; Sache 2 ; Sache 3 ; Zeit ; Form

s 2 ; s 1 ; s 3 ; z ; f (oder eine andere sinnvolle Reihenfolge der Sachschlagwörter) s 3 ; s 2 ; s 1 ; z ; f

d) Geographisches Schlagwort (umfasst auch ethnographisches Schlagwort und Sprachbezeichnung)

1. Geographikum ; Form

2. Geographikum ; Zeit ; Form

3. Geographikum ; Sache ; Zeit ; Form $\mathrm{s} ; \mathrm{g} ; \mathrm{z} ; \mathrm{f}$

4. Geographikum ; Sache 1 ; Sache 2 ; Zeit ; Form

$\mathrm{s} 1 ; \mathrm{s} 2 ; \mathrm{g} ; \mathrm{z} ; \mathrm{f}$

$\mathrm{s} 2 ; \mathrm{s} 1 ; \mathrm{g} ; \mathrm{z} ; \mathrm{f}$

5. Geographikum 1 ; Geographikum 2 ; Form

$\mathrm{g} 2$; g 1 ; f

6. Geographikum 1 ; Geographikum 2 ; Zeit ; Form g 2 ; g 1 ; z ;

Bei Vergleichen und gegenseitiger Beeinflussung zwischen mehreren geographischen Schlagwörtern mit mehrfachem Ablauf der Reihenfolge: 
7. Geographikum 1 ; Sache ; Geographikum 2 ; Zeit ; Form

$\mathrm{s} ; \mathrm{g} 1 ; \mathrm{g} 2 ; \mathrm{z} ; \mathrm{f}$

g $2 ; \mathrm{s} ; \mathrm{g} 1 ; \mathrm{z} ; \mathrm{f}$

8. Geographikum 1 ; Sache 1 ; Sache 2 ; Geographikum 2 ; Zeit ; Form $\mathrm{s} 1$; 2 ;g 1 ; g 2 ; z ;

$\mathrm{s} 2 ; \mathrm{s} 1 ; \mathrm{g} 1 ; \mathrm{g} 2 ; \mathrm{z} ; \mathrm{f}$

g 2 ; s 1 ; s 2 ; g 1 ; z;f

9. Geographikum 1 ; Sache 1 ; Geographikum 2 ; Sache 2 ; Zeit ; Form

$\mathrm{s} 1$; 1 ; g 2 ; s 2 ; z;f

g 2 ; 2 ; g 1 ; 1 ; z;f

$\mathrm{s} 2$; 2 ; g 1 ; s 1 ; z; f

10. Geographikum 1 ; Sache 1 ; Zeit 1 ; Geographikum 2 ; Sache 2 ; Zeit 2
$\mathrm{s} 1 ; \mathrm{g} 1 ; \mathrm{z} 1 ; \mathrm{g} 2 ; \mathrm{s} 2 ; \mathrm{z} 2$
g 2 ; s 2 ; 2 ; g 1 ; s 1 ; 1
$\mathrm{s} 2$; g 2 ; z 2 ; g 1 ; s 1 ; z 1

e) Personenschlagwort

1. Person ; Form

2. Person ; Zeit ; Form

3. Person ; Sache ; Zeit ; Form

$\mathrm{s} ; \mathrm{p} ; \mathrm{z} ; \mathrm{f}$

4. Person ; Sache 1 ; Sache 2 ; Zeit ; Form

$\mathrm{s} 1 ; \mathrm{s} 2 ; \mathrm{p} ; \mathrm{z} ; \mathrm{f}$

$\mathrm{s} 2 ; \mathrm{s} 1 ; \mathrm{p} ; \mathrm{z} ; \mathrm{f}$

5. Person ; Geographikum ; Form

$\mathrm{g} ; \mathrm{p} ; \mathrm{f}$

6. Person ; Geographikum ; Sache ; Zeit ; Form

$\mathrm{g} ; \mathrm{s} ; \mathrm{p} ; \mathrm{z} ; \mathrm{f}$

$\mathrm{s} ; \mathrm{g} ; \mathrm{p} ; \mathrm{z} ; \mathrm{f}$

7. Person 1 ; Person 2 ; Form $\mathrm{p} 2$; p 1 ; f

Bei Vergleichen und gegenseitiger Beeinflussung zwischen mehreren Personenschlagwörtern mit mehrfachem Ablauf der Reihenfolge:

8. Person 1 ; Sache ; Person 2 ; Zeit ; Form

$$
\begin{aligned}
& \text { s; } 1 \text { 1 p } 2 ; \mathrm{z} ; \mathrm{f} \\
& \mathrm{p} 2 ; \mathrm{s} ; \mathrm{p} 1 ; \mathrm{z} ; \mathrm{f}
\end{aligned}
$$

9. Person 1 ; Sache 1 ; Sache 2 ; Person 2 ; Zeit ; Form

$$
\begin{aligned}
& \text { s } 1 ; \mathrm{s} 2 ; \mathrm{p} 1 ; \mathrm{p} 2 ; \mathrm{z} ; \mathrm{f} \\
& \mathrm{s} 2 ; \mathrm{s} 1 ; \mathrm{p} 1 ; \mathrm{p} 2 ; \mathrm{z} ; \mathrm{f} \\
& \mathrm{p} 2 ; \mathrm{s} 1 ; \mathrm{s} 2 ; \mathrm{p} 1 ; \mathrm{z} ; \mathrm{f}
\end{aligned}
$$

10. Person 1 ; Sache 1 ; Person 2 ; Sache 2 ; Zeit ; Form

$$
\begin{aligned}
& \text { s } 1 ; \mathrm{p} 1 ; \mathrm{p} 2 ; \mathrm{s} 2 ; \mathrm{z} ; \mathrm{f} \\
& \mathrm{p} 2 ; \mathrm{s} 2 ; \mathrm{p} 1 ; \mathrm{s} 1 ; \mathrm{z} ; \mathrm{f} \\
& \mathrm{s} 2 ; \mathrm{p} 2 ; \mathrm{p} 1 ; \mathrm{s} 1 ; \mathrm{z} ; \mathrm{f}
\end{aligned}
$$


11. Person 1 ; Sache 1 ; Zeit 1 ; Person 2 ; Sache 2 ; Zeit 2

$\mathrm{s} 1 ; \mathrm{p} 1 ; \mathrm{z} 1 ; \mathrm{p} 2 ; \mathrm{s} 2 ; \mathrm{z} 2$

$\mathrm{p} 2 ; \mathrm{s} 2 ; \mathrm{z} 2 ; \mathrm{p} 1 ; \mathrm{s} 1 ; \mathrm{z} 1$

$\mathrm{s} 2$; $\mathrm{p} 2$; 2 ; p 1 ; s 1 ; 1

\section{§ 16 Rechtschreibung, Zeichenvorrat}

1. Schlagwörter und Verweisungen werden grundsätzlich mit großen Anfangsbuchstaben geschrieben. (Ausnahme vgl. u.a. § 302,2.)

2. Maßgeblich für die Rechtschreibung der Schlagwörter ist die jeweils neueste Ausgabe des „Duden, Rechtschreibung der deutschen Sprache“. Wenn das Wort dort nicht enthalten ist, werden auch für die Rechtschreibung Allgemeinenzyklopädien sowie fachliche Nachschlagewerke herangezogen. (Einzelheiten und Ausnahmen bei Personennamen vgl. §§ 102; 109; 110, bei geographischen/ethnographischen Begriffen vgl. §§ 202; 212b, bei Sachbegriffen vgl. § 302, bei Körperschaften vgl. § 602, bei Werktiteln vgl. § 709).

3. Es werden die in MAB2 Anhang 2 vorgesehenen Zeichen verwendet (Codierung nach ISO 5424). Akzente und diakritische Zeichen (vgl. RAK § 803,2-4) werden in Fremdwörtern und fremdsprachigen Namen unabhängig von der Form des Nachschlagewerks berücksichtigt. Für nichtlateinische Schriftzeichen gelten i.d.R. die nach RAK maßgeblichen Umschrifttabellen. (Vgl. auch §§ 109; 110, Formeln vgl. § 314.)

Anm. 1: Es können nicht alle Kombinationen von Zeichen und Diakritika dargestellt werden.

Anm. 2: Das Zeichen „ß“ war bis 1997 in der SWD nicht realisiert.

4. In Wörtern und Namen der lateinischen Sprache wird der Buchstabe j als i angesetzt. Lehnwörter richten sich nach der deutschen Rechtschreibung.

5. Bei strittiger Schreibweise von c, $\mathrm{k}$ und $\mathrm{z}$ in biologischen, chemischen und medizinischen Bezeichnungen wird i.d.R. c gewählt. Von den anderen üblichen Schreibvarianten wird verwiesen.

6. Sind bei der Ansetzungsform von Fremdwörtern oder fremdsprachigen Namen Akzente oder diakritische Zeichen berücksichtigt, und werden diese datentechnisch anders behandelt als die Grundform, so wird diese als Synonym erfasst.

\section{§ 17 Zahlen und sonstige Zeichen}

1. Zahlen und sonstige Zeichen werden, soweit im Folgenden nichts anderes bestimmt ist, unter einer verbalen Auflösung angesetzt.

$\begin{array}{ll}\text { SW } & \text { Zwanzigster Juli } \\ \text { SW } & \text { Kohlendioxid } \\ \text { SW } & \text { Einundzwanzig-Zentimeter-Linie } \\ \text { SW } & \text { Dreißigjähriger Krieg } \\ \text { SW } & \text { Dekalog } \\ \text { BF } & \text { Zehn Gebote }\end{array}$


2. Sie werden in folgenden Fällen nicht aufgelöst:

a) Jahresangaben

aa) Jahresangaben in Verbindung mit 'Geschichte', einem Kompositum mit '-geschichte' und 'Prognose' (vgl. § 403) oder einem Formschlagwort (vgl. § 503). Die Ziffern werden nach Spatium angehängt.

SWW Wien ; Geschichte 1915-1955

SWW Deutschland; Sozialgeschichte 1517-1585

SWW Weltwirtschaft; Prognose 1998-2000

SWW Fontane, Theodor; Biographie 1840-1860

ab) Jahreszahlen als Homonymenzusatz bei Personennamen vgl. § 106,3, bei historischen Einzelereignissen vgl. § 415a,1,a, bei Veranstaltungen vgl. § 607, bei Werktiteln vgl. $\S 710$, bei Gesetzen vgl. § 715,10, bei Verträgen und Verfassungen vgl. §§ 716; 717. Die Ziffern werden in Winkelklammern nachgestellt.

SW $\quad$ Butler, Samuel <Schriftsteller, 1835-1902>

SW Weltkrieg <1939-1945>

SW Deutschland / Reichshofratsordnung $<1654>$

SW $\quad$ Frankreich / Verfassung $<1958>$

SW Kant, Immanuel / Kritik der reinen Vernunft $<1787>$

b) Formeln, naturwissenschaftliche und technische Zeichen und Symbole (vgl. § 314)

ba) Ziffern innerhalb oder am Ende der Bezeichnung werden im allgemeinen durch einen Bindestrich mit den Buchstaben verbunden.

SW SU-3-Symmetrie

SW Uran-235

SW H-II-Gebiet

Eine ungünstige Sortierung in Listenfunktionen wird in Kauf genommen.

bb) Ziffern als Bestandteil chemischer Namen und anderer fachsprachlicher Bezeichnungen, die bei der alphabetischen Einordnung übergangen werden, werden als Homonymenzusatz in Winkelklammern nachgestellt (vgl. § 314,2,b).

SW Nitrophenol <2->

c) Ziffern im Innern oder am Ende von Individualnamen, z. B. geographischen Namen, Produkt- und Typenbezeichnungen (vgl. § 306a,3) werden nach Vorlage, im Zweifelsfall zwischen Spatium bzw. nach Spatium angesetzt.

$\begin{array}{ll}S W & \text { Autobahn } 93 \\ S W & \mathrm{~K} 2 \\ S W & \text { DB2 } \\ S W & \text { OS } / 2\end{array}$

d) Ziffern, die lediglich der Zählung gleichartiger Schlagwörter dienen, werden mit Spatium nachgestellt (vgl. § 305,1,b). Ausnahme: Zählung bei Altersstufen, z. B. Kind <3 Jahre>, und Zählung bei Körperschaften (vgl. § 602,5). 
SW Schuljahr 1

SW Hauptsatz der Thermodynamik 2

e) Ziffern in Titeln von Werken, sofern der Einheitssachtitel mit Ziffern angesetzt wird (vgl. RAK § 206,1).

SW Cambio 16

SW Fahrenheit 451

f) Zählungen der Teile von Werken werden mit Spatium an den Werktitel angehängt (vgl. $\S 711,2)$.

SW Johannesevangelium 1,1-18

g) Zahlen, Symbole und sonstige Zeichen in Körperschaftsnamen werden nach RAK § 206,1 angesetzt. Dies gilt analog für andere Namen.

SW Verein 1000 Jahre Kronach

SW Berlin 2000 Olympia GmbH

3. a) Römische Ziffern werden verwendet bei Herrschernamen und für die Wertigkeit chemischer Elemente in Verbindungen.

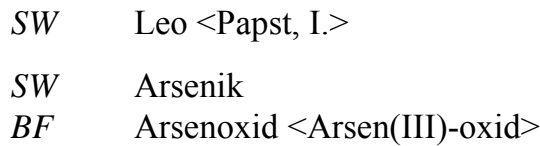

b) Römische Ziffern können bei Sachtiteln von Werken und in Individualnamen nur verwendet werden, sofern sie gebräuchlich sind. Bei schwankendem Gebrauch von römischen und arabischen Ziffern wird auf arabische Ziffern normiert.

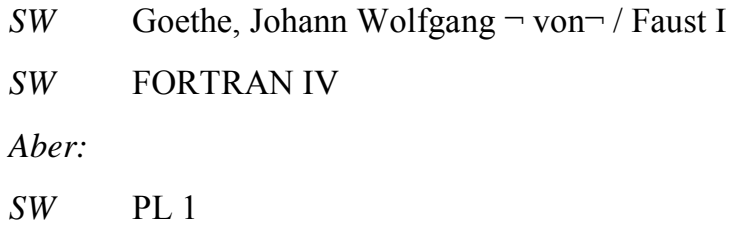

4. Formeln, naturwissenschaftliche und technische Zeichen und Symbole vgl. § 314.

\section{$\S 18$ Codierungen in Schlagwortsätzen}

Die Codierungen der SWD-Sätze dienen u. a. dem Wiederauffinden von Schlagwörtern zum Zwecke des Indexierens und der Terminologiearbeit sowie darüber hinaus der systematischen Recherche und dem Erstellen fachlicher Teilausgaben der SWD.

1. SWD-Notation

Die Schlagwörter werden in der SWD nach den SWD-Sachgruppen klassifiziert (vgl. „Traiser, Walther: SWD-Sachgruppen. Leitfaden zu ihrer Vergabe. - Frankfurt am Main: Die Deutsche Bibliothek, 2000"). Die Notation wird mit dem Symbol SYS eingeleitet. Schlagwörter können bis zu fünf Notationen erhalten. Sprachbezeichnungen erhalten i. d. R. keine SWD-Notation, sondern nur einen oder mehrere Ländercodes bzw. Sprachencodes. Geographische Schlagwörter erhalten neben einem oder mehreren Ländercodes nur dann eine SWD-Notation, wenn sie sachlich zugeordnet werden können (vgl. § 213a). 
SW Mathematikunterricht

SYS $\quad 6.4$

SW Informationsverarbeitung

SYS $\quad$ 5.3; 5.5; 27.3d; 30; 31.9b

Unspezifische Allgemeinbegriffe, die nur in Verbindung mit anderen Schlagwörtern und nichtpermutierend zu benutzen sind, sowie nicht klassifizierbare Personennamen erhalten die Notation 00 bzw. 00p. Allgemeinbegriffe, die in Verknüpfung mit anderen Schlagwörtern aussagekräftig und in mehr als fünf SWD-Sachgruppen fachsprachlich gebräuchlich sind, erhalten die Notation 1.

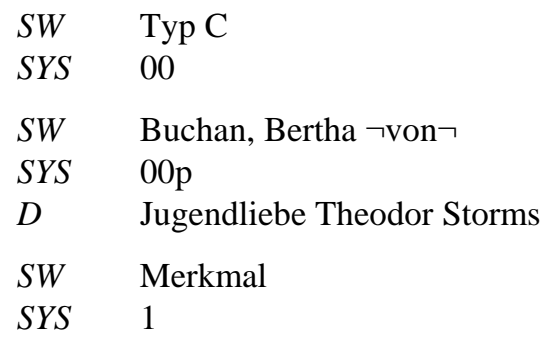

2. Ländercode

Der Ländercode nach DIN EN 23166 (Symbol LC) systematisiert folgende Gruppen von Schlagwörtern nach ihrer geographischen Zugehörigkeit:

- Geographische Namen,

SW Deutschland

$L C \quad$ XA-DE

- Ethnographische Namen,

SW Sioux

$L C \quad$ XD-US

- Sprachbezeichnungen,

SW Catawba-Sprache

$L C \quad$ XD-US

- Personennamen,

SW Beckett, Samuel

SYS 12.2p

LC XA-IE; XA-GB; XA-FR

- Körperschaftsnamen,

SW IBM Deutschland Informationssysteme GmbH

SYS $\quad 10.12 b$

$L C \quad \mathrm{XA}-\mathrm{DE}-\mathrm{BW}$

BF Stuttgart / IBM Deutschland Informationssysteme GmbH

SW Bremen / Kunstverein Bremen

SYS 13.1a

LC XA-DE-HB 
- Sachschlagwörter, in denen (z. B. durch die Verweisung oder durch die Notation 16.5) ein geographischer Bezug zum Ausdruck gebracht wird,

$\begin{array}{ll}\text { SW } & \text { Kibbuz } \\ \text { SYS } & 9.3 \mathrm{~b} \\ \text { LC } & \text { XA-IS } \\ \text { BF } & \text { Israel / Kibbuz }\end{array}$

- Anonyme Werktitel mit eindeutigem geographischen Bezug,

$\begin{array}{ll}\text { SW } & \neg \text { Der } \neg \text { Zürcher Oberländer } \\ \text { SYS } & 2.3 \\ \text { LC } & \text { XA-CH } \\ \text { MO } & \text { Schweiz; Zeitung } \\ & \text { Zeitung; Schweiz }\end{array}$

- Mehrgliedrige Schlagwörter für Individualbegriffe, die mit einem Schlagwort angesetzt werden, das einen Ländercode erhält.

$\begin{array}{ll}\text { SW } & \text { Drusen / Aufstand <1925-1926> } \\ \text { SYS } & 16.5 \\ \text { LC } & \text { XB-SY } \\ \text { MO } & \text { Syrien ; Geschichte 1925-1926 }\end{array}$

3. Sprachencode

Der Sprachencode (Symbol SC) nach ISO/DIS 639-2/B systematisiert folgende Gruppen von Schlagwörtern nach ihrer sprachlichen Zugehörigkeit:

- Sprachbezeichnungen,

$\begin{array}{ll}\text { SW } & \text { Catawba-Sprache } \\ \text { LC } & \text { XD-US } \\ \text { SC } & \text { sio }\end{array}$

- Personen, die im weiteren Sinne literarische, philosophische und theologische Werke verfasst haben,

$\begin{array}{ll}\text { SW } & \text { Beckett, Samuel } \\ \text { SYS } & 12.2 p \\ \text { LC } & \text { XA-IE; XA-GB; XA-FR } \\ \text { SC } & \text { eng; fre }\end{array}$

Beckett hat Werke in mehreren Sprachen verfasst.

- Werktitel für sprachgebundene Werke,

$\begin{array}{ll}\text { SW } & \text { Exodus }<\text { Altenglisches Epos }> \\ \text { SYS } & 12.2 \mathrm{~b} \\ \text { LC } & \text { XA-GB } \\ \text { SC } & \text { ang } \\ \text { MO } & \text { Altenglisch ; Epos } \\ \text { SW } & \text { Beckett, Samuel / Mal vu mal dit } \\ \text { SYS } & 12.2 \mathrm{p} \\ \text { LC } & \text { XA-IE, XA-GB; XA-FR } \\ \text { SC } & \text { fre } \\ \text { SW } & \text { Les @ soirées de Paris } \\ \text { SYS } & 2.3 ; 12.1 \mathrm{~b} \\ \text { LC } & \text { XA-FR } \\ \text { SC } & \text { fre } \\ M O & \text { Frankreich / Literarische Zeitschrift } \\ & \text { Literarische Zeitschrift / Frankreich }\end{array}$


- Sachschlagwörter für Begriffe der Linguistik und literarische Gattungen, die nur in einer Sprache vorkommen.

$\begin{array}{ll}\text { SW } & \text { Fablel } \\ \text { SYS } & 12.3 \\ \text { LC } & \text { XA-FR } \\ \text { SC } & \text { fro } \\ \text { BF } & \text { Altfranzösisch / Fablel }\end{array}$

- Körperschaften, deren Aufgabenschwerpunkt mit Sprache oder Literatur verbunden ist.

SW Darmstadt / Deutsche Akademie für Sprache und Dichtung

SYS 11.1a; 12.1b; 6.5

LC XA-DE*HE

$S C$ ger

4. Zeitcode

Der Zeitcode (Symbol ZC) dient dem Retrieval von zeitlichen Aspekten in einfacher, stets gleich strukturierter Form. Er soll sowohl allein wie in Kombination mit anderen Datenelementen suchfähig sein (vgl. § 418; Anl. 9).

\section{§ 19 Bemerkungen in Schlagwortsätzen}

1. Quellenangabe

Die Quellenangabe ist Nachweis der Gebräuchlickeit eines Schlagwortes (vgl. § 9,3) und dient damit der terminologischen Kontrolle. Sie wird mit dem Symbol Q eingeleitet und enthält folgende Angaben:

- Angabe der Quelle des Schlagworts in abgekürzter Form entsprechend der „Liste der Nachschlagewerke“ (vgl. § 9,3). Ist das Schlagwort in keinem dieser Nachschlagewerke nachweisbar, so ist die Quellenangabe 'Vorlage' oder der Titel eines weiteren Nachschlagewerks in möglichst kurzer Form.

$$
\begin{array}{ll}
S W & \text { Niveaulinie } \\
Q & \text { Naas-Schmid }
\end{array}
$$

- Erfolgt die Ansetzung eines Schlagwortes unter Bezug auf eine bestimmte Regelung der RSWK oder der „Praxisregeln“, so wird im Feld für die Quelle die Formulierung 'Nach § ... RSWK' bzw. 'Nach Praxisregel zu § ... RSWK' erfasst.

SW Islamische Presse

Q $\quad$ Nach Praxisregel zu § 305,2 RSWK

- Erfolgt die Ansetzung eines Schlagwortes entsprechend einer in der SWD festgelegten Leitlinie, z.B. dem Hinweis, dass mit einem bestimmten Grundwort in einem definierten Sachgebiet Komposita zu bilden sind, so wird in der Quellenangabe 'analog' eingetragen. Dem Vermerk 'analog' sollte stets der Hinweis auf das Schlagwort folgen, bei dem die herangezogene Regelung im Verwendungshinweis verankert ist.

$\begin{array}{ll}\text { SW } & \text { Handel } \\ H & \text { Mit dem jeweiligen Gut wird i.d.R. ein Kompositum gebildet. } \\ \text { SW } & \text { Bernsteinhandel } \\ Q & \text { analog Verwendungshinweis bei Handel }\end{array}$


2. Definition

Definitionen (Symbol D) dienen der Information der Benutzer und der Festlegungskontrolle. Sie sind nur dann erforderlich, wenn begriffliche Unklarheiten vorliegen, insbesondere dann, wenn ein Schlagwort allgemeinsprachigen Missverständnissen unterliegt. Im Zweifelsfalle ist eine Definition anzugeben. Die Angabe der Quelle oder der SWD-Notation ersetzt nicht die Definition.

SW Nichtsesshafter

D Person ohne festen Wohnsitz, die im Gegensatz zu Obdachlosen keine Obdachlosenoder Notunterkünfte bewohnt.

Die Definition ist erforderlich zur Abgrenzung von 'Obdachloser'.

SW Proband

$D \quad$ Zur Bewährung entlassener Strafgefangener

Die Definition ist erforderlich, weil unter Proband überwiegend eine Versuchsperson verstanden wird.

3. Verwendungshinweis

Verwendungshinweise enthalten für Benutzer wie für Bearbeiter Informationen über die Benutzung eines Schlagworts in Ansetzungen und Verknüpfungen. Sie werden mit dem Symbol $\mathrm{H}$ eingeleitet und

erläutern die Verknüpfungsmöglichkeiten eines Schlagwortes mit anderen Schlagwörtern zu einer Schlagwortkette,

SW Wissensrepräsentation

$H \quad$ Verknüpfe mit Anwendungsgebiet, z.B. Erkenntnistheorie, Kognitive Psychologie oder spezifischeren Schlagwörtern. Künstliche Intelligenz entfällt als pleonastisch.

weisen auf die Verwendung anderer Schlagwörter in anderen bzw. ähnlichen Zusammenhängen hin,

SW Trekking

D $\quad$ Mehrtägige meist organisierte Wanderung i.d.R. mit Führer durch unwegsames oder unerschlossenes Gebiet meist außerhalb Europas.

H Wandern bzw. Bergwandern für kürzere bzw. eintägige Touren und für Hüttenwandern bevorzugt zu benutzen.

grenzen das Schlagwort gegenüber anderen Schlagwörtern ab,

SW Training

$H \quad$ Außerhalb des Sports nicht zu verwenden, stattdessen Übung, z.B. Aufmerksamkeit ; Übung

geben Hinweise zur Ansetzung von Komposita,

SW Bewältigung

$H \quad$ In Verbindung mit kritischen Lebensereignissen (Krankheit, Tod von Angehörigen) i.d.R. nicht permutierendes Schlagwort. Keine Kompositumbildung außer mit Angst, Konflikt, Leben, Stress, Vergangenheit. In Verbindung mit Formschlagwort Ratgeber und Sachverhalten wie Koabhängigkeit, Alkoholismus oder vergleichbaren verhaltensrelevanten Besonderheiten entfällt Bewältigung als redundant. 
weisen auf bestimmte Regeln hin und geben damit Hinweise auf weitere Suchmöglichkeiten.

SW Schule

$H \quad$ Einzelne Schulen werden als Körperschaft behandelt, z. B. Frankfurt $<$ Main $>$ / Freie Schule. Im übertragenen Sinne für die Schulen einzelner Künstler, Wissenschaftler etc. in Verbindung mit Personennamen wird Schule nicht benutzt, statt dessen werden die Personen mit Schlagwörtern wie Künstlerschule, Philosophenschule oder Wissenschaftliche Schule (bzw. Verknüpfung aus jeweiliger Wissenschaftsdisziplin und Wissen schaftliche Schule) verknüpft.

4. Redaktionelle Bemerkung

Redaktionelle Bemerkungen (Symbol R) enthalten für die Bearbeiter Informationen zur Genese eines Schlagwortsatzes. Solche Informationen weisen u. a. hin

auf die Gründe für die Ansetzung eines Schlagwortes und auf die Entscheidungsbildung bei Änderungen oder bei der Löschung von Schlagwörtern zugunsten einer Normierung auf eine Vorzugsbezeichung.

SW Streptococcus

$R \quad$ Synonymie-Verweisung von Lactococcus wurde gelöscht, da Lactococcus als Gattung 1985 neu definiert wurde.

auf die Vorläufigkeit einer Ansetzung (vgl. § 9,1).

5. Bemerkungen zu einzelnen Verweisungsformen

$\mathrm{Zu}$ einzelnen Verweisungsformen werden bei Bedarf Bemerkungen mit * erfasst, z. B. 'Quasisynonym', die Quelle der Verweisungsform (nur in begründeten Fällen), 'Früherer Titel', 'Späterer Titel', Erscheinungsjahr usw.

SW Mineralischer Rohstoff

BF $\quad$ Bodenschätze *Quasisynonym

\section{§ 20 Gestaltung der Schlagwort-Recherche im Online-Katalog}

1. Die Gestaltung des Retrievals von Schlagwörtern und ihrer Anzeige im Online-Katalog wird durch das vorliegende Regelwerk nicht normiert, sondern ist Aufgabe des jeweiligen OPACs. Im Folgenden können nur einzelne Hinweise gegeben werden, insbesondere zu Punkten, an denen die Regeln für die Erschließung mit der Gestaltung des Retrievals zusammenhängen.

2. Die besondere Stärke des Online-Katalogs ist das postkoordinierende Retrieval. Darunter versteht man die Eigenschaft eines Indexierungs- und Retrievalsystems, beliebige Sachverhalte aus ihren begrifflichen Komponenten im Zuge des Retrievals zusammenzusetzen - im Unterschied zur Präkombination, bei der Begriffe während der Indexierung zusammengesetzt werden.

Auf der Ebene der Schlagwörter erfordert dies, dass das Vokabular der SWD so gewählt werden muss, dass es für ein postkoordinierendes Retrieval geeignet ist. Dies wird mit Hilfe der Zerlegungskontrolle (vgl. § 8,5) gesichert.

Auf der Ebene der Schlagwortketten erfordert dies, dass - soweit nötig - auch pleonastische Begriffe oder Begriffsteile in der Schlagwortkette verwendet werden (vgl. § 324). 
3. Dieses Regelwerk geht aus von der Führung der SWD (einer Schlagwortdatei) in einer getrennten Datei (Normdatei), die mit den Titeldaten verknüpft ist.

Die Schlagwortsätze werden wortweise indexiert. Eine phrasenweise Indexierung (insbesondere für Einwortbegriffe) ist jedoch ebenso erforderlich. Homonymenzusätze sollten getrennt indexiert werden, z. B. mit den Winkelklammern, da sie bei Allgemeinbegriffen einen hohen Anteil an Ballast ergeben.

Synonyme werden zusammen mit den Ansetzungsformen indexiert. Die Suche mit der synonymen Form führt automatisch zur Ansetzungsform, mit der in den Titeldaten weiter recherchiert wird. Synonomie-Verweisungen sollten also automatisch nachvollzogen werden.

Andere Formen von Verweisungen sollten gemeinsam mit Ansetzungen und Synonymen wie auch in getrennten Suchfragen angezeigt werden können, da Schlagwortsätze häufig sehr komplexe Informationen enthalten.

Codierungen, Notationen und Indikatoren sollten jeweils getrennt suchbar sein (vgl. § 20,6).

4. Eine Suchanfrage kann entweder auf die SWD oder auf Schlagwortketten gerichtet sein. Ein Wechsel zwischen beiden Formen der Suche sollte abhängig von der Treffermenge möglich sein.

Bei der Suche in der SWD sollten als Retrievalergebnis, ggf. abhängig von der Treffermenge, Schlagwortsätze der SWD oder direkt Titelsätze angezeigt werden (zweistufige oder einstufige Suche).

Die SWD sollte sowohl mit ihren einzelnen Schlagwortsätzen wie in Registerform angezeigt werden können. Der Umfang der Anzeige der Schlagwortsätze hängt vom jeweiligen OPAC ab.

5. Die Suche nach Schlagwortketten sollte sowohl im Anschluss an eine Suche in der SWD als auch direkt möglich sein. Als Ergebnis sollten, ggf. abhängig von der Treffermenge, Titelsätze oder Schlagwortketten angezeigt werden (einstufige oder zweistufige Suche). Eine Phrasensuche (insbesondere für Ketten aus nur einem Schlagwort) ist jedoch ebenfalls erforderlich.

Die Schlagwortketten sollten, um ein Browsing durch den Benutzer zu erleichtern, in Listen aufbereitet (sortiert) werden. Sortierte Schlagwortkettenlisten eignen sich darüber hinaus sehr gut als sachlich informative Kurzanzeigeform für Suchergebnisse aller Art.

6. Welche Indikatoren online indexiert werden, hängt von den jeweiligen Bedürfnissen ab.

Formschlagwörter sollten i. d. R. getrennt indexiert werden, da sonst in vielen Fällen ein hoher Anteil an Ballast entsteht, wenn nach dem gleichlautenden Sachschlagwort gesucht wird.

Formschlagwörter können in der Anzeige als solche gekennzeichnet werden (z. B. mit dem Indikator und farbig unterlegt), um die Verständlichkeit der Schlagwortkette zu verbessern.

7. Suchanfragen des Benutzers sollten durch Hilfsmittel der Benutzerführung unterstützt werden, insbesondere, wenn kein Treffer erzielt wird:

- Semantische Zerlegung von Suchanfragen,

- Reduktion auf die Stammform, z. B. von Plural auf den Singular,

- Phonetische Suche.

Die SWD berücksichtigt dies insoweit, als Verweisungen von der semantisch zerlegten, postkoordinierten Form auf das als Schlagwort gewählte Kompositum i. d. R. gemacht werden (vgl. $\S 12,2, b)$. Verweisungen, die unterschiedliche Flexionsformen oder phonetische 
Schreibvarianten berücksichtigen, werden hingegen nur in geringem Umfang ausgeführt. Für diese Sucheinstiege sollten entsprechende maschinelle Verfahren implementiert werden.

Anm: Die Verweisung von zwei oder mehr Schlagwörtern auf das Kompositum wird jedoch i.d.R. gemacht.

8. Im Hinblick auf das Stichwort-Retrieval im Online-Katalog wird i.d.R. auf Übergehungsverweisungen verzichtet.

SW Deutscher Verein für das Höhere Mädchenschulwesen

ohne Vw von Verein für das Höhere Mädchenschulwesen

Auf Umkehrungsverweisungen und die Permutation von mehrgliedrigen Oberbegriffen wird jedoch im Hinblick auf Listenfunktionen nicht verzichtet.

SW London / British Library

BF British Library / London

9. Verweisungen werden in der SWD und in Registern reziprok dargestellt. In der SWD soll zwischen verschiedenen Verweisungsformen gewechselt werden können (Navigieren). 



\section{Personenschlagwörter}

\section{Definition und Verwendung}

\section{§ 101 Definition}

1. Als Personenschlagwörter gelten Namen natürlicher Personen (persönliche Namen, Notnamen, Familiennamen mit Vornamen und Namen von Familien), Namen von mythologischen und literarischen Gestalten sowie Personengruppen aus der Mythologie und der Literatur, die eine feste Anzahl von Personen umfassen. Personenschlagwörter erhalten in der SWD den Indikator $\mathrm{p}$, in der PND die Satzart Tp.

$\begin{array}{ll}S W & \text { Heinrich }<\text { von Morungen }> \\ S W & \text { E. S. }<\text { Meister }> \\ S W & \text { Mozart, Wolfgang Amadeus } \\ S W & \text { Fugger }<\text { Familie }> \\ S W & \text { Orpheus } \\ S W & \text { Tristan und Isolde } \\ S W & \text { Holmes, Sherlock } \\ S W & \text { Parzen }\end{array}$

2. Sonstige Personengruppen werden als Sachschlagwort (vgl. § 303,2,e) bzw. als Körperschaft angesetzt und behandelt.

SW s Scilitanische Märtyrer

SW k Jesuiten

\section{§ 101a Verwendung}

1. Personennamen werden Schlagwort bei Dokumenten über Leben und Werk einer Person einschließlich der autobiographischen Darstellungen, Briefe und Gespräche.

Personennamen entfallen i.d.R. nicht als pleonastisch in Verbindung mit geographischen/ ethnographischen oder Sachschlagwörtern, die überwiegend oder ausschließlich mit einer bestimmten Person vorkommen.

$$
\begin{array}{ll}
\text { SWW } & \text { Bultmann, Rudolf; Entmythologisierung } \\
\text { SWW } & \text { Wagner, Richard ; Tristan-Akkord }
\end{array}
$$

Werden diese Gegenstände aber unabhängig von einer solchen Person behandelt, so wird sie bei der Bildung der Schlagwortkette nicht berücksichtigt.

\footnotetext{
Inhalt: Die Anthroposophie nach Rudolf Steiner

SW Anthroposophie

nicht: Steiner, Rudolf ; Anthroposophie
} 
2. Der Personenname wird Teil eines mehrgliedrigen Schlagworts, wenn es sich um ein literarisches, wissenschaftliches, künstlerisches oder musikalisches Werk einer Person handelt (vgl. $\S \S 707$; 708; 724ff.; 743) oder um ein historisches Einzelereignis, an dem eine Person maßgeblichen Anteil hatte (vgl. § 415).

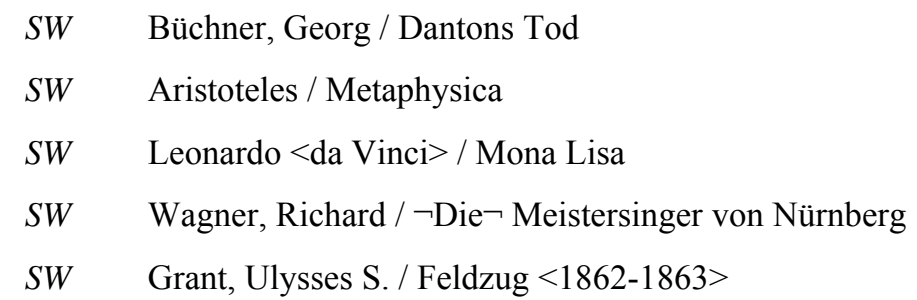

3. Bei der Ansetzung von Schriftdenkmälern, ortsgebundenen Kunstwerken, Filmen, Hörfunkoder Fernsehsendungen u.ä. werden beteiligte Personen (z.B. Künstler, Architekten, Regisseure) in Synonymie-Verweisungen berücksichtigt (vgl. §§ 722,1; 725,4; 730,1,a; 731,5; $733,3$ und $4 ; 736,1 ; 743)$.

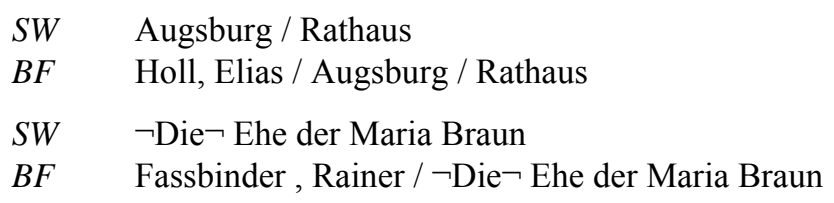

4. Wird ein Thema maßgeblich von einer Person geprägt (insbesondere Herrscher, Politiker) und hat darüber hinaus Bedeutung, z.B. für das betreffende Geographikum, so kann neben der Schlagwortkette mit dem Personennamen eine weitere gebildet werden, die z.B. den geographischen Aspekt berücksichtigt.

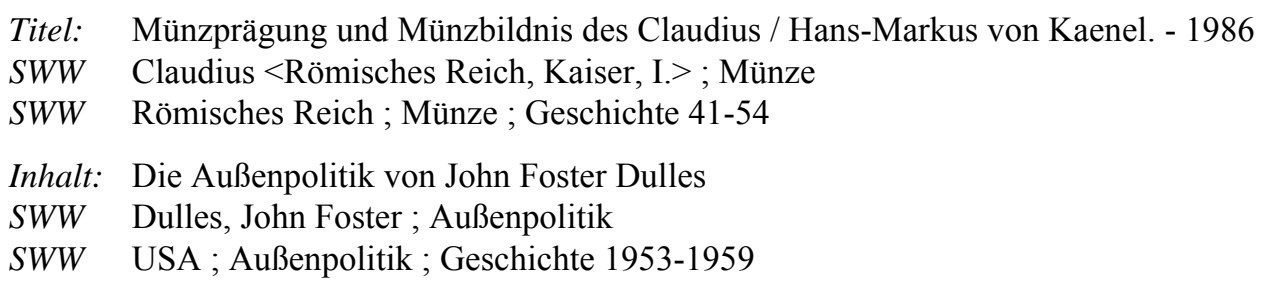

5. Dient die Angabe einer Person nur der zeitlichen Bestimmung eines Gegenstandes, so wird der Personenname bei der Bildung der Schlagwortkette nicht berücksichtigt. Die Zeitangabe wird durch 'Geschichte' mit den entsprechenden Jahreszahlen ausgedrückt.

Titel: England in the age of Chaucer / William Woods. - 1976

SWW England; Geschichte 1350-1400

6. Bei Festschriften wird die gefeierte Person nur dann berücksichtigt, wenn über die Widmung hinaus biographisches bzw. bibliographisches Material enthalten ist.

Titel: Bestandserschließung und Bibliotheksstruktur : Rolf Kluth zum 10.2.1979 / hrsg. von Rainer Alsheimer. - 1979

SWW Kluth, Rolf; Bibliographie

SWW Inhaltserschließung; Aufsatzsammlung 


\section{Ansetzung}

\section{\$ 102 Grundregeln}

1. Personennamen werden nach RAK angesetzt, soweit in den folgenden Paragraphen keine andere Regelung getroffen wird. Für den Schlagwortkatalog wird die gleiche RAK-Version (RAK-WB, RAK-ÖB) wie für den Alphabetischen Katalog angewendet (vgl. §§ 108,4,b; $109,2 ; 110,6)$.

2. Abweichende Namensformen werden i. d. R. als Synonym erfasst. Für die in der PND ggf. abweichende Ansetzungsform nach RAK ist dies obligatorisch.

$\begin{array}{lll}S W & \text { De Gasperi, Alcide } & \text { (Italiener) } \\ B F & \text { Gasperi, Alcide } \neg \mathrm{de} \neg & \\ & \text { DeGasperi, Alcide } & \\ S W & \text { Palissot de Montenoy, Charles } & \text { (Franzose) } \\ B F & \text { Montenoy, Charles Palissot } \neg \text { de } \neg & \\ S W & \text { Oliveira, Raimundo Falcão } \neg \text { de } \neg & \text { (Portugiese) } \\ B F & \text { Falcão de Oliveira, Raimundo } & \\ S W & \text { Franz }<\text { von Assisi }> & \\ B F & \text { Franciscus }<\text { Assisias }> & \text { (Ansetzungsform nach RAK) } \\ & \text { Francesco }<\text { d'Assisi }> & \\ & \text { Franziskus }<\text { von Assisi }> & \\ & \text { Bernardone, Giovanni } & \\ S W & \text { Doolittle, Hilda } \\ B F & \text { H. D. }\end{array}$

\section{$\S 103$ Pseudonyme}

1. Hat eine Person ein oder mehrere Pseudonyme oder einen aus dem wirklichen Namen und einem Pseudonym zusammengesetzten Namen benutzt, so wird sie i. d. R. mit ihrem wirklichen Namen angesetzt. Pseudonyme bzw. zusammengesetzte Namen werden als Synonyme erfasst (vgl. RAK § 308).

$\begin{array}{ll}S W & \text { Bugenhagen, Johannes } \\ B F & \text { Pomeranus, Johannes } \\ S W & \text { Sjöberg, Erik } \\ B F & \text { Vitalis }<\text { Schriftsteller }>\end{array}$

2. Ist jedoch eine Person unter ihrem Pseudonym, einem ihrer Pseudonyme oder einem aus wirklichem Namen und Pseudonym zusammengesetzten Namen sehr viel bekannter, so wird sie damit angesetzt. Der wirkliche Name wird als Synonym erfasst, soweit Persönlichkeitsrechte das nicht ausschließen. Der Bekanntheitsgrad von wirklichem Namen und Pseudonym wird anhand der „Liste der Nachschlagewerke“ festgestellt (vgl. § 9,3).

Pseudonyme werden i.d.R. nach denselben Grundsätzen wie die wirklichen Namen angesetzt (vgl. RAK § 308).

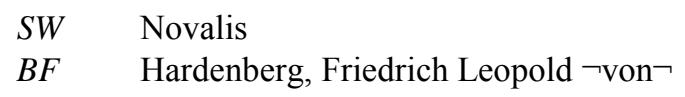




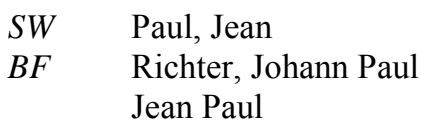

3. Ist der wirkliche Name nicht zu ermitteln bzw. darf er aus Gründen des Persönlichkeitsschutzes nicht bekannt gemacht werden, so wird mit dem Pseudonym bzw. mit dem aus wirklichem Namen und Pseudonym zusammengesetzten Namen angesetzt.

Unter Persönlichkeitsschutz im Sinne dieses Regelwerks stehen Personen, die nach 1885 geboren und/oder nach 1915 gestorben sind. Pseudonym und wirklicher Name bleiben ohne Verknüpfung.

Ist das Pseudonym jedoch in einem Nachschlagewerk oder in einem Werk der betreffenden Person bereits gelüftet worden, so wird diese Person nach den Bestimmungen von $\S 103,1$ und 2 behandelt.

\section{$\S 104$ Notnamen und Monogrammisten}

Personen, deren Namen unbekannt sind, die aber üblicherweise mit Notnamen (Behelfsnamen) oder Initialen belegt werden, sind mit der gebräuchlichen Form anzusetzen, die anhand der „Liste der Nachschlagewerke“ (vgl. § 9,3) festgestellt wird. Andere Namensformen können als Synonym erfasst werden. Initialen werden in der Reihenfolge angesetzt, die das Nachschlagewerk bzw. die Vorlage gewählt hat. Die einzelnen Buchstaben werden durch Punkt und Spatium getrennt (vgl. RAK § 310).

$\begin{array}{ll}S W & \text { Hausbuchmeister } \\ Q & \text { M } \\ B F & \text { Meister des Hausbuches } \\ S W & \text { Jack }<\text { the Ripper }> \\ S W & \text { E. S. }<\text { Meister }> \\ B F & \text { Meister E. S. }\end{array}$

\section{$\S 105$ Vornamen und Namensbestandteile, die in der Ordnungsgruppe der Vornamen angesetzt werden}

1. Die modernen Vornamen werden in der von der Person überwiegend gebrauchten Reihenfolge und Form angesetzt. (vgl. RAK § 320).

$\begin{array}{ll}\text { SW } & \text { Hegel, Georg Wilhelm Friedrich } \\ \text { SW } & \text { Sartre, Jean-Paul } \\ \text { SW } & \text { Stockhausen, Karlheinz } \\ \text { SW } & \text { Brown, Charles B. }\end{array}$

2. In der Ordnungsgruppe der Vornamen anzusetzende andere Namensbestandteile (z. B. nomen gentile bei römischen Namen und Vatersnamen bei russischen Namen) werden wie Vornamen analog RAK behandelt.

$\begin{array}{ll}S W & \text { Tacitus, Cornelius } \\ S W & \text { Seneca, Lucius Annaeus }<\text { Philosophus }> \\ S W & \text { Dostoevskij, Fedor M. } \\ S W & \text { King, Martin Luther }\end{array}$




\section{$\S 106$ Homonyme Personennamen}

1. Homonyme Personennamen werden i.d. R. durch individualisierende Merkmale unterschieden. Homonymenzusätze werden gebildet:

a) in den nach RAK vorgesehenen Fällen als Ordnungshilfe, i. d. R. in der im Deutschen gebräuchlichen Form,

b) als unterscheidende Zusätze gemäß § 10,1.

2. Nach den RAK sind in den folgenden Fällen Ordnungshilfen vorgesehen:

a) bei Personen mit Beinamen (vgl. RAK-WB §§ 327-332, 342),

Anm.: Zur Bildung der Ordnungshilfe nach RSWK vgl. § 108,4 und 5.

$S W \quad$ Thomas $<$ von Aquin $>$

$S W \quad$ Daniel $<$ Prophet $>$

SW $\quad$ Lanfranco $<$ da Milano $>$

$Q \quad$ M

BF $\quad$ Lanfrancus $<$ Mediolanensis $>$ (Ansetzungsform nach $R A K-W B$ )

Lanfrank $<$ von Mailand $>$

SW $\quad$ Simon $<$ Magus $>$

b) bei regierenden Fürsten, Mitgliedern von Fürstenhäusern und geistlichen Würdenträgern (vgl. RAK-WB $\S \S 337-342$ ),

Anm.: Zur Bildung der Ordnungshilfe nach RSWK vgl. § 108,7-9

$S W \quad$ Friedrich $<$ Preußen, König, II. $>$

SW $\quad$ Paris $<$ Salzburg, Erzbischof $>$

c) bei Pseudonymen, Spitznamen und dgl. (vgl. RAK-WB § 308,5), bei mit einzelnen Buchstaben oder Buchstabengruppen abgekürzten Namen (vgl. RAK-WB § 309a) und bei Notnamen (RAK-WB § 310),

$\begin{array}{ll}S W & \text { Nee, } \ldots<\text { Watchman }> \\ S W & \mathrm{X}<\text { Doktor }> \\ S W & \text { Mönch }<\text { vom Main }>\end{array}$

d) bei sehr bekannten Personen, die regelmäßig mit unterscheidenden Zusätzen zitiert werden (nur in den in RAK-WB § 311 als Beispiele genannten Fällen).

$S W \quad$ Cranach, Lucas $<$ der Ältere $>$

$S W \quad$ Cranach, Lucas $<$ der Jüngere $>$

3. Für die zur Unterscheidung gleichnamiger Personen gebildeten Homonymenzusätze sind in der angegebenen Reihenfolge heranzuziehen:

a) eine normierte Bezeichnung für den Beruf der Person, unter dem sie bekannt ist,

$S W \quad$ Marx, Karl $<$ Komponist $>$

$S W \quad$ Marx, Karl $<$ Künstler $>$

Anm.: Die als unterscheidende Zusätze zugelassenen Bezeichnungen sind in den „Praxisregeln zu den Regeln für den Schlagwortkatalog (RSWK) und der Schlagwortnormdatei (SWD)“ enthalten.

b) eine der SWD zu entnehmende Bezeichnung für den Tätigkeitsbereich einer Person (einschließlich ihrer Religionszugehörigkeit oder Weltanschauung), wenn sie darunter bekannt ist,

SW Wunderlich, Rudolf $<$ Widerstandskämpfer $>$

nicht: Wunderlich, Rudolf $<$ Schriftsetzer $>$

c) Lebensjahre, ersatzweise Wirkungsjahre, falls Beruf bzw. Tätigkeitsbereich nicht zu ermitteln bzw. unklar oder mit dem einer anderen homonymen Person identisch ist (vgl. $\S 17,2, a)$, 


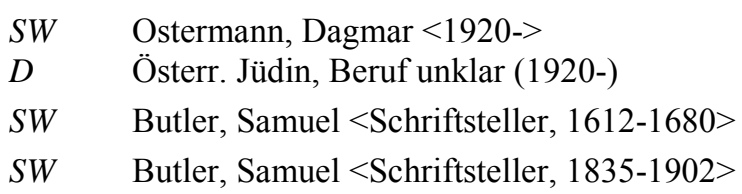

d) sonstige zur Unterscheidung geeignete Merkmale der Person, falls Abs. a - c nicht zutreffen.

e) Ist eine Person sehr viel bekannter, so kann sie ohne unterscheidenden Homonymenzusatz bleiben.

SW Marx, Karl (für den Philosophen)

Anm.: Als sehr viel bekannter gelten Personen mit einem eigenen Eintrag im Hauptteil der neuesten Ausgabe der deutschen Allgemeinenzyklopädie einschl. ihrer Nachträge.

4. Wird eine Namensform als Synonymieverweisung erfasst und ist sie zeichengleich zu einer anderen Namensform, so erhält sie keinen unterscheidenden Homonymenzusatz. Auch bei Zeichengleichheit zur Ansetzungsform einer Person bleiben beide Namensformen ohne unterscheidenden Homonymenzusatz.

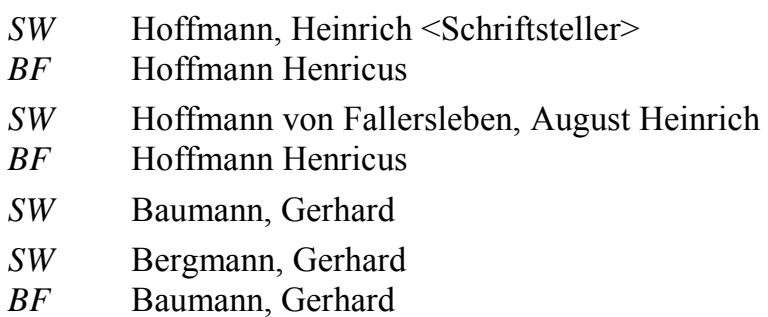

5. Personennamen erhalten auch dann keine Homonymenzusätze, wenn sie zu Schlagwörtern anderer Schlagwortkategorien homonym sind.

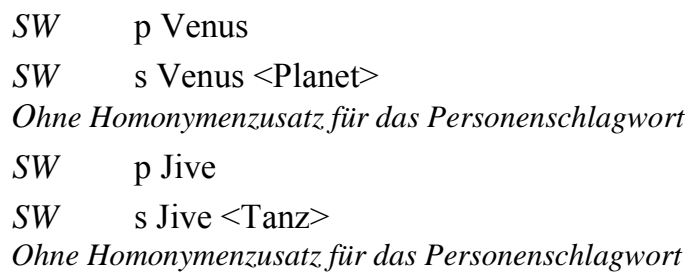

\section{$\$ 107$ Familien und Geschwister}

1. Familien werden wie die zugehörigen Personen angesetzt. Sie erhalten den Homonymenzusatz $<$ Familie $>$. Gleichnamige Familien werden durch einen weiteren geeigneten Homonymenzusatz oder mehrere weitere Homonymenzusätze unterschieden: Geographikum (Land, Landschaft oder Ort), Beruf, Jahreszahlen.
$S W \quad$ Bismarck $<$ Familie $>$
$S W \quad$ Tolstoj $<$ Familie $>$
$S W \quad$ Hahn $<$ Familie, Sylt $>$
SW Hahn $<$ Familie, Theologe $>$

Ist der Familienname selbst Gegenstand der Darstellung, so wird er als Sachschlagwort mit dem Homonymenzusatz $<$ Familienname $>$ angesetzt.

Titel: Etymologie des Familiennamens Sonnleitner / Hans Sonnleitner. - 1995

$S W \quad$ s Sonnleitner $<$ Familienname $>$

2. Herrscher- und Adelsfamilien werden im Plural angesetzt, wenn sie in dieser Form in deutschsprachigen Nachschlagewerken nachzuweisen sind.
SW Flavier
$S W \quad$ Karolinger
SW Wittelsbacher 
Der Homonymenzusatz $<$ Familie $>$ wird nur bei Bedarf angesetzt.

$\begin{array}{ll}\text { SW } & \text { Hohenzollern }<\text { Familie }> \\ S W & \text { Hohenzollern }<\text { Burg }> \\ \text { SW } & \text { Julier }<\text { Familie }> \\ \text { SW } & \text { Julier }<\text { Pass }>\end{array}$

3. Bis zu 5 Geschwister können einzeln mit ihrem Namen angesetzt werden. Mehr als fünf Geschwister werden als Familie behandelt.

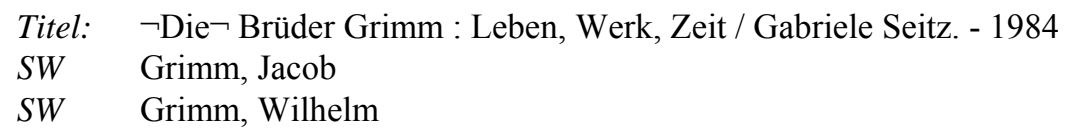

\section{§ 108 Personen des Altertums und des europäischen Mittelalters sowie biblische Personen, Fürsten und geistliche Würdenträger}

1. Namen von Personen des Altertums (mit Ausnahme römischer Namen und von Autoren der griechischen Antike) und des europäischen Mittelalters sowie Namen von biblischen Personen, Fürsten und geistlichen Würdenträgern werden i. d. R. in der im Deutschen gebräuchlichen Form angesetzt.

2. Für die Ansetzung sind die in der „Liste der Nachschlagewerke“ genannten Werke (vgl. § 9,3) heranzuziehen.

3. Abweichende Namensformen werden gemäß $§ 102,2$ als Synonyme erfasst. Dies ist für eine in der PND ggf. abweichende Ansetzungsform nach RAK oder eine Namensform mit Beinamen obligatorisch.

4. Personen des Altertums

a) Römische Personen werden nach RAK § 329 angesetzt.

$\begin{array}{ll}\text { SW } & \text { Cicero, Marcus Tullius } \\ \text { BF } & \text { Cicero } \\ \text { SW } & \text { Horatius Flaccus, Quintus } \\ \text { BF } & \text { Horaz } \\ \text { SW } & \text { Martianus }<\text { Capella }> \\ \text { SW } & \text { Spartacus } \\ \text { BF } & \text { Spartakus }\end{array}$

Götter, mythologische und literarische Gestalten sowie Heilige und Selige, die nicht als Autoren auftreten, werden gemäß der „Liste der Nachschlagewerke“ (vgl. § 9,3) angesetzt.

$\begin{array}{ll}S W & \text { Merkur } \\ B F & \text { Mercurius } \\ V B & \text { Hermes } \\ S W & \text { Florian }<\text { Heiliger }> \\ S W & \text { Monika }<\text { Heilige }>\end{array}$


b) Griechische Namen werden, soweit es sich um Autoren handelt, latinisiert nach RAK $\S 328$ angesetzt.

$\begin{array}{ll}S W & \text { Homerus } \\ B F & \text { Homer } \\ & \text { Homēros } \\ S W & \text { Menander } \\ B F & \text { Menandros }<\text { von Athen }> \\ S W & \text { Zeno }<\text { Citieus }> \\ B F & \text { Zenon }<\text { von Kition }>\end{array}$

Bibliotheken, die im Alphabetischen Katalog RAK-ÖB anwenden, können griechische Autoren nach der „Liste der Nachschlagewerke“ (vgl. § 9,3) ansetzen.

$\begin{array}{ll}\text { SW } & \text { Aischylos } \\ \text { SW } & \text { Homer }\end{array}$

c) Sonstige Personen des Altertums werden nach der „Liste der Nachschlagewerke“ (vgl. $\S 9,3$ ) angesetzt, biblische Personen jedoch nach $\S 108,6$, Fürsten nach $\S 108,7$, Päpste nach $\S 108,9$.

$\begin{array}{lll}\text { SW } & \text { Perikles } & \\ \text { BF } & \text { Pericles } & \\ \text { SW } & \text { Lysipp <von Sikyon> } & \text { (Bildhauer) } \\ \text { BF } & \text { Lysippos } & \\ \text { SW } & \text { Ariovist } & \text { (germanischer Heerführer) } \\ \text { SW } & \text { Bar Kochba } & \text { (jüdischer Freiheitskämpfer) }\end{array}$

5. Personen des europäischen Mittelalters

Personen des europäischen Mittelalters (Todesjahr 501-1500) werden i. d. R. mit ihrem persönlichen Namen und dem Beinamen als Homonymenzusatz angesetzt. Sind sie jedoch unter ihrem Beinamen bzw. Familiennamen bekannter, werden sie mit diesem angesetzt. Persönlicher Name und Beiname werden gemäß der „Liste der Nachschlagewerke“ (vgl. § 9,3) angesetzt. Abweichende Namensformen werden i. d. R. als Synonym erfasst. Für die in der PND ggf. abweichende Ansetzungsform nach RAK ist dies obligatorisch.

Anm.: Geistliche Würdenträger des Mittelalters werden wie Personen ihrer Zeit angesetzt. Zur Ansetzung weltlicher Fürsten des Mittelalters vgl. § 108,7, zur Ansetzung geistlicher Würdenträger der Neuzeit vgl. $\S 108,8$.

$\begin{array}{ll}S W & \text { Oswald }<\text { von Wolkenstein }> \\ B F & \text { Wolkenstein, Oswald } \neg \text { von } \neg \\ \text { SW } & \text { Otto }<\text { von Freising }> \\ B F & \text { Otto }<\text { Frisingensis }> \\ \text { SW } & \text { Lullus, Raimundus } \\ B F & \text { Lull, Ramón } \\ S W & \text { Valla, Lorenzo } \\ B F & \text { Valla, Laurentius }\end{array}$


6. Biblische Personen

Namen biblischer Personen werden nach der „Liste der Nachschlagewerke“ (vgl. § 9,3) angesetzt. Soweit erforderlich, ist ein Homonymenzusatz mit anzusetzen. Abweichende Namensformen werden als Synonyme erfasst.

$\begin{array}{ll}\text { SW } & \text { Markus }<\text { Evangelist }> \\ \text { BF } & \text { Marcus }<\text { Evangelista }> \\ \text { SW } & \text { Paulus <Apostel }> \\ \text { BF } & \text { Paulus }<\text { Apostolus }> \\ \text { SW } & \text { Potifar } \\ \text { BF } & \text { Potiphar } \\ & \text { Putiphar }\end{array}$

7. Fürsten und Mitglieder regierender Familien

a) Ein regierender Fürst wird i. d. R. mit dem persönlichen Namen in der im Deutschen gebräuchlichen Form angesetzt, auch wenn er unter einer anderen Namensform bekannter ist. Wenn eine fremdsprachige Ansetzungsform nach RAK existiert, wird diese als Synonym erfasst. Regierende Fürsten des Altertums sowie früher oder außereuropäischer Kulturen können jedoch mit dem gebräuchlichsten Namen bzw. Namensteil angesetzt werden (vgl. RAK § 337).

Auf den persönlichen Namen folgt ein Homonymenzusatz in deutscher Sprache, der aus Territorium, Titel und ggf. Zählung (in römischen Ziffern) besteht. Regiert ein Fürst mehrere Territorien, so wird das im maßgeblichen Nachschlagewerk zuerst genannte, bei Konkurrenz das ranghöchste, bei Ranggleichheit das zuerst regierte Territorium Teil des Homonymenzusatzes (vgl. RAK § 337). Die sprachliche Form des Territoriums folgt den Nachschlagewerken und entspricht nicht immer seiner Ansetzungsform in der SWD, sondern kann dort als Synonym erfasst sein. Liegt eine Zählung nicht vor, so werden gleichnamige Mitglieder eines Fürstenhauses durch Regierungs- oder Lebensdaten unterschieden. (Zu chinesischen Herrschern vgl. § 110,3.)

$\begin{array}{ll}\text { SW } & \text { Gustav Adolf }<\text { Schweden, König, II. }> \\ \text { BF } & \text { Gustaf Adolf }<\text { Sverige, Konung, II. }> \\ \text { SW } & \text { Alexander }<\text { Russland, Zar, I.> } \\ \text { BF } & \text { Alexander Pawlowitsch }<\text { Russland, Zar }> \\ & \text { Aleksandr }<\text { Rossija, Imperator, I.> } \\ \text { SW } & \text { Ludwig }<\text { Mailand, Herzog }> \\ \text { BF } & \text { Ludovico }<\text { Milano, Duca }> \\ & \text { Sforza, Ludovico }\end{array}$

SW $\quad$ Augustus $<$ Römisches Reich, Kaiser $>$

$B F \quad$ Augustus $<$ Imperium Romanum, Imperator $>$

SW Echnaton $<$ Ägypten, Pharao $>$

SW $\quad$ Faisal $<$ Saudi-Arabien, König $>$

SW $\quad$ Muhammad $<$ Osmanisches Reich, Sultan, VI. $>$

SW Viktoria $<$ Großbritannien, Königin $>$

BF $\quad$ Victoria $<$ Great Britain, Queen $>$

Viktoria $<$ Indien, Kaiserin $>$

Großbritannien ist im maßgeblichen Nachschlagewerk als erstes der regierten Territorien genannt. 
SW $\quad$ Heinrich $<$ Sachsen, Herzog, III.>

(seit 1142)

BF $\quad$ Heinrich $<$ der Löwe $>$

Heinrich $<$ Bayern, Herzog, XII.>

(seit 1154)

b) Mitglieder regierender Fürstenhäuser werden normiert angesetzt (Persönlicher Name, Territorium, Titel sowie bei Bedarf Lebensdaten), sofern ihr Status nicht (z. B. durch Thronverzicht oder Heirat) verändert wurde oder die Nachschlagewerke nicht eine andere Titulatur oder einen anderen Beinamen als gebräuchlich ausweisen.

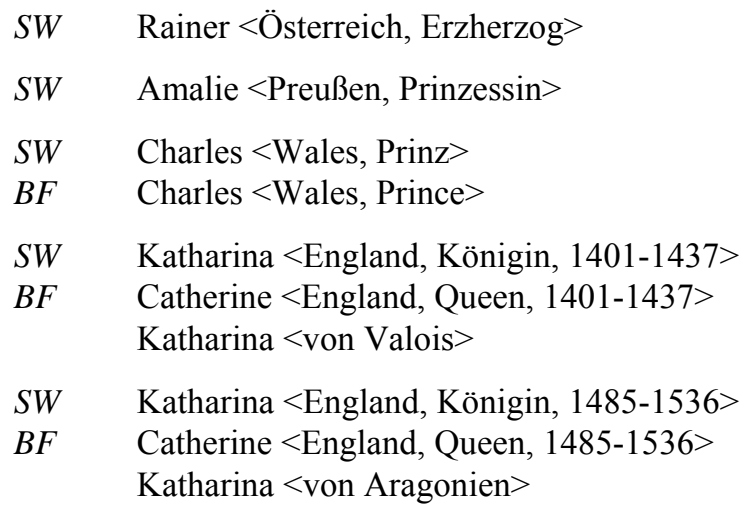

Frauen, die durch mehrmalige Heirat mit verschiedenen regierenden Fürsten mit mehreren Homonymenzusätzen angesetzt werden könnten, werden mit dem bekanntesten Namen, eventuell auch dem Mädchennamen, angesetzt.

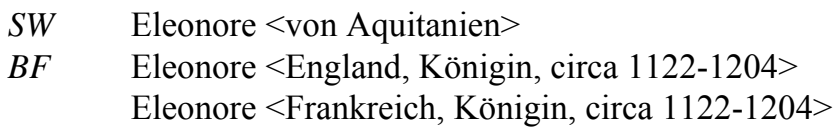

c) Nicht regierende Fürsten und Mitglieder nicht mehr regierender Fürstenhäuser werden wie Personen ihrer Zeit angesetzt, wenn nicht die Nachschlagewerke andere Namensformen als gebräuchlich ausweisen. Als Familienname gilt der Name des Hauses (z. B. 'Bayern' oder 'Preußen'); der Geschlechtsname ('Wittelsbach' oder 'Habsburg') wird ggf. als Synonym erfasst. Wenn die Ansetzungsform mit dem Familiennamen beginnt, werden Adelstitel weggelassen.

Anm.: Zur Festlegung der Ansetzungsform nach § 108,7,a oder 108,7,c vgl. „Praxisregeln“.

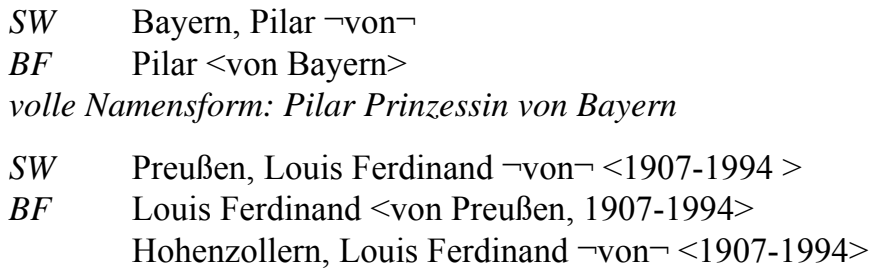

8. Geistliche Würdenträger, Ordensmitglieder, Heilige und Selige der Neuzeit

a) Geistliche Fürsten

Als geistliche Fürsten gelten diejenigen Erzbischöfe und Bischöfe, die bis 1803 dem Reichsfürstenstand angehörten (vgl. Anl. 1). Sie werden mit dem persönlichen Namen in der im Deutschen gebräuchlichen Form mit dem Homonymenzusatz Territorium, Titel und ggf. Zählung angesetzt.

Führt ein Fürst weltliche und geistliche Titel nebeneinander, wie z. B. den des Kurfürsten und des Erzbischofs, so wird für den Homonymenzusatz der geistliche Titel gewählt, so- 
fern er mindestens ranggleich ist. Zur weiteren Reihenfolge der Territorien bei Ranggleichheit vgl. § 108,7,a.

Anm.: Geistliche Fürsten des Mittelalters vgl. § 108,5.

$\begin{array}{ll}S W & \text { Franz }<\text { Münster, Bischof }> \\ B F & \text { Waldeck, Franz } \neg \text { von } \neg \\ S W & \text { Friedrich Karl }<\text { Mainz, Erzbischof }> \\ B F & \text { Erthal, Friedrich Karl } \neg \text { von } \neg \\ & \text { Friedrich Karl }<\text { Mainz, Kurfürst }> \\ & \text { Friedrich Karl }<\text { Worms, Bischof }>\end{array}$

b) Sonstige geistliche Würdenträger (Kardinäle, Bischöfe, Äbte usw.), Ordensmitglieder, Heilige und Selige werden i.d.R. wie sonstige Personen ihrer Zeit angesetzt.

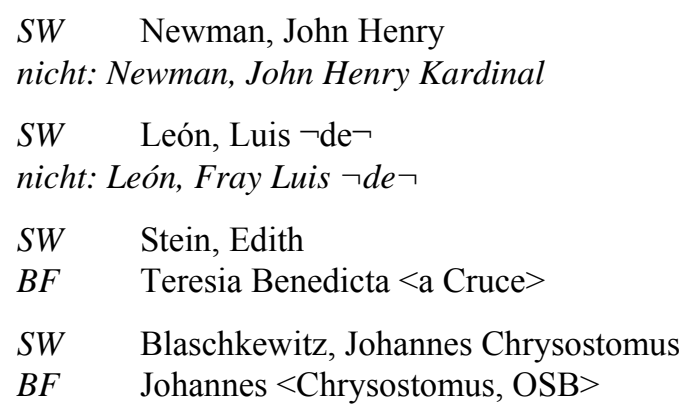

Ist ein Kardinal, Bischof, Abt, Ordensmitglied, Heiliger oder Seliger der Neuzeit unter seinem persönlichen oder geistlichen Namen bekannter, so wird er mit diesem angesetzt. Dabei werden Beinamen, auch solche, die von einer anderen Person übernommen wurden, oder Familiennamen, die als Beinamen angesehen werden können, dem persönlichen bzw. dem geistlichen Namen als Homonymenzusatz hinzugefügt. Von der Ansetzungsform abweichende Namensformen werden als Synonyme erfasst.

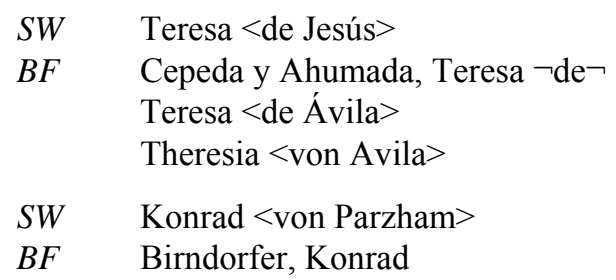

9. Päpste und Patriarchen

a) Päpste werden mit ihrem Papstnamen in der im Deutschen gebräuchlichen Namensform angesetzt. Als Homonymenzusatz folgen die Bezeichnung 'Papst' und ggf. die Zählung in römischen Ziffern. Der bürgerliche Name wird als Synonym erfasst, ebenso die Ansetzungsform nach RAK.

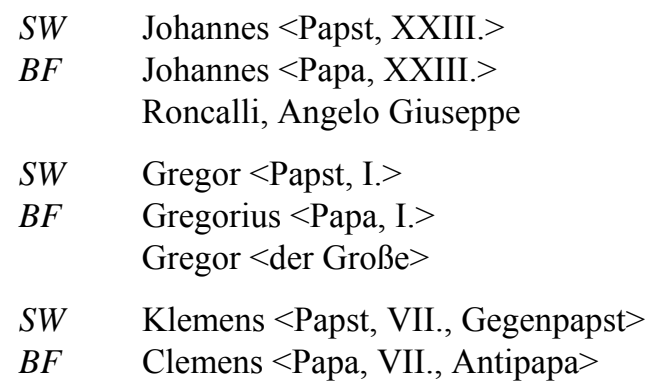


b) Patriarchen, die oberste Würdenträger der Ostkirchen sind, werden mit ihrem geistlichen Namen mit Ort bzw. Territorium, Titel und ggf. Zählung als Homonymenzusatz angesetzt. Der bürgerliche Name wird als Synonym erfasst, ebenso die Ansetzungsform nach RAK.
SW $\quad$ Pimen $<$ Moskau und ganz Russland, Patriarch $>$
BF $\quad$ Pimen $<$ Patriarch Moskovskij i Vseja Rusi, I. $>$
Izvekov, Sergej M.

\section{§ 109 Moderne Personennamen aus Sprachen mit griechischer und ky- rillischer Schrift}

1. Moderne Personennamen (d. h. Todesjahr nach 1500) aus Sprachen mit griechischer und kyrillischer Schrift werden nach RAK angesetzt. Bekannte Namensformen, die von der Ansetzungsform abweichen, sowie die nach der Duden-Umschrift transskribierte Namensform werden als Synonym erfasst. (Zur Umschrift kyrillischer Alphabete nichtslawischer Sprachen nach RAK vgl. „Praxisregeln“ $§ 109,1$.

$\begin{array}{ll}\text { SW } & \text { Čechov, Anton P. } \\ \text { BF } & \text { Tschechow, Anton P. } \\ \text { SW } & \text { Theodōrakēs, Mikēs } \\ \text { BF } & \text { Theodorakis, Mikis }\end{array}$

2. Bibliotheken, die im Alphabetischen Katalog RAK-ÖB anwenden, können moderne Personennamen aus Sprachen mit griechischer und kyrillischer Schrift in der im Deutschen gebräuchlichen Form nach Maßgabe der Nachschlagewerke in Duden-Umschrift ansetzen.

Anm.: Die SWD enthält sowohl die Ansetzungsformen nach RAK-WB als auch - mit besonderer Kennzeichnung - nach RAK-ÖB. Letztere werden allerdings nur aufgeführt, wenn sie im Personenregister der BrockhausEnzyklopädie bzw. von Meyers Enzyklopädie nachzuweisen sind oder wenn über die betreffende Person deutschsprachige Literatur vorliegt.

\section{$\S 110$ Personennamen aus Sprachen mit sonstigen nichtlateinischen Schriften}

1. Für die Ansetzung der Personennamen aus Sprachen in arabischer Schrift gilt gemäß RAK Anl. 5.3 die Umschrift nach DIN 31635.

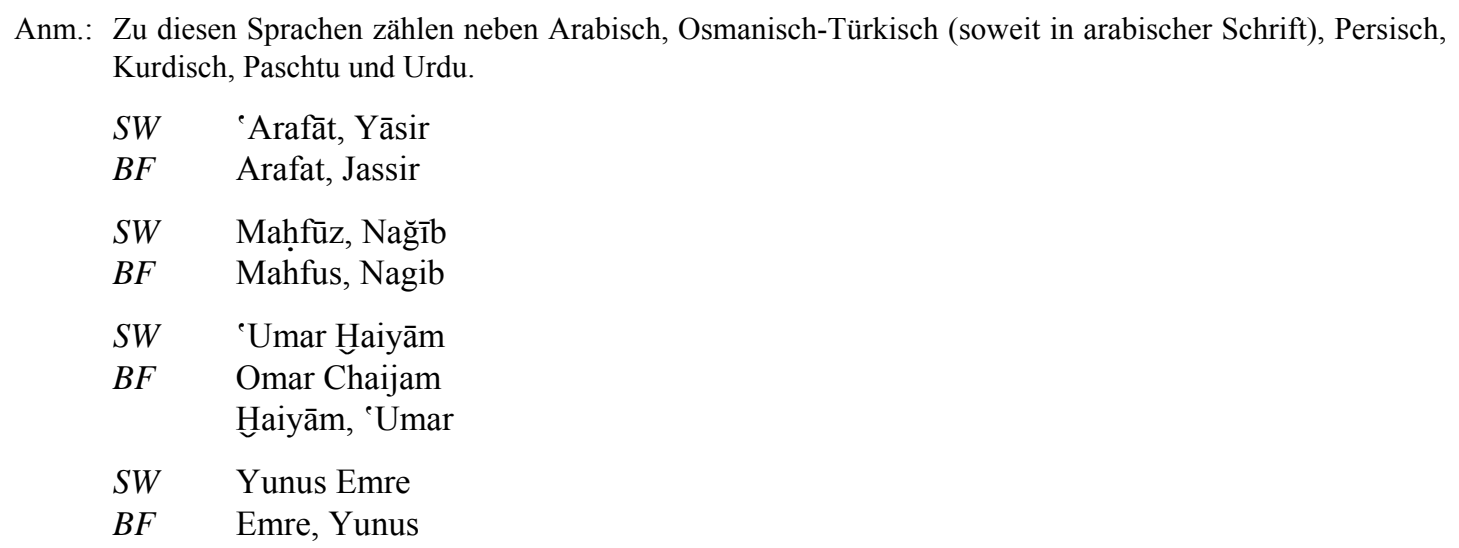


2. Für die Ansetzung der Personennamen aus Sprachen mit hebräischer Schrift gilt gemäß RAK Anl. 5.4 die Umschrift nach DIN 31636.

$\begin{array}{lll}S W & \text { Ben-Gûryôn, Dāwid } & \\ B F & \text { Ben-Gurion, David } & \text { (so M, B 1986) } \\ & \text { Ben Gurion, David } & \\ & \text { Gruen, David } & \\ S W & \text { Perec, Icchok Leib } & \\ B F & \text { Perez, Jizchak Lejb } & \text { (so B 1986) } \\ & \text { Peres, Jișhāa Lēb } & \end{array}$

3. Personennamen aus Sprachen in chinesischer und japanischer Schrift werden nach RAK angesetzt und gemäß Pinyin bzw. Hepburn-Umschrift transskribiert. Die Umschrift nach Wade-Giles wird i. d. R. als Synonym erfasst. Dies gilt auch für Fürsten und geistliche Würdenträger. Chinesischen Herrschernamen wird i. d. R. der Name ihrer Dynastie vorangestellt.

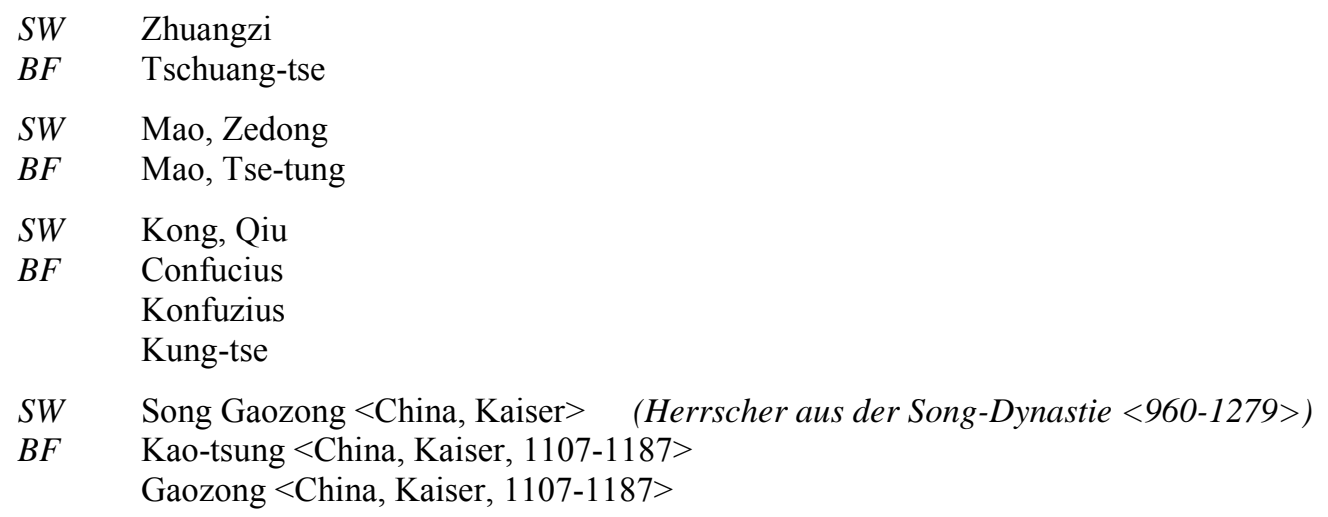

4. Namen von Angehörigen der Nationalitäten in der GUS bzw. der ehemaligen Sowjetunion, die nicht die lateinische, kyrillische oder griechische Schrift verwenden, werden nach der neuesten Ausgabe der deutschsprachigen Enzyklopädien angesetzt. Sind sie dort nicht enthalten, wird die Ansetzungsform nach den nationalsprachigen Enzyklopädien und Nachschlagewerken unter Verwendung der entsprechenden Transliterationstabellen nach RAK gebildet. Die russische Namensform wird i. d. R. als Synonym erfasst.

Personennamen aus Sprachen mit armenischer und georgischer Schrift werden nach RAK angesetzt (zur Umschrift vgl. „Praxisregeln“ $§ 110,4$ ). Die russische Namensform bzw. Namensformen deutschsprachiger Enzyklopädien werden i. d. R. als Synonym erfasst.

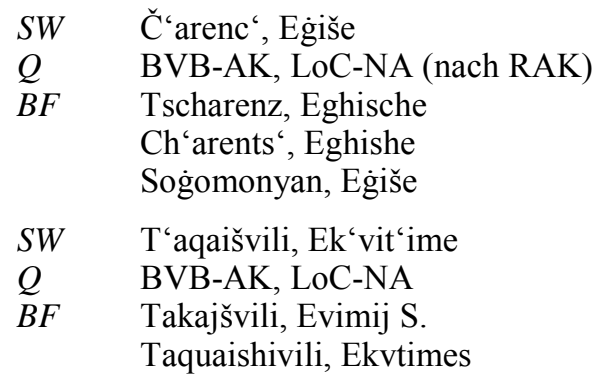

5. Personennamen aus anderen Sprachen mit nichtlateinischen Schriften werden nach folgender Regelung angesetzt:

1. „Liste der Nachschlagewerke“ (vgl. § 9,3).

2. Sind sie dort nicht enthalten, werden sie nach Speziallexika angesetzt.

3. Vorlage. 
Soweit möglich ist der anzusetzende Name nach RAK zu strukturieren (vgl. RAK Anlage 20). Sobald für die jeweilige Sprache Ansetzungsregeln für RAK vorliegen, werden die Namen danach angesetzt.

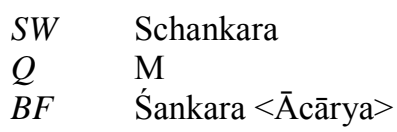

6. Bibliotheken, die im Alphabetischen Katalog RAK-ÖB anwenden, können im Falle von $\S 110,1-4$ wie bei $\S 110,5$ verfahren.

\section{§ 110a Literarische und mythologische Gestalten}

Namen literarischer und mythologischer Gestalten werden nach den gleichen Regeln angesetzt wie die natürlicher Personen.

Sie werden selbständig angesetzt, auch wenn sie nur in einem einzigen Werk vorkommen. In diesem Fall wird die literarische Gestalt mit dem Werk verknüpft. Ein Schlagwortsatz kann für mehrere gleichnamige Personen gelten.

Bei Bedarf kann eine andere gebräuchliche Namensstruktur als Synonym erfasst werden.

$\begin{array}{ll}S W & \text { Lotte }<\text { Literarische Gestalt }> \\ S W & \text { Ödipus } \\ S W & \text { Holmes, Sherlock } \\ B F & \text { Sherlock Holmes } \\ S W & \text { Marple, Jane } \\ B F & \text { Marple }<\text { Miss }>\end{array}$

\section{§ 111 Personennamen als Bestandteil präkombinierter Schlagwörter}

1. Zu Personennamen als Bestandteil präkombinierter Sachschlagwörter vgl. § 305,2,d.

2. Personennamen als Bestandteil präkombinierter geographischer/ethnographischer Schlagwörter werden nach den für diese geltenden Regeln angesetzt (vgl. auch § 202,3).

$$
\begin{array}{ll}
S W & \text { g Van-Diemen-Golf } \\
\text { SW } & \text { g Prince Edward Island }
\end{array}
$$

3. Zu Personennamen als Bestandteil von Körperschaftsnamen vgl. § 602,8.

\section{§ 111a Datensatz für Personenschlagwörter}

Datensätze für Personenschlagwörter werden überregional in der Personennamendatei (PND) geführt.

In lokalen Anwendungen ist auch eine Datenhaltung in der SWD möglich (Indikator p). Personensätze haben in der PND die Satzart Tp. Sind sie als Schlagwort genutzt oder in einem Schlagwortsatz verwendet, tragen sie das Teilbestandskennzeichen s.

Überblick über die wichtigsten Informationen in einem Personenschlagwortsatz:

- Satzart Tp (bei Datenhaltung in der SWD Indikator p) (Angabe obligatorisch)

- Teilbestandskennzeichen s (Angabe obligatorisch) 
- Personenschlagwort in Ansetzungsform (Angabe obligatorisch)

- Quelle (Angabe obligatorisch, vgl. § 19,1)

- Definition: Individualisierende Angaben zur Person, z. B. Beruf oder Tätigkeit, in nicht normierter Form (Angabe obligatorisch, soweit nicht in normierter Form angegeben, vgl. § 19,2)

- Verwendungshinweis (Angabe bei Zutreffen obligatorisch, vgl. § 19,3)

- Redaktionelle Bemerkung (Angabe fakultativ, vgl. § 19,4)

- Lebensdaten, ersatzweise Wirkungsdaten in normierter Form (Angabe, sofern ermittelbar, obligatorisch)

- Notation (Angabe obligatorisch, vgl. § 18,1)

- Ländercode (Angabe obligatorisch, vgl. § 18,2)

- Sprachencode (Angabe gemäß § 18,3)

- Zeitcode (Angabe obligatorisch, vgl. §§ 18,4; 418)

- Ansetzungsform nach RAK, wenn von der RSWK-Ansetzung unterschiedlich (Angabe obli gatorisch soweit in der PND, vgl. §§ 108,4-7; 108,9; 110,3; 110,5)

- Alternative Ansetzungsform nach RAK-ÖB (Angabe obligatorisch, vgl. §§ 108,4,b; 109,2; 110,6)

- Synonymie-Verweisungen (vgl. §§ 12,2; 102,2); ggf. mit Bemerkung eingeleitet durch *

- Verwandte Begriffe (Angabe fakultativ, z. B. Sammelpseudonyme; Sachschlagwörter, die von einer Person abgeleitet sind; Körperschaften, die maßgeblich mit einer Person befasst sind, vgl. §§ 12,5,e; 108,4,a; 305,2,d; 602,8)

Anm. 1: Die Datensätze der PND können für unterschiedliche Anwendungen gemeinsam genutzt werden. Personenschlagwortsätze haben in der PND keinen Indikator, da sie durch ihre Satzart hinreichend gekennzeichnet sind. In Anzeigeformaten kann der Indikator p bei Bedarf hinzugesteuert werden.

Anm. 2: In den beiden Beispielen ist der Zeitcode gemäß UDK wiedergegeben (vgl. Anl. 9).

SW p Arnim, Bettina $\neg$ von $\neg$

Q $\quad \mathrm{M}$

Z 1785-1859

D Dt. Schriftstellerin

SYS 12.2p

LC XA-DE

SC ger

ZC $\quad 17 ; 180 ; 181 ; 182 ; 183 ; 184 ; 185$

BF p Brentano, Bettina

SW p Aristoteles

Q PAN

Z 384 v. Chr.-322 v. Chr.

D Griech. Philosoph

R TITAN

SYS 4.7p;11.2p;8.1p;24.3p;25.3p

LC XS

SC grc

ZC v03

$\mathrm{BF} \quad \mathrm{p}$ Aristoteles $<$ Stagirites $>$

BF p Aristoteles < Atheniensis $>$

BF p Pseudo-Aristoteles

VB s Aristotelismus

\section{$\S \S 112$ - 114 entfallen}




\section{Verknüpfung und Permutation}

\section{§ 115 Das Personenschlagwort in der Grundkette}

Zur Stellung des Personenschlagworts in der Grundkette vgl. § 15.

\section{§ 115a Verknüpfung mehrerer Personenschlagwörter}

Anm.: Im Folgenden sind Permutationsmuster nach $\S 117$ angegeben.

1. Hat ein Dokument Vergleiche oder Beziehungen zwischen zwei oder mehreren Personen zum Gegenstand, so werden sie in einer Schlagwortkette verknüpft (vgl. § 13,1). Dabei wird eine sinnvolle Reihenfolge gewählt. Sind mehrere Reihenfolgen gleich sinnvoll, so kann alphabetisch geordnet werden (vgl. $\S \S 13,2 ; 15,2)$.

$S W W \quad$ p Hamilton, Emma ; p Hamilton, William $<$ Diplomat $>$; p Nelson, Horatio (213) (312)

2. Damit zu verknüpfende geographische/ethnographische, Sach- oder Zeitschlagwörter werden dabei dem Personenschlagwort zugeordnet, zu dem sie gehören (vgl. § 15,9).

SWW p Luther, Martin; s Zweireichelehre; $\mathrm{p}$ Boff, Leonardo ; s Theologie der Befreiung (2134) (3412) (4312)

Ein geographisches/ethnographisches, Sach- oder Zeitschlagwort, das zu mehreren Personenschlagwörtern gehört, wird dem ersten Personenschlagwort zugeordnet (vgl. § 15,5).

SWW p Sartre, Jean-Paul ; s Existentialismus ; p Camus, Albert

(213) (321)

\section{$\S 116$ Verknüpfung eines Personenschlagworts mit Schlagwörtern anderer Kategorien}

Anm.: Im Folgenden sind Permutationsmuster nach $\S 117$ angegeben.

1. Gesamtdarstellungen über Leben und Werk einer Person werden nur mit dem Personenschlagwort indexiert. Ist das Gesamtwerk dargestellt, entfallen auch die allgemeinen Schlagwörter 'Werk', 'Kunst', 'Literatur', 'Musik' und 'Politik', nicht dagegen spezifischere Schlagwörter wie 'Aquarell', 'Lüftlmalerei', 'Naturlyrik' usw.

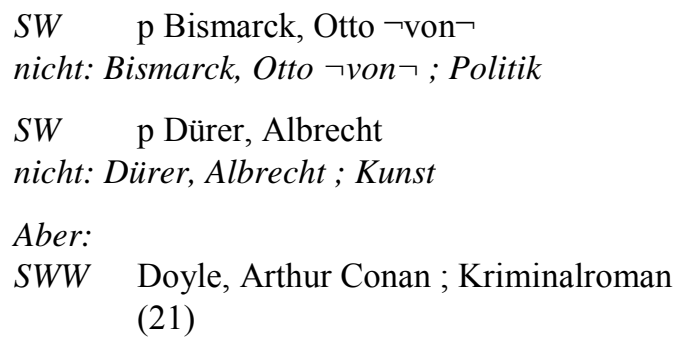

A. C. Doyle schrieb fast ausschließlich Kriminalromane; sie bilden sein Gesamtwerk. 
2. Personenschlagwörter gehen in der Grundkette den Schlagwörtern anderer Kategorien voran (vgl. § 15,3).

Für die weitere Reihenfolge der Kettenglieder gilt:

a) Gattungsbezeichnung, die den Werktitel ersetzt (vgl. aber Abs. c).

SWW p Picasso, Pablo; s Graphik ; s Krieg <Motiv>

(321)

SWW p Curtis, Edward S. ; s Photographie ; g Nordamerika ; g Indianer (2341) (3421) (4321)

b) Geographisches/ethnographisches Schlagwort und Sprachbezeichnung bzw. historisches Einzelereignis und Körperschaft, bei denen der erste Teil der Ansetzungsform aus einem Geographikum/Ethnographikum besteht.

SWW p Goethe, Johann Wolfgang $\neg$ von $\neg$; g Italien ; f Bildband (213)

SWW p Luther, Martin; c Worms / Reichstag (231)

SWW p Solženicyn, Aleksandr I. ; c Sowjetunion / KGB (231)

c) Sachschlagwort (zu Pleonasmus bei Verknüpfung mit Personenschlagwort vgl. § 312) bzw. historisches Einzelereignis und Körperschaft, deren Ansetzungsform aus einem Individualnamen besteht.

SWW p Aristoteles; s Naturphilosophie

(21)

SWW p Dürer, Albrecht ; s Selbstbildnis

(21)

SWW p Goethe, Johann Wolfgang $\neg$ von $\urcorner$; s Französische Revolution (21)

SWW $\quad$ p Ignacio $<$ de Loyola $>$; $k$ Jesuiten (21)

Sachschlagwörter, die sich auf das Gesamtwerk einer Person oder die Mehrzahl der Werke beziehen, werden i. d. R. unmittelbar mit dem Personennamen verknüpft, ohne dass 'Werk', 'Drama', 'Roman' und dgl. eingefügt wird (vgl. § 116,1).

Titel: $\quad$ Shakespeare and the Renaissance concept of honor / Curtis Brown Watson . - 1976

SWW p Shakespeare, William; s Ehre $<$ Motiv $>$

nicht: Shakespeare, William ; Drama ; Ehre <Motiv>

Drama entfällt, weil Shakespeare überwiegend Dramen geschrieben hat.

In der Literatur, Kunst und Musik tritt der Werktitel immer hinzu, wenn ein bestimmtes Werk behandelt wird, auch wenn vom Autor nur dieses eine Werk überliefert ist.

SWW p Shakespeare, William / t Measure for measure ; s Gnade $<$ Motiv $>$ (312)

SWW p Lucanus, Marcus Annaeus / t Pharsalia ; s Götter (312) 
d) Zeitschlagwort: Einzelne Abschnitte des Lebens oder Werkes einer Person werden dabei durch Verknüpfung mit 'Geschichte' und Jahreszahlen ausgedrückt.

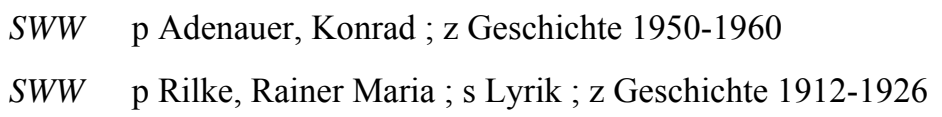

Zur Verknüpfung mit Epochenbezeichnungen vgl. § 410,2. Zur Verknüpfung mit historischen Einzelereignissen vgl. § 116,2,b und c.

e) Formschlagwort: Steht bei chronologischer Darstellung die Lebensbeschreibung einer Person im Vordergrund, wird mit dem Formschlagwort 'Biographie' verknüpft (vgl. Anl. 6). Einzelne Lebensabschnitte werden dabei durch die Angabe von Jahreszahlen ausgedrückt. Das gilt auch für andere Formschlagwörter, die durch Zeitangaben erweitert werden können (vgl. § 503,1).

$$
\begin{array}{ll}
\text { SWW } & \text { p Joyce, James ; f Biographie 1888-1898 } \\
\text { SWW } & \text { p Gerlach, Walther ; f Bibliographie 1912-1979 }
\end{array}
$$

3. Bei einem Vergleich oder der Darstellung von Beziehungen in einer Schlagwortkette mit einem Personenschlagwort werden Sach- und ggf. Zeitschlagwörter dem Schlagwort zugeordnet, zu dem sie gehören (vgl. § 15,9).

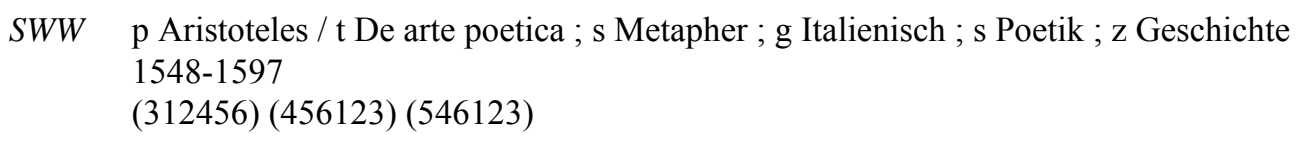

\section{$\S 117$ Permutation}

Für Listenfunktionen können die Glieder einer Grundkette mit Personenschlagwort permutiert werden. In diesen Fällen gilt:

1. Bei der Permutation wird gemäß den Schemata von $\S 15,10$,e verfahren. Teilketten bleiben dabei erhalten und permutieren in sich (vgl. § 116,3).

2. Bei mehreren Personenschlagwörtern in der Grundkette erhält jedes eine Eintragung (vgl. $\S 115 \mathrm{a}, 1)$.

3. Das gilt auch für eine Grundkette aus Personenschlagwort und einem oder mehreren geographisch/ethnographischen Schlagwörtern (vgl. Beispiele § 116,2,b).

4. Aussagekräftige Sachschlagwörter werden in einer Grundkette mit Personenschlagwort permutiert (vgl. § 116,2,c).

Die Permutation unterbleibt

- bei Sachschlagwörtern, die sich auf die Lebensumstände der Einzelperson beziehen und daher keine allgemeine Bedeutung haben (vgl. Anl. 2 bzw. entsprechende Hinweise beim jeweiligen Sachschlagwort in der SWD).

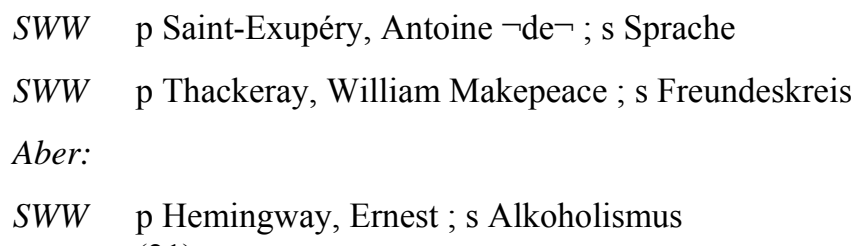


- bei weiten literarischen oder künstlerischen Gattungsbezeichnungen auch in Verbindung mit einem weiteren aussagekräftigen Sachschlagwort (vgl. Anl. 2).

SWW p Friedrich, Caspar David ; s Zeichnung

SWW p Schiller, Friedrich ; s Drama ; s Hof $<$ Motiv $>$

(321) nicht: (231)

Aber:

SWW p Raimund, Ferdinand ; s Märchendrama

(21)

SWW p Larsson, Carl ; s Aquarell

(21)

- bei Bezeichnungen für umfassende Wissenschaftsfächer (vgl. Anl. 2)

SWW p Luther, Martin; s Theologie

Aber:

SWW p Luther, Martin; s Ekklesiologie

(21)

5. Zeit- und Formschlagwörter werden nicht permutiert (vgl. § 15,10,e,1 und 2).

\section{§§ 118 - 123 entfallen}





\section{Geographische/ethnographische Schlagwörter Geographische Schlagwörter}

\section{Definition und Verwendung}

\section{$\S 201$ Definition}

1. Geographische Namen sind Individualnamen für bestimmte Örtlichkeiten oder Gebiete der Erdoberfläche bzw. der obersten Schichten der Erde. Geographische Namen werden als geographische Schlagwörter angesetzt und erhalten in der SWD den Indikator g.

Als geographische Schlagwörter gelten

a) die aktuellen und historischen Namen von Gebietskörperschaften bzw. Verwaltungseinheiten und den dazugehörigen Gebieten (Staaten und Gliedstaaten, Verwaltungsbezirke, Orte, Ortsteile und sonstige Siedlungen). Zwischen der Gebietskörperschaft und ihrem Gebiet wird dabei nicht unterschieden.

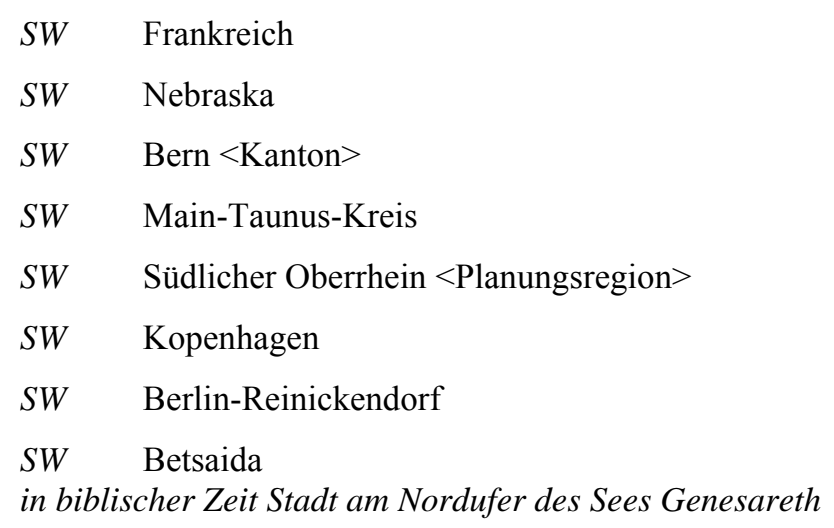

b) die Namen von naturräumlichen Einheiten (Kontinente, Landschaften, Gebirge, Berge, Inseln, Küsten, Täler, Flüsse, Seen, Meere, Meeresteile u.ä.),

$\begin{array}{ll}\text { SW } & \text { Afrika } \\ \text { SW } & \text { Gobi } \\ \text { SW } & \text { Großer Schneeberg } \\ \text { SW } & \text { Helgoland } \\ \text { SW } & \text { Côte d'Azur } \\ \text { SW } & \text { Pustertal } \\ \text { SW } & \text { Etsch } \\ \text { SW } & \text { Victoriasee } \\ S W & \text { Atlantischer Ozean } \\ S W & \text { Deutsche Bucht }\end{array}$


c) die Namen von bio-, paläobio- und paläogeographischen Regionen, sowie die Namen von räumlich begrenzten geologischen bzw. stofflich-räumlichen stratigraphischen Einheiten.

SW Neotropische Region

SW Paläarktis

SW Germanisches Becken

SW Tethysmeer

SW Green-River-Formation

d) die Namen von Wegen, Grenzen und geographischen Linien aller Art.

SW Äquator

SW Frankenschnellweg

SW Warschau / Krakowskie Przedmieście

SW Oder-Neiße-Linie

SW Tonale-Linie

e) die Namen von fiktiven geographischen Einheiten.

SW Atlantis

SW Eldorado

SW Schlaraffenland

f) die Namen von Sprachgebieten.

SW Englisches Sprachgebiet

SW Frankophones Afrika

g) die Namen von Ländergruppen mit geographischen oder politisch-ökonomischen Gemeinsamkeiten sowie die Namen von Gruppen von Gliedstaaten, Provinzen und anderen Unterteilungen von Staaten. ( $\mathrm{Zu}$ den Gebieten internationaler Körperschaften bzw. ihrer Mitgliedsstaaten vgl. § 211,2.)
SW Andenstaaten
SW Entwicklungsländer
SW Sozialistische Staaten
SW Außereuropäische Länder
SW USA / Südstaaten

2. Die geographischen Namen sind zu unterscheiden von geographischen Gattungsbezeichnungen, die als Sachschlagwörter angesetzt werden.

$\begin{array}{ll}\text { SW } & \text { s Kleinstaat } \\ \text { SW } & \text { s Wüste } \\ \text { SW } & \text { s Trockental }\end{array}$

3. Nicht als Geographikum, sondern als Sachschlagwort werden alle Räumlichkeiten außerhalb der Erde wie einzelne Galaxien, Sternengruppen, Sterne, Planeten, Monde und Regionen auf diesen angesetzt, ebenso der Bereich der Erdatmosphäre und ihre Bestandteile. 


$$
\begin{array}{ll}
S W & \text { s Alphonsus }<\text { Mondkrater }> \\
S W & \text { s Venus }<\text { Planet }> \\
S W & \text { s Troposphäre }
\end{array}
$$

4. Zur Definition ethnographischer Schlagwörter vgl. § 212.

5. Zu Sprachbezeichnungen vgl. § 701.

\section{§ 201a Verwendung}

1. Ist ein Geographikum in einem Dokument als Gegenstand thematisiert, so wird es i. d. R. berücksichtigt und durch ein oder mehrere geographische Schlagwörter wiedergegeben.

2. Ist an einer kleineren geographischen Einheit exemplarisch ein Sachverhalt mit umfassenderem Geltungsbereich dargestellt, so kann neben der Schlagwortkette mit der speziellen eine zusätzliche für die umfassendere geographische Einheit gebildet werden, wenn beide gleichgewichtig Gegenstand der Darstellung sind (vgl. § 13,4). Sehr spezielle geographische Bezüge, die ausschließlich exemplarisch für die eigentlich thematisierte übergeordnete Einheit behandelt sind, werden aber i. d. R. in der Schlagwortkette nicht berücksichtigt (vgl. § 8,2).
Titel: Möglichkeiten und Grenzen der Versicherungswirtschaft in Entwicklungsländern : Darstellung und Analyse am Beispiel Ghanas / Albert Kwaku Gemegah. - 1995
SWW Ghana; Versicherungswirtschaft
$S W W \quad$ Entwicklungsländer ; Versicherungswirtschaft

3. Gibt ein Sachschlagwort (oder Körperschaftsname etc.) einen Sachverhalt wieder, der überwiegend in einer bestimmten geographischen Einheit auftritt, so wird die Kombination aus dem zugehörigen geographischen Schlagwort und dem betreffenden Sachschlagwort (oder Körperschaftsnamen etc.) als Synonym erfasst. In Schlagwortketten entfällt dann i. d. R. das geographische Schlagwort (vgl. § 13,3).

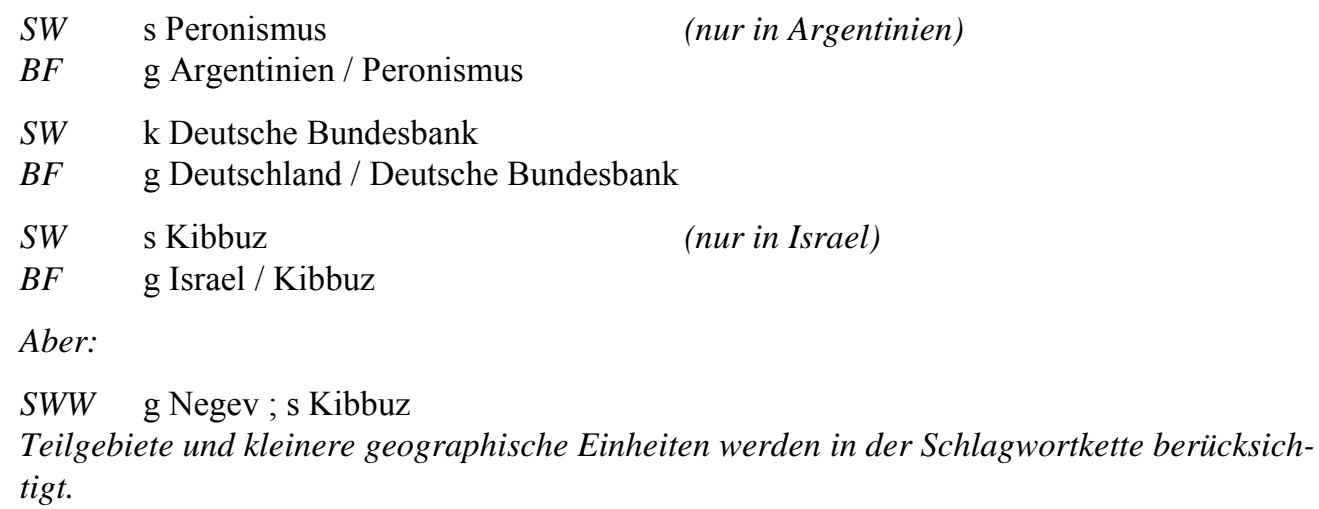

Dies gilt nicht für Fachausdrücke des Rechts, der Verwaltung und des Schulwesens der Gegenwart im deutschen Sprachgebiet (vgl. § 311,2).

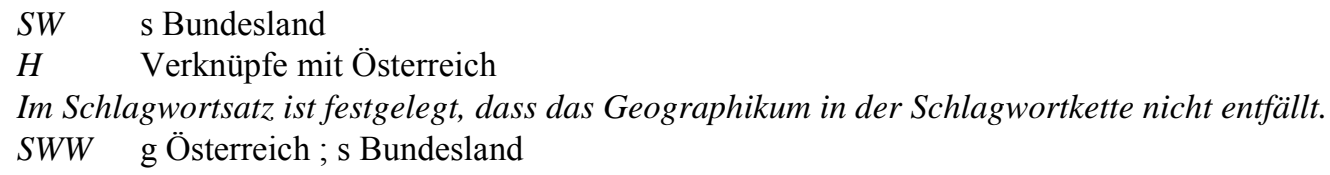


Inhalt: Allgemeinbildende höhere Schulen in Österreich SWW g Österreich; s Allgemein bildende höhere Schule Spezifisch österreichische Schulform; das Geographikum wird bei Fachausdrücken der Verwaltung im deutschen Sprachgebiet mit in die Schlagwortkette aufgenommen.

Werden aber bei komplexeren Gegenständen noch andere Schlagwörter (oder Körperschaftsnamen, Geographika etc.) in die Schlagwortkette aufgenommen, so entfällt das geographische Schlagwort nicht.

Inhalt: Arbeiterbewegung und Peronismus

SWW g Argentinien; s Arbeiterbewegung; s Peronismus

Titel: Potentialorientierte Geldmengenpolitik : die Zinsstruktur als geldpolitisches Problem / Peter Westerheide. - 1995

SWW g Deutschland; s Zinsstruktur ; s Geldmengenpolitik ; s Geldmengenziel ; k Deutsche Bundesbank

4. Wird in einem Dokument ein Geographikum lediglich als Untersuchungsbereich genannt, ohne dass es maßgebliche Bedeutung für den Inhalt des Dokuments hat, so entfällt es in der Schlagwortkette.

Titel: Schwermetallgehalte von Nutzpflanzen bei unterschiedlicher Bodenbewirtschaftung in einem landwirtschaftlichen Dauerversuch / Martin Brodowski. - 1997

$S W W \quad$ Nutzpflanzen; Schwermetallbelastung ; Bodennutzung; Dauerversuch Es handelt sich um einen Feldversuch in Berlin-Dahlem. Untersucht werden die Einflüsse verschiedener Bodennutzungsarten auf den Schwermetallgehalt von Nutzpflanzen unter gleichbleibenden Standortbedingungen. Der Einfluss des Standorts ist weitgehend ausgeklammert.

Aber:

Titel: Duales System Deutschland : DSD ; Bestandsaufnahme am Beispiel der Stadt Bielefeld / Klaus Finck. - 1995

SWW Bielefeld; Duales System Deutschland GmbH

Dargestellt ist die spezifische Situation in der Stadt Bielefeld. Auf die Angabe des

Untersuchungsbereichs kann in diesem Fall nicht verzichtet werden.

5. In Bibliotheken mit überwiegend deutschsprachigen Beständen kann bei einer lokalen Anwendung dieses Regelwerks in Listenfunktionen auf den Sucheinstieg unter dem Schlagwort 'Deutschland' verzichtet werden, jedoch nicht in Verbindung mit den in $\S 220,4$,b genannten Sachschlagwörtern oder solchen Formschlagwörtern, die sich unmittelbar auf die geographische Einheit beziehen.
SWW Siedlungsgeographie ; Deutschland
SWW Hausform; Deutschland
Aber:
SWW Deutschland; Kunst ; Geschichte
SWW Deutschland; Führer

6. Das Schlagwort 'Europa' wird verwendet, wenn Europa als politisch-gesellschaftliche Einheit Thema der Darstellung ist, wenn Themen aus der belebten und unbelebten Natur vorliegen oder wenn die Schlagwortkette ohne das Geographikum für den vorliegenden Gegenstand nicht eindeutig ist, so z. B. in Verbindung mit den in Anl. 5 genannten Sachschlagwörtern oder solchen Formschlagwörtern, die sich unmittelbar auf die geographische Einheit beziehen. 


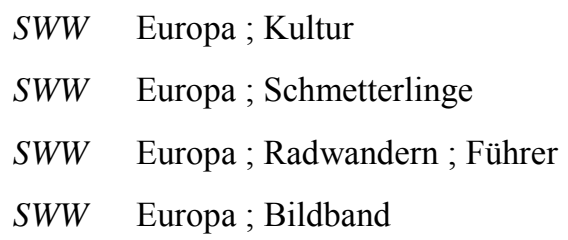

Das Schlagwort 'Europa' entfällt über die in $\S 201 \mathrm{a}, 3$ geregelten Fälle hinaus bei allen Sachverhalten, die in der europäischen Literatur weitgehend nur auf Europa bezogen sind, insbesondere bei historischen und kulturellen Gegenständen vor 1800 (vgl. § 13,3).

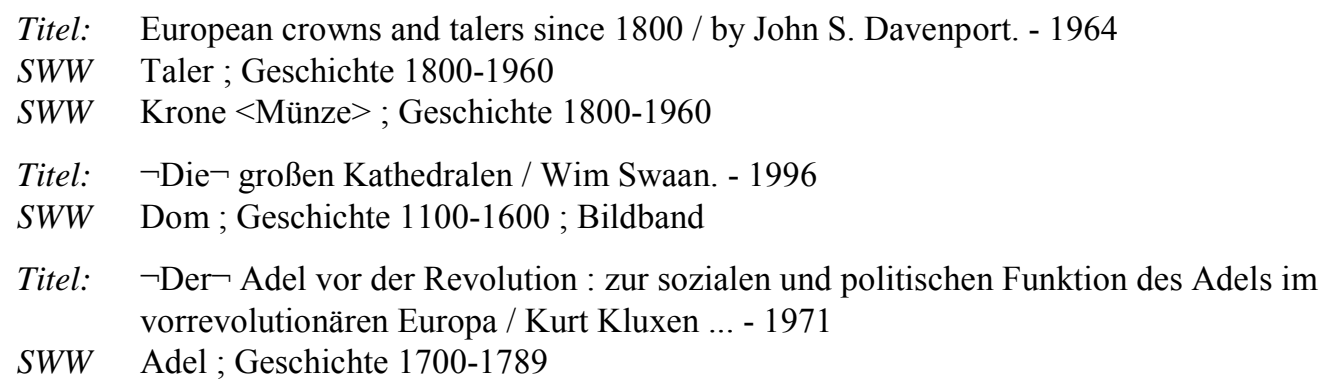

7. Der Ortsname wird Teil eines mehrgliedrigen Schlagworts, bei der Ansetzung von ortsgebundenen Körperschaften (vgl. § 605) und ortsgebundenen Kunstwerken (vgl. §§ 730-731).

\section{Ansetzung}

\section{$\S 202$ Grundregeln}

1. Geographische Namen werden i. d. R. in der im Deutschen gebräuchlichen Form gemäß der „Liste der Nachschlagewerke“ (vgl. § 9,3) angesetzt. (Zu Namensänderungen vgl. § 207. Zum obligatorischen Homonymenzusatz bei Orten der USA, Australiens und Kanadas vgl. $\S 203,3$, a.)

$\begin{array}{ll}S W & \text { Berlin } \\ Q & \text { Orts-Mü., B } 1986 \\ S W & \text { Zugspitze } \\ Q & \text { Geo-Du } \\ S W & \text { Wolga } \\ Q & \text { M }\end{array}$

Bieten die Nachschlagewerke keinen Nachweis, so werden geographische Namen gemäß Vorlage angesetzt.

$\begin{array}{ll}S W & \text { Cabo Blanco }<\text { Mallorca }> \\ Q & \text { Vorlage } \\ D & \text { Ort auf Mallorca }\end{array}$

2. Abweichende Namensformen werden i. d. R. als Synonym erfasst. Für die ggf. abweichende Ansetzungsform der GKD ist dies obligatorisch.

$\begin{array}{ll}S W & \text { Mainz } \\ Q & \text { Orts-Mü., M, B } 1986 \\ B F & \text { Moguntiacum } \\ & \text { Mogontiacum }\end{array}$




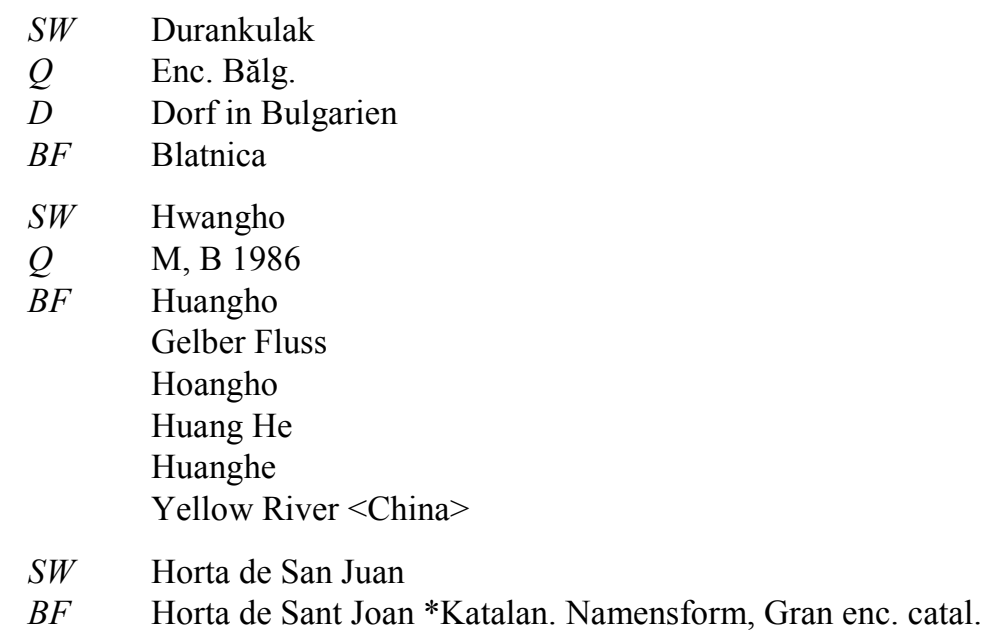

Ist zum Namen einer Gebietskörperschaft bereits ein GKD-Datensatz vorhanden, so wird die GKD-Nummer in einem speziellen Feld des SWD-Satzes als Verknüpfungsnummer angegeben, um die Ansetzungsform der GKD als Synonymie-Verweisung einzubringen. Falls frühere (spätere) Namensformen betroffen sind, werden ggf. mehrere GKD-Nummern erfasst.

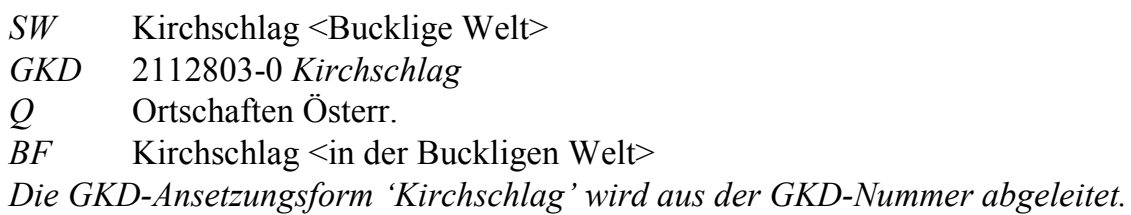

Anm.: Dies ist noch nicht realisiert, deshalb ist zwar die GKD-Nummer anzugeben, die abweichende Namensform der GKD wird aber vorläufig wie bisher als Synonymie-Verweisung erfasst.

3. Bei Namen aus Sprachen mit nichtlateinischen Schriften wird nicht auf eine spezielle Umschrift normiert, sondern die im maßgeblichen Nachschlagewerk bzw. in der Vorlage verwendete Form als Ansetzung gewählt.

$\begin{array}{ll}S W & \text { Gatchina } \\ G K D & 1218007-5 \text { Gatčina } \\ Q & \text { Knaurs WA } \\ S W & \text { Novozybkov } \\ Q & \text { Knaurs WA } \\ D & \text { Ort in Russland } \\ S W & \text { Nowosibirsk } \\ G K D & 1028691-3 \text { Novosibirsk } \\ Q & \text { B 1986, M } \\ D & \text { Stadt in Russland }\end{array}$

Das gilt auch für Personennamen als Bestandteil geographischer Schlagwörter.

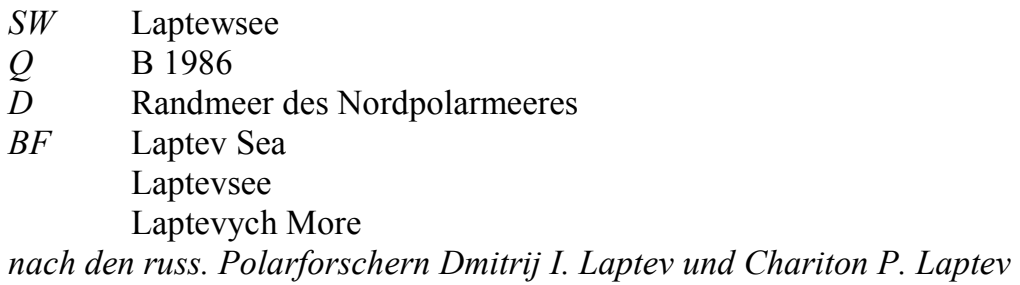


4. Geographika aus den ehemaligen deutschen Ost- und Siedlungsgebieten werden nur dann in der im Deutschen gebräuchlichen Form angesetzt, wenn sie so in einem aktuellen, nicht auf historische Ortsnamen bezogenen deutschsprachigen Nachschlagewerk nachweisbar sind. Historische Ortsnamensverzeichnisse gelten nicht als aktuelle Nachschlagewerke. In allen anderen Fällen wird der fremdsprachigen Ansetzungsform der Vorzug gegeben. Im Zweifelsfall gilt die Haupteintragung des maßgeblichen Nachschlagewerks als Ansetzungsform.

$\begin{array}{ll}S W & \text { Marienbad } \\ Q & \text { B 1986 } \\ B F & \text { Mariánské Lázně } \\ S W & \text { Königsberg } \\ Q & \text { B 1996 } \\ B F & \text { Kaliningrad <Pregel> } \\ S W & \text { Hostouň } \\ Q & \text { Knaurs WA } \\ B F & \text { Hostau *Geo-Du. }\end{array}$

5. Hat eine geographische Einheit keinen Individualnamen, so wird sie durch die Verknüpfung eines die geographische Lage charakterisierenden Schlagworts mit einem weiteren Geographikum bzw. mit einem Sachschlagwort wiedergegeben (vgl. $\S \S 8,4 ; 13,2 ; 205,3 ; 209,4)$.
SWW g Donau; g Österreich
SWW g Lahn; s Einzugsgebiet
SWW g Deutschland; s Staatsgrenze

Bei der Bildung solcher Schlagwortketten wird für naturräumliche Einheiten ein möglichst spezifisches Geographikum herangezogen; für Gebietskörperschaften ist dagegen i. d. R. der jeweilige Staat als Oberbegriff zu wählen.
SWW g Frankreich; g Mittelmeerküste
nicht: $\quad$ g Frankreich $<$ Süd $>$; g Mittelmeerküste
SWW g Dänemark; s Staatsgrenze ; g Deutschland
nicht: $\quad$ g Dänemark ; s Staatsgrenze ; $g$ Schleswig-Holstein

6. Die Ansetzungsformen von Geographika, die sich stark überschneiden, aber nicht deckungsgleich sind, werden jeweils beim anderen als verwandter Begriff erfasst.

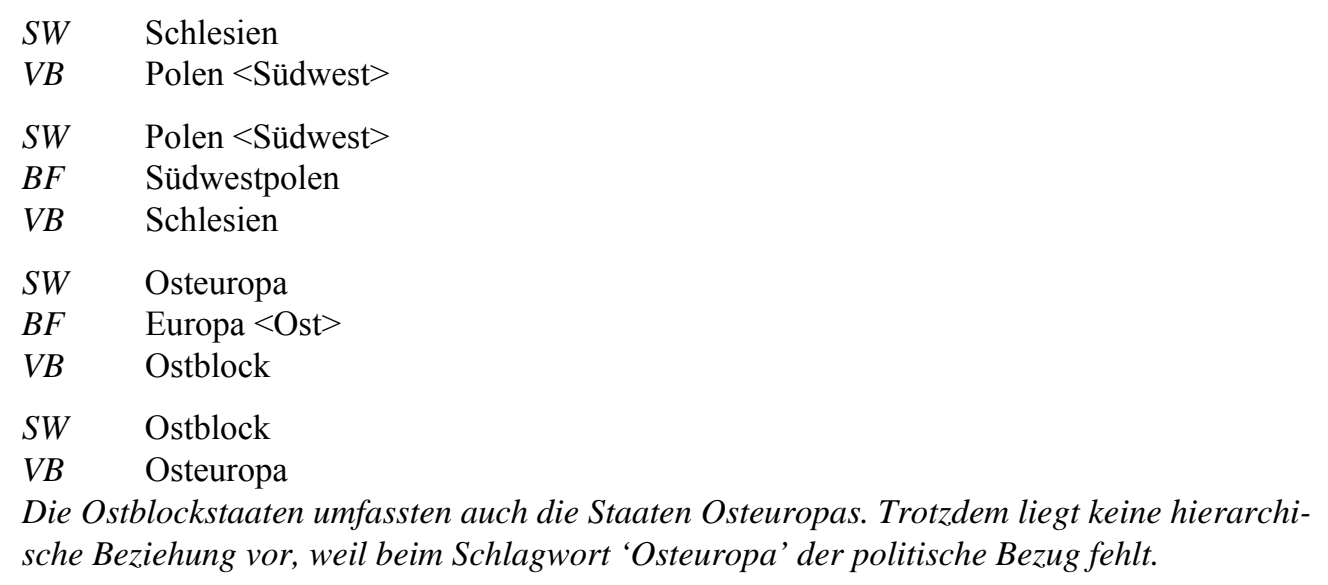


SW Österreichische Niederlande

BF Südliche Niederlande / Geschichte 1714-1794

VB Spanische Niederlande

SW Spanische Niederlande

BF Südliche Niederlande / Geschichte 1581-1714

$V B \quad$ Österreichische Niederlande

Beide Geographika sind räumlich nahezu deckungsgleich, können aber wegen ihrer unterschiedlichen politischen Zugehörigkeit nicht als Synonyme behandelt werden.

\section{$\S$ 202a Geographische Namen mit Präfixen, einleitenden Bezeichnungen und präpositionalen Wendungen innerhalb des Namens}

1. Feststehende, zu einem geographischen Namen gehörende Präfixe (Präpositionen, Artikel, und Verschmelzungen aus Präposition und Artikel oder Artikel und Adjektiv) werden in der Form des offiziellen Namens angesetzt (vgl. RAK $\S 208,3$ ). Dies gilt auch für Verwandtschaftsbezeichnungen und Präfixe von Personennamen als Bestandteil eines geographischen Namens. Die nicht gewählten Namensformen werden als Synonyme erfasst.

$\begin{array}{ll}\text { SW } & \text { Le Havre } \\ B F & \text { Havre } \\ & \text { LeHavre } \\ & \\ \text { SW } & \text { Les Sept-̂̂les } \\ \text { BF } & \text { LesSept-Îles } \\ & \text { Sept-Îles } \\ & \\ \text { SW } & \text { Van-Diemen-Golf } \\ B F & \text { Diemen-Golf } \\ & \text { Van Diemen-Golf } \\ & \text { VanDiemen-Golf }\end{array}$

Artikel am Anfang geographischer Namen in arabischer und hebräischer Sprache gelten nicht als feststehende Präfixe (vgl. RAK $\S 208,3$,a). Bei ihnen wird der Artikel dem Namen mit Nichtsortierzeichen vorangestellt. Die Form mit Artikel und Namen in ununterbrochener Buchstabenfolge sowie die Form mit Spatium werden als Synonyme erfasst. 


$\begin{array}{ll}\text { SW } & \neg \text { ar- } \neg \text { Rijad } \\ B F & \text { ArRijad } \\ & \text { Ar Rijad } \\ \text { SW } & \neg \text { el- } \neg \text { Alamain } \\ B F & \text { AlAlamein } \\ & \text { ElAlamain } \\ & \text { Al Alamain }\end{array}$

2. Geographische Namen, die im Namensinneren präpositionale Wendungen enthalten wie Präpositionen, Artikel oder Verschmelzungen aus Präposition und Artikel, werden i.d.R. mit allen Bestandteilen als Wortfolge angesetzt. ( $\mathrm{Zu}$ präpositionalen Wendungen in erläuternden Bestandteilen bei Ortsnamen vgl. § 202b; zu präpositionalen Wendungen in geographischen Namen, die mit einer geomorphologischen Gattungsbezeichnung beginnen, vgl. § 204.)

$\begin{array}{ll}\text { SW } & \text { Rio Grande do Sul } \\ \text { SW } & \text { Rio de la Plata } \\ \text { BF } & \text { Rio de LaPlata } \\ \text { SW } & \text { Castellón de la Plana } \\ \text { BF } & \text { Castellón de LaPlana }\end{array}$

3. Den Namen einleitende Bezeichnungen wie 'Sankt' und seine Entsprechungen in anderen Sprachen, ebenso wie 'Markt', 'Stadt', 'Siedlung', 'Fort' u.ä., die im maßgeblichen Nachschlagewerk fester Bestandteil des geographischen Namens sind, werden mit angesetzt. Dasselbe gilt für Kreise und andere Gebietskörperschaften, deren Eintragung im maßgeblichen Nachschlagewerk mit 'Herzogtum', 'Grafschaft' u.ä. beginnt. Die invertierte Namensform bzw. der Name ohne einleitende Bezeichnung wird ggf. für Listenfunktionen als Synonym erfasst.

$\begin{array}{ll}\text { SW } & \text { Sankt Gallen } \\ \text { SW } & \text { San Marino } \\ \text { SW } & \text { São Paulo } \\ \text { SW } & \text { Sveti Stefan } \\ \text { SW } & \text { Markt Sankt Florian } \\ \text { BF } & \text { Sankt Florian, Markt } \\ \text { SW } & \text { Siedlung Heinzelspitze } \\ B F & \text { Heinzelspitze, Siedlung } \\ \text { SW } & \text { Fort Knox }<\text { Ky. }> \\ S W & \text { Ciudad Bolivar } \\ S W & \text { Herzogtum Lauenburg }<\text { Kreis }> \\ B F & \text { Lauenburg }<\text { Elbe, Kreis }> \\ S W & \text { Grafschaft Hoya }<\text { Kreis }> \\ B F & \text { Hoya }<\text { Kreis }>\end{array}$

Aber:

SW Lauenburg $<$ Herzogtum $>$

SW $\quad$ Hoya $<$ Grafschaft $>$ 
4. Die selbständige Bezeichnung 'Bad' oder ähnliche Bezeichnungen, z.B. 'Seebad', 'Ostseebad', 'Kurort' und vergleichbare Entsprechungen in anderen Sprachen vor Ortsnamen bzw. Ortsteilen entfallen, es sei denn, der Namen lässt sonst nicht mehr erkennen, dass es sich um einen Ort handelt. Die nicht für die Ansetzung gewählte Form mit vorangestelltem 'Bad' usw. wird als Synonym erfasst.

$\begin{array}{ll}\text { SW } & \text { Hofgastein } \\ \text { BF } & \text { Bad Hofgastein } \\ \text { SW } & \text { Bonn-Godesberg } \\ \text { BF } & \text { Bonn- Bad Godesberg } \\ \text { Aber: } & \\ \text { SW } & \text { Banja Luka }\end{array}$

\section{§ 202b Erläuternde Bestandteile des Ortsnamens}

1. Erläuternde Bestandteile, d.h. Ergänzungen, die dem Ortsnamen im maßgeblichen Nachschlagewerk in gleicher typographischer Form beigefügt sind, gelten als Teil der Ansetzungsform.

2. Bei deutschsprachigen Ortsnamen werden diese Bestandteile dem Namen in Winkelklammern nachgestellt und in der Form des Nachschlagewerks übernommen. Sie sind wie Homonymenzusätze zu behandeln (vgl. § 203).

Bei der Ansetzung des Bestandteiles entfallen jedoch Präpositionen und Artikel, auch dann, wenn darauf ein dekliniertes Adjektiv folgt. Adjektive und andere Nomina werden im Nominativ angesetzt. Die nicht gewählte Namensform, in der der Bestandteil mit Präpositionen und Artikel, ggf. flektiert, angegeben ist, wird als Synonym erfasst.

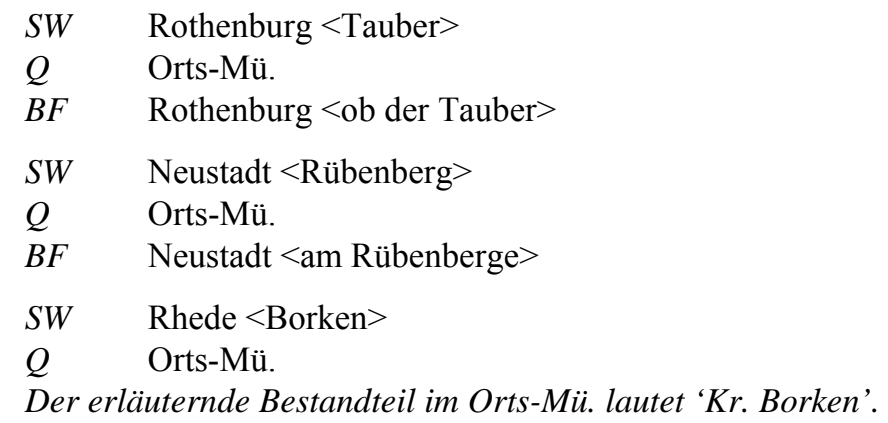

Wird ein Ortsteilname mit Bindestrich an den Ortsnamen angefügt, entfallen etwaige erläuternde Bestandteile (vgl. § 209,1,a).

3. Bei Ortsnamen aus Ländern, in denen es üblich ist, erläuternde Bestandteile mit Bindestrich anzuschließen, nämlich Frankreich, Großbritannien und Russland, werden der landessprachlich angesetzte Name und die einzelnen Glieder des erläuternden Bestandteils mit Bindestrichen verbunden. Dies gilt auch für englisch-, französisch- und russischsprachige Namensformen von Orten anderer Länder sowie für englisch-, französisch- und russischsprachige Synonyme zu einer im Deutschen gebräuchlichen Ansetzungsform. Die nicht für die Ansetzung gewählte Namensform mit dem Bestandteil in Winkelklammern wird als Synonym erfasst. Der Bestandteil wird dabei nach $\S 202$ b,2 gebildet. 


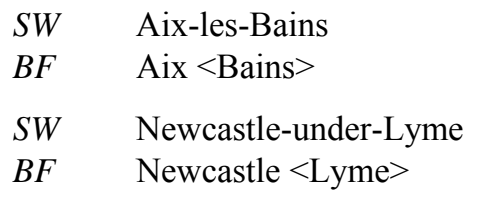

Aber:

SW $\quad$ Rostow $<$ Don $>$

im Deutschen gebräuchliche Form

Q M, B 19862.

BF Rostov-na-Donu

Rostow $<$ am Don>

4. Bei allen anderen fremdsprachigen Ortsnamen wird der Name mit dem erläuternden Bestandteil als Wortfolge angesetzt. Die nicht für die Ansetzung gewählte Namensform mit dem Bestandteil in Winkelklammern wird als Synonym erfasst.

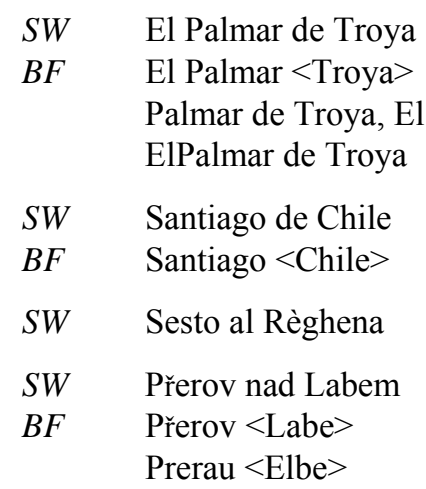

5. Verwaltungseinheiten, deren Namen aus zwei oder mehreren Ortsnamen gebildet sind, werden ohne erläuternde Bestandteile angesetzt, es sei denn, diese sind durch Bindestriche mit dem Ortsnamen verbunden (vgl. RAK $\S 441,3$ ) oder als Wortfolge angesetzt. Entfällt der Bestandteil, wird die Form mit Bestandteil als Synonym erfasst.

$$
\begin{array}{ll}
S W & \text { Neuburg-Schrobenhausen }<\text { Kreis }> \\
B F & \text { Neuburg }<\text { Donau }>\text { - Schrobenhausen }<\text { Kreis }>
\end{array}
$$

Ist eine Verwaltungseinheit (z. B. Bezirk, Kreis usw.) nach einem Ort mit erläuterndem Bestandteil benannt, so wird dieser zusammen mit dem Homonymenzusatz, der die Art der Verwaltungseinheit bezeichnet, in Winkelklammern angesetzt (vgl. auch § 203,2).

$$
\begin{array}{ll}
\text { SW } & \text { Oldenburg }<\text { Oldenburg }> \\
\text { SW } & \text { Oldenburg }<\text { Oldenburg, Bezirk }> \\
\text { SW } & \text { Oldenburg }<\text { Oldenburg, Kreis }>
\end{array}
$$

Im Falle von Staaten oder Gliedstaaten, deren Name homonym zu einem Ortsnamen mit erläuterndem Bestandteil ist, bleibt dieser bei der Ansetzungsform des Staates oder Gliedstaates unberücksichtigt.

SW Oldenburg $<$ Staat $>$
nicht: Oldenburg $<$ Oldenburg, Staat $>$ 


\section{$\S 203$ Homonyme geographische Namen}

1. Gleichnamige geographische Namen werden durch Homonymenzusätze unterschieden. Diese sollen möglichst dem für die Ansetzung maßgeblichen Nachschlagewerk entnommen und so spezifisch gewählt werden, dass Verwechslungen ausgeschlossen sind. Ist eine der homonymen geographischen Einheiten sehr viel bekannter als die anderen, so entfällt bei ihr der Homonymenzusatz.

$\begin{array}{ll}\mathrm{S} W & \text { London } \\ \mathrm{S} W & \text { London }<\text { Ontario }> \\ \mathrm{S} W & \text { London }<\text { Tex. }> \\ \mathrm{S} W & \text { Guinea } \\ \mathrm{S} W & \text { Guinea }<\text { Landschaft }> \\ \mathrm{S} W & \text { Newport }<\text { Gwent }> \\ \mathrm{S} W & \text { Newport }<\text { Wight }> \\ \text { nicht }: & \text { Newport }<\text { Großbritannien }>\end{array}$

Wird ein Ortsteilname mit Bindestrich an den Ortsnamen angefügt, entfallen etwaige Homonymenzusätze (vgl. § 209,1,a).

2. Die als Homonymenzusatz verwendete Bezeichnung muss i. d. R. als Ansetzungsform in der SWD vorhanden sein. Wird ein geographischer Name als Homonymenzusatz gewählt, so entfallen bei ihm ggf. Zusätze, welche die Art der Verwaltungseinheit kennzeichnen (vgl. $\S 203,4)$. Dies gilt entsprechend auch für erläuternde Bestandteile (vgl. § 202b,2 und 5).

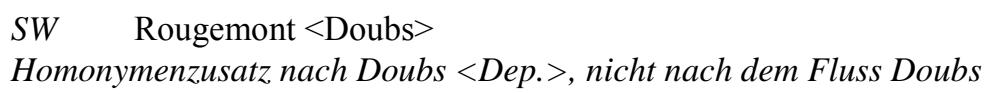

Ist die Angabe mehrerer Homonymenzusätze notwendig, so werden sie, durch Komma getrennt, in eine Winkelklammer gesetzt. Ein geographischer Name steht dabei an erster Stelle.

$S W \quad$ Bocholt $<$ Borken, Borken $>$

Ansetzungsform des als Homonymenzusatz gewählten Geographikums ist Borken 〈Borken>

SW $\quad$ Neustadt $<$ Waldnaab, Kreis $>$

SW $\quad$ Feldberg $<$ Schwarzwald, Berg $>$

3. a) Sind geographische Namen homonym, so wird, soweit für Gebietskörperschaften nicht anders geregelt, der Name eines für die geographische Lage kennzeichnenden Flusses, Berges, Ortes etc. als Homonymenzusatz hinzugefügt (vgl. auch RAK § 447, 1). Für Orte wird i. d. R. die entsprechende Gebietskörperschaft gewählt. Ist dies nicht möglich oder üblich (wie z. B. in Frankreich oder der Schweiz) oder reicht dies zur Unterscheidung nicht aus, dient der Name der nächstübergeordneten geographischen Einheit als Homonymenzusatz. Verwaltungseinheiten werden dabei vor Landschaftsnamen bevorzugt.

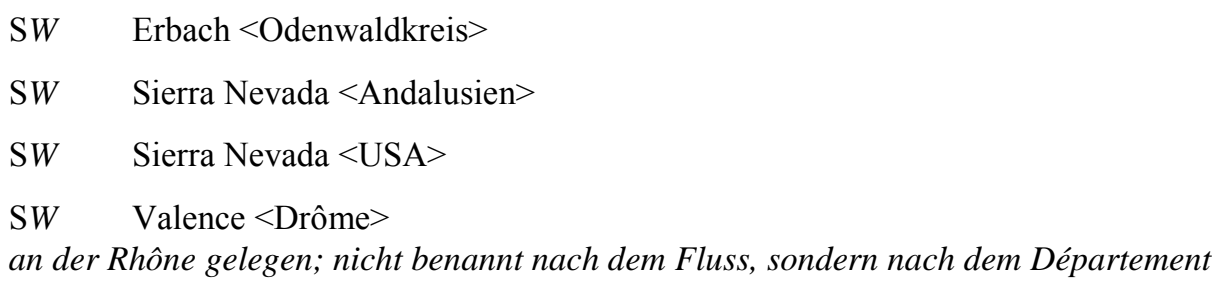


Bei der Ansetzung von Orten der USA wird als Namenszusatz immer der Bundesstaat in der nach Anl. 4 verbindlichen Abkürzung hinzugefügt (vgl. auch RAK, Anl. 8).

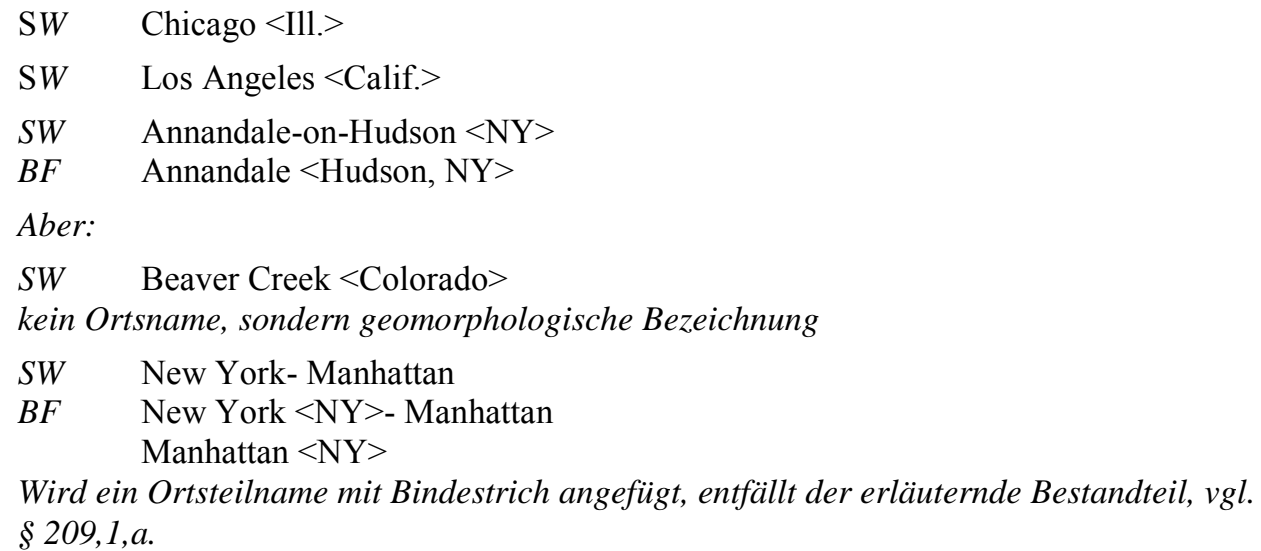

Bei der Ansetzung von Ortsnamen Australiens wird der Bundesstaat, bei Ortsnamen Kanadas die Provinz in nicht abgekürzter Form als Namenszusatz stets hinzugefügt, es sei denn der Ort ist in RAK Anl. 16 aufgeführt (vgl. RAK § 447,1 mit Erl. 1)

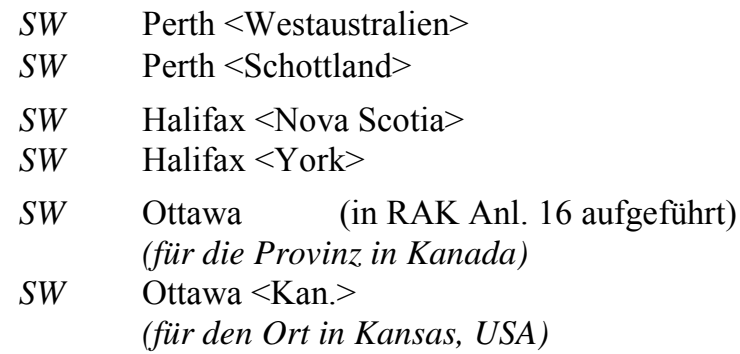

Bei der Ansetzung von Ortsnamen Indiens wird der Bundesstaat, die Provinz und dgl., bei Ortsnamen Japans die Präfektur als Homonymenzusatz in nicht abgekürzter Form hinzugefügt, wenn der Ort von anderen gleichnamigen Gebietskörperschaften unterschieden werden muss (vgl. RAK § 447,1,Erl. 1).

$\begin{array}{ll}S W & \text { Aurangabad }<\text { Maharashtra }> \\ S W & \text { Aurangabad }<\text { Bihar }> \\ S W & \text { Yuzawa }<\text { Akita }> \\ S W & \text { Yuzawa }<\text { Niigata }>\end{array}$

b) Ist ein Ort homonym zu einer naturräumlichen Einheit oder einem Ethnographikum und bietet die geographische Lage keine ausreichende Unterscheidung, so bleibt der Ortsname i. d. R. ohne Homonymenzusatz und dem Namen der naturräumlichen bzw. ethnographischen Einheit wird eine zutreffende Gattungsbezeichnung als Homonymenzusatz hinzugefügt.

$\begin{array}{ll}\text { SW } & \text { Traun } \\ \text { Der } & \text { Ortsname bleibt ohne Homonymenzusatz. } \\ \text { SW } & \text { Traun }<\text { Bayern, Fluss }> \\ \text { SW } & \text { Traun }<\text { Österreich, Fluss }> \\ S W & \text { Fulda } \\ S W & \text { Fulda }<\text { Fluss }> \\ S W & \text { Traunstein } \\ \text { SW } & \text { Traunstein }<\text { Berg }>\end{array}$


c) Gleichnamige Gebietskörperschaften unterschiedlicher Ausdehnung, für die die geographische Lage keine ausreichende Unterscheidung bietet, werden durch Homonymenzusätze unterschieden, die die Art der Gebietskörperschaft kennzeichnen.

Die wichtigsten für die einzelnen Arten von Verwaltungseinheiten zu wählenden Homonymenzusätze sind in $\S 203,4$ aufgeführt.

$$
\begin{array}{ll}
S W & \text { Luzern }<\text { Kanton }> \\
S W & \text { Celle }<\text { Kreis }> \\
S W & \text { Darmstadt }<\text { Bezirk }>
\end{array}
$$

Die Ansetzungsformen für Staaten bleiben i. d. R. ohne Homonymenzusatz.

Ist ein Ort namensgleich mit einem Staat oder Gliedstaat, erhält i. d. R. der Ort den Homonymenzusatz $<$ Stadt $>$.

$\begin{array}{ll}S W & \text { Luxemburg } \\ S W & \text { Luxemburg }<\text { Distrikt }> \\ S W & \text { Luxemburg }<\text { Provinz }> \\ S W & \text { Luxemburg }<\text { Stadt }> \\ S W & \text { Mexiko } \\ S W & \text { Mexiko }<\text { Land }> \\ S W & \text { Mexiko }<\text { Stadt }>\end{array}$

Ändert sich der gebräuchliche Name einer Gebietskörperschaft nicht, so bleiben auch starke Veränderungen im Gebietsstand für die Ansetzung unberücksichtigt.

Auch Verfassungs- oder Statusänderungen, die nicht mit einer Namensänderung einhergehen, werden i. d. R. nicht durch Homonymenzusätze unterschieden (vgl. aber § 207,3). Ist gleichzeitig eine Unterscheidung von anderen gleichnamigen Gebietskörperschaften nötig, so wird bei Staaten, Gliedstaaten und deren historischen Entsprechungen auf den Homonymenzusatz $<$ Staat $>$ normiert.

Die Namensformen mit den jeweiligen historischen Statusangaben als Homonymenzusatz werden als Synonyme erfasst.

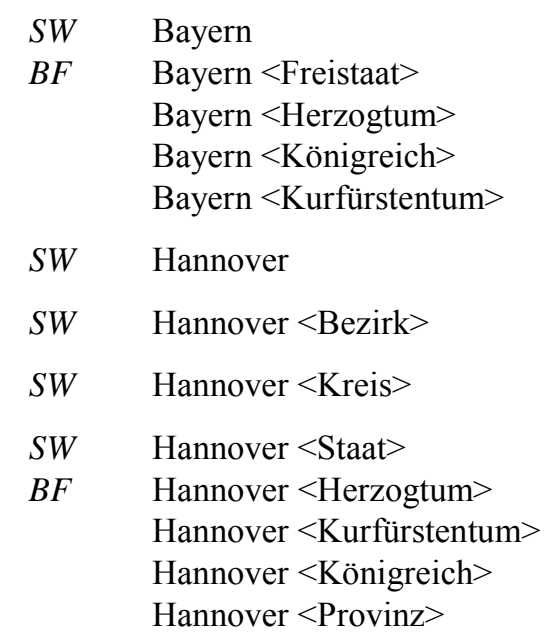

Ist eine Gebietskörperschaft homonym zu einer naturräumlichen Einheit gleicher oder annähernd gleicher geographischer Lage, so wird auf eine Ansetzungsform normiert. 


$\begin{array}{ll}\text { SW } & \text { Greyerzer Land } \\ \text { BF } & \text { Greyerz }<\text { Bezirk }> \\ \text { SW } & \text { Calvados }<\text { Dep. }> \\ \text { BF } & \text { Calvados }<\text { Landschaft }>\end{array}$

Sind homonyme Gebietskörperschaften und Landschaften in ihrer geographischen Lage nicht deckungsgleich, so wird i.d.R. der Landschaftsbezeichnung der Homonymenzusatz $<$ Landschaft $>$ oder ein anderer geeigneter Homonymenzusatz beigefügt. Sie wird ggf. bei der Gebietskörperschaft als Oberbegriff erfasst.

$\begin{array}{ll}S W & \text { Makedonien (für die Republik) } \\ O B & \text { Makedonien }<\text { Landschaft }> \\ S W & \text { Makedonien }<\text { Griechenland }> \\ O B & \text { Makedonien }<\text { Landschaft }> \\ S W & \text { Makedonien }<\text { Landschaft }>\end{array}$

Bei Landkreisen wird der Homonymenzusatz $<$ Kreis $>$ auch dann hinzugefügt, wenn es keine anderen homonymen Geographika gibt, es sei denn, die Bezeichnung 'Kreis' oder 'Landkreis' ist bereits Bestandteil des Namens. Gibt es eine zum Kreis in etwa gebietsgleiche homonyme Landschaft, so wird auf eine Ansetzungsform ohne Homonymenzusatz normiert. Die nicht gewählte Namensform mit Homonymenzusatz wird als Synonym erfasst.

$\begin{array}{ll}\text { SW } & \text { Tölz-Wolfratshausen }<\text { Kreis }> \\ \text { SW } & \text { Hochsauerlandkreis } \\ \text { SW } & \text { Main-Taunus-Kreis } \\ \text { SW } & \text { Berchtesgadener Land } \\ \text { BF } & \text { Berchtesgadener Land }<\text { Kreis }>\end{array}$

Ist eine Gebietskörperschaft nach einem Ort benannt, der mit Homonymenzusatz angesetzt ist, so wird dieser bei der Ansetzung der Gebietskörperschaft i.d.R. übernommen.

SW $\quad$ Cham $<$ Oberpfalz, Kreis $>$

4. Liste der Homonymenzusätze bei Verwaltungseinheiten

Die in der nachfolgenden Liste aufgeführten Verwaltungseinheiten sind in der angegebenen Form als Homonymenzusätze verbindlich. Im Einzelfall weichen sie von der Ansetzungsform der SWD ab.

In bestimmten Fällen werden speziellere Verwaltungseinheiten auf allgemeinere normiert. Ein geographischer Name mit der speziellen Einheit als Homonymenzusatz kann ggf. als Synonym erfasst werden.

$$
\begin{array}{ll}
\text { SW } & \text { Arnsberg }<\text { Bezirk }> \\
\text { BF } & \text { Arnsberg }<\text { Regierungsbezirk }>
\end{array}
$$

Die Liste ist nicht abschließend. Es können weitere, hier nicht genannte Verwaltungseinheiten, jeweils in der Ansetzungsform des Sachschlagworts, als Homonymenzusatz herangezogen werden. Ein Sachschlagwort, das als Homonymenzusatz bei geographischen Namen zugelassen ist, erhält in der SWD einen entsprechenden Verwendungshinweis. 
Abtei BS Kloster

$<$ Amt $>$

auch für Amtsbezirk, z.B. in Nordrhein-Westfalen, Rheinland-Pfalz, Preußen

$<$ Archidiakonat $>$

$<$ Arrondissement $>$

in Frankreich

$<$ Autonome Region $>$

$<$ Bezirk $>$

auch für Regierungs-, Verwaltungsbezirk

Bezirksamt $B S<$ Kreis $>$

Bistum $B S<$ Diözese $>$

Bundesland $B S<$ Land $>$

Bundesstaat $B S<$ Staat $>$

Chorherrenstift BS Stift

$<$ County $>$

in Großbritannien, USA, Irland

$<$ Dekanat $>$

vgl. Anmerkung

$<$ Dep. $>$

für Département u. Departamento

$<$ Diözese $>$

für Bistum und Erzbistum

$<$ Distrikt $>$

in Großbritannien, Frankreich, USA, Tansania

Erzbistum $B S<$ Diözese $>$

Erzdiözese $B S<$ Diözese $>$

Erzstift $B S<$ Hochstift $>$

Fürstabtei BS Kloster

Fürstbistum $B S<$ Hochstift $>$

$<$ Fürstentum $>$

Fürsterzbistum $B S<$ Hochstift $>$

Fürstpropstei BS Stift

Fürststift BS Stift 
$<\mathrm{Gau}>$

Geistliches Fürstentum $B S<$ Hochstift $>$

Gemeinde $B S<$ Ort $>$

$<$ Gerichtsbezirk $>$

$<$ Gouvernement $>$

$<$ Grafschaft $>$

$<$ Herrschaft $>$

$<$ Herzogtum $>$

$<$ Hochstift $>$

$<$ Judet $>$

$<$ Kanton $>$

$<$ Khanat $>$

Kirchenbezirk $B S<$ Kirchenkreis $>$

Kirchengemeinde $B S<$ Pfarrei $>$

$<$ Kirchenkreis $>$

$<$ Kirchenprovinz $>$

Kirchspiel $B S<$ Pfarrei $>$

Kloster

$<$ Königreich $>$

$<$ Komitat $>$

$<$ Kreis $>$
z.B. für Gebietsgliederung der NSDAP

bei Klöstern und Stiften BS Kloster bzw. Stift

für Kirchengemeinden, Kirchspiele usw., die mehr als einen Ort umfassen, $B S<$ Pfarrei $>$. Innerörtliche Kirchengemeinden werden als ortsgebundene Körperschaften angesetzt (vgl. § 618,2).

für Land-, Oberlandes-, Amtsgerichtsbezirk

in Russland

nicht für County

Gebiet, über das eine reichsständische Familie Souveränität besaß (auch BF Standesherrschaft)

für den weltlichen Geltungsbereich von Bistum und Erzbistum; für das Gebiet von Klöstern verknüpfe mit 'Territorium'.

in Rumänien

in der Schweiz, in Belgien, Frankreich

soweit innerhalb eines Ortes, als ortsgebundene Körperschaft angesetzt

vgl. Anmerkung

soweit innerhalb eines Ortes, als ortsgebundene Körperschaft angesetzt

wird als Körperschaft angesetzt (vgl. $\S 618,3$ ); für das Gebiet verknüpfe mit 'Territorium'. 
$<$ Kurfürstentum $>$

Kurstift $B S<$ Hochstift $>$

Län $B S<$ Provinz $>$

Län $B S<$ Bezirk $>$

$<$ Land $>$

Landgerichtsbezirk $B S<$ Gerichtsbezirk $>$

Landkapitel $B S<$ Dekanat $>$

Landkreis $B S<$ Kreis $>$

$<$ Landschaftsverband $>$

$<$ Markgrafschaft $>$

Metropolitanverband

$B S<$ Kirchenprovinz $>$

$<$ Nomos $>$

$<$ Oberamt $>$

$<$ Oblast $>$

Oberlandesgerichtsbezirk

$B S<$ Gerichtsbezirk $>$

$<$ Ort $>$

$<$ Patriarchat $>$

$<$ Pfarrei $>$

$<$ Pfleggericht $>$

Planungsgemeinschaft

$B S<$ Planungsregion $>$

$<$ Planungsregion $>$

$<$ Präfektur $>$ in Finnland

in Schweden

für Bundesländer sowie für andere Gliedstaaten, soweit $<$ Staat $>$ nicht ausreichend und keine spezielleren

Homonymenzusätze vorhanden in Nordrhein-Westfalen

in Griechenland

in Württemberg

z. B. in der Sowjetunion bzw. ihren Nachfolgestaaten

für nichtstädtische Gemeinden, entfällt i.d.R., vgl.

$\S 203,3, \mathrm{~b}$

für Pfarrgemeinden, Kirchspiele etc., die mehr als einen Ort umfassen (vgl. § 618,1)

auch für Pflegamt

in Japan 
$<$ Propstei $>$

$<$ Provinz $>$

Regierungsbezirk $B S<$ Bezirk $>$

$<$ Region $>$

Reichsabtei $B S$ Kloster

Reichsbistum $B S<$ Hochstift $>$ bzw.

$<$ Diözese $>$

Reichsstift $B S$ Stift

$<$ Republik $>$

$<$ Samtgemeinde $>$

$<$ Staat $>$

$<$ Stadt $>$

Standesherrschaft $B S<$ Herrschaft $>$

Stift

$<$ Superintendentur $>$

$<$ Territorium $>$

Territorium

$<$ Umlandverband $>$

$<$ Verbandsgemeinde $>$

Verwaltungsbezirk $B S<$ Bezirk $>$

$<$ Verwaltungsgemeinschaft $>$

$<$ Woiwodschaft $>$ vgl. Anmerkung; nicht für das Gebiet eines Stifts, hier verknüpfe mit 'Territorium'.

für die Verwaltungseinheit, soweit kein spezieller Homonymenzusatz möglich; zu $<$ Region $>$ im Sinne von Umgebung vgl. $§ 204 \mathrm{a}$ nur soweit $<$ Staat $>$ nicht möglich

in Niedersachsen

für Gesamt- und für Gliedstaaten; Bundesland $B S<$ Land $>$

wird als ortsgebundene Körperschaft angesetzt (vgl. § 618,3); für das Gebiet verknüpfe mit 'Territorium'

vgl. Anmerkung

zu verknüpfen für die Region der Reichsstädte, Reichsabteien, Fürstabteien und Fürstpropsteien

in Hessen

in Rheinland-Pfalz

Anm.: $<$ Dekanat $>,<$ Kirchenkreis $>$, $<$ Propstei $>,<$ Superintendentur $>$ werden je nach landeskirchlichem Sprachgebrauch für einen Verband von Kirchengemeinden angesetzt. 
5. Ist das geographische Schlagwort zu Schlagwörtern anderer Schlagwortkategorien homo nym, so erhält das Geographikum i. d. R. einen Homonymenzusatz, der nach Möglichkeit entsprechend $\S 203,3$ gebildet wird. Ist dies nicht möglich, wird die entsprechende Gattungsbezeichnung für die geographische Einheit verwendet.

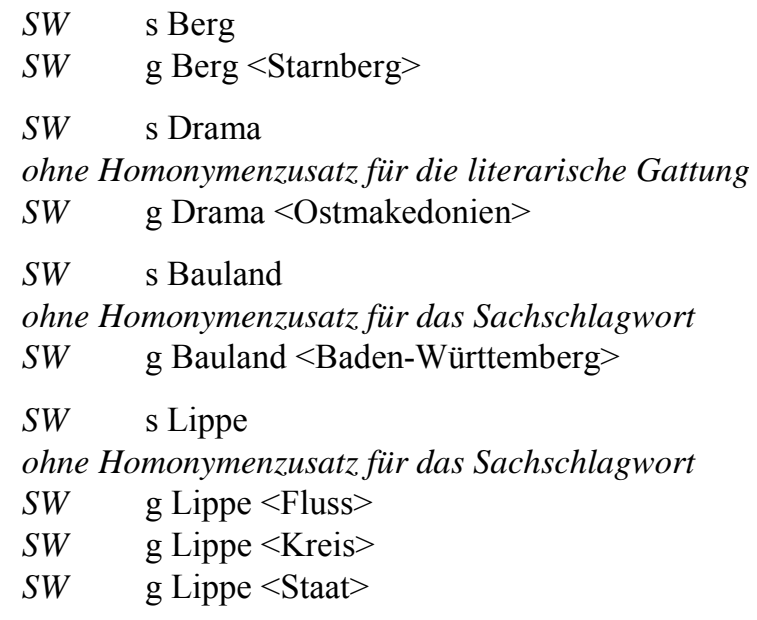

Unspezifische Namen einzelner Verwaltungseinheiten erhalten einen Homonymenzusatz.

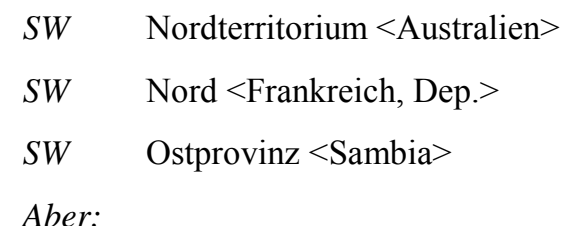

SW USA / Südstaaten

\section{$\S 204$ Mit geomorphologischen Gattungsbezeichnungen gebildete Namen}

1. Geographika, die in ihren Namen eine geomorphologische Bezeichnung enthalten, werden i. d. R. in der im maßgeblichen Nachschlagewerk nachgewiesenen Form angesetzt, sofern nicht nachweisbar, in der Vorlageform. Ansetzungsform kann ein Kompositum bzw. eine Adjektiv-Substantiv-Verbindung sein, in der die geomorphologische Bezeichnung das Grundwort ist, oder eine Wortfolge mit präpositionalen Wendungen, die mit der Gattungsbezeichnung beginnt.

$$
\begin{array}{ll}
S W & \text { Riesengebirge } \\
S W & \text { Mondsee } \\
\text { SW } & \text { Hohenloher Ebene } \\
\text { SW } & \text { Col de l'Iseran }
\end{array}
$$

Ist der geographische Name im maßgeblichen Nachschlagewerk in invertierter Form angegeben, so wird er davon abweichend als Wortfolge angesetzt. Die Namensform des Nachschlagewerks wird als Synonym erfasst.

$\begin{array}{ll}S W & \text { Hügelland von Aschanti } \\ B F & \text { Aschanti, Hügelland von }\end{array}$ 


$\begin{array}{ll}\text { SW } & \text { Golf von Neapel } \\ \text { BF } & \text { Neapel }<\text { Golf }> \\ \text { SW } & \text { Isthmus von Korinth } \\ \text { BF } & \text { Korinth }<\text { Isthmus }>\end{array}$

Die geomorphologische Bezeichnung wird in solchen Fällen i.d.R. nicht auf die für das Sachschlagwort gewählte Ansetzungsform normiert, sondern bleibt in der im maßgeblichen Nachschlagewerk oder in der Vorlage nachgewiesenen Form. Bei Namen aus Sprachen mit nichtlateinischen Alphabeten wird die geomorphologische Bezeichnung in Wortfolgen stets in der Dudentranskription angesetzt.

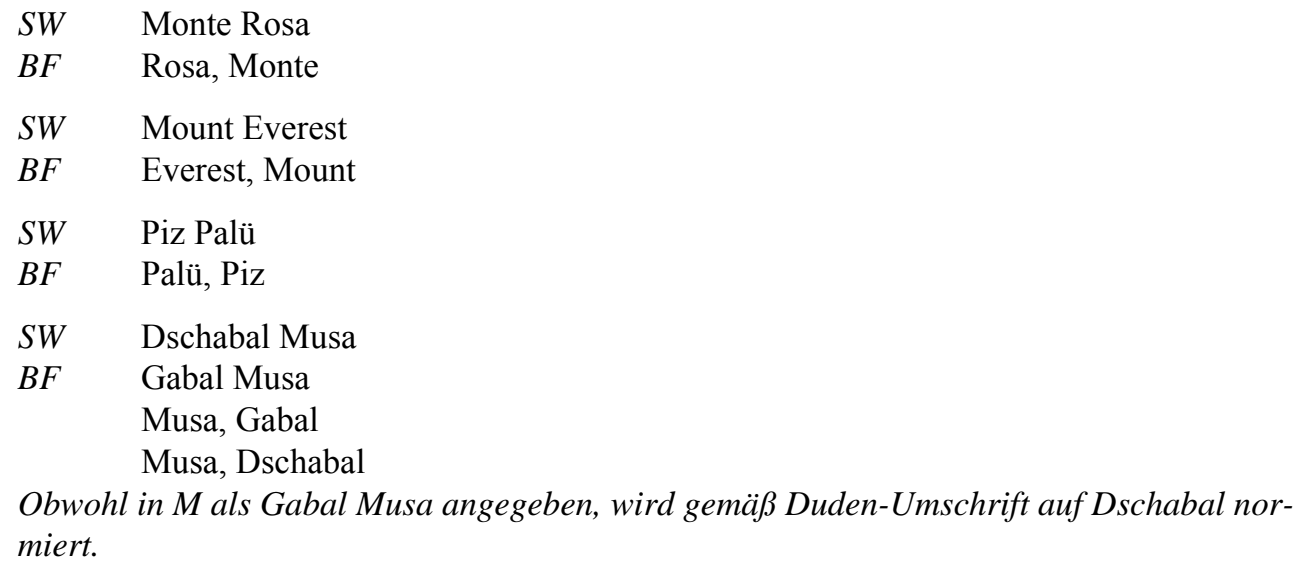

2. Sind die Namen einzelner Küsten, Inseln, Täler oder Becken u.ä. in den Nachschlagewerken nicht nachweisbar, so wird in Analogie aus dem betreffenden Geographikum als Bestimmungswort und der Bezeichnung 'Küste' usw. ein Kompositum oder eine AdjektivSubstantiv-Verbindung gebildet und als geographischer Name angesetzt. Dies gilt auch für fremdsprachige Geographika. Die fremdsprachigen Vorlageformen werden als Synonym erfasst. Komposita mit '-tal' und '-küste' werden i.d.R. in ununterbrochener Buchstabenfolge geschrieben, Komposita mit '-Becken' oder '-Inseln' werden mit Bindestrich angesetzt, es sei denn, sie sind im maßgeblichen Nachschlagewerk in ununterbrochener Buchstabenfolge nachweisbar.

$\begin{array}{ll}\text { SW } & \text { Nordseeküste } \\ \text { SW } & \text { Rhein-Main-Gebiet } \\ \text { SW } & \text { Nordfriesische Inseln } \\ \text { SW } & \text { Tennesseetal } \\ \text { BF } & \text { Tennessee Valley } \\ \text { Aber: } & \\ \text { SW } & \text { Tarimbecken } \\ \text { Q } & \text { M, B 1986 } \\ \text { ohne Bindestrich nach Nachschlagewerk }\end{array}$

Ist ein Kompositum bzw. eine Adjektiv-Substantiv-Verbindung nicht möglich und ist auch kein anderer Name nachweisbar, so wird das betreffende Geographikum mit dem Schlagwort für die geographische Gattungsbezeichnung verknüpft.

SWW g Iran ; s Küste ; g Kaspisches Meer 


\section{§ 204a Die Umgebung geographischer Einheiten}

1. Gebiete, die naturräumliche geographische Einheiten wie Berge, Seen, Flüsse etc. umgeben, werden i.d.R. als Kompositum aus dem Namen der naturräumlichen Einheit und der mit Bindestrich angefügten Bezeichnung 'Gebiet' angesetzt, es sei denn, im maßgeblichen Nachschlagewerk ist eine andere Form nachweisbar.

Der Name der naturräumlichen Einheit mit dem Zusatz $<$ Region $>$ wird als Synonym erfasst.

$\begin{array}{ll}S W & \text { Hekla-Gebiet } \\ B F & \text { Hekla }<\text { Region }> \\ S W & \text { Bodensee-Gebiet } \\ B F & \text { Bodensee }<\text { Region }> \\ & \text { Bodenseeraum } \\ S W & \text { Seine-Gebiet } \\ B F & \text { Seine }<\text { Region }>\end{array}$

Ist das Kompositum mit '-Gebiet' sprachlich sehr unübersichtlich oder unzulässig, wird der naturräumliche geographische Name mit dem Zusatz $<$ Region $>$ angesetzt. Die nicht gewählte Form wird als Synonym erfasst.

$\begin{array}{ll}S W & \text { Großer Sklavensee }<\text { Region }> \\ B F & \text { Großer-Sklavensee-Gebiet } \\ \text { SW } & \text { Arctic Red River }<\text { Region }> \\ \text { BF } & \text { Arctic-Red-River-Gebiet }\end{array}$

2. Für das Umland einzelner Städte und Gemeinden wird, sofern das maßgebliche Nachschlagewerk keinen anderen Nachweis bietet, der Name der jeweiligen Gebietskörperschaft mit dem Zusatz $<$ Region $>$ angesetzt. Die Form als Kompositum mit '-Gebiet' wird i.d.R. nicht als Synonym erfasst.

$$
\text { SW } \quad \text { Leipzig }<\text { Region }>
$$

\section{§ 205 Namen von Teileinheiten}

1. Unterteilung nach der Himmelsrichtung

a) Wird eine geographische Einheit durch die Angabe einer Himmelsrichtung unterteilt, so ist die Teileinheit mit dem Namen der Gesamteinheit und der als Zusatz angefügten Himmelsrichtung anzusetzen, sofern keine Ausnahme nach b)-d) vorliegt. Das Kompositum bzw. die Adjektiv-Substantiv-Verbindung mit der vorangestellten Himmelsrichtung bzw. fremdsprachliche Äquivalente können als Synonyme erfasst werden.

$\begin{array}{ll}S W & \text { Markgräfler Land }<\text { Nord }> \\ B F & \text { Nördliches Markgräfler Land } \\ S W & \text { Kentucky }<\text { Ost }> \\ B F & \text { Ostkentucky } \\ & \text { Eastern Kentucky } \\ S W & \text { Harz }<\text { Südwest }> \\ B F & \text { Südwestharz }\end{array}$

b) Ist im maßgeblichen Nachschlagewerk die Bezeichnung mit der vorangestellten Himmelsrichtung als eigene Eintragung nachweisbar, so wird dieser Name angesetzt. Analo- 
ge Ansetzungsformen werden nicht gebildet. Die Form mit Himmelsrichtung als Zusatz kann als Synonym erfasst werden.

$\begin{array}{ll}S W & \text { Südtirol } \\ Q & \text { B 1986 } \\ B F & \text { Tirol < Süd> } \\ S W & \text { Westalpen } \\ Q & \text { Geo-Du., B 1986 } \\ B F & \text { Alpen <West> } \\ \text { SW } & \text { Südlicher Bug } \\ Q & \text { M, B 1986 1 } \\ \text { BF } & \text { Južnyj Bug } \\ \text { SW } & \text { Ostchinesisches Meer } \\ Q & \text { M }\end{array}$

c) Gebietskörperschaften mit entsprechenden Namen werden unabhängig von einem Nachweis in den Nachschlagewerken als Kompositum bzw. Adjektiv-SubstantivVerbindung mit der Himmelsrichtung angesetzt.
SW Nordschwarzwald
Q $\quad$ B 1986 unter Baden-Württemberg
$B F \quad$ Nordschwarzwald $<$ Planungsregion $>$
Schwarzwald $<$ Nord $>$

d) Gibt es für die betreffende geographische Einheit eine nahezu deckungsgleiche andere Landschaftsbezeichnung, die nicht mit der Himmelsrichtung gebildet ist, so wird diese als Ansetzungsform bevorzugt. Die mit der Himmelsrichtung gebildete Namensform wird als Synonym erfasst.
SW Matabeleland
BF $\quad$ Simbabwe $<$ West $>$
Westsimbabwe

e) Bei der mit der Himmelsrichtung angesetzten Teileinheit wird der Name der nächstübergeordneten Gesamteinheit i.d.R. als Oberbegriff erfasst.

$\begin{array}{ll}S W & \text { Harz < Südwest> } \\ O B & \text { Harz } \\ S W & \text { Nordwestdeutschland } \\ \text { OB } & \text { Norddeutschland } \\ \text { nicht: } & \text { OB Deutschland }\end{array}$

2. Unterteilung mit anderen Wendungen

Wird eine geographische Einheit mit Wendungen unterteilt wie 'Mittel-', 'Ober-', 'Unter-', 'Nieder-', 'Zentral-', 'Außer-', 'Inner-', 'Vorder-', 'Hinter-', 'Alt-', 'Neu-', 'Trans-' oder Entsprechungen in anderen Sprachen, so wird ihr Name als Kompositum bzw. AdjektivSubstantiv-Verbindung mit dieser Wendung angesetzt, sofern keine andere Bezeichnung gebräuchlich ist. Ein Nachweis in den Nachschlagewerken ist dabei nicht erforderlich. Der Name der nächstübergeordneten Gesamteinheit wird i. d. R. als Oberbegriff erfasst.

$\begin{array}{ll}S W & \text { Mittelrhein } \\ O B & \text { Rhein } \\ S W & \text { Oberlausitz } \\ O B & \text { Lausitz }\end{array}$




$\begin{array}{ll}S W & \text { Central Plains } \\ B F & \text { Interior Plains } \\ O B & \text { Great Plains } \\ \text { SW } & \text { Oberer Salween } \\ B F & \text { Nu Jiang } \\ O B & \text { Salween } \\ S W & \text { Äußere Hebriden } \\ O B & \text { Hebriden }\end{array}$

3. Überschneidungsgebiete

Für geographische Überschneidungsgebiete werden Komposita bzw. Adjektiv-SubstantivVerbindungen aus den Namen der sich überschneidenden Gebiete i. d. R. nicht angesetzt. Diese werden stattdessen verknüpft (vgl. § 13,2).

SWW Anden; Peru

nicht: Peruanische Anden

SWW Arktis ; Kanada

nicht: Kanadische Arktis

Ein Kompositum bzw. eine Adjektiv-Substantiv-Verbindung wird dagegen angesetzt, wenn eine solche Namensform in den Nachschlagewerken als eigener Sucheinstieg oder neben einer Haupteintragung als gebräuchliche Form hervorgehoben ist.

$$
\begin{array}{ll}
\text { SW } & \text { Bayerische Alpen } \\
\text { Q } & \text { B } 1996
\end{array}
$$

\section{§ 206 Historische Geographika}

1. Historische geographische Namen werden nach der „Liste der Nachschlagewerke“ (vgl. $\S 9,3$ ) angesetzt, wenn es für die betreffende geographische Einheit keine moderne Bezeichnung gibt (vgl. aber § 207).

$\begin{array}{ll}\text { SW } & \text { Amarna } \\ \text { SW } & \text { Troja } \\ \text { SW } & \text { Bithynien } \\ \text { SW } & \text { Römisches Reich } \\ \text { SW } & \text { Kirchenstaat } \\ \text { SW } & \text { Inkareich }\end{array}$

2. Bei folgenden Ländern, die vom Altertum bis zur Neuzeit mit demselben Namen angesetzt werden, jedoch keine historische Kontinuität aufweisen, wird der Homonymenzusatz $<$ Altertum $>$ für diesen Zeitraum hinzugefügt. Die Ansetzungsformen für die historischen und heutigen Einheiten werden durch chronologische Verweisungen verbunden.

$\begin{array}{llll}S W & \text { Ägypten }<\text { Altertum }> & S W & \text { Ägypten } \\ C F & \text { später Ägypten } & C F & \text { früher Ägypten }<\text { Altertum }> \\ S W & \text { Griechenland }<\text { Altertum }> & S W & \text { Griechenland } \\ C F & \text { später Griechenland } & C F & \text { früher Griechenland }<\text { Altertum }>\end{array}$




$\begin{array}{llll}S W & \text { Iran }<\text { Altertum }> & S W & \text { Iran } \\ C F & \text { später } \text { Iran } & C F & \text { früher } \text { Iran }<\text { Altertum }> \\ S W & \text { Israel }<\text { Altertum }> & S W & \text { Israel } \\ C F & \text { später } \text { Israel } & C F & \text { früher } \text { Israel }<\text { Altertum }> \\ S W & \text { Makedonien }<\text { Altertum }> & & \end{array}$

\section{$\S 207$ Namensänderungen}

1. Hat eine geographische Einheit ihren Namen geändert, so wird i. d. R. der neueste Name als Ansetzungsform gewählt. Die früheren Namen werden als Synonyme erfasst.

$\begin{array}{ll}S W & \text { Salzburg } \\ B F & \text { Iuvavum } \\ S W & \text { Sankt Petersburg } \\ B F & \text { Leningrad } \\ & \text { Petrograd }\end{array}$

2. Das gilt auch, wenn der Namensänderung eine Status- oder Gebietsänderung zu Grunde liegt, wie z. B. im Falle ehemaliger Kolonien bei der Erlangung der staatlichen Unabhängigkeit.

\begin{tabular}{|c|c|}
\hline$S W$ & Sambia \\
\hline$B F$ & Nordrhodesien \\
\hline$S W$ & Zentralafrikanische Republik \\
\hline$B F$ & $\begin{array}{l}\text { Zentralafrikanisches Kaiserreich } \\
\text { Ubangi-Schari }\end{array}$ \\
\hline$S W$ & Bangladesch \\
\hline$B F$ & Ostpakistan \\
\hline
\end{tabular}

3. Ist aber ein Staat oder Gliedstaat in verschiedenen Epochen unter unterschiedlichen Namen bekannt geworden und ist die Namensänderung mit einer einschneidenden Veränderung seines Status oder Gebietsstandes verbunden, werden früherer und späterer Name nebeneinander angesetzt und durch chronologische Verweisungen verbunden (vgl. § 12,7). Im Zweifelsfall wird keine wesentliche Änderung angenommen.

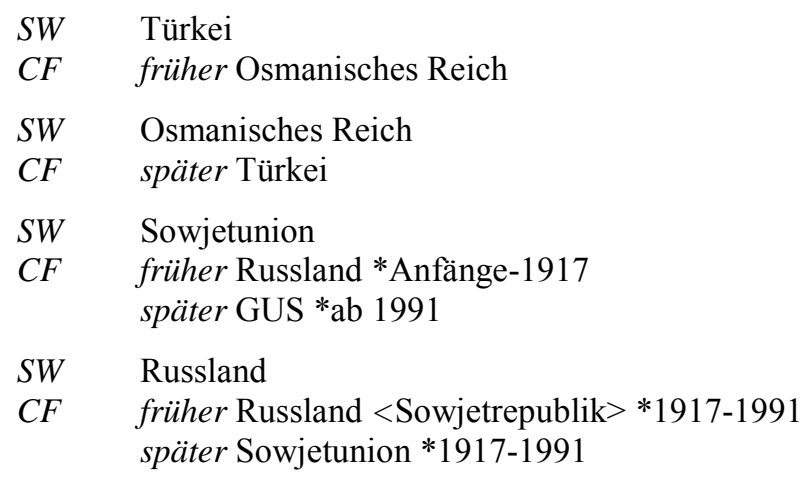

4. Bei Teilungen und Zusammenschlüssen von Gebietskörperschaften bzw. Verwaltungseinheiten werden die früheren Namen stets neben den heutigen angesetzt und durch chronologische Verweisungen verbunden. Dies gilt insbesondere auch für die innergebietliche Neuordnung (z. B. für Ein- und Umgemeindungen, Teilungen und Zusammenschlüsse) von Orten, Kreisen, Bezirken und vergleichbaren Gebietskörperschaften (vgl. § 12,7). 


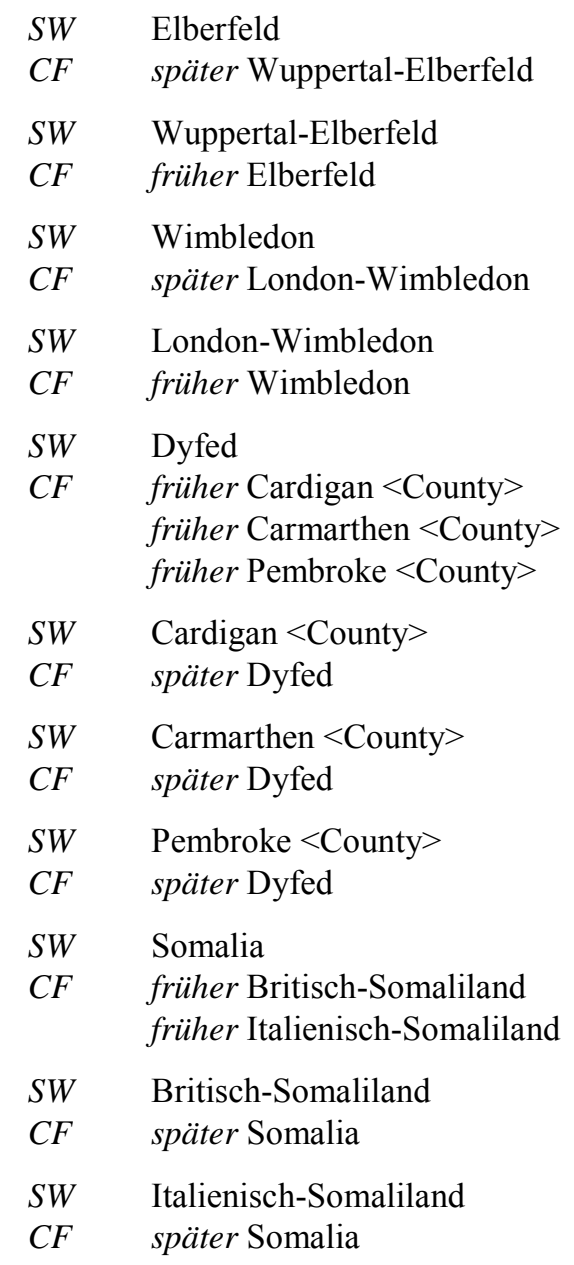

Zur Behandlung von eingemeindeten Ortsteilen, die in den entsprechenden Ortsverzeichnissen als selbständige Orte angesetzt werden, sowie zur Behandlung von Ortsteilen in Doppelorten vgl. $\S 209,1$.

5. Hat der frühere Name eines Ortes eine eigene Eintragung in der maßgeblichen Allgemeinenzyklopädie, so wird er neben dem heutigen Namen angesetzt und durch eine chronologische Verweisung mit ihm verbunden.

$\begin{array}{ll}S W & \text { Pergamon } \\ C F & \text { später Bergama } \\ S W & \text { Bergama } \\ C F & \text { früher } \text { Pergamon } \\ S W & \text { Byzanz } \\ C F & \text { später Konstantinopel } \\ \text { SW } & \text { Konstantinopel } \\ C F & \text { früher } \text { Byzanz } \\ & \text { später Istanbul } \\ S W & \text { Istanbul } \\ C F & \text { früher Konstantinopel } \\ S W & \text { Stalingrad } \\ C F & \text { später } \text { Wolgograd }\end{array}$


$\begin{array}{ll}\text { SW } & \text { Wolgograd } \\ \text { CF } & \text { früher Stalingrad }\end{array}$

6. Gibt es für eine geographische Einheit auf Grund ihrer historischen Entwicklung mehrere Ansetzungsformen, so wird bei der Beschlagwortung eines Dokumentes die zeitlich zutreffende, für Gesamtdarstellungen die neueste Namensform verwendet (z. B. bei Byzanz Konstantinopel - Istanbul).

\section{$\S 208$ entfällt}

\section{§ 209 Namen von Ortsteilen und kleinräumigen Geographika}

1. a) Ortsteile werden als Kompositum aus dem Namen des Hauptortes und dem mit Bindestrich angefügten Namen des Ortsteils angesetzt. Dabei entfallen ggf. zum Namen des Hauptortes oder des Ortsteiles gehörige Homonymenzusätze bzw. erläuternde Bestandteile in Winkelklammern. Analog RAK § 203,2 wird nach dem Bindestrich dann ein Spatium gesetzt, wenn Hauptort oder Vorort aus mehr als einem Ordnungswort bestehen. Der Name des Ortsteiles, ggf. mit Homonymenzusatz bzw. erläuterndem Bestandteil, wird als Synonym erfasst bzw. durch chronologische Verweisungen verbunden. Entfällt in der Ansetzungsform ein Homonymenzusatz bzw. ein erläuternder Bestandteil beim Hauptort, so wird die Form mit Zusatz bzw. Bestandteil als Synonym erfasst.

$\begin{array}{ll}S W & \text { München-Maxvorstadt } \\ B F & \text { Maxvorstadt }<\text { München }> \\ S W & \text { New York- Manhattan } \\ B F & \text { Manhattan }<\text { NY }> \\ & \text { New York }<\text { NY }>\text { - Manhattan } \\ & \text { Gelsenkirchen-Schalke } \\ C F & \text { früher Schalke }<\text { Gelsenkirchen }> \\ S W & \text { Bonn-Godesberg } \\ B F & \text { Bonn- Bad Godesberg } \\ C F & \text { früher Godesberg }\end{array}$

b) Lässt sich bei einer geographischen Einheit nicht feststellen, ob es sich um einen Ortsteil oder einen verwaltungsmäßig selbständigen Ort handelt, wird sie als selbständiger Ort angesetzt.

Ist bei einem Ortsteil nicht ohne großen Aufwand feststellbar, ob dieser früher selbständig war und erst nachträglich eingemeindet bzw. mit dem jetzigen Hauptort vereinigt wurde, so wird der Name des Ortsteils als Synonym zur Hauptort-Ortsteil-Ansetzung erfasst. Stellt sich nachträglich heraus, dass eine Eingemeindung bzw. ein Zusammenschluss stattgefunden hat, so wird korrigiert und der Name des ehemals selbständigen Orts neben der Hauptort-Ortsteil-Ansetzung als Schlagwort angesetzt und durch chronologische Verweisungen verbunden.

c) Besteht der Name des Hauptorts aus den durch Bindestrich verbundenen Namen der zuvor selbständigen Ortsteile (Doppelort), so wird das Schlagwort für den früher selbständigen Ort auch für den Ortsteil verwendet. Das Kompositum aus dem Namen des Hauptorts und des Ortsteils wird i. d. R. nicht als Synonym erfasst. 


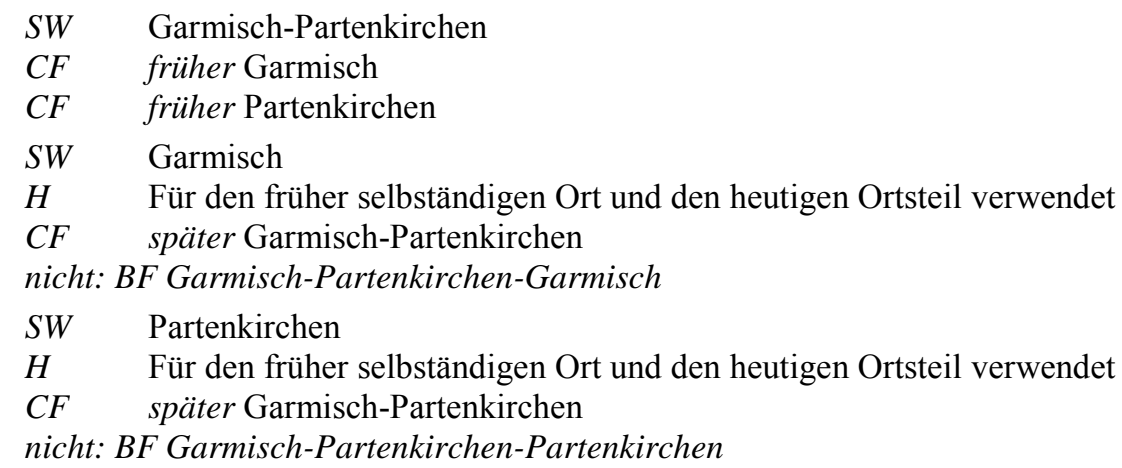

2. Ortsteile im deutschen Sprachgebiet und in der gesamten Schweiz, d. h. einschließlich der französischen, italienischen und rätoromanischen Landesteile, werden wie selbständige Orte ohne den Namen des Hauptortes mit ihrem Namen angesetzt, wenn sie eine eigene Eintragung in den maßgeblichen Ortsverzeichnissen gemäß der „Liste der Nachschlagewerke“ (vgl. § 9,3) haben, und zwar selbst dann, wenn klar erkennbar ist, dass es sich um einen Ortsteil handelt. Das Kompositum aus den Namen des Hauptorts und des Ortsteils wird als Synonym erfasst.

$\begin{array}{ll}S W & \text { Porz }<\text { Rhein }> \\ B F & \text { Köln-Porz } \\ S W & \text { Ehrendorf } \\ B F & \text { Lohne-Ehrendorf } \\ S W & \text { Champex } \\ B F & \text { Orsières-Champex }\end{array}$

3. Alle anderen Ortsteile außerhalb des deutschen Sprachgebiets und der gesamten Schweiz werden nur dann wie selbständige Orte angesetzt, wenn sie eine eigene Eintragung im maßgeblichen Nachschlagewerk haben und in dieser nicht eindeutig als Ortsteil gekennzeichnet sind.

SW $\quad$ Oseberg

Aus den Eintragungen unter Oseberg bzw. Pietroasa im Nachschlagewerk ist nicht ersichtlich, ob es sich um einen Ortsteil handelt.

Aber:

SW Paris-Montmartre

BF Montmartre

SW Neapel-Barra

BF $\quad$ Barra $<$ Neapel $>$

$S W \quad$ Los Angeles- Hollywood

BF $\quad$ Hollywood $<$ Calif. $>$

Montmartre, Barra und Hollywood sind im Nachschlagewerk eindeutig als Ortsteile charakterisiert.

4. Kleinräumige Geographika innerhalb eines Ortes werden i. d. R. als mehrgliedriges Schlagwort mit dem Ortsnamen als erstem und dem Namen des kleinräumigen Geographikums als zweitem Glied angesetzt. Die permutierte Form kann als Synonym erfasst werden. Straßen und Plätze eines Ortes werden wie kleinräumige Geographika behandelt, auf eine Synonymie-Verweisung von der permutierten Form wird dabei i. d. R. verzichtet. (Zu ortsgebundenen Kunstwerken einschließlich Bauwerken vgl. § 730,1; zu Straßen, Wegen und Linien außerhalb von Orten vgl. § 210.)

$\begin{array}{ll}S W & \text { Hannover / Maschsee } \\ B F & \text { Maschsee / Hannover } \\ S W & \text { Budapest / Margareteninsel } \\ B F & \text { Margareteninsel / Budapest }\end{array}$




\section{SW Hamburg / Hafenstraße}

SW Rom / Piazza Navona

Haben kleinräumige Geographika innerhalb eines Ortes keinen Eigennamen, so wird der Ortsname mit der einschlägigen geographischen Gattungsbezeichnung verknüpft (vgl. $\S 202,5$ ). (Zu Ausnahmeregelungen bei der Bildung mehrgliedriger Schlagwörter für ortsgebundene Kunstwerke bzw. Bauwerke vgl. § 730,1.)

\section{SWW Spaichingen; Stadtwald}

5. Kleinräumige Geographika sowie ortsgebundene Kunstwerke bzw. Bauwerke (vgl. § 730,1), als deren Standort ein unselbständig angesetzter Ortsteil bzw. ein Teil eines Doppelorts genannt ist, werden, sofern sie einen Individualnamen haben, i. d. R. als mehrgliedriges Schlagwort mit dem Namen des Hauptorts bzw. Doppelorts als erstem Glied angesetzt. Die Form mit dem Ortsteilnamen als erstem Glied wird als Synonym erfasst. (Zu Veranstaltungsorten bei Ausstellungen und Kongressen vgl. §504,3; zu Ortsteilen bei Körperschaften vgl. $\S 605,7$.

SW Dresden / Schloss Albrechtsberg

$B F \quad$ Dresden-Loschwitz / Schloss Albrechtsberg

$S W \quad$ Garmisch-Partenkirchen / Mariae Himmelfahrt

BF Partenkirchen / Mariae Himmelfahrt

Ist kein Individualname nachweisbar, wird i. d. R. der Name des Hauptortes mit der einschlägigen Gattungsbezeichnung verknüpft. ( $\mathrm{Zu}$ Ausnahmen bei Kunstwerken bzw. Bauwerken vgl. $§ 730,1$.

Ist der Ortsteil aber als Standort sehr viel bekannter, d. h. ist er im maßgeblichen Nachschlagewerk so angegeben, so wird mit dem Kompositum aus Hauptort und Ortsteil (bei Doppelorten mit dem betreffenden Ortsteil) angesetzt. Die nicht gewählte Form mit dem Hauptort (bzw. mit dem Doppelort) als erstem Glied und dem Namen mit dem Ortsteil als weiterem Glied kann als Synonym erfasst werden.

$\begin{array}{ll}S W & \text { Berlin-Grunewald / Jagdschloss } \\ Q & \text { B 1986 unter Grunewald } \\ B F & \text { Berlin / Jagdschloss Grunewald } \\ S W & \text { Rom- Castel Fusano / Villa Chigi } \\ Q & \text { Guida d'Italia } \\ S W & \text { Villingen }<\text { Schwarzwald }>\text { / Franziskanerkirche } \\ Q & \text { Dehio, Reclam } \\ B F & \text { Villingen-Schwenningen / Franziskanerkirche }\end{array}$

Gibt es in einem Ort mehrere namensgleiche kleinräumige Geographika oder Bauwerke, so werden diese mit dem Kompositum aus Hauptort und Ortsteil (bei Doppelorten mit dem betreffenden Ortsteil) als erstem Glied eines mehrgliedrigen Schlagworts angesetzt. Kleinräumige Geographika bzw. Bauwerke im Ortskern werden aber i. d. R. mit dem Namen des Hauptorts als erstem Glied angesetzt.

$$
\begin{array}{ll}
S W & \text { München / Sankt Michael } \\
\text { SW } & \text { München-Perlach / Sankt Michael }
\end{array}
$$

6. Kleinräumige Geographika außerhalb eines Ortes werden mit ihren Individualnamen angesetzt.

(Zur Ansetzung von Kunstwerken bzw. Bauwerken außerhalb von Orten vgl. § 730,2.)

$$
\text { SW Forstenrieder Park }
$$

7. Zur Ansetzung ortsgebundener Körperschaften vgl. § 605 . 


\section{§ 209a Namen von naturräumlichen Einheiten, von bio-, paläobio- und paläogeographischen Regionen sowie von räumlich begrenzten geologischen bzw. stofflich-räumlichen stratigraphischen Einheiten}

1. Namen von naturräumlichen Einheiten (vgl. § 201,1,b), von bio-, paläobio- und paläogeographischen Regionen sowie von räumlich begrenzten geologischen bzw. stofflich-räumlichen stratigraphischen Einheiten (vgl. § 201,1,c; zu geologischen Epochenbezeichnungen vgl. § 408a,4) werden gemäß §§ 201a - 205 verwendet und angesetzt.

2. Bei naturräumlichen Einheiten können das übergeordnete Geographikum sowie die einschlägige geographische Gattungsbezeichnung als Oberbegriffe erfasst werden.

$\begin{array}{ll}S W & \text { g Gepatschferner } \\ O B & \text { g Ötztaler Alpen } \\ & \text { s Gletscher } \\ S W & \text { g Takla Makan } \\ O B & \text { g Tarimbecken } \\ & \text { s Sandwüste } \\ S W & \text { g Valromey } \\ O B & \text { g Französischer Jura } \\ S W & \text { g Tagula } \\ O B & \text { g Louisiade-Archipel }\end{array}$

3. Wie naturräumliche Einheiten werden auch Nationalparks, Naturparks, Natur- und Landschaftsschutzgebiete behandelt. Bei ihnen wird ein mehrgliedriger Oberbegriff aus dem übergeordneten Geographikum (entsprechend dem Ländercode) und der einschlägigen geographischen Gattungsbezeichnung erfasst. Die Ergänzung weiterer Oberbegriffe ist möglich.

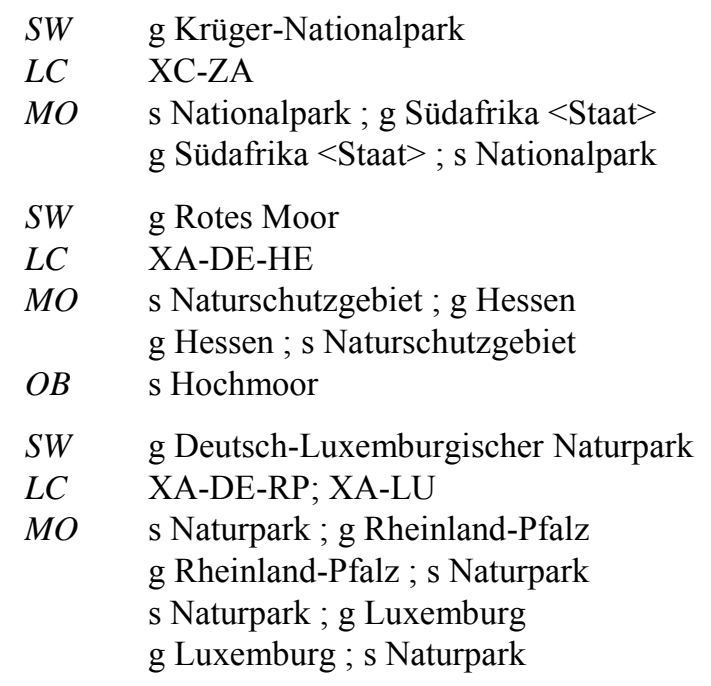

4. Im Fall von bio-, paläobio- und paläogeographischen Regionen wird die einschlägige geographische Gattungsbezeichnung als Oberbegriff erfasst.

$\begin{array}{ll}S W & \text { g Neotropische Region } \\ O B & \text { s Faunenregion }\end{array}$ 
5. Bei räumlich begrenzten geologischen bzw. stofflich-stratigraphischen Einheiten werden die Kombination mit dem übergeordneten Geographikum (entsprechend dem Ländercode) als Synonym, die einschlägigen geologischen Gattungsbezeichnungen und soweit möglich die erdgeschichtliche Epochenbezeichnung als Oberbegriffe erfasst.

$\begin{array}{ll}S W & \text { g Mainzer Becken } \\ L C & \text { XA-DE-HE; XA-DE-RP } \\ B F & \text { g Hessen / Mainzer Becken } \\ & \text { g Rheinland-Pfalz / Mainzer Becken } \\ O B & \text { s Becken }<\text { Geologie }> \\ & \\ S W & \text { g Green-River-Formation } \\ L C & \text { XD-US } \\ B F & \text { g USA / Green-River-Formation } \\ O B & \text { s Eozän }\end{array}$

6. Lagerstätten und Gruben als räumliche Einheiten werden im Gegensatz zu bergbaulich tätigen Körperschaften als Geographika mit ihren Individualnamen angesetzt. Die Kombination mit dem übergeordneten Geographikum wird als Synonym, die einschlägige geologische Gattungsbezeichnung als Oberbegriff erfasst.

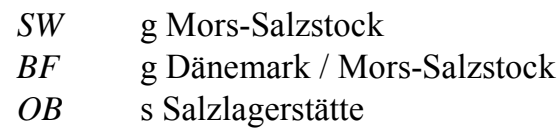

\section{$\S 210$ Namen von Wegen, Grenzen, Linien}

1. Zu den Wegen zählen Verkehrs-, Transport- und Versorgungswege aller Art, wie Autobahnen, Handelsstraßen, Bahnlinien, Flugverkehrswege, Wasserstraßen, Pipelines und andere Ingenieurbauten wie Tunnel, Brücken, Kanäle usw. (vgl. auch § 730,2).

$\begin{array}{ll}S W & \text { Brennerautobahn } \\ S W & \text { Polarroute } \\ \text { SW } & \text { Mittellandkanal } \\ S W & \text { Trans-Arabian Pipeline } \\ \text { SW } & \text { Vogelfluglinie } \\ \text { SW } & \text { Lermooser Tunnel }\end{array}$

$\mathrm{Zu}$ den Grenzen zählen natürliche, politische, administrative und militärische Trennungslinien, z. B. zwischen Staaten, Bezirken, Klimazonen usw.

$$
\begin{array}{ll}
S W & \text { Oder-Neiße-Linie } \\
S W & \text { Maginotlinie }
\end{array}
$$

$\mathrm{Zu}$ den Linien zählen alle sonstigen in ihrer geographischen Lage bestimmten Linien wie Planungslinien, Entwicklungsachsen, gedachte Linien (z. B. Längen- und Breitengrade) usw.

$\begin{array}{ll}S W & \text { Rheinschiene Mitte } \\ S W & \text { Äquator }\end{array}$

2. Wege, Grenzen und Linien außerhalb von Orten werden mit ihren im Deutschen gebräuchlichen Namen angesetzt. Der einschlägige geographische Gattungsbegriff wird als Oberbegriff erfasst. Gibt es keinen Individualnamen, so gilt die amtliche Bezeichnung als gebräuchlicher 
Name. Wird dieselbe amtliche Bezeichnung in unterschiedlichen Gebietskörperschaften verwendet, so wird der Name der betreffenden Gebietskörperschaft als Homonymenzusatz hinzugefügt. Die Streckenendpunkte in Verbindung mit dem einschlägigen Gattungsbegriff werden als Synonym erfasst. (Zu Wegen, Straßen und Plätzen innerhalb von Orten vgl. $\S 209,4$.)

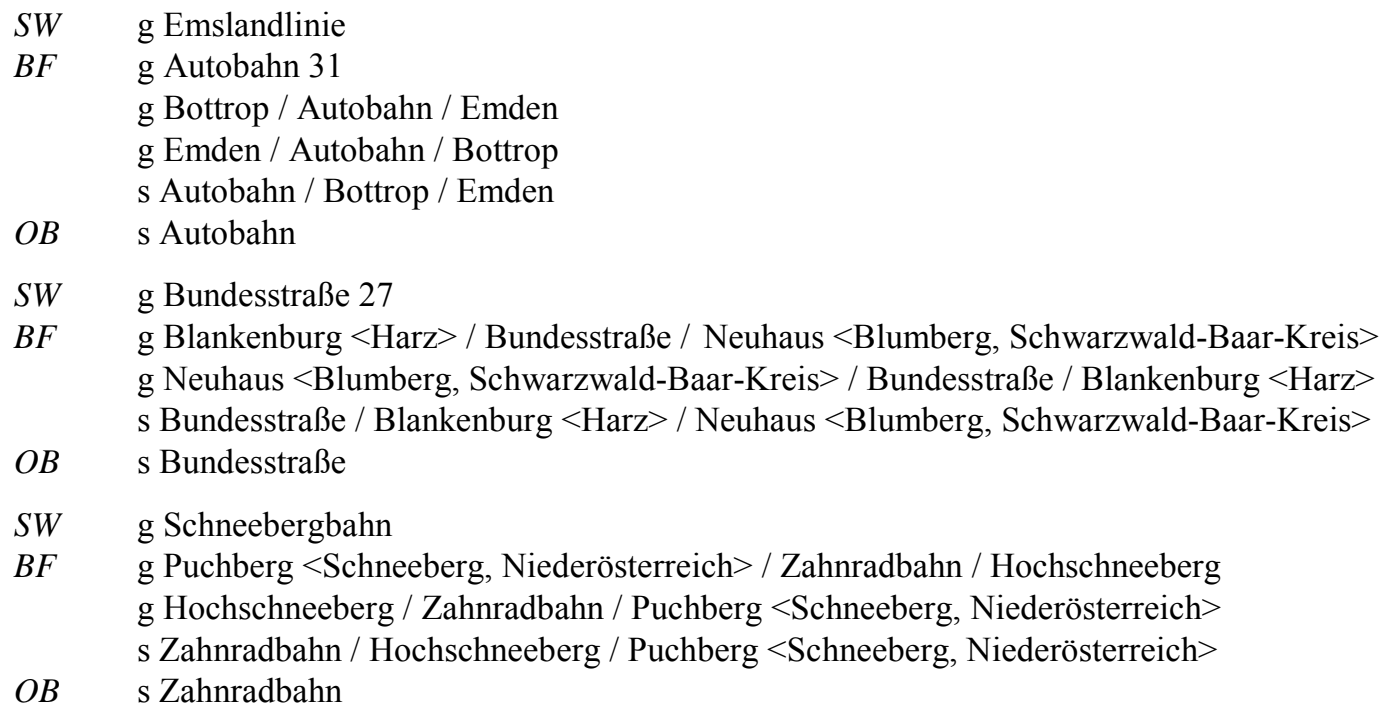

Lässt sich das Gebiet bestimmen, durch das eine Strecke oder Linie führt, so kann sein Name in Kombination mit dem Streckennamen als Synonym erfasst werden.

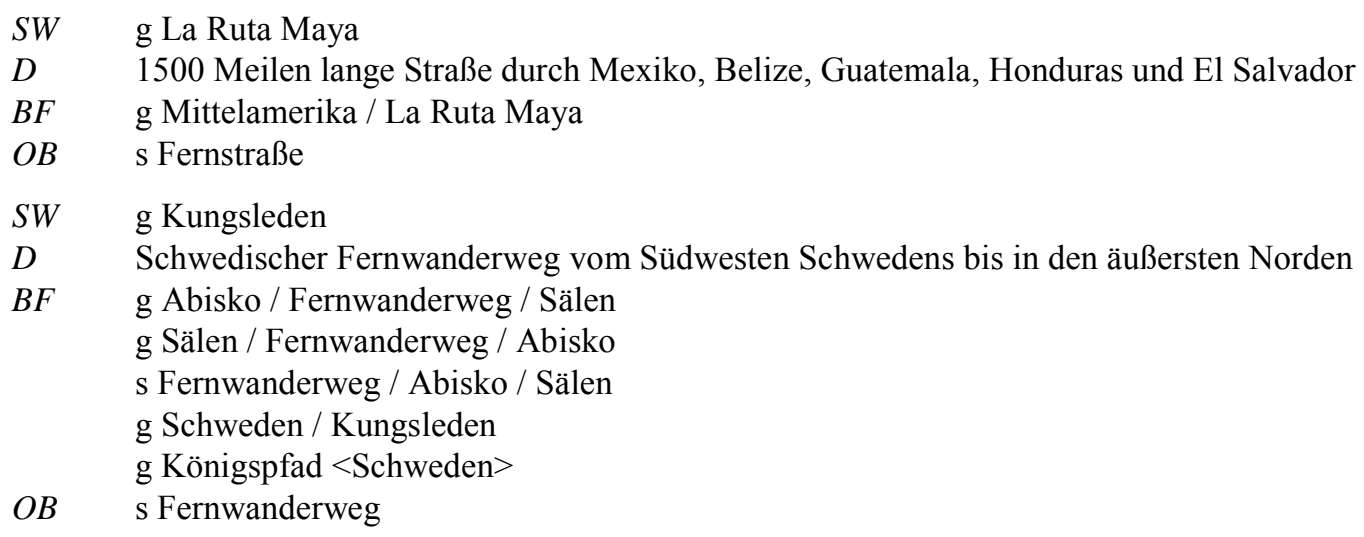

Für Teilstrecken, die keinen Individualnamen haben, wird das Schlagwort für die Gesamtstrecke mit den Bezeichnungen für die Endpunkte der Teilstrecke verknüpft.

SWW Digne; Route Napoléon ; Sisteron

3. Lässt sich kein Individualname ermitteln, so werden die Bezeichnungen für die Streckenendpunkte mit dem einschlägigen Gattungsbegriff für den Weg, die Grenze oder Linie verknüpft. Im Zweifelsfalle wird die Verknüpfung bevorzugt.

$S W W \quad$ Forchheim $<$ Oberfranken $>$; Eisenbahnlinie ; Höchstadt $<$ Aisch $>$

SWW Hessen; Landesgrenze; Bayern 
4. Einzelne Ingenieurbauten außerhalb von Ortschaften sowie sonstige Teilstrecken von Wegen (Grenzen, Linien) werden, wenn sie einen Individualnamen haben, mit diesem angesetzt. Der Name der Gesamtstrecke und der einschlägige Gattungsbegriff werden als Oberbegriffe erfasst.

$\begin{array}{ll}\text { SW } & \text { g Europabrücke } \\ \text { OB } & \text { g Brennerautobahn } \\ & \text { s Autobahnbrücke } \\ & \\ \text { SW } & \text { g Brandleitetunnel } \\ \text { MO } & \text { g Erfurt ; Eisenbahnlinie ; Ritschenhausen } \\ \text { OB } & \text { s Eisenbahntunnel }\end{array}$

\section{§ 211 Namen von Ländergruppen}

1. Ländergruppen werden im Plural in der im Deutschen gebräuchlichen Form als geographische Schlagwörter angesetzt, wenn

a) sie nach geographischen bzw. ethnographischen Gemeinsamkeiten benannt sind. Sofern in den Nachschlagewerken kein anderer Name nachweisbar ist, wird dem Kompositum aus geographischem Namen und dem Grundwort 'Staaten' der Vorzug gegeben. Das Kompositum wird in ununterbrochener Buchstabenfolge geschrieben. Andere gebräuchliche Namensformen werden als Synonyme erfasst.
SW Andenstaaten
$D \quad$ Soweit räumlich über die Anden hinausgehend, sonst SW Anden
BF Andenländer

Bei Anliegerstaaten von Meeren werden Komposita mit '-raum' bevorzugt, da in der Literatur Länder und Meer meist zusammen behandelt werden. Ist in solchen Fällen das Meer als Adjektiv-Substantiv-Verbindung angesetzt, so wird der Homonymenzusatz $<$ Region $>$ angefügt.

$\begin{array}{ll}S W & \text { Ostseeraum } \\ B F & \text { Ostseeländer } \\ & \text { Ostseestaaten } \\ & \text { Ostseegebiet } \\ & \text { Indischer Ozean }<\text { Region }> \\ B F & \text { Indik-Staaten } \\ & \text { Indik-Länder }\end{array}$

b) sie nach politischen oder ökonomischen Gemeinsamkeiten benannt sind. Auch in diesen Fällen wird, falls die Nachschlagewerke keinen anderen Nachweis bieten, das Kompositum mit 'Staaten' bevorzugt.

$\begin{array}{ll}S W & \text { Industriestaaten } \\ S W & \text { Sozialistische Staaten } \\ S W & \text { Entwicklungsländer } \\ Q & \text { B } 1986 \\ S W & \text { Schwellenländer } \\ Q & \text { Lex. 3 Welt }\end{array}$


Aber:

SW s Kleinstaat

SW s Großmacht

2. Nicht als Geographikum angesetzt wird die Gesamtheit der Mitgliedsstaaten internationaler Körperschaften. Das Schlagwort für die internationale Körperschaft wird auch für ihr Gebiet bzw. für das Gebiet ihrer Mitgliedsstaaten verwendet.

SWW k OECD ; s Umwelterziehung; s Schule ; s Projekt

SWW g Österreich; s Wirtschaftsbeziehungen ; k OPEC

Das Sachschlagwort 'Mitgliedsstaaten' wird in der Schlagwortkette nur verwendet, wenn ohne es ein anderer Sachverhalt ausgedrückt bzw. der Dokumenteninhalt nicht hinreichend wiedergegeben würde.

SWW g Europäische Union; s Mitgliedsstaaten; s Verfassung

Aber:

SWW k Association of South-East Asian Nations ; s Sicherheitspolitik

SWW g Deutschland; s Auslandsinvestition; k Association of South-East Asian Nations

\section{Ethnographische Schlagwörter}

\section{Definition und Verwendung}

\section{$\S 212$ Definition}

Als ethnographische Schlagwörter gelten Namen von heutigen und historischen Völkern, ethnischen Gruppen, Minderheiten und Stämmen. Zu ihnen zählen auch heutige und historische Rassen. In der SWD erhalten sie den Indikator g. (Zur Behandlung von Sprachbezeichnungen vgl. $\S 701$.

$\begin{array}{ll}\text { SW } & \text { Araber } \\ \text { SW } & \text { Buschmänner } \\ \text { SW } & \text { Buren } \\ \text { SW } & \text { Russen } \\ \text { SW } & \text { Goten } \\ \text { SW } & \text { Hunnen } \\ \text { SW } & \text { Parther } \\ \text { SW } & \text { Schwarze }\end{array}$




\section{§ 212a Verwendung}

1. Ethnographische Schlagwörter werden verwendet, wenn

a) kein dem Ethnographikum entsprechendes eigenes oder eindeutig zuzuordnendes Territorium vorhanden ist,

$$
\begin{array}{ll}
S W & \text { Irokesen } \\
S W & \text { Awaren } \\
S W & \text { Wikinger }
\end{array}
$$

b) es sich um nationale Minderheiten handelt,

$\begin{array}{ll}S W & \text { Deutschbalten } \\ S W & \text { Frankokanadier } \\ S W & \text { Sorben }\end{array}$

c) Ethnographika außerhalb ihres Territoriums thematisiert sind.

Inhalt: Les Français dans l'histoire du Brésil

$S W W \quad$ Brasilien; Franzosen ; Geschichte

Titel:: $\neg$ Die $\neg$ Auslandsdeutschen / Rudolf Aschenauer. - 1981

SWW Deutsche; Ausland

2. Werden Ethnographika aber innerhalb ihres eigenen Territoriums thematisiert, wird anstelle des ethnographischen Schlagworts das entsprechende geographische Schlagwort verwendet.

Titel: $\quad$ Kultur und Freizeit : Ergebnisse des Mikrozensus 1992 / bearb. im Österreichischen Statistischen Zentralamt. - 1995

SWW Österreich; Alltagskultur ; Freizeitverhalten; Geschichte 1992; Umfrage nicht: Österreicher ; Alltagskultur ; Freizeitverhalten ; Geschichte 1992 ; Umfrage

Aber:

Titel: Was Deutsche über Türken und Türken über Deutsche schon immer wissen wollten / Rudolf Blauth (Hg.). - 1992

$S W W \quad$ Deutsche ; Einstellung; Türken

Bei Vergleichen oder Beziehungen zu anderen Volksgruppen wird das ethnographische Schlagwort verwendet.

3. Werden in einem Dokument die Einwohner einer Stadt bzw. eines Ortes thematisiert, so wird das geographische Schlagwort für die Stadt, ggf. mit dem Schlagwort 'Einwohner', und kein ethnographisches Schlagwort verwendet.

Titel: $\quad$ Einwohner- und Familienbuch Kirchberg : 1350 - 1900 / von Werner Gath. - 1996

SWW Kirchberg < Niedenstein>; Einwohner ; Geschichte 1350-1900; Verzeichnis

Titel: „Ich bin halt ein Frankfurter child“ : Kanada-Auswanderer erzählen. - 1996

SWW Kanada ; Deutscher Einwanderer ; Frankfurt <Main $>$; Geschichte 1946-1960 ; Erlebnisbericht

4. Wird durch ein Sachschlagwort ein Sachverhalt wiedergegeben, der nur für ein bestimmtes Ethnographikum zutrifft, so wird die Kombination aus ethnographischem Schlagwort und Sachschlagwort als Synonym erfasst. In Schlagwortketten entfällt dann i. d. R. das ethnographische Schlagwort. 


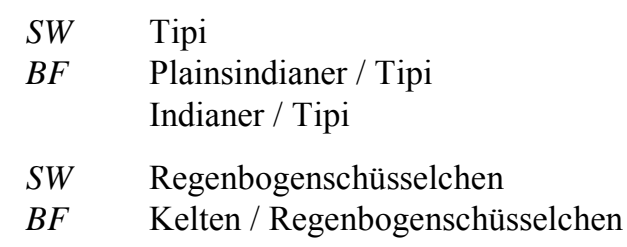

5. Die Regelungen in $\S 212 b, 1-3$ gelten entsprechend auch für weibliche Angehörige ethnischer Gruppen und sonstige Personengruppen mit ethnographischem Adjektiv. Sie werden aber als Sachschlagwörter angesetzt (vgl. § 305,2,e) und als solche verwendet.

Titel: $\quad$,... ich habe mich selber gekauft" : türkische Frauen in der Bundesrepublik / Ülkü Görkan . - 3. Aufl. - 1985

SWW g Deutschland <Bundesrepublik>; s Türkin ; s Soziale Situation

Titel: $\quad$ Ich bin eine deutsche Türkin / Ranka Keser. - 1995

$S W W \quad$ g Deutschland ; s Türkisches Mädchen ; s Kulturkonflikt ; f Jugendbuch

\section{§ 212b Ansetzung}

1. Ethnographische Schlagwörter werden i. d. R. im Plural in der im Deutschen gebräuchlichen Form gemäß der „Liste der Nachschlagewerke“ (vgl. § 9,3) angesetzt.

Abweichende Namensformen werden i. d. R. als Synonyme erfasst.

$\begin{array}{ll}S W & \text { Russen } \\ B F & \text { Russkije } \\ & \text { Großrussen } \\ & \\ B W & \text { Westgoten } \\ B F & \text { Visigothae } \\ & \text { Terwingen } \\ & \text { Visigoten } \\ & \text { Wisigoten }\end{array}$

2. a) Bei Bedarf werden zu ethnographischen Schlagwörtern Oberbegriffe erfasst.

$\begin{array}{ll}S W & \text { Mescalero } \\ O B & \text { Apachen } \\ & \\ S W & \text { Westgoten } \\ O B & \text { Goten }\end{array}$

b) Ethnographische Schlagwörter werden beim Namen des zugehörigen Territoriums als verwandte Begriffe erfasst und umgekehrt.

$\begin{array}{ll}S W & \text { Italiener } \\ V B & \text { Italien } \\ S W & \text { Italien } \\ V B & \text { Italiener }\end{array}$

Die weibliche Form (vgl. § 212a,5) eines ethnographischen Schlagworts wird zu diesem als verwandter Begriff erfasst und umgekehrt.

$\begin{array}{ll}S W & \text { g Franzosen } \\ V B & \text { s Französin } \\ & \text { g Frankreich }\end{array}$


$\begin{array}{ll}S W & \text { s Französin } \\ V B & \text { g Franzosen }\end{array}$

3. a) Ist der Name eines Staatsvolks homonym zum Namen des von ihm bewohnten Territoriums, so wird er mit dem Homonymenzusatz $<$ Volk $>$ beim Territorium als Synonym erfasst.

$\begin{array}{ll}S W & \text { Polen } \\ B F & \text { Polen }<\text { Volk }> \\ S W & \text { Bayern } \\ B F & \text { Bayern }<\text { Volk }>\end{array}$

b) Die Namen von Ethnographika, denen kein Territorium zugeordnet werden kann und die zu anderen Schlagwörtern homonym sind, werden ebenfalls mit dem Homonymenzusatz $<$ Volk $>$ angesetzt. Das gilt auch für germanische Volksstämme.

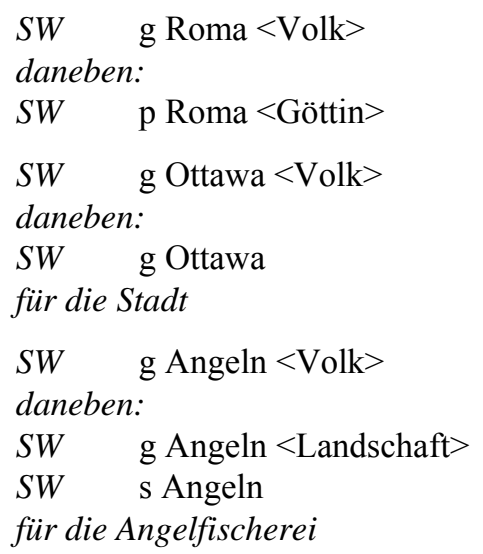

c) Die Namen von Ethnographika außerhalb ihres eigenen Territoriums werden mit dem Homonymenzusatz <Volksgruppe $>$ angesetzt, wenn ihre Namen homonym zu ihren Territorien sind.

$$
\begin{array}{ll}
\text { SW } & \text { Polen }<\text { Volksgruppe }> \\
\text { SW } & \text { Bayern }<\text { Volksgruppe }>
\end{array}
$$

\section{$\S 213$ Geographische/ethnographische Namen als Bestandteil prä- kombinierter Schlagwörter}

$\mathrm{Zu}$ geographischen/ethnographischen Namen als Bestandteil präkombinierter Sachschlagwörter vgl. § 305,2,e.

$\mathrm{Zu}$ geographischen/ethnographischen Namen als Bestandteil von historischen Einzelereignissen, Körperschaftsnamen, nicht ortsgebundenen Kunstwerken vgl. §§ 415a; 606; 727,3.

\section{§ 213a SWD-Datensatz}

Überblick über die wichtigsten Informationen in einem Datensatz der SWD für ein geographisches/ethnographisches Schlagwort (vgl. § 7,4).

- Indikator g (Angabe obligatorisch bei allen geographischen/ethnographischen Schlagwörtern, vgl. $\S \S 201,2 ; 212)$ 
- geographisches/ethnographisches Schlagwort in Ansetzungsform (Angabe obligatorisch, vgl. $\S \S 202,1 ; 212 \mathrm{a})$

- GKD-Nummer (Angabe obligatorisch, vgl. § 202,2) bzw. Alternativform nach RAK (Angabe fakultativ)

- Quelle (Angabe obligatorisch, vgl. § 19,1)

- Definition (Angabe fakultativ, vgl. § 19,2)

- Verwendungshinweis (Angabe fakultativ, vgl. § 19,3)

- Redaktionelle Bemerkung (Angabe fakultativ, vgl. § 19,4)

- Notation (Angabe bei Geographika, die sachlich zugeordnet werden können, vgl. § 18,1)

- Ländercode (Angabe obligatorisch, vgl. § 18,2)

- Zeitcode (Angabe fakultativ, vgl. §§ 18,4; 418)

- Synonymie-Verweisungen (vgl. $\S \S 12,2 ; 202,2 ; 212 b, 1)$, ggf. mit Bemerkung, eingeleitet durch *

- Oberbegriffe

- ein in der SWD enthaltenes begrifflich übergeordnetes Schlagwort (vgl. §§ 12,3; 203,3,c; 205,1,e; 205,2; 209a,2-6; 210,2+4; 212b,2,a), ggf. mit Bemerkung, eingeleitet durch *

- mehrgliedriger Oberbegriff in Form einer Schlagwortkette (vgl. $\S 12,4 ; 209 a, 3)$, ggf. mit Bemerkung, eingeleitet durch *

- Unterbegriffe

- Verwandte Begriffe (vgl. $\S \S 12,5 ; 202,6 ; 212 b, 2, b)$

- Chronologische Beziehungen (vgl. §§ 12,7; 206; 207; 209)

- frühere Namensform, ggf. mit Bemerkung, eingeleitet durch *

- spätere Namensform, ggf. mit Bemerkung, eingeleitet durch *

SW g Türkei

GKD 35434-X Türkiye

Q $\quad$ M, B 1986

H Verwendet ab 1923 und bei Gesamtdarstellungen

LC XB-TR

BF g Türkiye Cumhuriyeti *B 1986, GKD

VB g Türken

CF früher g Osmanisches Reich

SW g Copper-Eskimo

Q $\quad$ B 1986 und M unter Eskimo

D Eskimogruppe an der Nordküste des kanadischen Festlands

LC XD-CA

BF $\quad$ g Kupfer-Eskimo *Lindig Indianer

BF $\quad$ g Copper Inuit *Vorlage

BF g Copper-Inuit

OB g Eskimo

\section{$\S \S 214$ - 216 entfallen}




\section{Verknüpfung und Permutation}

\section{§ 217 Das geographische/ethnographische Schlagwort in der Grundkette}

Zur Stellung des geographischen/ethnographischen Schlagwortes in der Grundkette vgl. § 15.

\section{§ 218 Verknüpfung mehrerer geographischer/ethnographischer Schlagwörter}

Anm.: Im Folgenden sind Permutationsmuster nach $\S 220$ angegeben.

1. Hat ein Dokument Vergleiche oder Beziehungen zwischen zwei oder mehreren Geographika/Ethnographika zum Thema, so werden sie in einer Schlagwortkette verknüpft (vgl. § 13). Dabei wird eine sinnvolle Reihenfolge gewählt. Sind mehrere Reihenfolgen gleich sinnvoll, so kann alphabetisch geordnet werden (vgl. §§ 13,2; 15,2).

Titel: Deux siècles de relations hispano-francaises. - 1987

SWW g Frankreich ; g Spanien ; z Geschichte 1460-1700

(213)

2. Damit zu verknüpfende Personen-, Sach- oder Zeitschlagwörter werden dabei dem geographischen/ethnographischen Schlagwort zugeordnet, zu dem sie gehören (vgl. § 15,5).

Titel: Deutsche Militärpolitik und schwedische Neutralität : 1939-1942 / Hans-Jürgen Lutzhöft. - 1981

SWW g Deutschland ; s Militärpolitik; g Schweden ; s Neutralität ; z Geschichte 1939-1942 (21345) (34125) (43125)

Ein Personen-, Sach- oder Zeitschlagwort, das zu mehreren geographischen/ethnographischen Schlagwörtern gehört, wird dem ersten zugeordnet (vgl. § 15,5). Das gilt auch im Fall von Überschneidungsgebieten (vgl. § 205,3).

Titel: $\quad \neg$ The $\neg$ United States and Canada : the quest for free trade / Paul Wonnacott. - 1987

SWW g Kanada; s Freihandel;g USA

(213) (321)

Titel: $\quad \neg$ The $\neg$ Maasai and the state / Kaj Arhem. - 1985

SWW g Tansania; s Entwicklungsplanung; g Massai (213) (321)

\section{$\S 219$ Verknüpfung eines geographischen/ethnographischen Schlagworts mit Schlagwörtern anderer Kategorien}

Anm.: Im Folgenden sind Permutationsmuster nach $\S 220$ angegeben.

1. Geographische/ethnographische Schlagwörter folgen in der Grundkette den Personenschlagwörtern, gehen aber den Sach-, Zeit- und Formschlagwörtern voran (vgl. § 15,4).

Titel: $\quad$ Keynes, the Treasury and British economic policy / by G. C. Peden. - 1988

SWW p Keynes, John Maynard ; g Großbritannien ; s Wirtschaftspolitik ; z Geschichte 1918-1945

(2314) (3214) 
2. Bei einem Vergleich oder der Darstellung von Beziehungen in einer Schlagwortkette mit einem geographischen/ethnographischen Schlagwort werden Sach- und ggf. Zeitschlagwörter dem Schlagwort zugeordnet, zu dem sie gehören (vgl. § 15,9).

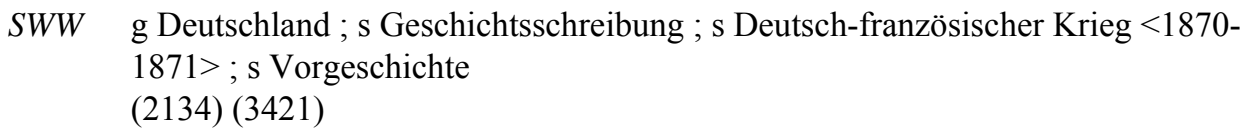

3. Zur Verknüpfung eines geographischen/ethnographischen Schlagworts mit einer Epochenbebezeichnung vgl. § 410, mit einem historischen Einzelereignis vgl. § 416, mit einer Körperschaft vgl. $\S 622$.

\section{$\S 220$ Permutation}

Für Listenfunktionen können die Glieder einer Grundkette mit geographischem/ethnographischem Schlagwort permutiert werden. In diesen Fällen gilt:

1. Bei der Permutation wird gemäß den Schemata von $\S 15,10$,d verfahren. Teilketten bleiben dabei erhalten und permutieren in sich.

2. Bei einem oder mehreren geographischen/ethnographischen Schlagwörtern in der Grundkette erhält jedes eine Eintragung (vgl. § 218).

3. Das gilt auch für eine Grundkette aus geographischem/ethnographischem Schlagwort und einem oder mehreren Personenschlagwörtern (vgl. Beispiele § 116,2,b).

4. a) Aussagekräftige Sachschlagwörter werden in einer Grundkette mit geographischem/ethnographischem Schlagwort ebenfalls permutiert (vgl. § 219).

b) Die Permutation unterbleibt bei folgenden Sachschlagwörtern. (Vgl. auch $\S 15,4$; Anl. 5 bzw. entsprechende Hinweise beim jeweiligen Sachschlagwort in der SWD.)

$\begin{array}{ll}\text { Ausgrabung } & \text { Landeskunde } \\ \text { Außenpolitik } & \text { Natur } \\ \text { Funde } & \text { Pflanzen } \\ \text { Geographie } & \text { Politik } \\ \text { Heimatkunde } & \text { Recht } \\ \text { Innenpolitik } & \text { Tiere } \\ \text { Kultur } & \text { Wirtschaft } \\ \text { Kunst } & \end{array}$

In Verbindung mit einem weiteren aussagekräftigen Sachschlagwort oder bei Verknüpfung von zwei Sachschlagwörtern aus der obigen Liste werden jedoch beide permutiert. (Vgl. aber $\S 701,5$,a und $\S 703,1$,a.)

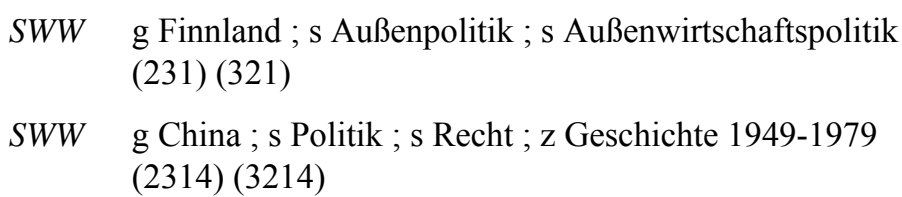


Präkombinierte Sachschlagwörter mit den in der Liste genannten Begriffen werden ebenfalls permutiert.

SWW g Langobarden; s Eherecht

(21)

SWW g Großbritannien ; s Historische Geographie

(21)

5. Zeit- und Formschlagwörter werden nicht permutiert (vgl. § 15,10,d,1 und 2).

\section{$\S \S 221$ - 232 entfallen}





\section{Sachschlagwörter}

\section{Definition und Verwendung}

\section{§ 301 Definition}

Als Sachschlagwörter gelten Bezeichnungen für Allgemeinbegriffe und Individualbegriffe (zu Individualnamen vgl. § 306a). Sachschlagwörter erhalten in der SWD i. d. R. den Indikator s. Titel von Werken erhalten den Indikator t (vgl. §§ 707-708).

Anm.: Allgemeinbegriffe, die zu den Geographika zählen, vgl. § 201,1,d, Zeitschlagwörter vgl. §§ 405, 408-409, Formschlagwörter vgl. §§ 501ff., Individualnamen von Personen vgl. §§ 101ff., geographische/ethnographische Namen vgl. §§ 201ff., historische Einzelereignisse vgl. § 415, Körperschaften vgl. §§ 601ff., Sprachbezeichnungen vgl. § 701.

\section{Ansetzung}

\section{$\S 302$ Rechtschreibung}

1. Allgemeines

Für die Rechtschreibung gilt $\S 16$, soweit nicht im Folgenden andere Bestimmungen getroffen werden. Gebräuchliche Schreibvarianten werden als Synonyme erfasst (vgl. § 16,2).

Anm.: Das gilt auch für nach der Rechtschreibreform alternativ zugelassene Schreibungen. Ist die bisherige Schreibung eines Schlagworts als Alternative zugelassen, so wird diese als Ansetzungsform beibehalten; die neue Form wird als Synonym erfasst.

Die Schreibweise sollte im Stammwort und in allen Komposita einheitlich sein. Ist dies nicht möglich, muss bei abweichenden Komposita jeweils von der dem Stammwort entsprechenden Schreibung verwiesen werden. Das gilt auch bei Sachschlagwörtern, die von Individualnamen abgeleitet sind.

$\begin{array}{ll}S W & \text { Klipper } \\ B F & \text { Clipper } \\ S W & \text { Carcinogenität } \\ B F & \text { Karzinogenität } \\ S W & \text { Cytologie } \\ B F & \text { Zytologie } \\ S W & \text { Photographie } \\ B F & \text { Fotografie } \\ S W & \text { Wolhynisches Fieber } \\ B F & \text { Wolynisches Fieber }\end{array}$


2. Groß- und Kleinschreibung

a) Sachschlagwörter werden i. d. R. mit großem Anfangsbuchstaben geschrieben. Abweichend davon klein geschrieben werden einzelne Substantive und substantivierte Wörter aus Sprachen, Sprachstufen oder Mundarten mit Kleinschreibung der Substantive, sowie nichtsubstantivische Wörter und Wortteile, die als Gegenstand sprach- oder begriffsgeschichtlicher Untersuchungen angesetzt werden (vgl. § 305,1,c).

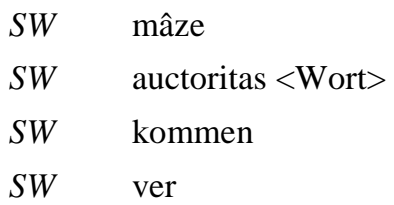

b) In präkombinierten Sachschlagwörtern, also Komposita, Adjektiv-Substantiv-Verbindungen, Schlagwörtern mit Homonymenzusatz und Wortfolgen, wird das erste Wort mit großem Anfangsbuchstaben geschrieben; für die folgenden Wörter gelten die Rechtschreibregeln der deutschen Sprache, d. h. bei präkombinierten Bezeichnungen mit fremdsprachigen Bestandteilen gilt für Substantive Großschreibung. Für feststehende fremdsprachige Redewendungen im Sinne eines Zitats gelten jedoch weiterhin die Rechtschreibregeln der betreffenden Sprache.

$\begin{array}{ll}S W & \text { Captatio Benevolentiae } \\ S W & \text { Lettre de Cachet } \\ \text { SW } & \text { Modern Dance } \\ S W & \text { Information Retrieval } \\ S W & \text { Self-consistent Field } \\ \text { SW } & \text { Methode der kleinsten Quadrate } \\ \text { Aber: } & \\ \text { SW } & \text { In dubio pro reo }\end{array}$

3. Schreibung von Abkürzungen

Die Schreibung von Abkürzungen richtet sich nach den Nachschlagewerken; wenn sie dort nicht nachweisbar sind, werden sie nach der Vorlage geschrieben.

$\begin{array}{ll}S W & \text { ABC-Waffen } \\ S W & \text { GmbH } \\ S W & \text { Radar } \\ S W & \text { Hi-Fi }\end{array}$

4. Bindestrich in Komposita

Komposita werden i. d. R. ohne Bindestrich in einem Wort geschrieben. Mit Bindestrich werden jedoch i. d. R. geschrieben

- Komposita mit fremdsprachigen Bestandteilen

$\begin{array}{lll}\text { SW } & \text { Break-even-Analyse } \\ \text { SW } & \text { Maximum-Likelihood-Schätzung } \\ \text { Aber: } & & \\ \text { SW } & \text { Campingplatz } & \text { (nach Duden) } \\ \text { SW } & \text { Dumpingpreis } & \text { (nach Duden) }\end{array}$


- Komposita, deren Elemente Gegensätzlichkeit bezeichnen

$\begin{array}{ll}S W & \text { Minimum-Maximum-Prinzip } \\ S W & \text { Rechts-links-Shunt } \\ \text { SW } & \text { Ost-West-Konflikt }\end{array}$

- Komposita mit unübersichtlichen Aneinanderreihungen, z. B. ein Grundwort mit mehreren Bestimmungswörtern

$\begin{array}{ll}S W & \text { Hals-Nasen-Ohren-Heilkunde } \\ \text { SW } & \text { Ein-Maschinen-Reihenfolgeproblem }\end{array}$

- Komposita, die mit einem Personennamen beginnen

SW Lorentz-Gruppe

SW Geiger-Müller-Zählrohr

Aber:

SW Dieselmotor (gemäß Nachschlagewerk)

Stets mit Bindestrich geschrieben werden Komposita, die Abkürzungen oder einzelne bedeutungstragende Buchstaben enthalten.

$\begin{array}{ll}S W & \text { pk-Wert } \\ S W & \text { UKW-Antenne } \\ S W & \text { K-Theorie } \\ S W & \text { Zungen-R }\end{array}$

Bei fremdsprachigen Komposita gelten die Bindestrichregeln der deutschen Sprache. Die Form der Fremdsprache mit oder ohne Bindestrich wird als Synonym erfasst.

$\begin{array}{lll}S W & \text { Sciencefiction } & \text { (nach Duden) } \\ B F & \text { Science Fiction } & \\ B F & \text { Science-Fiction } & \\ & & \\ S W & \text { Offshore-Banking } & \text { (nach Gabler Bank) } \\ B F & \text { Offshore Banking } & \\ B F & \text { Offshorebanking } & \end{array}$

Anm.: Für die Wahl der Ansetzung werden die jeweils neuesten Ausgaben der Duden in folgender Reihenfolge konsultiert:

1. Duden, Das große Wörterbuch der deutschen Sprache (Du.)

2. Duden, Die deutsche Rechtschreibung (Du. Rechtschreibung)

3. Duden, Fremdwörterbuch (Du. Fremdwörter)

\section{§ 303 Singular oder Plural}

1. Das Sachschlagwort wird grundsätzlich im Singular angesetzt.

$\begin{array}{ll}S W & \text { Kind } \\ \text { SW } & \text { Kopfschmerz } \\ \text { SW } & \text { Ulan }\end{array}$




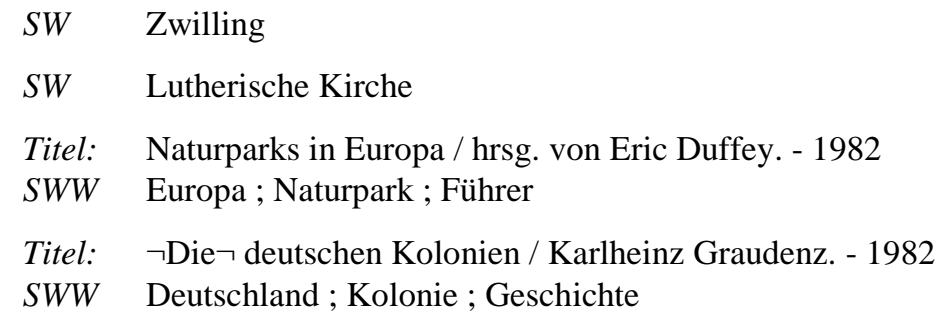

2. Folgende Sachschlagwörter werden im Plural angesetzt:

a) Pluraliatantum, Quasipluraliatantum (Bezeichnungen, die nicht oder so gut wie nicht im Singular verwendet werden) sowie Bezeichnungen, die im allgemeinen und fachlichen Sprachgebrauch einheitlich im Plural nachweisbar sind, z. B. weil sie aus einer genau definierten Anzahl von Gegenständen bestehen.

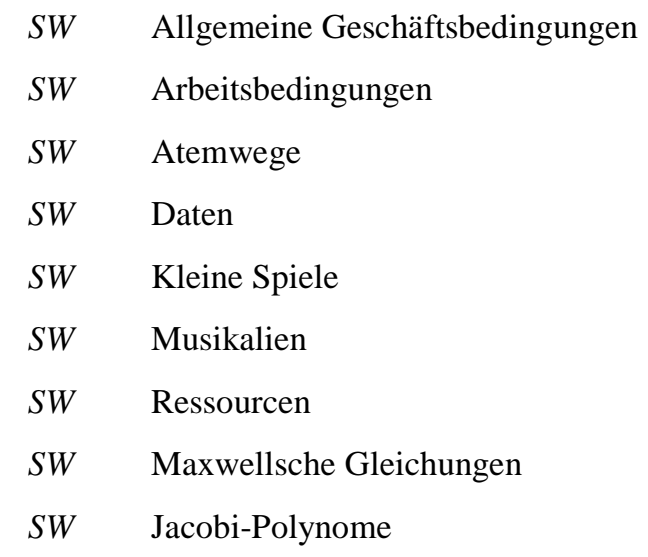

b) Namen der systematischen Botanik und Zoologie, soweit sie zu den systematischen Einheiten Reich bis Tribus gehören (d. h. oberhalb der Gattungen).

$\begin{array}{lll}\text { SW } & \text { Rosenpflanzen } & \text { (Ordnung) } \\ \text { SW } & \text { Rosengewächse } & \text { (Familie) } \\ \text { Aber: } & & \\ \text { SW } & \text { Rose } & \text { (Gattung) } \\ \text { SW } & \text { Heckenrose } & (\text { Art })\end{array}$

Wenn Gattung, Art und Familie bzw. Unterfamilie gleich benannt sind, werden die Homonymenzusätze $<$ Gattung $>$, $<$ Familie $>$ bzw. $<$ Unterfamilie $>$ hinzugefügt. Bei den Arten als dem häufigsten Fall entfällt der Homonymenzusatz.
SW $\quad$ Pferde $<$ Familie $>$
SW $\quad$ Pferd <Gattung $>$
SW Pferd

(Art)

Wird die taxonomische Einheit im Plural angesetzt, dann sind auch die entsprechenden Grundwörter in präkombinierten Schlagwörtern im Plural anzusetzen.
SW Pflanzen
SW Baumschulpflanzen
SW Bedrohte Pflanzen 
SW Fische

SW Fossile Fische

SW Aquarienfische

SW Vögel

SW Zugvögel

Aber:

SW Vogelzug (anderes Grundwort)

c) die chemischen und biochemischen Gruppenbezeichnungen, die der internationalen Nomenklatur unterliegen (auch Stoffgruppen, die in Medizin oder Technik benutzt werden), sowie Bezeichnungen von Mineralgruppen.

$\begin{array}{ll}S W & \text { Alkene } \\ S W & \text { Lipide } \\ S W & \text { Kohlenwasserstoffe } \\ S W & \text { Wolframate } \\ S W & \text { Decarboxylasen } \\ S W & \text { Polymere } \\ S W & \text { Interleukine }\end{array}$

Dagegen werden Substanzen, die auch außerhalb der Chemie und der Biowissenschaften bzw. in den angewandten Disziplinen gebraucht werden, sowie Gesteine mit dem Singular bezeichnet.

$\begin{array}{ll}S W & \text { Metall } \\ S W & \text { Nichteisenmetall } \\ S W & \text { Kunststoff } \\ S W & \text { Salz } \\ S W & \text { Säure } \\ S W & \text { Enzym } \\ S W & \text { Neuroleptikum } \\ S W & \text { Basalt } \\ S W & \text { Quarzit }\end{array}$

d) die lateinische Nomenklatur der Anatomie, soweit sie im Plural gebräuchlich ist.

SW Arteriae bronchiales

e) Bezeichnungen für Personengruppen (vgl. auch § 101) und Gruppen von historischen Einzelereignissen (vgl. § 415a,3). Zu Gruppen von Texten vgl. § 707; 708,2, zu Länderund Sprachgruppen vgl. § 201,1,g.

SW s Präraffaeliten

SW p Parzen （vgl. § 101,1)

SW s Kirchenväter 


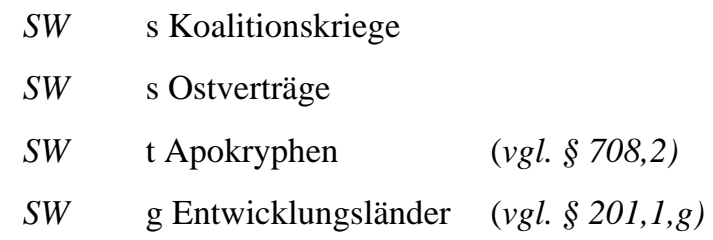

Für die Entscheidung zwischen Singular und Plural ist die Eintragung im „Duden“ maßgeblich.

f) zusammenfassende Bezeichnungen für mehrere Wissenschaftsdisziplinen.
SW Geisteswissenschaften
SW Ingenieurwissenschaften

3. Im Singular angesetzt werden auch solche Bezeichnungen, die im allgemeinen Sprachgebrauch überwiegend im Plural verwendet werden, bei denen jedoch auch das Einzelphänomen Gegenstand der Darstellung sein kann.

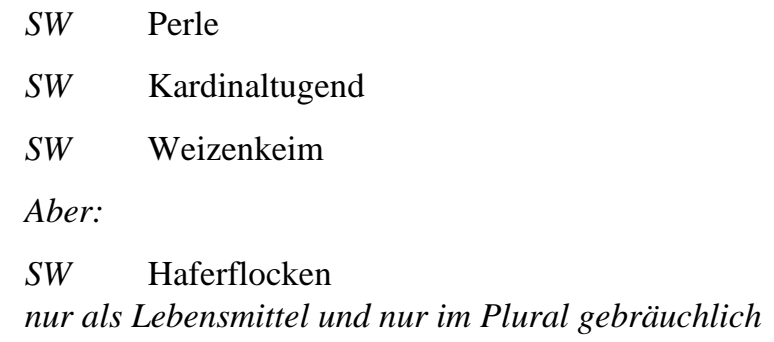

4. Plural und Singular eines Wortes dürfen i.d.R. nicht nebeneinander als Schlagwort vorkommen, ohne durch einen Homonymenzusatz gekennzeichnet zu sein.

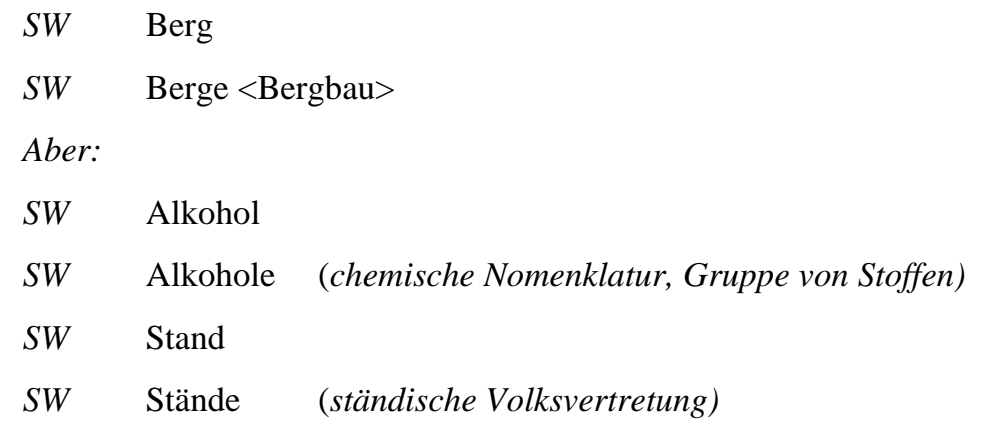

5. In allen Ausnahme- und Zweifelsfällen wird von der nicht gewählten Form verwiesen.

$\begin{array}{ll}S W & \text { Metallseife } \\ B F & \text { Metallseifen } \\ S W & \text { Sozialwissenschaften } \\ B F & \text { Sozialwissenschaft } \\ \text { SW } & \text { Hamilton-Gleichungen } \\ B F & \text { Hamilton-Gleichung } \\ \text { SW } & \text { Logograph } \\ B F & \text { Logographen }\end{array}$




\section{§ 303a Weibliche Form des Sachschlagworts}

1. Zur Bezeichnung weiblicher Personengruppen wird i.d.R. ein Wort mit femininer Endung (z.B. '-in') oder ein Kompositum mit '-frau' gewählt.

$\begin{array}{ll}\text { SW } & \text { Lehrerin } \\ \text { SW } & \text { Schülerin } \\ \text { SW } & \text { Türkin (vgl. § 212a,5) } \\ \text { SW } & \text { Souffleuse } \\ \text { SW } & \text { Hotelfachfrau }\end{array}$

2. Wenn das Femininum mit dem Plural verwechselt werden kann oder keine Femininform existiert, wird die Umschreibung mit 'weiblich' angesetzt.

SW Weibliche Abgeordnete

SW Weibliches Mitglied

3. Die männliche und weibliche Form eines Schlagworts werden immer durch eine assoziative Verweisung verbunden.

$\begin{array}{ll}\text { SW } & \text { Ausreißerin } \\ V B & \text { Ausreißer } \\ \text { SW } & \text { Molkereifachfrau } \\ V B & \text { Molkereifachmann } \\ \text { SW } & \text { Angestellter } \\ V B & \text { Weibliche Angestellte }\end{array}$

4. Zur Verwendung der weiblichen Bezeichnungen bei zusammenfassender Darstellung weiblicher und männlicher Personen vgl. § 316,4.

\section{§ 304 Wiedergabe von Allgemeinbegriffen durch Sachschlagwörter}

1. Grundlagen

a) Es gilt das Prinzip der Gebräuchlichkeit (vgl. § 9,3), eingeschränkt durch Normierungen und andere Festlegungen, die, dem Prinzip der syntaktischen Indexierung folgend, die Wiedergabe von Begriffen durch mehrere in einer Kette verknüpfte Schlagwörter erlauben, u.a. um so der postkoordinierenden Suche in Online-Katalogen zu entsprechen und die Voraussehbarkeit der einzelnen Schlagwörter zu erhöhen.

b) Gemäß §§ 4, 8 und 10 kann ein Begriff wiedergegeben werden

- durch ein einzelnes Schlagwort, das aus einem Lexem oder einer Kombination mehrerer Lexeme (präkombiniertes Schlagwort) bestehen kann,

- durch ein mehrgliedriges Schlagwort (beim Sachschlagwort nur im Bereich der Individualbegriffe),

- durch eine Verknüpfung mehrerer Schlagwörter, die zusammen den Begriffsinhalt präzise und möglichst unmissverständlich ausdrücken.

c) Bestehen Zweifel, ob bestimmte präkombinierte Bezeichnungen gebräuchlich oder für Erschließung und Retrieval praktikabel sind, so wird für Einzelbegriffe oder ganze Begriffskomplexe in SWD bzw. „Praxisregeln“ festgelegt, ob und wie Schlagwörter ange- 
setzt bzw. verknüpft werden. Die Fachterminologie in Natur-, Wirtschafts-, Sozial- und Geisteswissenschaften erfordert hierbei ein differenziertes Vorgehen. Es ist darauf zu achten, dass Festlegungen, die für bestimmte Bereiche sinnvoll sind, nicht in die gebräuchliche Terminologie anderer Disziplinen eingreifen.

d) In einem der Gebräuchlichkeit folgenden, multidisziplinär aufgebauten Vokabular ist es unvermeidlich, dass Normierungen nicht immer konsequent über den gesamten Wortschatz gelten können und präkombinierte Schlagwörter und zerlegte Begriffe nebeneinander vorkommen.

Anm.: Da bestimmte Regelungen erst sukzessive eingeführt wurden, müssen auch Inkonsequenzen in Kauf genommen werden, weil Änderungen nicht immer vollständig im vorhandenen Vokabular umgesetzt werden können.

2. Auswahl der Schlagwörter für neue Begriffsinhalte

a) Zunächst muss geprüft werden, ob es zur Wiedergabe des Begriffs eine gebräuchliche Bezeichnung gibt; hierbei wird nach § 9 verfahren. Für den Nachweis einer Bezeichnung in den Nachschlagewerken ist i.d.R. ein eigener Eintrag oder eine Hervorhebung innerhalb eines Lexikonartikels erforderlich. Bloße Erwähnung im laufenden Text genügt nur in Ausnahmefällen als alleiniger Nachweis, kann aber als zusätzliche Quelle zur Erläuterung in der SWD herangezogen werden. Gebräuchliche und treffende Bezeichnungen werden i.d.R. als Schlagwort gewählt.

b) Ist keine gebräuchliche Bezeichnung nachweisbar oder ist eine nachgewiesene Bezeichnung nicht praktikabel, nicht in die vorhandene Terminologie einzupassen oder soll sie aufgrund bestehender Regelungen nicht angesetzt werden, so wird der neue Begriff gemäß $\S 8,5$ durch eine Verknüpfung vorhandener Schlagwörter wiedergegeben (vgl. $\S 304,3)$.

c) Ist weder eine gebräuchliche Bezeichnung nachweisbar noch eine sinnvolle Verknüpfung möglich, so wird gemäß § 9,3 eine treffende Bezeichnung dem vorliegenden Dokument entnommen bzw. analog zu vorhandenen Schlagwörtern gemäß den Regeln modifiziert.

d) Mit Rücksicht auf die Homogenität der in der SWD vorhandenen Terminologie sind auch analoge Ansetzungen erlaubt. Die Fälle, in denen damit vom Prinzip der Orientierung an Nachschlagewerken abgewichen wird, sind in der SWD und in den „Praxisregeln“ festgelegt. Dies erlaubt

- die Zulassung analog gebildeter präkombinierter Schlagwörter durch Regelungen für geschlossene Begriffskomplexe oder aber für einzelne Begriffe, die i.d.R. als letzter Bestandteil (Grundwort) von Komposita bzw. als Substantiv, dem Adjektive vorangestellt werden, vorkommen.

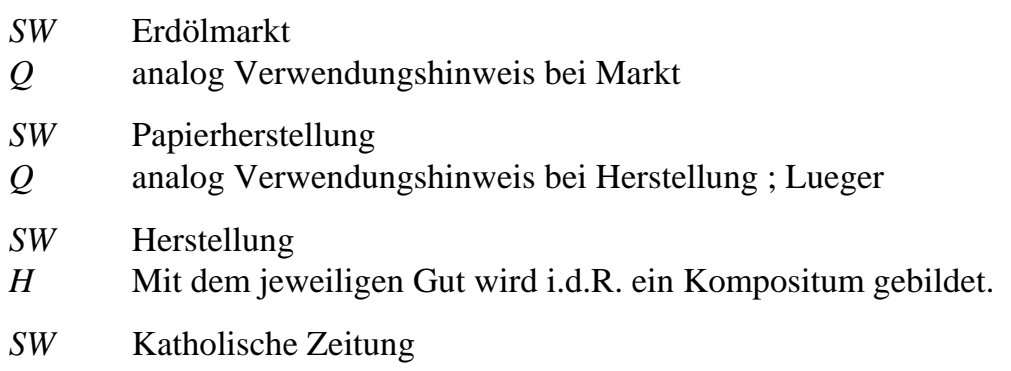

- die Zerlegung nachgewiesener Komposita, um Einheitlichkeit innerhalb eines Komplexes analoger Fälle zu erreichen (z.B. in Naturwissenschaften und Technik, wo Bezeichnungen für Materialien und Stoffe beteiligt sind). In diesen Fällen wird i.d.R. der 
Sucheinstieg vom Kompositum als Hinweissatz in der SWD verankert, wenn die nicht als Schlagwort gewählte präkombinierte Form in einem Nachschlagewerk nachgewiesen ist.

SWW Verbundträger; Stahl

Hinweissatz, gekennzeichnet in MAB Feld 067

$B F \quad$ Stahlverbundträger

SWW Eisen ; Schwefel ; Bor ; Clusterverbindungen

nicht: Bor-Eisen-Schwefel-Cluster

- die Begrenzung analoger Präkombination durch Einzelfallregelungen in der SWD, indem wenige zugelassene präkombinierte Schlagwörter mit engeren Bezeichnungen verknüpft werden.

SWW Katholisches Krankenhaus ; Kinderkrankenhaus

nicht: Katholisches Kinderkrankenhaus

SWW Plastik; Christliche Kunst

nicht: Christliche Plastik

SWW Fische ; Bedrohte Tiere

nicht: Bedrohte Fische

SWW Kohlenwasserstoffe ; Flüchtiger Stoff

nicht: Flüchtige Kohlenwasserstoffe

SWW Wintergerste ; Gerstensorte

nicht: Wintergerstensorte

3. Wiedergabe von Allgemeinbegriffen durch Verknüpfung von Sachschlagwörtern (Begriffszerlegung)

Abgesehen von den grundsätzlichen Voraussetzungen (vgl. § 304,1 und 2) wird eine Verknüpfung mehrerer Schlagwörter zur Wiedergabe eines Begriffs bevorzugt,

- wenn es keine gebräuchliche Bezeichnung als Einzelschlagwort gibt,

SWW Analysis; Mathematikunterricht

nicht: Analysisunterricht

- wenn nur eine extrem lange präkombinierte Form möglich wäre (vgl. § 305,2,b),

SWW Kindergarten ; Bedarfsplanung

nicht: Kindergartenbedarfsplanung

- wenn trotz Nachweis einzelner präkombinierter Bezeichnungen die Wiedergabe als Schlagwortkette unter Berücksichtigung analoger Fälle deutlich bessere, mit den vorhandenen Katalogdaten konsistente Sucheinstiege bietet.

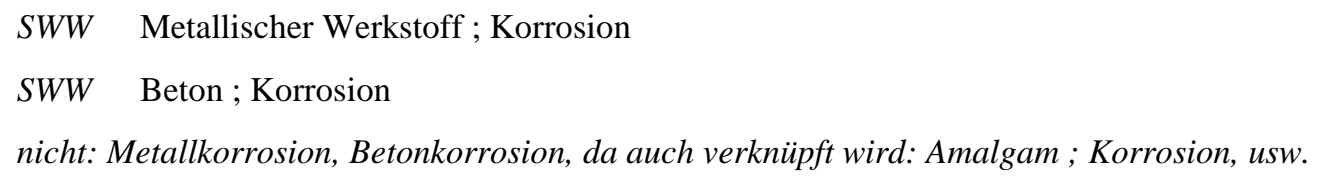

4. Grenzen der Begriffszerlegung

Abgesehen von den grundsätzlichen Voraussetzungen (vgl. § 304,1 und 2) ist die Verknüpfung mehrerer Schlagwörter zur Wiedergabe eines Begriffs jedoch nur dann möglich, wenn alle einzelnen Elemente nach den Regeln angesetzt sind und zusammen den Begriffsinhalt 
adäquat und möglichst unmissverständlich ausdrücken. In folgenden Fällen kann daher eine präkombinierte Bezeichnung nicht durch eine Schlagwortkette ersetzt werden:

- Eine nur morphologische, aber semantisch falsche Zerlegung unterbleibt, wenn ein Bestandteil für sich allein eine andere Bedeutung hat.

SW Computervirus

Computer; Viren wäre semantisch falsch.

SW Kraftfahrzeugbeleuchtung

SW Beleuchtung wird i. d. R. für Räume benutzt, wäre in Verknüpfung mit SW Kraftfahrzeug irrefuihrend.

SW Publikumszeitschrift

Publikum ; Zeitschrift wäre semantisch falsch.

SW Materialfluss

nicht zerlegbar in Material; Fluss, da das SW Fluss eine andere Bedeutung hat.

- Eine Zerlegung in nicht aussagekräftige Bezeichnungen oder Allgemeinwörter ohne selbständigen Suchwert bzw. ohne Nähe zum dargestellten Begriff unterbleibt.

SW Informationssystem

SW System ist zu allgemein.

- Eine Zerlegung unterbleibt, wenn die mögliche Schlagwortkette auch eine andere Bedeutung ergeben kann und für die Erschließung von Dokumenten mit anderen Sachverhalten benötigt wird (vgl. § 305,2,e).

SW Kinderkrankheit

nicht zerlegbar in SWW Kind ; Krankheit

SW Glücksspiel

Benutzt für Spiele, die durch Zufall bzw. Glück entschieden werden; SWW Glück ; Spiel wären zu verknüpfen für „, Glück im Spiel“.

SW Kanadaforschung

Die SWW Kanada ; Forschung wären zu verknüpfen für 'Forschung in Kanada'

- Die Zahl der zu verknüpfenden Schlagwörter für einen Begriff sollte nur ausnahmsweise mehr als zwei betragen (vgl. auch § 305,2,b).

SWW Arzneimittel ; Versicherungsleistung ; Festbetrag

nicht: Arzneimittelfestbetrag

5. Synonymie-Verweisungen bei präkombinierten Schlagwörtern

Wird eine präkombinierte Form Schlagwort, so werden semantisch äquivalente Verknüpfungen mehrerer Schlagwörter als Synonyme erfasst. Dabei werden die gleichen spezifischen Bezeichnungen verwendet, die gemäß § 324 für eine Schlagwortkette zu wählen wären. Auch die Verknüpfung mit dem als Ergebnis einer morphologischen Zerlegung ermittelten Oberbegriff, der auch als Sucheinstieg zu erwarten ist, wird erfasst, wenn sie semantisch äquivalent ist.

$\begin{array}{ll}S W & \text { Spirituosenhandel } \\ B F & \text { Spirituosen / Getränkehandel } \\ & \text { Spirituosen / Handel } \\ O B & \text { Getränkehandel }\end{array}$


SW Ärztlicher Kunstfehler

BF Arzt / Kunstfehler

Ärztliche Behandlung / Fehler

SW Drittmittelforschung

$B F \quad$ Drittmittel / Forschung

$O B \quad$ Forschung

\section{§ 305 Lexikalische Form}

1. Das Sachschlagwort kann aus allen einfachen Wörtern bestehen.

a) einfache Substantive, substantivierte Verben und substantivierte Adjektive der deutschen Sprache

$\begin{array}{ll}\text { SW } & \text { Philosophie } \\ \text { SW } & \text { Hepatitis } \\ \text { SW } & \text { Gesellschaft } \\ \text { SW } & \text { Hund } \\ \text { SW } & \text { Beamter }\end{array}$

Substantivierte Verben werden nur benutzt, soweit es kein eindeutiges entsprechendes Substantiv gibt oder es sich um fachsprachlich gebräuchliche Termini handelt bzw. die Bezeichnung für einen Vorgang von der Bezeichnung für ein Ergebnis unterschieden werden soll.

\begin{tabular}{|c|c|}
\hline$S W$ & Lesen \\
\hline$S W$ & Lernen \\
\hline$S W$ & Löten \\
\hline SW & Sticken \\
\hline SW & Stickerei \\
\hline$S W$ & Umformen \\
\hline$B F$ & Umformung \\
\hline
\end{tabular}

Substantivierte Adjektive werden mit bestimmtem Artikel angesetzt, der als Suchwort übergangen wird.

$$
\begin{array}{ll}
\text { SW } & \neg \text { Das } \neg \text { Gute } \\
\text { SW } & \neg \text { Das } \neg \text { Heilige }
\end{array}
$$

Substantivische Verbaladjektive und Partizipien werden ohne bestimmten Artikel angesetzt.

SW Ungeborenes

b) Zahlwörter (vgl. § 17)

Wenn Zahlwörter selbst Gegenstand einer Untersuchung sind oder mit einem Sachschlagwort eine feste Verbindung bilden, werden sie in aufgelöster Form angesetzt.

SW Fünf

z.B. SWW Fünf ; Märchen 

SW Drei Könige
SW Zweiter Bildungsweg
SW Sieben Weltwunder

Ziffern, die lediglich der Zählung gleichartiger Sachschlagwörter dienen, werden mit Spatium nachgestellt. (Vgl. § 17,2,d; zu Ziffern in Formeln vgl. § 314, in Eigennamen von Produkten vgl. § 306a,3.)
SW Sekundarstufe 2
SW Homotopiegruppe 2
SW Satz 4

c) Buchstaben, Morpheme und Wörter als Gegenstand linguistischer Untersuchungen

Schlagwörter dieses Typs bezeichnen weder Allgemein- noch Individualbegriffe, sondern innersprachliche Phänomene. Alle Wortarten, Wortgruppen, Morpheme und Lautzeichen aus allen Sprachen, Sprachgruppen, Sprachstufen und Mundarten können als Sachschlagwörter angesetzt werden, wenn sie Gegenstand linguistischer Untersuchungen sind. Dabei treten die Sprachbezeichnung und die Bezeichnung für die genaue Wort- bzw. Morphemart bzw. Schlagwörter wie 'Wortfeld' oder 'Wortfamilie', bei Lauten die Schlagwörter 'Phonetik' bzw. 'Phonologie', in der Kette hinzu.

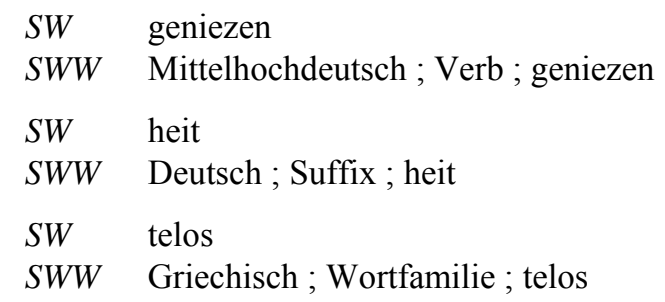

Statt substantivierter Formen werden die ursprünglichen Wortarten verwendet. Anstelle substantivischer Fremdwörter des Neuhochdeutschen werden die originalsprachigen Bezeichnungen benutzt.

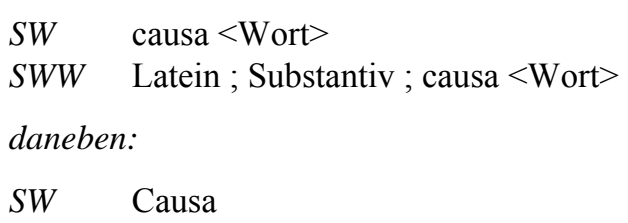

Bindestriche entfallen bei der Ansetzung, sofern sie keine Laute repräsentieren; Asterisken entfallen stets. Alle anderen diakritischen Zeichen und Akzente werden jedoch angesetzt.

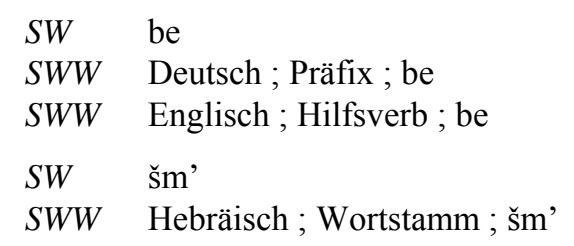

Bei Homonymie zu Individualnamen und Allgemeinbegriffen erhalten aus Buchstabenfolgen bestehende Wörter immer den Homomymenzusatz $<$ Wort $>$, Wortelemente den Homonymenzusatz $<$ Morphem $>$ und Laute den Homonymenzusatz $<$ Phonem $>$. Als Homonyme gelten dabei auch Bezeichnungen, die sich nur in der Schreibweise (auch Groß-/ 
Kleinschreibung) oder in diakritischen Zeichen unterscheiden. Wörter und Allgemeinbegriffe mit gleicher Etymologie werden jedoch nicht unterschieden.

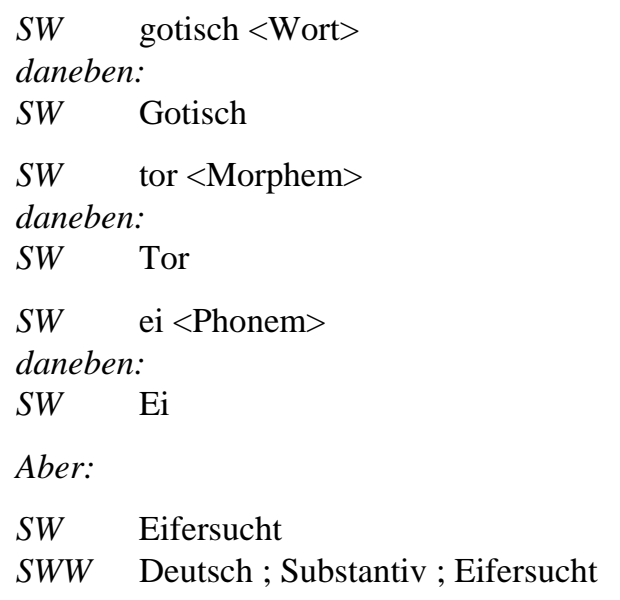

Einzelbuchstaben bleiben ohne Homonymenzusatz, auch wenn sie unterschiedliche Formen mit diakritischen Zeichen repräsentieren. Identische Buchstabenfolgen und Einzelbuchstaben werden nur einmal angesetzt und durch den Kontext in der Schlagwortkette identifiziert.

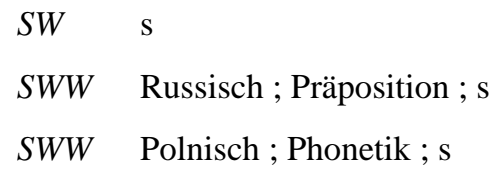

Bei Wortfeld- und Begriffsuntersuchungen wird das Archilexem (die Bezeichnung, die das Wortfeld oder den Begriff repräsentiert) bevorzugt in deutscher Sprache angegeben.

SWW Griechisch ; Wortfeld ; Schicksal

2. Sachschlagwörter können außerdem präkombinierte Bezeichnungen sein, nämlich

- Komposita

SW Musikerziehung

SW Hochtemperatursupraleiter

SW Bundestagswahl

SW Bayes-Verfahren

- Adjektiv-Substantiv-Verbindungen

Die invertierte Form wird weder als Ansetzungs- noch als Verweisungsform erfasst.

SW Medizinische Ethik

nicht: Ethik, medizinische

SW Partielle Differentialgleichung

nicht: Differentialgleichung, partielle

- Schlagwörter mit Homonymenzusatz (vgl. §§ 306; 705)

SW $\quad$ Knoten $<$ Mathematik $>$

SW $\quad$ Fibel $<$ Gewandnadel $>$ 
- Wortfolgen

SW Diktatur des Proletariats

SW Kauf auf Probe

a) Finden sich mehrere gebräuchliche Bezeichnungen für den gleichen Begriff in unterschiedlicher Form, so gilt folgende Vorzugsreihenfolge:

1. Kompositum,

2. Adjektiv-Substantiv-Verbindung,

3. Schlagwort mit Homonymenzusatz,

4. Wortfolge.

Die ermittelten Formen, die nicht Schlagwort werden, sind als Synonyme zu erfassen.

$\begin{array}{ll}S W & \text { Mischverfassung } \\ B F & \text { Gemischte Verfassung } \\ \text { SW } & \text { Interessenverband } \\ B F & \text { Verband < Politik> } \\ \text { SW } & \text { Sprachliche Universalien } \\ \text { BF } & \text { Universalien < Linguistik }>\end{array}$

b) Präkombinierte Schlagwörter aus drei und mehr bedeutungstragenden Lexemen sollen nach Möglichkeit nur angesetzt werden, wenn sie in Nachschlagewerken nachgewiesen und nicht sinnvoll zerlegbar sind oder wenn nur diese Formen dem juristischen, offiziellen oder fachlichen Sprachgebrauch entsprechen.
SW Lineare partielle Differentialgleichung
SW Öffentlicher Personennahverkehr
SW Kostenträgererfolgsrechnung

c) Verkürzte Komposita werden in zwei voneinander getrennte Bezeichnungen aufgelöst, sofern jeder Bestandteil bei gleicher Bedeutung für sich stehen kann.

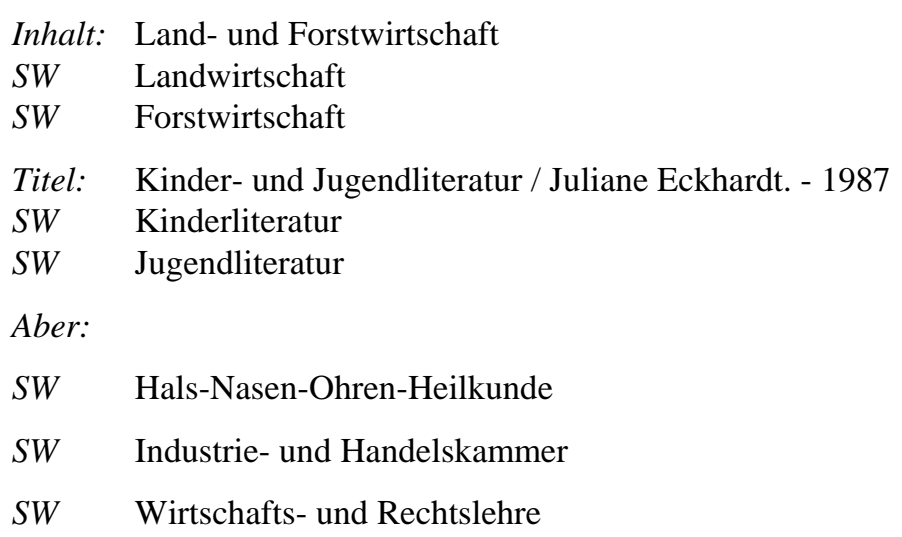

d) Präkombinierte Bezeichnungen, deren erster Teil ein Personenname ist, werden als Sachschlagwörter angesetzt, wenn sie in den Nachschlagewerken nachgewiesen sind. Sie sind z.B. in der Mathematik und anderen exakten Wissenschaften teils als Kompositum, teils als Adjektiv-Substantiv-Verbindung gebräuchlich. Hier wird i.d.R. das Kompositum bevorzugt, im Einzelfall auch gegen die Nachschlagewerke. Soweit möglich wird innerhalb eines Namens einheitlich verfahren. 
SW s Marienverehrung

Komposita aus Name und '-verehrung' werden jedoch nicht analog gebildet.

SW s Galois-Darstellung

BF s Galoissche Darstellung

SW s Hopf-Verzweigung

$B F \quad$ s Hopfsche Verzweigung

Aber:

SW $\quad$ s Noetherscher Ring

SW s Vernersches Gesetz

Werden Personennamen aus Sprachen mit nichtlateinischer Schrift Bestandteil präkombinierter Sachschlagwörter für Allgemeinbegriffe, so werden sie i.d.R. nach $\S \S 109$ und 110 angesetzt.

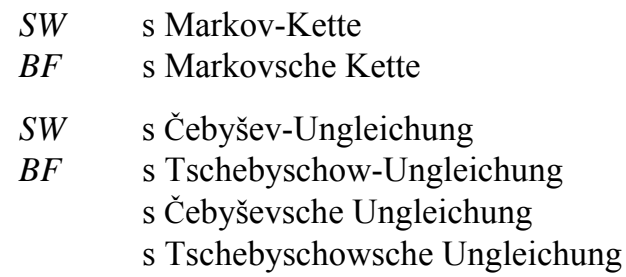

Bei Sachschlagwörtern, die mit einem Personennamen präkombiniert oder von ihm abgeleitet sind, kann das Personenschlagwort als verwandter Begriff erfasst werden (vgl. $\S 12,5, \mathrm{e})$.

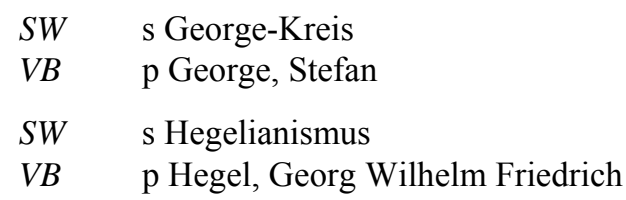

Schulen einzelner Künstler oder Wissenschaftler werden, wenn sie nicht als feste Verbindungen nachzuweisen sind, durch Verknüpfung des Personennamens mit Schlagwörtern wie 'Künstlerschule', 'Wissenschaftliche Schule' oder 'Umkreis' wiedergegeben.

SW s George-Kreis

SWW p Raffaello < Sanzio $>$; s Künstlerschule

e) Präkombinierte Bezeichnungen aus Sach- und geographischem/ethnographischem Schlagwort werden, teilweise abweichend von den Nachschlagewerken, nur angesetzt

- bei Individualnamen (vgl. § 306a)

SW s Meißener Porzellan

SW $\quad$ s Chicago-Schule $<$ Architektur $>$

- als Adjektiv-Substantiv-Verbindungen zur Bezeichnung von Volksgruppen im Ausland nach einer abgeschlossenen Liste von Substantiven, denen ein die ethnische Herkunft bzw. Nationalität bezeichnendes Adjektiv vorangestellt wird (vgl. § 212a,5):

Arbeitnehmer Junge

Ehefrau Kind und die Unterbegriffe wie Kleinkind, Vorschulkind, Säugling 


$\begin{array}{ll}\text { Ehemann } & \text { Kriegsgefangener } \\ \text { Einwanderer } & \text { Lehrer } \\ \text { Eltern } & \text { Mädchen } \\ \text { Familie } & \text { Schüler } \\ \text { Flüchtling } & \text { Soldat } \\ \text { Internierter } & \text { Student } \\ \text { Jugendlicher } & \text { Urlauber }\end{array}$

sowie ggf. die weiblichen Formen.

$$
\begin{array}{ll}
\text { SW } & \text { s Türkischer Schüler } \\
\text { SW } & \text { s Deutscher Urlauber } \\
\text { SW } & \text { s Italienischer Jugendlicher } \\
\text { nicht: } & \text { Italienische Jugend }
\end{array}
$$

Alle übrigen Bezeichnungen für Personen- und Berufsgruppen werden mit dem ethnographischen Schlagwort verknüpft.

SWW g USA ; s Schauspielerin; g Deutsche

- wenn der Begriff durch die Verknüpfung von geographischem/ethnographischem Schlagwort und Sachschlagwort nicht semantisch äquivalent ausgedrückt werden kann (vgl. $\S 304,4)$.

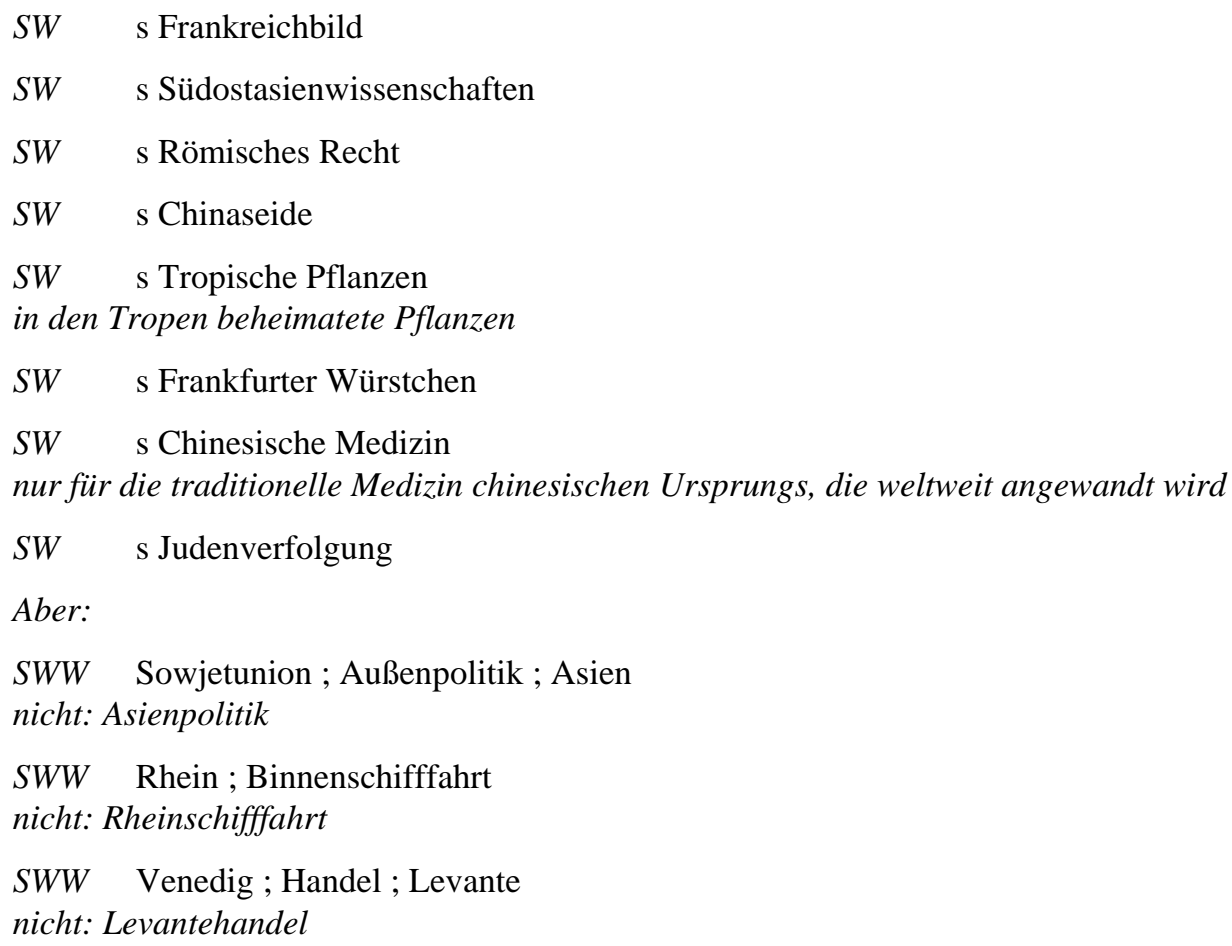

f) Präkombinierte Bezeichnungen aus Sachschlagwort und Namen von Körperschaften werden nur in Ausnahmefällen gebildet.

SW Bundestagswahl 
g) Sehr gebräuchliche präkombinierte Schlagwörter können auch dann gebildet werden, wenn der eine Bestandteil auch als Formschlagwort dient. I. d. R. wird jedoch in solchen Fällen ebenso verknüpft, wie dies zwischen Sach- und Formschlagwort geschieht. Als Formschlagwort sind präkombinierte Begriffe nur zulässig, soweit sie in Anl. 6 enthalten sind (vgl. § 502).

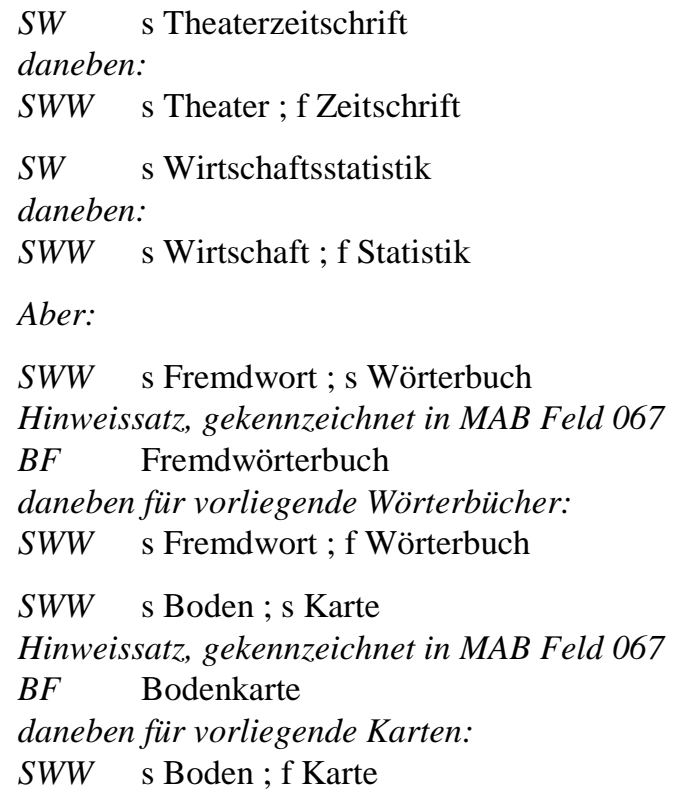

\section{§306 Homonyme}

1. Gleich lautende Sachschlagwörter (Homonyme, vgl. § 10) können sowohl Wörter verschiedenen Ursprungs sein, z. B. Ball (= Spielball) und Ball (= Tanzfest) als auch Wörter mit ursprünglich gleichem Bedeutungsinhalt, die in verschiedenen Sachgebieten unterschiedliche Bedeutungskomponenten entwickelt haben (Polyseme), z. B. Knie (= Teil des Beines) und Knie (= Teil eines Abflussrohres).

2. In manchen Fällen ist eine klare Unterscheidung von Homonym und Polysem nur mit Hilfe der historischen Linguistik möglich. Entscheidend für die Ansetzung ist daher der derzeitige Sprachgebrauch, wie er sich vor allem in der Bedeutungsdifferenzierung der Nachschlagewerke ausdrückt. Zum Zweck der Selektion, besonders in Online-Katalogen, ist es sinnvoll, ohne Rücksicht auf sprachhistorische Gegebenheiten Bedeutungsunterschiede zu kennzeichnen. Im Folgenden wird für gleich lautende Wörter mit mehreren Bedeutungen unterschiedslos die Bezeichnung Homonym verwendet.

3. Homonyme werden durch einen Homonymenzusatz in substantivischer, nicht abgekürzter Form unterschieden. Der Homonymenzusatz gibt i. d. R. das betreffende Fachgebiet an, muss aber so spezifisch gewählt werden, dass Verwechslungen mit anderen Homonymen ausgeschlossen sind.

$\begin{array}{ll}S W & \text { Entlastung }<\text { Psychologie }> \\ S W & \text { Entlastung }<\text { Recht }> \\ S W & \text { Entlastung }<\text { Technik }> \\ S W & \text { Entlastung }<\text { Raumordnung }> \\ S W & \text { Immunität }<\text { Medizin }> \\ S W & \text { Immunität }<\text { Recht }>\end{array}$



SW Versetzung < Arbeitsrecht $>$
$S W \quad$ Versetzung $<$ Beamtenrecht $>$
$S W \quad$ Versetzung $<$ Kristallographie $>$
$S W \quad$ Versetzung $<$ Pädagogik $>$

4. Bei Individualnamen besteht der Homonymenzusatz aus einem einschlägigen Sachschlagwort.

$\begin{array}{ll}S W & \text { Venus } \quad \text { (für die Göttin) } \\ S W & \text { Venus }<\text { Planet }> \\ S W & \text { Venus }<\text { Raumsonde }> \\ S W & \text { Lektor }<\text { Hochschule }> \\ S W & \text { Lektor }<\text { Liturgie }> \\ S W & \text { Lektor }<\text { Verlag }> \\ S W & \text { LEKTOR }<\text { Programmiersprache }>\end{array}$

5. Repräsentiert eines der Homonyme die Grundbedeutung bzw. ist es sehr viel gebräuchlicher als die anderen oder ist wesentlich mehr Literatur zu diesem Thema zu erwarten, so kann hier der Homonymenzusatz entfallen.

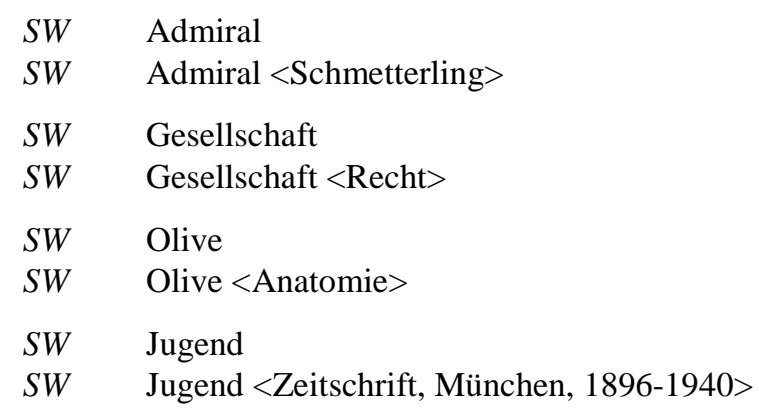

Sind Zweifel möglich, ob eines der Homonyme weit gebräuchlicher ist, so erhält auch dieses einen Homonymenzusatz.
SW $\quad$ Projektion $<$ Mathematik $>$
$S W \quad$ Projektion $<$ Optik $>$
$S W \quad$ Projektion $<$ Linguistik $>$
$S W \quad$ Projektion $<$ Psychologie $>$

Werden mit Homonymenzusatz versehene Bezeichnungen Bestandteil präkombinierter Schlagwörter, so entfällt der Homonymenzusatz.

$\begin{array}{ll}S W & \text { Schale }<\text { Gefäß> } \\ S W & \text { Holzschale } \\ S W & \text { Immunität }<\text { Recht }> \\ S W & \text { Staatenimmunität }\end{array}$

6. Homonyme sollen vermieden werden, wenn sie durch gebräuchliche Synonyme, i. d. R. in Form präkombinierter Schlagwörter, ersetzt werden können.

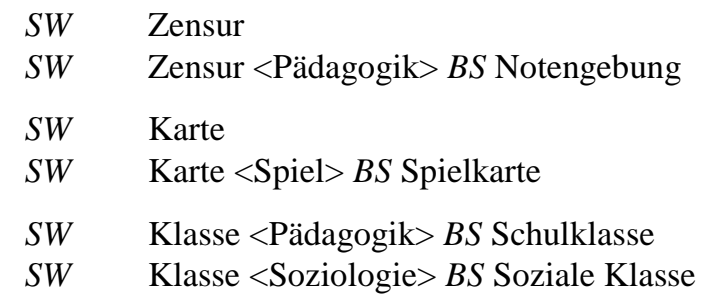


7. Bedeutungsunterschiede einer Bezeichnung je nach ihrer Verwendung in verschiedenen Fachsprachen oder in Allgemein- und Fachsprache können zwar für die Suche relevant sein, werden aber nicht immer durch Homonymenzusätze ausgedrückt, da sich sonst zahllose Varianten ergäben. Dies gilt besonders dann, wenn die ursprüngliche Bedeutung sich nicht grundlegend geändert hat oder der Bedeutungsunterschied so gering ist, dass er beim Sucheinstieg nicht zu falschen Ergebnissen führen kann. Die Eindeutigkeit der Bedeutung wird durch die Schlagwortkette hergestellt. In Online-Katalogen ist auch der Einsatz einer Klassifikation zur Trennung verschiedener Anwendungsgebiete möglich.

$\begin{array}{ll}\text { SWW } & \text { Präferenz; Außenhan } \\ \text { SWW } & \text { Musikhören ; Präfere } \\ \text { SWW } & \text { Präferenz ; Nachfrage } \\ \text { SWW } & \text { Präferenz; Konversation } \\ \text { SWW } & \text { Kanon; Literatur } \\ \text { SWW } & \text { Kanon; Neues Testan } \\ \text { SWW } & \text { Kanon; Konfuzianisn } \\ \text { Aber: } & \\ \text { SW } & \text { Kanon <Musik> } \\ \text { SW } & \text { Kanon < Hymnodie> } \\ \text { SWW } & \text { Utopie ; Literatur } \\ \text { SWW } & \text { Utopie ; Philosophie } \\ \text { SWW } & \text { Utopie ; Kunst }\end{array}$

In Zweifels- und Problemfällen, besonders wenn aufgrund großer Treffermengen Unübersichtlichkeit auch in der Anzeige von Schlagwortketten zu erwarten ist, sollten grundsätzlich Homonymenzusätze vergeben werden, um wichtige Bedeutungsvarianten auszugliedern, rascher erkennbar und zur Selektion relevanter Dokumente verwertbar zu machen, jedoch nur dann, wenn das Schlagwort kein unspezifisches Allgemeinwort, sondern eine fachsprachliche Bezeichnung ist.

$\begin{array}{ll}S W & \text { Morphologie (für die allgemeine Gestaltlehre) } \\ S W & \text { Morphologie }<\text { Linguistik }> \\ S W & \text { Morphologie }<\text { Biologie }> \\ S W & \text { Harmonie } \\ H & \text { Verknüpfe mit Anwendungsgebiet } \\ S W & \text { Harmonie }<\text { Musik }> \\ S W & \text { Montage } \quad \text { (für die Technik) } \\ S W & \text { Montage }<\text { Künste }> \\ S W W & \text { Montage }<\text { Künste }>\text {; Literatur } \\ S W W & \text { Montage }<\text { Künste }>\text {; Film }\end{array}$

8. Individualnamen in Form von Kunstwörtern oder Abkürzungen erhalten immer einen Homonymenzusatz, wenn sie sinntragenden Wörtern der gesprochenen Sprache (auch aus dem Englischen, Französischen oder Italienischen) bzw. gebräuchlichen Namen entsprechen.

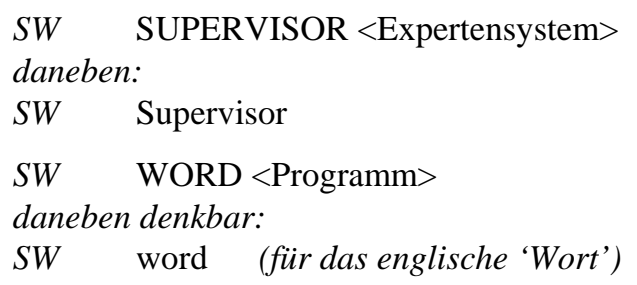


SW $\quad$ GISELA $<$ Datenbanksystem $>$

9. Homonymenzusätze dienen nicht der Erläuterung von Schlagwörtern, die, obwohl fachsprachlich eindeutig, alltagssprachlich missverständlich sein können. Solche Schlagwörter werden durch Definitionen bzw. Verwendungshinweise eindeutig gemacht.
SW Gemischtwirtschaftliche Betriebsweise
$D \quad$ Nur für die Landwirtschaft
kein Homonymenzusatz <Landwirtschaft>

\section{§ 306a Individualnamen}

1. Individualnamen, die weder Personennamen noch geographische/ethnographische Namen, Sprachbezeichnungen oder Körperschaftsnamen sind, werden als Sachschlagwörter behandelt.

Anm.: Zu historischen Einzelereignissen vgl. § 415; zu Werktiteln mit Indikator t vgl. § 708.

2. Individualnamen werden wie andere Eigennamen angesetzt, wenn sie den Gegenstand präzise beschreiben. Eine begriffliche Zerlegung in Allgemeinbegriffe ist i.d.R. ohne Verlust an Spezifität nicht möglich. Individualnamen sind z.B. alle Produktbezeichnungen, Namen von Auszeichnungen wie Preise und Ehrenzeichen, Wettbewerbe, Projekte, Forschungs- und Förderungsprogramme sowie die Namen politischer, künstlerischer u.a. Bewegungen, Geheimbünde, Sekten, Kasten, Künstler- und Schriftstellergruppen, soweit sie nicht Körperschaften im Sinn des Regelwerks, aber von solchen schwer abgrenzbar sind (vgl. aber § 306a,10).

3. Produkte werden mit ihrem Individualnamen (Produkt- oder Typenbezeichnung) angesetzt. Als Individualname gilt auch eine Kombination einzelner Buchstaben und Ziffern. (Zur Ansetzung von Ziffern vgl. § 17,2,c.) Der Marken- oder Firmenname mit der Typenbezeichnung als Zusatz kann als Synonym erfasst werden.

$\begin{array}{ll}\text { SW } & \text { Fieseler-Storch } \\ \text { SW } & \text { Boeing 737 } \\ \text { SW } & \text { Ju 88 } \\ \text { BF } & \text { Junkers Ju 88 }\end{array}$

Im Produktnamen kann eine andere Form des Firmennamens auftreten als im Schlagwort für die Firma selbst.

$\begin{array}{ll}\text { SW } & \text { CDC } 6600 \\ \text { SW } & \text { Control Data Corporation } \\ \text { BF } & \text { CDC }\end{array}$

Software- und Hardwareprodukte werden je nach offizieller Namensform groß oder klein geschrieben, im Zweifelsfall in Großbuchstaben.

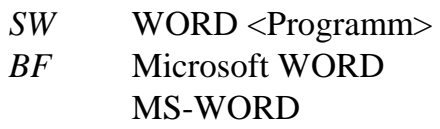

Verschiedene Versionen von Programmen werden entsprechend offizieller Zählung unterschieden. Die Grundform wird verwendet, wenn das Dokument sich auf mehrere oder alle Versionen bezieht. 
$\begin{array}{ll}\text { SW } & \text { WORD } 5.0 \\ B F & \text { WORD }<\text { Programm }>5.0\end{array}$

Der Homonymenzusatz entfällt in der Ansetzungsform, da keine Verwechslungsgefahr besteht.

Hard- oder Software, die von mehreren Firmen unter verschiedenen Namen vertrieben wird, kann auf eine Form vereinheitlicht werden, wenn es sich um identische Produkte handelt.

$\begin{array}{ll}\text { SW } & \text { Mikroprozessor } 68000 \\ \text { BF } & \text { MC } 68000\end{array}$

Anm.: Datenbanken, Textkorpora und andere überwiegend aus gespeicherten Textdaten bestehende Produkte erhalten den Indikator t (vgl. § 708).

4. Gruppen von Produkten einer Firma können als Individualname (präkombiniertes Schlagwort aus Firmenname und Allgemeinbegriff) angesetzt werden, wenn der Name zu einem Stilbegriff geworden und in Nachschlagewerken so nachzuweisen ist. Der Firmenname mit der Produktbezeichnung als weiterem Kettenglied wird als Synonym erfasst.

SW Meißener Porzellan

BF Staatliche Porzellan-Manufaktur Meißen / Porzellan

In allen anderen Fällen werden Produktgruppen als Verknüpfung von Markenname und Allgemeinbegriff wiedergegeben, und zwar auch dann, wenn der Markenname nur einen einzigen Produkttyp repräsentiert. Die Markennamen werden neben den Firmennamen (Körperschaften) in die SWD aufgenommen; von einem Firmennamen mit dem Markennamen als weiterem Kettenglied kann eine Synonymie-Verweisung auf den Markennamen gemacht werden. Ist der Markenname nicht nachweisbar, wird mit dem Firmennamen (Körperschaft) verknüpft.

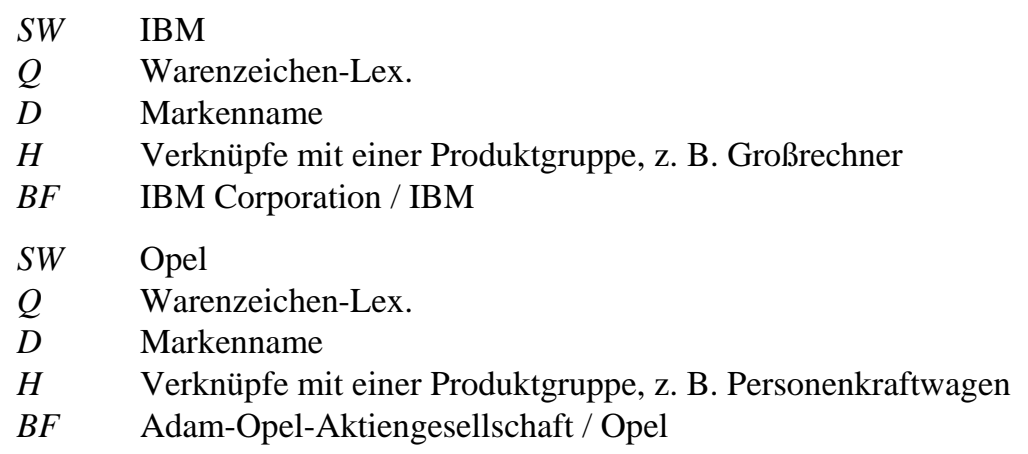

Ist der Markenname homonym zur Verweisung auf den Firmennamen oder zu einem anderen Schlagwort, so erhält er den Homonymenzusatz <Marke> (vgl. § 306,7).

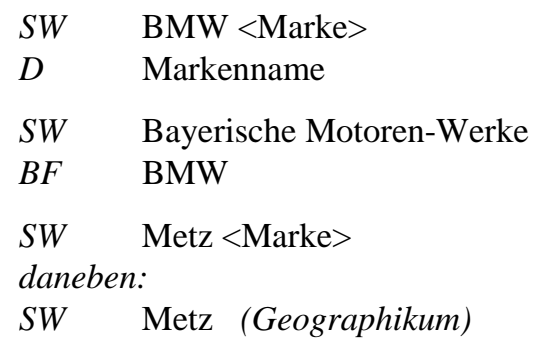

5. Bei Preisen und Wettbewerben kann die verleihende Körperschaft in einer SynonymieVerweisung erfasst werden; außerdem kann die namengebende Person in einer SynonymieVerweisung oder in einem mehrgliedrigen Oberbegriff erfasst werden. (Zu sportlichen Wettbewerben vgl. § 607.) 


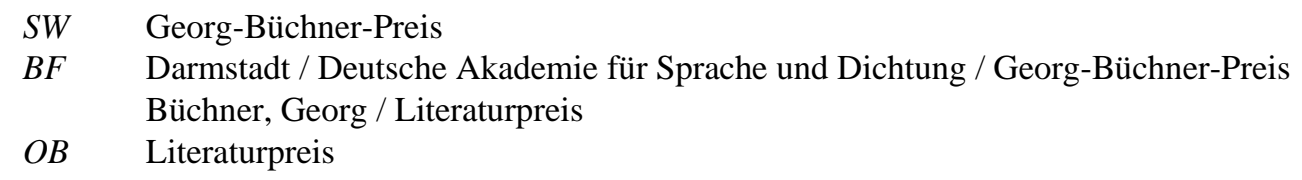

Besteht bei Preisen und Wettbewerben der Name aus einer unspezifischen Bezeichnung und dem Namen der verleihenden Körperschaft, so wird mit der verleihenden Körperschaft und der unspezifischen Bezeichnung als zweitem Glied angesetzt.

SW Bundesärztekammer / Literaturpreis

6. Bei Individualnamen werden stets Oberbegriffe erfasst, um sie unter gängigen Gattungsbezeichnungen auffindbar zu machen. Der Oberbegriff kann ein- oder mehrgliedrig sein (vgl. $\S 12,4)$.

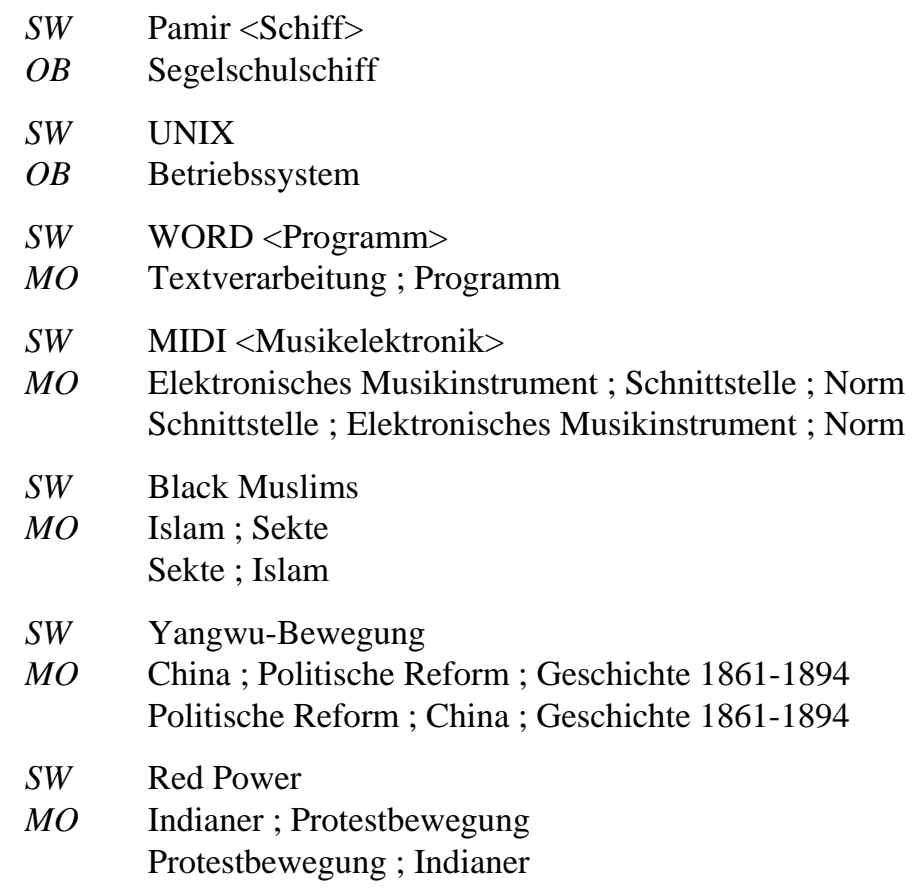

7. Namen von Stilrichtungen, Gebräuchen, Kunst- und Literaturgattungen, die auf einzelne außereuropäische Länder bzw. Völker beschränkt sind, erhalten mehrgliedrige Oberbegriffe. Obwohl diese Schlagwörter nicht zu den Individualnamen im Sinn des Regelwerks zählen, ist dies sinnvoll, da die Bezeichnungen oft fremdsprachig und weniger gängig sind und sachlich den Individualnamen nahestehen.

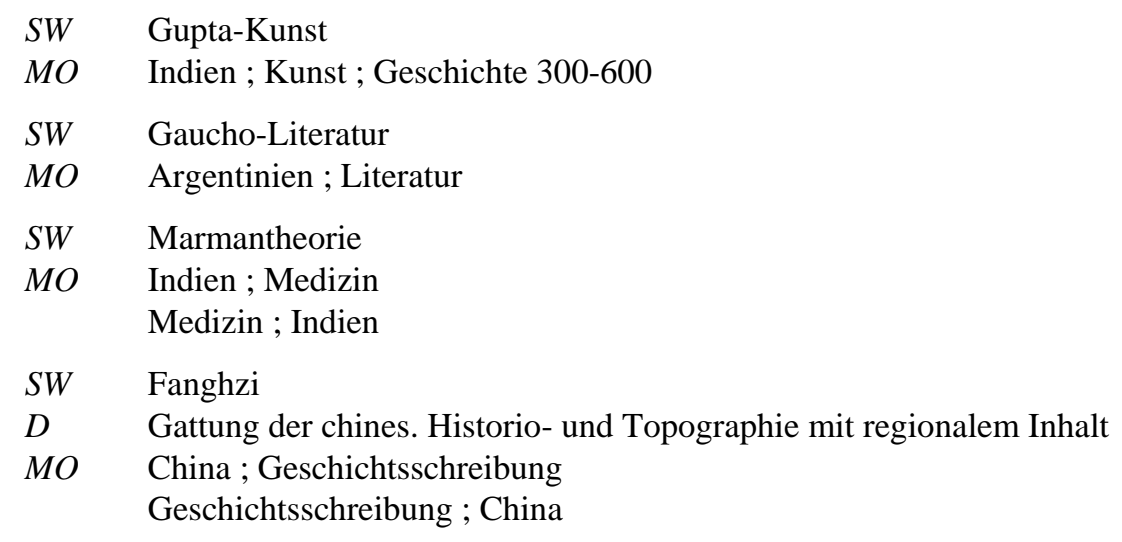




\section{SW AN.TAH.SUM-Fest \\ $M O \quad$ Hethiter; Fest \\ Fest ; Hethiter}

8. Begriffe aus der Nomenklatur der Botanik, Zoologie (Tier- und Pflanzennamen), Biochemie und Chemie (Bezeichnungen einzelner nachweisbarer Stoffe und Stoffgruppen) werden wie Individualnamen behandelt; eine Zerlegung ist i. d. R. nicht möglich. Ein unkontrolliertes Wachstum der Zahl der Schlagwörter kann für einzelne Bereiche geregelt werden, z. B. werden in der Chemie Pluralformen gegenüber einzelnen Isomeren z. T. bevorzugt verwendet; in der Genetik werden Gene wo möglich nicht durch die Komposita mit '-gen', sondern durch die Verknüpfung des Schlagwortes 'Gen' mit dem jeweiligen Genprodukt (Protein bzw. Enzym) indexiert. Näheres regeln die „Praxisregeln“ und die SWD.

In der chemischen Nomenklatur sollen durch hierarchische Verweisungen Verbindungen und Verbindungsklassen sinnvoll zusammengeführt werden.

$$
\begin{array}{ll}
S W & \text { Digitonin } \\
O B & \text { Saponine } \\
& \\
S W & \text { Alkane } \\
O B & \text { Kohlenwasserstoffe }
\end{array}
$$

Chemisch definierte Monosubstanzpräparate werden mit ihrer chemischen Kurzbezeichnung, soweit vorhanden mit ihrem internationalen wissenschaftlichen Freinamen angesetzt. Handelsnamen sowie die exakte chemische Bezeichnung können als Synonyme erfasst werden.

$$
\begin{array}{ll}
\text { SW } & \text { Ampicillin } \\
\text { BF } & \text { Binotal } \\
& \text { Amblosin } \\
& \text { Penbrock }
\end{array}
$$

Kombinationspräparate werden mit dem jeweiligen Handelsnamen angesetzt, wenn sie nicht unter der chemischen Bezeichnung in der „Pharmazeutischen Stoffliste“ nachzuweisen sind.

Arzneimittel erhalten eine hierarchische Verweisung von der Gattungsbezeichnung.

$$
\begin{array}{ll}
S W & \text { Nefiracetam } \\
O B & \text { Nootropikum }
\end{array}
$$

9. Tier- und Pflanzennamen werden deutsch angesetzt, wenn in Nachschlagewerken eine eindeutige deutsche Bezeichnung nachweisbar ist.

$$
\begin{array}{ll}
S W & \text { Windenschwärmer } \\
B F & \text { Agrius convolvuli } \\
& \text { Herse convolvuli }
\end{array}
$$

Es sollen keine Mischformen aus griechisch-lateinischen Wortstämmen und deutschen Endungen gebildet werden, auch wenn sich diese in Nachschlagewerken finden.

$$
\begin{array}{ll}
\text { SW } & \text { Streptococcus } \\
B F & \text { Streptokokken }
\end{array}
$$

Im Bereich der biologischen Nomenklatur werden in der SWD folgende hierarchische Verweisungen gemacht:

- bei Arten, Gattungen und Unterfamilien wird als Oberbegriff jeweils die Familie angegeben.

$$
\text { SW Grünerle }
$$

$B F \quad$ Alnus viridis

$O B \quad$ Birkengewächse

SW Rhoptropus barnardi

$O B \quad$ Geckos

- bei Kulturpflanzen und Nutztieren kann für das Retrieval ein Oberbegriff angegeben werden.

SW Merinoschaf

$O B \quad$ Schaf 
SW Gartentulpe

$O B \quad$ Tulpe

- bei Tieren und Pflanzen, die unter dem Grundwort bekannter sind, sowie in terminologisch unklaren Fällen können Oberbegriffe angegeben werden.

$\begin{array}{ll}S W & \text { Großer Waldgärtner } \\ O B & \text { Waldgärtner } \\ S W & \text { Krähen } \\ O B & \text { Rabenvögel }\end{array}$

10. Statt entlegener Individualnamen sind Allgemeinbegriffe für die Erschließung häufig besser geeignet (vgl. § 8,2). In diesen Fällen werden anstelle der Verwendung von Individualnamen Schlagwörter für Allgemeinbegriffe miteinander, ggf. auch mit Geographika, Körperschaftsnamen oder anderen Schlagwörtern verknüpft.

Neue Bezeichnungen, insbesondere für Methoden und Verfahren, sollen nur dann angesetzt werden, wenn sie in den Nachschlagewerken nachweisbar sind. Kommen sie zum ersten Mal oder nur in wenigen Veröffentlichungen vor, müssen sie besonders kritisch daraufhin geprüft werden, ob nicht eine Erschließung mit gebräuchlichen, umschreibenden Schlagwörtern bessere Voraussehbarkeit und damit bessere Retrievalergebnisse bringt.

Beispiele für die Benutzung von umschreibenden Schlagwörtern:

SWW Umweltchemikalie ; Umwelt ; Modell

nicht: EXINT

SWW Englischunterricht ; Gesamtschule ; Leistungsdifferenzierung ; Modell nicht: FEGA-Modell

Anm.: In Online-Katalogen wird eine in Sachtiteln (einschließlich Zusatz) von Veröffentlichungen genannte Individualbezeichnung über eine Titelstichwort-Recherche auffindbar sein.

Beispiel für die Ansetzung eines Schlagworts für ein neues Verfahren:

SW Direktsynthese

Die chemische Methode ist in den Nachschlagewerken nicht nachgewiesen, wird aber dennoch angesetzt, da eine zutreffende Wiedergabe durch umschreibende Schlagwörter nicht möglich ist.

Projekte, Forschungs- und Förderungsprogramme werden nur dann mit der Individualbezeichnung angesetzt, wenn diese in Nachschlagewerken nachweisbar ist. Eine solche Bezeichnung wird nur dann verwendet, wenn im vorliegenden Dokument das Projekt selbst Thema der Darstellung ist.

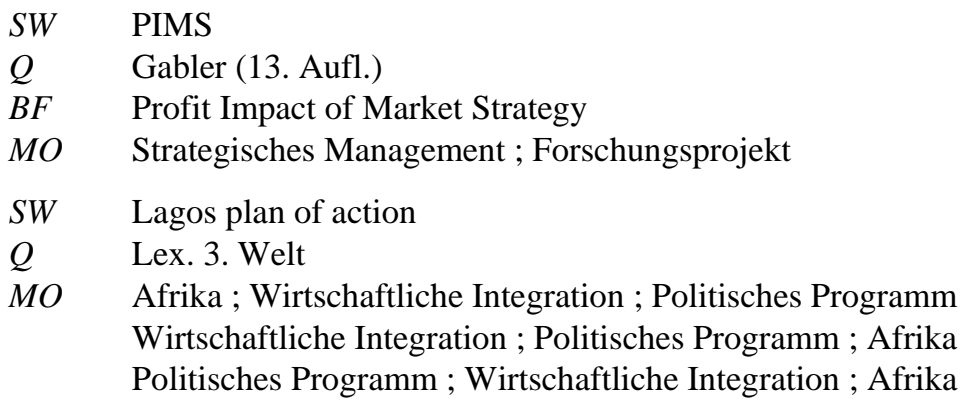

In allen Fällen, in denen eine Individualbezeichnung nicht angesetzt wird, ist eine Schlagwortkette zu bilden, die den Gegenstand des Projekts wiedergibt. Ist das Projekt selbst Thema der Darstellung, steht am Ende der Kette das Schlagwort 'Projekt' (bzw. 'Forschungsprogramm', 'Förderungsprogramm').

Titel: $\quad \neg$ Das $\neg$ Programm Sanasilva. - 1985

SWW Schweiz ; Waldschaden ; Forschungsprogramm 


\section{$\S 307$ Synonyme}

1. Liegen für einen Begriff mehrere bedeutungsgleiche oder quasisynonyme Bezeichnungen vor, so wählt man eine davon als Schlagwort, die übrigen werden als Synonyme erfasst (Quasisynonyme vgl. § 315).

2. Bei der Entscheidung für eine Ansetzungsform sollen folgende Kriterien in der angegebenen Reihenfolge angewandt werden:

a) Gebräuchlichkeit: Nach dem in § 9,3 erläuterten Prinzip soll die im aktuellen Sprachgebrauch meistbenutzte Bezeichnung gewählt werden (vgl. §§ 308-314).

b) Eignung zur Kompositabildung: Es soll diejenige Bezeichnung gewählt werden, die häufiger in präkombinierten Schlagwörtern vorkommt.

$\begin{array}{ll}\text { SW } & \text { Meer } \\ \text { BF } & \text { Ozean }\end{array}$

Wenn aber beide Synonyme in festen Verbindungen unauswechselbar auftreten, lässt sich eine gleichzeitige Verwendung beider synonymer Elemente nicht vermeiden.

$\begin{array}{ll}\text { SW } & \text { Eheschließung } \\ B F & \text { Heirat } \\ \text { SW } & \text { Ehevermittlung } \\ B F & \text { Heiratsvermittlung } \\ \text { Aber: } & \\ \text { SW } & \text { Heiratsanzeige } \\ \text { SW } & \text { Heiratsschwindler }\end{array}$

c) breitere Anwendbarkeit: Ggf. sollte die Bezeichnung gewählt werden, die sich in breiterem Kontext verwenden lässt, wenn dies unter dem Aspekt der Struktur des Vokabulars der SWD sinnvoll ist.

SW Oberboden

Q B 1986 unter Bodenhorizont 1.

BF A-Horizont

Oberboden ist nicht nur in der Bodenkunde, sondern auch in Bautechnik und Landwirtschaft verwendbar.

d) Kürze: Trifft keines der unter a - c genannten Kriterien zu, so soll das kürzere Synonym bevorzugt werden.

$\begin{array}{ll}S W & \text { Massenmedien } \\ B F & \text { Massenkommunikationsmittel } \\ \text { SW } & \text { Umweltpolitik } \\ B F & \text { Umweltschutzpolitik }\end{array}$

e) Wenn ein Sachverhalt durch dieselben Lexeme, aber in unterschiedlicher sprachlicher Form ausgedrückt werden kann, gilt die Vorzugsreihenfolge von § 305,2,a.

3. Bei Fachausdrücken des Rechts und der Verwaltung, die in Rechtsnormen eindeutig definiert und einheitlich verwendet werden, wird i.d.R. die amtliche Terminologie benutzt.

SW Justizvollzugsanstalt

deutsche Terminologie der Gegenwart nach § 139 Strafvollzugsgesetz 
SW Gefängnis

international verwendet als allgemeinster Begriff; in Deutschland früher Bezeichnung für eine Sonderform

SW Kraftfahrtversicherung

gegen B und M nach der einschlägigen Rechtsnorm „Allgemeine Bedingungen für die Kraftfahrtversicherung “, inzwischen in B 1986 übernommen

Aber:

SW Klassenarbeit

BF $\quad$ Schulaufgabe $<$ Klassenarbeit $>$

Es gibt in Deutschland keine einheitliche amtliche Terminologie; die bayerische Terminologie, geregelt u.a. in der „Gymnasialschulordnung“, wird auf die überwiegende deutsche Terminologie normiert.

SW Schelf

BF $\quad$ Festlandsockel

Geographischer Begriff; in der juristischen Literatur ist einheitlich von Festlandsockel die Rede.

\section{§ 308 Deutsche oder fremdsprachige Bezeichnung}

1. Das Sachschlagwort wird i.d.R. in seiner deutschen Form (als Erb- oder Lehnwort) angesetzt. In der Fachsprache geläufige fremdsprachige Bezeichnungen werden i.d.R. als Synonyme erfasst (vgl. aber auch § 309).

$\begin{array}{ll}S W & \text { Beratung } \\ B F & \text { Counseling } \\ S W & \text { Fiskalpolitik } \\ B F & \text { Fiscal policy } \\ S W & \text { Offener Unterricht } \\ B F & \text { Open classroom } \\ S W & \text { Außenseiter } \\ B F & \text { Outsider } \\ S W & \text { Bewältigung } \\ B F & \text { Coping }\end{array}$

2. Fremdsprachige Bezeichnungen werden bevorzugt, wenn es keine eindeutig entsprechenden deutschen Bezeichnungen gibt. Zum Nachweis der Gebräuchlichkeit vgl. § 9,3.

$\begin{array}{ll}\text { SW } & \text { Accent grave } \\ \text { SW } & \text { Container } \\ \text { SW } & \text { Dolce stil nuovo } \\ \text { SW } & \text { Microteaching } \\ \text { SW } & \text { Nouveau roman } \\ \text { SW } & \text { Reformatio in peius } \\ \text { SW } & \text { Sciencefiction } \\ \text { SW } & \text { Political correctness }\end{array}$




\section{§ 309 Allgemeinsprache oder Fachsprache}

Für die Entscheidung zwischen wissenschaftlicher Fachsprache und Allgemeinsprache sind die neuesten Ausgaben der deutschsprachigen Allgemeinenzyklopädien heranzuziehen (vgl. § 9,3). Ist die Bezeichnung dort nicht enthalten, so wird die Bezeichnung aus den Fachlexika gewählt; in Zweifelsfällen hat der Fachterminus Vorrang. Die nicht gewählte Bezeichnung wird i. d. R. als Synonym erfasst.

$\begin{array}{ll}S W & \text { Inkunabel } \\ B F & \text { Wiegendruck } \\ S W & \text { Rhinitis } \\ B F & \text { Schnupfen } \\ S W & \text { Ruderfußkrebse } \\ B F & \text { Copepoda } \\ S W & \text { Hämoglobin } \\ B F & \text { Roter Blutfarbstoff } \\ S W & \text { Astronomie } \\ B F & \text { Himmelskunde } \\ S W & \text { Fremdenverkehr } \\ B F & \text { Tourismus } \\ & \text { Touristik }\end{array}$

\section{§310 Veraltete oder aktuelle Bezeichnung}

1. Als Schlagwort wird die aktuelle Bezeichnung gewählt, soweit sie sich im Sprachgebrauch durchgesetzt hat. Das gilt auch für die Erschließung älterer Dokumente. Die nicht gewählte Bezeichnung wird i. d. R. als Synonym erfasst (vgl. § 12,5,b).

$\begin{array}{ll}S W & \text { Taxi } \\ B F & \text { Kraftdroschke }\end{array}$

Kraftdroschke ist eine ältere Bezeichnung, die aber heute noch in der Rechtssprache verwendet wird.

SW Lernbehindertenschule

$B F \quad$ Hilfsschule

$S W \quad$ Ausländischer Arbeitnehmer

BF Gastarbeiter

2. Ist mit dem Wechsel der Bezeichnung aber auch eine Modifikation der Bedeutung verbunden, so bleiben beide Schlagwörter nebeneinander bestehen und werden durch assoziative Verweisungen verknüpft (vgl. § 12,5,b).

$\begin{array}{ll}S W & \text { Fürsorge } \\ V B & \text { Sozialhilfe }\end{array}$

3. Bei historischen Sachverhalten wird ein älterer Terminus verwendet, soweit es keinen adäquaten neuen gibt.

$\begin{array}{ll}S W & \text { Tote Hand } \\ S W & \text { Hofmeister } \\ V B & \text { Privatlehrer }\end{array}$




\section{§ 311 Regional unterschiedlicher Sprachgebrauch}

1. Liegen für den gleichen Gegenstand in verschiedenen deutschsprachigen Gebieten unterschiedliche Bezeichnungen vor, so wird die allgemein übliche Bezeichnung entsprechend den Nachschlagewerken angesetzt. Die nicht gewählten Bezeichnungen, soweit sie ermittelt wurden, werden als Synonyme erfasst; dabei wird das geographische Schlagwort, das die jeweilige Region kennzeichnet, nicht hinzugesetzt.

$\begin{array}{ll}S W & \text { Stadtstreicher } \\ B F & \text { Sandler } \\ & \\ S W & \text { Fleischer } \\ B F & \text { Metzger } \\ & \text { Schlachter } \\ & \text { Selcher } \\ & \text { Fleischhauer } \\ & \text { Knochenhauer } \\ & \text { Schlächter } \\ & \\ \text { SW } & \text { Intellektueller } \\ B F & \text { Intelligenzler } \\ \text { Aber: } & \\ \text { SW } & \\ \text { VB } & \text { Karneval } \\ \end{array}$

2. Bei Fachausdrücken des Rechts, der Verwaltung und des Schulwesens (vgl. § 307,3) wird die im jeweiligen deutschsprachigen Staat gebräuchliche Terminologie verwendet. Zwischen den zugehörigen Sachbegriffen werden assoziative Verweisungen gemacht. Das jeweilige Sachschlagwort wird mit dem jeweiligen Geographikum verknüpft.

$\begin{array}{ll}S W W & \text { Österreich ; Außerstreitverfahren } \\ S W & \text { Außerstreitverfahren } \\ V B & \text { Freiwillige Gerichtsbarkeit } \\ S W W & \text { Schweiz ; Mehrwertanteil } \\ S W & \text { Mehrwertanteil } \\ V B & \text { Zugewinn } \\ S W W & \text { Schweiz ; Fahrnis } \\ S W & \text { Fahrnis } \\ V B & \text { Bewegliche Sache }\end{array}$

Aber:

SW Verordnungsermächtigung

BF Ermächtigung zum Erlass von Rechtsverordnungen

Die angesetzte Bezeichnung ist offizielle österreichische Terminologie; in Deutschland ist im Grundgesetz und in Nachschlagewerken die präpositionale Wendung nachweisbar, doch kommt das Kompositum hier in der juristischen Literatur auch vor.

SW Allgemein bildende höhere Schule für Österreich amtliche Bezeichnung

Aber:

SWW Schweiz; Gymnasium

Die Terminologie in der Schweiz ist uneinheitlich. 
Für das nicht deutschsprachige Ausland wird von allen Anwendern der (bundes)deutsche Terminus benutzt.

SWW Zwangsvollstreckung ; Römisches Recht

\section{§ 312 Pleonasmus im Schlagwort}

Pleonastische Begriffe oder Begriffsteile, die nicht notwendig sind, um einen Begriffsinhalt eindeutig wiederzugeben, und verallgemeinernde Formen, die die Bedeutung des Grundworts nicht ändern, sollen vermieden werden. Dabei darf aber nicht gegen die Fachterminologie verstoßen werden (vgl. § 9,4; zum Pleonasmus in Schlagwortketten vgl. § 324).

Zu den Begriffsteilen, die pleonastisch sein können, zählen vor allem: ‘-frage', '-heit', ‘-kunde’, ‘lehre', '-methode', '-problem', '-technik', '-theorie', '-verfahren', '-welt', '-wesen'.

Die nicht gewählte Bezeichnung kann als Synonym erfasst werden.

\begin{tabular}{|c|c|}
\hline \multicolumn{2}{|c|}{ 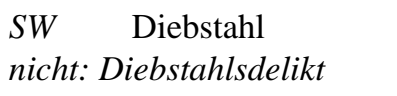 } \\
\hline $\begin{array}{l}\text { SW } \\
\text { nicht: }\end{array}$ & $\begin{array}{l}\text { Sinn } \\
\text { innfrage }\end{array}$ \\
\hline $\begin{array}{l}\text { SW } \\
\text { nicht: }\end{array}$ & $\begin{array}{l}\text { Ritter } \\
\text { itterstand, Rittertum }\end{array}$ \\
\hline $\begin{array}{l}\text { SW } \\
\text { nicht: }\end{array}$ & $\begin{array}{l}\text { Thymus } \\
\text { hymusdrüse }\end{array}$ \\
\hline $\begin{array}{l}\text { SW } \\
\text { nicht: }\end{array}$ & $\begin{array}{l}\text { Bibliothek } \\
\text { ibliothekswesen }\end{array}$ \\
\hline $\begin{array}{l}\text { SW } \\
\text { nicht: }\end{array}$ & $\begin{array}{l}\text { Aquarium } \\
\text { quarienkunde }\end{array}$ \\
\hline $\begin{array}{l}\text { SW } \\
\text { nicht: }\end{array}$ & $\begin{array}{l}\text { Staat } \\
\text { Staatswesen }\end{array}$ \\
\hline Aber: & \\
\hline $\begin{array}{l}S W \\
S W\end{array}$ & $\begin{array}{l}\text { Bildungswesen } \\
\text { Bildung }\end{array}$ \\
\hline $\begin{array}{l}S W \\
S W\end{array}$ & $\begin{array}{l}\text { Christentum } \\
\text { Christ }\end{array}$ \\
\hline $\begin{array}{l}S W \\
S W\end{array}$ & $\begin{array}{l}\text { Gesundheitswesen } \\
\text { Gesundheit }\end{array}$ \\
\hline $\begin{array}{l}S W \\
S W\end{array}$ & $\begin{array}{l}\text { Mengenlehre } \\
\text { Menge }\end{array}$ \\
\hline
\end{tabular}

Als pleonastisch vermieden werden auch Begriffsteile wie '-bild', '-idee', '-gedanke', '-vorstellung' usw., die lediglich dazu dienen, bei Verknüpfung mit einem Personenschlagwort die Einstellung einer Person zur Sache auszudrücken. Solche Begriffsteile werden jedoch angesetzt, wenn ein wesentlicher inhaltlicher Unterschied ausgedrückt werden soll.

SWW Clausewitz, Carl $\neg$ Von $\neg$; Krieg

nicht: Clausewitz, Carl $\neg$ von $\neg$; Kriegsbild 
SWW Shaw, George Bernard ; Drama ; Frau <Motiv $>$

nicht: Shaw, George Bernard ; Drama ; Frauenbild

Aber:

SWW Mörike, Eduard ; Menschenbild

\section{§ 313 Abkürzungen}

1. Abkürzungen werden i.d.R. aufgelöst. Die Abkürzung wird i.d.R. als Synonym erfasst (zur Rechtschreibung vgl. § 302,3).

$\begin{array}{ll}\text { SW } & \text { Hochtemperaturreaktor } \\ B F & \text { HTR } \\ \text { SW } & \text { Intelligenzquotient } \\ B F & \text { IQ }\end{array}$

2. Die Abkürzung kann Schlagwort werden, wobei die aufgelöste Form als Synonym erfasst wird:

a) bei Abkürzungen für sehr lange Bezeichnungen,

$\begin{array}{ll}S W & \text { DDT } \\ B F & \text { Dichlordiphenyltrichlorethan <1,1,1-Trichlor-2,2-bis(4-Chlorphenyl)ethan> } \\ \text { SW } & \text { DNS } \\ B F & \text { Desoxyribonucleinsäure }\end{array}$

b) bei Abkürzungen, die als Kunstwörter gesprochen werden,

$\begin{array}{ll}S W & \text { AIDS } \\ B F & \text { Acquired immune deficiency syndrom } \\ \text { SW } & \text { Hi-Fi } \\ \text { BF } & \text { High fidelity } \\ \text { SW } & \text { Bit } \\ \text { BF } & \text { Binary digit }\end{array}$

c) bei der Ansetzung von psychologischen Tests (vgl. § 714),

d) wenn bei Untersuchungsmethoden die Abkürzung gebräuchlicher ist.
SW HPPLC
BF High pressure planar liquid chromatography
Hochdruckplanarflüssigkeitschromatographie

3. In Komposita kann die Abkürzung auftreten, auch wenn sie als Einzelwort nicht angesetzt wird.

$\begin{array}{ll}\text { SW } & \text { Magnetische Kernresonanz } \\ \text { BF } & \text { NMR } \\ \text { SW } & \text { NMR-Spektroskopie }\end{array}$

4. Zur Abkürzung von Körperschaftsnamen vgl. § 602,4. 


\section{$\S 314$ Formeln, naturwissenschaftliche und technische Zeichen und Symbole}

1. Naturwissenschaftliche, technische und mathematische Begriffe, die ganz oder zum Teil aus Zahlzeichen, Buchstaben nichtlateinischer Alphabete, hoch- bzw. tiefgestellten Zeichen oder Sonderzeichen bestehen, werden soweit wie möglich mit einer verbalen Bezeichnung angesetzt, die keines der genannten Zeichen enthält.

\begin{tabular}{lll} 
Vorlage & \multicolumn{2}{l}{ Schlagwort } \\
$\nabla^{2}$ & $S W$ & Laplace-Operator \\
$\alpha$ Ori & $S W$ & Beteigeuze \\
$\mathrm{a}^{2}+\mathrm{b}^{2}=\mathrm{c}^{2}$ & $S W$ & Pythagoreischer Lehrsatz \\
$\mathrm{FeS}_{2}$ & $S W$ & Eisendisulfid
\end{tabular}

Die Bezeichnung mit Zahlzeichen, Sonderzeichen usw. wird nur dann als Synonym erfasst, wenn sie im allgemeinen Sprachgebrauch bekannt ist.
SW
Radiokarbonmethode
$B F$
C-14-Methode

2. Ist eine rein verbale Ansetzung nicht möglich, so gelten folgende Richtlinien:

a) Die Bildung von Komposita erfolgt nach den Rechtschreibregeln des „Duden“. Zum Zusammentreffen von Ziffern und Buchstaben vgl. Abs. e).

SW Vitamin B12

SW Vitamin-B12-Mangel

b) Werden im fachsprachlichen Gebrauch bei der alphabetischen Ordnung Ziffern, einzelne Buchstaben, Vorsilben oder Sonderzeichen übergangen, so werden diese ordnungsunwichtigen Teile in der Form eines Homonymenzusatzes in Winkelklammern nachgestellt. Dabei werden griechische Buchstaben und Sonderzeichen, die im Zeichenvorrat (vgl. $\S 16,3$ ) nicht enthalten sind, verbal aufgelöst, Ziffern und die im Zeichenvorrat enthaltenen Sonderzeichen dagegen nicht aufgelöst. Werden Ziffern usw. aus dem Wortinneren bei der Sortierung übergangen, so muss im Homonymenzusatz das ganze Schlagwort einschließlich der nichtsortierenden Teile angegeben werden.

Bei der Sortierung chemischer und biochemischer Verbindungsnamen und der daraus abgeleiteten Komposita (z.B. Enzyme) werden übergangen: durch Zahlen oder griechische Buchstaben ausgedrückte Stellungsbezeichnungen, Stereodeskriptoren (z.B. D-, L-) und andere Deskriptoren (z.B. Drehsinn des polarisierten Lichts $[(+)(-)]$, Ladungsangaben $[(3+)(4-)]$ und Oxidationsstufen [(III)(3)]).

Die Groß- bzw. Kleinschreibung richtet sich nach dem fachsprachlichen Gebrauch.

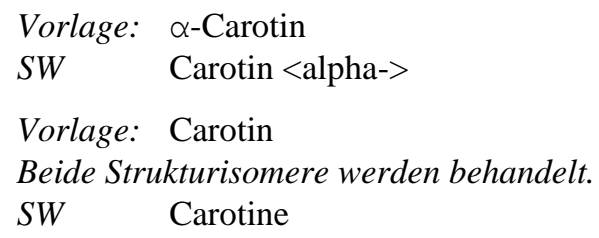


Aber:

Vorlage: n-Halbleiter

SW n-Halbleiter

c) Griechische Buchstaben werden in aufgelöster Form angesetzt.
SW Alphastrahlung
SW Lambda-Kalkül
SW Sigma-Hyperon

d) Ziffern am Wortanfang werden i.d.R. durch das entsprechende Zahlwort ersetzt (Ausnahme vgl. Abs. b).
SW Einundzwanzig-Zentimeter-Linie
SW Acht-Bit-Mikroprozessor
SW Drei-Fünf-Halbleiter

e) Ziffern (auch römische) im Wort oder am Wortende werden nicht aufgelöst. Treffen in einem Schlagwort Buchstaben und Ziffern unmittelbar oder unter Einschub von Sonderzeichen aufeinander, so werden sie i.d.R. durch einen Bindestrich verbunden. Das gilt nicht, wenn eine andere Schreibweise (z.B. mit runder Klammer, Punkt, Spatium, unmittelbare Abfolge Ziffer/Buchstabe) einheitlich angewandt wird.
Vorlage: $\mathrm{SU}(3)-S y m m e t r i e$
SW SU-3-Symmetrie
Vorlage: V.24-Schnittstelle
SW V.24-Schnittstelle

f) Hoch- und tiefgestellte Ziffern und Buchstaben werden auf die Grundlinie gesetzt und bei der Sortierung berücksichtigt.
SW Uran-235
SW Uran-235-Target
SW Vitamin A1

Anm.: Bibliotheken und Verbünde mit ausreichendem Zeichenvorrat können die fachsprachlich korrekte Hoch- oder Tiefstellung wiedergeben.

g) Zeichen, die dem Zeichenvorrat nach MAB2 Anhang 2 (vgl. § 16,3) nicht entsprechen und das Zeichen * werden durch ihre verbale Bezeichnung ersetzt.
Vorlage: C*-Algebra
SW C-Stern-Algebra

Anm.: Bibliotheken und Verbünde mit ausreichendem Zeichenvorrat können diese Zeichen wiedergeben.

h) Bei Mischformen der unter Abs. b - g genannten Fälle ist im Zweifel eine Auflösung der Zeichen vorzuziehen („geschrieben wie gesprochen“).

i) Bei der sprachlichen Auflösung von Reaktionsformeln werden Teilchenwechselwirkungen unter Angabe der wechselwirkenden Teilchen als Komposita angesetzt (Reihenfolge der Teilchen wie in der Reaktionsgleichung).

$$
\begin{array}{ll}
\text { Vorlage: } & \mathrm{p}+\mathrm{p} \rightarrow \mathrm{m}^{+}+\mathrm{d} \\
\text { SW } & \text { Proton-Proton-Wechselwirkung }
\end{array}
$$


Kernreaktionen erfordern als minimale Angaben die Ansetzung des Nuklids und des Projektils.

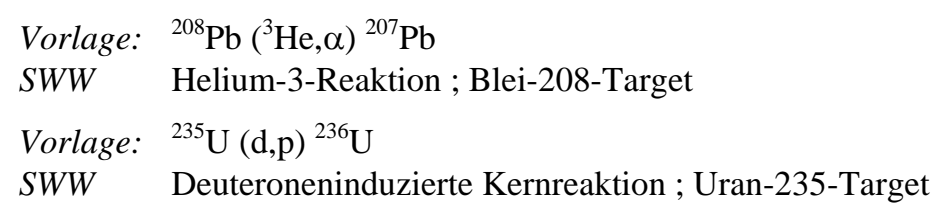

3. Führt die Anwendung der Regelungen Abs. b - i auf zu komplexe oder nicht als Sucheinstieg geeignete Bezeichnungen, so wählt man stattdessen einen geeigneten Oberbegriff oder eine vereinfachte Bezeichnung als Schlagwort.

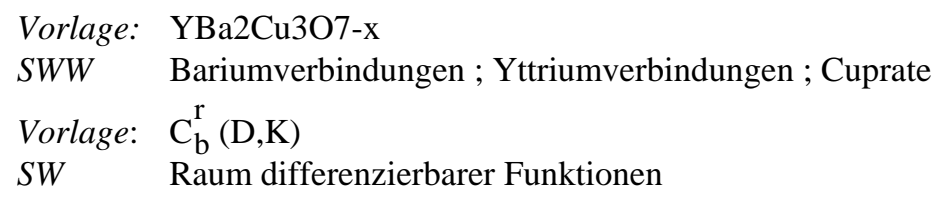

\section{§ 315 Quasisynonyme}

1. Synonyme sind häufig nur in einem bestimmten Kontext voll austauschbar. Der Übergang zu Quasisynonymen, die zwar nicht eigentlich bedeutungsgleich sind, aber vorwiegend so gebraucht werden, und zu lediglich sinnverwandten Bezeichnungen (vgl. § 317) ist fließend. Quasisynonyme werden i.d.R. auf die gebräuchlichere Bezeichnung normiert (vgl. § 307,2); die nicht gewählten Bezeichnungen werden als Synonyme erfasst.

$\begin{array}{ll}S W & \text { Eisenerz } \\ B F & \text { Oxidisches Eisenerz } \\ \text { SW } & \text { Allergie } \\ \text { BF } & \text { Allergose }\end{array}$

Wann bedeutungsähnliche Bezeichnungen als Quasisynonyme betrachtet werden, kann nur pragmatisch, vom mutmaßlichen Suchverhalten ausgehend, entschieden werden. Folgende Kriterien können zur Entscheidung herangezogen werden:

a) Die begriffliche Überschneidung zweier Bezeichnungen geht so weit, dass sie im allgemeinen Sprachgebrauch in der überwiegenden Zahl der Fälle gegeneinander ausgetauscht werden können.

b) Der Bedeutungsunterschied ist auch im Dokument i.d.R. nicht eindeutig zu erkennen, so dass die Wahl der Bezeichnung von der jeweiligen Titelfassung abhängig werden kann. Uneinheitlichkeit in der Verwendung durch die Autoren deutet meist darauf hin, dass auch den meisten Katalogbenutzern ein Unterschied nicht klar sein dürfte.

c) Eine der beiden Bezeichnungen wird in der Praxis häufig als Sucheinstieg für den Begriffsinhalt der anderen benutzt.

$\begin{array}{ll}S W & \text { Bestattung } \\ B F & \text { Begräbnis } \\ S W & \text { Straßenverkehr } \\ B F & \text { Kraftfahrzeugverkehr } \\ S W & \text { Diät } \\ B F & \text { Ernährungstherapie }\end{array}$


$\begin{array}{ll}\text { SW } & \text { Bedrohte Tiere } \\ \text { BF } & \text { Aussterbende Tiere }\end{array}$

2. Als Quasisynonyme im Sinn des Regelwerks können z.B. gelten:

a) Begriffe mit negierendem Inhalt bzw. Antonyme: Bei Gegensätzen sind oft beide Begriffe im gleichen Sachverhalt impliziert. Wenn die Unterscheidung nicht notwendig erscheint, können die Bezeichnungen zusammengelegt werden, wobei die positive Form bevorzugt wird.

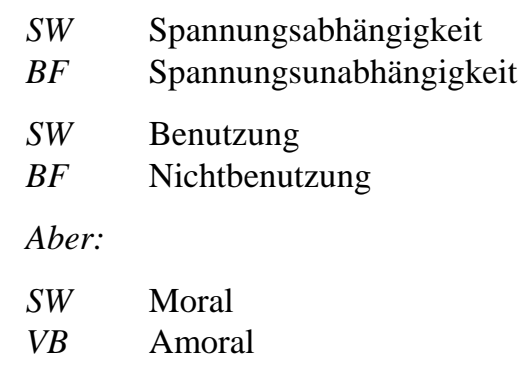

b) Ober- und Unterbegriffe: Werden ein Ober- und ein Unterbegriff in den Dokumenten überwiegend für den gleichen Gegenstand verwendet, so kann auf die übergeordnete Bezeichnung normiert werden.

$\begin{array}{ll}\text { SW } & \text { Transplantation } \\ B F & \text { Organtransplantation } \\ \text { SW } & \text { Märchen } \\ \text { BF } & \text { Volksmärchen } \\ \text { daneben } & \text { aber: } \\ \text { SW } & \text { Kunstmärchen } \\ \text { SW } & \text { Zeitung } \\ \text { BF } & \text { Tageszeitung } \\ \text { daneben aber: } \\ \text { SW } & \text { Wochenzeitung } \\ \text { SW } & \text { Studium } \\ \text { BF } & \text { Hochschulstudium } \\ \text { SW } & \text { Hochschulsport } \\ B F & \text { Studentensport } \\ \text { SW } & \text { Verkehrslärm } \\ B F & \text { Straßenverkehrslärm }\end{array}$

Diese Regelung gilt auch für Pflanzen- und Tiernamen, bei denen der übergeordnete Name vorwiegend als Bezeichnung für eine bestimmte Art gebraucht wird, die durch die Landwirtschaft allgemein bekannt ist.

$\begin{array}{ll}S W & \text { Schwein } \\ B F & \text { Hausschwein } \\ \text { SW } & \text { Gerste } \\ B F & \text { Saatgerste }\end{array}$

Aber:

SW Hühnerei

daneben:

SW $\quad \mathrm{Ei}$ 
c) verschiedene Begriffskategorien, deren Bezeichnungen zum Zweck der konsistenten Erschließung auf ein Schlagwort normiert werden (vgl. aber § 317).

$\begin{array}{ll}\text { SW } & \text { Alter } \\ \text { BF } & \text { Alter Mensch } \\ \text { SW } & \text { Schulschwierigkeit } \\ \text { BF } & \text { Problemschüler } \\ \text { SW } & \text { Sprachnorm } \\ \text { BF } & \text { Sprache / Vereinheitlichung } \\ & \text { Vereinheitlichung / Sprache }\end{array}$

3. Kommen verwandte Begriffe (vgl. § 316) in Komposita mit dem gleichen Grundwort vor, so sind sie häufig als quasisynonym anzusehen.

$\begin{array}{ll}S W & \text { Pädagogische Einrichtung } \\ B F & \text { Erziehungseinrichtung } \\ \text { Aber: } & \\ S W & \text { Pädagogik } \\ V B & \text { Erziehung } \\ S W & \text { Schriftsprache } \\ B F & \text { Schreibsprache } \\ \text { Aber: } & \\ S W & \text { Schrift } \\ V B & \text { Schreiben }\end{array}$

4. Bei chemischen Verbindungen wird i.d.R. nicht das einzelne Strukturisomer, sondern die verbale Beschreibung der Summenformel, d.h. der Oberbegriff im Plural, angesetzt. Die Gewichtung in dem erschlossenen Dokument entscheidet, ob das einzelne Isomer als Quasisynonym gilt oder ggf. angesetzt werden muss.

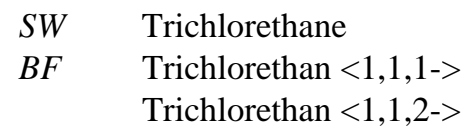

\section{$\S 316$ Verwandte Begriffe: Allgemeines}

1. Verwandte Begriffe sind Begriffe,
a) die sich in ihrem Begriffsumfang teilweise überschneiden,
b) die nicht als Synonyme oder Quasisynonyme anzusehen sind,
c) die nicht in einer hierarchischen Beziehung stehen,
d) auf deren gegenseitige Beziehung der Benutzer bei der Suche hingewiesen werden muss, weil möglicherweise ein Teil der mit dem einen Suchbegriff gesuchten Dokumente mit dem anderen Schlagwort erschlossen ist.

2. Bei verwandten Begriffen werden beide Bezeichnungen angesetzt. Bei beiden Schlagwörtern wird reziprok jeweils der verwandte Begriff als assoziative Verweisung erfasst (vgl. $\S 12,5, \mathrm{~b})$.

3. Zu den verschiedenen Typen verwandter Begriffe und Beispielen dazu vgl. § 12,5,b. 
4. Ein Gegenstand soll i.d.R. nicht durch zwei verwandte Begriffe erschlossen werden. In derselben Schlagwortkette dürfen zwei verwandte Begriffe nur vorkommen, wenn ein Vergleich oder eine sonstige Beziehung zwischen ihnen Thema der Darstellung ist (vgl. § 324,2).

Werden männliche und weibliche Personen geschlechtsneutral behandelt und hierfür eine grammatisch männliche (maskuline) Form in generischer Bedeutung verwendet, so kann daneben eine Kette mit der weiblichen Form gebildet werden, wenn mit Schlagwörtern verknüpft wird, die üblicherweise in geschlechtsspezifischem Kontext stehen.

Inhalt: Geschlechtsspezifische Körpersprache als prägendes Element des Unterrichtsstils

SWW Lehrer; Geschlechtsunterschied ; Körpersprache ; Unterrichtsstil ; Prägung

SWW Lehrerin ; Geschlechtsunterschied ; Körpersprache ; Unterrichtsstil ; Prägung

\section{$\S 317$ Verwandte Begriffe: Gleicher Sachverhalt - verschiedene Begriffskategorien}

1. Der gleiche Sachverhalt kann in verschiedenen Begriffskategorien ausgedrückt sein, wie z.B. ein Vorgang auch durch ein Produkt oder ein Instrument, eine Eigenschaft durch einen Stoff usw.

In manchen Fällen können die Bezeichnungen für verschiedene Begriffskategorien als Quasisynonyme behandelt werden (vgl. § 315,2,c), i.d.R. handelt es sich aber um verwandte Begriffe. Wichtig ist, dass jeweils die Bezeichnung als Schlagwort gewählt wird, die dem Inhalt des Dokuments am besten entspricht.

$\begin{array}{ll}S W & \text { Schwerbehinderter } \\ V B & \text { Schwerbehinderung } \\ \text { SW } & \text { Arbeitsloser } \\ V B & \text { Arbeitslosigkeit } \\ \text { SW } & \text { Chemische Waffe } \\ V B & \text { Chemischer Krieg } \\ \text { SW } & \text { Schreiben } \\ V B & \text { Schrift }\end{array}$

2. In bestimmten Fällen kann versucht werden, eine der möglichen Begriffskategorien bevorzugt zu verwenden, um größere Konsistenz der Daten zu erreichen.

a) Sachbegriff - Personengruppe

Wenn die Bezeichnungen für einen Sachbegriff und eine Personengruppe ähnliche Begriffsinhalte ausdrücken, so wird das Schlagwort für den Sachbegriff vorgezogen (zur Quasisynonymie vgl. § 315,2,c).

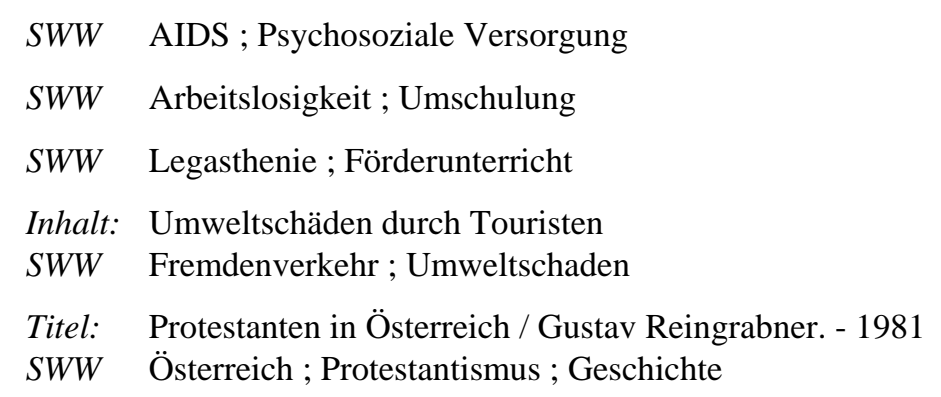


Titel: Behinderte Jugendliche vor der Berufswahl. - 1989

$S W W \quad$ Jugend ; Behinderung; Berufswahl

Das Schlagwort für die Personengruppe wird nur in folgenden Fällen benutzt:

- der Beruf bzw. Berufsstand ist Gegenstand der Darstellung (das gilt immer bei Ausbildungsberufen, vgl. § 771,2).

SWW Zahnarzt ; Prestige

SWW Buchhändler; Berufsausbildung

nicht: Buchhandel ; Berufsausbildung

- soziologische, psychische o. ä. Merkmale beziehen sich auf eine bestimmte Personengruppe,

SWW Student ; Psychische Störung

SWW Polizist ; Alkoholismus

SWW Arbeitnehmer; Behinderung

SWW Katholik; Diskriminierung

Alkoholismus bzw. Behinderung wird als Merkmal der sozialen Gruppe verstanden; auf diese Verknüpfung wird normiert, da auch die Verknüpfung Polizist ; Alkoholiker bzw. Arbeitnehmer; Behinderter sinnvoll begründet werden kann, beides nebeneinander aber nicht gerechtfertigt ist. Von beiden Lösungen wäre außerdem die Verknüpfung beider Schlagwörter für Personengruppen häufiger zweideutig.

- das Verhältnis von Personengruppen zueinander oder die Einstellung von Personen zu bestimmten Sachverhalten ist Gegenstand der Darstellung,

SWW Psychisch Kranker ; Einstellung ; Psychotherapie

- die Bezeichnung für die Personengruppe kann nicht durch ein gleichwertiges Abstraktum ersetzt werden bzw. steht gleichzeitig für das Abstraktum.

$\begin{array}{ll}S W & \text { Kind } \\ B F & \text { Kindheit } \\ S W & \text { Erwachsener } \\ B F & \text { Erwachsenenalter } \\ S W & \text { Rentner } \\ B F & \text { Rentenstand }\end{array}$

Zur Verdeutlichung der Normierung können Schlagwortketten als Hinweissatz in die SWD aufgenommen werden.

SWW Sport ; Ernährung

Hinweissatz, gekennzeichnet in MAB Feld 067

$B F \quad$ Sportler / Ernährung

Sporternährung

b) Sachbegriff - dazugehörige Wissenschaftsdisziplin

Bei allgemeinen Darstellungen eines Sachgebiets und vor Formschlagwörtern können beide mit dem gleichen Bedeutungsinhalt auftreten. In vielen Fällen wird die Bezeichnung für das Sachgebiet ausreichen oder allein zutreffen, auch wenn es sich um eine wissenschaftliche Darstellung handelt. In Zweifelsfällen werden zwei Ketten gebildet. 


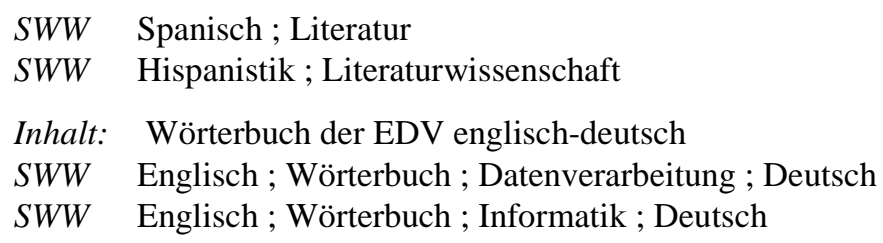

\section{$\S 318$ SWD-Datensatz}

Überblick über die wichtigsten Informationen in einem Datensatz für ein Sachschlagwort (vgl. $\S 7,4)$

- Indikator s bzw. (bei Wertktiteln) t (Angabe obligatorisch bei allen Sachschlagwörtern)

- Sachschlagwort in Ansetzungsform (Angabe obligatorisch)

- Quelle (Angabe obligatorisch, vgl. § 19,1)

- Definition (Angabe fakultativ, vgl. § 19,2)

- Verwendungshinweis (Angabe fakultativ, vgl. § 19,3)

- Redaktionelle Bemerkung (Angabe fakultativ, vgl. § 19,4)

- Notation (Angabe obligatorisch, vgl. § 18,1)

- Ländercode (bei Schlagwörtern, die räumlich zugeordnet werden können; immer dann, wenn in einer Synonymie-Verweisung ein geographisches Schlagwort enthalten ist, vgl. § 18,2)

- Zeitcode (bei historischen Begriffen, die einen eingrenzbaren, engeren Zeitraum umfassen, vgl. $\S \S 18,4 ; 418,3)$

- Synonymie-Verweisungen (einschließlich Quasisynonyme); ggf. mit Bemerkung, eingeleitet durch *

- Synonyme Bezeichnungen einschließlich abweichende sprachliche Formen (vgl. §§ 12,2; 302; 307,1)

- zur Ansetzungsform semantisch äquivalenter Schlagwortketten (vgl. §§ 12,2; 304,5)

- quasisynonyme Begriffe (vgl. §§ 12,2; 315)

- Oberbegriffe; ggf. mit Bemerkung, eingeleitet durch *

- ein in der SWD enthaltenes begrifflich übergeordnetes Schlagwort (vgl. §§ 12,3; § 306a,5-10)

- mehrgliedriger Oberbegriff in Form einer Schlagwortkette (vgl. §§ 12,4; 306a,5-10)

- Unterbegriffe

- Verwandte Begriffe (vgl. §§ 12,5; 316; 317), ggf. mit Bemerkung, eingeleitet durch *

SW s Honorar

Q B 1996

D Vergütung bei freien Berufen

H Keine Kompositabildung mit Berufsbezeichnungen, sondern Verknüpfung mit dem jeweiligen Beruf, z. B. SWW Arzt ; Honorar

R Konsens betr. Verknüpfung, 1995

SYS 10.12; 7.11c

BF $\quad$ s Liquidation $<$ Honorar $>$

$\mathrm{OB} \quad \mathrm{s}$ Vergütung

UB s Erfolgshonorar

VB s Honorierungssystem 
SW s Gruppo 63

Q B 1986, Lett. it.

D Ital. Schriftstellergruppe (1963-ca.1969)

R Ansetzung ohne Apostroph nach Diz. enc., Lett. it., gegen B 1986

SYS 12.1b

LC XA-IT

ZC 1963-1969

BF s Gruppo sessantatre

MO g Italien ; s Schriftstellergruppe

MO s Schriftstellergruppe ; g Italien

MO g Italienisch ; s Literatur ; z Geschichte 1963-1969

\section{Verknüpfung und Permutation}

\section{$\S \S 319,320$ entfallen}

\section{§ 321 Das Sachschlagwort in der Grundkette}

Zur Stellung des Sachschlagworts in der Grundkette vgl. § 15.

\section{§ 322 Verknüpfung mehrerer Sachschlagwörter}

1. Obwohl die Art der Beziehung der in einer Kette verknüpften Schlagwörter nicht dargestellt werden kann (vgl. § 14), d.h. Eindeutigkeit der inhaltlichen Aussage durch die Kette nicht in allen Fällen zu erzielen ist, kann die Verständlichkeit durch die Reihenfolge gefördert werden. Deshalb sollte auch in allen nicht ausdrücklich geregelten Fällen eine Reihenfolge gewählt werden, die im Rahmen der formalen Abfolge nach Schlagwortkategorien (vgl. § 15,1) den aufgrund der Inhaltsanalyse gewählten Schlüsselbegriffen Priorität einräumt und Zweideutigkeiten in der Grundkette möglichst vermeidet. Bei der Bildung von Schlagwortketten sollte man sich an der Struktur des vorhandenen Datenbestandes orientieren.

Es wird aber davon ausgegangen, dass

- die angezeigten Grundketten im Allgemeinen auch bei variierender Reihenfolge gleichermaßen verständlich sind,

- falls permutiert wird, in Listenfunktionen ohnehin mehrere gleichwertige Reihenfolgen entstehen.

Beispiele für Reihenfolgen der Kettenglieder, die früher nach RSWK vorgeschrieben waren, jetzt aber als austauschbar gelten:

SWW Fußballfan ; Gewalttätigkeit

SWW Kernkraftwerk; Abwärme

$S W W$ Lunge ; Blutgefäß

Ganzes - Teil/Eigenschaft, RSWK 2. Aufl. § 323,4

SWW Organische Verbindungen; Adsorption; Aktivkohle

Objekt - Handlung - Mittel, RSWK 2. Aufl. § 323,1

SWW Eltern; Kind

Begriffspaar mit gebräuchlicher Reihenfolge, RSWK 2. Aufl. § 322,2,b 
2. Inhaltlich eng zusammengehörige Schlagwörter werden nicht getrennt, insbesondere bei Vergleich und Gegenüberstellung bzw. der Anwendung eines Gegenstandes auf einen anderen bzw. der Darstellung eines Sachverhalts unter einem Aspekt.

Anm.: Im Folgenden sind Permutationsmuster nach § 325 angegeben.

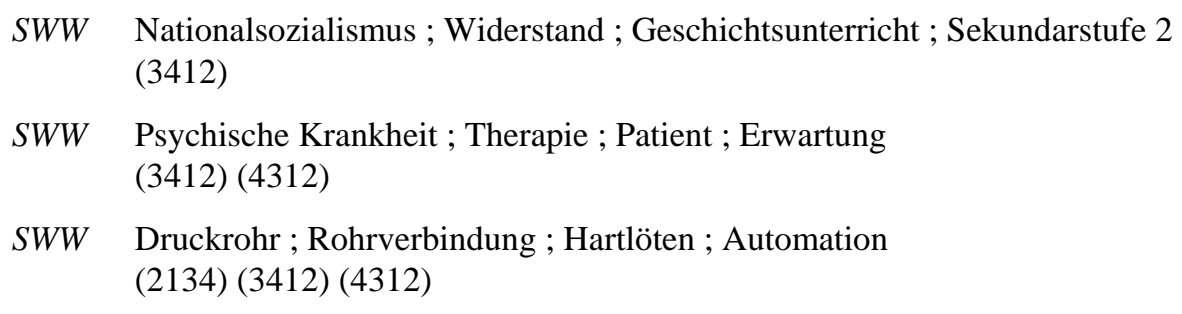

Die ersten beiden und die letzten beiden Schlagwörter gehören jeweils zusammen.

3. Nach einem aussagekräftigen Sachschlagwort, auf das sie sich beziehen, stehen

a) Schlagwörter, die nur der näheren Erläuterung des anderen Schlagworts dienen, für den spezifischen Gegenstand aber zu weit oder zu farblos sind (z.B. 'Soziologie', 'Philosophie', 'Recht'); diese permutieren auch hier nicht.

SWW Gentechnologie ; Recht

SWW Weisheitsliteratur ; Theologie

b) Schlagwörter, die eine Eigenschaft oder einen Zustand des Gegenstandes ausdrücken, mit dessen Bezeichnung sie verknüpft werden.

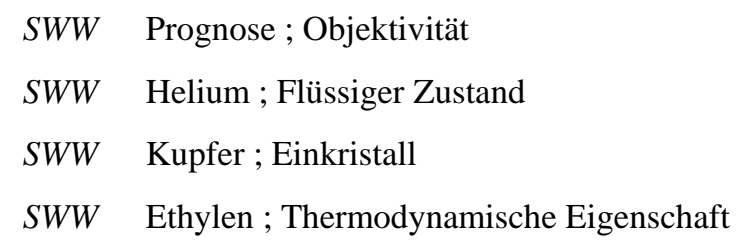

c) alle in der SWD oder in Anl. 5 als nicht aussagekräftig gekennzeichneten Schlagwörter (diese permutieren dann auch nicht).

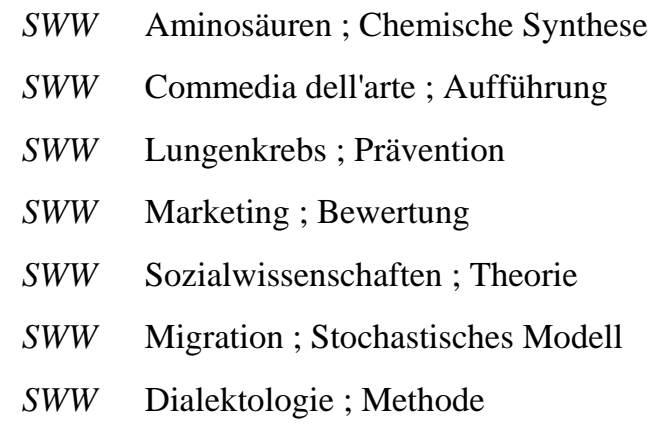

4. Bei linguistischen Untersuchungen folgt gemäß § 305,1,c in der Kette nach Sprachbezeichnungen die Wortart (oder Schlagwort 'Phonetik' bzw. 'Phonologie') und danach die untersuchte sprachliche Einheit.

SWW Deutsch; Substantiv ; Haus

(321)

5. Schlagwörter, die eine Untersuchungsmethode oder einen Gesichtspunkt der Darstellung ausdrücken, stehen in der Grundkette bzw. Teilkette an letzter Stelle, ggf. vor einem Formschlagwort. 
SWW Bakterien ; Identifikation ; Fettsäuren ; Gaschromatographie (2134) (3214) (4123)

SWW Humanistisches Gymnasium ; Gymnasiast ; Bildungsgang ; Längsschnittuntersuchung (2134) (3214)

SWW USA ; Geschichtsschreibung ; Oktoberrevolution ; Quellenkritik (2134) (3124)

\section{$\S 323$ entfällt}

\section{§ 324 Pleonasmus in der Schlagwortkette}

1. In einer Kette mehrerer Sachschlagwörter können in Komposita und Adjektiv-SubstantivVerbindungen pleonastische Bestandteile auftreten. Grundsätzlich wird für jedes Schlagwort der Kette die präzise Bezeichnung gewählt (vgl. § 7,3).

$\begin{array}{ll}\text { SWW } & \text { Gebirgswald; Waldtiere } \\ \text { SWW } & \text { Kniegelenkverletzung; Sportverletzung } \\ \text { SWW } & \text { Krankenhausabfall ; Abfallbeseitigung } \\ S W W & \text { Kleinkind ; Kinderpsychologie } \\ S W W & \text { Krankenhausarzt; Arztrecht } \\ S W W & \text { Musikhandschrift; Handschriftenkatalogisierung } \\ \text { SWW } & \text { Erwachsenenbildung; Bildungssoziologie }\end{array}$

2. Gemäß $\S 6$ soll die Schlagwortkette den einzelnen Gegenstand präzise kennzeichnen und keine über den Dokumenteninhalt hinausgehenden übergeordneten Schlagwörter enthalten. Bei Ketten aus Schlagwörtern für Allgemeinbegriffe ist darauf zu achten, dass nicht ein Begriff in der Kette steht, der gemäß SWD eine hierarchische oder assoziative Beziehung zu einem anderen Begriff der Kette hat. Dies gilt aber nur für Begriffe, die durch je ein einzelnes Schlagwort repräsentiert werden.

SWW Psychiatrische Klinik ; Management

nicht: Psychiatrische Klinik ; Krankenhaus ; Management

SWW Jugendkriminalität ; Prävention

nicht: Jugendkriminalität ; Verbrechen ; Prävention

Es können jedoch pleonastische Verknüpfungen vorkommen, wenn sich die durch die Schlagwörter repräsentierten Begriffe ergänzen und teilweise überschneiden, ohne gemäß $\S 316$ in hierarchischer oder assoziativer Beziehung zu stehen.

SWW Tennis ; Sportverletzung ; Kniegelenkverletzung

SWW Druckmaschine; Maschinenlärm ; Lärmschutz

Zwischen den einzelnen Kettengliedern besteht keine hierarchische oder assoziative Relation.

Insbesondere ist dies angebracht, damit ein Schlagwort aus einer gängigen Verknüpfung als Sucheinstieg nicht entfallen muss, weil ein weiteres Schlagwort mit pleonastischem Bestandteil hinzutritt.

SWW Deutsch ; Aussprache ; Deutschunterricht ; Ausländer

Deutsch entfällt nicht als pleonastisch. 
SWW Vögel ; Bedrohte Tiere ; Vogelkrankheit

SWW Kind ; Schwere Krankheit ; Kinderkrankenschwester ; Kinderpsychologie

$S W W \quad$ Eltern ; Kind ; Elternarbeit ; Evangelische Kirche

SWW Fußboden ; Holz ; Fußbodenheizung

In den in $\S 305,1$,c geregelten Fällen werden für linguistische Untersuchungen sprachliche Einheiten mit der zugehörigen Sprachbezeichnung und Wortart verknüpft, auch wenn sie für sich bereits eindeutig sind.

SWW Französisch ; Substantiv; gueule

3. Werden Schlagwörter für Allgemeinbegriffe mit Individualnamen (Geographika, Ethnographika, Körperschaftsnamen, historischen Einzelereignissen, Produktnamen usw.) verknüpft, so sind grundsätzlich die spezifischen Sachschlagwörter zu verwenden. Dies entspricht dem Grundsatz, dass gleiche Gegenstände gleich erschlossen werden sollen, um durch Verknüpfung der gleichen Suchbegriffe wieder auffindbar zu sein.

$S W W \quad$ Wilhelm Gustloff $<$ Schiff $>$; Schiffsuntergang

SWW Nürnberg ; Stadtverkehr ; Verkehrsplanung

SWW Bodensee; Binnenschifffahrt

nicht: Bodensee ; Schifffahrt

daneben:

SWW See ; Binnenschifffahrt

SWW Spanien / Cortes ; Parlamentswahl

daneben:

SWW Spanien ; Parlamentswahl

Schlagwörter für Allgemeinbegriffe entfallen jedoch in der Kette, wenn ihre semantischen Merkmale im Individualnamen bzw. in einer Epochenbezeichnung vollständig enthalten sind.

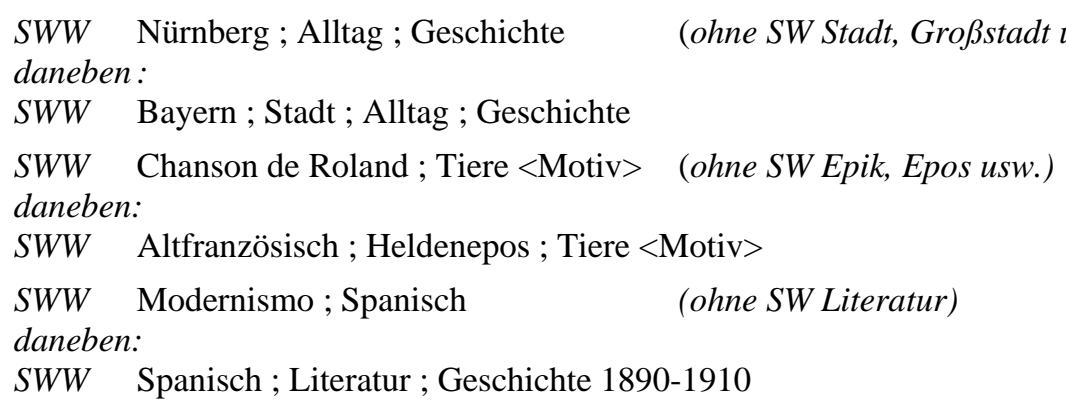

Ein geographischer, ethnographischer oder sprachlicher Bezug kann aber auch dann ausgedrückt werden, wenn er bereits in einem Individualnamen enthalten ist, aber in Verknüpfung mit einem anderen Schlagwort der Kette recherchierbar sein soll (vgl. § 13,3).

SWW Frankreich ; Schulpolitik ; Kommunistische Partei Frankreichs

SWW Homerus ; Griechisch ; Verb ; telein

Linguistische Phänomene sollen gemäß \& 305,1,c mit der Sprachbezeichnung recherchierbar sein.

Aber:

SWW Eichendorff, Joseph $\neg$ von $\neg$; Lyrik $\quad$ (ohne SW Deutsch)

4. Als pleonastisch zu betrachten ist bis auf wenige Ausnahmen das Schlagwort 'Mensch', ferner das Schlagwort 'Staat' bei politischen und das Schlagwort 'Christentum' bei theologischen Themen. 
Titel: $\quad$ Systematische Anatomie des Menschen / hrsg. von Rolf Bertolini. - 1987

SW Anatomie

Titel: $\quad$ Naturwissenschaft im NS-Staat / Rainer Brauer [Hrsg.]. - 1983

SWW Nationalsozialismus ; Naturwissenschaften ; Geschichte ; Aufsatzsammlung

SWW Deutschland ; Naturwissenschaften ; Geschichte 1933-1945 ; Aufsatzsammlung

SWW Drittes Reich ; Naturwissenschaften ; Aufsatzsammlung

Titel: $\quad$ Anders beten : so reden junge Menschen mit Gott / Josef Prinz [Hrsg.]. - 1983

SWW Jugend ; Gebet ; Anthologie

\section{§ 325 Permutation}

Für Listenfunktionen können die Glieder einer Grundkette mit Sachschlagwort permutiert werden. In diesem Falle gilt:

1. Bei der Permutation wird gemäß den Schemata von $\S 15,10$,c-e verfahren. Teilketten bleiben dabei erhalten und permutieren in sich (vgl. auch § 322,2).

2 a) Bei einem oder mehreren aussagekräftigen Sachschlagwörtern in der Grundkette erhält jedes eine Eintragung (vgl. §§ 117,4; 220,4,b; 322).

b) Für sich allein nicht aussagekräftige Sachschlagwörter, die in der SWD bzw. in Anl. 2 oder Anl. 5 einen entsprechenden Hinweis tragen, werden nicht permutiert (vgl. § 322,3).

3. Zur Permutation von Sachschlagwörtern in einer Grundkette mit Personenschlagwort vgl. $\S 117,4$; mit geographischem/ethnographischem Schlagwort vgl. § 220,4; mit Zeitschlagwort vgl. $\S \S 15,6$; 406; mit Formschlagwort vgl. §§ 15,8; 504.

\section{§§ 326 - 329 entfallen}





\section{Zeitschlagwörter und andere Zeitaspekte Zeitschlagwörter}

\section{Definition und Verwendung}

\section{§ 401 Definition}

Zeitschlagwörter bezeichnen einen Zeitpunkt oder Zeitraum und erhalten in der SWD den Indikator $\mathrm{z}$.

Als Zeitschlagwörter gelten 'Geschichte', die zugelassenen Komposita mit '-geschichte' sowie 'Prognose' ggf. erweitert durch Jahreszahlen.

$$
\begin{array}{ll}
\text { SW } & \text { z Kirchengeschichte } \\
\text { SW } & \text { z Geschichte 1500-1600 } \\
\text { SW } & \text { z Prognose 2000-2005 }
\end{array}
$$

\section{§ 401a Verwendung}

1. 'Geschichte' und die zugelassenen Komposita mit '-geschichte' (vgl. § 402,1) werden verwendet

- wenn im vorliegenden Dokument ganz oder überwiegend ältere Zustände behandelt werden, der Gegenstand jedoch auch in der Gegenwart vorkommen kann, oder

- wenn eine chronologische Darstellung vorliegt, oder

- wenn, unabhängig von der Form der Darstellung, eine zeitliche Einschränkung des Themas erforderlich ist.

2. a) Für historische Gesamtdarstellungen eines Gegenstands von dessen Anfängen bis zum Ende bzw. bis zum Erscheinungsjahr des vorliegenden Dokuments wird ein Zeitschlagwort ohne Jahreszahl verwendet.

Titel: $\quad \neg$ Der $\neg$ Dreißigjährige Krieg / Georg Schmidt. - 1995

SWW s Dreißigjähriger Krieg ; z Geschichte

Behandelt ist der Zeitraum von 1618-1648.

Titel: Bayerische Kirchengeschichte / Karl Hausberger ; Benno Hubensteiner . - 1987

SWW g Bayern ; z Kirchengeschichte

Behandelt ist der Zeitraum von den Anfängen bis 1987.

b) Bei Dokumenteninhalten mit zeitlicher Begrenzung wird das Zeitschlagwort durch entsprechende Jahreszahlen erweitert.

Titel $\quad \neg$ Die $\neg$ Rheinlande in der Franzosenzeit : 1750-1815 / Alexander Conrady. - 1922

SWW g Rheinlande ; z Geschichte 1750-1815

Titel Sozialgeschichte Baden-Württembergs : 1800-1988 / Willi A. Boelcke. - 1989

SWW g Baden-Württemberg ; z Sozialgeschichte 1800-1988 
c) Bei älteren Gesamtdarstellungen, Reprints und unveränderten Neuauflagen, bei denen der Dokumenteninhalt durch das ursprüngliche Erscheinungsjahr des Dokuments wesentlich eingeschränkt ist, wird das Zeitschlagwort mit den entsprechenden Jahreszahlen verwendet.

Titel: Geschichte der Oper / von Hermann Kretzschmar. - [Nachdr. der Ausg. Leipzig 1919]. - 1983

SWW s Oper ; z Geschichte Anfänge-1919

Titel: $\quad \neg$ An $\neg$ introduction to genetics / A. H. Sturtevant ; G. W. Beadle. - Repr. [der Ausg.] Philadelphia 1939. - 1988

SWW s Genetik ; z Geschichte 1939 ; f Quelle

Aber:

Titel: $\quad$ Ausführliche Grammatik der lateinischen Sprache / Raphael Kühnen. - Nachdr. der 2. Aufl. 1912-1914. - 1976-1978

SWW g Latein ; s Grammatik

Der Inhalt ist unverändert gültig und wird durch das ursprüngliche Erscheinungsjahre nicht eingeschränkt.

3. Auf ein Zeitschlagwort wird verzichtet,

a) wenn es sich um eine aktuelle Darstellung handelt, es sei denn, es wird ein genau umrissener Zeitraum behandelt.

Titel $\quad \neg$ The $\neg$ English language today / ed. by Sidney Greenbaum. - 1985

SW g Englisch

Aber:

Titel: $\quad$ Modern music and after / Paul Griffiths. - 1995

SWW s Musik; z Geschichte 1945-1994

Zeitangaben nach Dokumenteninhalt

b) bei historisch geprägten Begriffen, außer es handelt sich um chronologische Gesamtdarstellungen.

SW k Allgemeiner Deutscher Arbeiterverein keine chronologische Darstellung

c) bei historischen Einzelereignissen, die ein Jahr oder kürzer gedauert haben.

SW s Oktoberrevolution

ohne Zeitschlagwort, auch wenn Vorgeschichte und Auswirkungen mitbehandelt sind

4. 'Prognose' wird als Zeitschlagwort verwendet, wenn bestimmte in der Zukunft liegende Zeiträume heranzuziehen sind.

Titel: $\quad$ Optionen bis 2030 : Szenarien für Wirtschaft und Gesellschaft in der Bundesrepublik Deutschland / Bruno Tietz. - 1986

SWW g Deutschland <Bundesrepublik> ; s Gesellschaft ; z Prognose 1986-2030

SWW g Deutschland <Bundesrepublik> ; s Wirtschaftsentwicklung ; z Prognose 1986-2030 


\section{Ansetzung}

\section{$\S 402$ Grundregeln}

1. Neben 'Geschichte' und 'Prognose' werden folgende Komposita als Zeitschlagwort angesetzt:

z Geistesgeschichte $\quad$ z Sozialgeschichte

z Ideengeschichte $\quad$ z Vor- und Frühgeschichte (vgl. § 402,2)

z Kirchengeschichte $\quad$ z Weltgeschichte (vgl. § 406,3)

Von synonymen Bezeichnungen wird verwiesen. Zugehörige Oberbegriffe bzw. verwandte Begriffe werden soweit sinnvoll erfasst.

2. Für Vorgeschichte (= Urgeschichte) und/oder Frühgeschichte wird auf das Zeitschlagwort 'Vor- und Frühgeschichte' normiert, unabhängig davon, ob in einem Dokument beide Perioden zugleich oder nur eine behandelt sind. (Einzelne Epochen der Vor- und Frühgeschichte vgl. § 408a,4.)

Titel: $\quad \neg$ Die $\neg$ Welt des frühen Spanien / Antonio Pando. - 1975

$S W W \quad$ g Spanien ; z Vor- und Frühgeschichte

Titel Ancient voyagers in Polynesia / Andrew Sharp. - 1964

SWW g Polynesien; s Schifffahrt ; z Vor- und Frühgeschichte

3. Alle übrigen Komposita mit '-geschichte' werden i.d. R. in Sachschlagwort und Zeitschlagwort zerlegt (vgl. aber § 405,3).

$S W W \quad$ s Begriff; z Geschichte

SWW g Spanien ; s Kultur ; z Geschichte 1650-1730

\section{$\S 403$ Zeitangaben}

1. Jahreszahlen nach Zeitschlagwörtern werden in arabischen Ziffern ohne Winkelklammern angesetzt. Zeiträume werden i. d. R. mit Anfangs- und Endjahr verbunden durch Bindestrich ohne Spatium wiedergegeben (vgl. § 17,2,a).

Die uniforme Verwendung des Zeitschlagworts und seine Erweiterung durch Jahreszahlen ermöglicht ein einheitliches Retrieval für Online-Kataloge und stellt für Listenfunktionen eine chronologische Ordnung der Schlagwortketten sicher. (Zur Wiedergabe von Epochenbezeichnungen durch 'Geschichte' mit Jahreszahlen vgl. $\S \S 408 \mathrm{a} ; 410,2$.)

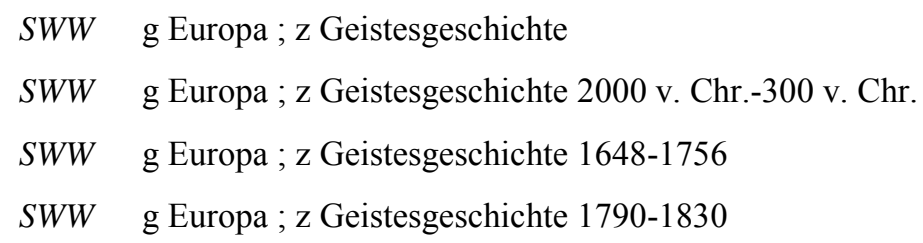

2. Es wird der im vorliegenden Dokument tatsächlich behandelte Zeitraum angesetzt. Dabei wird ein Jahrzehnt durch die Angabe ' $0-0$ ', ein Jahrhundert durch '00-00' und die Zeitwende durch '1 v. Chr.' bzw. '1-' ausgedrückt. 
Titel: $\quad \neg \mathrm{Die} \neg$ sechziger Jahre : Deutschland zwischen Protest und Erstarrung (1962-1972)/

Uwe Reimer. - 1993

SWW g Deutschland ; z Geschichte 1962-1972

Titel: $\quad$ Everyday fashion of the thirties / ed. by Stella Blum. - 1986

SWW g USA; s Mode ; z Geschichte 1930-1940

Titel: $\quad \neg$ L' $\neg$ Italia nell'ottocento / Ottavio Barié. - 1964

SWW g Italien ; s Kultur ; z Geschichte 1800-1900

Sind die Grenzen des im vorliegenden Dokument behandelten Zeitraums nicht genau festzustellen, werden Näherungswerte angesetzt.

Titel: $\quad \neg$ Der $\neg$ deutsche Roman im 20. Jahrhundert / Werner Welzig. - 1970

SWW g Deutsch; s Roman; z Geschichte 1900-1970

Näherungswert, da keine genaueren Angaben im Dokument zu ermitteln

3. Kleinere Zeiteinheiten als Jahre werden nicht berücksichtigt.

Titel: $\quad$ Trois journées pour détruire la monarchie : 14 juillet 1789 - 6 octobre 1789, 10 août 1792 / Noelle Destremau. - 1988

SWW s Französische Revolution ; z Geschichte 1789

SWW s Französische Revolution ; z Geschichte 1792

Aber:

SW s Zwanzigster Juli $\quad$ (vgl. $\S 415)$

4. Jahre vor Christi Geburt werden mit dem Zusatz 'v. Chr.' angesetzt.

Titel: $\quad$ Ninus und Semiramis in Sage und Geschichte : iranische Staaten und Reiternomaden vor Darius / Wolfram Nagel. - 1982

SWW g Iran <Altertum> ; z Geschichte 647 v. Chr.-546 v. Chr.

5. Ist die Festlegung eines Anfangsjahres nicht möglich, so wird 'Anfänge' angesetzt.

Titel: $\quad \neg$ Die $\neg$ Kammermusik Alt-Englands : vom Mittelalter bis zum Tode Henry Purcells / Ernst Hermann Meyer. - 1958

SWW g England ; s Kammermusik; z Geschichte Anfänge-1695

6. Steht bei einem Dokument das Ende des behandelten Zeitraums noch nicht fest, so wird hinter der Angabe des Anfangsjahres nur ein Bindestrich gesetzt. Das gilt i. d. R. auch für Werke, die noch nicht vollständig erschienen sind.

Titel: Quellen zu den deutsch-britischen Beziehungen. - Bd. 1 (1997) -

SWW g Deutschland ; s Außenpolitik ; g Großbritannien ; z Geschichte 1815- ; f Quelle

Aber:

Titel: Stück-Werk : [deutschsprachige Dramatik der 90er Jahre] / [hrsg. von Frank Hörnigk]. - 1997

SWW g Deutsch ; s Drama ; z Geschichte 1987-1997 ; f Aufsatzsammlung

Zeitangabe des Anfangsjahres nach Dokumenteninhalt, des Endjahres nach § 403,2.

nicht: Deutsch ; Drama ; Geschichte 1987- ; Aufsatzsammlung

7. Das Zeitschlagwort 'Geschichte' vor Jahreszahlen entfällt

a) in Homonymenzusätzen (vgl. $\S \S 106,3, c ; 415 \mathrm{a}, 1$,a; 710; 715,10; 716; 717)

b) nach bestimmten Formschlagwörtern (vgl. $\S \S 503 ; 735$; Anl. 6)

\section{$\S 404$ entfällt}




\section{§ 405 'Geschichte', 'Prognose' und Komposita mit '-geschichte' als Sachschlagwörter}

1. Die Zeitschlagwörter 'Geschichte' und 'Prognose' werden als Sachschlagwörter bei Dokumenten angesetzt, die das Wesen, den Begriff usw. von 'Geschichte' bzw. 'Prognose' zum Gegenstand haben.

Titel: Wörterbuch zur Geschichte / Erich Bayer ; Frank Wende. - 1995

SWW s Geschichte; f Wörterbuch

Aber:

Titel: $\quad \neg$ Das $\neg$ Fach Geschichte an der Universität Graz : 1729-1848 / Walter Koflechner. 1975

SWW c Graz/Universität ; s Geschichtswissenschaft ; z Geschichte 1729-1848

2. Alle Komposita mit '-geschichte' sind als Sachschlagwörter mit Homonymenzusatz $<$ Fach $>$ anzusetzen, wenn es sich um Wissenschaftsdisziplinen handelt.

SW $\quad$ s Kunstgeschichte $<$ Fach $>$

daneben:

SWW s Kunst; z Geschichte

SWW $\quad$ s Zeitgeschichte $<$ Fach $>$; s Geschichtsunterricht

SW $\quad$ s Kirchengeschichte $<$ Fach $>$

daneben:

SW $\quad$ z Kirchengeschichte

nicht: s Kirchengeschichte

Titel: $\quad$ Sozialgeschichte : Begriff, Entwicklung, Probleme / Jürgen Kocka. - 1986

SW $\quad$ s Sozialgeschichte $<$ Fach $>$

3. Daneben gibt es einzelne Komposita mit '-geschichte', die keinen konkreten zeitlichen Verlauf meinen und daher als Sachschlagwörter behandelt werden, z. B. 'Heilsgeschichte'. Als Sachschlagwörter gelten auch 'Textgeschichte' und 'Vorgeschichte' (dies nur bei historischen Einzelereignissen, vgl. § 415-416) sowie 'Formgeschichte'.

\section{§ 405a SWD-Datensatz}

Überblick über die wichtigsten Informationen in einem Datensatz der SWD für ein Zeitschlagwort (vgl. § 7,4) mit oder ohne Jahreszahl.

- Indikator z (Angabe obligatorisch bei allen Zeitschlagwörtern)

- Zeitschlagwort in Ansetzungsform (Angabe obligatorisch; vgl. §§ 402; 403)

- Quelle (Angabe obligatorisch, vgl. § 19,1)

- Definition (Angabe fakultativ, vgl. § 19,2)

- Verwendungshinweis (Angabe fakultativ, vgl. § 19,3)

- Redaktionelle Bemerkung (Angabe fakultativ, vgl. § 19,4)

- Notation (Angabe fakultativ, vgl. § 18,1)

- Zeitcode (Angabe obligatorisch, sofern Jahreszahlen folgen, vgl. §§ 18,4; 418)

- Synonymie-Verweisungen (vgl. § 12,2; 402,1); ggf. mit Bemerkung, eingeleitet durch * 
- Oberbegriffe (vgl. § 402,1); ggf. mit Bemerkung, eingeleitet durch *

- Verwandte Begriffe (vgl. § 402,1); ggf. mit Bemerkung, eingeleitet durch *

SW z Sozialgeschichte

Q $\quad$ M, RSWK $\S 402$

D Zeitschlagwort

H In Verknüpfung mit Geographika und Sachschlagwörtern nicht permutierend, vgl. § 406 RSWK

SYS $\quad 9.1$

BF $\quad$ z Gesellschaft / Geschichte

BF $\quad$ z Gesellschaftsgeschichte

OB z Geschichte

VB s Wirtschaft ; z Geschichte

\section{Verknüpfung und Permutation}

\section{§ 406 Verknüpfung und Permutation}

1. Zur Stellung des Zeitschlagworts in der Grundkette vgl. § 15,7.

2. Die Zeitschlagwörter 'Geschichte' und 'Prognose' sowie 'Geistesgeschichte', 'Ideengeschichte', 'Kirchengeschichte', 'Sozialgeschichte' und 'Vor- und Frühgeschichte' stehen in der Grundkette i. d. R. an letzter Stelle vor dem Formschlagwort.

Titel: Bibliographie zur Geschichte der deutschen Arbeiterbewegung : 1914-1945 / Kurt Klotzbach. - 1981

SWW g Deutschland ; s Arbeiterbewegung ; z Geschichte 1914-1945 ; f Bibliographie 19451974

SWW g Großbritannien ; s Fußball ; z Sozialgeschichte 1890-1970

3. Die Zeitschlagwörter 'Geistesgeschichte', 'Ideengeschichte', 'Kirchengeschichte' und 'Sozialgeschichte' werden bei historischen räumlich nicht begrenzten Darstellungen erstes Schlagwort, ggf. mit Zeitangaben in Jahren.

Titel: $\quad$ Kirchengeschichte der Neuzeit. - 1989-1993

SWW z Kirchengeschichte 1500-1965

'Weltgeschichte' wird nur erstes Schlagwort und zwar bei historischen räumlich und sachlich nicht begrenzten Darstellungen, ggf. mit Zeitangaben in Jahren.

In allen anderen Fällen wird mit 'Geschichte’ verknüpft.

Titel: Zeitgeschichte aus erster Hand : Augenzeugenberichte und Reportagen über die Zeit nach dem 2. Weltkrieg / [Hrsg.:] Heinrich Pleticha. - 1988

SWW z Weltgeschichte 1945-1987 ; f Quelle

Aber:

Titel: $\quad$ Weltgeschichte der Malerei / hrsg. von Claude Schaeffner. - 1965-1968

SWW s Malerei ; z Geschichte

4. Von der Reihenfolge der Grundkette wird abgewichen, wenn eine falsche Zuordnung des Zeitbegriffs entstünde (vgl. § 322).

SWW g Deutschland ; z Geschichte 1918-1933 ; s Geschichtsschreibung daneben:

SWW g Deutschland ; s Geschichtsschreibung ; z Geschichte 1918-1933

SWW g China ; z Geschichte 1896-1900 ; g Großbritannien ; s Presse 
5. Zur Verknüpfung eines Zeitschlagworts mit einem Personenschlagwort vgl. §§ 15,3; 116,2,d; mit einem geographischen/ethnographischen Schlagwort vgl. §15,4; mit einem Sachschlagwort vgl. § 15,6; mit einem Formschlagwort vgl. § 15,8.

6. Permutation

Zeitschlagwörter werden i. d. R. nicht permutiert (vgl. § 15,10,b-e).

\section{$\S 407$ entfällt}

\section{Epochenbezeichnungen}

\section{Definition und Verwendung}

\section{$\S 408$ Definition}

Epochenbezeichnungen charakterisieren die gesamte Kultur, Kunst, Geistesgeschichte oder das politische und gesellschaftliche System eines längeren Zeitabschnitts und drücken sowohl einen sachlichen wie einen zeitlichen Aspekt aus. Als Epochenbezeichnungen gelten auch Begriffe, die räumlich oder auf einzelnen Gebieten der Kunst eingeschränkt verwendet werden. Sie erhalten in der SWD den Indikator s und sind dort mit Verwendungshinweisen als solche gekennzeichnet.

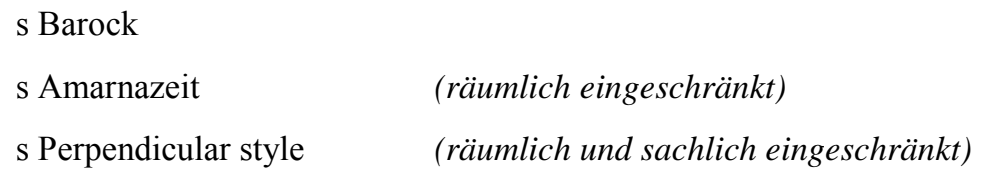

\section{§ 408a Verwendung}

1. a) Epochenbezeichnungen, welche die Kultur einer Epoche bzw. kunst-, kultur- und geistesgeschichtliche Richtungen und Stile kennzeichnen, werden wegen ihrer Gebräuchlichkeit und Relevanz als zusätzlicher Sucheinstieg neben dem Zeitschlagwort mit Jahreszahlen verwendet. Diese richten sich dabei nach dem im vorliegenden Dokument behandelten Zeitraum, ersatzweise nach Näherungswerten, die für Epochenbezeichnungen in der SWD bzw. in den Nachschlagewerken angegeben sind. Tritt der zeitliche Aspekt zugunsten des sachlichen stark zurück, entfällt die Schlagwortkette mit dem Zeitschlagwort und Jahreszahlen.

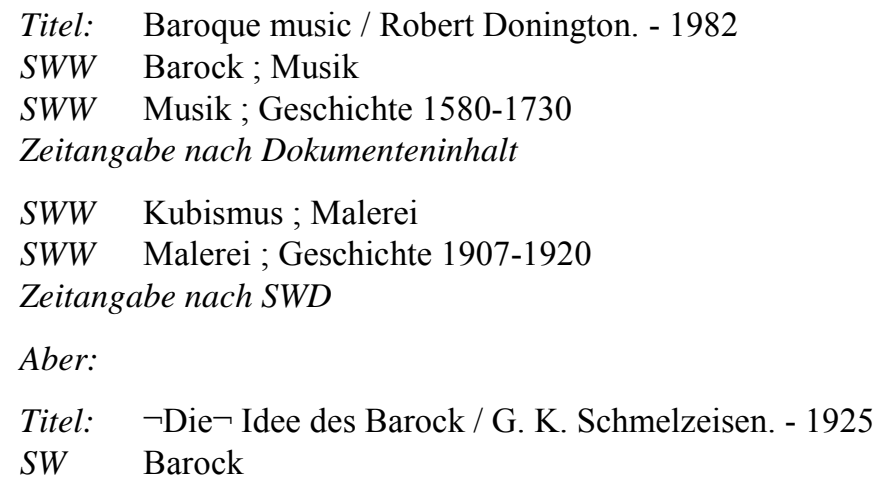


Titel: $\quad$ Antike in der Moderne / hrsg. von Wolfgang Schuller. - 1985

SWW Antike ; Rezeption ; Kongress ; Konstanz <1984>

b) Bezeichnungen für Kulturepochen usw. werden nicht verwendet, wenn sie lediglich als Zeitangabe dienen (vor allem für die politische Geschichte) oder auf andere Länder bzw. Sachverhalte übertragen werden. (Zum Wegfall der Epochenbezeichnung in der Schlagwortkette vgl. auch $\S 410$.)

Titel: $\quad$ Elektrizität im Barock / Fritz Fraunberger. - 1971

SWW Elektrizität ; Geschichte 1600-1750

Zeitangabe nach $S W D$

Titel: Italienische Renaissance-Literatur : eine Anthologie / Marion Steinbach . - 1996

SWW Italienisch ; Literatur ; Geschichte 1420-1600 ; Anthologie

Zeitangabe nach Dokumenteninhalt

c) Tritt dasselbe Schlagwort sowohl als Bezeichnung für eine Kulturepoche als auch als Allgemeinbegriff auf, dann wird es je nach Dokumenteninhalt verwendet

- als Bezeichnung für eine Kulturepoche

Titel: $\quad$ Deutsche Literatur im bürgerlichen Realismus 1848-1898 / Fritz Martini. - 1981

SWW Realismus ; Literatur ; Deutsch

SWW Deutsch ; Literatur ; Geschichte 1848-1898

- als Allgemeinbegriff

Titel: $\quad$ Realistische Kunst in Wien : 1945-1995. - 1996

SWW Wien ; Realismus ; Kunst ; Geschichte 1945-1995 ; Ausstellung ; Wien <1996>

2. a) Epochenbezeichnungen vorwiegend politischen Ursprungs (insbesondere von Personen abgeleitete) werden i. d. R. nicht verwendet, auch wenn sie in kultur- oder geistesgeschichtlichem Zusammenhang vorkommen, da sie nach Ausweis der Nachschlagewerke weniger gebräuchlich sind und der von ihnen abgedeckte Zeitraum eindeutig durch ein Zeitschlagwort mit Jahrzehnten wiedergegeben werden kann.

Titel: $\quad \neg$ Die $\neg$ augusteische Kultur / Richard Heinze. - 4. Aufl. - 1983

SWW Römisches Reich; Kultur ; Geschichte 27 v. Chr.-14

Titel: Viktorianisches England in deutscher Perspektive / hrsg. von Adolf M. Birke. - 1983

SWW Deutschland ; Großbritannien ; Geschichte 1837-1901 ; Kongress ; Coburg <1981>

Titel $\neg$ Das $\neg$ Zeitalter des Imperialismus / Gregor Schöllgen. - 1986

SW Weltgeschichte 1880-1918

Von der nicht zugelassenen Epochenbezeichnung wird auf den betreffenden Sachverhalt mit 'Geschichte' und Jahreszahl verwiesen.

SWW Römisches Reich ; Geschichte 27 v. Chr.-14

Hinweissatz, gekennzeichnet in MAB Feld 067

$B F \quad$ Augusteisches Zeitalter

b) Wegen ihrer Bedeutung als Sucheinstiege sind jedoch folgende politische Epochenbezeichnungen zugelassen:

- 'Weimarer Republik' und 'Drittes Reich'

Titel: $\quad \neg$ Das $\neg$ nationalsozialistische Deutschland : 1933-1945 / Ludolf Herbst. - 1996

SWW Drittes Reich; Geschichte

SWW Deutschland; Geschichte 1933-1945 
SWW Weimarer Republik; Partei

SWW Deutschland ; Partei ; Geschichte 1918-1933

- Bezeichnungen chinesischer Herrscherdynastien

SWW Tangdynastie; Recht

SWW China ; Recht ; Geschichte 618-907

SWW Mingdynastie ; Porzellan

SWW China ; Porzellan; Geschichte 1368-1644

3. a) 'Altertum', 'Antike', und 'Spätantike' werden als Epochenbezeichnungen nur für räumlich umfassende Darstellungen verwendet, d. h. den Mittelmeerraum und den Alten Orient (bei 'Altertum') bzw. den Mittelmeerraum (bei 'Antike' und 'Spätantike').

Anm.: $\mathrm{Zu}<$ Altertum> als Homonymenzusatz bei Ländern der alten Welt vgl. § 206,2.

Titel: $\quad \neg \mathrm{La} \neg$ divination dans l'Antiquité / Raymond Bloch. - 1984

$S W W$ Antike; Wahrsagen

$S W W \quad$ Griechenland <Altertum> ; Wahrsagen ; Geschichte 800 v. Chr.-500

SWW Römisches Reich; Wahrsagen ; Geschichte 800 v. Chr.-500

nicht: Wahrsagen ; Geschichte 800 v. Chr.-500

Aber:

SWW Sardinien ; Bergwerk ; Geschichte 800 v. Chr.-500

b) 'Mittelalter' und 'Neuzeit' werden nur verwendet, wenn alle Bereiche der betreffenden Epoche behandelt sind und nicht durch einen geographischen/ethnographischen oder sachlichen Aspekt präzisiert werden.

Anm.: 'Mittelalter' wird im Sinn des europäischen Mittelalters verwendet, 'Neuzeit' für alle Kontinente.

Titel: $\quad$ Encyclopedia of the Middle Ages / Matthew E. Buneson. - 1995

$S W W \quad$ Mittelalter; Wörterbuch

SWW Europa ; Geschichte 500-1500; Wörterbuch

Aber:

Titel: $\quad \neg$ Das $\neg$ römische Recht im Mittelalter / hrsg. von Eltjo J. H. Schrage. - 1987

SWW Römisches Recht; Geschichte 500-1500 ; Aufsatzsammlung

Zeitangabe nach SWD

Titel: $\quad \neg$ Die $\neg$ Architektur der Neuzeit / hrsg. von Martin Grassnick. - 1982

SWW Architektur; Geschichte 1500-1970

Zeitangabe nach Dokumenteninhalt

4. Epochenbezeichnungen der Geologie und der Vor- und Frühgeschichte einschließlich der Bezeichnungen 'Römerzeit', 'Völkerwanderungszeit' und 'Präkolumbianische Zeit' werden wie Sachschlagwörter verwendet. Die Wiedergabe durch ein Zeitschlagwort mit Jahreszahlen entfällt, da diese meist nicht eindeutig $\mathrm{zu}$ ermitteln sind. ( $\mathrm{Zu}$ räumlich begrenzten geologischen bzw. stofflich-räumlichen stratigraphischen Einheiten vgl. § 209a.)

$\begin{array}{ll}S W & \text { Tertiär } \\ S W & \text { Eifelium } \\ S W & \text { Neolithikum } \\ S W & \text { Bronzezeit } \\ S W W & \text { Köln ; Römerzeit }\end{array}$


5. Nicht als Epochenbezeichnungen gelten und wie Sachschlagwörter zu verwenden sind

a) Stile und Richtungen, die nicht eine ganze Epoche bestimmen, sondern nur eine von mehreren Richtungen innerhalb des jeweiligen Faches oder Raumes darstellen.

$\begin{array}{ll}S W & \text { Neugotik } \\ S W & \text { Manierismus } \\ S W & \text { Surrealismus }\end{array}$

b) Einzelne Schulen und Künstlervereinigungen

$\begin{array}{ll}S W & \text { Bauhaus } \\ S W & \text { Blauer Reiter } \\ S W & \text { Düsseldorfer Malerschule } \\ S W & \text { Photorealismus }\end{array}$

\section{Ansetzung}

\section{§ 409 Ansetzung}

1. Epochenbezeichnungen werden i. d. R. in der im Deutschen gebräuchlichen Form gemäß der „Liste der Nachschlagewerke“ (vgl. § 9,3) angesetzt. Von synonymen Bezeichnungen wird verwiesen. Zugehörige Oberbegriffe bzw. verwandte Begriffe werden soweit sinnvoll erfasst.

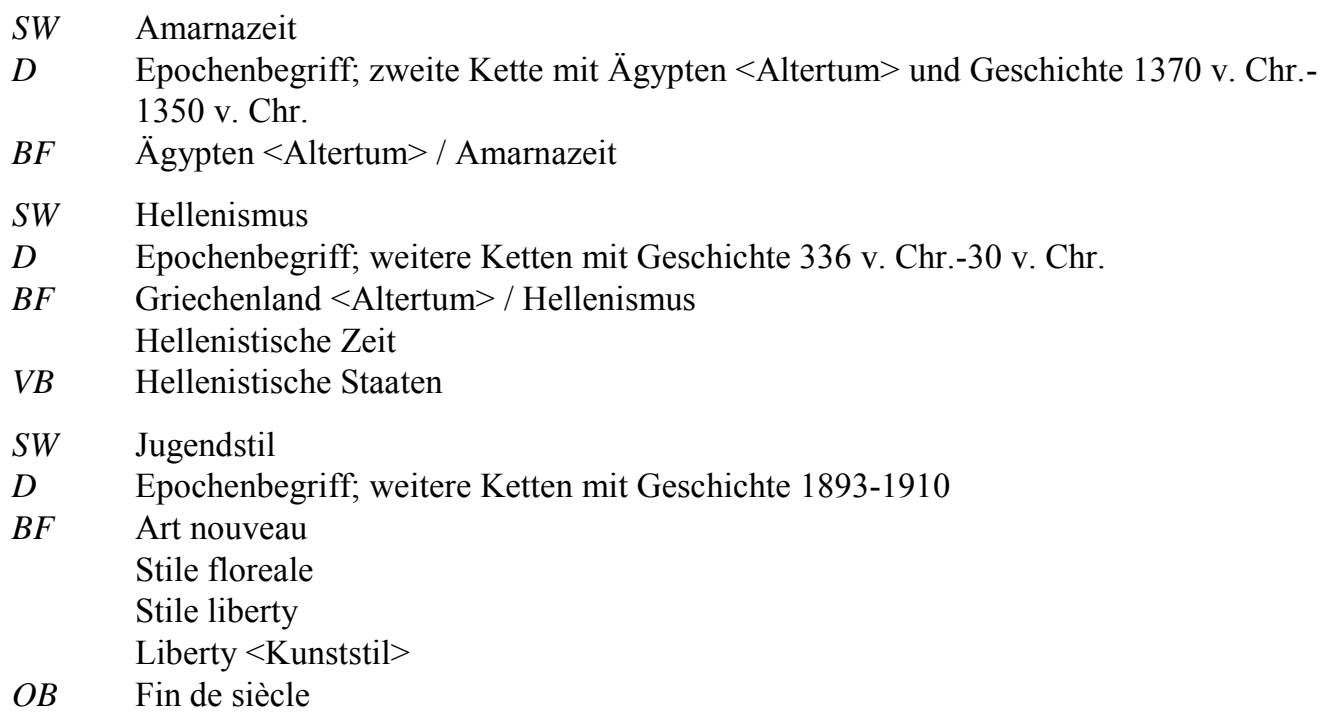

2. Epochenbezeichnungen werden, von Individualnamen abgesehen, nicht als Bestandteil präkombinierter Schlagwörter angesetzt (vgl. aber § 409,3).

SWW Barock; Musik

nicht: Barockmusik

3. Komposita mit 'Früh-', 'Hoch-', 'Spät-' usw. bei Epochenbezeichnungen und Allgemeinbegriffen werden nur dann angesetzt, wenn sie im maßgeblichen Nachschlagewerk eine eigene Eintragung haben. Andernfalls werden sie beim Grundbegriff als Synonym erfasst. 


$\begin{array}{lll}S W & \text { Spätantike } & \text { (Epochenbezeichnung) } \\ Q & \text { M } & \\ O B & \text { Antike } & \\ S W & \text { Neokeynesianismus } & \text { (Allgemeinbegriff) } \\ Q & \text { HdWW } & \\ V B & \text { Keynessche Theorie } & \\ & \text { Neue Makroökonomie } & \\ \text { Aber: } & & \\ S W & \text { Gotik } & \text { (Epochenbezeichnung) } \\ B F & \text { Frühgotik } & \\ & \text { Spätgotik } & \text { (Allgemeinbegriff) } \\ S W & \text { Humanismus } & \\ B F & \text { Frühhumanismus } & \text { (Epochenbezeichnung) } \\ V B & \text { Renaissance } & \end{array}$

\section{Verknüpfung und Permutation}

\section{$\S 410$ Verknüpfung und Permutation}

Anm.: Im Folgenden sind Permutationsmuster nach $\S 410,3$ angegeben.

1. Hat ein Dokument Vergleiche oder Beziehungen zwischen zwei oder mehreren Epochenbezeichnungen bzw. zwischen einer Epochenbezeichnung und einem Allgemeinbegriff zum Gegenstand, so werden sie in einer Schlagwortkette verknüpft. Dabei wird eine sinnvolle Reihenfolge gewählt. Damit zu verknüpfende geographische/ethnographische, Sach- oder Zeitschlagwörter werden dabei der Epochenbezeichnung zugeordnet, zu der sie gehören. Gehören sie zu mehreren, werden sie der ersten Epochenbezeichnung zugeordnet (vgl. § 15,2 und 5).

Titel: $\quad \neg$ The $\neg$ Renaissance discovery of classical antiquity / by Roberto Weiss. - 1969

SWW Antike ; Rezeption ; Renaissance

Titel: Christianity and the Hellenistic world / Ronald H. Nash. - 1985

SWW Hellenismus; Christentum

2. Wegen ihrer inhaltlichen Bedeutung folgt die Epochenbezeichnung in der Grundkette dem Personenschlagwort und geht den Schlagwörtern anderer Kategorien voran. Bei Verknüpfung mit einem Allgemeinbegriff und einem geographischen Schlagwort steht dieses am Schluss der Kette.

Zur Abdeckung des zeitlichen Aspekts wird i. d. R. eine zweite Grundkette aus Gegenstand und Zeitschlagwort mit Jahreszahlen gebildet.

Titel: $\quad$ Bruckner und die Musik der Romantik. - 1989

SWW p Bruckner, Anton ; s Romantik ; s Musik ; f Kongress ; g Linz <1987> (23145)

SWW p Bruckner, Anton ; s Musik ; z Geschichte 1790-1830 ; f Kongress ; g Linz <1987> (23145)

Zeitangabe nach SWD 
Titel: $\quad$ Gotische Kathedralen und Kunstschätze in Frankreich / Hervé Kergall. - 1990

$S W W \quad$ s Gotik; g Frankreich

SWW g Frankreich ; s Kunst ; z Geschichte 1150-1520

Zeitangabe nach Dokumenteninhalt

Titel: $\quad \neg$ Die $\neg$ deutsche Plastik : 1350-1550 / M. J. Liebmann. - 1982

SWW s Gotik; s Plastik; g Deutschland ; z Geschichte 1350-1520

SWW s Renaissance ; s Plastik ; g Deutschland ; z Geschichte 1500-1550

SWW g Deutschland; s Plastik; z Geschichte 1350-1550

(213)

Titel: $\quad \neg$ The $\neg$ cubist print / Burr Wallen; Donna Stein. - 1981

SWW s Kubismus ; s Druckgraphik ; z Geschichte 1907-1914;

f Ausstellung;g Washington $<$ DC, 1981>

SWW s Druckgraphik ; z Geschichte 1907-1914 ; f Ausstellung ; g Washington <DC, 1981>

Die Zeitangabe nach Dokumenteninhalt ist auch in der ersten Kette notwendig, da im Doku-

ment nur ein zeitlicher Abschnitt aus dem Kubismus 1907-1920 behandelt wird.

SWW s Antike ; s Elegie ; z Geschichte 200 v. Chr.-100

SWW g Griechisch; s Elegie ; z Geschichte 200 v. Chr.-100

SWW g Latein; s Elegie ; z Geschichte 200 v. Chr.-100

3. Permutation

Epochenbezeichnungen werden i. d. R. nicht permutiert (vgl. aber $§ 410,1$ ), sofern die zweite Grundkette mit ihren Permutationen die für Listenfunktionen relevanten Sucheinstiege abdeckt.

\section{$\S \$ 411$ - 414 entfallen}

\section{Historische Einzelereignisse}

\section{$\S 415$ Definition}

Als historische Einzelereignisse gelten Kriege, Schlachten, Belagerungen, Revolutionen, Konferenzen, Kongresse, Konzilien, Synoden u. ä. Sie erhalten in der SWD

- den Indikator p, wenn ihre Ansetzungsform mit einem Personenschlagwort beginnt

SW p Luther, Martin / Thesenanschlag

- den Indikator g, wenn ihre Ansetzungsform mit einem geographischen/ethnographischen Schlagwort beginnt

$$
\text { SW g Brest-Litowsk / Friede }
$$

- den Indikator s bei Sachschlagwörtern

SW s Französische Revolution

- den Indikator k bei Körperschaften

SW k Wiener Kongress 


\section{§ 415a Ansetzung}

1. a) Historische Einzelereignisse werden i.d.R. in der im Deutschen gebräuchlichen Form gemäß der „Liste der Nachschlagewerke“ (vgl. § 9,3) angesetzt, soweit ein solcher Individualname in den Nachschlagwerken auch innerhalb eines umfassenden Artikels zu ermitteln ist. Von synonymen Bezeichnungen wird verwiesen. Zugehörige Oberbegriffe, d.h. übergeordnetes historisches Einzelereignis oder Geographikum ; Geschichte Jahr(e) sowie verwandte Begriffe werden soweit sinnvoll erfasst. (Verträge vgl. auch § 716.)

$\begin{array}{ll}\text { SW } & \text { Burenkrieg } \\ \text { BF } & \begin{array}{l}\text { Südafrikanischer Krieg <1899-1902> } \\ \text { Südafrika / Burenkrieg }\end{array} \\ \text { MO } & \begin{array}{l}\text { Großbritannien ; Geschichte 1899-1902 } \\ \text { Südafrika ; Geschichte 1899-1902 }\end{array} \\ & \text { Oktoberrevolution } \\ \text { BW } & \text { Russische Revolution <1917, Oktober > } \\ & \text { Russland / Oktoberrevolution } \\ & \text { Sowjetunion / Oktoberrevolution } \\ \text { MO } & \text { Russland ; Geschichte 1917 } \\ \text { SW } & \text { Emser Depesche } \\ \text { OB } & \text { Deutsch-französischer Krieg <1870-1871> } \\ \text { SW } & \text { Rapallovertrag } \\ M O & \text { Deutschland ; Geschichte 1922 } \\ & \text { Sowjetunion ; Geschichte 1922 }\end{array}$

Gleichnamige Ereignisse werden i.d.R. durch Jahreszahlen als Homonymenzusatz unterschieden (vgl. § 17,2,a).

$\begin{array}{ll}\text { SW } & \text { Punischer Krieg }<218 \text { v. Chr.-201 v. Chr. } \\ \text { SW } & \text { Weltwirtschaftskrise }<1929-1932>\end{array}$

b) Regelmäßig wiederkehrende oder häufig auftretende Ereignisse wie Wahlen, Streiks, Feste, Katastrophen usw. werden nicht als historische Einzelereignisse angesetzt, sondern durch Verknüpfung mit einem Allgemeinbegriff wiedergegeben. Im Zweifelsfall wird kein historisches Einzelereignis angenommen.

$\begin{array}{ll}\text { SWW } & \text { USA ; Präsidentenwahl ; Geschichte } 1984 \\ \text { SWW } & \text { San Francisco <Calif.> ; Erdbeben ; Geschichte } 1906\end{array}$

2. Ist in den Nachschlagewerken kein Individualname nachgewiesen oder ist dieser nicht spezifisch genug, so wird ein mehrgliedriges Schlagwort aus dem betreffenden Personen- oder geographischen/ethnographischen Namen und einem das Ereignis kennzeichnenden Allgemeinbegriff (wie 'Krieg', 'Schlacht', 'Revolution', 'Friede', 'Konferenz', 'Konzil', 'Synode' usw., vgl. dazu die Aufstellung in den „Praxisregeln“ § 415,2) angesetzt. Dieser sollte möglichst der Ansetzungsform des Sachschlagworts entsprechen. Wenn es sich für Listenfunktionen um einen relevanten Sucheinstieg handelt, wird vom Sachschlagwort mit dem geographischen/ethnographischen bzw. Personenschlagwort als zweitem Glied verwiesen.

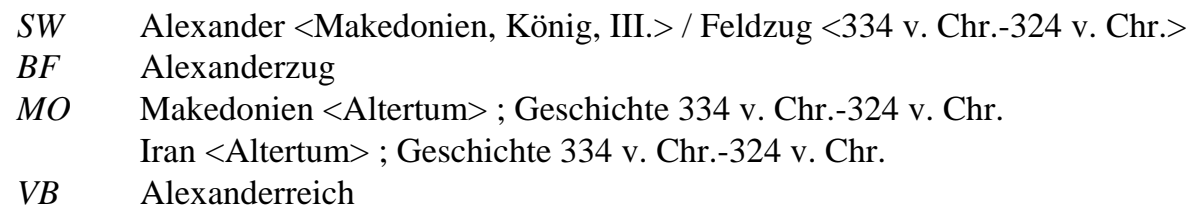




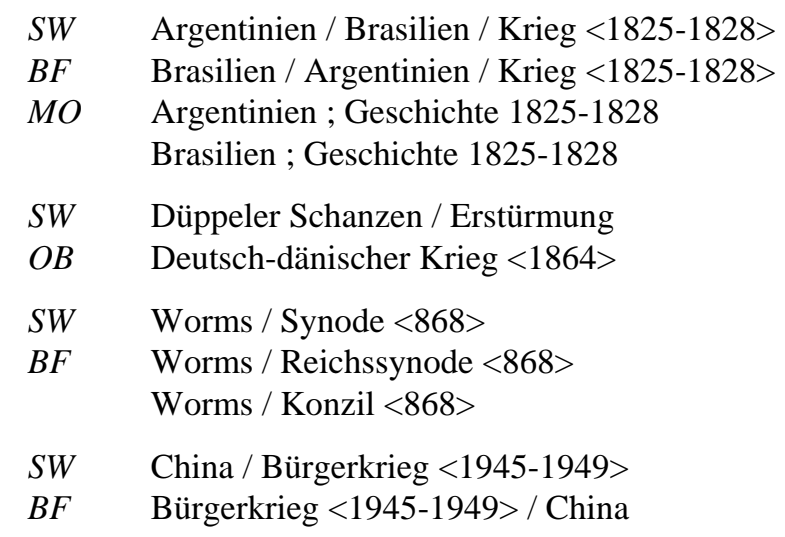

Veranstaltungen werden im Zweifelsfall nicht als Körperschaft angesetzt (vgl. auch §§ 601,2; 607).

3. Mehr als zwei gleichnamige historische Ereignisse werden mit ihrer Pluralform ohne Homonymenzusatz angesetzt.

Titel: $\quad \neg$ The $\neg$ Punic wars / Nigel Bagnall. - 1990

SW Punische Kriege

4. Kürzere Zeiträume innerhalb eines längeren historischen Einzelereignisses werden mit 'Geschichte' und Jahreszahlen angesetzt.

Titel: $\quad$ Revolution und Konterrevolution in Katalonien / Carlos Semprun-Maura. - 1983

SWW Katalonien ; Spanischer Bürgerkrieg ; Geschichte 1936-1937

Zeitangabe nach Dokumenteninhalt

\section{§ 416 Verknüpfung und Permutation}

Historische Einzelereignisse, die durch Individualnamen wiedergegeben werden, sind in der Grundkette wie Sachschlagwörter zu verknüpfen und für Listenfunktionen zu permutieren.

SWW g Großbritannien ; s Biafrakonflikt ; s Nahrungsmittelhilfe (231) (321)

Bei mehrgliedrigen Ansetzungsformen richtet sich die Stellung in der Grundkette nach dem ersten Glied.

SWW p Luther, Martin / Thesenanschlag ; s Reformation

SWW p Goethe, Johann Wolfgang $\neg$ von $\neg$; g Valmy / Kanonade (231)

SWW g Nizäa / Konzil <787> ; s Bilderstreit (312)

\section{§ 417 entfällt}




\section{Zeitcode}

\section{§ 418 Zeitcode}

1. Der Zeitcode (Symbol ZC) dient dem Retrieval nach historischen Sachverhalten in einfacher, stets gleich strukturierter Form. Er soll sowohl allein wie in Kombination mit anderen Datenelementen suchfähig sein.

Der Zeitcode wird für alle Sachverhalte verwendet, nicht nur für die politische Geschichte und nicht nur für räumlich umfassende Darstellungen. Um zu hohe Trefferzahlen zu vermeiden, sollte er jedoch nur vergeben werden, wenn der Inhalt einen engen Bezug zu der betreffenden Zeit hat. Werden sehr umfangreiche Zeiträume behandelt, so kann der Zeitcode auf den Kern der behandelten Zeit beschränkt werden.

Titel: Geschichte von Berchtesgaden : Stift, Markt, Land ; zwischen Salzburg und Bayern (bis 1594). - 1991

SWW Berchtesgaden ; Geschichte Anfänge-1594

ZC 1100-1594

ab Gründung des Stifts, obwohl bei der Jungsteinzeit beginnend

Aber:

Titel: Geschichte der deutschen Literatur : von den Anfängen bis zur Gegenwart / von Wolf Wucherpfennig. - 1996

SWW Deutsch ; Literatur ; Geschichte

ZC 880-1990

Wenn im Dokument mehrere Zeiträume behandelt werden, so wird für jeden ein Zeitcode vergeben.

Titel: $\quad$ Übersetzung und Literaturkritik : Aspekte der Rezeption zeitgenössischer deutschsprachiger Literatur in Großbritannien, 1960-1981 / Uta Kreuter. - 1985

SWW Deutsch ; Literatur ; Geschichte 1800-1980 ; Rezeption ; Großbritannien ; Geschichte 1960-1981

ZC $\quad 1800-1980 ; 1960-1981$

Auf einen Zeitcode wird verzichtet, wenn es sich um eine aktuelle Darstellung handelt, es sei denn, es wird ein genau umrissener Zeitraum dargestellt (vgl. § 401a,3,a).

2. Der Zeitcode kann in zwei Formen vergeben werden:

- als Jahreszahlen (hierfür gelten die Bestimmungen von §§ 401ff.)

- fakultativ als UDK-Code, der aus Jahreszahlen durch Trunkierung abgeleitet ist (vgl. Anl. 9).

Anm.: Dieser Code wurde im Projekt TITAN für Werke der griechischen und lateinischen Literatur erfasst.

Welcher Code im OPAC verwendet wird, ist davon abhängig, welche Möglichkeiten das Retrievalsystem bietet. Die Verwendung von Jahreszahlen erlaubt eine genauere Recherche, die Suche nach Erstreckungen und eine maschinelle Entscheidung über die Relevanz eines Titels (z. B. hinsichtlich des Grads der Überschneidung der Jahreszahlen und der Präzision im Vergleich der gesuchten und der gefundenen Jahreszahlen).

Bei der Verwendung des UDK-Codes werden Zeiträume durch alle zutreffenden Codes ersetzt. Eine solche Recherche ist leichter zu realisieren, jedoch weniger informativ. 
Beide Formen des Codes sind sowohl in der SWD bzw. lokalen Schlagwortdatei wie in den Titeldaten zulässig. Der Code in den Titeldaten dient vorzugsweise für das Retrieval des Benutzers, der Code in der SWD vorzugsweise zur internen Bearbeitung.

Es wird empfohlen, den Zeitcode soweit möglich maschinell aus der SWD bzw. den Schlagwortketten abzuleiten.

3. In der SWD wird ein Zeitcode in der Form von Jahreszahlen erfasst für

- Personenschlagwörter; soweit es sich um natürliche Personen handelt. Gewählt werden die Lebensdaten, soweit diese nicht bekannt sind die Wirkungsdaten, bei Herrschern die Regierungszeit.

SW Goethe, Johann Wolfgang $\neg$ von $\neg$

ZC 1749-1832

- Historische, d. h. heute nicht mehr existierende Geographika und Ethnographika (soweit ohne besonderen Aufwand zu ermitteln)

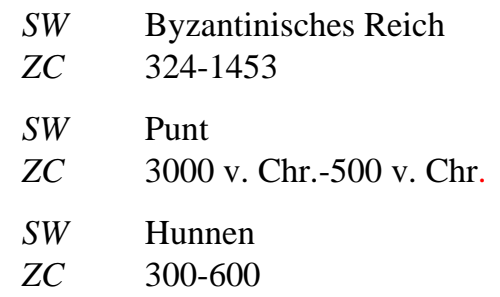

- Sachschlagwörter, die einen eingrenzbaren engeren Zeitraum erfassen
SW Hanse
ZC 1150-1669

- Historische Einzelereignisse

$\begin{array}{ll}\text { SW } & \text { Leipzig / Völkerschlacht } \\ \text { ZC } & 1813 \\ \text { SW } & \text { Weltkrieg <1939-1945> } \\ \text { ZC } & 1939-1945\end{array}$

- Epochenbezeichnungen

$\begin{array}{ll}\text { SW } & \text { Romanik } \\ \text { ZC } & 950-1250 \\ \text { SW } & \text { Bronzezeit } \\ \text { ZC } & 1800 \text { v. Chr.-800 v. Chr. }\end{array}$

- Körperschaften, soweit sie heute nicht mehr existieren

SW Deutschland / Immerwährender Reichstag

ZC 1663-1806

Der Zeitcode wird auch bei Veranstaltungen vergeben.

- Ältere Sprachstufen
SW Mittelhochdeutsch
ZC $\quad 1050-1350$

- Werke

z. B. Handschriften, historische Quellen, literarische, künstlerische, musikalische, philosophische, theologische Werke (nicht jedoch biblische Bücher), 
Filme, Fernsehsendungen: i. d. R. das Erscheinungsjahr; Bauwerke: soweit die Erbauungszeit klar definierbar ist.

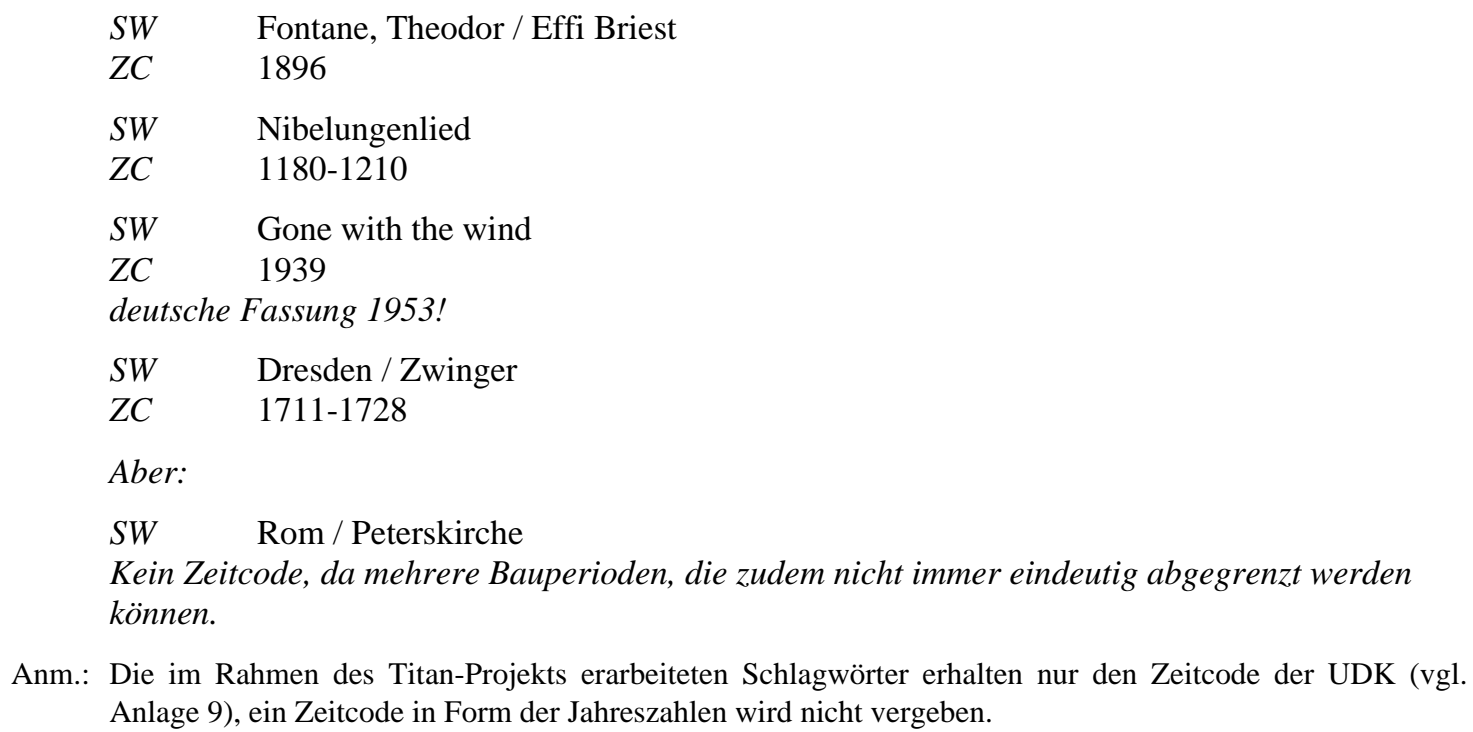

Anm.: Die im Rahmen des Titan-Projekts erarbeiteten Schlagwörter erhalten nur den Zeitcode der UDK (vgl. Anlage 9), ein Zeitcode in Form der Jahreszahlen wird nicht vergeben.

Bei längeren Zeiträumen wird die jeweils längste Erstreckung gewählt; kleinere Zeiträume sind nur in der Schlagwortkette anzugeben. Ungefähre Angaben werden nicht als solche gekennzeichnet.

$\begin{array}{ll}\text { SW } & \text { Bronzezeit } \\ \text { ZC } & 1800 \mathrm{v} \text {. Chr.-800 v. Chr. }\end{array}$

Nach B 1986 gilt diese Zeit im Wesentlichen für den europäischen Raum.

4. In den Titeldaten werden Jahreszahlen in das Feld für den Zeitcode übernommen

a) vorrangig aus den Jahreszahlen nach dem Zeitschlagwort (Geschichte und zugelassene Komposita bzw. Prognose). Jahreszahlen nach Formschlagwörtern werden übergangen. Eine Jahreszahl nach dem Zeitschlagwort hat Vorrang vor einer anderen Jahreszahl der SWD.

b) falls es solche nicht gibt, aus den entsprechenden Jahreszahlen der SWD

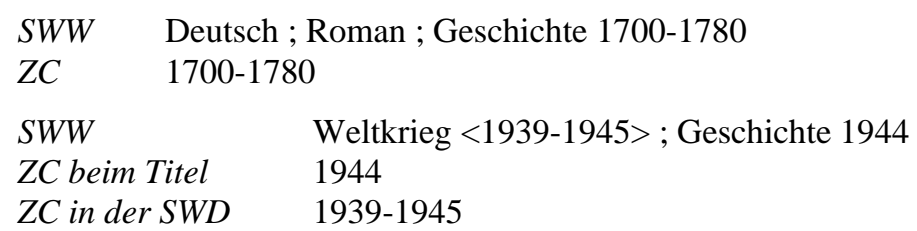

c) falls weder a) noch b) zutrifft, werden die Jahreszahlen aus dem vorliegenden Dokument ermittelt und in das Feld für den Zeitcode übernommen. Diese haben ggf. Vorrang vor Jahreszahlen aus der SWD.

Titel: $\quad$ Geschichte der deutschen Literatur / Hans Gerd Rötzer. - 1993

SWW Deutsch ; Literatur ; Geschichte

ZC $\quad$ 880-1990

gemäß vorliegendem Dokument

5. Bietet das Retrievalsystem die Möglichkeiten einer Recherche nach Jahreszahlen nicht, so wird in den Titeldaten der UDK-Code erfasst. Hierbei handelt es sich um verkürzte Jahreszahlen, die bis zum 18. Jahrhundert immer zweistellig, für das 19. und 20. Jahrhundert i. d. R. dreistellig angegeben werden. Der Zeitcode bezeichnet die im gesamten vorliegenden Do- 
kument behandelte Zeit. Es können mehrere Zeitcodes vergeben werden; z. B. bei einer längeren Erstreckung.

$\begin{array}{ll}\text { Jahr } & \text { Code } \\ \begin{array}{l}501-600 \\ \text { (bzw. } 500-600)\end{array} & 05 \\ \begin{array}{l}600 \text { v. Chr.-501 v. Chr. } \\ \text { (bzw. } 600 \text { v. Chr.-500 v. Chr.) }\end{array} & \text { v05 } \\ 1901-1910 & 190 \\ 1000-1500 & 10 ; 11 ; 12 ; 13 ; 14\end{array}$

Der UDK-Code in den Titeldaten wird möglichst maschinell aus Jahreszahlen nach dem Zeitschlagwort bzw. aus der SWD abgeleitet. Es gilt dabei die gleiche Rangfolge wie in $\S 418,4$ :

a) Vorrangig aus den Jahreszahlen nach dem Zeitschlagwort

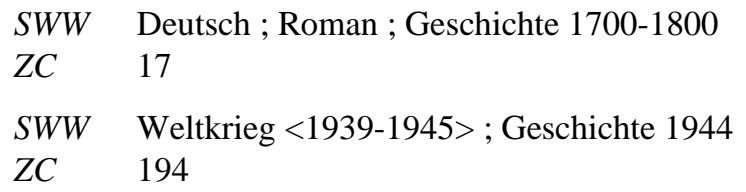

b) soweit es solche nicht gibt, aus den Jahreszahlen der SWD

$\begin{array}{ll}\text { SW } & \text { Stalingrad / Schlacht } \\ \text { ZC } & 194 \\ \text { SW } & \text { Weltkrieg <1939-1945> } \\ \text { ZC } & 193 ; 194\end{array}$

c) aus dem vorliegenden Dokument, falls weder a) noch b) zutreffen.

SWW Deutsch; Literatur; Geschichte

ZC $\quad 08 ; 09 ; 10 ; 11 ; 12 ; 13 ; 14 ; 15 ; 16 ; 17 ; 18 ; 19$ 


\section{Formschlagwörter}

\section{§ 501 Definition}

Formschlagwörter kennzeichnen die Erscheinungsweise, die Art der Darstellung, die physische Form eines Dokuments (den Dokumenttyp) sowie in Einzelfällen das Niveau der Darstellung. Formbegriffe (Dokumenttypen) werden neben Schlagwörtern für den begrifflichen Inhalt eines Werkes nur insoweit berücksichtigt, als sie den Inhalt des Dokuments zusätzlich charakterisieren. Formschlagwörter erhalten in der SWD den Indikator f.

Anm. 1: Zum Formschlagwort bei Ausstellungen vgl. § 735, bei audiovisuellen Medien vgl. § 737, bei elektronischen Publikationen vgl. § 737a, bei schöner Literatur vgl. §§ 760-762, bei Kinder- und Jugendliteratur vgl. §§ 763766, bei Schulbüchern vgl. §§ 767-773, bei Musikdrucken und Musiktonträgern vgl. §§ 744-752 und „Regeln für den Schlagwortkatalog (RSWK)/Musikalien und Musiktonträger. Entwurf. 1991“.

Anm. 2: Zum Verzicht auf die Erschließung bestimmter Literaturgattungen vgl. § 3,2,b.

$\begin{array}{lll}S W W & \text { s Fremdenverkehrsgeographie; f Schriftenreihe } & \text { (Erscheinungsweise) } \\ \text { SWW } & \text { p Piaget, Jean; f Bibliographie } & \text { (Art der Darstellung) } \\ \text { SWW } & \text { g Deutschland; z Geschichte 1500-1600; f Bildband } & \text { (Art der Darstellung) } \\ S W W & \text { g Hamburg / Mundart; f Tonträger } & \text { (physische Form) } \\ \text { SWW } & \text { s Anatomie; f Einführung } & \text { (Niveau der Darstellung) }\end{array}$

\section{§ 502 Ansetzung}

Die Ansetzung der Formschlagwörter ist in der 'Liste der Formschlagwörter' festgelegt (vgl. Anl. 6).

Anm.: Anl. 6 enthält die für die Erschließung der herkömmlichen Bibliotheksmaterialien erforderlichen Formschlagwörter. Zur Erschließung spezieller Materialien (wie spezialisierte Kartensammlungen, unselbständige Literatur unterschiedlichen Typs, Museumsobjekte, Internetressourcen) kann die Liste erweitert werden, z. B. Globussegment, Kunstwerk, Werbung.

Formschlagwörter sind i. d. R. gleich angesetzt wie das zugehörige Sachschlagwort, sind aber durch den Indikator $f$ unterschieden. Sie werden grundsätzlich im Singular angesetzt. Synonyme Bezeichnungen werden mit Indikator $f$ als Verweisung erfasst.

$$
\begin{aligned}
& \text { SW s Dia } \\
& \text { daneben: } \\
& \text { SW f Dia }
\end{aligned}
$$

Abweichungen von der Ansetzung des einschlägigen Sachschlagworts ergeben sich

- durch die Zusammenfassung von Unterbegriffen unter einen Oberbegriff oder von verwandten Begriffen, wo dies in einzelnen Fällen für das Retrieval als zweckmäßig erscheint, 


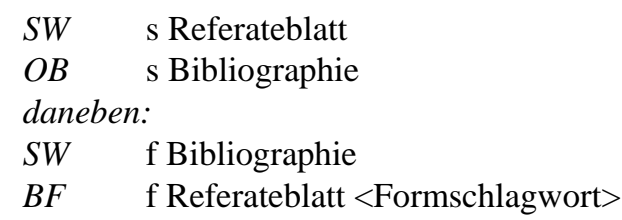

- durch die Wahl einer abweichenden Ansetzung, wo dies für die Verständlichkeit in der Schlagwortkette und die Trennung im Retrieval erforderlich erscheint,

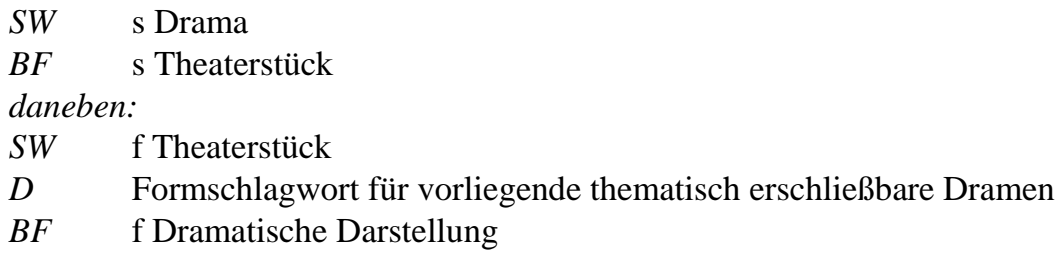

- durch die grundsätzliche Zerlegung von Komposita aus Sachschlagwort und Formschlagwort; Ausnahmen sind in der 'Liste der Formschlagwörter' beim einzelnen Formschlagwort angegeben (vgl. auch §§ 305,2,g; 505).

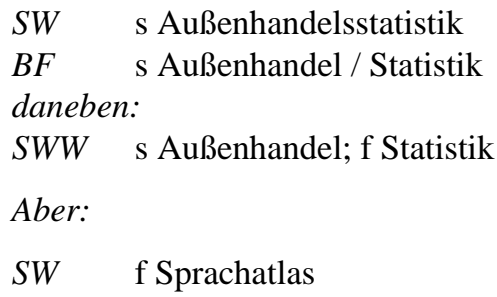

\section{§503 Zeitangaben}

1. Das Formschlagwort kann in Einzelfällen durch eine Zeitangabe erweitert werden, die aus den Jahreszahlen ohne den Zusatz 'Geschichte’ besteht (vgl. § 17,2,a).

Anm.: Dies kann technisch durch eine Freitexterweiterung des Formschlagworts oder durch einen eigenen Satz in der SWD realisiert werden.

Eine solche Erweiterung ist nur in den folgenden Fällen zulässig (vgl. auch Anl. 6):

a) Die Zeitangabe bezieht sich nur auf das Formschlagwort, nicht auf die Schlagwörter für den begrifflichen Inhalt. Dies ist der Fall bei 'Bibliographie', 'Katalog', 'Literaturbericht', 'Reisebericht', 'Statistik'.

SWW g Afrika ; f Reisebericht 1880-1885

Titel: $\quad$ Bibliographie zur deutschen Geschichte im Zeitalter der Glaubensspaltung : 15171585 / Karl Schottenloher

7. Schrifttum von 1938 bis 1960 / bearb. von Ulrich Thürauf. - 1966

SWW g Deutschland ; z Geschichte 1517-1585 ; f Bibliographie 1938-1960

b) Das Formschlagwort ist i. d. R. mit dem Personenschlagwort direkt verbunden. Dies ist bei 'Autobiographie', 'Biographie', 'Briefsammlung', 'Tagebuch’ und 'Werkverzeichnis' der Fall.

SWW p Goethe, Johann Wolfgang ᄀVonᄀ ; f Briefsammlung 1786-1788

2. Die Zeitangabe beim Formschlagwort entfällt, wenn sie identisch oder fast identisch mit dem Erscheinungsjahr des Dokuments ist. Das ist u. a. stets bei folgenden Formschlagwörtern der Fall: 
Adressbuch

Antiquariatskatalog

Atlas

Auktionskatalog

Bericht

Datensammlung

Entscheidungssammlung

Erlebnisbericht

Fahrplan
Führer

Gespräch

Kalender

Karte

Lehrplan

Schematismus

Telefaxverzeichnis

Telefonbuch

Telexverzeichnis

Inhalt: Geschäftsbericht der Stadtverwaltung Stuttgart (erschienen 1975)

SWW g Stuttgart; s Stadtverwaltung; f Bericht

nicht: $g$ Stuttgart ; s Stadtverwaltung ; f Bericht 1971-1974

Titel: $\quad$ Deutsches Kursbuch / Deutsche Reichsbahn, Kursbuchbüro. - 1937/38

SWW k Deutsche Reichsbahn ; f Fahrplan

nicht: $k$ Deutsche Reichsbahn ; f Fahrplan 1937-1938

Inhalt: Atlas von Europa (Reprint einer Ausgabe von 1865)

$S W W \quad$ g Europa ; f Atlas

nicht: $g$ Europa ; f Atlas 1865

3. Zeitangaben, die sich sowohl auf das Formschlagwort als auch auf andere Schlagwortkategorien beziehen, werden stets durch ein Zeitschlagwort wiedergegeben (vgl. §§ 401-406).

Titel: $\quad$ Augsburg in alten Ansichten / [hrsg.] von Josef Mancal. - 1983

SWW g Augsburg; z Geschichte 1880-1930; f Bildband

nicht: $g$ Augsburg ; f Bildband 1880-1930

Titel: $\quad$ Katalog der Sammlung Trivialliteratur des 19. Jahrhunderts in der Universitätsbibliothek Gießen / Ulrich Hain ; Jörg Schillinge. - 1970

$S W W \quad$ c Gießen / Universitätsbibliothek ; s Trivialliteratur ;

z Geschichte 1800-1900 ; f Katalog

nicht: c Gießen /Universitätsbibliothek ; s Trivialliteratur ; f Katalog 1800-1900

Titel: $\quad$ Urkunden und Akten der ehemaligen Reichsstadt Schwäbisch Gmünd : 777 bis 1500 / hrsg. vom Stadtarchiv Schwäbisch Gmünd. - 1966-1967

SWW g Schwäbisch Gmünd ; z Geschichte 777-1500 ; f Quelle

nicht: $g$ Schwäbisch Gmünd ; Quelle 777-1500

\section{§ 503a SWD-Datensatz}

Überblick über die wichtigsten Informationen in einem Datensatz der SWD für ein Formschlagwort (vgl. § 7,4).

- Indikator $\mathrm{f}$ (Angabe obligatorisch bei allen Formschlagwörtern)

- Formschlagwort in Ansetzungsform (Angabe obligatorisch, vgl. § 502)

- Quelle (Angabe obligatorisch; vgl. § 19,1; Anl. 6)

- Definition (Angabe fakultativ, vgl. § 19,2) 
- Verwendungshinweis (Angabe fakultativ, vgl. § 19,3)

- Redaktionelle Bemerkung (Angabe fakultativ, vgl. § 19,4)

- Notation: 1 (Angabe obligatorisch, vgl. § 18,1)

- Synonymie-Verweisungen (vgl. § 502; Indikator f); ggf. mit Bemerkung, eingeleitet durch *

- Oberbegriffe (Indikator f oder s); ggf. mit Bemerkung, eingeleitet durch *

- Unterbegriffe (Indikator f oder s)

- Verwandte Begriffe (Indikator f oder s); ggf. mit Bemerkung, eingeleitet durch *

SW f Autobiographie

Q Anl. 6 RSWK

D Für vorliegende Autobiographien einer Person oder Personengruppe, auch für solche in Tagebuchform.

H Zeitangaben werden nur nach Personennamen zum Formschlagwort hinzugefügt; bei Personengruppen wird z Geschichte mit Jahreszahlen verwendet.

Für Sammlungen benutze s Autobiographie ; f Anthologie. Zur Verwendung als Gattungsbegriff vgl. $\S 5,3$ und 4 .

SYS 1

BF f Erinnerungen $<$ Formschlagwort $>$

$\mathrm{BF} \quad \mathrm{f}$ Lebenserinnerungen

BF f Memoiren

BF f Selbstbiographie

OB fQuelle

VB fBiographie

VB f Erlebnisbericht

VB f Tagebuch

\section{§504 Verknüpfung}

1. Formschlagwörter bilden zusammen mit den Schlagwörtern für den begrifflichen Inhalt (Personenschlagwort, geographisches/ethnographisches Schlagwort, Sachschlagwort, Zeitschlagwort) eine Schlagwortkette. Sie stehen in der Schlagwortkette an letzter Stelle (vgl. $\S 15,8)$.

$$
\begin{array}{ll}
S W W & \text { g Weyarn / Sankt Peter und Paul ; s Musikhandschrift ; f Katalog } \\
S W W & \text { g Deutschland ; z Geschichte ; f Bildband }
\end{array}
$$

Sind für einen Gegenstand mehrere Formaspekte relevant, so werden mehrere Formschlagwörter vergeben. Das Schlagwort für die physische Form steht dabei i.d. R. an der letzten Stelle. Als zwei Gegenstände wird jedoch die Darstellung eines Themas und die Verknüpfung desselben Themas mit dem Formbegriff behandelt, wenn der Formaspekt beim vorliegenden Dokument sehr gewichtig ist (vgl. § 13,4,d). Ebenso werden mehrere Schlagwortketten gebildet, wenn es sich um mehrere physische Materialien handelt, die getrennt benutzt werden können.

$$
\begin{array}{ll}
S W W & \text { s Autogenes Training ; f Einführung; f Tonträger } \\
S W W & \text { s Englischunterricht ; f Wörterbuch ; f Schulbuch ; f CD-ROM }
\end{array}
$$


Aber:

Titel: $\quad$ Türkei / Klaus Liebe ; Gerhard P. Müller. - 1985

geschichtlich-landeskundliche Darstellung mit zahlreichen Illustrationen

SWW g Türkei; s Landeskunde

g Türkei ; f Bildband

Titel: Word für Windows 6.0 [Medienkombination] / Sylvia Böhmer ; Martin Böhmer. 1997

Buch. - $882 \mathrm{~S}$.

CD-ROM

gesamter Buchtext als Electronic-Publishing-Text auf der CD-ROM

SW S WORD für WINDOWS 6.0

$S W W \quad$ s WORD für WINDOWS 6.0 ; f CD-ROM

2. Bei Sprachwörterbüchern folgt das Formschlagwort 'Wörterbuch' in der Schlagwortkette i. d. R. direkt nach der Sprachbezeichnung (vgl. § 702).

3. Auf die Formschlagwörter 'Ausstellung' und 'Kongress' folgen Veranstaltungsort und -jahr in folgender Form:

Thema ; Formschlagwort ; Ort $<\mathrm{Jahr}>$

Bei Ausstellungen und Kongressen, die in einem unselbständig angesetzten Ortsteil oder Ortsteil eines Doppelortes stattgefunden haben, wird der Name des Hauptortes bzw. Doppelorts verwendet. (Zu Ausstellungen vgl. auch § 735.)

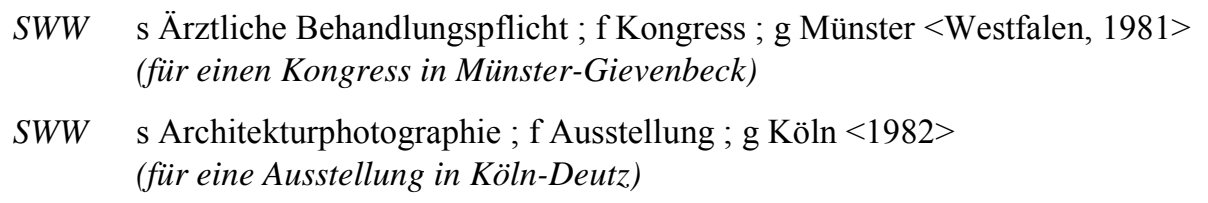

\section{§ 505 Formschlagwort als erstes Schlagwort in der Schlagwortkette}

Das Formschlagwort kann, ggf. gefolgt durch ein weiteres Formschlagwort, als einziges bzw. erstes Schlagwort auftreten, wenn der Inhalt des Dokuments durch keine andere Schlagwortkategorie erfasst werden kann. Das Formschlagwort 'Enzyklopädie' kann nur als erstes Schlagwort vorkommen.

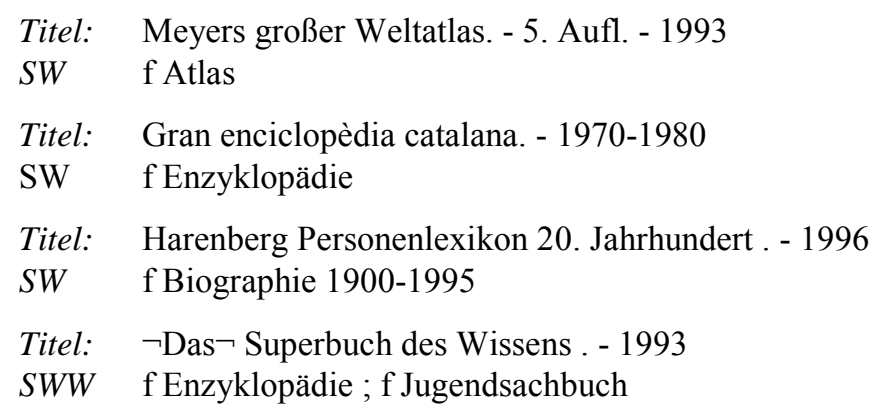




\section{§506 Permutation}

1. Formschlagwörter werden i. d. R. nicht permutiert (vgl. § 15,10,a).

2. Bibliotheken, bei denen der Bedarf besteht, für Listenfunktionen bestimmte formale Gruppen (z. B. Biographien, Bibliographien, Musikdrucke) zusammenzuführen, können bei lokaler Anwendung jeweils eine zusätzliche Eintragung unter dem betreffenden Formschlagwort als erstem Glied der Schlagwortkette erstellen. Die mit dem Formschlagwort ggf. verbundenen Zeitangaben entfallen.

$S W W \quad$ p Boyen, Hermann $\neg$ von $\neg$; f Biographie (2 1 )

SWW g Bayern ; z Geschichte ; f Bibliographie 1900-1945

und:

SWW f Bibliographie; g Bayern; z Geschichte 


\section{Sonderregeln}

\section{Körperschaftsnamen}

\section{Definition und Verwendung}

\section{§ 601 Definition}

1. Als Körperschaften gelten Personenvereinigungen, Organisationen und Institutionen unabhängig von ihrer juristischen Natur, die durch ihren Namen individuell bestimmbar sind und eine feste organisatorische Einheit bilden. Dazu zählen auch Organe von Gebietskörperschaften (vgl. $\S \S 613-615)$.

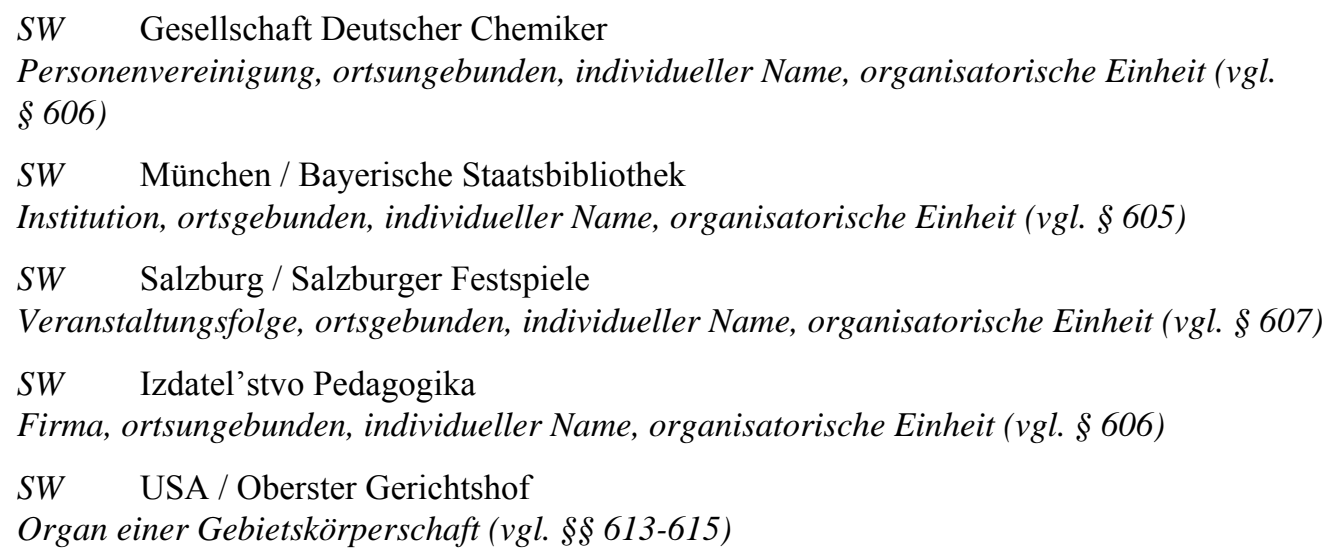

2. Im Zweifelsfall wird ein Begriff nicht den Körperschaften zugerechnet. Das gilt insbesondere für politische, soziale, künstlerische oder weltanschauliche Bewegungen ohne feste organisatorische Einheit, z.B. für Künstlervereinigungen, die für eine bestimmte Stilrichtung stehen (vgl. § 306a,2), und für historische Einzelereignisse (vgl. § 607, 8 und §§ 415-416).

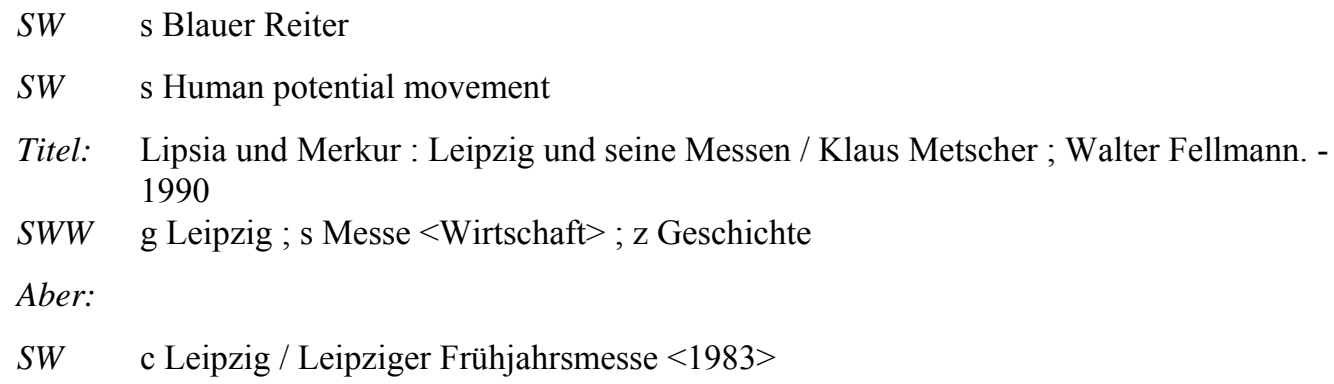

3. Körperschaftsschlagwörter erhalten in der SWD den Indikator k, wenn ihre Ansetzungsform mit dem Individualnamen, den Indikator c, wenn sie mit einer Gebietskörperschaft beginnen. 


\section{§ 601a Verwendung}

1. Körperschaftsnamen werden Schlagwort bei Dokumenten, in denen die Körperschaft selbst Gegenstand der Darstellung ist, nicht aber, wenn sie als Herausgeber oder Veranstalter auftritt. Ist eine Körperschaft an der Erarbeitung eines Dokuments beteiligt, so wird sie nur berücksichtigt, wenn es sich um eine Stellungnahme mit offiziellem bzw. repräsentativem Charakter handelt (vgl. § 4,2).

Titel: $\quad$ Max-Planck-Institut für Plasmaphysik / Reinhard Breuer ; Uwe Schumacher. - 1982

SW $\quad$ Garching $<$ München $>$ / Max-Planck-Institut für Plasmaphysik

Aber:

Titel: $\quad \neg$ Die $\neg$ Systematik im OPAC : Vorträge aus den bibliothekarischen Arbeitsgruppen der 16. Jahrestagung der Gesellschaft für Klassifikation, Dortmund 1992. - 1993

SWW Klassifikation ; Online-Katalog ; Kongress ; Dortmund $<1992>$

nicht: Gesellschaft für Klassifikation ; Kongress ; Dortmund <1992>; diese ist Veranstalter, aber nicht Gegenstand der Darstellung

2. Körperschaftsnamen werden außerdem verwendet, wenn sie zur näheren Bestimmung eines individuellen Gegenstands ohne Individualnamen notwendig sind (vgl. Produktnamen $\S 306 a, 3$ und 4; Preise und Wettbewerbe $\S$ 306a,5; Periodika $\S 708,5$ und 6; Schriftdenkmäler $\S \S 718-722$; nicht ortsgebundene Kunstwerke $\S 727$; Bauwerke $\S 730$; Sammlungen $\S 736,6)$.

\section{Ansetzung}

\section{§ 602 Grundregeln}

1. Körperschaften werden mit ihrem Namen nach RAK angesetzt, soweit in den folgenden Paragraphen keine andere Regelung getroffen wird.

Wesentliches Nachschlagewerk für die Ansetzung ist die Gemeinsame Körperschaftsdatei (GKD), wobei der Name i.d.R. nach den folgenden Regeln zu strukturieren ist. Im Übrigen gilt die „Liste der Nachschlagewerke“ (vgl. § 9,3).

Die Bildung des Körperschaftsschlagworts erfolgt in zwei Schritten:

a) Bestimmung des Körperschaftsnamens (z.B. 'Bayerische Staatsbibliothek')

b) Ansetzung der Körperschaft (z.B. 'München / Bayerische Staatsbibliothek')

2. Abweichende Namensformen werden i.d.R. als Synonym erfasst.

Für die ggf. abweichende Ansetzungsform der GKD ist dies obligatorisch. Ist ein entsprechender GKD-Datensatz vorhanden, so wird die GKD-Nummer in einem speziellen Feld des SWD-Satzes als Verknüpfungsnummer angegeben, um die Ansetzungsform der GKD als Verweisungsform verfügbar zu machen. Falls frühere (spätere) Namensformen betroffen sind, werden ggf. mehrere GKD-Nummern erfasst. 


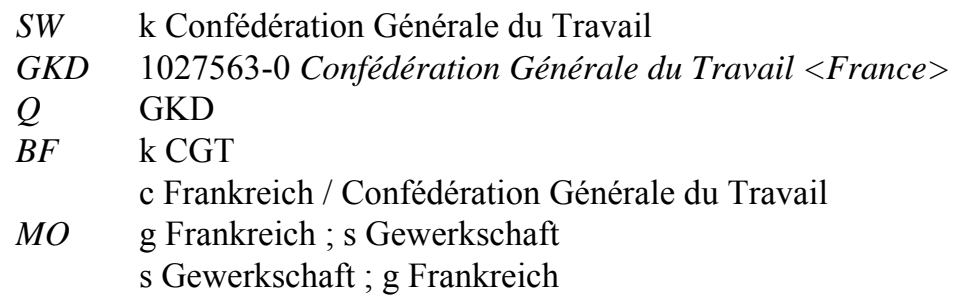

Anm.: Dies ist noch nicht realisiert, deshalb ist zwar die GKD-Nummer anzugeben, die abweichende Namensform der GKD wird aber vorläufig wie bisher als Synonymie-Verweisung erfasst.

3. Teile von Körperschaftsnamen aus Sprachen mit nicht lateinischen Schriften werden nicht der jeweiligen Umschrift nach RAK angepasst, sondern dem maßgeblichen Nachschlagewerk entnommen.

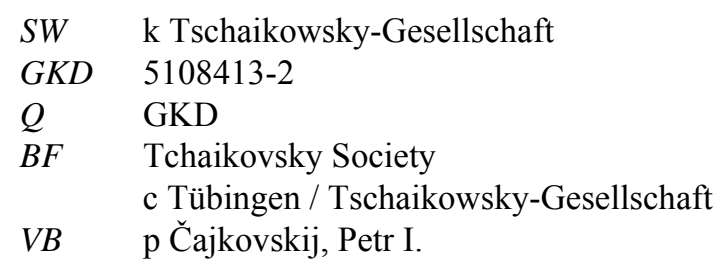

4. Abkürzungen von Körperschaftsnamen werden angesetzt, wenn sie in Nachschlagewerken oder den zu erschließenden Dokumenten wesentlich gebräuchlicher sind als die volle Form, die als Synonym erfasst wird. (vgl. RAK $\S 401,2$ ). Dasselbe gilt entsprechend auch für Abkürzungen als Bestandteil von Körperschaftsnamen. (Zu juristischen Wendungen als Bestandteil von Körperschaftsnamen vgl. § 602,5).

Anm. 1: Die Schreibung der Abkürzungen (z.B. mit Groß- oder Kleinbuchstaben) richtet sich nach den Nachschlagewerken (vgl. RAK $\S 117$ und $\S 201 \mathrm{f}$.).

Anm 2: Das Präfix 'Sankt' sowie seine fremdsprachigen Entsprechungen werden abweichend von der GKD als Bestandteil von Körperschaftsnamen ausgeschrieben. Der Name mit der abgekürzten Form wird als Synonym erfasst.

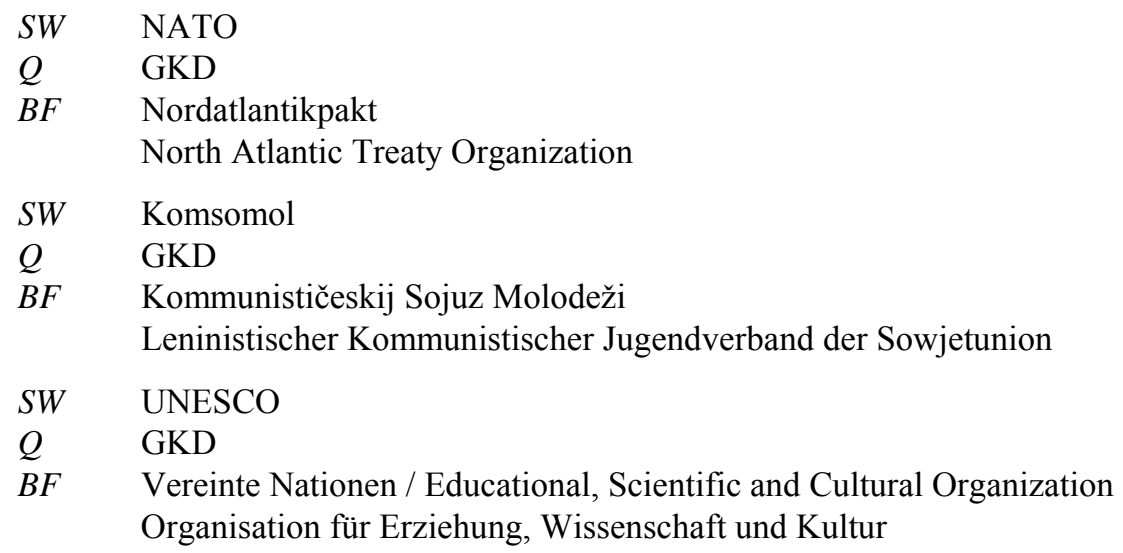




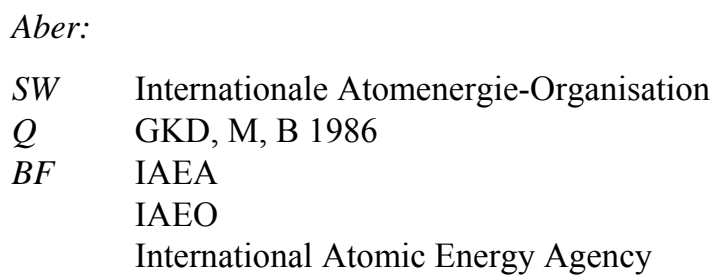

In den Nachschlagewerken wird hier, auch wegen der Mehrdeutigkeit der Abkürzung, die volle Form bevorzugt.

Abkürzungen werden als Synonyme erfasst, wenn sie in der GKD, einem Nachschlagewerk oder dem vorliegenden Dokument nachgewiesen sind. Gleichlautende Abkürzungen sind nicht durch Homonymenzusätze unterschieden, es sei denn, eine Abkürzung ist homonym zu einer Ansetzungsform, die i.d.R. ohne Homonymenzusatz bleibt (vgl. auch § 12,2,d).

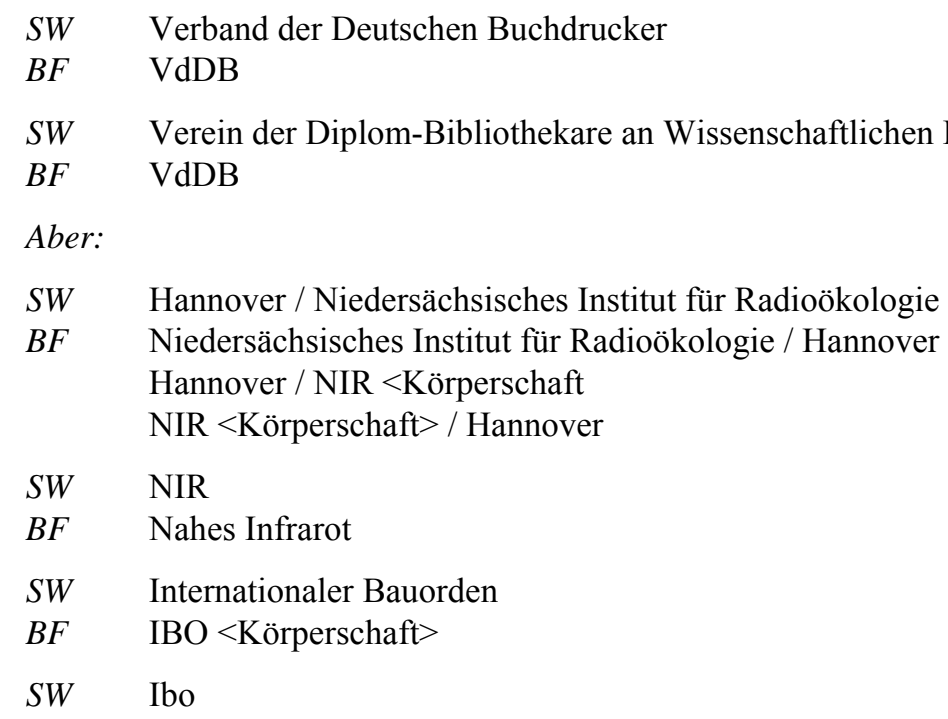

5. Nicht berücksichtigt bei der Ansetzung des Namens werden Zählungen sowie Wendungen, die den juristischen Charakter der Körperschaft bezeichnen, es sei denn, dass sie unlösbarer Bestandteil des Namens sind oder ohne sie nicht kenntlich ist, dass es sich um eine Körperschaft handelt (vgl. RAK $\S 404$,a und d). (Zu Weglassungen bei der Ansetzung von Organen einer Gebietskörperschaft vgl. § 614,3, einer Religionsgemeinschaft vgl. § 619,1.)

Die Entscheidung, ob eine den juristischen Charakter der Körperschaft bezeichnende Wendung als Namensbestandteil mit anzusetzen ist und ob diese Ansetzung in voller oder in abgekürzter Form erfolgt, ist nach der GKD zu treffen.

Offizielle Form

Verein Deutscher Bibliothekare e.V.

Verlag Die Runde GmbH

Wien / II. Universitäts-Frauenklinik

Aber:

Hessische Elektrizitäts AG

Texaco Inc.

Führungskräfte der Druckindustrie und Informationsverarbeitung e.V.
Ansetzungsform

SW Verein Deutscher Bibliothekare

SW Verlag Die Runde

SW Wien / Universitäts-Frauenklinik $<2>$

SW Hessische Elektrizitäts-Aktiengesellschaft

SW Texaco Inc.

SW Führungskräfte der Druckindustrie und Informationsverarbeitung e.V. 
6. Bei ortsgebundenen Körperschaften wird aus Ort und Individualnamen eine mehrgliedrige Ansetzungsform gebildet (vgl. § 605).

Orte und Ortsteile als Bestandteile des Namens nicht ortsgebundener Körperschaften werden mit angesetzt (für ortsgebundene Körperschaften vgl. § 605,3).

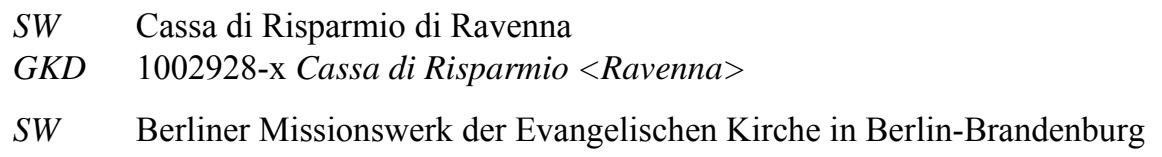

7. Für die Rechtschreibung in Körperschaftsnamen gelten die Bestimmungen in RAK $\S \S 117$; 118. Danach werden alle Wörter außer Artikeln, Präpositionen und Konjunktionen im Innern der Namen großgeschrieben. Ansonsten gelten, unabhängig von der Typographie der Vorlage, die Rechtschreibregeln der betreffenden Sprache.

SW Verein Deutscher Ingenieure

SW Ligue Internationale contre le Racisme et l'Antisémitisme

8. Personennamen als Teil von Körperschaftsnamen werden nach den für Körperschaften geltenden Bestimmungen angesetzt.

Sind Körperschaften maßgeblich mit Personen thematisch befasst oder in anderer Weise mit ihnen verbunden, so kann das Personenschlagwort als Teil des mehrgliedrigen Oberbegriffs (vgl. § 602,9 und „Praxisregeln“) bzw. als verwandter Begriff erfasst werden (vgl. § 12,5,e).

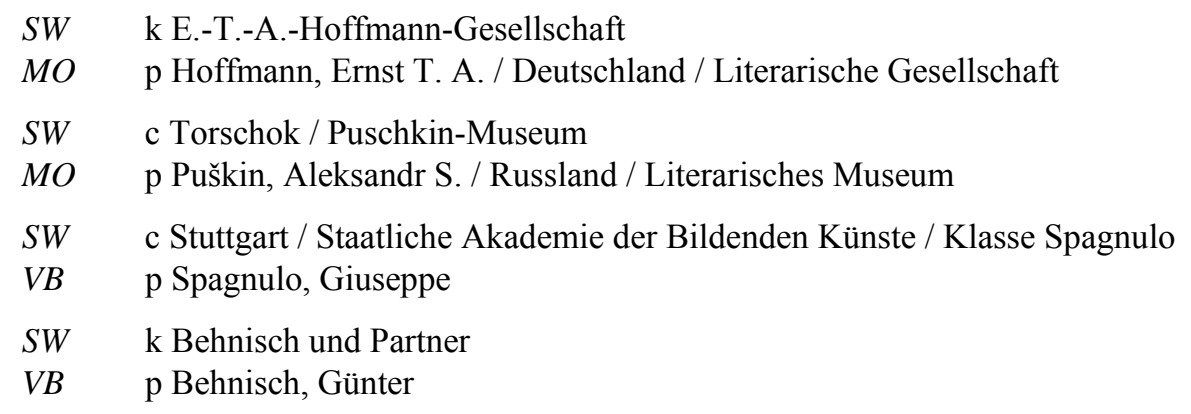

9. Bei der Ansetzung von Körperschaften wird der zugehörige Gattungsbegriff bzw. der übergeordnete Sachverhalt i. d. R. als mehrgliedriger Oberbegriff erfasst (vgl. § 12,4 und „Praxisregeln").

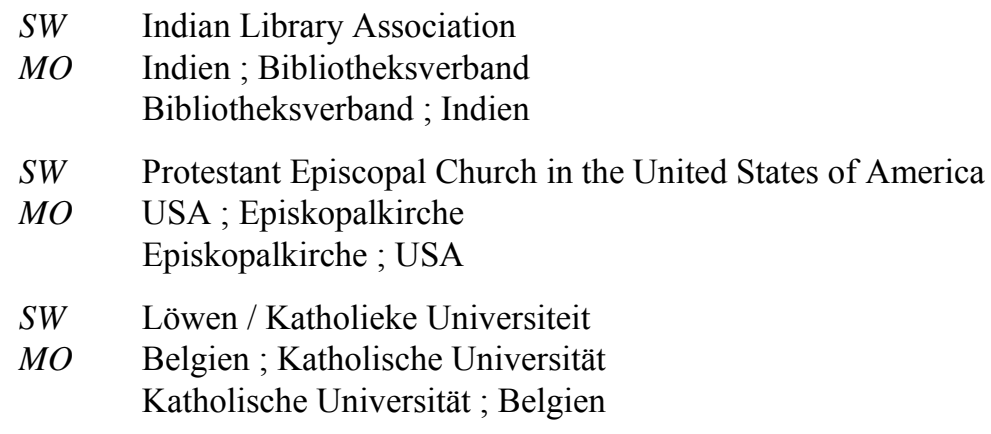




\section{$\S 603$ Deutsche oder fremdsprachige Form des Körperschaftsnamens}

Für die Ansetzung des Körperschaftsnamens gilt:

1. Gibt es einen offiziellen, d. h. von der Körperschaft selbst verwendeten deutschen Namen, so wird dieser gewählt. Die Ermittlung erfolgt gemäß der „Liste der Nachschlagewerke“ (vgl. $\S 9,3$ ). (Zu Körperschaftsnamen, die normiert mit einer Gattungsbezeichnung angesetzt werden vgl. $\S \S 605,4 ; 614,5 ; 618,3$.)

$$
\begin{array}{ll}
S W & \text { Österreichischer Gewerkschaftsbund } \\
S W & \text { Eidgenössischer Turnverein } \\
\text { SW } & \text { Verband Deutscher Lehrer im Ausland }
\end{array}
$$

2. Gibt es keinen offiziellen deutschen, aber einen im Deutschen gebräuchlichen Namen, der gemäß der „Liste der Nachschlagewerke“ ermittelt wird, so wird dieser gewählt. Der offizielle Name wird i. d. R. als Synonym erfasst.

$\begin{array}{ll}S W & \text { Internationaler Gerichtshof } \\ B F & \text { International Court of Justice / Vereinte Nationen } \\ & \text { Vereinte Nationen / International Court of Justice } \\ S W & \begin{array}{l}\text { London / Britisches Museum } \\ \text { BF }\end{array} \\ & \begin{array}{l}\text { London / British Museum } \\ \text { Britisches Museum / London }\end{array} \\ S W & \text { Weltgesundheitsorganisation } \\ B F & \text { World Health Organization } \\ S W & \text { Nordischer Rat } \\ B F & \text { Nordisk Råd } \\ & \text { Nordic Council }\end{array}$

Bei allen Beispielen erfolgte die Ansetzung nach einer deutschen Verweisungsform der GKD.

Gattungsbezeichnungen unter einer Ortseintragung in einer Enzyklopädie (z. B. ,hat ein Archiv") gelten nicht als Nachweis für einen im Deutschen gebräuchlichen Namen.

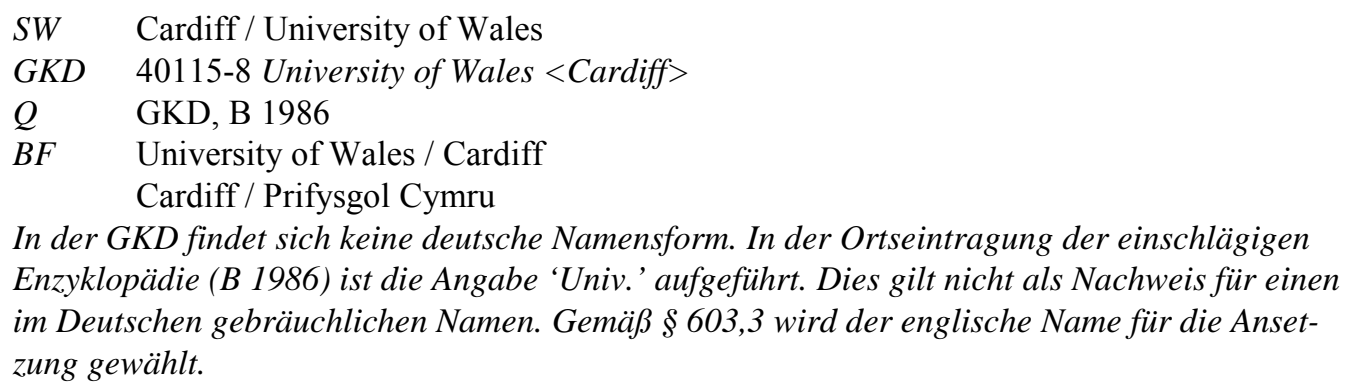

Eine deutschsprachige Vorlageform kann, sofern sie der Übersetzung des offiziellen Namens entspricht, als Ansetzungsform gewählt werden. (Vgl. aber $\S \S 605,4 ; 609,2, b$.)

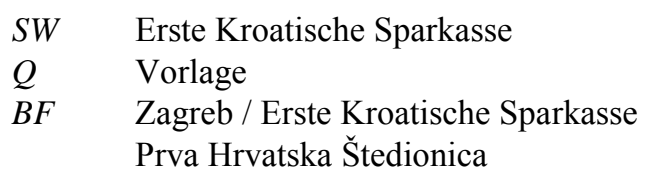

Eine im Deutschen gebräuchliche Namensform ist gemäß der „Liste der Nachschlagewerke“ nicht zu ermitteln. Die deutschsprachige Vorlageform entspricht der Übersetzung des offiziellen Namens. 
3. Liegt weder ein offizieller deutscher Name noch eine im Deutschen gebräuchliche Bezeichnung vor und gehört der offizielle Name einer germanischen oder romanischen Sprache an, so wird der offizielle Name gemäß der „Liste der Nachschlagewerke“ (vgl. § 9,3) gewählt.

$\begin{array}{ll}S W & \text { Associated Press } \\ B F & \text { AP } \\ S W & \text { Russell Sage Foundation } \\ S W & \text { Dansk Etnografisk Forening } \\ S W & \text { Ente Nazionale Idrocarburi } \\ B F & \text { ENI }<\text { Körperschaft }> \\ S W & \text { Lissabon / Laboratorio Nacional de Engenharia Civil } \\ S W & \text { New York }<\text { NY }>\text { / Metropolitan Museum of Art / Bibliothek }\end{array}$

4. Gehört der offizielle Name einer sonstigen europäischen oder einer außereuropäischen Sprache an und gibt es keine im Deutschen gebräuchliche Bezeichnung, so wird soweit möglich ein englischer oder französischer Name gemäß der „Liste der Nachschlagewerke“ (vgl. § 9,3) gewählt. Der offizielle Name wird i.d.R. als Synonym erfasst.

$\begin{array}{ll}S W & \text { Society of Cypriote Studies } \\ B F & \text { Hetaireia Kypriakōn Spudōn } \\ S W & \text { Ungarn / Central Statistical Office } \\ B F & \text { Ungarn / Központi Statisztikai Hivatal } \\ & \text { Központi Statisztikai Hivatal / Ungarn } \\ S W & \text { Japanese Society for Bacteriology } \\ B F & \text { Nihon-Saikin-Gakkai } \\ S W & \text { Belgrad / Institut Mathématique } \\ B F & \text { Belgrad / Matematički Institut }\end{array}$

5. Trifft keiner der Fälle 1 bis 4 zu, so ist der offizielle fremdsprachige bzw. der vorliegende Name zu wählen.

$\begin{array}{ll}\text { SW } & \text { Slovenská Spoločnost’ Antropologická } \\ \text { SW } & \text { Ankara / Millî Folklor Enstitüsü }\end{array}$

\section{§ 604 Körperschaften mit offiziellen Namen in mehreren Sprachen}

Führt eine Körperschaft gleichzeitig offizielle Namen in mehreren Sprachen, so wird der für die Ansetzungsform heranzuziehende Name analog zu $\S 603$ und RAK $\S 406$ bestimmt nach der Rangfolge

- offizieller deutscher Name,

- im Deutschen gebräuchliche Bezeichnung,

- offizieller Name in Englisch, danach in Französisch,

- sonst der offizielle Name in der geläufigeren Sprache vor der weniger geläufigen.

SW Internationale Architektenunion

$B F \quad$ International Union of Architects

Union Internationale des Architectes

SW Juridiska Föreningen i Finland

BF Suomalainen Lakimiesten Yhdistys 
SW Bilbao / Academia de la Lengua Vasca

BF Bilbao / Euskaltzaindia

\section{§ 605 Ortsbindung von Körperschaften}

1. Als ortsgebundene Körperschaften gelten

a) alle lokalen Organisationen, z.B. Vereine und Verbände eines Ortes.

b) alle Körperschaften, zu deren wesentlichem Bestand eine ortsfeste Einrichtung gehört: Akademien, Hochschulen und ihre Einrichtungen, Theater, Orchester, Schulen, Bibliotheken, Archive, Museen, Observatorien, Versuchs- und Forschungsanstalten, Institute, Botanische und Zoologische Gärten, Krankenhäuser und Heime.

c) nicht zentrale Organe einer Gebietskörperschaft (vgl. § 615).

d) lokale Einheiten einer Religionsgemeinschaft (vgl. § 618,2).

e) Veranstaltungen, die ganz oder überwiegend an einem Ort stattfinden (vgl. § 607).

Anm.: Die Liste in RAK $\S 413,1$, Anm. findet keine Anwendung.

2. Ortsgebundene Körperschaften werden als mehrgliedrige Schlagwörter mit dem Ort als erstem und dem Körperschaftsnamen als zweitem Glied angesetzt. (Zur Ansetzung des Körperschaftsnamens vgl. $\S$ 602-604, zur Ansetzung der Ortsnamen vgl. $§ 202$ und 209). Der Name der Körperschaft mit dem Ort als zweitem Glied wird als Synonym erfasst.

\begin{tabular}{|c|c|c|}
\hline$S W$ & Rothenburg $<$ Tauber $>$ / Verein Alt-Rothenburg & \\
\hline$B F$ & Verein Alt-Rothenburg / Rothenburg <Tauber $>$ & \\
\hline SW & Montpellier / Société Archéologique de Montpellier & (lokaler Verein) \\
\hline$B F$ & Société Archéologique de Montpellier / Montpellier & \\
\hline SW & Göttingen / Akademie der Wissenschaften & \\
\hline$B F$ & Akademie der Wissenschaften / Göttingen & \\
\hline SW & London / Tate Gallery & \\
\hline$B F$ & Tate Gallery / London & \\
\hline SW & Hamburg / Meteorologisches Observatorium & \\
\hline$B F$ & Meteorologisches Observatorium / Hamburg & \\
\hline$S W$ & Paris / Musée des Arts Décoratifs & \\
\hline$B F$ & Musée des Arts Décoratifs / Paris & \\
\hline
\end{tabular}

3. Orte und Ortsteile am Beginn und am Ende von Namen ortsgebundener Körperschaften - auch in adjektivischer Form - werden mit angesetzt, auch dann, wenn nicht zweifelsfrei feststellbar ist, ob sie zum Namen gehören. (Vgl. aber $\S \S 605,4 ; 609,2 ; 618,3$.)

Offizielle Form

Hamburger Sportverein

Musikverein Sigmarszell
Ansetzungsform

SW Hamburg / Hamburger Sportverein

SW Sigmarszell / Musikverein Sigmarszell

4. Universitäten, allgemeine technische Hochschulen und Gesamthochschulen des deutschen Sprachgebietes werden i.d.R. mit ihrem Sitz und 'Universität', 'Technische Hochschule' bzw. 'Technische Universität' oder 'Gesamthochschule' als zweitem Glied angesetzt (vgl. RAK $\S 402)$. Der offizielle Name wird als Synonym erfasst.

SW $\quad$ Frankfurt $<$ Main $>/$ Universität

BF $\quad$ Frankfurt $<$ Main $>/$ Johann-Wolfgang-Goethe-Universität 
SW Zürich / Technische Hochschule

BF Zürich / Eidgenössische Technische Hochschule

ETH / Zürich

Zürich / ETH

Aber:

SW Hamburg / Universität der Bundeswehr

(spezielle Art einer Universität)

$B F \quad$ Universität der Bundeswehr / Hamburg

Universitäten außerhalb des deutschen Sprachraums werden in der Form 'Ort / Individualname' gemäß den vorstehenden Regeln angesetzt. Wenn allerdings die Übersetzung des Namens nur aus dem Wort 'Universität' und dem Ortsnamen besteht (das gilt auch für das italienische 'Università degli Studi') wird 'Ort / Universität' angesetzt. Die originalsprachige Namensform wird als Synonym erfasst. Gibt es mehrere Universitäten an einem Ort, so dass die Ansetzungsform mit 'Universität' homonym mit der Schlagwortkette 'Ort ; Sachschlagwort' wäre, so wird der Form 'Ort / Universität' der Ortsname im zweiten Glied hinzugefügt (vgl. § 602,6).

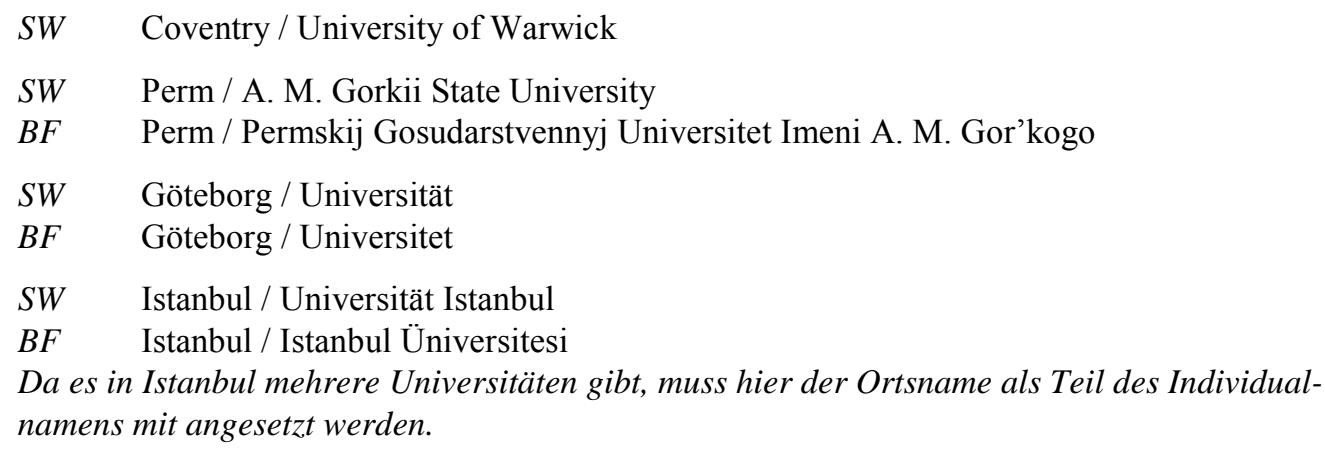

Da es in Istanbul mehrere Universitäten gibt, muss hier der Ortsname als Teil des Individualnamens mit angesetzt werden.

5. Hat eine ortsgebundene Körperschaft mehrere Ortssitze oder sind ihr weitere ortsgebundene Körperschaften an anderen Orten untergeordnet, so wird die Teilkörperschaft bzw. untergeordnete Körperschaft stets mit dem Ort angesetzt, an dem sie ihren Sitz hat.

Für die Gesamtkörperschaft und den Körperschaftsteil am Hauptsitz wird dasselbe Schlagwort verwendet.

a) Haupt- und Nebensitz

Bei einer ortsgebundenen Körperschaft mit Hauptsitz und Nebensitzen wird der Körperschaftsteil am Nebensitz mit diesem angesetzt. Hauptsitz und Nebensitze werden durch assoziative Verweisungen verbunden.

$\begin{array}{lll}S W & \text { Düsseldorf / Deutsche Oper am Rhein } & \text { (Hauptsitz und Gesamtkörperschaft) } \\ V B & \text { Duisburg / Deutsche Oper am Rhein } & \\ S W & \text { Duisburg / Deutsche Oper am Rhein } & \text { (Nebensitz) } \\ V B & \text { Düsseldorf / Deutsche Oper am Rhein } & \end{array}$

b) Unterordnung

Bei ortsgebundenen Körperschaften mit untergeordneten ortsgebundenen Körperschaften an anderen Orten wird unterschieden (vgl. § 609)

selbständige Ansetzung der untergeordneten Körperschaft:

Die übergeordnete Körperschaft mit dem nach Schrägstrich nachgestellten Namen der untergeordneten Körperschaft als zweitem Glied wird als Synonym erfasst. 
SW Schnaittach / Jüdisches Museum Franken

BF Fürth $<$ Bayern $>$ / Jüdisches Museum Franken / Schnaittach / Außenstelle Schnaittach

unselbständige Ansetzung der untergeordneten Körperschaft:

Die Ansetzung erfolgt mit dem jeweiligen Ortssitz und dem Namen der übergeordneten Körperschaft als zweitem sowie dem Namen der untergeordneten Körperschaft als drittem Glied. Von der nicht gewählten Form als Abteilung der übergeordneten Körperschaft wird verwiesen. Dem Namen der untergeordneten Körperschaft wird dabei i. d. R. der Ortsname beigefügt.
SW Sankt Petersburg / Russische Akademie der Wissenschaften / Bibliothek
BF Moskau / Russische Akademie der Wissenschaften / Sankt Petersburg / Bibliothek
keine Beifügung des Ortsnamens wegen Normierung nach $\$ 605,3$

6. Ortsgebundene Körperschaften werden i. d. R. mit der aktuellen Namensform des Ortes angesetzt, an dem sie ihren Sitz haben. Der frühere Ortsname mit dem Namen der Körperschaft als zweitem Glied wird als Synonym erfasst, sofern die Körperschaft bereits während der Geltungsdauer des früheren Ortsnamens Bestand hatte. Körperschaften, die zu bestehen aufhörten, als der frühere Ortsname noch galt, werden jedoch mit diesem angesetzt. Der spätere Ortsname mit dem Namen der Körperschaft als zweitem Glied wird i. d. R. als Synonym erfasst.

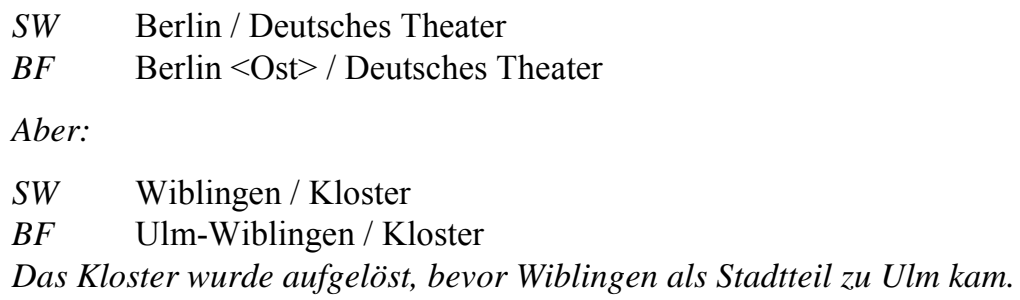

7. Körperschaften, bei denen als Sitz ein unselbständig angesetzter Ortsteil bzw. der Teil eines Doppelorts angegeben ist, werden i. d. R. mit dem Namen des Hauptorts bzw. Doppelorts als erstem Glied angesetzt. Ist der Ortsteil aber als Standort der Körperschaft sehr viel bekannter oder ist er zur Unterscheidung von einer anderen gleichnamigen Körperschaft notwendig, so wird mit dem Kompositum aus Hauptort und Ortsteil (bei Doppelorten mit dem betreffenden Ortsteil) angesetzt (vgl. § 209,5).

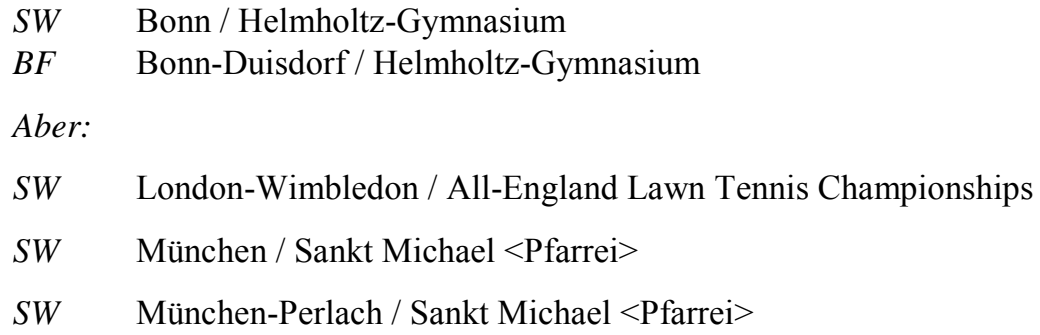

\section{§ 606 Nicht ortsgebundene Körperschaften}

1. Als nicht ortsgebundene Körperschaften gelten

a) alle nicht lokalen Personenvereinigungen und Vereinigungen von Körperschaften selbst, z. B. Ausschüsse, Kommissionen, Stiftungen, Gesellschaften, Vereine, Verbände, Parteien, berufsständische Kammern, Musikgruppen und andere Künstlervereinigungen, zu deren wesentlichem Bestand keine ortsfeste Einrichtung gehört. 
SW Bundesverband Deutscher Banken

SW Fondation Maeght

SW Geological Society of China

SW Union des Démocrates pour la République

SW Basler Missionsgesellschaft

SW Deutsche Angestellten-Gewerkschaft

b) Gewerbebetriebe und gemeinwirtschaftliche Betriebe, z. B. Industrie- und Handelsbetriebe, Banken, Sparkassen, Versicherungsanstalten und -gesellschaften (abweichend von RAK §413,1,Anm.) sowie Rundfunk- und Fernsehanstalten, öffentliche Dienstleistungs- und Versorgungsbetriebe.

$\begin{array}{ll}\text { SW } & \text { Friedrich Pustet }<\text { Firma }> \\ \text { SW } & \text { Daimler-Benz-Aktiengesellschaft } \\ \text { SW } & \text { Münchener Rückversicherungs-Gesellschaft } \\ \text { SW } & \text { ZDF } \\ \text { SW } & \text { Wasserwerk Mannheim } \\ \text { SW } & \text { Frankfurter Verkehrs- und Tarifverbund }\end{array}$

c) personelle Einheiten einer Religionsgemeinschaft (Orden u.ä. vgl. § 618,4).

Anm.: Als nicht ortsgebundene Körperschaften werden im Allgemeinen auch nicht lokale Körperschaften behandelt, deren Name folgende Bezeichnungen enthält: Arbeitsbereich, Ausschuss, Bund, Gemeinschaft, Genossenschaft, Gesellschaft, Gewerkschaft, Gruppe, Klub, Komitee, Kommission, Kreis, Kuratorium, Rat, Stiftung, Verband, Verein, Vereinigung und die ihnen entsprechenden fremdsprachigen Bezeichnungen. Das gilt auch für Zusammensetzungen wie Arbeitskreis, Berufsgenossenschaft usw. Die Liste in RAK $\S 414,1$, Anm. findet keine Anwendung.

2. Nicht ortsgebundene Körperschaften werden mit ihrem Namen angesetzt. Soweit sinnvoll wird der Ortssitz bzw. der Wirkungsbereich mit dem Körperschaftsnamen als zweitem Glied als Synonym erfasst.

$\begin{array}{ll}S W & \text { Waldorf-Astoria Hotel } \\ B F & \text { New York }<\mathrm{NY}>/ \text { Waldorf-Astoria Hotel } \\ \text { SW } & \text { Democrazia Cristiana } \\ B F & \text { Italien / Democrazia Cristiana } \\ \text { SW } & \text { Handwerkskammer für Mittelfranken } \\ \text { BF } & \text { Nürnberg / Handwerkskammer für Mittelfranken } \\ & \text { Mittelfranken / Handwerkskammer für Mittelfranken }\end{array}$

Ein orts- oder regional gebundener Teil einer nicht ortsgebundenen Körperschaft wird mit dem Namen der Körperschaft mit dem die Unterordnung bezeichnenden Teil des Körperschaftsnamens einschließlich des Ortes oder der Region als zweitem Glied angesetzt. Der Ort oder die Region mit dem Namen der Körperschaft als zweitem Glied und der Bezeichnung für die Unterordnung als drittem Glied werden als Synonym erfasst (vgl. auch $\S 609)$.

SW Deutscher Alpenverein / Sektion Tübingen

BF Tübingen / Deutscher Alpenverein / Sektion Tübingen

SW Christlich-Demokratische Union Deutschlands / Landesverband Hessen

BF Hessen / Christlich-Demokratische Union Deutschlands / Landesverband Hessen 
SW Sozialdemokratische Partei Deutschlands / Ortsverein Itzehoe

BF Itzehoe / Sozialdemokratische Partei Deutschlands / Ortsverein Itzehoe

Besteht der Name der untergeordneten Körperschaft nur aus dem der übergeordneten Körperschaft und dem Ort, so ist die Körperschaft selbständig anzusetzen.
SW Malteser-Hilfsdienst Memmingen
BF Memmingen / Malteser-Hilfsdienst Memmingen

\section{§ 607 Veranstaltungen}

1. Veranstaltungen werden wie Körperschaften behandelt. Als Veranstaltungen gelten Kongresse, Messen, Festwochen, Auktionen, Volksfeste, sportliche Veranstaltungen, Ausstellungen usw. (Ausstellungskataloge vgl. § 504,3; Preise und Wettbewerbe vgl. § 306a,5; historische Einzelereignisse vgl. $\S \S 415 \mathrm{a} ; 601,2$.

Anm.: Kongresse im Sinne dieses Regelwerks sind zeitlich begrenzte Zusammenkünfte von Personen oder Körperschaften zu wissenschaftlichen, kulturellen, politischen, wirtschaftlichen, religiösen, sozialen u. ä. Zwecken, z. B.Tagungen, Konferenzen, Kolloquien, Symposien u. ä. (vgl. auch RAK §§ 679-681; dort werden jedoch einige Veranstaltungen per Definition nicht als solche angesehen). Zu Kongressschriften vgl. $\S 504,3$.

2. Eine Erschließung mit dem Namen der Körperschaft erfolgt nur dann, wenn die Veranstaltung selbst Gegenstand der Darstellung ist (vgl. § 601a,1).

Titel: $\quad \neg$ Das $\neg$ Buch der Frankfurter Buchmesse / Text: Wolf Krämer. - 1996

SW $\quad$ Frankfurt $<$ Main $>$ / Frankfurter Buchmesse $<1996>$

3. Veranstaltungen werden als ortsgebundene Körperschaften angesetzt, sofern sie ganz oder überwiegend an einem Ort stattfinden. Handelt es sich um eine Folge von Veranstaltungen am gleichen Ort, so wird bei der einzelnen Veranstaltung das Veranstaltungsjahr als Homonymenzusatz zum Namen hinzugefügt. (Veranstaltungen einer Körperschaft ohne individuellen Namen vgl. § 607,7.)

Der Name der Veranstaltung mit dem Ort als zweitem Glied wird i. d.R. als Synonym erfasst.

$\begin{array}{lll}\text { SW } & \text { Frankfurt }<\text { Main }>/ \text { Frankfurter Buchmesse } & \text { (Zusammenfassung) } \\ \text { BF } & \text { Frankfurter Buchmesse } / \text { Frankfurt }<\text { Main }> & \\ \text { SW } & \text { Frankfurt }<\text { Main }>/ \text { Frankfurter Buchmesse }<1994> & \text { (einzelne Veranstaltung) } \\ \text { BF } & \text { Frankfurter Buchmesse }<1994>/ \text { Frankfurt }<\text { Main }> & \end{array}$

4. Einzelveranstaltungen aus Veranstaltungsfolgen an wechselnden Orten werden nach der Grundregel mit dem Veranstaltungsort und dem Namen der Veranstaltung als zweitem Glied sowie dem Veranstaltungsjahr als Homonymenzusatz angesetzt. Der Name der Veranstaltung mit dem Veranstaltungsjahr als Homonymenzusatz und dem Ort als zweitem Glied wird als Synonym erfasst, ebenso soweit sinnvoll der Name mit einer Zählung als Homonymenzusatz. (Veranstaltungsfolgen einer Körperschaft ohne individuellen Namen vgl. § 607,7.)

Titel: Kirche und Stadt : Dokumentation über den 15. Evangelischen Kirchbautag, Dortmund 1973. - 1974

SW Dortmund / Evangelischer Kirchbautag $<1973>$

BF $\quad$ Evangelischer Kirchbautag $<1973>/$ Dortmund

Dortmund / Evangelischer Kirchbautag $<15,1973>$

Evangelischer Kirchbautag $<15$, 1973 $>$ / Dortmund 
5. Veranstaltungsfolgen an wechselnden Orten als Gesamtheit werden nur mit ihrem Namen angesetzt.

Titel: $\quad \neg$ An $\neg$ approved history of the Olympic games / by Bill Henry \& Patricia Henry Yeomans. - 1984

SWW Olympische Spiele ; Geschichte

6. Veranstaltungen, die gleichzeitig an mehreren Orten stattfinden (oder sich über einen größeren Raum erstrecken), gelten nicht als ortsgebunden und werden mit dem individuellen Namen angesetzt. Das gilt nicht, wenn einer der Veranstaltungsorte als Hauptort hervortritt.

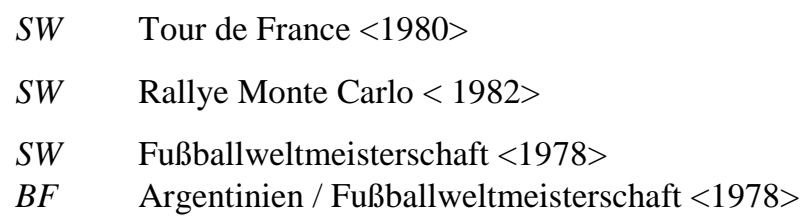

Aber:

Titel: $\quad \neg$ Die $\neg$ Spiele der XX. Olympiade, München, Kiel 1972. - 1972

SW $\quad$ München / Olympische Spiele $<1972>$

$B F \quad$ Olympische Spiele $<1972>$ / München

München tritt gegenüber Augsburg und Kiel als Hauptveranstaltungsort hervor.

7. Hat die Veranstaltung einer Körperschaft keinen individuellen Namen, so wird sie mit dem Körperschaftsnamen angesetzt. Der Veranstaltungsort mit der gewählten Ansetzung als zweitem Glied kann als Synonym erfasst werden. (Zu Synoden und Konzilien vgl. die „Praxisregel“ $§ 415$.

Titel: Parteitag der Sozialdemokratischen Partei Deutschlands : 19. bis 23. April 1982 München, Olympiahalle. - 1982

SW $\quad$ Sozialdemokratische Partei Deutschlands / Parteitag <1982>

BF München / Sozialdemokratische Partei Deutschlands / Parteitag <1982>

8. Veranstaltungen und Veranstaltungsfolgen mit großer allgemeinpolitischer bzw. religiöser Bedeutung, und zwar sowohl historische als auch solche der Gegenwart, werden mit ihrem Namen angesetzt, soweit sie in den Nachschlagewerken unter einem individuellen Namen nachweisbar sind (vgl. §§ 415; 415a,1). Bieten die Nachschlagewerke keinen Nachweis, so wird gemäß § 607,3-7 angesetzt.

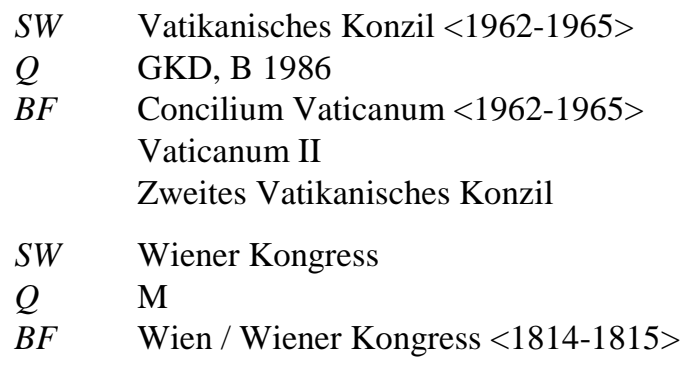

\section{§ 608 Untergeordnete Körperschaften}

1. Als untergeordnet gelten Körperschaften, die einer oder mehreren anderen Körperschaften unterstellt oder zugehörig sind.

2. Zur Ansetzung der Organe einer Gebietskörperschaft vgl. §§ 614; 615, einer militärischen Körperschaft vgl. § 616, einer Religionsgemeinschaft vgl. § 619. 


\section{§ 609 Selbständige oder unselbständige Ansetzung bei Unterordnung unter eine Körperschaft}

1. Körperschaften, die einer Körperschaft unterstellt oder zugehörig sind, werden selbständig angesetzt, wenn ihr Name

a) ohne den der übergeordneten Körperschaft eine ausreichende, allein zitierfähige Bezeichnung ergibt,

SW Dresden / Rüstkammer

$B F \quad$ Dresden / Staatliche Sammlungen / Rüstkammer

b) mit dem Namen der übergeordneten Körperschaft nach der geltenden Rechtschreibung in ununterbrochener Buchstabenfolge geschrieben werden kann,

$\begin{array}{ll}S W & \text { Greifswald / Universitätsbibliothek } \\ B F & \text { Greifswald / Universität / Universitätsbibliothek } \\ S W & \text { Eichstätt / Diözesanarchiv Eichstätt } \\ B F & \text { Eichstätt <Diözese > / Domkapitel / Archiv }\end{array}$

c) nur Teile des Namens der übergeordneten Körperschaft enthält, aus denen nicht hervorgeht, dass es sich um eine Körperschaft handelt (vgl. auch RAK § 429).

SW $\quad$ Frankfurt $<$ Main $>$ / Max-Planck-Institut für Hirnforschung

BF $\quad$ Max-Planck-Institut für Hirnforschung / Frankfurt < Main>

Max-Planck-Gesellschaft zur Förderung der Wissenschaften / Frankfurt $<$ Main $>$ /

Max-Planck-Institut für Hirnforschung

Die für die Ansetzung nicht berücksichtigte unselbständige Form wird als Synonym erfasst, wenn der Name der übergeordneten Körperschaft in der Vorlage oder der GKD genannt ist (vgl. oben).

2. Die Ansetzung erfolgt i. d. R. unselbständig, d. h. als Abteilung der übergeordneten Körperschaft, wenn der Name

a) mit Bezeichnungen gebildet ist, die eindeutig eine Unterordnung zum Ausdruck bringen, wie z. B. Abteilung, Direktion, Klasse, Sektion, Zweigstelle und entsprechende fremdsprachige Bezeichnungen,

$\begin{array}{ll}S W & \text { Rockefeller Foundation / International Health Division } \\ S W & \text { Berlin / Akademie der Künste / Sektion für Dichtkunst }\end{array}$

b) mit Bezeichnungen gebildet ist, die häufig eine Unterordnung zum Ausdruck bringen, wie z. B. Arbeitsgemeinschaft, Arbeitskreis, Ausschuss, Beirat, Fakultät, Gruppe, Kommission, Komitee, Lehrstuhl, Projekt, Seminar und entsprechende fremdsprachige Bezeichnungen (vgl. RAK § 430).

SW Frankenbund / Gruppe Bamberg

Besteht der Name nur aus den Bezeichnungen 'Bibliothek' oder 'Archiv' bzw. entsprechenden fremdsprachigen Benennungen und dem Namen der übergeordneten Körperschaft, erfolgt die Ansetzung ebenfalls i. d. R. unselbständig als Abteilung der übergeordneten Körperschaft, bei fremdsprachigen Namen i. d. R. mit der ins Deutsche übersetzten Form 'Bibliothek' bzw. 'Archiv'.

$\begin{array}{ll}S W & \text { London / Royal Society / Bibliothek } \\ B F & \text { London / Royal Society / Library }\end{array}$ 
SW Prag / Karls-Universität / Archiv

BF Prag / Archiv Univerzity Karlovy

Eine Synonymie-Verweisung von der Abteilung mit der übergeordneten Körperschaft als zweitem Glied wird bei Bedarf gemacht, entfällt aber bei dreistufig angesetzten ortsgebundenen Körperschaften.

SW Deutsche Gesellschaft für Betriebswirtschaft / Arbeitsausschuss Fertigungswirtschaft

BF Arbeitsausschuss Fertigungswirtschaft / Deutsche Gesellschaft für Betriebswirtschaft

SW Daressalam / Universität / Faculty of Engineering

3. Im Zweifelsfall wird eine untergeordnete Körperschaft selbständig angesetzt.

Anm.: Ist eine untergeordnete Körperschaft in der GKD enthalten, so wird die Entscheidung für selbständige bzw. unselbständige Ansetzung von dort übernommen.

4. Bei der Ansetzung der untergeordneten Körperschaft wird der in ihrem Namen enthaltene Name der übergeordneten Körperschaft i.d.R. sowohl bei selbständiger als auch bei unselbständiger Ansetzung weggelassen.

5. Die Form unter Einschluss des Namens der übergeordneten Körperschaft kann dabei als Synonym erfasst werden. Dies geschieht i.d.R. dann, wenn die übergeordnete Körperschaft am Anfang des Namens der untergeordneten als eine Folge von Initialen oder ähnliche Buchstabenfolge genannt ist.

Anm.: Zu weiteren Namensbestandteilen, die bei der Ansetzung nicht berücksichtigt werden, vgl. § 602,5.

\section{§ 610 Selbständige oder unselbständige Ansetzung bei Unterordnung unter mehrere Körperschaften}

Körperschaften, die zwei oder mehreren Körperschaften direkt unterstellt oder zugehörig sind, werden i.d.R. selbständig angesetzt. Dabei entfallen die Namen der übergeordneten Körperschaften im Namen der untergeordneten, es sei denn deren Name ergibt ohne sie keine ausreichende Bezeichnung oder es wird durch Wörter wie z.B. 'gemeinsam' und fremdsprachige Entsprechungen die Zugehörigkeit zu mehreren Körperschaften ausgedrückt. Der Name der übergeordneten Körperschaften mit der untergeordneten als Abteilung wird i.d.R. als Synonym erfasst (vgl. RAK $\S \S 433 ; 434)$.

SW Gemeinsamer Ausschuss des Deutschen Bundestages und des Bundesrates nach Artikel 77 des Grundgesetzes

BF Deutschland / Vermittlungsausschuss

Deutschland / Bundestag / Gemeinsamer Ausschuss des Deutschen Bundestags und des Bundesrates nach Artikel 77 des Grundgesetzes

Deutschland / Bundesrat / Gemeinsamer Ausschuss des Deutschen Bundestages und des Bundesrates nach Artikel 77 des Grundgesetzes

Deutschland / Gemeinsamer Ausschuss des Deutschen Bundestages und des Bundes rates nach Artikel 77 des Grundgesetzes

SW Deutsche Elektrotechnische Kommission

BF Berlin / Deutsches Institut für Normung / Deutsche Elektrotechnische Kommission Verband Deutscher Elektrotechniker / Deutsche Elektrotechnische Kommission 


\section{§ 611 Namensänderungen von Körperschaften}

Hat eine Körperschaft im Laufe der Zeit verschiedene Namen angenommen, so wird i.d.R. der neueste als Ansetzungsform gewählt. Die früheren Namen werden als Synonyme erfasst.

$$
\begin{array}{ll}
\text { SW } & \text { Traunstein / Chiemgau-Gymnasium } \\
\text { BF } & \text { Traunstein / Oberrealschule Traunstein }
\end{array}
$$

Ist die Namensänderungs allerdings mit einer grundlegenden Änderung des Charakters bzw. der Identität der Körperschaft verbunden, so werden früherer und späterer Name nebeneinander angesetzt und durch chronologische Verweisungen verbunden (vgl. § 12,7). Im Zweifelsfall wird keine grundlegende Veränderung angenommen.

Grundlegende Änderungen des Charakters oder der Identität der Körperschaft, die nicht mit einer Namensänderung verbunden sind, werden nicht berücksichtigt.

Anm.: Im Unterschied zu RSWK wird nach RAK für die Ansetzung im Allgemeinen jeweils derjenige Name benutzt, den die Körperschaft zu dem Zeitpunkt ihrer Beteiligung am Zustandekommen der zu katalogisierenden Veröffentlichung geführt hat (vgl. RAK $\S \S 407-409)$.

1. Nicht als wesentliche Änderung gelten Namensänderungen infolge

- Änderung von selbständig zu unselbständig und umgekehrt,

SW Leipzig / Sächsische Akademie der Wissenschaften / Historische Kommission

BF Leipzig / Sächsische Kommission für Geschichte *Name 1896-1945

Sächsische Kommission für Geschichte / Leipzig

- Änderung von ortsgebunden zu nicht ortsgebunden und umgekehrt,

SW Sozialdemokratische Partei Deutschlands / Ortsverein Nördlingen

BF Nördlingen / Sozialdemokratischer Verein

Sozialdemokratischer Verein / Nördlingen

- Änderung von Organ zu Nichtorgan und umgekehrt,

$S W \quad$ Österreich / Bundesamt für Agrarbiologie

BF Linz / Landwirtschaftlich-chemische Versuchsanstalt

- Ortswechsel bei ortsgebundenen Körperschaften.

SW Strausberg / Sozialwissenschaftliches Institut

$B F \quad$ Sozialwissenschaftliches Institut / Strausberg

München / Sozialwissenschaftliches Institut

2. Als wesentliche Änderung gelten Namensänderungen infolge

- grundlegender Änderung des Selbstverständnisses oder des Aufgabenbereiches der Körperschaft

$$
\begin{aligned}
& \text { SW OEEC } \\
& C F \text { später OECD } \\
& \text { SW OECD } \\
& C F \text { früher OEEC }
\end{aligned}
$$

- Teilungen und Zusammenschlüssen, Abspaltungen, Aufspaltungen, Änderungen bei Aufgabenbereichen von Ministerien,

$S W \quad$ Cham $<$ Oberpfalz $>$ / Joseph-von-Fraunhofer-Gymnasium
CF früher Cham $<$ Oberpfalz $>/$ Gymnasium Cham 
SW $\quad$ Cham $<$ Oberpfalz $>$ / Robert-Schuman-Gymnasium

CF früher Cham < Oberpfalz $>$ / Gymnasium Cham

SW Hennebergisch-Fränkischer Geschichtsverein

CF früher Verein für Sachsen-Meiningische Geschichte und Landeskunde

SW Verein für Sachsen-Meiningische Geschichte und Landeskunde

CF später Hennebergisch-Fränkischer Geschichtsverein

SW UNISON

CF früher National and Local Government Officers' Association

$C F$ früher Confederation of Health Service Employees

CF früher National Union of Public Employees

- Namensänderungen, bei denen dazwischen eine Neugründung stattgefunden hat.

SW Deutscher Turnerbund

H 1950 neu gegründet, versteht sich als Nachfolgeorganisation der Deutschen Turnerschaft

BF Deutschland / Deutscher Turnerbund

CF früher Deutsche Turnerschaft

SW Deutsche Turnerschaft

H 1934 in den Deutschen Reichsbund für Leibesübungen eingegliedert, 1936 Selbstauflösung, 1950 unter dem Namen Deutscher Turnerbund neu gegründet

CF später Deutscher Turnerbund

\section{§ 612 Homonyme Körperschaftsnamen}

1. Gleichnamige Körperschaftsnamen werden durch Homonymenzusätze unterschieden. Diese müssen dabei i. d. R. der jeweiligen Ansetzungsform der SWD entsprechen. Als Homonymenzusatz wird eine geeignete Angabe gewählt. (Zur Zählung als Unterscheidungsmerkmal vgl. § 602,5.) Ist eine der homonymen Körperschaften sehr viel bekannter als die anderen, so entfällt bei ihrer Ansetzungsform der Homonymenzusatz.

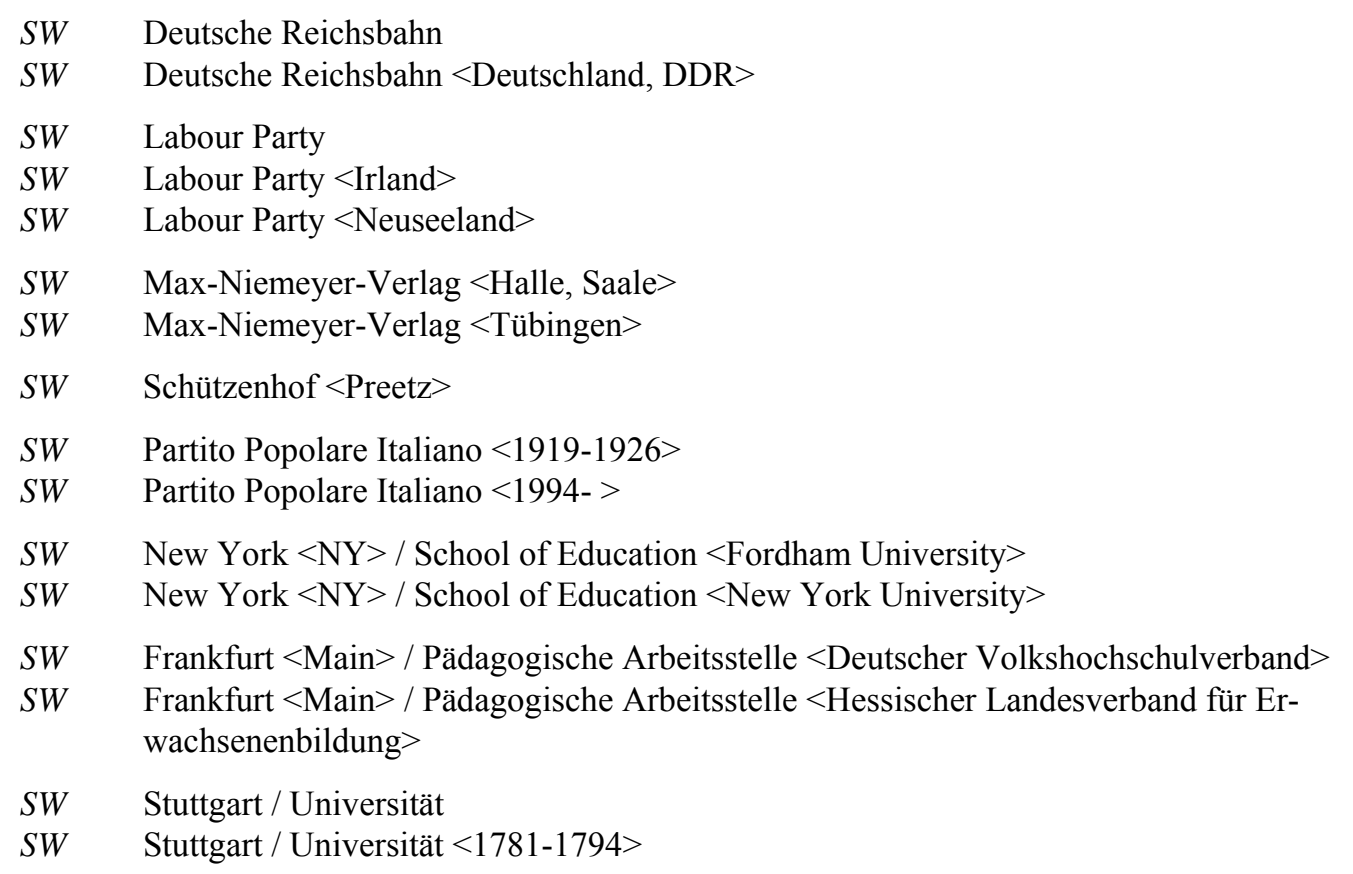


2. Ist ein Körperschaftsname zu Schlagwörtern anderer Schlagwortkategorien homonym, so wird er i. d. R. durch die Homonymenzusätze $<$ Körperschaft $>$, $<$ Firma $>$, $<$ Künstlervereinigung $>$, $<$ Musikgruppe $>$ oder $<$ Veranstaltung $>$ unterschieden.

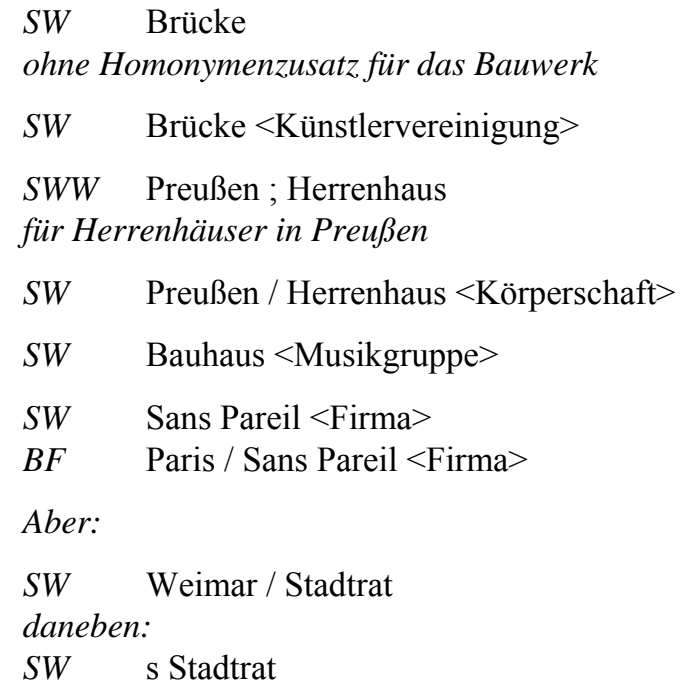

\section{§ 613 Gebietskörperschaften}

1. Gebietskörperschaften sind Körperschaften des öffentlichen Rechts, deren Gebietshoheit einen räumlich abgegrenzten Teil des Staatsgebiets sowie dessen Bewohner als gesetzliche Mitglieder ihrer Organisation erfasst, z. B. Bund, Länder, Regierungsbezirke, Landkreise, Gemeinden und die ihnen entsprechenden Institutionen in anderen Staaten.

Ein Gliedstaat oder Verwaltungsbezirk, dessen Name mit einem die Art der Einheit bezeichnenden Ausdruck beginnt, z. B. Kanton, Regierungsbezirk, Kreis, wird unter dem um diesen Ausdruck verkürzten Namen angesetzt, es sei denn, dass der Rest des Namens nicht für sich allein bestehen kann (vgl. RAK § 441).

2. Gebietskörperschaften werden als geographische Schlagwörter behandelt und erhalten den Indikator g (vgl. §§ $201 \mathrm{ff}$.).

3. Regionale Einheiten von Religionsgemeinschaften vgl. § 618,1.

\section{§ 614 Organe einer Gebietskörperschaft}

1. Als Organe einer Gebietskörperschaft im Sinne dieses Regelwerks gelten Parlamente, Regierungen, Ministerien und vergleichbare Institutionen auf Landes- und Kreisebene, Bundesgerichte und Oberste Landesgerichte, ferner die der Gebietskörperschaft nachgeordneten Behörden, deren räumliche Zuständigkeit die gesamte Gebietskörperschaft umfasst.

2. Organe einer Gebietskörperschaft werden i. d. R. als deren Abteilung angesetzt und erhalten den Indikator c. Die Wahl der Sprache erfolgt nach $\S 603$ (vgl. RAK §§ 448-453). Der Name des Organs mit der Gebietskörperschaft als zweitem Glied wird als Synonym erfasst.

$\begin{array}{ll}\text { SW } & \text { Weimar / Stadtrat } \\ \text { BF } & \text { Stadtrat / Weimar }\end{array}$


SW USA / Oberster Gerichtshof

BF USA / Supreme Court

Oberster Gerichtshof / USA

Supreme Court / USA

SW Großbritannien / Department of Employment and Productivity

$B F \quad$ Department of Employment and Productivity / Großbritannien

SW Schweden / Reichstag

BF Reichstag / Schweden

Riksdagen / Schweden

Schweden / Riksdagen

SW Frankreich / Nationalversammlung

BF Assemblée Nationale / Frankreich

Frankreich / Assemblée Nationale

Nationalversammlung / Frankreich

Vom Ortssitz des Organs einer Gebietskörperschaft, z. B. Bundesgerichte und oberste Landesbehörden mit dem Namen des Organs als weiterem Glied kann eine SynonymieVerweisung gemacht werden.

$\begin{array}{ll}S W & \text { Deutschland / Bundesverfassungsgericht } \\ B F & \begin{array}{l}\text { Bundesverfassungsgericht / Deutschland } \\ \text { Karlsruhe / Bundesverfassungsgericht }\end{array} \\ & \text { Sachsen / Statistisches Landesamt } \\ \text { BF } & \begin{array}{l}\text { Kamenz / Statistisches Landesamt } \\ \text { Statistisches Landesamt / Sachsen }\end{array}\end{array}$

Botschaften, Gesandtschaften, Konsulate usw. werden als Organ des sie entsendenden Staates angesetzt. Der Name des fremden Staates, in dem sich die Botschaft usw., bei Konsulaten usw. die Stadt, in der sich das Konsulat befindet, wird als Homonymenzusatz hinzugefügt. Vom Ortssitz der Botschaft usw. wird eine Synonymie-Verweisung gemacht.

\section{SW $\quad$ Deutschland / Botschaft < Tschechische Republik> \\ $B F \quad$ Tschechische Republik / Deutsche Botschaft \\ Prag / Deutsche Botschaft \\ Prag / Botschaft / Deutschland}

3. Bei der Ansetzung eines Organs als Abteilung einer Gebietskörperschaft werden folgende Namensbestandteile weggelassen, soweit sie nicht mit dem Namen des Organs in ununterbrochener Buchstabenfolge geschrieben werden können bzw. für die eindeutige Identifizierung unerlässlich sind (vgl. § 602,5):

a) der Name der Gebietskörperschaft;

b) Zugehörigkeitsangaben wie 'staatlich', 'städtisch', 'des Bundes', 'des Landes', 'der Stadt' und entsprechende fremdsprachige Bezeichnungen;

c) von Titulaturen abgeleitete Angaben, wie 'kurfürstlich', 'königlich' und entsprechende fremdsprachige Bezeichnungen (vgl. RAK § 450).

$\begin{array}{ll}S W & \text { Deutschland / Reichstag } \\ B F & \text { Deutscher Reichstag } \\ & \text { Deutschland / Deutscher Reichstag } \\ & \text { Reichstag / Deutschland }\end{array}$




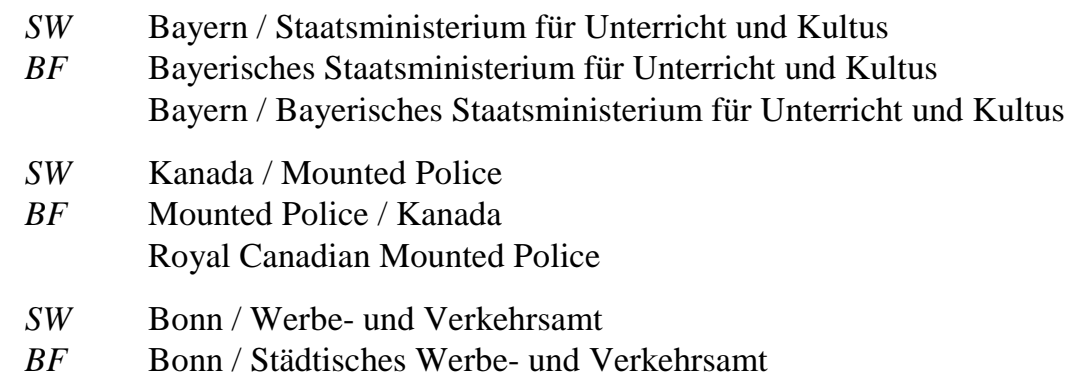

4. Bei der Ansetzung eines Organs einer Gebietskörperschaft werden Zwischenstufen übergangen, es sei denn, sie sind zur eindeutigen Bezeichnung des Organs unerläßlich (vgl. RAK $\S 449)$.

SW Hamburg / Amt für Marktwesen

BF Hamburg / Behörde für Wirtschaft und Verkehr / Amt für Marktwesen

$S W \quad$ Deutschland / Presse- und Informationsamt

$B F \quad$ Deutschland / Bundesregierung / Presse- und Informationsamt

Aber:

SW USA / Landwirtschaftsministerium / Bureau of Statistics

$S W \quad$ USA / Wirtschaftsministerium / Bureau of Statistics

5. Als „klassische“ Ministerien des In- und Auslands werden normiert angesetzt:

$\begin{array}{lll}S W & \text { Außenministerium } & \text { (auch für Auswärtiges Amt) } \\ S W & \text { Finanzministerium } & \\ S W & \text { Innenministerium } & \\ S W & \text { Justizministerium } & \\ S W & \text { Landwirtschaftsministerium } & \\ S W & \text { Verteidigungsministerium } & \text { (zu verwenden erst ab 1945) } \\ S W & \text { Wirtschaftsministerium } & \end{array}$

Der offizielle Name wird als Synonym erfasst. Diese Normierung gilt nicht für Stadtstaaten.
SW Deutschland / Innenministerium
$B F \quad$ Deutschland / Bundesministerium des Innern
SW Großbritannien / Innenministerium
$B F \quad$ Großbritannien / Home Office
SW Ungarn / Justizministerium
$B F \quad$ Ungarn / Igazságügyi Minisztérium 


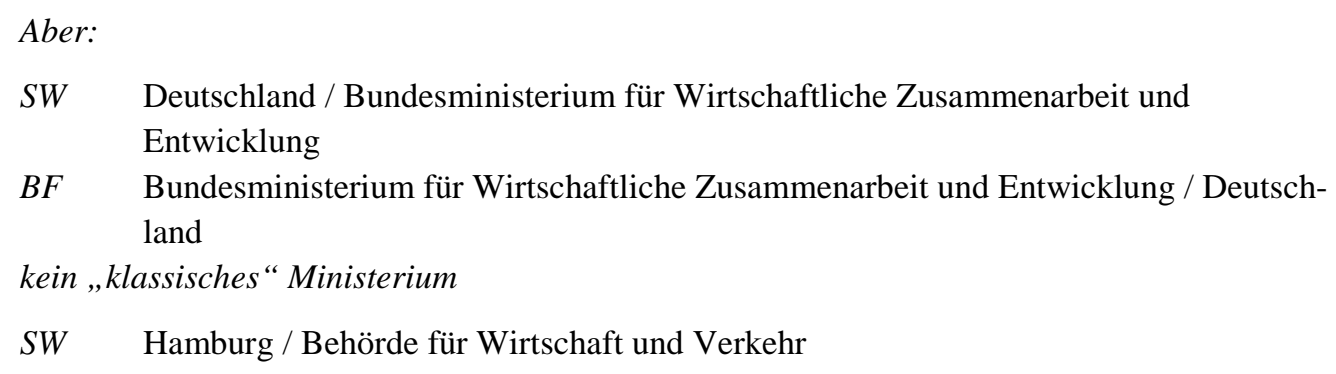

\section{§ 615 Nicht zentrale Organe einer Gebietskörperschaft}

1. Nicht als zentrale Organe einer Gebietskörperschaft gelten die ihr unterstellten oder zugehörigen Körperschaften, die sich vorwiegend mit erzieherischen, kulturellen, wissenschaftlichen, technischen, religiösen, sozialen u. ä. Aufgaben befassen, wie z. B. Schulen, Bibliotheken, Theater, Museen, Forschungsinstitute, Post- und Verkehrseinrichtungen, Kirchen, Krankenhäuser, Heime und vergleichbare Bundes- und Landesanstalten. Dazu gehören auch nachgeordnete Organe mit regional begrenzten Aufgaben wie Gerichte, Polizeibehörden usw.

2. Einer Gebietskörperschaft unterstellte oder zugehörige Körperschaften, die nicht als Organ gelten, werden selbständig angesetzt. Von der Namensform als Organ kann eine SynonymieVerweisung gemacht werden (vgl. § 609,5).

$\begin{array}{ll}S W & \text { Saarbrücken / Oberlandesgericht Saarbrücken } \\ B F & \text { Saarland / Oberlandesgericht Saarbrücken } \\ S W & \text { Hamburg / Arbeitsamt Hamburg } \\ S W & \text { Traunstein / Landgericht Traunstein } \\ S W & \text { Nürnberg / Bundesanstalt für Arbeit } \\ B F & \text { Bundesanstalt für Arbeit / Nürnberg }\end{array}$

\section{§ 616 Militärische Körperschaften}

1. Die Gesamtstreitkräfte eines Staates sowie die Teilstreitkräfte werden nicht als Körperschaften behandelt, sondern in einer Schlagwortkette als Sachschlagwörter mit dem betreffenden Geographikum verknüpft; für Listenfunktionen kann permutiert werden.

$\begin{array}{lll}S W & \text { s Militär } & \text { (für die Gesamtstreitkräfte eines Landes) } \\ S W & \text { s Heer } & \text { (für die Landstreitkräfte eines Landes) } \\ S W & \text { s Luftwaffe } & \text { (für die Luftstreitkräfte eines Landes) } \\ S W & \text { s Marine } & \text { (für die Seestreitkräfte eines Landes) }\end{array}$

Nur die deutschen, österreichischen und schweizerischen Gesamtstreitkräfte werden als Körperschaften angesetzt:

SW c Deutschland / Bundeswehr

für die Zeit ab 1991

SW c Deutschland < Bundesrepublik> / Bundeswehr

für die Zeit 1954-1990 


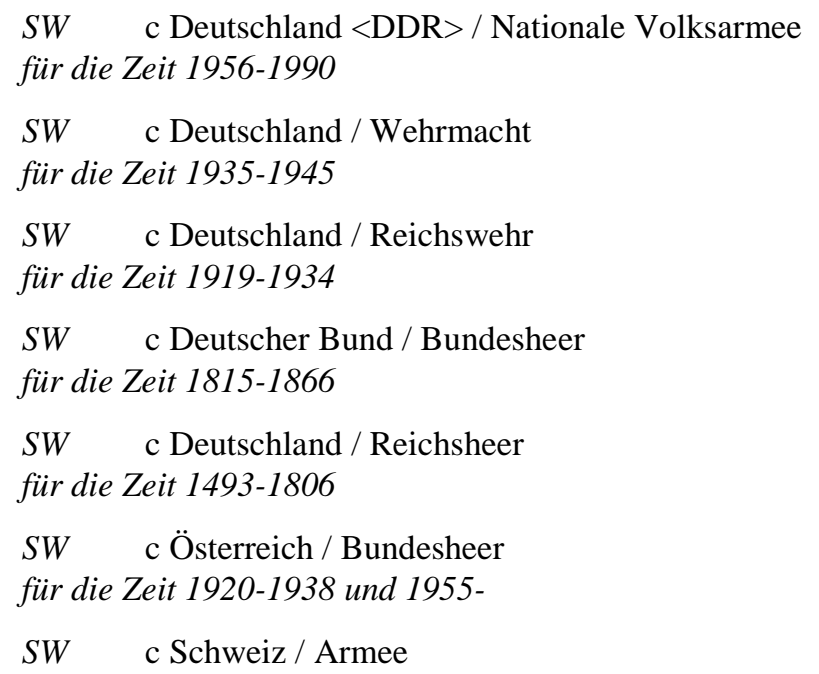

Für Gesamtdarstellungen und Zeiträume, in denen es keinen Individualnamen gab, wird eine Schlagwortkette aus dem Namen der Gebietskörperschaft und dem Sachschlagwort 'Militär' gebildet.

2. Einzelne militärische Einheiten und Verbände werden i. d. R. als Abteilung ihrer Gebietskörperschaft angesetzt. Die Wahl der Sprache erfolgt nach § 603 (vgl. RAK §§ 448-453). Die Verknüpfung aus Geographikum und Sachschlagwort für die Streitkräfte (vgl. § 616,1), denen die militärische Körperschaft angehört, wird i. d. R. als mehrgliedriger Oberbegriff erfasst, der Name der militärischen Körperschaft mit dem Geographikum als zweitem Glied i. d. R. als Synonym.

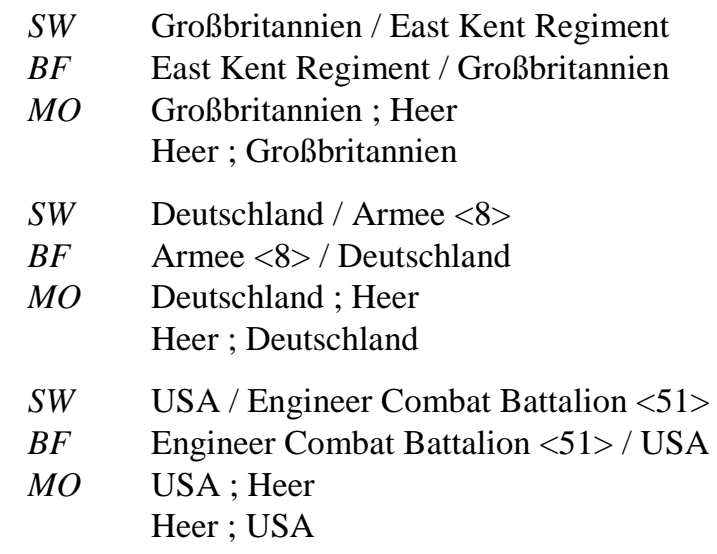

3. Militärischen Körperschaften unterstellte Körperschaften mit einer ortsfesten Einrichtung, die sich überwiegend mit nicht militärischen Aufgaben befassen, wozu insbesondere militärische Ausbildungsstätten gehören, werden nicht als nachgeordnete Organe der militärischen Körperschaft aufgefasst, sondern selbständig angesetzt. Von der unselbständigen Ansetzungsform wird eine Synonymie-Verweisung gemacht.

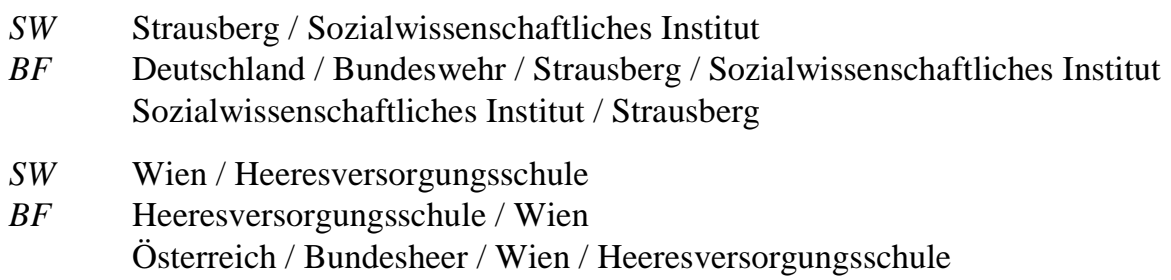


4. Kann eine militärische Körperschaft nicht eindeutig als Abteilung einer Gebietskörperschaft zugeordnet werden, so wird sie mit ihrem Individualnamen angesetzt, soweit erforderlich mit Ansetzung der untergeordneten Einheit als zweitem Glied. Die invertierte Form wird soweit sinnvoll als Synonym erfasst.

$\begin{array}{ll}S W & \text { Lützowsches Freikorps } \\ S W & \text { Brigade Ehrhardt } \\ S W & \text { Armee im Lande }<\text { Polen }>\text { / Poleska Dywizja Piechoty <30> } \\ B F & \text { Poleska Dywizja Piechoty <30> / Armee im Lande <Polen> } \\ S W & \text { Forces Françaises de l'Intérieur / Corps Franc du Sidobre } \\ B F & \text { Corps Franc du Sidobre / Forces Françaises de l’Intérieur } \\ S W & \text { Volksbefreiungsarmee < Jugoslawien }>\text { / Divizija }<4>\end{array}$

\section{§ 617 Religionsgemeinschaften}

1. Unter Religionsgemeinschaften (Religionsgesellschaften, Glaubensverbänden) versteht man Gemeinschaften, zu denen sich Angehörige eines Bekenntnisses oder mehrerer verwandter Bekenntnisse zusammengeschlossen haben. Dazu gehören die christlichen Kirchen ebenso wie nichtchristliche Gemeinschaften.

2. Religionsgemeinschaften werden i. d. R. mit ihrem Namen entsprechend den Bestimmungen von $\S \S 601-612$ angesetzt. Gibt es keinen Namen, so erfolgt die Ansetzung mit dem Sachschlagwort.

$\begin{array}{ll}S W & \text { Bund Evangelisch-Freikirchlicher Gemeinden in Deutschland } \\ S W & \text { Evangelische Kirche in Deutschland } \\ B F & \text { EKD } \\ S W & \text { Evangelisch-Reformierte Landeskirche des Kantons Bern } \\ S W & \text { Deutscher Bahaibund } \\ S W & \text { Buddhistische Gemeinschaft Österreichs } \\ \text { Aber: } & \\ \text { SWW } & \text { g Brandenburg-Ansbach <Markgrafschaft> ; s Evangelische Kirche } \\ \text { Hierfür gibt es keinen individuellen Körperschaftsnamen. 'Evangelische Kirche' ist Sach- } \\ \text { schlagwort (Konfessionsbezeichnung) und kein Körperschaftsname. }\end{array}$

\section{$\S 618$ Regionale, lokale und personelle Einheiten einer Religionsge} meinschaft

1. Regionale Einheiten einer Religionsgemeinschaft (Diözesen, Dekanate, Hochstifte, Kirchenkreise, Propsteien, Superintendenturen, überörtliche Pfarreien usw.) werden mit dem geographischen Namen und der entsprechenden Verwaltungseinheit als Homonymenzusatz angesetzt (vgl. § 203,4). Sie gelten als geographische Schlagwörter.

$$
\begin{array}{ll}
S W & \text { g Erlangen }<\text { Kirchenkreis }> \\
S W & \text { g Freiburg }<\text { Breisgau, Diözese }> \\
S W & \text { g Brixen }<\text { Hochstift }>
\end{array}
$$


SW $\quad$ g Endorf < Oberbayern, Pfarrei>

Die Pfarrei umfasst mehrere selbständig anzusetzende Orte.

2. Lokale Einheiten einer Religionsgemeinschaft (Pfarreien innerhalb eines Ortes, Kirchengemeinden, Klöster usw.) werden mit ihrem Namen und dem betreffenden Ort bzw. Ortsteil (vgl. § 605,6-7) als erstem Glied angesetzt (vgl. RAK § 464).

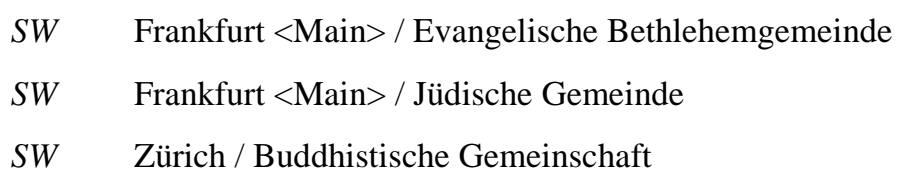

Pfarreien der katholischen Kirche innerhalb eines Ortes werden i. d. R. normiert in der Form Ort / Patrozinium <Pfarrei $>$ angesetzt. Gibt es gleichnamige Pfarreien an einem Ort, so wird zur Unterscheidung der Name des Ortsteils dem Namen des Hauptorts hinzugefügt (vgl. $\S 605,7)$.

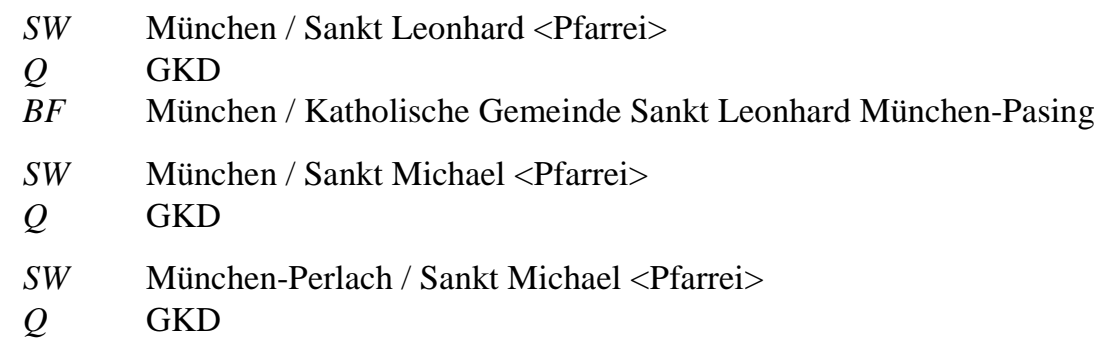

Evangelische Kirchengemeinden sind dagegen mit Ort / Individualname anzusetzen.

SW Hamburg / Kirchengemeinde Sankt Nikolai

Zu Kirchenbauten vgl. § 731.

3. Klöster und Stifte werden als lokale Einheiten von Religionsgemeinschaften normiert mit dem Ort bzw. Ortsteil und der Gattungsbezeichnung 'Kloster' bzw. 'Stift' angesetzt (vgl. $\S$ 605,6-7). Da beide Bezeichnungen häufig quasisynonym benutzt werden, ist bei Zweifelsfällen die genaue Rechtsform zu ermitteln. Als Stifte gelten insbesondere Kollegiat-, Chorherren-, Augustiner-Chorherren-, Fräulein-, Prämonstratenser- und Damenstifte. Der Individualname wird als Synonym erfasst. (Zur Ansetzung von Hochstiften vgl. § 618,1; zur Ansetzung von Domstiften im Sinne von Domkapiteln vgl. § 619; zur Ansetzung von Archiven und Bibliotheken von Domen, Klöstern und Stiften vgl. § 609.)

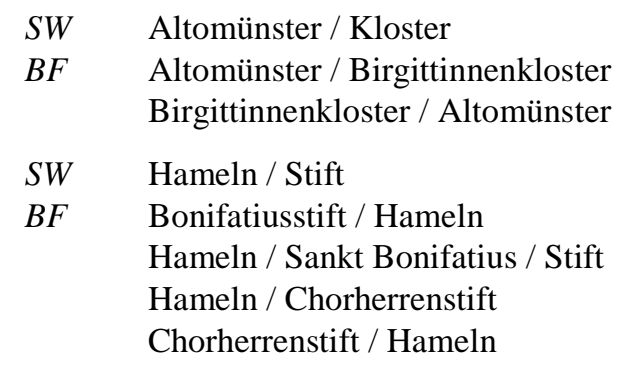

Bei mehreren Klöstern bzw. Stiften an einem Ort wird eine mehrgliedrige Ansetzungsform mit dem Namen der Kirche (Patrozinium, Eigenname oder anderer gebräuchlicher Name) in der Form Ort / Name der Kirche / Kloster bzw. Stift gebildet. 
SW Regensburg / Sankt Emmeram / Kloster

BF Reichsstift Sankt Emmeram / Regensburg

Regensburg / Reichsstift Sankt Emmeram

Benediktinerkloster Sankt Emmeram / Regensburg

Regensburg / Benediktinerkloster Sankt Emmeram

Klöster bzw. Stifte, als deren Sitz sich ehemalige bzw. aufgelassene Orte oder sonstige geographische Bezeichnungen bestimmen lassen, werden mit diesen geographischen Namen angesetzt.

\author{
SW Tennenbach / Kloster \\ Tennenbach ist ein aufgelassener Ort.
}

Lässt sich für ein Kloster bzw. Stift kein Ortssitz bestimmen (z.B. bei alleinstehenden Klöstern bzw. Stiften), so wird mit dem Individualnamen angesetzt.

SW Sinaikloster

Die Anlage liegt außerhalb jeder Siedlung am Fuße des Gabal Katrina.

4. Personelle Einheiten einer Religionsgemeinschaft, wie z.B. Orden und ähnliche religiöse Gemeinschaften, werden selbständig mit ihrem Namen entsprechend den Bestimmungen von $\S 603$ angesetzt. Eine ggf. abweichende offizielle Namensform wird als Synonym erfasst (vgl. RAK $\S \S 465-466)$.

$\begin{array}{ll}S W & \text { Franziskaner } \\ Q & \text { GKD, M } \\ B F & \text { Ordo Fratrum Minorum } \\ S W & \text { Benediktiner } \\ Q & \text { GKD, M } \\ B F & \text { Ordo Sancti Benedicti } \\ S W & \text { Franziskanerinnen von der Heiligen Familie } \\ Q & \text { GKD, Heimbucher }\end{array}$

Eine regionale Einheit eines Ordens usw. wird als seine Abteilung angesetzt.

$\begin{array}{ll}S W & \text { Benediktiner / Bayerische Kongregation } \\ B F & \text { Bayerische Kongregation der Benediktiner } \\ S W & \text { Deutscher Orden / Ballei Thüringen } \\ \text { BF } & \text { Ballei Thüringen / Deutscher Orden }\end{array}$

Eine lokale Einheit eines Ordens usw. wird entsprechend $\S 618,2$ behandelt.

\title{
§ 619 Organe einer Religionsgemeinschaft
}

1. Ein Organ einer Religionsgemeinschaft ist als deren Abteilung anzusetzen, wenn sein Name ohne den der übergeordneten Körperschaft keine ausreichende Bezeichnung ergibt. Andernfalls wird das Organ selbständig angesetzt. Bei der Ansetzung werden Zwischenstufen i.d.R. übergangen und folgende Namensbestandteile weggelassen:

a) der Name der Religionsgemeinschaft;

b) konfessionelle und sonstige Zugehörigkeitsangaben wie 'katholisch', 'evangelisch', 'kirchlich', 'landeskirchlich', 'der Kirche', 'der Diözese'und entsprechende fremdsprachige Bezeichnungen; 
c) von Titulaturen abgeleitete Angaben wie 'bischöflich', 'erzbischöflich', 'päpstlich' und entsprechende fremdsprachige Bezeichnungen.

Offizielle Form

Evangelisches Kirchenbauamt Baden

Bischöfliches Seelsorgeamt, Augsburg

Kirchenamt der Evangelischen Kirche in Deutschland

Metropolitankapitel zu München

Ecclesia Catholica, Sacra Romana Rota

\section{Unselbständige Ansetzungsform}

SW Evangelische Landeskirche in Baden /

Kirchenbauamt

BF Evangelisches Kirchenbauamt Baden

SW Augsburg $<$ Diözese $>$ / Seelsorgeamt

SW Evangelische Kirche in Deutschland / Kirchenamt

SW München-Freising < Diözese > / Domkapitel

Selbständige Ansetzungsform

SW Rota

BF Katholische Kirche / Sacra Romana Rota Sacra Romana Rota

Romana Rota

2. Spitzenorgane von Religionsgemeinschaften, deren Namen aus der Amtsbezeichnung bzw. dem Titel des obersten geistlichen Würdenträgers bestehen, werden nicht wie Körperschaften angesetzt, vielmehr wird das Sachschlagwort für die Amtsbezeichnung bzw. den Titel mit dem Namen der Religionsgemeinschaft bzw. dem Geographikum für die betreffende regionale Einheit der Religionsgemeinschaft verknüpft.

$$
\begin{array}{ll}
\text { SWW } & \text { g Köln }<\text { Diözese }>\text {; s Erzbischof } \\
\text { SWW } & \text { g Passau }<\text { Diözese }>\text {; s Bischof }
\end{array}
$$

3. Nuntiaturen werden als Organe einer Religionsgemeinschaft selbständig angesetzt. Der Name des Staates, in der sich die Nuntiatur befindet, wird als Homonymenzusatz hinzugefügt. Historische Nuntiaturen (bis 1918) erhalten dagegen als Homonymenzusatz den Sitz der Nuntiatur.

$$
\begin{array}{ll}
\text { SW } & \text { Nuntiatur }<\text { Polen }> \\
\text { BF } & \text { Katholische Kirche / Nuntiatur }<\text { Polen }> \\
& \text { Heiliger Stuhl } / \text { Nuntiatur }<\text { Polen }> \\
\text { Apostolische Nuntiatur }<\text { Polen }> \\
\text { CF früher Nuntiatur }<\text { Warschau }> \\
\text { SW } \quad \text { Nuntiatur }<\text { Warschau }> \\
\text { CF später Nuntiatur }<\text { Polen }>
\end{array}
$$

\section{§ 620 Körperschaftsnamen als Bestandteil präkombinierter Schlagwör- ter}

$\mathrm{Zu}$ präkombinierten Bezeichnungen aus Sachschlagwort und Namen von Körperschaften vgl. $\S 305,2$,f. 


\section{§ 620a SWD-Datensatz}

Überblick über die wichtigsten Informationen in einem Datensatz der SWD für die Ansetzungsform einer Körperschaft (vgl. § 7,4).

- Indikator k bzw. c für ortsgebundene Körperschaften (Angabe obligatorisch bei allen Körperschaftsnamen, vgl. § 601,3)

- Körperschaftsname in Ansetzungsform (Angabe obligatorisch, vgl. § 602)

- GKD-Nummer (Angabe obligatorisch, vgl. § 602,2) bzw. Alternativform nach RAK (Angabe fakultativ)

- Quelle (Angabe obligatorisch, vgl. § 19,1)

- Definition (Angabe fakultativ, vgl. § 19,2)

- Verwendungshinweis (Angabe fakultativ, vgl. § 19,3)

- Redaktionelle Bemerkung (Angabe fakultativ, vgl. § 19,4)

- Notation (Angabe obligatorisch, vgl. § 18,1)

- Ländercode (Angabe obligatorisch, vgl. § 18,2)

- Sprachencode (Angabe fakultativ, vgl. § 18,3)

- Zeitcode (Angabe fakultativ, vgl. §§ 18,4; 418)

- Synonymie-Verweisungen (vgl. §§ 12,2; 602,2); ggf. mit Bemerkung, eingeleitet durch *

- Mehrgliedrige Oberbegriffe in Form einer Schlagwortkette (vgl. §§ 12,4; 602,9); ggf. mit Bemerkung, eingeleitet durch *

- Verwandte Begriffe (vgl. §§ 12,5; 602,8; 605,5,a)

- Chronologische Beziehungen (vgl. §§ 12,7; 611) frühere Namensform; ggf. mit Bemerkung, eingeleitet durch * spätere Namensform; ggf. mit Bemerkung, eingeleitet durch *

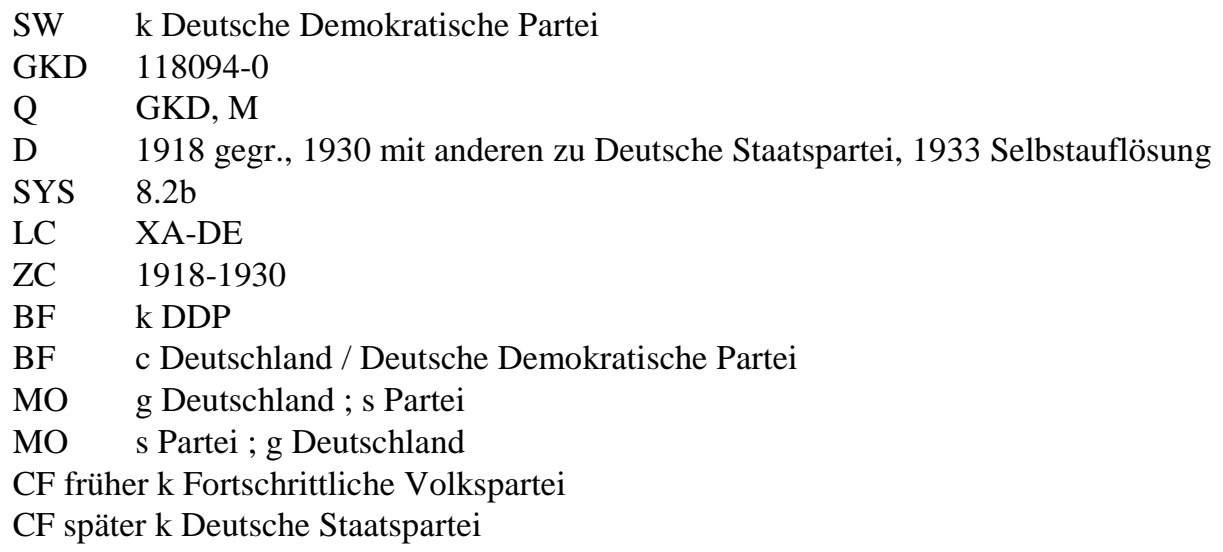


SW c Paris /Théâtre National de l'Odéon

GKD 1096967-6 Théâtre National de l'Odéon 〈Paris〉

Q Engler unter Théâtre de l'Odéon, GKD

D Einweihung des Theatersaals 1782, 1959-1968 Sitz des Théâtre de France, Umbenennung 1971

SYS 15.1

LC XA-FR

ZC 1782-

BF k Théâtre National de l'Odéon / Paris

BF c Paris / Odéon-Théâtre de France

BF k Odéon-Théâtre de France / Paris

BF c Paris / Odéon <Körperschaft $>$

BF k Odéon $<$ Körperschaft $>$ / Paris

MO g Frankreich; s Theater

MO s Theater; g Frankreich

\section{$\S 621$ entfällt}

\section{Verknüpfung und Permutation}

\section{$\S 622$ Verknüpfung und Permutation}

Körperschaftsnamen werden in der Grundkette verknüpft und permutiert (vgl. §§ 11,2; 15)

wie geographische Schlagwörter, wenn ihre Ansetzungsform mit einem Geographikum beginnt (vgl. auch $\S \S 15,4 ; 116,2, \mathrm{~b})$

SWW p Gagern <Familie> ; z Geschichte ; c Koblenz / Bundesarchiv ; f Inventar (34125)

SWW c Großbritannien / Unterhaus ; s Politische Ethik ; c USA / Kongress (31245) (45312)

SWW c Wien / Graphische Sammlung Albertina ; s Zeichnung ; g Italien ; z Geschichte 1300-1850 (34512) (43512)

wie Sachschlagwörter in den übrigen Fällen (vgl. auch §§ 15,6; 116,2,c)

SWW p Bismarck, Otto ᄀvon $\neg$; k Deutsche Zentrumspartei ; z Geschichte 1877-1879 (213)

SWW g Deutschland < Bundesrepublik> ; s Industrie ; k Deutsche Bank ; z Geschichte (2314) (3214)

SWW k Labour Party ; s Sicherheitspolitik ; k Sozialdemokratische Partei Deutschlands (213) (321)

\section{$\S \S 623$ - 631 entfallen}




\section{Weitere Sonderregeln}

\section{Sprache, Wörterbücher, Literatur}

\section{$\S 701$ Sprache}

1. a) Sprachen werden wie geographische Schlagwörter behandelt und erhalten in der SWD den Indikator $\mathrm{g}$.

Sie werden i. d. R. mit dem von der geographischen oder ethnographischen Bezeichnung abgeleiteten Adjektiv in undeklinierter Form angesetzt.

$\begin{array}{ll}\text { SW } & \text { Afrikaans } \\ \text { SW } & \text { Deutsch } \\ \text { SW } & \text { Judenspanisch } \\ \text { SW } & \text { Mandschurisch } \\ \text { SW } & \text { Thailändisch }\end{array}$

Gebräuchliche Adjektiv-Substantiv-Verbindungen (Sprachadjektiv und Schlagwort 'Sprache') und andere nicht gewählte Formen werden als Synonyme erfasst.

$\begin{array}{ll}\text { SW } & \text { Russisch } \\ \text { BF } & \text { Russische Sprache } \\ & \text { Großrussisch }\end{array}$

b) Gibt es für eine Sprache eine andere eindeutige Bezeichnung in nicht adjektivischer Form, so wird mit dieser angesetzt. Nicht gewählte Formen werden als Synonyme erfasst.

$\begin{array}{ll}\text { SW } & \text { Latein } \\ \text { BF } & \text { Lateinische Sprache } \\ & \text { Lateinisch } \\ \text { SW } & \text { Tamil } \\ \text { BF } & \text { Damul } \\ & \text { Tamilisch } \\ & \text { Tamilische Sprache } \\ & \text { Tamul }\end{array}$

c) Gibt es kein inhaltlich zutreffendes, eindeutiges und gebräuchliches Adjektiv oder keine andere eindeutige Bezeichnung, so wird ein Kompositum oder eine Adjektiv-SubstantivVerbindung aus dem ethnographischen oder geographischen Schlagwort und dem Zusatz 'Sprache' bzw. 'Sprachen' (bei Sprachgruppen) gebildet.

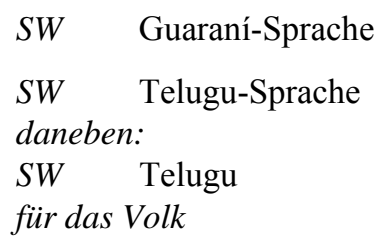


SW Bantusprachen

SW Germanische Sprachen

SW Uralische Sprachen

Verweisungen, die sowohl für das Geographikum/Ethnographikum als auch für die präkombinierte Sprachbezeichnung relevant sind, werden i. d. R. nur beim Grundwort erfasst.

$\begin{array}{ll}\text { SW } & \text { Ibo } \\ B F & \text { Igbo } \\ \text { SW } & \text { Ibo-Sprache } \\ \text { BF } & \text { Ibo / Sprache } \\ & \text { Ibo }<\text { Sprache }> \\ \text { nicht: } & \text { BF Igbo-Sprache }\end{array}$

d) Für Darstellungen zu mehreren Sprachen innerhalb einer geographischen Einheit wird, wenn es keine übergeordnete Bezeichnung gibt, das geographische Schlagwort mit dem Schlagwort 'Sprache' verknüpft.
SWW Afrika; Sprache
daneben aber auch:
SW Afrikanische Sprachen
Q M, B 1986
für die einheimischen Sprachen in Schwarzafrika
SWW Schweiz; Sprache

Aber:

SW Balkansprachen

Q $\quad$ M, B 1986

e) Ist das Verbreitungsgebiet einer Sprache durch ein Geographikum eingeschränkt, werden Sprachbezeichnung und Geographikum verknüpft (vgl. § 13,2).
SWW Englisch; Indien
SWW Spanisch; Antillen

Bieten die Nachschlagewerke jedoch für die Sprache dieses Raumes eine präkombinierte Bezeichnung, so wird diese angesetzt (für Gegenstände aus dem Bereich der Literatur vgl. aber $\S 703,2)$.

$\begin{array}{ll}S W & \text { Amerikanisches Englisch } \\ Q & \mathrm{M} \\ B F & \text { Englisch / USA } \\ S W & \text { Frankokanadisch } \\ Q & \text { Klose, Du. } \\ B F & \text { Französisch / Kanada } \\ \text { SW } & \text { Sudan-Arabisch } \\ Q & \text { Meier-Sprache } \\ B F & \text { Arabisch / Sudan }\end{array}$

Die Verbindung von Sprache und Geographikum bleibt erhalten, wenn bei Bildung der Schlagwortkette ein Sachschlagwort aus dem Bereich der Linguistik hinzutritt (für Gegenstände aus dem Bereich Literatur vgl. § 703,2,a). 
SWW Spanisch; Argentinien; Verb

(213) (312)

Bei derartigen Verknüpfungen wird die Bezeichnung für die Sprache verwendet, nicht die von dieser abgeleitete Bezeichnung für ein Verbreitungsgebiet.

SWW Französisch; Afrika; Wortschatz

nicht: Frankophones Afrika ; Wortschatz

f) Bei einzelnen Sprachen wird soweit möglich die jeweilige Sprachfamilie und bei regionalen Sprachvarianten die übergeordnete Sprache als Oberbegriff erfasst.

$\begin{array}{ll}\text { SW } & \text { Laotisch } \\ O B & \text { Thaisprachen } \\ \text { SW } & \text { Sudan-Arabisch } \\ \text { OB } & \text { Arabisch }\end{array}$

2. a) Mundarten einzelner Regionen werden mit dem vom Landschaftsnamen abgeleiteten Adjektiv angesetzt. Ist das unüblich oder nicht möglich, wird aus dem Landschaftsnamen mit dem Schlagwort „Mundart“ ein mehrgliedriges Schlagwort gebildet.

$\begin{array}{ll}\text { SW } & \text { Hessisch } \\ \text { BF } & \text { Hessen / Mundart } \\ \text { SW } & \text { Schlesisch } \\ \text { SW } & \text { Wallonisch } \\ \text { SW } & \text { Schweizerdeutsch } \\ \text { Aber: } & \\ \text { SW } & \text { Artois / Mundart } \\ \text { nicht: } & \text { Artesisch } \\ \text { SW } & \text { Spessart / Mundart }\end{array}$

b) Für Mundarten einzelner Orte wird aus dem Ortsnamen und dem Schlagwort „Mundart“ ein mehrgliedriges Schlagwort gebildet.

SW $\quad$ Frankfurt $<$ Main $>$ / Mundart

c) Bei einzelnen Mundarten wird i.d. R. die übergeordnete Großmundart oder Sprachbezeichnung als ein- oder mehrgliedriger Oberbegriff erfasst.

$\begin{array}{ll}\text { SW } & \text { Mecklenburgisch } \\ O B & \text { Ostniederdeutsch } \\ \text { SW } & \text { Pikardisch } \\ \text { MO } & \text { Französisch ; Mundart } \\ \text { SW } & \text { Memmingen / Mundart } \\ O B & \text { Schwäbisch }\end{array}$

3. a) Einzelne Stufen einer Sprache, die mit 'alt-', 'mittel-', 'früh-', 'spät-', 'neu-', 'ur-', 'proto-' bezeichnet werden, sind als eigenes Schlagwort anzusetzen, wobei die Zusammensetzung mit 'Neu-' meist als pleonastisch entfällt. 


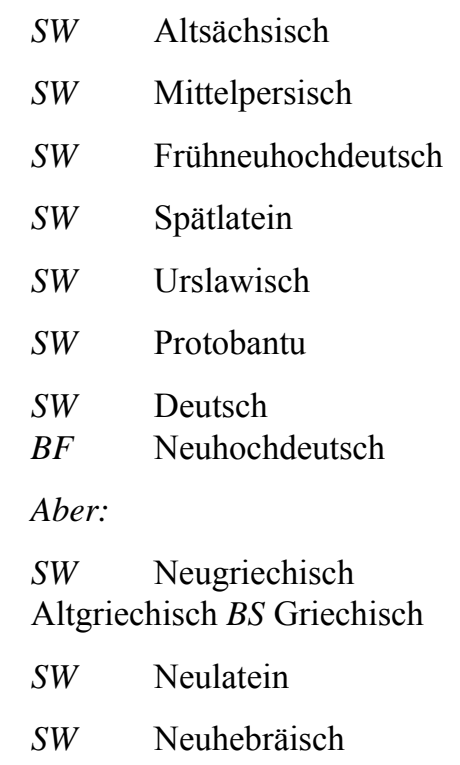

b) Bei Mundarten werden Sprachstufen nicht als eigenes Schlagwort angesetzt. Stattdessen wird das Schlagwort für die Mundart mit dem entsprechenden Zeitschlagwort verknüpft.

SWW Bairisch; Geschichte Anfänge-1050

nicht: Altbairisch

c) Geographisch bestimmte Formen einer Sprache oder einer Mundart werden als eigenes Schlagwort angesetzt. Die übergeordnete Einheit wird als Oberbegriff erfasst.
SW Hochpreußisch
$O B \quad$ Preußisch
SW Mittelfränkisch
$O B \quad$ Westmitteldeutsch
SW Ostkaukasische Sprachen
$O B \quad$ Kaukasische Sprachen

4. a) Sondersprachen werden i.d. R. in präkombinierter Form als Sachschlagwort angesetzt und ggf. mit einer Sprachbezeichnung verknüpft.

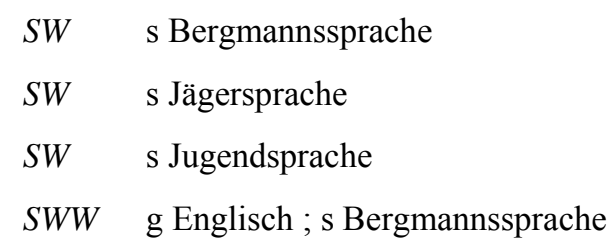

b) Bei Fachsprachen wird i. d. R. das Schlagwort für das Fachgebiet mit dem Schlagwort 'Fachsprache' sowie ggf. mit einer Sprachbezeichnung verknüpft. Bei diesen Verknüpfungen steht in der Schlagwortkette das Schlagwort 'Fachsprache' jeweils hinter der Fach- bzw. Sprachbezeichnung.

SWW Maschinenbau; Fachsprache

SWW Englisch; Fachsprache ; Maschinenbau 


\section{c) entfällt}

5. a) Bei der Verknüpfung von Sprachschlagwörtern mit Sachschlagwörtern aus dem Bereich der Linguistik werden für Listenfunktionen Eintragungen gemäß $§ 220,4$ unter der Sprache und unter dem Sachbegriff gemacht (zur Bildung der Grundkette vgl. auch § 706,2).

SWW Finnisch; Vokal

(21)

SWW Deutsch; Gaunersprache ; Lehnwort (231) (321)

Die Eintragung unter dem Sachschlagwort entfällt dann bei:

Akzent

Aussprache

Etymologie

Phonologie

Fachsprache

Rechtschreibung

Grammatik

Semantik

Morphologie $<$ Linguistik $>$

Stilistik

Phonetik

Syntax

Wortschatz

Zeichensetzung

Die Eintragung entfällt auch, wenn weitere Sachschlagwörter hinzutreten.

SWW Englisch; Adverbiale; Syntax (231)

b) Das Schlagwort für die Sprache bzw. Mundart entfällt als pleonastisch, wenn es sich um eine Erscheinung handelt, die nur in einer Sprache bzw. Mundart auftritt (vgl. § 13,3).

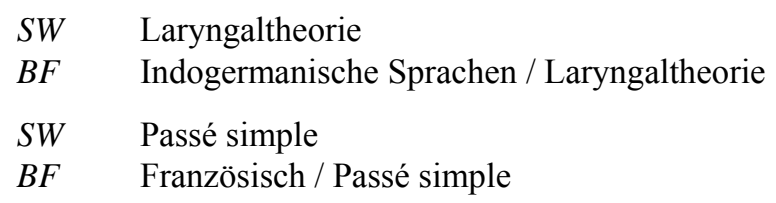

Dies gilt nicht, wenn weitere einschlägige Sachschlagwörter hinzutreten. Diese stehen in der Grundkette dann unmittelbar hinter der Sprachbezeichnung (vgl. auch § 201a,3).

SWW Französisch ; Zeitungssprache ; Passé simple (231) (321)

\section{§ 702 Wörterbücher}

1. Für allgemeine und fachlich begrenzte Sprachwörterbücher wird entsprechend der „Liste der Formschlagwörter" (vgl. Anl. 6) das Formschlagwort 'Wörterbuch' verwendet. Es steht entgegen $\S 15$ zwecks übersichtlicher Sortierung für Listenfunktionen i. d. R. an zweiter Stelle 
der Schlagwortkette, ausgenommen in den Fällen, in denen eine Verknüpfung zur Wiedergabe des Sachaspekts notwendig ist (vgl. § 504,2).

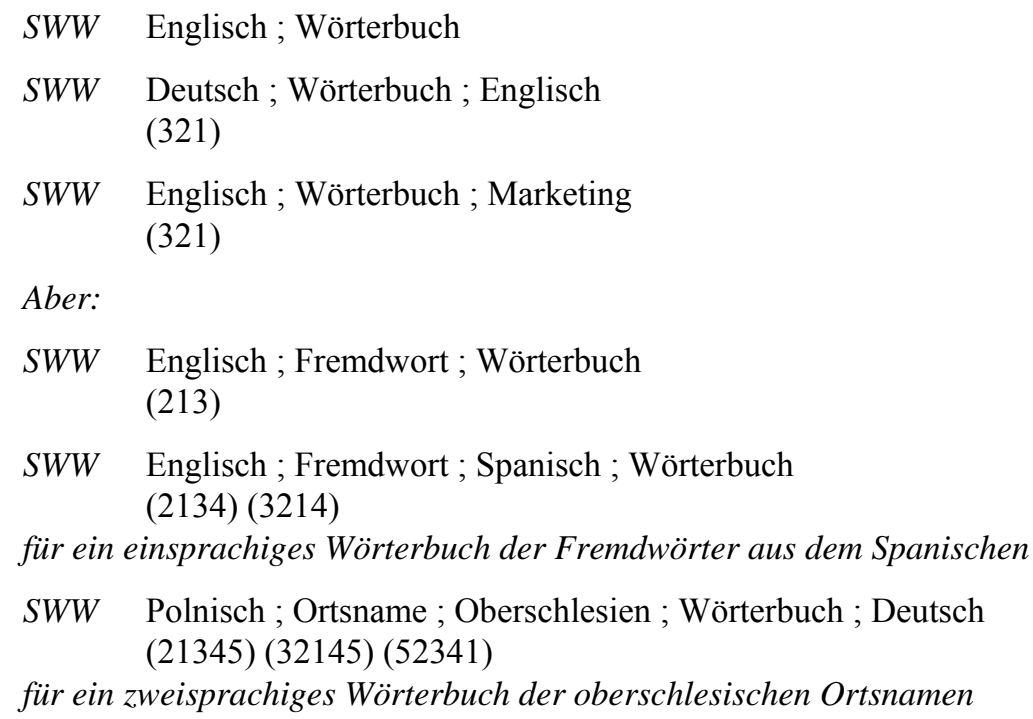

2. Allgemeine Sprachwörterbücher

a) Bei einsprachigen allgemeinen Sprachwörterbüchern wird die Sprach- bzw. Mundartbezeichnung mit dem Formschlagwort 'Wörterbuch' verknüpft. Bei Sondersprachen tritt gemäß $\S 701,4$,a das entsprechende Sachschlagwort zur Sprachbezeichnung und steht in der Schlagwortkette vor dem Formschlagwort.

Titel: $\quad \neg$ The $\neg$ Oxford English dictionary / prepared by J. A. Simpson ... - 2. ed. - 1989

SWW Englisch; Wörterbuch

Titel: $\quad$ Soldatendeutsch / hrsg. von Georg Wilhelm Haupt-Heydemarck. - 1934

SWW Deutsch; Soldatensprache; Wörterbuch (213)

b) Zweisprachige allgemeine Sprachwörterbücher stehen unter den behandelten Sprachen bzw. Mundarten. Für Sondersprachen gilt $§ 702,2$,a analog.

Titel: $\quad \neg \mathrm{A} \neg$ comprehensive English-Arabic dictionary. - 1983

SWW Arabisch; Wörterbuch; Englisch

(321)

SWW Deutsch ; Jugendsprache ; Wörterbuch ; Französisch (2134) (4231)

c) Bei drei- und mehrsprachigen allgemeinen Sprachwörterbüchern wird die Ausgangssprache mit dem Formschlagwort 'Wörterbuch <mehrsprachig>' verknüpft. Weitere enthaltene Sprachen können berücksichtigt werden, soweit sie durch Register erschlossen sind.

Titel: $\quad \neg \mathrm{A} \neg$ dictionary of Urdu, classical Hindi, and English / John T. Platts. - 1960

SWW Urdu; Wörterbuch $<$ mehrsprachig $>$

$S W W \quad$ Hindi ; Wörterbuch $<$ mehrsprachig $>$

SWW Englisch; Wörterbuch $<$ mehrsprachig $>$

3. Fachliche Sprachwörterbücher (Titel, bei denen der Akzent auf der Übertragung des Fachwortschatzes liegt) 
a) Bei einsprachigen fachlichen Sprachwörterbüchern steht in der Grundkette das Formschlagwort 'Wörterbuch' an zweiter Stelle vor der Fachbezeichnung.

Titel: Deutsch-medizinisch : das umgekehrte Medizin-Wörterbuch / Reinhard von Normann. - 1987

SWW Deutsch; Wörterbuch ; Medizin (321)

Es handelt sich um ein Wörterbuch deutscher Begriffe mit ihren Entsprechungen aus der medizinischen Fachsprache ohne inhaltliche Erläuterungen.

b) Zweisprachige fachliche Sprachwörterbücher erhalten Grundketten in folgender Form

1. Ausgangssprache ; 'Wörterbuch' ; Fachbezeichnung ; Zielsprache

2. Fachbezeichnung; 'Wörterbuch $<$ mehrsprachig $>$ '

Titel: Dictionnaire anglais-français des termes relatifs à l'électronique ... - 14. éd. - 1983

SWW Englisch; Wörterbuch ; Elektronik ; Französisch

(4231)

SWW Elektronik; Wörterbuch $<$ mehrsprachig $>$

c) Bei drei- und mehrsprachigen fachlichen Sprachwörterbüchern wird die Fachbezeichnung mit dem Formschlagwort 'Wörterbuch <mehrsprachig>' verknüpft. Bei Bedarf können die enthaltenen Sprachen berücksichtigt werden.

Titel: Langenscheidts Sportwörterbuch : deutsch, englisch, französisch, spanisch / bearb. von Franz Hepp. - 1977

SWW Sport ; Wörterbuch $<$ mehrsprachig $>$

SWW Englisch; Wörterbuch $<$ mehrsprachig $>$; Sport

SWW Französisch; Wörterbuch $<$ mehrsprachig $>$; Sport

SWW Spanisch; Wörterbuch $<$ mehrsprachig $>$; Sport

4. Für einsprachige Fachlexika wird ebenfalls das Formschlagwort 'Wörterbuch' verwendet Die Sprachbezeichnung entfällt.

Titel: Dictionary of psychology / I. P. Chaplin. - 1985

SWW Psychologie; Wörterbuch

Titel: Handwörterbuch des deutschen Aberglaubens / hrsg. von Hanns Bächtold-Stäubli. 1927-1942

SWW Deutschland; Aberglaube; Wörterbuch (213)

\section{§ 703 Literatur}

1. a) Bei Gegenständen aus dem Bereich der Literatur wird i.d. R. die Sprach- bzw. Mundartbezeichnung mit dem entsprechenden Sachschlagwort verknüpft. Dabei wird nicht unterschieden, ob es sich um das gesamte Verbreitungsgebiet einer Sprache bzw. Mundart oder nur um das Hauptverbreitungsgebiet handelt. Für Listenfunktionen werden Eintragungen analog $\S 701,5$,a gemacht.
SWW Französisch; Literatur
SWW Russisch ; Historischer Roman
SWW Mittelhochdeutsch; Höfische Literatur
SWW Niederdeutsch; Märchen
SWW Berlin / Mundart; Anekdote 
SWW Englisch; Komödie

sowohl für die Komödie Großbritanniens wie die des gesamten englischen Sprachgebiets

Die Eintragung unter dem Sachschlagwort entfällt in Listenfunktionen bei:

Drama Literatur

Epik Lyrik

Epos Prosa

Erzählung Roman

Die Eintragung entfällt auch, wenn weitere Sachschlagwörter hinzutreten.

SWW Deutsch ; Drama ; Dialog ; Geschichte 1790-1957

(3214)

b) Das Schlagwort für die Sprache bzw. Mundart entfällt als pleonastisch, wenn es sich um eine literarische Gattung handelt, die nur in einer Sprache auftritt (vgl. § 13,3).

SW Fablel

BF Altfranzösisch / Fablel

Französisch / Fablel

Dies gilt nicht, wenn weitere einschlägige Sachschlagwörter hinzutreten. Diese stehen in der Grundkette dann unmittelbar hinter der Sprachbezeichnung (vgl. auch § 201a,3).

SWW Altfranzösisch ; Reim ; Fablel

(231) (321)

2. a) Handelt es sich nur um einen Teil des Verbreitungsgebiets einer Sprache oder Mundart, und zwar nicht um das Hauptverbreitungsgebiet, tritt das einschränkende Geographikum als weiteres Schlagwort hinzu. In der Grundkette steht es hinter der Gattungsbezeichnung.

$\begin{array}{ll}\text { SWW } & \text { Deutsch; Drama; Schweiz } \\ \text { SWW } & \text { Slowenisch; Lyrik; Österreich } \\ \text { SWW } & \text { Englisch; Kurzgeschichte; Indien }\end{array}$

Bei der Verknüpfung wird analog $§ 701,1$,e das Grundwort für die Sprache verwendet, nicht die von der Sprache abgeleitete Bezeichnung für das Verbreitungsgebiet.

SWW Französisch ; Erzählung; Afrika

nicht: Frankophones Afrika ; Erzählung

SWW Deutsch; Drama; Schweiz

nicht: Deutsche Schweiz ; Drama

b) Die Sprachbezeichnung kann pleonastisch sein, sofern die betreffende Sprache oder Mundart in der Region eindeutig überwiegt. Sie entfällt unter dieser Voraussetzung bei Staaten sowie i. d. R. bei den Sprachen deutsch, englisch, französisch und spanisch.

SWW Österreich; Lyrik

nicht: Deutsch ; Lyrik ; Österreich

SWW Australien; Satire 


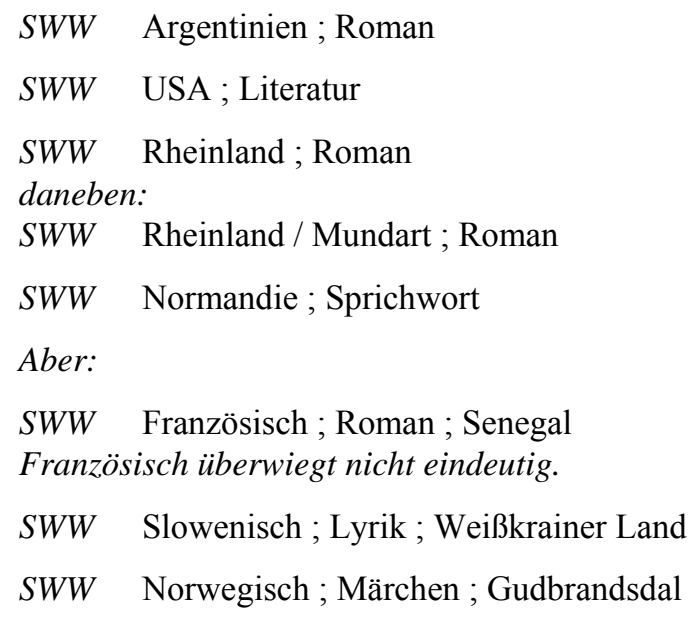

c) Bei Bedarf wird eine Schlagwortkette in die SWD aufgenommen und die Sprachbezeichnung in Verknüpfung mit dem Schlagwort 'Literatur' und dem jeweiligen Staat bzw der Region als Synonym erfasst, ebenso eine eigenständige Sprachbezeichnung für die Sprache dieses Raumes, falls eine solche existiert.

SWW Argentinien ; Literatur
Hinweissatz, gekennzeichnet in MAB Feld 067
BF $\quad$ Spanisch / Literatur / Argentinien
SWW USA ; Literatur
Hinweissatz, gekennzeichnet in MAB Feld 067
BF $\quad$ Englisch / Literatur / USA
Amerikanisches Englisch / Literatur
SWW Hispanoamerika ; Literatur
Hinweissatz, gekennzeichnet in MAB Feld 067
BF Spanisch / Literatur / Hispanoamerika
Spanisch / Literatur / Lateinamerika
Hispanoamerikanisch / Literatur

3. Für die Gesamtheit der Literatur oder einer literarischen Gattung innerhalb einer mehrsprachigen Region wird das Geographikum mit dem entsprechenden Sachschlagwort verknüpft.

$$
\begin{array}{ll}
\text { SWW } & \text { Indien; Literatur } \\
\text { SWW } & \text { Schweiz; Novelle }
\end{array}
$$

4. Ethnographische Namen werden in Verbindung mit 'Literatur' und literarischen Gattungen nur verwendet, wenn weder eine Sprachbezeichnung noch eine geographische Bezeichnung als Schlagwort in Frage kommt oder zur vollständigen Wiedergabe des Gegenstandes ausreicht. Ein Kompositum wird nicht gebildet.
SWW Sinti ; Märchen
SWW Chicanos ; Literatur
SWW USA ; Literatur ; Schwarze 


\section{§ 704 Sprachbezeichnung oder Geographikum bei Verknüpfung mit Sachschlagwörtern}

In unmittelbarer Verbindung mit Sprach- und Mundartbezeichnungen können i. d. R. nur folgende Sachschlagwörter verwendet werden:

a) Bezeichnungen für literarische Gattungen, sprach- und literaturwissenschaftliche Termini, Begriffe der Stilistik und Rhetorik sowie Fach- oder Sondersprachen (vgl. § 701,4).

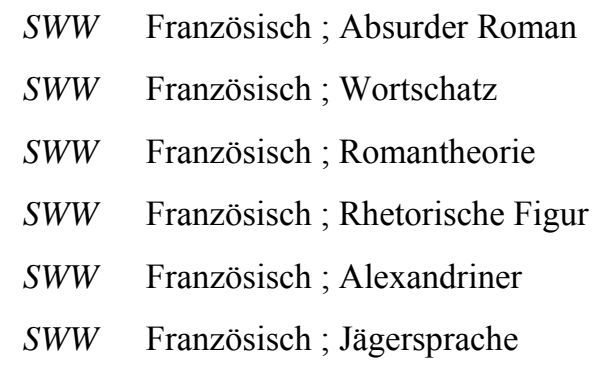

Im Zweifelsfall ist statt der Sprache das Geographikum als Schlagwort zu verwenden, i. d. R. mit entsprechendem Verwendungshinweis in der SWD.

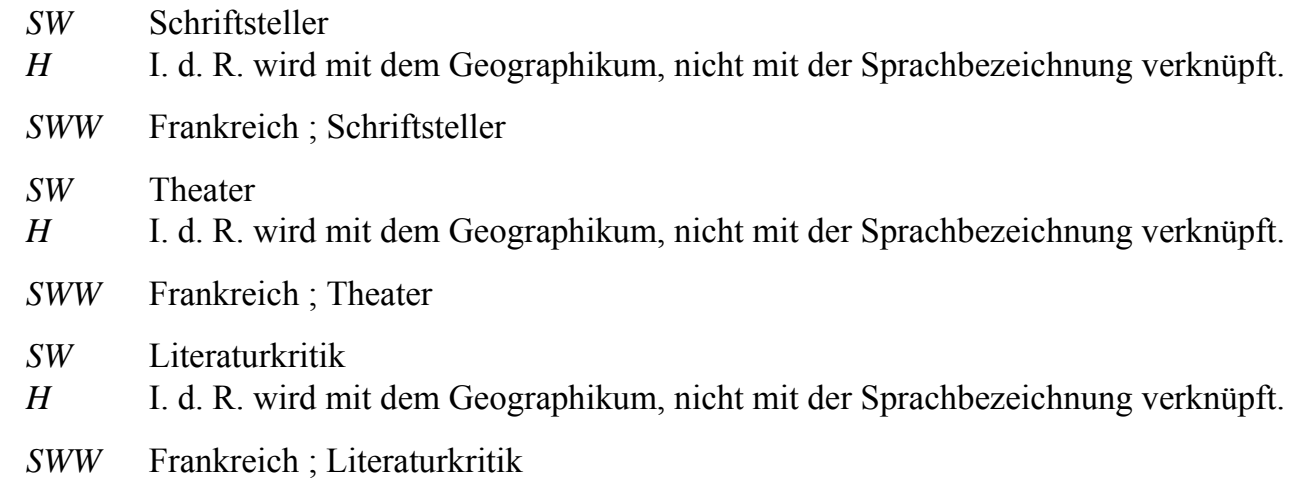

Ebenso:

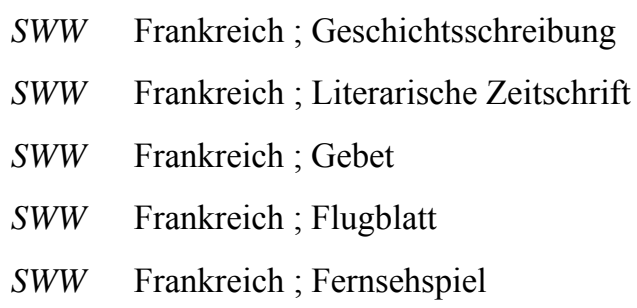

Ausnahmen werden gemacht, wenn für die eindeutige Wiedergabe eines Gegenstandes auf die Sprachbezeichnung nicht verzichtet werden kann. Auch können verschiedene Aspekte desselben Themas als je eigene Gegenstände behandelt werden, wenn sie nicht durch eine einzige Schlagwortkette vollständig dargestellt werden können (vgl. § 13,4).

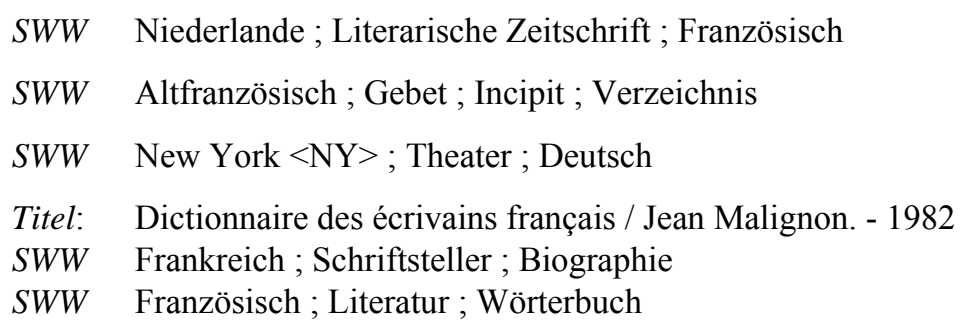


Bei einzelnen Schlagwörtern ist abhängig vom Sachverhalt eine Verknüpfung entweder mit einem Geographikum oder auch mit einer Sprachbezeichnung möglich.

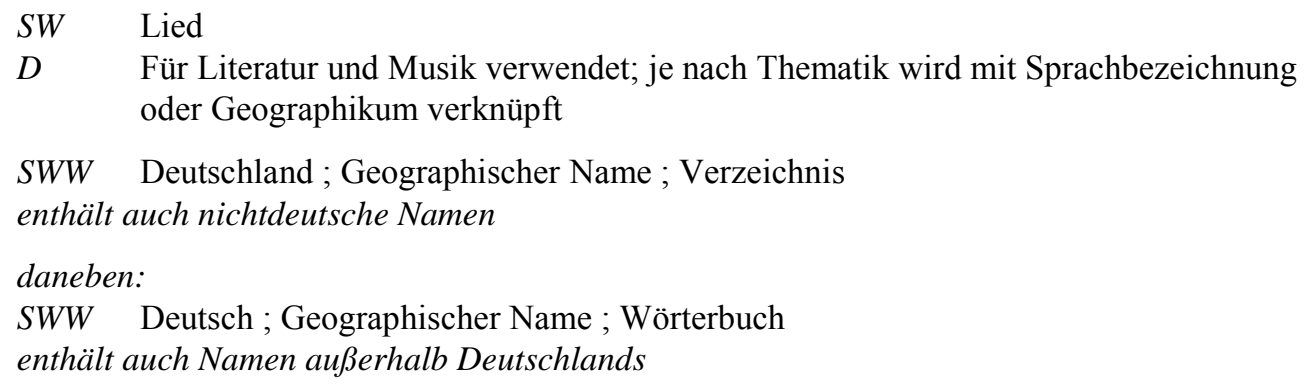

b) 'Handschrift', 'Inschrift', 'Schrift', 'Philologie' und deren Unterbegriffe, sofern die sprachliche Herkunft ausgedrückt werden soll.

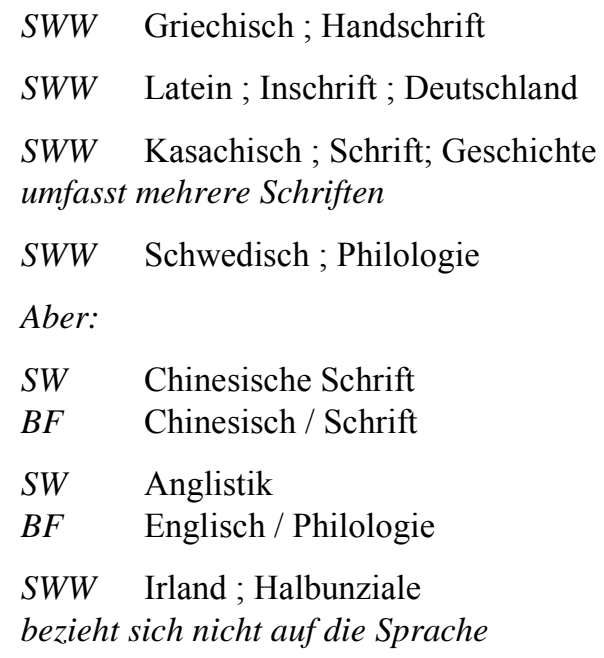

\section{$\S 705$ Motive}

1. Bezeichnungen für Motive, Stoffe und Themen aus den Bereichen Literatur, Musik (vgl. $\S 744$ ), bildende und darstellende Kunst werden Schlagwort zur Indexierung von Sekundärliteratur über diese Themen. Sie werden mit dem Zusatz $<$ Motiv $>$ angesetzt, der in diesem Fall nicht zur Unterscheidung von Homonymen, sondern als differenzierender Zusatz benutzt wird (vgl. § 10,1). (Zur Verwendung von Schlagwörtern mit Zusatz $<$ Motiv $>$ bei der lokalen Indexierung von Musikdrucken vgl. § 744; zu musikalischen Werken vgl. auch $\S 737,2$.)

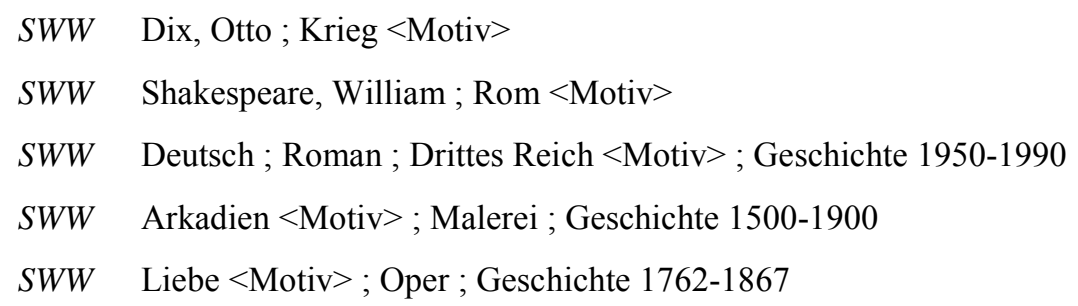




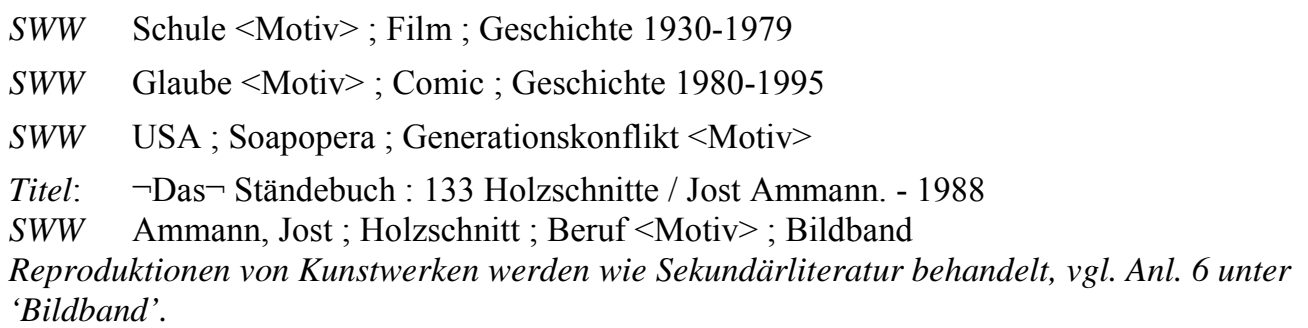

2. Bei mehrgliedrigen Schlagwörtern (z. B. Körperschaft, Bauwerk, Historisches Einzelereignis) wird der Zusatz dem letzten Glied des Schlagworts hinzugefügt (vgl. § 10,4).

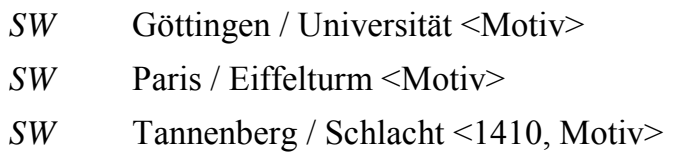

3. a) Komposita von Motivbezeichnungen mit '-darstellung', '-dichtung' usw. sind nur zulässig, wenn sie in den Nachschlagewerken nachzuweisen sind.

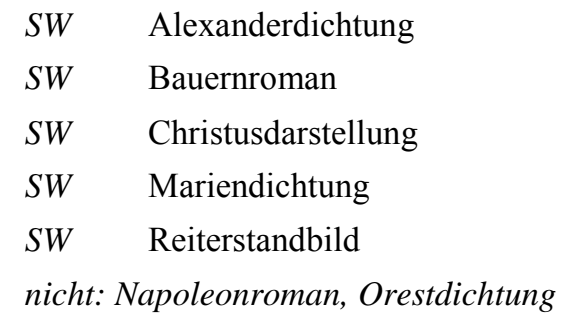

b) Komposita mit '-bild' sind zulässig in Verbindung mit Erdteilen, Staaten und umfassenden ethnographischen Bezeichnungen. Sie werden i. d. R. nur für die Fachgebiete Literatur, Politik, Soziologie, Psychologie, Publizistik und Kulturgeschichte verwendet. Im Fachgebiet Literatur dienen sie als Motivbezeichnung. Das Geographikum bzw. Ethnographikum mit dem Zusatz <Motiv> wird in den Fällen, in denen Komposita mit '-bild' zulässig sind, nur für die bildende Kunst bzw. Musik verwendet.

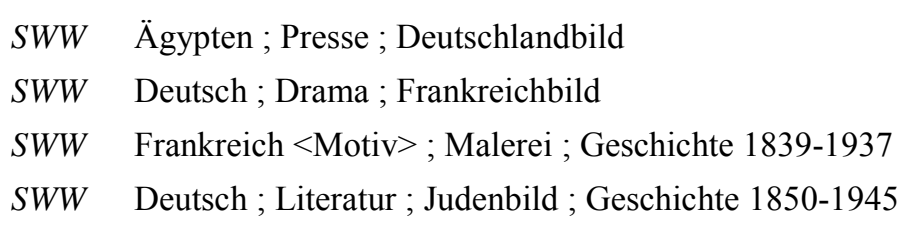

Aber:

Ist ein Kompositum aus dem Namen des Staates und -bild sprachlich nicht möglich, wird mit dem zutreffenden Sachschlagwort (z. B. Stereotyp, Bild <Psychologie〉) verknüpft.

SWW Dominikanische Republik; Stereotyp

Komposita mit '-bild' werden darüber hinaus auch für Sachschlagwörter zur Wiedergabe von Themen aus den Bereichen Philosophie, Gesellschaft, Kultur und Psychologie gebildet.

$\begin{array}{ll}S W & \text { Berufsbild } \\ S W & \text { Männerbild } \\ S W & \text { Selbstbild } \\ S W & \text { Weltbild } \\ \text { Aber: } & \\ S W & \text { Mann }<\text { Motiv }> \\ B F & \text { Männerbild / Literatur }\end{array}$


4. Motivbezeichnungen können in Form und Verwendung vom entsprechenden Sachschlagwort abweichen.

$\begin{array}{ll}S W & \text { Böse Schwiegermutter } \\ S W & \text { Bruder und Schwester } \\ D & \text { Nur für das Motiv verwendet } \\ \text { Aber: } & \\ S W W & \text { Bruder ; Rollentausch ; Schwester } \\ S W & \text { Körperliche Züchtigung }<\text { Motiv }> \\ \text { Aber: } & \\ \text { Körperliche Züchtigung } B S \text { Züchtigungsrecht } \\ \text { SW } & \neg \text { Die } \neg \text { verfeindeten Brüder } \\ \text { Aber: } & \\ S W W & \text { Bruder ; Feindschaft }\end{array}$

5. Der Zusatz entfällt bei Personennamen sowie bei Gegenständen, die ausschließlich als Motive (Stoffe, Themen) in Kunst, Literatur und Musik vorkommen, desgleichen, wenn Werke selbst als Motiv verwendet werden. Bei Sachschlagwörtern kann die Ansetzungsform mit dem Zusatz $<$ Motiv $>$ als Synonymie-Verweisung oder ein hierarchischer Oberbegriff mit Zusatz $<$ Motiv $>$ erfasst werden.

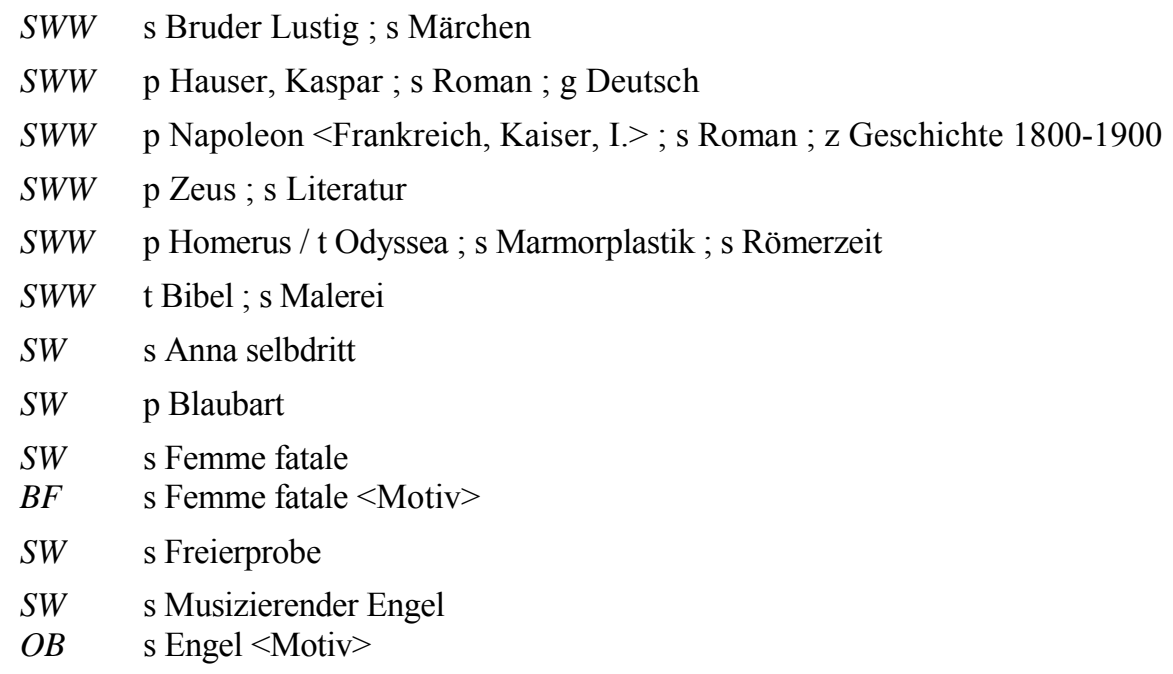

6. Stilformen, äußere und innere Darstellungsweisen sind nicht als Motiv zu werten. Ebenso wird dem Sachschlagwort ohne Zusatz der Vorzug gegeben, wenn zweifelhaft ist, ob es sich um ein literarisch-künstlerisches Motiv oder um die Beziehung einer Person zu einem Sachbegriff, Geographikum usw. handelt.

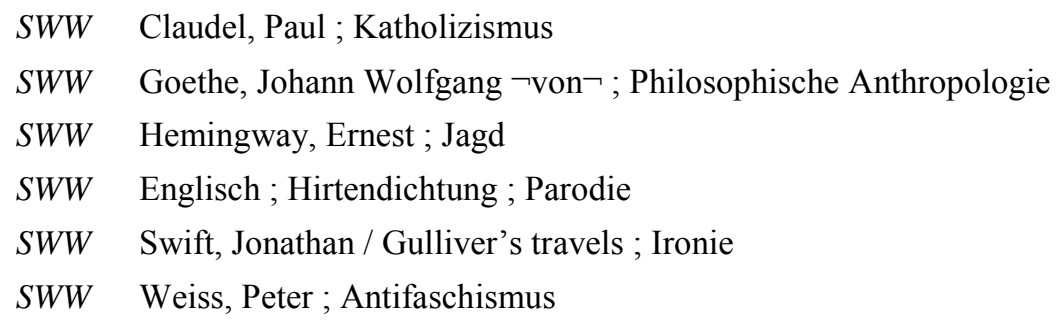

7. a) Bildet ein komplexer Begriff, der durch zwei oder mehr Schlagwörter ausgedrückt wird, das Motiv, erhalten beide bzw. alle Schlagwörter außer Personen- und Zeitschlagwörtern den Zusatz $<$ Motiv $>$. 


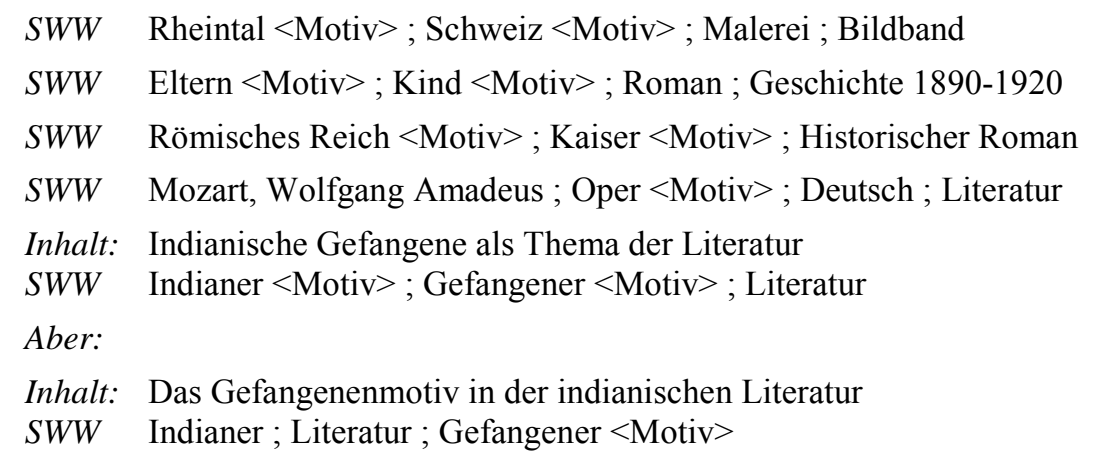

b) Zeitschlagwörter erhalten nie den Zusatz $<$ Motiv $>$.

$S W W \quad$ Spanisch; Literatur ; Inkareich $<$ Motiv $>$; Geschichte

SWW Deutschland <Bundesrepublik, Motiv> ; Geschichte 1949-1955 ; Deutsch ; Literatur ; Geschichte 1949-1980

8. a) Bei der Erschließung von Texten der schönen Literatur, Kinder- und Jugendliteratur (vgl. $\S \S 761 ; 764)$, von photographischen, karikaturistischen und humoristischen Darstellungen (außer bei Originalgraphik und Reproduktionen von Kunstwerken) sowie von Filmen, Hörfunk- und Fernsehsendungen werden Schlagwörter mit dem Zusatz $<$ Motiv $>$ nicht verwendet. Sie entfallen immer bei Verknüpfung mit entsprechenden Formschlagwörtern (vgl. im Einzelnen die Hinweise in Anl. 6). (Zur Erschließung von Sekundärliteratur über Filme, Hörfunk- und Fernsehsendungen unter Verwendung des Zusatzes $<$ Motiv $>$ vgl. $\S 734,4$.)
SWW Frühling; Lyrik; Anthologie
SWW Pariser Kommune ; Belletristische Darstellung
SWW Ruhrgebiet ; Arbeitslosigkeit ; Geschichte 1990-1995 ; Film 35 mm
SWW London; Waisenkind ; Geschichte 1830-1835; Jugendbuch
SWW Deutschland; Ausländerfeindlichkeit; Theaterstück

b) Auf Schlagwörter mit dem Zusatz $<$ Motiv $>$ wird ebenfalls verzichtet bei Themen, die die Berichterstattung in den Medien (Presse, Rundfunk usw.) betreffen.

SWW Deutschland; Ausländerfeindlichkeit ; Massenmedien ; Berichterstattung

c) Bei der Beschlagwortung von Sekundärliteratur über einzelne Werke wird der Werkinhalt nicht zusätzlich motivisch erschlossen (vgl. § 725,4).
SW Remarque, Erich Maria / Im Westen nichts Neues
nicht zusätzlich: Westfront <1914-1918, Motiv>
SW $\quad$ Bruegel, Pieter $<$ der Ältere $>/ \neg$ Der $\neg$ Turmbau zu Babel nicht zusätzlich: Babylonischer Turm

9. Die Bezeichnung für das Motiv steht in der Grundkette i. d. R. vor dem die Gattung bezeichnenden Schlagwort.

$\begin{array}{ll}S W W & \text { Katze }<\text { Motiv }>\text {; Malerei ; Geschichte } \\ S W W & \text { Friede }<\text { Motiv }>\text {; Lyrik ; Geschichte ; Aufsatzsammlung }\end{array}$ 
Steht am Anfang der Grundkette ein Personenschlagwort, ein Geographikum, eine Sprachoder Epochenbezeichnung, so tritt die Gattung jedoch vor das Motiv. Diese Reihenfolge wird entgegen der Standardfolge auch dann eingehalten, wenn das Motiv selbst ein Geographikum ist.

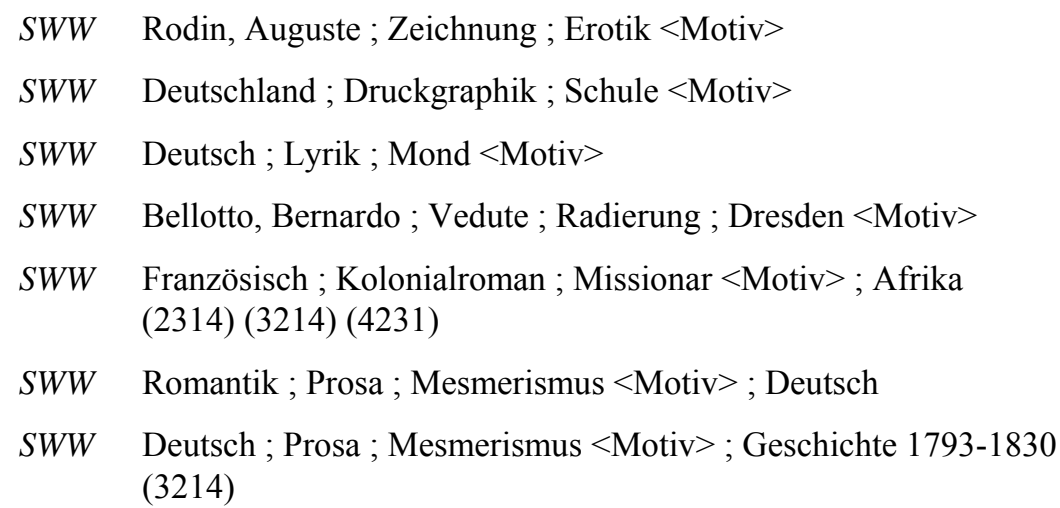

10. Wäre ein Schlagwort innerhalb derselben Schlagwortkette sowohl mit als auch ohne Zusatz $<$ Motiv $>$ zu verwenden, so entfällt die Ansetzung mit $<$ Motiv $>$.

Inhalt: Die kubanische Schule im kubanischen Spielfilm

SWW Kuba; Film; Schule $<$ Motiv $>$

nicht: Kuba ; Film ; Kuba $<$ Motiv $>$; Schule $<$ Motiv $>$

\section{§ 706 Verknüpfung von Sprachbezeichnungen}

1. Sprachbezeichnungen werden wie geographische Schlagwörter verknüpft (vgl. §§ 217-219). Besondere Regelungen gelten für Fachsprachen (vgl. § 701,4,b), für Wörterbücher (vgl. $\S 702$ ), für Teilgebiete einer Sprache (vgl. § 701,1,e) bzw. Literatur (vgl. § 703,2,a), für Motive (vgl. § 705,9), für Buchstaben, Morpheme und Wörter als Gegenstand linguistischer Untersuchungen (vgl. $\S \S 305,1$,c; 322,4) sowie generell für die Verwendung im Zusammenhang mit Sachschlagwörtern aus dem linguistischen/literarischen Bereich (vgl. §§ 701,5; 703,1) bzw. aus dem nichtlinguistischen/-literarischen Bereich (vgl. § 704).

2. Beim Zusammentreffen der Sprachbezeichnung mit mehreren Sachschlagwörtern wird in der Grundkette analog § 322 eine sinnvolle Reihenfolge gewählt (vgl. auch §§ 13,2;15).

Ganzes-Teil-Eigenschaft

SWW Deutsch; Substantiv ; Grundmorphem

SWW Altindisch; Reduplizierendes Verb ; Langvokal

SWW Urslawisch; Vokal; Anlaut

Gegenstand - Anwendungs-/Untersuchungsbereich

SWW Deutsch; Sachtext; Stilistik

$S W W \quad$ Finnisch ; Verb ; Morphologie $<$ Linguistik $>$

SWW Deutsch; Verb; Dependenzgrammatik

SWW Deutsch; Politische Lyrik ; Literaturtheorie

Vergleich, Gegenüberstellung; inhaltlich eng zusammengehörige SWW

SWW Altirisch ; Verb ; Kompositum ; Gälische Sprachen ; Präfix ; uts

SWW Deutsch; Verb; Syntax; Deutschunterricht ; Ausländer

$S W W$ Deutsch; Fremdsprache ; Verb ; Präfix ; ab ; Semantik 
Sind mehrere Reihenfolgen gleich sinnvoll, so kann alphabetisch geordnet werden (vgl. $\S 13,2)$.
SWW Deutsch ; Semantik ; Syntax
SWW Französisch; Morphonologie ; Prosodie

\section{Werke}

\section{$\S 707$ Definition}

1. Als Werk wird eine geistige Schöpfung bzw. eine Gesamtheit von mehreren geistigen Schöpfungen bezeichnet, die als Veröffentlichung in einer oder mehreren Ausgaben erschienen ist (vgl. RAK § 3). Werke umfassen

- literarische und wissenschaftliche Werke (einschließlich Werkgruppen, Textkorpora und Datenbanken),

- musikalische Werke,

- Werke der darstellenden und bildenden Kunst (einschließlich Filme, Hörfunk- und Fernsehsendungen).

Nicht als Werke im Sinne von RAK gelten

- psychologische Tests,

- Rechtsnormen,

- Schriftdenkmäler.

2. Als Verfasserwerk wird eine Ausgabe eines Werkes bezeichnet, die die Haupteintragung unter einem Verfasser erhält (vgl. RAK § 35,1).

3. Als Urheberwerk wird eine Ausgabe eines Werkes bezeichnet, die die Haupteintragung unter einem Urheber erhält (vgl. RAK § 35,2).

4. Als Sachtitelwerk wird eine Ausgabe eines Werkes bezeichnet, die die Haupteintragung unter dem Sachtitel erhält (vgl. RAK § 35,3).

5. Als anonymes Werk wird ein Werk bezeichnet, dessen Verfasser weder genannt noch ermittelt sind; im Sinn des vorliegenden Regelwerkes ferner Werke, die nach speziellen Vorschriften der RAK wie anonyme Werke, d.h. als Sachtitel- oder Urheberwerke, behandelt werden (vgl. RAK § 17).

\section{§ 708 Grundregeln}

1. Titel literarischer und wissenschaftlicher Werke werden nur dann Schlagwort, wenn Sekundärliteratur zu dem betreffenden Werk vorliegt.

2. Titel von Verfasserwerken, Sachtitelwerken und anonymen Werken erhalten in der SWD den Indikator t. Urheberwerke erhalten den Indikator $t$, wenn sie mit ihrem Sachtitel angesetzt werden (vgl. § 708,6). Darüber hinaus wird der Indikator t in folgenden Fällen vergeben: 
a) für Werktitel personengebundener Kunstwerke (vgl. § 727,1),

b) für nicht ortsgebundene Kunstwerke (vgl. § 727,3), für Filme, Hörfunk- und Fernsehsendungen (vgl. § 733,1), musikalische Werke (vgl. § 739,1) sowie Schriftdenkmäler (vgl. $\S 718$,a), die selbständig mit individuellem Werktitel angesetzt werden.

c) für Rechtsnormen (vgl. § 715,1), historische Rechtsnormen (vgl. § 715,10), Verträge (vgl. § 716) und Verfassungen (vgl. § 717),

d) für psychologische Tests (vgl. § 714),

e) für die Bibel und Teile der Bibel (vgl. § 713) sowie für vergleichbare Texte anderer Religionen,

f) für Werkgruppen, Textkorpora und Datenbanken (vgl. $\S \S 303,2$,e; 306a,3).

3. Ein Verfasserwerk wird als mehrgliedriges Schlagwort mit dem Namen des Verfassers angesetzt; der Werktitel wird zweites Glied der Ansetzung. Ein gemeinschaftliches Werk von zwei oder drei Verfassern erhält mit jedem eine Ansetzung.

$\begin{array}{ll}S W & \text { p Büchner, Georg / t Dantons Tod } \\ S W & \text { p Holz, Arno } / \mathrm{t} \neg \text { Die } \neg \text { Familie Selicke } \\ S W & \text { p Schlaf, Johannes } / \mathrm{t} \neg \text { Die } \neg \text { Familie Selicke } \\ S W & \text { p Guillaume }<\text { de Lorris }>/ \mathrm{t} \text { Roman de la rose } \\ S W & \text { p Jean }<\text { de Meung }>\text { / } \text { Roman de la rose }\end{array}$

4. Bei strittiger Verfasserschaft erfolgt die Ansetzung entsprechend der herrschenden Meinung in der Forschung. Im Zweifelsfall wird anonym angesetzt. Werke der Antike werden jedoch nicht anonym angesetzt, wenn sie in der Tradition, die meist mit der handschriftlichen Überlieferung identisch ist, einem bestimmten Autor fälschlich zugeschrieben werden, d. h. in seinem Korpus überliefert sind.

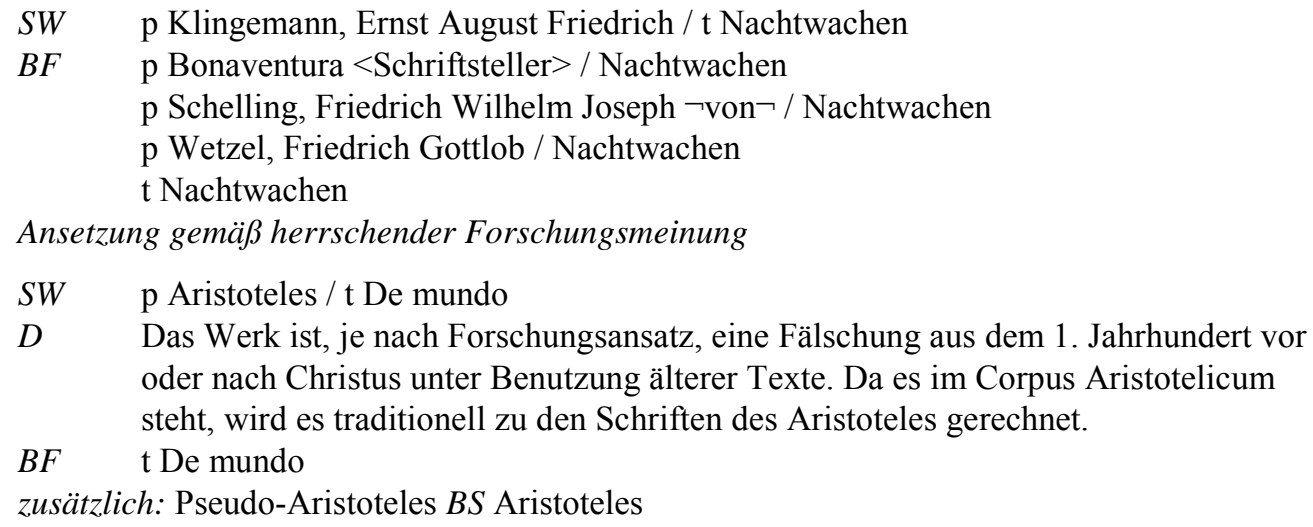

5. Ein Urheberwerk wird als mehrgliedriges Schlagwort mit dem Namen des Urhebers angesetzt; der Sachtitel wird zweites Glied der Ansetzung.

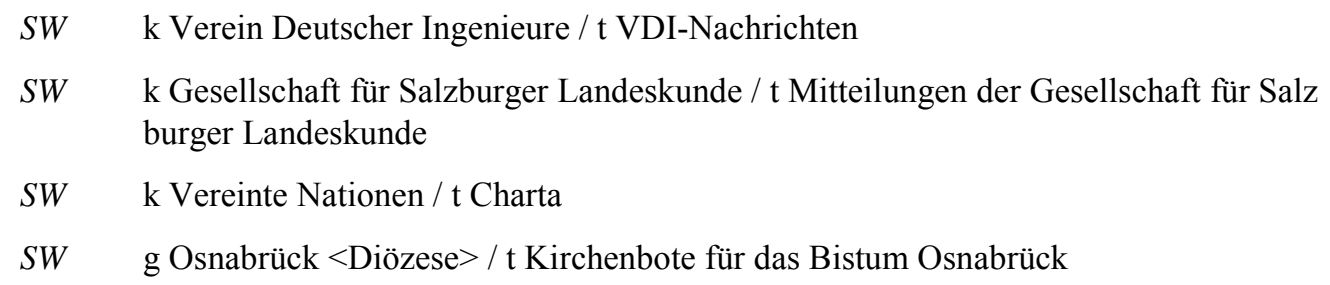

6. Wie bei RAK erfolgt jedoch bei Urheberwerken, die üblicherweise mit dem Sachtitel zitiert werden, die Ansetzung mit diesem Sachtitel. 
SW t Godesberger Grundsatzprogramm

BF k Sozialdemokratische Partei Deutschlands / Godesberger Grundsatzprogramm

7. Sachtitelwerke, dazu zählen auch Werke mit mehr als drei Verfassern, werden mit dem Sachtitel angesetzt.

$\begin{array}{ll}S W & \text { t Nibelungenlied } \\ S W & \text { t Göttingische gelehrte Anzeigen } \\ S W & \text { t Kinder- und Hausmärchen } \\ B F & \text { t Grimms Märchen } \\ & \text { p Grimm, Jacob / Kinder- und Hausmärchen } \\ & \text { p Grimm, Wilhelm / Kinder- und Hausmärchen }\end{array}$

8. a) Ändern fortlaufende Sammelwerke ihren Titel, so erfolgt die Ansetzung abweichend von RAK mit ihrem neuesten Titel. Frühere Titel werden als Synonyme erfasst.
SW t Deutsches Soldatenjahrbuch
$B F \quad$ t Deutscher Soldatenkalender
SW t Literarische Revue
$B F \quad \mathrm{t} \neg \mathrm{Die} \neg$ Fähre $<$ Zeitschrift, München $>$

b) Ist eine frühere Titelvariante als wesentlich gebräuchlicher nachgewiesen, wird mit dieser angesetzt, jedoch nur bei nicht mehr erscheinenden Publikationen.

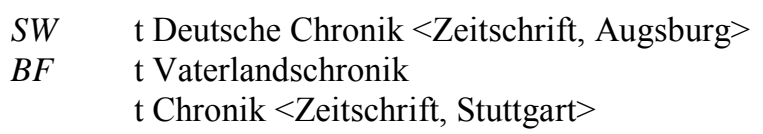

c) Besteht zwischen zwei Werken keine zeitliche Kontinuität, werden zwei getrennte Schlagwörter angesetzt; falls eine inhaltliche Beziehung besteht, werden sie durch assoziative Verweisungen verbunden.

$S W \quad$ t Publik $<$ Zeitung $>$
$V B \quad$ t Publik-Forum
Nachfolgepublikation

9. a) Gebräuchliche Sachtitel, die von der Ansetzung abweichen, werden als Synonyme erfasst.
$S W \quad \mathrm{t}$ Kinder- und Hausmärchen
$B F \quad$ t Grimms Märchen

b) Der Herausgeber fortlaufender Sammelwerke wird in einer Synonymie-Verweisung i. d. R. nur berücksichtigt, wenn er überwiegend Verfasser der Beiträge ist. Neben dem Herausgeber kann auch der Verlag in einer Synonymie-Verweisung erfasst werden. Der Sachtitel wird in beiden Fällen zweiter Teil der Verweisung.

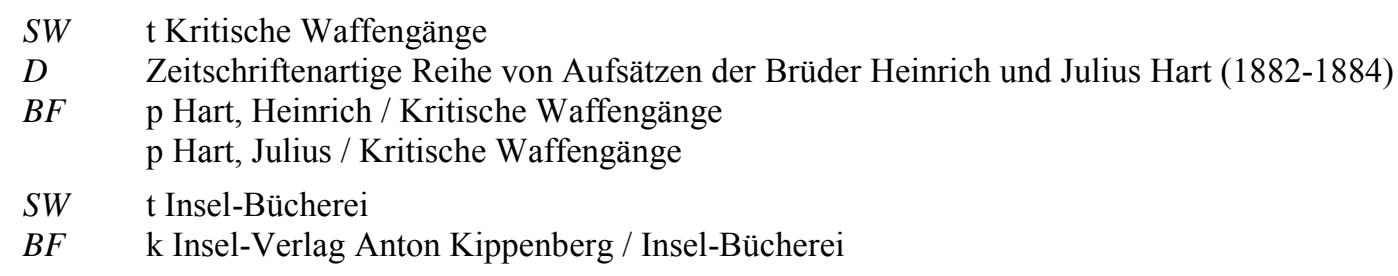

10. Fortlaufende Sammelwerke erhalten einen mehrgliedrigen Oberbegriff, der aus dem Geographikum (Erscheinungsland) und der spezifischsten Gattungsbezeichnung besteht. Für Tages- und Wochenzeitungen wird einheitlich 'Zeitung' verwendet. Existiert keine Gattungsbezeichnung, sind die entsprechenden Einzelschlagwörter zu verknüpfen. 


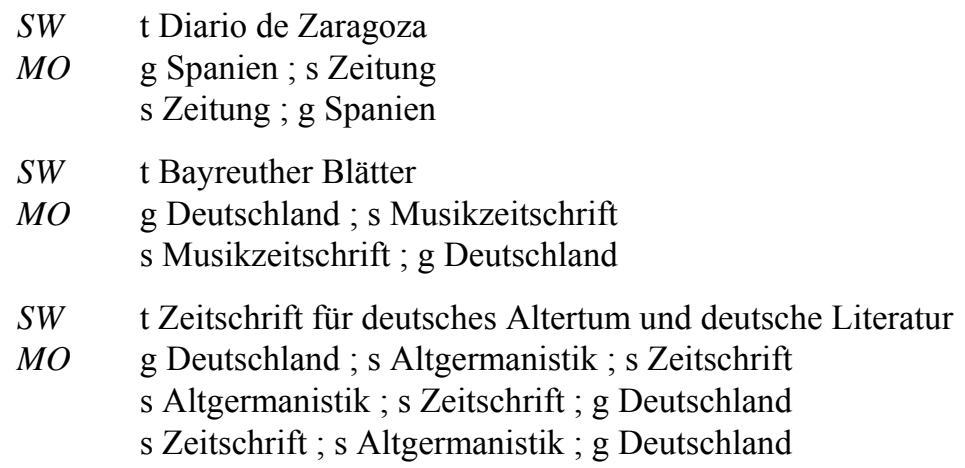

11. Verfasserwerke werden in der Schlagwortkette als mehrgliedrige Schlagwörter wie Personenschlagwörter behandelt (Indikatoren $\mathrm{p} / \mathrm{t}$ ), Urheberwerke wie Sachschlagwörter (Indikatoren $\mathrm{k}$ oder c/t) bzw. wie geographische Schlagwörter (Indikatoren $\mathrm{g} / \mathrm{t}$ ), Sachtitelwerke wie Sachschlagwörter (Indikator t, vgl. § 708,6).

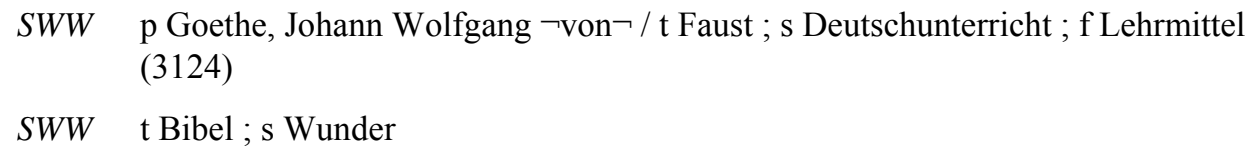

\section{§ 709 Einheitssachtitel oder deutscher gebräuchlicher Titel}

1. Sachtitel von Werken werden i. d. R. mit dem Einheitssachtitel (das ist i. d. R. der Sachtitel der ersten vollständigen Ausgabe in der Originalsprache des Werkes) angesetzt. Die Ansetzung erfolgt mit dem Hauptsachtitel, wenn der Einheitssachtitel in der Vorlage nicht genannt und nur mit großem Aufwand oder gar nicht zu ermitteln ist.

Die Rechtschreibung und ggf. Transliteration der Titel richtet sich nach RAK (vgl. RAK $\S 117,6)$. Bei Titeln älterer Sprachstufen folgt die Schreibung der in Nachschlagewerken und Sekundärliteratur geläufigen Form, d. h. i. d. R. der modernisierten Rechtschreibung. Wo keine modernisierte Form nachweisbar ist, wird die Originalform beibehalten.

$\begin{array}{ll}S W & \text { Kant, Immanuel / Kritik der Urteilskraft } \\ B F & \text { Kant, Immanuel / Kritik der Urtheilskraft }\end{array}$

Aber:

SW Schottel, Justus Georg / Ausführliche Arbeit von der teutschen Haubtsprache

2. Ist der Originaltitel eines Werkes, das einen gebräuchlichen Zitiertitel hat, wenig bekannt, so erfolgt die Ansetzung mit dem gebräuchlichen Zitiertitel. Einleitende Wörter und Sätze sowie Umfangs- und Bandangaben im Sachtitel werden nicht als Teile des Sachtitels angesetzt (vgl. RAK § 502).

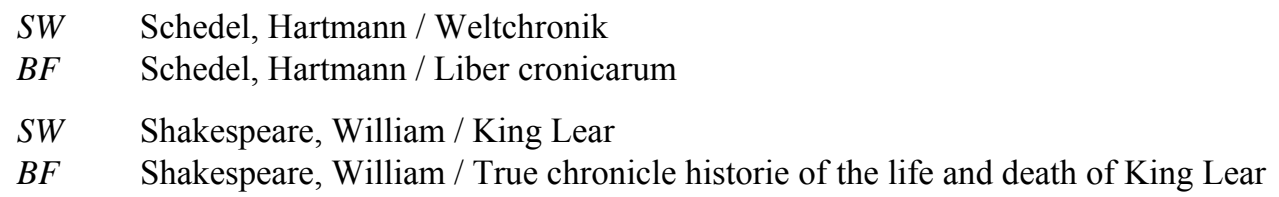

3. Bibliotheken, die RAK-ÖB-A anwenden, können einen im Deutschen gebräuchlichen Sachtitel als Einheitssachtitel verwenden. Dafür wird in der SWD eine ÖB-Alternativform angesetzt. Andere Titel auch deutscher Ausgaben werden gemäß $§ 708,9$ als Synonyme erfasst. 


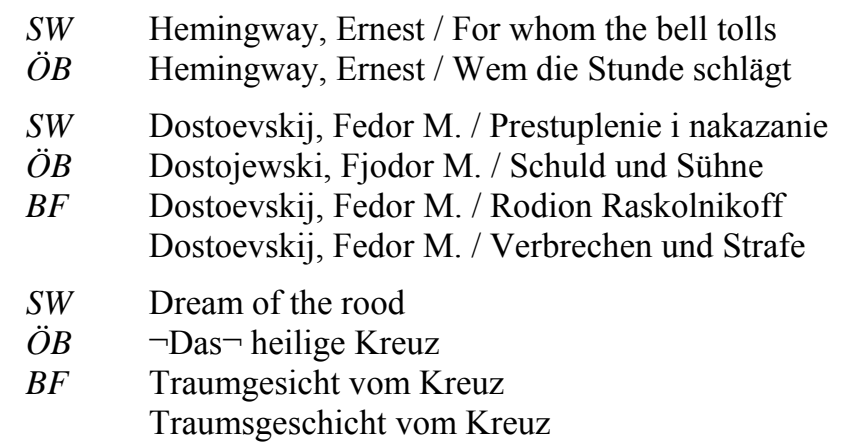

Anm.: Zur Ansetzung von Werken des Altertums, des Mittelalters und der frühen Neuzeit vgl. § 712, zur Ansetzung der Bibel und ihrer Teile vgl. § 713, zur Ansetzung psychologischer Tests vgl. § 714.

\section{§ 710 Homonymenzusatz}

1. Zur Unterscheidung verschiedener Ausgaben desselben Verfasser-, Urheber- oder Sachtitelwerks mit gleichem Titel wird das Erscheinungsjahr als Homonymenzusatz zum Sachtitel hinzugefügt.
SW Kant, Immanuel / Kritik der reinen Vernunft <1781>
SW Kant, Immanuel / Kritik der reinen Vernunft $<1787>$

2. Ist der Titel eines Sachtitelwerks mit einem anderen Schlagwort - auch Begriffen aus dem Englischen, Französischen oder Italienischen - identisch, wird als Homonymenzusatz eine Gattungsbezeichnung hinzugefügt. Dies gilt auch, wenn im Titel ein Artikel voransteht.

$\begin{array}{ll}S W & \text { Hippokrates }<\text { Zeitschrift }> \\ S W & \text { Alto Adige }<\text { Zeitung }> \\ S W & \text { Pastoraltheologie }<\text { Zeitschrift }> \\ S W & \neg \text { Der } \neg \text { Maikäfer }<\text { Zeitschrift }> \\ S W & \neg \text { The } \neg \text { ladder }<\text { Zeitschrift }>\end{array}$

3. Zur Unterscheidung verschiedener Sachtitelwerke mit gleichem Sachtitel werden Homonymenzusätze in folgender Reihenfolge hinzugefügt: Gattung, Erscheinungsort, Erscheinungszeitraum.

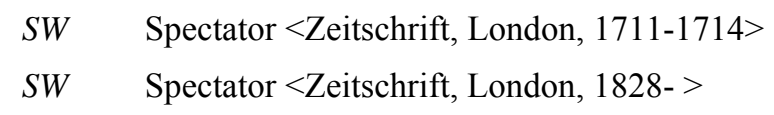

Die Gattungsbezeichnung entfällt, wenn sie als Homonymenzusatz pleonastisch oder nicht aussagekräftig ist.
SW Abendzeitung $<$ München $>$
SW Abendzeitung $<$ Nürnberg $>$

4. Kein Homonymenzusatz wird hinzugefügt, wenn der Titel eines Sachtitelwerks identisch mit dem Sachtitel eines Verfasser- oder mit dem Urheber angesetzten Urheberwerks ist.

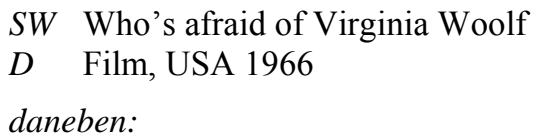

SW Albee, Edward / Who's afraid of Virginia Woolf 


\section{§ 711 Teile von Werken und Werkgruppen}

1. a) Teile eines Werkes werden i. d. R. unselbständig angesetzt.

$S W \quad \mathrm{p}$ Proust, Marcel / t A la recherche du temps perdu / $\neg \mathrm{Le} \neg$ temps retrouvé

SW $\quad$ p Goethe, Johann Wolfgang ᄀvon $\urcorner$ / t Faust I / Walpurgisnacht

Sofern sie überwiegend selbständig zitiert werden, erfolgt die Ansetzung mit dem Sachtitel des Teiles. Das Gesamtwerk mit dem Sachtitel des Teiles wird als Synonym erfasst. Als selbständig zitiert gelten auch Teile, die unter einem Kurz- oder Zitiertitel bekannt sind, desgleichen Gedichte, Erzählungen, Novellen u. ä. selbst dann, wenn sie nicht selbständig, sondern als Teil einer Sammlung erschienen sind.

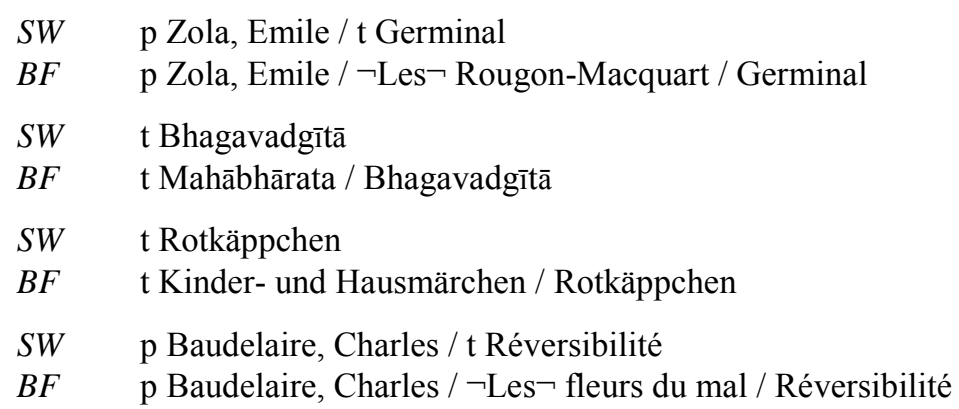

b) Teile von Werkgruppen werden i. d. R. selbständig angesetzt. Die Werkgruppe wird bei gattungsbezogenen Sammlungstiteln (vgl. § 712,2) in Verbindung mit dem Werktitel als Synonym, in den übrigen Fällen als Oberbegriff erfasst.

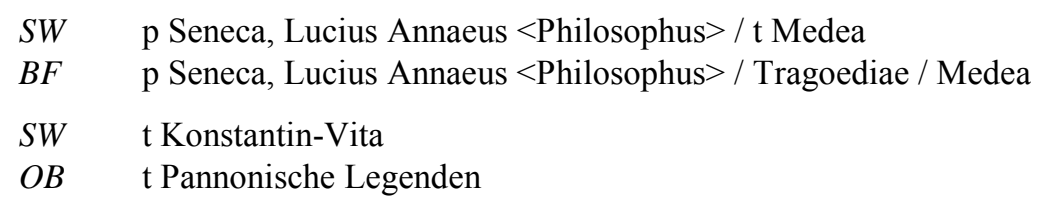

2. Für gezählte Unterabteilungen von Werken wird die Zählung nach Spatium an den Titel angehängt.

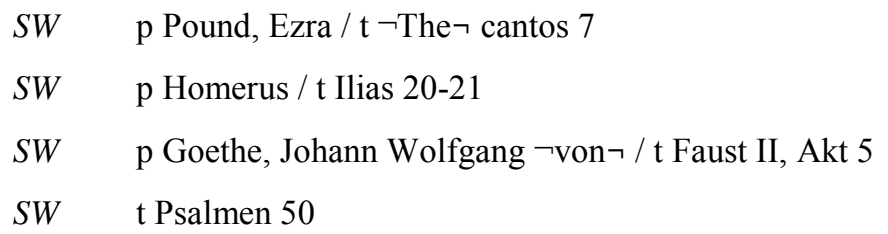

Wenn jedoch für den betreffenden Abschnitt eine gebräuchliche Bezeichnung vorhanden ist, wird diese angesetzt. Die Version mit Zählung wird als Synonym erfasst.

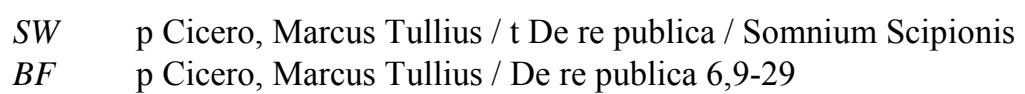

3. Bezeichnungen wie 'Vorwort', 'Prooemium' usw. können bei der Ansetzung verwendet werden. Wo in diesen Fällen aber eine Zählung für das Werk vorhanden ist, wird diese bevorzugt.

$\begin{array}{ll}S W & \text { p Boccaccio, Giovanni / } \mathrm{t} \neg \mathrm{Il} \neg \text { Decamerone / Proemio } \\ S W & \text { p Homerus / t Ilias 1,1-47 } \\ B F & \text { p Homerus / Ilias / Prooemium }\end{array}$




\section{§ 712 Werke des Altertums, des Mittelalters und der frühen Neuzeit}

1. Bei Werken des Altertums, des Mittelalters und der frühen Neuzeit (bis 1550) werden die in der wissenschaftlichen Tradition gebrauchten Bezeichnungen als Einheitssachtitel verwen$\operatorname{det}(\operatorname{vgl}$. RAK $\S 509)$.

2. Der Einheitssachtitel wird primär gemäß den Fachnachschlagewerken (vgl. § 9,3) ermittelt. Lateinische Einheitssachtitel können bei Bedarf auch analog gebildet werden, um Einheitlichkeit bei häufig vorkommenden Titelformulierungen zu erreichen. Sofern sich für das Gesamtwerk oder für Werkgruppen eines Autors feste, von Gattungsbezeichnungen oder Bezeichnungen für Werkgruppen abgeleitete Titel eingebürgert haben, sind diese als Werktitel anzusetzen.

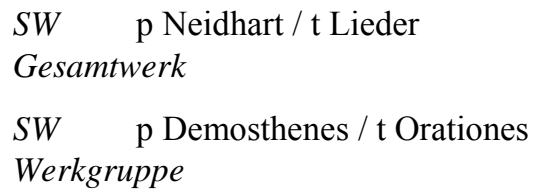

3. Anonyme Werke des Mittelalters

a) Anonyme Werke des Mittelalters aus europäischen Literaturen werden angesetzt nach der Liste:

Anonymous classics : a list of uniform headings for European literatures / ed. by Rosemary C. Hewett. - London: IFLA Internat. Office for UBC, 1978 (oder neuere Auflage).

Es ist darin üblich, verschiedene Fassungen und Stufen des Textes als einheitliches Werk unter einem Einheitssachtitel zusammenzufassen. Die Unterscheidung erfolgt für den Schlagwortkatalog durch Homonymenzusatz. Werke, die in dieser Liste nicht enthalten sind, werden nach $\S 712,1$ bzw. 712,2 angesetzt.

$$
\begin{array}{ll}
S W & \text { Salomon und Markolf }<\text { Spielmannsepos }> \\
B F & \text { Salman und Morolf } \\
S W & \text { Salomon und Markolf }<\text { Spruchdichtung }>
\end{array}
$$

b) Soweit erforderlich, werden Homonymenzusätze hinzugefügt, und zwar

- bei Werken mit gleichlautendem Titel in verschiedenen Sprachen die Sprachbezeichnung,

- bei Werken mit gleichlautenden Titeln in derselben Sprache soweit möglich die Gattungsbezeichnung gemäß SWD,

- bei Werktiteln mit Homonymie zu Schlagwörtern anderer Kategorien ebenfalls die Gattungsbezeichnung.

Sind sowohl Sprachbezeichnung als auch Gattungsbezeichnung zur Differenzierung notwendig, erscheinen beide, durch Komma getrennt, als Homonymenzusatz. Ggf. kann eine Zeitangabe zur weiteren Unterscheidung hinzutreten.

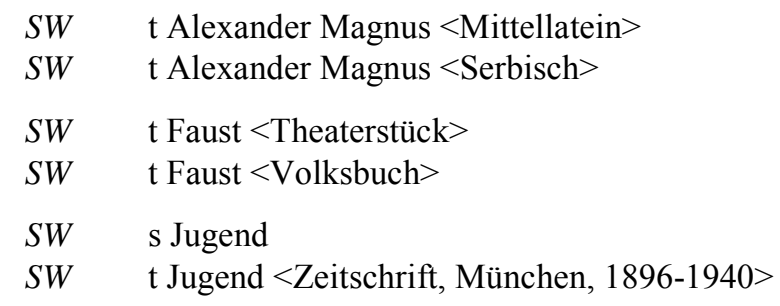


SW t Tirol und Fridebant

$D \quad$ Zusammenfassung für die verschiedenen Versionen

SW $\quad$ t Tirol und Fridebant $<$ Lehrgedicht $>$

$S W \quad$ t Tirol und Fridebant $<$ Rätsel $>$

SW $\quad \mathrm{t}$ Tirol und Fridebant $<$ Epik $>$

SW p Lanzelot

$D \quad$ Ritter der Tafelrunde

SW t Lancelot du lac

BF $\quad \mathrm{t}$ Lanzelot $<$ Altfranzösisch, Prosa $>$

SW t Lanseloet van Denemarken

$B F \quad$ t Lanzelot $<$ Mittelniederländisch, Prosa $>$

SW $\quad$ t Lanzelot $<$ Mittelhochdeutsch, Prosa $>$

In Einzelfällen ist zur Unterscheidung auch eine andere eindeutig charakterisierende Bezeichnung möglich.

SW $\quad$ t Morte Arthur $<$ Alliterierendes Gedicht $>$

SW t Morte Arthur < Strophisches Gedicht $>$

c) Von namentlich bekannten Bearbeitern des Stoffes wird eine Synonymie-Verweisung gemacht; der Einheitssachtitel wird in diesem Fall zweiter Teil der Verweisung.

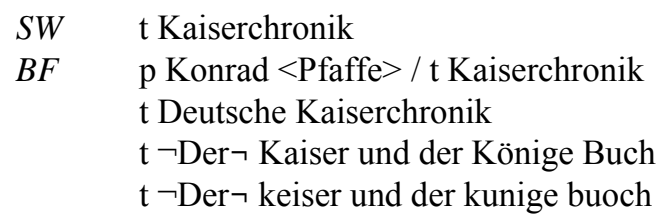

4. Bibliotheken, die RAK-ÖB-A anwenden, können für Werke des Altertums, des Mittelalters und der frühen Neuzeit einen im Deutschen gebräuchlichen Sachtitel als Einheitssachtitel verwenden. Dafür wird in der SWD eine ÖB-Alternativform angesetzt (vgl. § 709,3).

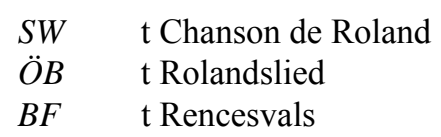

5. Gängige Sachtitel, die von der Ansetzung abweichen, werden gemäß $§ 708,9$ als Synonyme erfasst.

SW t Kaiserchronik

BF t Deutsche Kaiserchronik

6. Anonyme Werke der Literatur und Fachliteratur des Altertums (mit Ausnahme der biblischen Bücher), des Mittelalters und der Neuzeit erhalten i. d. R. mehrgliedrige Oberbegriffe aus der Verknüpfung von Sprachbezeichnung und Gattung. Dabei wird, soweit ermittelbar, das Schlagwort für den spezifischsten zutreffenden Gattungsbegriff gewählt. Der im Werk behandelte Gegenstand wird bei der Ansetzung nicht als Oberbegriff berücksichtigt.

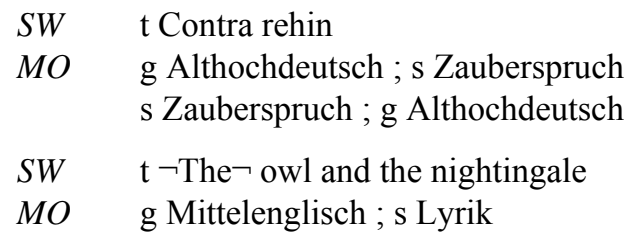




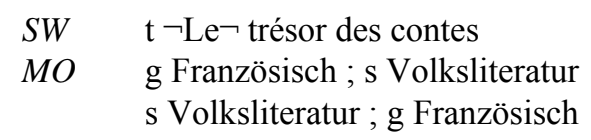

Der mehrgliedrige Oberbegriff entfällt, wenn die Sprachbezeichnung in Verknüpfung mit der Gattung unüblich oder pleonastisch ist. In diesen Fällen wird nur der Gattungsbegriff als Oberbegriff erfasst.

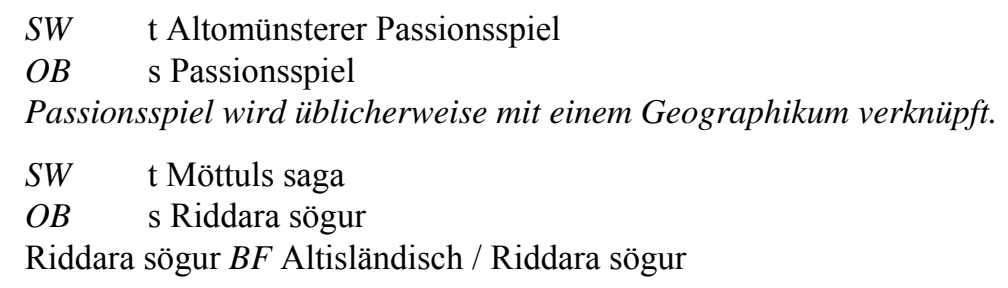

\section{§ 713 Die Bibel und Teile der Bibel}

1. Die Bibel und Teile der Bibel werden in der deutschsprachigen Form nach der Einheitsübersetzung der Heiligen Schrift bzw. den Loccumer Richtlinien angesetzt (vgl. „Liste der Nachschlagewerke“).

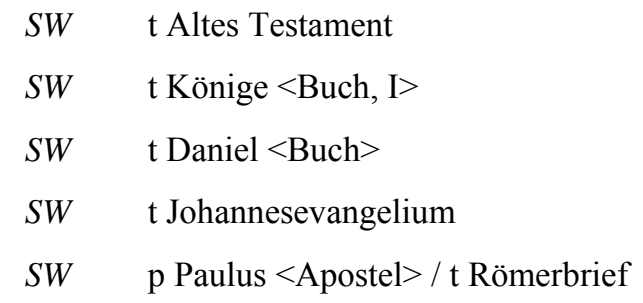

2. Bestimmte Bibelausgaben, Übersetzungen usw. werden mit ihrem Zitiertitel angesetzt; für Ausgaben, die nach Personen benannt sind, wird i.d. R. eine Schlagwortkette mit dem Personennamen bevorzugt.

$$
\begin{array}{ll}
S W & \mathrm{t} \text { Zürcher Bibel } \\
S W & \mathrm{t} \text { Winchester-Bibel } \\
\text { SWW } & \text { p Ulfilas; s Übersetzung; t Bibel }
\end{array}
$$

Aber:

SW t Luther-Bibel

3. Bei Perikopen hat die verbale Bezeichnung Vorrang vor der formalen (biblisches Buch, Kapitel, Verse), sofern sie geläufig und nachweisbar ist und den formalen Ansetzungskriterien entspricht. Die formale Bezeichnung und andere nicht gewählte Bezeichnungen werden als Synonyme erfasst.

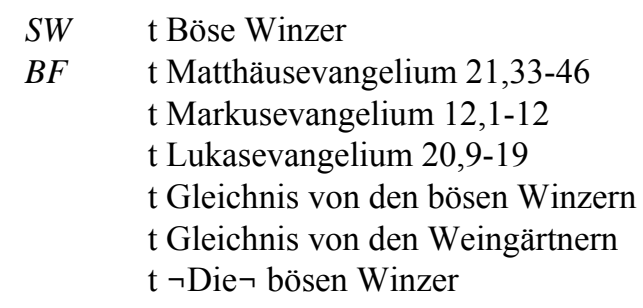




\section{$\S 714$ Psychologische Tests}

Psychologische Tests (Testmaterial und Sekundärliteratur) sind als anonyme Werke zu behandeln und vorzugsweise mit den Abkürzungen anzusetzen, unter denen sie zitiert werden. Das einschlägige Sachschlagwort wird als Oberbegriff, die mehrgliedrige Form als Verfasserschrift ggf. als Synonym erfasst.

Anm.: Zum Formschlagwort 'Testmaterial' vgl. Anl. 6.

$\begin{array}{ll}S W & \text { t MMPI } \\ B F & \text { t Minnesota multiphasic personality inventory } \\ O B & \text { s Persönlichkeitstest } \\ & \\ \text { SW } & \text { t Rorschach-Test } \\ B F & \text { p Rorschach, Hermann / t Rorschach-Test } \\ O B & \text { s Deutungstest }\end{array}$

\section{Rechtsmaterien}

\section{§ 715 Rechtsnormen (Gesetze u. ä.)}

1. Rechtsnormen sind Gesetze, Verordnungen, Erlasse u. ä., die von rechtsetzenden Institutionen erlassen werden. Rechtsetzende Institutionen sind Gebietskörperschaften und deren Organe, internationale Zusammenschlüsse von Gebietskörperschaften und in bestimmten Fällen auch die Kirchen (vgl. „Praxisregeln“).

Rechtsnormen werden Schlagwort zur Indexierung von Textausgaben einzelner Rechtsnormen sowie Kommentaren und Abhandlungen dazu.

Die Titel der Rechtsnormen erhalten in der SWD den Indikator t.

SW g Bayern / t Bauordnung

SW k Europäische Gemeinschaften / t Fernsehrichtlinie

Aber:

Titel: $\quad$ Richtlinien für schweißtechnische Lehrgänge. - 1987

SWW g Deutschland; s Schweißer; s Berufsausbildung; f Richtlinie

Deutschsprachige Rechtsnormen werden als mehrgliedriges Schlagwort mit der Gebietskörperschaft, d.h. dem geographischen Schlagwort als erstem Glied und mit dem amtlichen Kurzsachtitel oder, falls dieser nicht vorhanden ist, mit einem gebräuchlichen Zitiertitel als zweitem Glied angesetzt. Das geographische Adjektiv des Titels entfällt dabei.

Der amtliche Kurzsachtitel bzw. Zitiertitel mit dem geographischen Schlagwort als zweitem Glied wird als Synonym erfasst, ebenso eine abweichende RAK-Ansetzung. Die volle Form des Gesetzestitels kann unter Weglassung des einleitenden geographischen Adjektivs als Synonym erfasst werden.

Titel: Niedersächsisches Abfallgesetz / hrsg. und bearb. von Werner Schmeken. - 1990

SW Niedersachsen / Abfallgesetz

BF Abfallgesetz / Niedersachsen

SW Niedersachsen / Landesplanungsgesetz

BF Landesplanungsgesetz / Niedersachsen

Niedersachsen / Gesetz über Raumordnung und Landesplanung 
Ist kein amtlicher Kurztitel bzw. kein gebräuchlicher Zitiertitel vorhanden, so wird der volle Titel der Rechtsnorm angesetzt.

SW Deutschland / Gesetz über befristete Arbeitsverträge mit wissenschaftlichem Personal an Hochschulen und Forschungseinrichtungen

Anm.: Zu Rechtsnormen, die mit dem Urheber angesetzt werden, vgl. § 708,5. Zu Schriftdenkmälern rechtlichen u. ä. Inhalts vgl. § 719 .

2. Die Schlagwörter 'Deutschland' bzw. 'Deutschland $<$ Bundesrepublik $>$ ' entfallen bei der Ansetzung nicht als pleonastisch, auch nicht bei lokaler Anwendung.

SW Deutschland / Städtebauförderungsgesetz

BF Städtebauförderungsgesetz / Deutschland

Zum Verzicht auf 'Deutschland' als erstem Schlagwort einer Grundkette bei lokaler Anwendung vgl. § 201a,5.

3. Die Abkürzung des Gesetzestitels bzw. des amtlichen Kurztitels wird bei Bedarf als Synonym erfasst.
$S W$
Deutschland / Bundesausbildungsförderungsgesetz
$B F$
BAföG

4. Das einschlägige Sachschlagwort wird bei Bedarf als Oberbegriff erfasst.

$\begin{array}{ll}\text { SW } & \text { Deutschland / Röntgenverordnung } \\ O B & \text { Strahlenschutzrecht }\end{array}$

5. Fremdsprachige Rechtsnormen werden als mehrgliedriges Schlagwort mit der Gebietskörperschaft, d.h. dem geographischen Schlagwort als erstem Glied und dem gebräuchlichen deutschen Übersetzungstitel als zweitem Glied angesetzt. Der gebräuchliche deutsche Übersetzungstitel mit dem geographischen Schlagwort als zweitem Glied wird als Synonym erfasst. Der originalsprachige Titel wird bei Bedarf als Synonym erfasst.

Ist kein gebräuchlicher deutscher Titel zu ermitteln, so wird das geographische Schlagwort mit dem fremdsprachigen Titel der Rechtsnorm als zweitem Glied des mehrgliedrigen Schlagworts angesetzt.

Titel: $\quad \neg$ Il $\neg$ nuovo codice di procedura penale. - 1988

SW Italien / Strafprozessordnung

BF $\quad$ Strafprozessordnung / Italien

Italien / Codice di procedura penale

SW USA / Age discrimination in employment act

Anm.: Zu fremdsprachigen juristischen Sachschlagwörtern vgl. § 308, zu regional unterschiedlichen Fachausdrücken des Rechts vgl. § 311,2.

6. Für Sammlungen von Rechtsnormen wird das geographische Schlagwort mit dem Sachschlagwort des Rechtsgebietes und dem Formschlagwort 'Quelle' verknüpft. Für Listenfunktionen kann permutiert werden.

SWW g Baden-Württemberg; s Naturschutzrecht; f Quelle

(213)

Titel: $\quad$ Legislación alimentaria española. - 1976-1983

SWW g Spanien; s Lebensmittelrecht; f Quelle

(213) 
7. Allgemeine Gesetzessammlungen, die kein spezielles Rechtsgebiet zum Gegenstand haben, werden mit dem geographischen Schlagwort, dem nicht permutierenden Sachschlagwort 'Recht' und dem Formschlagwort 'Quelle' indexiert.

SWW g Frankreich; s Recht; f Quelle

8. Sind einzelne Paragraphen bzw. Artikel von Rechtsnormen thematisiert, so wird der Inhalt durch Sachschlagwörter wiedergegeben.

Titel: $\quad \neg$ Der $\neg \S 218$ ist reformiert / Gabriele Schwietering. - 1992

SWW g Deutschland; s Schwangerschaftsabbruch; s Strafrecht (231)

Eine Verweisung vom Paragraphen bzw. Artikel auf das einschlägige Sachschlagwort wird i. d. R. nicht gemacht. Bei lokaler Anwendung können jedoch die entsprechenden Paragraphen als Synonym erfasst werden.

9. Bei Neufassungen von Rechtsnormen mit einer Änderung des Titels werden beide Titel angesetzt und durch assoziative Verweisungen verbunden.

$\begin{array}{lll}S W & \text { Deutschland / Viehseuchengesetz } & \text { (von 1909) } \\ V B & \text { Deutschland / Tierseuchengesetz } & \text { (von 1980) }\end{array}$

Novellierungen ohne Änderung des Titels werden nicht unterschieden.

SW Deutschland / Strafgesetzbuch

sukzessive grundlegende Novellierungen

Rechtsnormen, die wegen einer Umbenennung, einer Teilung oder eines Zusammenschlusses der Gebietskörperschaft getrennt anzusetzen sind, werden i. d. R. durch chronologische Verweisungen verbunden.
SW Tschechoslowakei / Zivilgesetzbuch
CF später Tschechische Republik / Zivilgesetzbuch

10. Historische, d. h. heute nicht mehr gültige Rechtsnormen werden gemäß $\S 715,1$ bzw. bei fremdsprachigen gemäß § 715,5 angesetzt (vgl. auch § 415a,1).

\begin{tabular}{|c|c|}
\hline $\begin{array}{l}S W \\
B F\end{array}$ & $\begin{array}{l}\text { England / Bill of rights } \\
\text { Bill of rights / England } \\
\text { Großbritannien / Bill of rights }\end{array}$ \\
\hline $\begin{array}{l}S W \\
B F\end{array}$ & $\begin{array}{l}\text { Preußen / Gesindeordnung } \\
\text { Gesindeordnung / Preußen }\end{array}$ \\
\hline & Rं \\
\hline
\end{tabular}

Gleichnamige Rechtsnormen sowie historische Rechtsnormen, deren Name mit einem Sachschlagwort übereinstimmt, werden durch Homonymenzusatz unterschieden.

$\begin{array}{ll}S W & \text { Deutschland / Reichshofratsordnung }<1559> \\ B F & \text { Reichshofratsordnung }<1559>/ \text { Deutschland } \\ S W & \text { Bayern / Landrecht }<1518> \\ B F & \text { Landrecht }<1518>/ \text { Bayern } \\ S W & \text { Duisburg / Stadtrecht }<1518> \\ B F & \text { Stadtrecht }<1518>/ \text { Duisburg } \\ S W & \text { Ancona / Stadtverfassung }<1566> \\ B F & \text { Stadtverfassung }<1566>\text { Ancona }\end{array}$


SW $\quad$ Oldenburg $<$ Staat $>/$ Kirchenordnung $<1725>$

$B F \quad$ Kirchenordnung $<1725>/$ Oldenburg $<$ Staat $>$

Ist eine Ansetzung mit dem geographischen Schlagwort als erstem Glied nicht möglich, werden historische Rechtsnormen nur mit ihrem Individualnamen angesetzt.

SW Codex Hammurapi

D Gesetzessammlung auf Stele, 1.Hälfte 18. Jahrhundert v. Chr.

11. Rechtsnormen, die internationale Zusammenschlüsse von Gebietskörperschaften erlassen, werden als mehrgliedriges Schlagwort angesetzt. Die durch den Zusammenschluss gebildete Gebietskörperschaft bzw. der Name des internationalen Zusammenschlusses ist dabei das erste Glied. Die Ansetzung des Titels als zweites Glied folgt bei deutschsprachigen Rechtsnormen $\S 715,1$, bei fremdsprachigen $\S 715,5$.
SW Europäische Union / Fernsehrichtlinie
SW Vereinte Nationen / UNCITRAL-Modellgesetz über die Beschaffung von Gütern, Bau- und Dienstleistungen

12. Rechtsnormen, die Kirchen als Körperschaften, die auf ein Gebiet bezogen sind, erlassen, (z. B. einzelne evangelische Landeskirchen oder katholische Diözesen), werden als mehrgliedriges Schlagwort mit der Körperschaft als erstem und dem Titel als zweitem Glied angesetzt.

SW Evangelische Kirche im Rheinland / Mitarbeitervertretungsgesetz

BF Mitarbeitervertretungsgesetz / Evangelische Kirche im Rheinland

Rechtsnormen, die Kirchen als Personenvereinigungen erlassen (z. B. die Katholische Kirche), werden nur mit dem Titel der Rechtsnorm angesetzt.

SW Codex iuris canonici

\section{$\S 716$ Verträge zwischen Staaten und Gliedstaaten}

Zur Indexierung von Vertragstexten und Abhandlungen über Verträge werden diese mit der gebräuchlichen deutschen Bezeichnung gemäß der „Liste der Nachschlagewerke“ (vgl. § 9,3) angesetzt. Fehlt eine deutsche Bezeichnung, so wird mit dem fremdsprachigen Titel angesetzt. Der Urheber bzw. die veranlassende Körperschaft eines Vertrages mit dem Titel des Vertrages als zweitem Glied wird als mehrgliedriges Synonym erfasst, ebenso eine abweichende RAKAnsetzung. (Historische Einzelereignisse vgl. § 415a.)

Die Titel der Verträge erhalten den Indikator t.

$\begin{array}{ll}S W & \text { Genfer Konventionen }<1949> \\ S W & \text { SALT II } \\ S W & \text { Antikominternpakt } \\ S W & \text { Übereinkommen über einen Verhaltenskodex für Linienkonferenzen } \\ B F & \text { UNCTAD / Übereinkommen über einen Verhaltenskodex für Linienkonferenzen } \\ S W & \text { Convention on international financial leasing } \\ S W & \text { Maastrichter Vertrag } \\ B F & \text { Vertrag über die Europäische Union }\end{array}$


Ist ein spezifischer Titel nicht nachweisbar, wird das geographische Schlagwort bzw. der Körperschaftsname mit einem passenden Sachschlagwort verknüpft. Für Listenfunktionen kann permutiert werden.

Titel: $\quad \neg \mathrm{La}\urcorner$ convention fiscale franco-britannique du 14 décembre 1950 / Fritz E. Koch ... 1954

SWW g Frankreich; s Doppelbesteuerungsabkommen; g Großbritannien (213) (321)

Titel: $\quad \neg \mathrm{A} \neg$ treaty of amity and commerce between his Majesty, the King of Prussia and the United States of America. - [1785]

SWW g Preußen; s Handelsvertrag ; g USA ; z Geschichte 1785 (2134) (3214)

SWW g Frankreich; s Konkordat ; z Geschichte 1516

\section{$\S 717$ Verfassungen}

Verfassungen sind Rechtsnormen, die die rechtliche Grundordnung eines Staates bzw. Gliedstaates konstituieren. Verfassungen werden als mehrgliedriges Schlagwort mit dem Staat als erstem Glied und 'Verfassung' mit dem Jahr der Entstehung in Winkelklammern angesetzt. Abweichende Namensformen können als Synonym erfasst werden.

$\begin{array}{ll}S W & \text { Preußen / Verfassung }<1848> \\ S W & \text { Deutschland / Verfassung <1919> } \\ B F & \text { Weimarer Reichsverfassung }\end{array}$

Ausnahmen von der normierten Ansetzung bilden die heute gültigen Verfassungen von Deutschland und Österreich.
SW Deutschland / Grundgesetz
$B F \quad$ Deutschland / Verfassung $<1949>$
$S W \quad$ Österreich / Bundes-Verfassungsgesetz
$B F \quad$ Österreich / Verfassung $<1920>$

Einzelne Stadtverfassungen, Kirchenordnungen und Kirchenverfassungen werden nach $\S 715,10$ angesetzt.

Entwürfe von Verfassungen werden als mehrgliedriges Schlagwort mit dem Staat bzw. Gliedstaat als erstem Glied und 'Verfassung < Entwurf, Jahr $>$ ' als weiterem Glied angesetzt.

SW $\quad$ Slowenien / Verfassung $<$ Entwurf, 1991 $>$

\section{Schriftdenkmäler}

\section{$\S 718$ Schriftdenkmäler ohne Schriften rechtlichen, wirtschaftlichen u. ä. Inhalts}

Schriftdenkmäler umfassen Handschriften, Inkunabeln, Manuskripte und andere Archivalien. Bei der Beschlagwortung von Sekundärliteratur zu Schriftdenkmälern gelten folgende Regeln :

Anm.: Im Zweifelsfall hat die Regelung für Schriftdenkmäler Vorrang vor der für Werke der bildenden Kunst und für Bauwerke. 
Zur Normierung der Schreibung von Signaturen vgl. die entsprechende Praxisregel.

1. Schriftdenkmäler mit Individualnamen

Ansetzungsform

Schriftdenkmäler werden mit ihrem im Deutschen gebräuchlichen Individualnamen angesetzt, sofern ein solcher für das Schriftdenkmal als Ganzes existiert. Die Gebräuchlichkeit eines solchen individuellen Werktitels wird an Hand der „Liste der fachlichen Nachschlagewerke“ (vgl. § 9,3) bestimmt. Referenzwerk kann auch der Handschriftenkatalog der besitzenden Bibliothek sein. Die Ansetzung nach Vorlagen ist möglich, wenn ein Individualname in der wissenschaftlichen Literatur (z. B. als Titel von Editionen) eingeführt und außerdem eindeutig ist. Mit geographischen Begriffen zusammengesetzte Individualnamen bedürfen jedoch immer des Nachweises in einem in der „Liste der fachlichen Nachschlagewerke“ aufgeführten Werk. Die Werktitel erhalten in der SWD den Indikator t.

Schriftdenkmäler, für die ein Individualname im Zusammenhang mit einer Person (Schreiber, Künstler, Auftraggeber, Vorbesitzer, Übersetzer usw.) in einem Werk der „Liste der fachlichen Nachschlagewerke" nachzuweisen ist, werden mit diesem Personennamen und dem Individualnamen analog zu Verfasserwerken angesetzt. Die Werktitel im zweiten Teil der Ansetzung erhalten in der SWD den Indikator t.

\section{Synonymie-Verweisungen}

Ort / Institution der Aufbewahrung des Schriftdenkmals / Signatur oder, falls diese nicht bekannt, Ort / Institution der Aufbewahrung des Schriftdenkmals / gewählte Ansetzungsform werden als Synonym erfasst. Darüber hinaus kann von einer oder mehreren weiteren Personen (bei der Ansetzung nicht berücksichtigte Verfasser, Schreiber, Künstler, Auftraggeber, Vorbesitzer, Übersetzer usw.) verwiesen werden mit einem Sachschlagwort und, bei Schriftdenkmälern, die unter einer Person angesetzt werden, mit dieser Person. Sofern weitere Individualnamen bekannt sind, ist von diesen zu verweisen. Schriftdenkmäler, die mit einem Personennamen und einem Individualnamen angesetzt werden, erhalten obligatorisch eine Synonymie-Verweisung vom Individualnamen.

\section{Oberbegriffe}

Bei Schriftdenkmälern mit Individualnamen wird der einschlägige Gattungsbegriff zusammen mit der Sprachbezeichnung als mehrgliedriger Oberbegriff erfasst. Bei Bibeln oder Teilen von Bibeln wird das Titelschlagwort „Bibel“ zusammen mit dem Sachschlagwort „Handschrift“ und der Sprachbezeichnung als mehrgliedriger Oberbegriff erfasst, es sei denn, es existiert eine eigene Gattungsbezeichnung als Sachschlagwort für Schriftdenkmäler, die den betr. Teil der Bibel enthalten (z. B. Evangeliar); dieses wird dann zusammen mit der Sprachbezeichnung als mehrgliedriger Oberbegriff erfasst.

Ist das Schriftdenkmal Teil einer Sammelhandschrift, so wird diese als Oberbegriff in der Form "Ort / Institution / Signatur" erfasst.

Nur wenn die Sprache des Schriftdenkmals nicht zu ermitteln ist, wird lediglich ein einfacher Oberbegriff eingetragen.

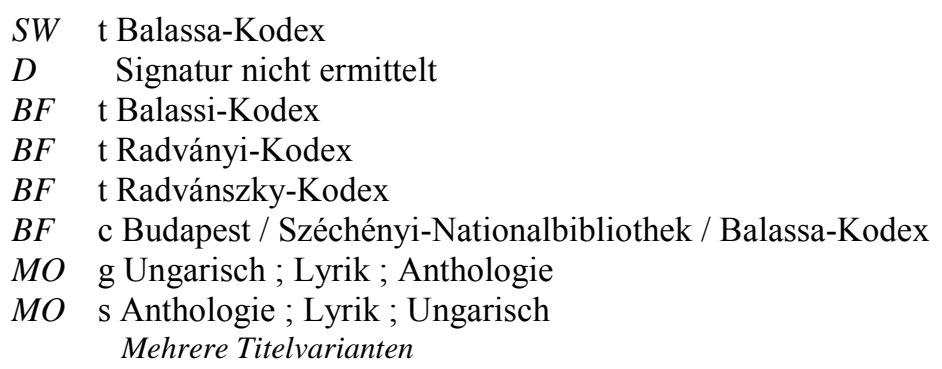


SW t Lochamer-Liederbuch

BF c Berlin / Staatsbibliothek / Mus. Ms. 40613

$B F \quad$ t Kretzmerische Handschrift

$B F \quad \mathrm{p}$ Wölflin < von Lochamer $>/$ Liederbuch

$M O$ g Mittelhochdeutsch; Liederbuch

$M O$ s Liederbuch; Mittelhochdeutsch

Titelvariante, bekannter Besitzer

SW t Manessische Handschrift

$B F \quad$ t Grosse Heidelberger Liederhandschrift

$B F$ c Heidelberg / Universitätsbibliothek / Cod. Pal. germ. 848

$B F \quad$ t Manessesche Handschrift

$M O$ g Mittelhochdeutsch; Liederhandschrift

$M O$ s Liederhandschrift; Mittelhochdeutsch

$O B$ t Heidelberger Liederhandschriften

Titelvariante, Teil eines Konvoluts

SW t Bamberger Apokalypse

$B F \quad$ c Bamberg / Staatsbibliothek / Ms. Bibl. 140

$M O$ g Latein; Bibel; Handschrift

MO s Bibel; Handschrift ; Latein

Teil der Bibel

$S W \quad$ t Book of Kells

$B F$ c Dublin / Trinity College / Bibliothek / Ms. A. I. 6,58

$B F \quad$ t Kells-Evangeliar

$B F \quad$ t Codex Ceannansis

$M O$ g Latein; Evangeliar

$M O \quad$ s Evangeliar; Latein

Titelvarianten

SW t Serbischer Psalter

$B F$ c München / Bayerische Staatsbibliothek / Cod. slav. 4

$M O$ g Altkirchenslawisch; Psalter

$M O$ s Psalter; Altkirchenslawisch

Mit geographischem Begriff zusammengesetzter Individualname

SW t Elisabeth-Psalter

$B F \quad$ c Cividale del Friuli / Museo Archeologico Nazionale / Ms. CXXXVII

$B F \quad$ p Elisabeth $<$ Thüringen, Landgräfin $>$ / Psalter

$B F \quad$ p Sophie $<$ Thüringen, Landgräfin $>$ / Psalter

$B F \quad$ t Elisabethpsalter

$M O$ g Latein; Psalter

$M O$ s Psalter; Latein

Variierende Schreibweise, mehrere bekannte Besitzerinnen

$S W \quad$ p Jean $<$ Berry, Herzog, II. $>/ \mathrm{t} \neg$ Les $\neg$ très riches heures

$B F \quad$ p Limburg, Jan $\neg$ van $\neg / \neg$ Les $\neg$ très riches heures / Jean $<$ Berry, Herzog, II. $>$

$B F \quad$ p Limburg, Hermann $\neg$ van $\neg / \neg$ Les $\neg$ très riches heures / Jean $<$ Berry, Herzog, II. $>$

$B F \quad$ p Limburg, Paul $\neg$ van $\neg / \neg$ Les $\neg$ très riches heures / Jean $<$ Berry, Herzog, II. $>$

$B F \quad \mathrm{t} \neg$ Les $\neg$ très riches heures du Duc de Berry

$B F \quad$ c Chantilly / Musée Condé / Ms. 1284

$B F \quad$ c Chantilly / Musée Condé / Ms. 65

MO s Stundenbuch; Latein

MO g Latein; Stundenbuch

Individualname im Zusammenhang mit einer Person 
2. Schriftdenkmäler ohne gebräuchlichen Individualnamen

a) Literarisches Werk

Ist kein Individualname für das Schriftdenkmal nachweisbar, besteht der Text des Schriftdenkmals aber aus einem literarischen Werk, so erfolgt die Ansetzung mit diesem gemäß $\S$ 707-713. Falls es sich bei dem anzusetzenden Werk um eine Übersetzung handelt, wird die Sprache in der Ansetzung nach dem Werktitel berücksichtigt. Das Schlagwort Übersetzung wird nicht Bestandteil der Ansetzung.

Ansetzungsform

Das literarische Werk wird mit einem in der Literatur üblichen Kürzel (z. B. ,Handschrift A') angesetzt. Wenn dies nicht möglich ist, wird das Werk mit dem Schlagwort ,Handschrift' oder einem spezifischeren Sachschlagwort (z. B. ,Autograph'), mit dem Ort, der aufbewahrenden Körperschaft und der Signatur als mehrgliedriges Schlagwort angesetzt.

Schriftdenkmäler anonymer literarischer Werke werden in der Form Ort / aufbewahrende Körperschaft / Werktitel / Sachschlagwort / Signatur angesetzt.

Ist keine Signatur bekannt, so werden lediglich Ort und aufbewahrende Institution oder - bei Schriftdenkmälern aus Privatsammlungen - die Person des Sammlers mit dem Werktitel und der Gattungsbezeichnung verknüpft. Für die Verankerung von Verweisungen wird ein Hinweissatz gebildet.

Durch die Beschränkung auf maximal sechsteilige Schlagwörter muss in Einzelfällen ein eigentlich vorgesehenes Kettenglied entfallen. Dies sollte das spezifische Sachschlagwort sein.

Der Inhalt des im Schriftdenkmal behandelten Gegenstandes kann als 2. Schlagwortkette in Verbindung mit dem Formschlagwort, Quelle' erfasst werden, wenn der Text des Schriftdenkmals in der Vorlage mit enthalten ist (vgl. § 720).

Synonymie-Verweisungen

Bei Ansetzung mit üblichem Kürzel:

Ort / Institution der Aufbewahrung des Schriftdenkmals / Signatur oder, falls bei der Ansetzung mit einem Kürzel die Signatur nicht bekannt ist, Ort / Institution der Aufbewahrung des Schriftdenkmals / [Verfasser] / Werktitel / [Sprache] / Kürzel werden als Synonym erfasst. Darüber hinaus kann verwiesen werden von einer oder mehreren weiteren Personen (bei der Ansetzung nicht berücksichtigte Verfasser, Schreiber, Künstler, Auftraggeber, Vorbesitzer, Übersetzer usw.) mit einem Sachschlagwort und, bei Schriftdenkmälern von Werken, die unter einer Person angesetzt werden, mit dieser Person. Ferner kann von einem bei der Ansetzung nicht zu berücksichtigenden Individualnamen der Handschrift verwiesen werden.

Bei Ansetzung mit Sachschlagwort:

Ort / Institution der Aufbewahrung des Schriftdenkmals / Signatur oder, falls diese nicht bekannt, Ort / Institution der Aufbewahrung des Schriftdenkmals / Verfasser / Werktitel / [Sprache] / das Schriftdenkmal kennzeichnendes Sachschlagwort werden als Synonym erfasst. Falls es sich um ein anonymes Werk handelt, wird von diesem mit dem das Schriftdenkmal kennzeichnenden Sachschlagwort, Ort / Institution der Aufbewahrung des Schriftdenkmals / Signatur verwiesen. Darüber hinaus kann verwiesen werden von einer oder mehreren weiteren Personen (bei der Ansetzung nicht berücksichtigte Verfasser, Schreiber, Künstler, Auftraggeber, Vorbesitzer, Übersetzer usw.) mit einem Sachschlagwort und, bei Schriftdenkmälern von Werken, die unter einer Person angesetzt werden, mit dieser Person. Ferner kann von einem bei der Ansetzung nicht zu berücksichtigenden Individualnamen der Handschrift verwiesen werden.

Oberbegriffe

Ist das Werk Teil einer Sammelhandschrift, so wird diese in der Form Ort / Institution der Aufbewahrung / Signatur als Oberbegriff erfasst.

Weitere Oberbegriffe werden nicht vergeben. 
SW p Hartmann < von Aue $>$ / t Iwein / x Handschrift A

$B F$ c Heidelberg / Universitätsbibliothek / Cod. Pal. Germ. 397

Verfasserwerk mit Kürzel

$S W$ t Nibelungenlied / $\mathrm{x}$ Handschrift C

$B F$ t Hohenems-Lassbergische Handschrift

$B F$ c Donaueschingen / Fürstlich-Fürstenbergische Hofbibliothek / Ms. 63

$B F$ c Karlsruhe / Badische Landesbibliothek / Hs. Don. 63

Anonymes literarisches Werk mit Kürzel

SW p Lombardus, Marcus / t Disputation zwischen einem Juden und einem Christen /

x Handschrift / x München / x Bayerische Staatsbibliothek / x Cgm 972

BF c München / Bayerische Staatsbibliothek / Cgm 972

Verfasserwerk ohne übliches Kürzel

SW p Büchner, Georg / t Woyzeck / x Autograph / x Weimar / x Goethe-und-Schiller-Archiv / $\mathrm{x} 10 / 3,1$

BF c Weimar / Goethe-und-Schiller-Archiv / 10/3, 1

Verfasserwerk

SW p Praetorius, Mattheus / t Deliciae Prussicae oder Preussische Schaubühne / x Wilna / x Lithuanian Academy of Sciences / x Bibliothek / x f. 129, N 1338/1-2

BF c Wilna / Lithuanian Academy of Sciences / Bibliothek / f. 129, N 1338/1-2 Verfasserwerk. Wegen der Beschränkung auf maximal sechsteilige SWW entfällt in Ansetzung und entsprechenden Verweisungen das Sachschlagwort „Autograph“.

SW p Nikolaus < von Dresden> / t Tabule novi et veteris coloris / $\mathrm{x}$ Böhmisch / $\mathrm{x}$ Göttingen / $\mathrm{x}$ Niedersächsische Staats- und Universitätsbibliothek / x Ms. theol. 182

$B F$ t Göttinger Hussitenkodex

$B F$ c Göttingen / Niedersächsische Staats- und Universitätsbibliothek / Ms. theol. 182

BF g Böhmisch / Nikolaus < von Dresden> / Tabule novi et veteris coloris / Göttingen / Niedersächsische Staats- und Universitätsbibliothek / Ms. theol. 182

Verfasserwerk mit Sprachbezeichnung. Wegen der Beschränkung auf maximal sechsteilige SWW ent fällt in Ansetzung und entsprechenden Verweisungen das Sachschlagwort „Handschrift“.

SW c Augsburg / x Staats- und Stadtbibliothek / x Etymachietraktat / x Handschrift / x 2. Cod. 160

$B F$ t Etymachietraktat / Handschrift / Augsburg / Staats- und Stadtbibliothek / 2. Cod. 160

$O B$ c Augsburg / Staats- und Stadtbibliothek / 2. Cod. 160.

Anonymes Werk. Die besitzende Körperschaft steht am Beginn des mehrgliedrigen SW, gefolgt vom Werktitel.

SW c Berlin / x Staatsbibliothek / x Berliner Weltgerichtsspiel / x Handschrift / x Ms. germ. fol. 722

$B F \quad \mathrm{t}$ Augsburger Buch vom Jüngsten Gericht

$B F$ t Berliner Weltgerichtsspiel / Handschrift / Berlin / Staatsbibliothek / Ms. germ. fol. 722

$B F \quad$ c Berlin / Staatsbibliothek / Ms. germ. fol. 722 Anonymes Werk

SW c Kassel / x Universitätsbibliothek, Landesbibliothek und Murhardsche Bibliothek / x Hildebrandslied / x Handschrift / x Ms. theol. 54

$B F \quad$ t Hildebrandslied / Handschrift / Kassel / Universitätsbibliothek, Landesbibliothek und Murhardsche Bibliothek / Ms. theol. 54

$O B$ c Kassel / Universitätsbibliothek, Landesbibliothek und Murhardsche Bibliothek / 2. Ms. theol. 54 Anonymes literarisches Werk als Teil einer Sammelhandschrift

SW c Krakau / x Jagellonische Bibliothek / x Neues Testament / x Niedersorbisch / x Handschrift / x Ms. slav. fol. 29

$D \quad$ Entstanden im 17. Jh., Teil einer Sammelhandschrift

$B F$ t Neues Testament / Niedersorbisch / Handschrift / Krakau / Jagellonische Bibliothek / Ms. slav. fol. 29

BF g Niedersorbisch / Handschrift / Neues Testament / Krakau / Jagellonische Bibliothek / Ms. slav. fol. 29

$O B$ c Krakau / Jagellonische Bibliothek / Ms. slav. fol. 29 Anonymes Werk mit Sprachbezeichnung als Teil einer Sammelhandschrift 
b) Kein literarisches Werk

Ist kein Individualname für das Schriftdenkmal nachweisbar, der mit dem Indikator t gemäß 1 . angesetzt werden kann und ist sein Inhalt auch nicht durch einen Werktitel wiederzugeben, so wird wie folgt verfahren:

- Nach einer Person benannte Schriftdenkmäler ohne gebräuchlichen Individualnamen

Ansetzungsform

Ist das Schriftdenkmal nach einer Person benannt, gibt es aber dazu keinen Individualnamen, so wird das Personenschlagwort mit einem das Schriftdenkmal kennzeichnenden Sachschlagwort, dem Ort, der aufbewahrenden Institution und der Signatur als ein mehrgliedriges Schlagwort angesetzt.

Ist keine Signatur bekannt, so werden lediglich das Personenschlagwort mit einem das Schriftdenkmal kennzeichnenden Sachschlagwort mit dem Ort und der aufbewahrenden Institution oder - bei Schriftdenkmälern aus Privatsammlungen - mit der Person des Sammlers verknüpft, sofern diese nicht bereits für die Ansetzung herangezogen wurde. Für die Verankerung von Verweisungen von nicht bei der Ansetzung berücksichtigten weiteren Personen oder Individualnamen wird ggf. ein Hinweissatz gebildet.

\section{Synonymie-Verweisungen}

Ort / Institution der Aufbewahrung des Schriftdenkmals / Signatur und Sachschlagwort / Personenschlagwort / Ort / Institution der Aufbewahrung / Signatur werden als Synonym erfasst. Darüber hinaus kann verwiesen werden von einer oder mehreren weiteren Personen (bei der Ansetzung nicht berücksichtigte Verfasser, Schreiber, Künstler, Auftraggeber, Vorbesitzer, Übersetzer usw.) mit einem Sachschlagwort, in der Hauptansetzung berücksichtigter Person und Ort / Institution der Aufbewahrung des Schriftdenkmals / Signatur. Ferner kann von weiteren nicht für die Ansetzung zu berücksichtigenden Individualnamen verwiesen werden.

Oberbegriffe

Oberbegriffe werden nicht vergeben, sofern es sich nicht um den Teil einer Sammelhandschrift handelt.

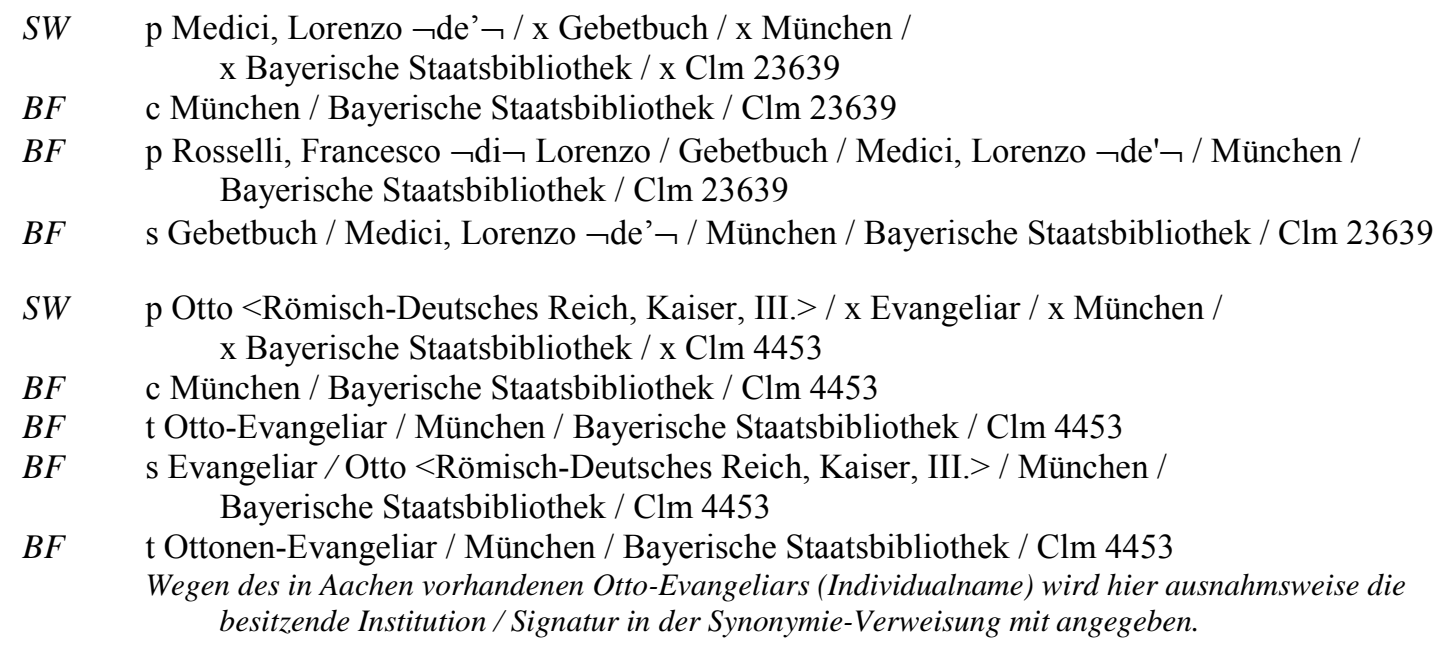


SWW p Meister des Antoine de Roche ; s Stundenbuch

$D \quad$ In Paris oder Lyon um 1500 entstandenes bilderreiches Stundenbuch, ehemals im Besitz der Familie Guémadeuc, Standort und Signatur nicht ermittelt

Hinweissatz, gekennzeichnet in MAB Feld 067

$B F \quad$ p Guémadeuc $<$ Familie $>$ / Stundenbuch

$B F \quad$ s Stundenbuch / Guémadeuc $<$ Familie $>$

- $\quad$ Nicht nach einer Person benannte Schriftdenkmäler ohne gebräuchlichen Individualnamen

Ansetzungsform

Ist das Schriftdenkmal ohne Individualnamen nicht nach einer Person benannt, wird ein mehrgliedriges Schlagwort aus der aufbewahrenden Institution, einem das Schriftdenkmal kennzeichnenden Sachschlagwort (Gattungsbezeichnung, auch für Sammelhandschriften) und der Signatur gebildet (vgl. auch $\S 736,5$ ).

Dies gilt auch für Teile von Sammelhandschriften.

Ist keine Signatur bekannt, so werden lediglich Ort und aufbewahrende Institution oder - bei Schriftdenkmälern aus Privatsammlungen die Person des Sammlers mit der Gattungsbezeichnung verknüpft. Für die Verankerung von Verweisungen von nicht bei der Ansetzung berücksichtigten Personen oder Individualnamen wird ggf. ein Hinweissatz gebildet

Synonymie-Verweisungen

Ort / Institution der Aufbewahrung des Schriftdenkmals / Signatur und Sachschlagwort / Ort / Institution der Aufbewahrung des Schriftdenkmals / Signatur werden als Synonym erfasst. Darüber hinaus kann verwiesen werden von einer oder mehreren Personen (bei der Ansetzung nicht berücksichtigte Verfasser, Schreiber, Künstler, Auftraggeber, Vorbesitzer, Übersetzer usw.) mit einem Sachschlagwort / Ort / Institution der Aufbewahrung des Schriftdenkmals / Signatur. Ferner kann von nicht für die Ansetzung zu berücksichtigenden Individualnamen verwiesen werden.

Oberbegriffe

Oberbegriffe werden nicht vergeben, sofern es sich nicht um den Teil einer Sammelhandschrift handelt.

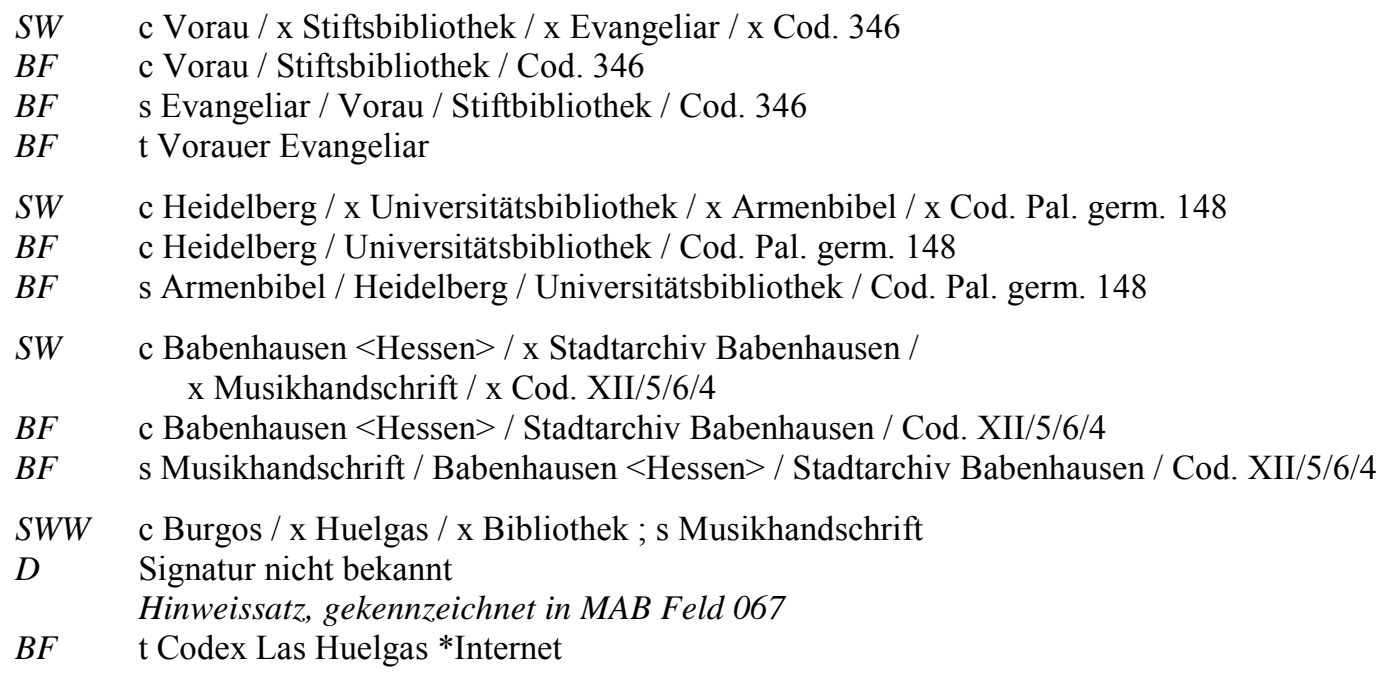


3. Übrige Fälle

Ansetzungsform

Ist eine Ansetzung gemäß 1. und 2. nicht möglich (insbesondere bei Sammelhandschriften, unspezifischen Archivalien usw.), so wird mit Ort und Institution der Aufbewahrung sowie der Signatur des Schriftdenkmals angesetzt. Für die Form der Signatur ist der Gebrauch der besitzenden Institution maßgeblich, der sich aus gedruckten Handschriftenkatalogen, Archiv-Repertorien u. ä. ergibt.

Handschriften- und Archivalienfonds werden entsprechend angesetzt.

Synonymie-Verweisungen

Es kann verwiesen werden von nicht bei der Ansetzung berücksichtigten Personen in der Form "Personenname / Ort / Institution / Signatur" sowie von nicht bei der Ansetzung berücksichtigten Individualnamen.

Oberbegriffe

Oberbegriffe werden nicht vergeben.

Der Inhalt des im Schriftdenkmal behandelten Gegenstandes kann als 2. Schlagwortkette in Verbindung mit dem Formschlagwort, Quelle' erfasst werden, wenn der Text des Schriftdenkmals in der Vorlage mit enthalten ist.

SW c München / x Bayerische Staatsbibliothek / x Clm 17142

$D \quad$ Sammelhandschrift aus Schäftlarn

SW c Dublin / x Chester Beatty Library / x Papyrus 16

SW $\quad$ c Nantes / x Archives Départementales de Loire-Atlantique / x Série Fi

SW c Frankreich / x Außenministerium / x Archiv / x Fonds Bourbons 


\section{§ 719 Schriftdenkmäler rechtlichen, wirtschaftlichen u. ä. Inhalts}

Bei der Indexierung von Sekundärliteratur zu Schriften rechtlichen, wirtschaftlichen u. ä. Inhalts (wie Urbare, Lagerbücher, Traditionsbücher, Lehnsbücher, Kopialbücher, Urkundenregister, Steuerverzeichnisse, Häuserbücher, Memorienbücher, Verbrüderungsbücher, Nekrologe usw.), die aus den Aktivitäten einer Person oder Körperschaft erwachsen, wird das Schlagwort für die Person bzw. Körperschaft mit einem das Schriftdenkmal kennzeichnenden Sachschlagwort verknüpft. Ggf. tritt ans Ende der Schlagwortkette eine Zeitangabe. Mit dem Sachschlagwort in Verbindung mit dem Personennamen oder der Körperschaft wird für Listenfunktionen eine zusätzliche Eintragung gemacht.

Falls es sinnvoll erscheint, ist es auch möglich einen Hinweissatz mit einer Verweisung von besitzender Institution in Verbindung mit der Signatur anzulegen.

$\begin{array}{ll}\text { SWW } & \text { c Corvey / x Kloster ; s Traditionsbuch ; z Geschichte 822-1023 } \\ \text { SWW } & \text { c Winchester / x New Minster / x Kloster ; s Verbrüderungsbuch } \\ & \text { Hinweissatz, gekennzeichnet in MAB Feld 067 } \\ \text { BF } & \text { c London / British Library / Stowe Ms. } 944\end{array}$

\section{§ 720 Quellenausgaben von Schriftdenkmälern}

Der Inhalt von Primärliteratur, d. h. Quellenausgaben einzelner Schriftdenkmäler oder einer Gruppe von Schriftdenkmälern, wird erschlossen, indem die Schlagwörter für den behandelten Gegenstand mit dem entsprechenden Formschlagwort ('Quelle', 'Matrikel' usw.) verknüpft werden (vgl. Anl. 6).

Titel: $\quad$ Urkunden und Regesten zur Geschichte der aufgehobenen Kartause Aggsbach, V.O.W.W. I bearb. von Adalbert Fr. Fuchs. - 1906

SWW c Aggsbach Dorf / x Kloster ; z Geschichte ; f Quelle

Titel: $\quad$ Akten zur deutschen auswärtigen Politik : 1918 bis 1945 ; aus dem Archiv des Auswärtigen Amtes. - 1982-1995

SWW g Deutschland ; s Außenpolitik ; z Geschichte 1918-1945 ; f Quelle

Titel: $\quad \neg$ Die $\neg$ Matrikel der Universität Leipzig / ... hrsg. von Georg Erler. - 1885-1902

SWW c Leipzig / x Universität ; z Geschichte 1409-1559 ; f Matrikel

\section{$\S 721$ entfällt}

\section{$\S 722$ entfällt}

\section{Werke der bildenden Kunst und Bauwerke}

\section{§ 723 Definition und Verwendung}

Als Werke der bildenden Kunst und als Bauwerke gelten einzelne Schöpfungen oder zusammenhängende Folgen von Schöpfungen, die einen individuellen Gegenstand darstellen. Diese haben entweder einen spezifischen oder einen unspezifischen Werktitel.

$\begin{array}{ll}\text { SW } & \text { Leonardo }<\text { da Vinci }>\text { / Mona Lisa } \\ \text { SW } & \text { Monet, Claude / Seerosen } \\ \text { SW } & \text { Köln / Dom }\end{array}$


Es wird unterschieden zwischen:

- nicht ortsgebundenen Kunstwerken (vgl. §§ 727-728),

- ortsgebundenen Kunstwerken (vgl. §§ 730-731).

Titel von Werken der bildenden Kunst werden sowohl für die Indexierung von Originalen bzw. Reproduktionen als auch der zugehörigen Sekundärliteratur verwendet.

$\begin{array}{ll}\text { SW } & \text { Grieshaber, HAP / Totentanz von Basel } \\ \text { SWW } & \text { Grieshaber, HAP / Totentanz von Basel ; Bildband }\end{array}$

Das Formschlagwort 'Bildband' zeigt an, dass Reproduktionen vorliegen.

\section{§ 724 Ansetzung der Künstlernamen, Aufbewahrungs- und Herkunfts orte}

Die Ansetzung der Künstlernamen erfolgt nach §§ 101ff.

SW Gogh, Vincent $\neg$ van $\neg$

Die Ansetzung der Orte erfolgt nach §§ 201ff., die Ansetzung der Ortsteile nach § 209.

SW Saint-Denis

SW Dresden-Loschwitz

Die zur Kennzeichnung von Bauwerken, Aufbewahrungsorten, Herkunftsorten etc. erforderlichen Körperschaften werden gemäß §§ 601ff. angesetzt.

SWW Frankfurt < Main> / Museum für Moderne Kunst ; Museumsbau

\section{$\S 725$ Ansetzung der Werktitel}

1. Für die Ansetzung der Werktitel sind die Nachschlagewerke gemäß der Rangfolge der „Liste der Nachschlagewerke“ (vgl. § 9,3) heranzuziehen.

2. Als Beleg für einen spezifischen Werktitel gilt die in den Nachschlagewerken angegebene Wortfolge und -fassung. Eine verbale Umschreibung im fortlaufenden Text ist nicht als spezifischer, sondern als unspezifischer Werktitel zu verstehen.

3. Für den spezifischen Werktitel wird im Gegensatz zu den literarischen und wissenschaftlichen Werken (vgl. §§ 707-712) kein Einheitssachtitel bestimmt, sondern er wird in der im Deutschen gebräuchlichen Form gemäß den Nachschlagewerken angesetzt. Wenn eine solche nicht zu ermitteln ist, wird die Vorlageform gewählt. Die nicht gewählte Form kann als Synonym erfasst werden.

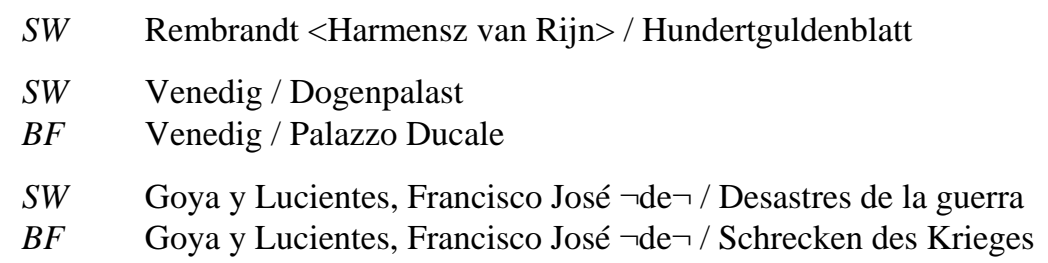

4. Bei der Ansetzung spezifischer Werktitel wird der Werkinhalt weder motivisch noch sachlich berücksichtigt.

SW $\quad$ Bruegel, Pieter < der Ältere $>$ / $\neg$ Der $\neg$ Turmbau zu Babel

nicht zusätzlich: $O B$ Babylonischer Turm 
SW Vecellio, Tiziano < Künstler, 1477-1576> / Spanien schützt die Religion

nicht zusätzlich: MO Spanien ; Religion

Oberbegriffe werden jedoch erfasst für anonyme Werke der Plastik und des Kunsthandwerks sowie für Bauwerke.

$\begin{array}{ll}S W & \text { Goldenes Rössl } \\ O B & \text { Andachtsbild } \\ & \text { Mariendarstellung } \\ & \text { Emailplastik } \\ & \text { Hildesheimer Silberfund } \\ O B & \text { Depotfund } \\ & \text { Tafelsilber } \\ S W & \text { Rom / Tempel des Vespasian } \\ O B & \text { Tempel }\end{array}$

Wenn in einem Kunstwerk eine Person oder Personengruppe (motivisch oder sachlich) Gegenstand der Darstellung ist, wird der Personenname oder das Schlagwort für die Personengruppe als Synonym des Werktitels in folgender Form erfasst:

Person; Werkgattung ; Künstler bzw. Ort oder Körperschaft

Die Ansetzung der Person erfolgt nach $\S \S 101 \mathrm{ff}$.

SW Dürer, Albrecht / Friedrich der Weise (spezifischer Werktitel)

$B F \quad$ Friedrich $<$ Sachsen, Kurfürst, III.> / Bildnis / Dürer, Albrecht

Bei mythologischen und religiösen Darstellungen (biblische Personen, Götter, Heilige) wird dagegen der Bezug zur Person nicht berücksichtigt.

SW Bosch, Hieronymus / Versuchung des heiligen Antonius

SW Rom / Tempel des Apollo Palatinus

5. Unspezifische Werktitel sind Umschreibungen des dargestellten Objekts oder Motivs, insbesondere Wortfolgen und Komposita aus Gattungsbezeichnungen und Personennamen (z. B. 'Denkmal für ...', 'Grab...', 'Grabmal der/des ...', 'Standbild von...', 'Statue'). Sie werden als unspezifische Werktitel behandelt, sofern sie nicht einen Sucheinstieg mit einem eigenen Artikel in der maßgeblichen deutschsprachigen Enzyklopädie aufweisen, und als Schlagwortketten wiedergegeben. Der unspezifische Werktitel kann als Synonym erfasst werden. Die Schlagwortketten werden mit entsprechendem Hinweissatz in die SWD aufgenommen. Für Listenfunktionen werden Permutationen erzeugt.

SWW Willibald $<$ Heiliger $>$; Denkmal ; Eichstätt / Dom

Hinweissatz, gekennzeichnet in MAB Feld 067

$B F \quad$ Hering, Loy / Willibald $<$ Heiliger $>$ / Denkmal / Eichstätt / Dom

Eichstätt / Dom / Hering, Loy / Denkmal / Willibald <Heiliger $>$

Im Thieme-Becker findet sich dazu unter Loy Hering folgender Eintrag: Er errichtete im Eichstätter Dom "für den Bischof Gabriel von Eyb das Denkmal des hl. Willibald".

SWW Luther, Martin; Denkmal; Wittenberg

Hinweissatz, gekennzeichnet in MAB Feld 067

$B F \quad$ Wittenberg / Lutherdenkmal

Schadow, Gottfried / Wittenberg / Lutherdenkmal

Schadow, Gottfried / Lutherdenkmal

Schadow, Gottfried / Luther, Martin / Denkmal / Wittenberg

$S W W \quad$ Della Scala $<$ Familie $>$; Grabmal ; Verona

Hinweissatz, gekennzeichnet in MAB Feld 067

$B F \quad$ Scaliger-Gräber

Verona / Scaliger-Gräber 
SWW Heinrich < bei Rhein, Pfalzgraf, II.> ; Grab ; Maria Laach / Klosterkirche (3421)

Titel: $\quad \neg$ The $\neg$ golden majesty of Sainte Foy at Conques / by Anne Murray Brown. - 1982

$S W W \quad$ Fides $<$ Heilige $>$; Statuette ; Conques / Sainte-Foy (2134) (3421)

In B 1996 unter Conques „Kirchenschatz, v.a. die Statuette der hl. Fides". Dies wird nicht als spezifischer Werktitel angesehen.

Titel: $\quad \neg$ Das $\neg$ Reiterrelief Giustiniani in Berlin / Wolf-Dieter Heilmeyer. - 1996.

$S W W \quad$ Berlin / Staatliche Museen / Antikensammlung ; Römisches Reich ; Grabrelief ; Reiter $<$ Motiv $>$ (456123) (564123) (654123)

Im Gegensatz dazu gelten bei Bauwerken (außer Grabbauwerken) Wortfolgen und Komposita aus Gattungsbezeichnungen und Personennamen als spezifische Werktitel und es wird nicht zerlegt.

SW Rom / Tempel des Vespasian

Zur Ansetzung von Bauwerken und Monumentalplastiken, bei denen der Namensgeber nicht dargestellt ist, vgl. Praxisregel zu § 725,5 (Abs. 8).

\section{$\S 726$ siehe $\$ 724$}

\section{§ 727 Nicht ortsgebundene Kunstwerke}

Nicht ortsgebundene Kunstwerke umfassen Werke der Malerei (einschließlich Wand- und Deckenmalerei, Mosaiken, vgl. § 728), der Graphik, der Plastik (ausgenommen Bauplastik und Monumentalplastik, vgl. § 730) und des Kunsthandwerks sowie neue Formen der bildenden Kunst wie Installationen, Environments usw.

1. Künstlername / Spezifischer Werktitel

Ist der Urheber bekannt, so wird das Werk als mehrgliedriges Schlagwort in Verbindung mit dem Personenschlagwort angesetzt (vgl. § 101a,2). Als einzelner Urheber gilt auch ein Künstler, der den Hauptteil oder den künstlerisch wichtigsten Teil eines Werkes geschaffen hat. Sind mehrere Künstler gleichzeitig beteiligt, so gelten bis zu drei als Urheber eines Werkes. Der Werktitel wird nur dann als Synonym erfasst, wenn Zweifel über die Verfasserschaft bestehen oder das Werk häufig ohne den Namen des Urhebers genannt wird.

Die Werktitel erhalten in der SWD den Indikator t.

$\begin{array}{ll}S W & \text { Leonardo }<\text { da Vinci }>\text { / Mona Lisa } \\ S W & \text { Eyck, Hubert } \neg \text { van } \neg / \text { Genter Altar } \\ B F & \text { Genter Altar } \\ S W & \text { Eyck, Jan } \neg \text { van } \neg / \text { Genter Altar } \\ B F & \text { Genter Altar } \\ S W & \text { Agasias }<\text { Sohn des Dositheos }>\text { / Borghesischer Fechter } \\ B F & \text { Borghesischer Fechter } \\ S W & \text { Meister des Bartholomäusaltars / Bartholomäusaltar } \\ B F & \text { Bartholomäusaltar / München / Alte Pinakothek }\end{array}$

Wenn eine Unterscheidung mehrerer gleichnamiger spezifischer Werktitel eines Künstlers erforderlich ist, wird die Form 'Künstlername / Werktitel' mit dem Aufbewahrungsort bzw. der aufbewahrenden Körperschaft verknüpft. Für Listenfunktionen kann permutiert werden. 


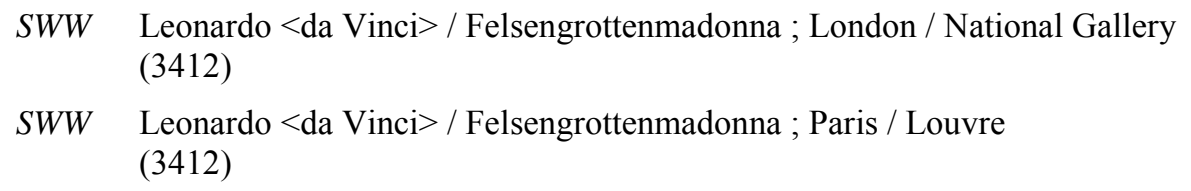

2. Künstlername / Unspezifischer Werktitel (Gattung) und mehrere gleichnamige Werke

Wenn das Werk eines Künstlers keinen spezifischen Werktitel hat, wird der Künstlername mit der Gattungsbezeichnung, bei mehrfach vorkommenden gleichnamigen Werken auch mit dem Aufbewahrungsort bzw. der aufbewahrenden Körperschaft verknüpft. Für Listenfunktionen kann permutiert werden.

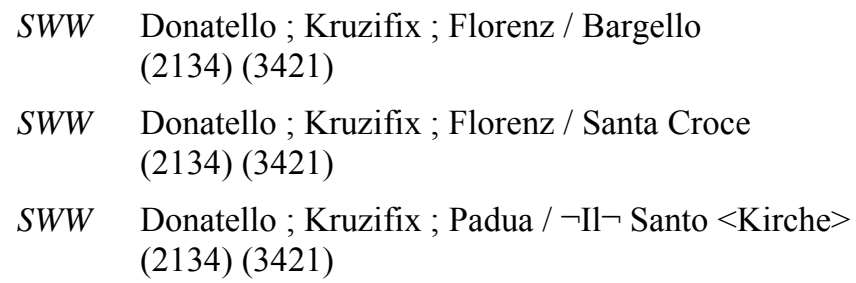

3. Anonymer spezifischer Werktitel

Ist ein Urheber nicht bekannt oder sind mehr als drei Künstler an einem Werk beteiligt, so wird das Werk unter seinem individuellen Namen entsprechend der „Liste der Nachschlagewerke" (vgl. § 9,3) angesetzt. Der Aufbewahrungsort und/oder Herkunftsort kann als Synonym in Verbindung mit dem Werktitel erfasst werden.

Die anonymen Werktitel erhalten in der SWD den Indikator t.

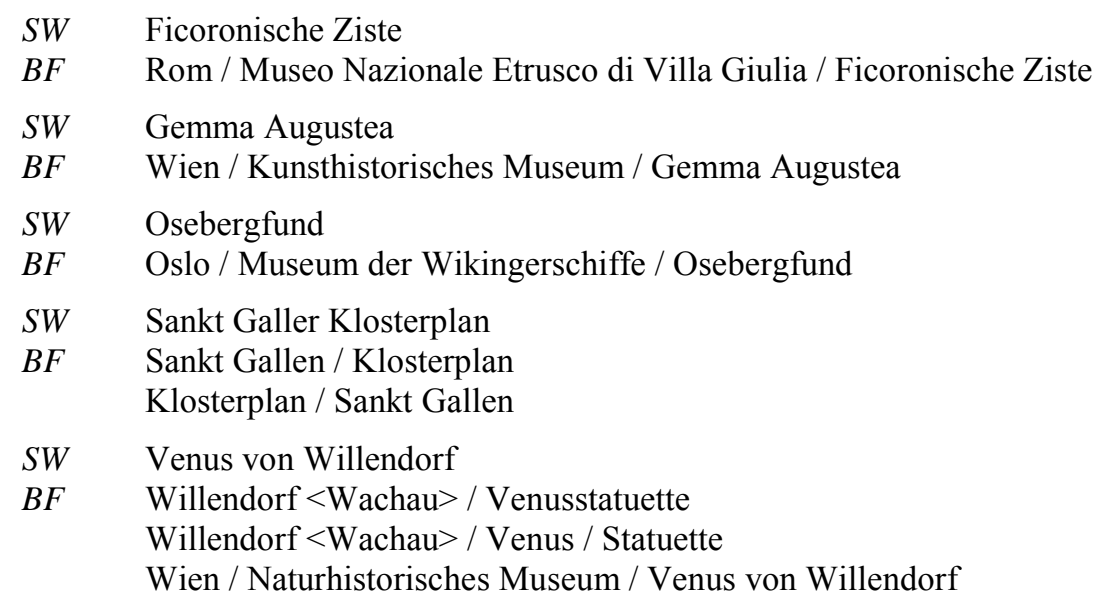

4. Anonymer unspezifischer Werktitel

Wenn bei einem anonymen Werk kein spezifischer Werktitel vorliegt, so wird je nach Gebräuchlichkeit eine Schlagwortkette aus dem Aufbewahrungs- oder Herkunftsort und dem entsprechenden Sachschlagwort gebildet. Der derzeitige Ort und eventuell die früheren Aufbewahrungsorte können in Verbindung mit dem zutreffenden Sachschlagwort als Synonyme erfasst werden. In diesen Fällen wird die Schlagwortkette als eigener Datensatz mit entsprechendem Hinweissatz in die SWD aufgenommen. Für Listenfunktionen kann permutiert werden.

SWW Minden $<$ Westfalen $>/$ Dom; Retabel

Hinweissatz, gekennzeichnet in MAB Feld 067

$B F \quad$ Berlin / Staatliche Museen / Skulpturensammlung / Retabel / Minden $<$ Westfalen $>$ / Dom 


\section{$\S 728$ Ansetzung von Werken der Wand- und Deckenmalerei, Mosa- iken u. a. beweglichen Ausstattungsgegenständen von Bauwerken}

Bei Wand- und Deckenmalerei, Mosaiken u. a. beweglichen Ausstattungsgegenständen von Bauwerken wird nach $\S 727$ verfahren.

a) Bei individuellen Werktiteln wird jedoch der Aufstellungs- bzw. Aufbewahrungsort in Verbindung mit dem Werktitel als Synonym erfasst.

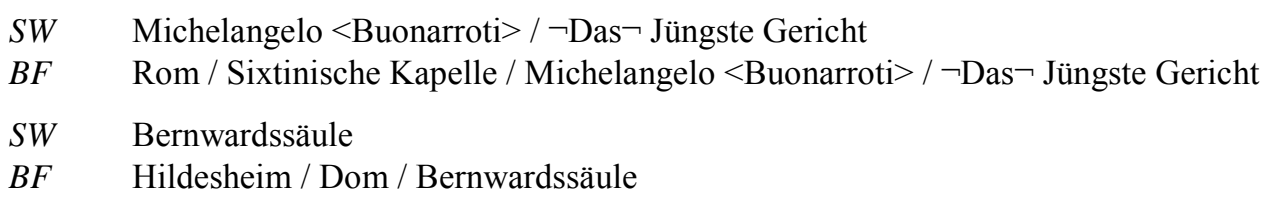

b) Bei unspezifischen Werktiteln werden Künstlername, Werkgattung und Aufstellungs- oder Aufbewahrungsort miteinander verknüpft (vgl. § 727,2). Für Listenfunktionen kann permutiert werden.

SWW Tiepolo, Giovanni Battista ; Freskomalerei ; Würzburg / Residenz (2134) (3421)

SWW Syrlin, Jörg < der Ältere> ; Chorgestühl ; Ulm / Münster (2134) (3421)

c) Bei anonymen Werken ohne spezifischen Werktitel werden ebenfalls Schlagwortketten gebildet. Für Listenfunktionen kann permutiert werden.

Titel: $\quad \neg \mathrm{Die} \neg$ silberne Taufschale zu Siegen : ein Werk aus der spanischen Kolonialzeit Perus / Friedrich Muthmann. - 1956

SWW Siegen / Nikolaikirche ; Taufschüssel (312)

SWW Comburg / Stiftskirche ; Radleuchter (312)

SWW Monreale / Dom ; Mosaik (312)

\section{§ 729 Kunsthandwerkliche Produkte von Firmen vgl. § 306a,4}

\section{§ 730 Ortsgebundene Kunstwerke (ausgenommen Kirchenbauten)}

1. Ortsgebundene Kunstwerke umfassen Werke der Architektur (einschließlich Bauplastik), Ingenieurbauten, bauliche Ensembles, archäologische Stätten mit Baudenkmälern und freistehende Objekte (Monumentalplastik, Denkmäler, Brunnen usw.). Sie erhalten in der SWD den Indikator g. Zur Ansetzung der Kunstwerke mit dem Ort bzw. mit dem Ortsteil vgl. $\S 209,5$. Folgende Fälle werden unterschieden:

a) Mehrgliedriges Schlagwort aus Ort / Individualname (spezifischer Werktitel)

Ortsgebundene Kunstwerke werden als mehrgliedriges Schlagwort mit dem Ort als erstem Glied und dem spezifischen Werktitel angesetzt, auch wenn sie das Werk von ein bis drei Künstlern sind (vgl. § 727,1). Künstler in Verbindung mit Ort und dem spezifischen Werktitel als weiteren Gliedern sowie - mit Ausnahme von Architekten - in Verbindung mit dem spezifischen Werktitel als zweitem Glied werden als Synonyme erfasst. 
SW $\quad$ Nürnberg $/ \neg$ Das $\neg$ Narrenschiff

BF $\quad$ Weber, Jürgen $<$ Künstler $>$ / Nürnberg / $\neg$ Das $\neg$ Narrenschiff

Weber, Jürgen $<$ Künstler $>/ \neg$ Das $\neg$ Narrenschiff

Monumentalplastik

SW Berlin / Reichstagsgebäude

BF Wallot, Paul / Berlin / Reichstagsgebäude

Der spezifische Werktitel wird nur dann als Synonym erfasst, wenn er einen Sucheinstieg in den allgemeinen Nachschlagewerken bildet; der Ort wird in diesem Fall als zweiter Teil in die Verweisung aufgenommen.

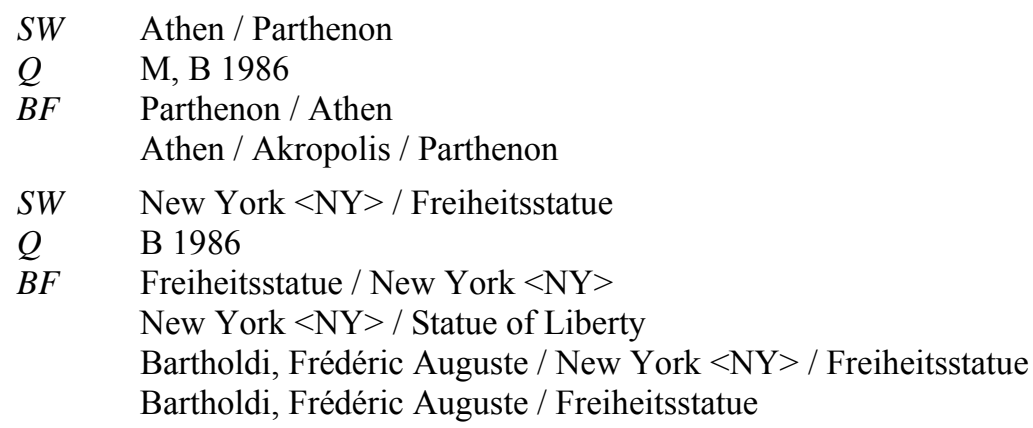

b) Mehrgliedriges Schlagwort aus bzw. Verknüpfung mit Ort und Sachschlagwort (unspezifischer Werktitel)

Stimmt die Bezeichnung eines ortsgebundenen Kunstwerks mit einem Sachschlagwort überein, so wird nur bei folgenden Baugattungen, die besonders oft als historische Bauwerke behandelt werden, ein mehrgliedriges Schlagwort angesetzt:

- Kirchen- und Sakralbauten aller Art (zu Kirchenbauten vgl. §731, daneben z. B. 'Moschee', 'Tempel', 'Synagoge'),

- Adelshäuser: 'Burg', 'Palast', 'Residenz', 'Schloss' und ihre Unterbegriffe (z. B. 'Wasserburg', 'Jagdschloss'). Floskeln wie 'Ehemalig fürstbischöflich' u. ä. werden bei der Ansetzung i. d. R. nicht berücksichtigt, können aber als Synonym erfasst werden.

- 'Rathaus' als häufigster Funktionsbau der bürgerlichen Stadt,

- 'Hafen',

- 'Theater' für Theaterbauten des Altertums

SW Würzburg / Residenz

$B F \quad$ Würzburg / Ehemalige fürstbischöfliche Residenz

SW Berlin-Charlottenburg / Schloss

BF Berlin / Charlottenburger Schloss

$S W \quad$ Düsseldorf / Hafen

SW Aigeira / Theater

Aber:

SW Flughafen München-Riem

vgl. „Praxisregel“ zu § 209,6

Namen von Straßen und Plätzen innerhalb eines Ortes werden immer als mehrgliedriges Schlagwort angesetzt, wenn es sich um individuelle amtliche Straßenbezeichnungen handelt, selbst wenn das zweite Glied unspezifisch ist. (Zur Ansetzung oder Verknüpfung mit dem Hauptort bzw. Ortsteil vgl. § 209,5.)

\section{SW Würzburg / Marktplatz}


In allen anderen Fällen wird verknüpft, wenn es keinen spezifischen Namen gibt. Das gilt z. B. für Befestigungsanlagen (Stadtmauer, Festung, Kastell, Zitadelle, Burgruine usw.) und häufig mit unspezifischer Bezeichnung wiederkehrende Anlagen wie Bahnhof, Friedhof, Jüdischer Friedhof, Ghetto, Judenviertel, Stadtpark, Kurpark, Schlosspark, Industriepark, Stadthalle, Stadion und sonstige kleinräumige Geographika.

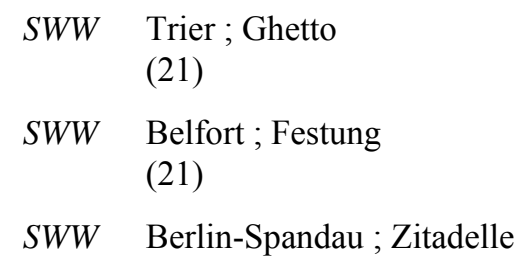

Bezeichnungen für Baugattungen, die nicht als Sachschlagwort angesetzt, sondern auf ein Schlagwort als Synonym verwiesen sind, gelten in Verbindung mit Ortsnamen i. d. R. als Individualnamen und werden daher als mehrgliedriges Schlagwort nach $\S 730,1$,a angesetzt.

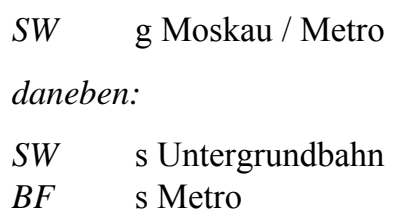

Als Individualname gilt unabhängig von vorhandenen Sachschlagwörtern auch eine Zusammensetzung mit Himmelsrichtungen, mit 'Zentral-' bzw. 'Haupt-', soweit es sich um Bauwerke handelt und nicht um Teile wie z. B. 'Westfassade'.

SW g Basel / Hauptbahnhof

c) Bauwerke ortsgebundener Körperschaften ohne Individualnamen

Bei Bauwerken ortsgebundener Körperschaften wird die mehrgliedrige Ansetzungsform für die Körperschaft mit dem zutreffenden Sachschlagwort für die Baugattung verknüpft. Ist der Name des Architekten bekannt, wird die Schlagwortkette als Hinweissatz in die SWD aufgenommen. Der Name des Architekten in Verbindung mit dem Bauwerk wird als Synonym erfasst.

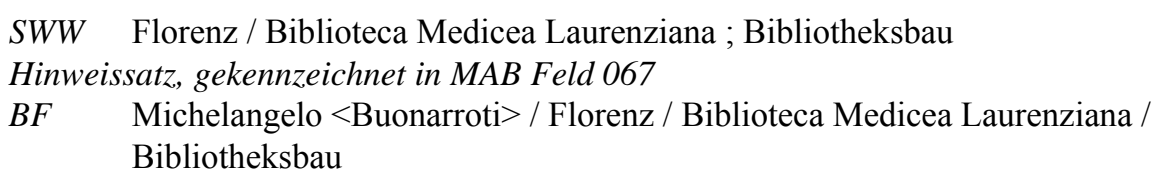

d) Bauwerke ortsgebundener Körperschaften mit Individualnamen

Wird das Bauwerk einer ortsgebundenen Körperschaft mit einem vom Körperschaftsnamen abweichenden Individualnamen angesetzt, so werden die Körperschaftsansetzung mit dem Individualnamen als zweitem Teil , sowie die Körperschaft mit dem zutreffenden Sachschlagwort als Synonym erfasst.

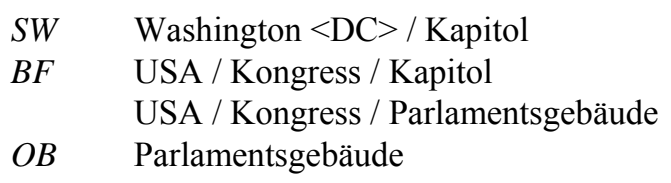


Die Baugattung wird im Fall der Ansetzungsform mit Individualnamen als Oberbegriff erfasst.

e) Bauwerke nicht ortsgebundener Körperschaften ohne Individualnamen

Bei Bauwerken nicht ortsgebundener Körperschaften wird die Ansetzungsform für die Körperschaft mit dem zutreffenden Sachschlagwort für die Baugattung verknüpft. Die Schlagwortkette wird als Hinweissatz in die SWD aufgenommen. Der Name des Ortes, in dem sich das Bauwerk befindet, wird in Verbindung mit dem Bauwerk als zweitem Teil als Synonym erfasst. Darüber hinaus wird ggf. der Name des Architekten in Verbindung mit dem Bauwerk als Synonym erfasst.

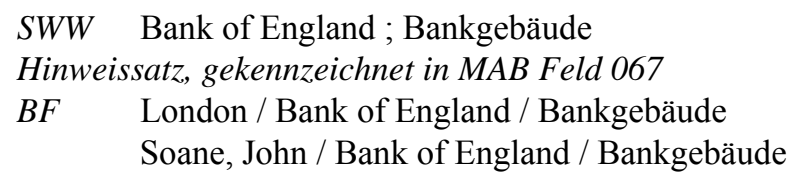

f) Bauwerke nicht ortsgebundener Körperschaften mit Individualnamen

Wird das Bauwerk einer nicht ortsgebundenen Körperschaft mit einem vom Körperschaftsnamen abweichenden Individualnamen mit dem Ort angesetzt, so wird die Körperschaftsansetzung mit dem Individualnamen als zweitem Teil als Synonym erfasst.

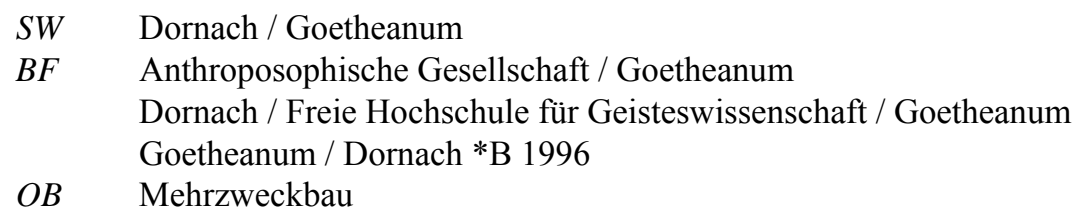

Die Baugattung wird im Fall der Ansetzungsform mit Individualnamen als Oberbegriff erfasst.

Anm.: Hat eine Körperschaft Bauwerke an verschiedenen Orten, so werden sie ggf. entsprechend deren Nachweis in den Nachschlagewerken unterschieden.

2. Kunstwerke außerhalb eines Ortes

Kunstwerke außerhalb eines Ortes werden mit ihrem Individualnamen angesetzt, wenn dieser als Sucheinstieg in den maßgeblichen Nachschlagewerken nachweisbar ist. Das gilt auch, wenn es zweifelhaft ist, ob das Kunstwerk zu einem benachbarten Ort gehört oder wenn der Name des Kunstwerks allein bekannter ist als eine möglicherweise zugehörige kleine Siedlung. Der Name einer benachbarten oder zugehörigen Siedlung mit dem Namen des Kunstwerks als zweitem Teil kann als Synonym erfasst werden.

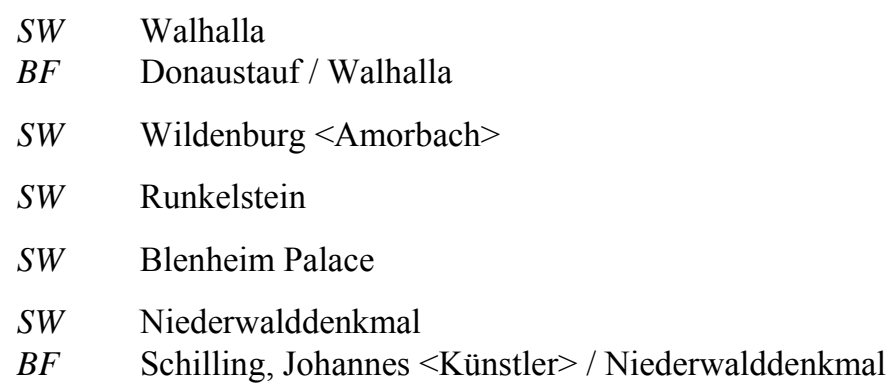

Zur Ansetzung von Kirchen außerhalb eines Ortes vgl. § 731.

$\mathrm{Zu}$ den Ingenieurbauten wie Tunneln, Brücken, Kanälen und anderen Verkehrs- und Versorgungswegen außerhalb eines Ortes vgl. § 210,4. 
3. Bezeichnungen für Teile eines Bauwerks und für Bauplastik werden mit der Bezeichnung des ortsgebundenen Kunstwerks verknüpft, soweit es sich nicht um Individualnamen handelt. Für Listenfunktion kann permutiert werden.

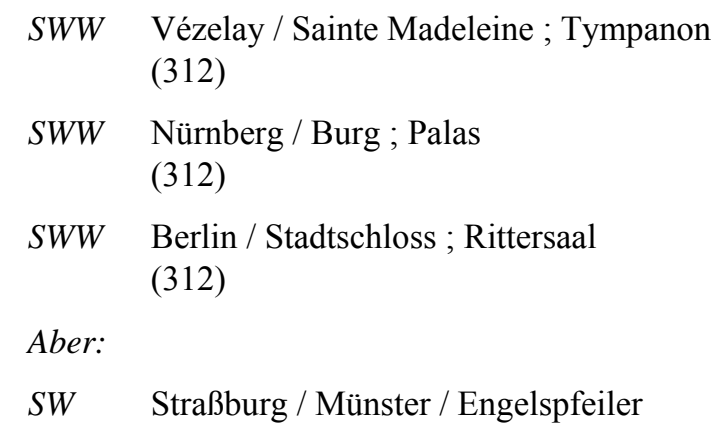

Zu Einzelheiten bezüglich der Ansetzung von Bauwerken vgl. die „Praxisregeln“ zu §§ 730; 730,$1 ; 730,3$.

\section{§ 731 Kirchenbauten}

Kirchenbauten werden als mehrgliedriges Schlagwort mit dem Ort gemäß § 730,1 als erstem und dem Individualnamen bzw. der Funktionsbezeichnung als zweitem Glied angesetzt.

1. I. d. R. erfolgt die Ansetzung in der Form Ort / Patrozinium.
SW München / Sankt Johann Nepomuk
SW Rom / San Giovanni in Laterano

2. Gibt es jedoch kein Patrozinium, sondern einen anderen Individualnamen oder ist ein anderer Individualname nach den Nachschlagewerken weitaus gebräuchlicher als das Patrozinium, so wird dieser angesetzt.

$\begin{array}{ll}S W & \text { Wiesbaden / Lutherkirche } \\ S W & \text { Wolgast / Petrikirche } \\ B F & \text { Wolgast / Sankt Petri } \\ S W & \text { Saloniki / Acheiropoietos-Basilika } \\ \text { BF } & \text { Saloniki / Hagia Paraskeuē }\end{array}$

3. Als weitaus gebräuchlicher werden auch die Funktionsbezeichnungen 'Dom', 'Kathedrale', 'Klosterkirche', 'Stiftskirche', 'Wallfahrtskirche' angesehen, sofern die Nachschlagewerke deren Gebräuchlichkeit belegen. Das Patrozinium wird als Synonym erfasst.

$\begin{array}{ll}\text { SW } & \text { Augsburg / Dom } \\ \text { Q } & \text { B 1986 } \\ \text { BF } & \text { Augsburg / Sankt Maria } \\ & \text { Augburg / Mariae Heimsuchung } \\ \text { SW } & \text { Gernrode }<\text { Quedlinburg }>\text { / Stiftskirche } \\ \text { Q } & \text { B 1986 } \\ \text { BF } & \text { Gernrode < Quedlinburg }>\text { / Sankt Cyriakus } \\ \text { SW } & \text { Maria Plain / Wallfahrtskirche } \\ \text { Q } & \text { B 1986, Reclam } \\ \text { BF } & \text { Maria Plain / Maria Himmelfahrt }\end{array}$


4. Andere Funktionsbezeichnungen (z.B. 'Pfarrkirche', 'Filialkirche', 'Kapelle') werden nur angesetzt, wenn weder ein Patrozinium noch ein anderer Individualname zu ermitteln ist.

SW Wintringen / Kapelle

5. Abweichende Namensformen werden als Synonyme erfasst. Ist der Architekt eines Kirchenbaus zu ermitteln, so wird von ihm verwiesen.

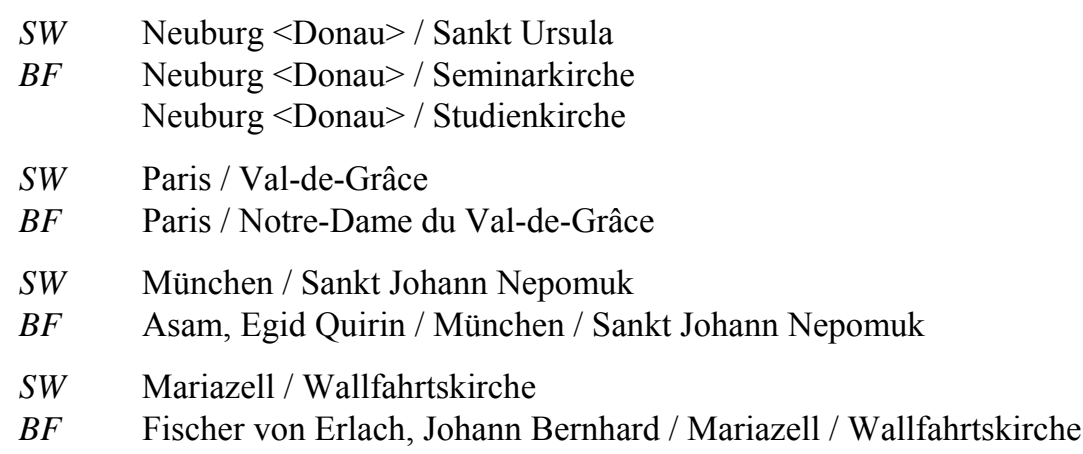

6. Kirchenbauten außerhalb eines Ortes werden abweichend von $\S 730,2$ mit dem Namen des nächst gelegenen Ortes analog zu $§ 731,1-5$ angesetzt. Der Individualname wird als Synonym erfasst.
SW Volkach / Sankt Maria im Weingarten
BF Sankt Maria im Weingarten
SW Wurmlingen $<$ Rottenburg, Neckar $>$ / Kapelle
BF Wurmlinger Kapelle

Zur Ansetzung von Kirchenbauten mit dem Ortsteil oder Hauptort vgl. § 209,5. Zur Ansetzung der katholischen und evangelischen Kirchengemeinden in Analogie bzw. im Unterschied zum zugehörigen Kirchenbau vgl. § 618,2.

\section{$\S 732$ entfällt}

\section{Filme, Hörfunk- und Fernsehsendungen}

Soweit möglich, wird der Inhalt von Filmen, Hörfunk- und Fernsehsendungen nach den Grundregeln erschlossen (vgl. § 8,4). Neben Schlagwörtern für den begrifflichen Inhalt eines Filmes, einer Hörfunk- oder Fernsehsendung (vgl. auch § 737,3) ist auch eine Erschließung mit Schlagwörtern für Form oder Gattung des Dokuments möglich (vgl. § 5,5).

\section{§ 733 Dokumente zu einem Film, einer Hörfunk- oder Fernsehsendung}

1. Filme, Hörfunk- oder Fernsehsendungen werden mit ihrem Einheitssachtitel (Originaltitel) angesetzt und erhalten den Indikator t. Wenn der Einheitssachtitel in der Vorlage nicht genannt ist und nur mit großem Aufwand ermittelt werden kann, wird mit dem vorliegenden Titel angesetzt.

$$
\begin{array}{ll}
S W & \neg \text { Die } \neg \text { bleierne Zeit } \\
S W & \text { Rund um die Berolina } \\
\text { SW } & \text { Einer wird gewinnen }
\end{array}
$$


Ist die Ansetzungsform ein fremdsprachiger Titel, wird der deutsche Filmtitel als Synonym erfasst, soweit eine deutsche Fassung vorliegt. Dies gilt auch für die deutschen Titel fremdsprachiger Hörfunk- und Fernsehsendungen, die im deutschsprachigen Raum übernommen wurden.
SW Scener ur ett äktenskap
BF Szenen einer Ehe
SW Married with children
$B F \quad \neg$ Eine $\urcorner$ schrecklich nette Familie

Ist der Titel gleichlautend mit einem anderen Begriff aus dem Deutschen, Englischen, Französischen oder Italienischen, so erhält er den Homonymenzusatz $<$ Film $>$, $<$ Hörfunksendung $>$ oder $<$ Fernsehsendung $>$.

$$
\begin{array}{ll}
S W & \neg \text { Das } \neg \text { Boot }<\text { Film }> \\
S W & \text { Radio-Essay }<\text { Hörfunksendung }> \\
S W & \text { Monitor }<\text { Fernsehsendung }>
\end{array}
$$

Gleichnamige Titel werden durch Hinzufügen des Erstaufführungsjahres unterschieden.

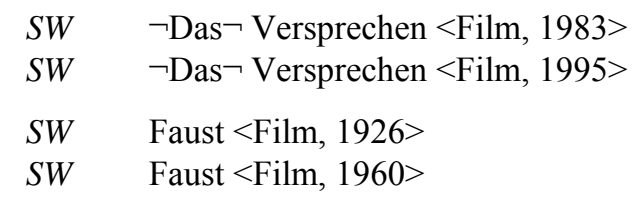

Für die Ansetzung von Filmtiteln sind die in der „Liste der Nachschlagewerke“ (vgl. § 9,3) genannten Werke heranzuziehen.

2. Bibliotheken, die RAK-ÖB-A anwenden, können bei Filmen sowie Hörfunk- und Fernsehsendungen einen im Deutschen gebräuchlichen Sachtitel als Einheitssachtitel verwenden. Dafür wird in der SWD eine ÖB-Alternativform angesetzt (vgl. § 709,3).

$\begin{array}{ll}S W & \text { Gone with the wind } \\ O ̈ B & \text { Vom Winde verweht } \\ S W & \text { NYPD blue } \\ \ddot{O B} & \text { New York cops }\end{array}$

3. Der Regisseur eines Films wird, gefolgt vom Filmtitel, als Synonym erfasst.

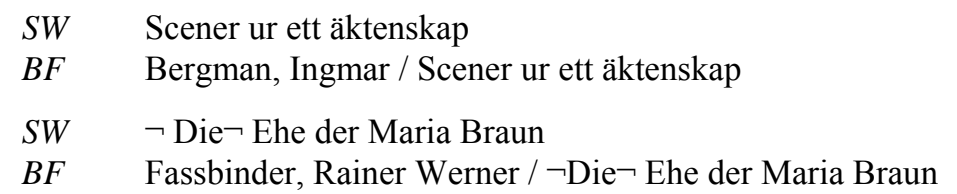

Werden in einem Dokument weitere an einem Film beteiligte Personen behandelt (z.B. Schauspieler, Drehbuchautoren oder Kameraleute), so wird deren Name mit dem Filmtitel verknüpft.

SW $\quad$ Schygulla, Hanna ; $\neg \mathrm{Die} \neg$ Ehe der Maria Braun

(21)

4. Autoren literarischer Vorlagen von Filmen oder Hörfunk- und Fernsehsendungen und Komponisten verfilmter musikalischer Werke können mit dem Sachtitel des literarischen oder musikalischen Werks und dem weiteren Schlagwort 'Film' bzw. 'Fernsehsendung' oder 
'Hörfunksendung' (falls nicht eindeutig, mit 'Geschichte' und Jahr der Erstaufführung) als Synonym erfasst werden.

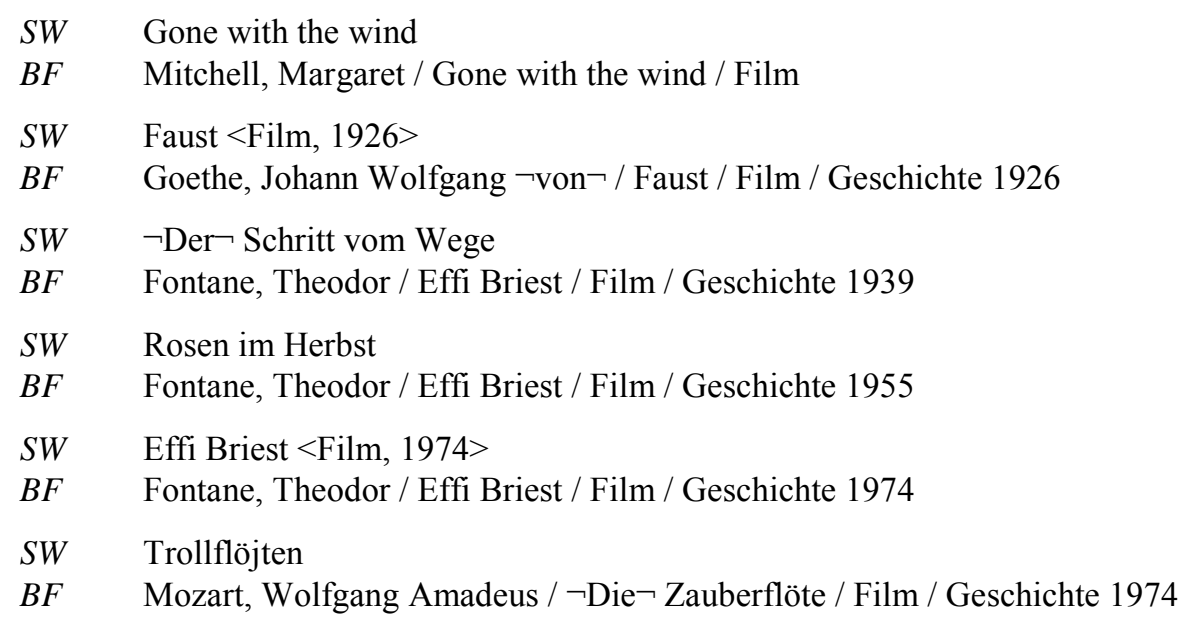

5. Bei Dokumentarfilmen sowie dokumentarischen Hörfunk- und Fernsehsendungen wird das Thema als mehrgliedriger Oberbegriff erfasst.

$\begin{array}{ll}S W & \text { Fremdsein in Deutschland } \\ M O & \text { Deutschland ; Fremdenfeindlichkeit ; Film } \\ & \text { Fremdenfeindlichkeit ; Film ; Deutschland } \\ & \text { Film ; Fremdenfeindlichkeit ; Deutschland } \\ & \\ S W & \neg \text { The }\urcorner \text { riddle of the Dead Sea scrolls } \\ M O & \text { Qumrantexte ; Fernsehsendung }\end{array}$

Bei Spielfilmen und Fernsehspielfilmen mit ausgeprägt historischem oder sachlichem Bezug wird ebenfalls ein mehrgliedriger Oberbegriff erfasst.

\begin{tabular}{|c|c|}
\hline 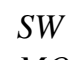 & Gone with the wind \\
\hline$M O$ & Sezessionskrieg $<1861-1865>$; Film \\
\hline $\begin{array}{l}S W \\
M O\end{array}$ & $\begin{array}{l}\neg \text { Das } \neg \text { Versprechen }<\text { Film, 1983> } \\
\text { Sexualdelikt ; Kind ; Film } \\
\text { Kind ; Sexualdelikt ; Film }\end{array}$ \\
\hline$s W$ & $\begin{array}{l}\text { Holocaust }<\text { Fernsehsendung }> \\
\text { Judenvernichtung ; Fernsehsendung }\end{array}$ \\
\hline
\end{tabular}

\section{$\S 734$ Dokumente zu mehreren Filmen, Hörfunk- oder Fernsehsendun- gen}

1. Sind in einem Dokument mehrere Filme, Hörfunk- oder Fernsehsendungen einer beteiligten Person behandelt, so wird der Personenname mit dem Schlagwort 'Film', 'Hörfunksendung' oder 'Fernsehsendung' verknüpft. Unter 'Film' wird für Listenfunktionen keine Eintragung gemacht.

$$
\begin{array}{ll}
S W W & \text { Schlöndorff, Volker; Film } \\
S W W & \text { Rühmann, Heinz; Film } \\
S W W & \text { Kuhlenkampff, Hans-Joachim ; Fernsehsendung }
\end{array}
$$


2. Sind in einem Dokument mehrere Film-, Hörfunk- oder Fernsehfassungen zu einem literarichen oder musikalischen Werk behandelt, so werden der Name des Autors oder des Komonisten in Verbindung mit dem Werktitel mit dem Schlagwort 'Film', 'Hörfunksendung' oder 'Fernsehsendung' verknüpft. Unter 'Film' wird für Listenfunktionen keine Eintragung gemacht.

\section{SWW Mann, Heinrich / Professor Unrat ; Film \\ SWW Shaw, George Bernard / Pygmalion ; Fernsehsendung}

3. Sind in einem Dokument mehrere Filme, Hörfunk- oder Fernsehsendungen nach mehreren Werken eines Autors behandelt, so werden der Name des Autors und die literarische oder musikalische Gattungsbezeichnung mit dem Schlagwort 'Film', 'Hörfunksendung' oder 'Fernsehsendung' verknüpft. Unter 'Film' wird für Listenfunktionen keine Eintragung geacht.

$$
\begin{array}{ll}
S W W & \text { Fontane, Theodor ; Roman ; Film } \\
\text { SWW } & \text { Mozart, Wolfgang Amadeus ; Oper ; Fernsehsendung }
\end{array}
$$

4. Werden in einem Dokument mehrere Filme, Hörfunk- oder Fernsehsendungen zu einem Gegenstand untersucht, so wird der behandelte Gegenstand mit dem Schlagwort 'Film', 'Hörfunksendung' oder 'Fernsehsendung' verknüpft. Für den Gegenstand wird der Zusatz $<$ Motiv> gemäß $§ 705$ beigefügt (vgl. aber $§ 705,8$ ).

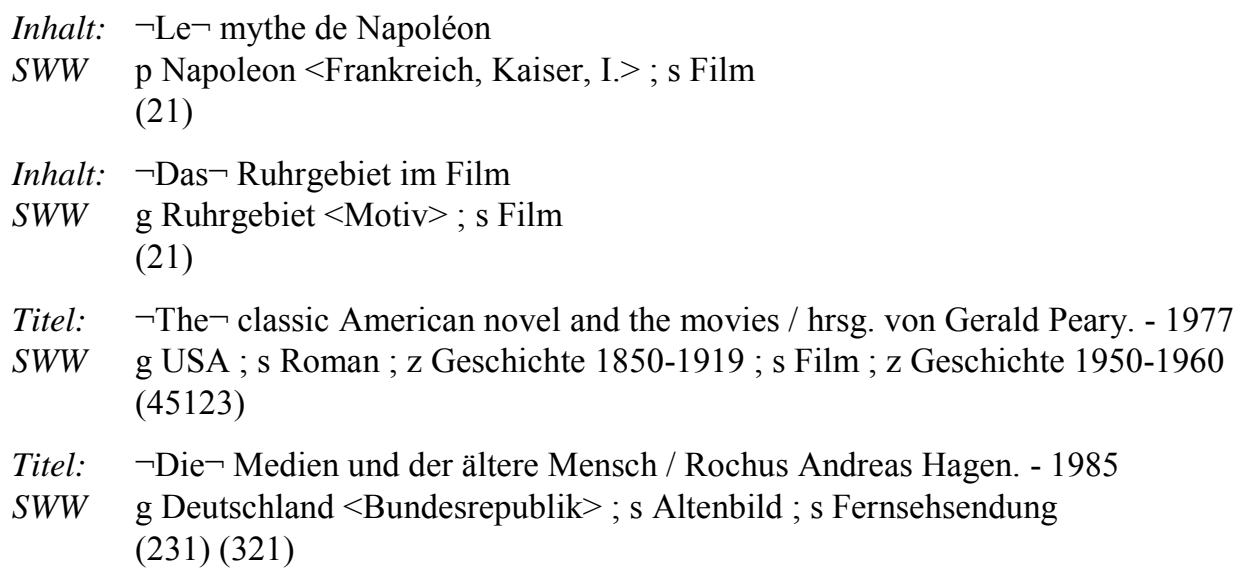

\section{Ausstellungen}

\section{$\S 735$ Ausstellungen}

1. Ausstellungen sind Veranstaltungen, auf denen religiöse, künstlerische, technische, kulturistorische, wirtschaftliche und andere Objekte und Dokumente für eine bestimmte Zeit zuammengestellt und gezeigt werden. Sie behandeln i. d. R. ein bestimmtes Thema und bieten dazu umfassendes Anschauungsmaterial. Bei Primärliteratur zu Ausstellungen - im Wesentlichen Ausstellungskataloge - werden die Schlagwörter in der folgenden Form verknüpft:

Thema ; 'Ausstellung' ; Ort $<$ Jahr $>$

Für Listenfunktionen kann permutiert werden (vgl. auch § 504,3). 
Titel: $\quad \neg$ Die $\neg$ Bibel im Mittelalter und in der frühen Neuzeit : Kasseler Handschriften und alte Drucke ; Katalog zur Ausstellung. - 1993

SWW Bibel ; Handschrift ; Geschichte 700-1556 ; Ausstellung ; Kassel <1993>

SWW Bibelausgabe ; Geschichte 1454-1711; Ausstellung ; Kassel <1993>

Titel: $\quad$ Kunst aus Argentinien : Argentina 1920-1994. - 1995

SWW Argentinien ; Kunst ; Geschichte 1920-1994 ; Ausstellung ; Stuttgart <1995>

Anm.: Für Sekundärliteratur zu einzelnen Ausstellungen (Aufbau, Geschichte u. ä.) wird die Ausstellung als Körperschaft angesetzt (vgl. § 607).

2. Die ausstellende Institution wird nur berücksichtigt, wenn sie selbst Gegenstand der Ausstellung ist bzw. wenn ein wesentlicher Bezug zwischen Ausstellungsthema und ausstellender Institution besteht.

Titel: $\quad$ Erwerbungen aus drei Jahrzehnten 1948-1978 : abendländische und orientalische Handschriften, Inkunabeln und seltene Drucke, Noten und Landkarten ; Ausstellung April - Juni 1978 / Bayerische Staatsbibliothek. - 1978

SWW München / Bayerische Staatsbibliothek ; Neuerwerbung ; Geschichte 1948-1978 ; Ausstellung; München $<1978>$

Titel: Deutsche Handzeichnungen der Romantik aus der Albertina in Wien : Ausstellung in der Kunsthalle Hamburg 1982. - 1982

SWW Wien / Graphische Sammlung Albertina ; Deutschland ; Zeichnung ; Geschichte 1780-1840 : Ausstellung; Hamburg $<1982>$ (3451267) (4351267)

SWW Romantik ; Zeichnung ; Deutschland ; Wien / Graphische Sammlung Albertina ; Ausstellung ; Hamburg <1982>

Titel: Harmonie als Fragment : Antike im Spiegel der Magdeburger Skulpturensammlung. 1996

SWW Magdeburg / Kulturhistorisches Museum ; Griechenland <Altertum > ; Plastik ; Gipsabguss ; Ausstellung ; Magdeburg <1996> (3451267) (4531267) (5431267)

3. Finden Ausstellungen an mehreren Orten statt, so wird nur ein Ort (der hervorgehobene bzw. erstgenannte) berücksichtigt.

Titel: Stilleben in Europa : Westfälisches Landesmuseum für Kunst und Kulturgeschichte Münster, 25.11.1979 - 24.2.1980, Staatliche Kunsthalle Baden-Baden, 15. 3.- 15. 6. 1980. - 1979

SWW Stillleben; Ausstellung ; Münster $<$ Westfalen, 1979>

4. Erstreckt sich der Ausstellungszeitraum über den 31. Dezember, so wird nur das Jahr des Ausstellungsbeginns angegeben.

Titel: Zwei Jahrhunderte englische Malerei : britische Kunst und Europa, 1680-1880 ; Ausstellung Haus der Kunst München, 21. November 1979 - 27. Januar 1980. - 1980

SWW Großbritannien; Malerei ; Geschichte 1680-1880 ; Ausstellung ; München <1979> (21345) 


\section{Sammlungen}

\section{§ 736 Sammlungen}

1. Sammlungen sind Gesamtheiten gesammelter Gegenstände, die von Personen, Familien oder Körperschaften (Archiven, Bibliotheken, Dokumentationsstellen, Museen usw.) aufgebaut werden, sich in deren Besitz befinden oder als Leihgabe, Stiftung, Geschenk oder durch Kauf einer anderen Institution eingegliedert sind. Sammelgegenstand können alle Arten von Gegenständen wie Autographen, Briefmarken, Handschriften, Kunstwerke, Münzen, Spielzeug usw. sein. Das Schlagwort 'Sammlung' wird für Listenfunktionen nicht permutiert.

Von Personen oder Familien stammende Sammlungen, deren Körperschaftscharakter nachweisbar ist, werden wie Körperschaften angesetzt. Der Name der Person bzw. der Familie mit dem für die Sammlung passenden Schlagwort (z. B. 'Bibliothek', 'Archiv') wird als Synonym erfasst.

$S W \quad$ Donaueschingen / Fürstlich-Fürstenbergische Sammlungen

$B F \quad$ Fürstenberg $<$ Familie; Schwaben $>$ / Kunstsammlung

Bekommen Sammlungen, die von Personen oder Familien stammen, nachträglich einen körperschaftlichen Charakter, ist bei der Körperschaft eine Synonymie-Verweisung mit Zeitangabe (Person / Sammlung / Geschichte Jahreszahl-) anzubringen.

$S W \quad$ Riehen $<$ Basel $>$ / Fondation Beyeler

$B F \quad$ Beyeler, Ernst / Sammlung / Geschichte 1997-

BF Beyeler, Hildy / Sammlung / Geschichte 1997-

2. Bei Sammlungen einer Person werden folgende Grundketten gebildet:

1.Grundkette: Name des Sammlers ; 'Sammlung'

2.Grundkette: Sammelgegenstand ; 'Sammlung'

Titel: $\quad$ Uhren der Hellmut-Kienzle-Sammlung / Richard Mühe. - 1982

$S W W \quad$ Kienzle, Hellmut ; Sammlung ; Ausstellung ; Villingen-Schwenningen $<1982>$

$S W W \quad$ Uhr ; Sammlung ; Ausstellung ; Villingen-Schwenningen <1982>

Titel: $\quad \neg$ The $\neg$ Baur Collection Geneva : Japanese lacquer / by Pierre-F. Schneeberger. - 1984

$S W W \quad$ Baur, Alfred ; Sammlung

$S W W \quad$ Japan ; Lackarbeit ; Sammlung

(213)

Titel: $\quad$ Sammlung Alice Boner ... : illustriertes Gesamtverzeichnis indischer Bilder. - 1994

$S W W \quad$ Boner, Alice; Sammlung; Katalog

$S W W \quad$ Indien; Buchmalerei ; Geschichte ; Sammlung ; Katalog

(21345)

3. Gibt es für eine Sammlung bis zu fünf Sammler bzw. Besitzer, so wird mit jedem Personennamen in Verknüpfung mit 'Sammlung' eine Schlagwortkette gebildet. Bei mehr als fünf Sammlern bzw. Besitzern wird nur der besonders hervorgehobene bzw. zuerst genannte berücksichtigt.

Titel: $\quad \neg$ Les $\neg$ dessins de la collection Armand-Valton / Emmanuelle Brugerolles. - 1984

SWW Armand, Alfred; Sammlung ; Katalog

$S W W \quad$ Valton, Prosper; Sammlung; Katalog

SWW Zeichnung; Geschichte 1500-1850 ; Sammlung; Katalog

4. Sind Dokumente über eine Person oder deren Werk Gegenstand einer Sammlung, so hat die Grundkette die Form

Gesammelte Person; 'Sammlung'; Sammler.

SWW Beuys, Joseph ; Sammlung ; Marx, Erich

(321) 
Bezieht sich eine Sammlung nur auf eine Gattung des Werkes eines Künstlers, so wird diese in der mit dem Namen des Künstlers gebildeten Grundkette berücksichtigt.

SWW Grieshaber, HAP ; Illustration ; Sammlung ; Hannsmann, Margarete (2134) (4312)

5. Bei Sammlungen einer Person, die in den Besitz von Körperschaften (Bibliothek, Museum usw.) übergegangen sind, werden Grundketten gemäß § 736,2 gebildet. Der Name der Körperschaft in Verbindung mit dem offiziellen Individualnamen der Sammlung wird als Synonym erfasst. Ist kein offizieller Name feststellbar, so wird sie in normierter Ansetzung (Name des Sammlers / Sammlung) in Verbindung mit der Körperschaft als Synonym erfasst. Hierzu wird die Schlagwortkette als eigener Datensatz mit entsprechendem Hinweissatz in die SWD aufgenommen.

Diese Regel gilt nicht nur, wenn es sich um einen Teilbestand einer Körperschaft handelt, sondern auch, wenn die Sammlung Grundbestand einer Körperschaft geworden ist. Für Listenfunktionen kann bei den Schlagwortketten zur Wiedergabe des Sammelgegenstandes permutiert werden.

Titel: $\quad \neg$ Das $\neg$ Evangelium in den Wohnungen der Völker : ökumenische und vergleichende Sammlung Weinhold ; Museum für Deutsche Volkskunde in Berlin. - 1979-1987

1.Grundkette:

SWW Weinhold, Gertrud; Sammlung

Hinweissatz, gekennzeichnet in MAB Feld 067

$B F \quad$ Berlin / Museum Europäischer Kulturen / Sammlung Weinhold

2.Grundkette:

SWW Religiöse Volkskunst ; Sammlung

Titel: Städels Sammlung im Städel : eine Ausstellung des Städelschen Kunstinstituts ... -

1991

1.Grundkette:

SWW Städel, Johann Friedrich ; Sammlung

Hinweissatz, gekennzeichnet in MAB Feld 067

$B F \quad$ Frankfurt $<$ Main $>$ / Städelsches Kunstinstitut / Sammlung Städel

2.Grundkette:

SWW Malerei ; Geschichte 1760-1815; Sammlung

Titel: Ansichten und Einsichten : Hans Grässels Fotosammlung zur Architekturgeschichte

1.Grundkette:

Münchens 1860-1945 / ... hrsg. von Richard Bauer. - 1994

SWW Grässel, Hans ; Sammlung

Hinweissatz, gekennzeichnet in MAB Feld 067

$B F \quad$ München / Stadtarchiv / Grässel, Hans / Sammlung

2.Grundkette:

SWW München; Architekturphotographie ; Geschichte 1860-1945 ; Sammlung (2134)

Einzelne Gegenstände, z. B. Handschriften und Sammelhandschriften mit unspezifischem Werktitel, aus dem Besitz eines Sammlers oder einer früheren Körperschaft werden stets mit dem heutigen Besitzer angesetzt (vgl. § 718,c-e).

SW Rom / Vatikanische Bibliothek / Cod. Ottob. lat. 3029

Handschrift aus der Bibliothek des Kardinals Ottoboni

6. Bei Sammlungen mit unspezifischem Namen, die sich im Besitz von Körperschaften befinden, wird eine Grundkette in folgender Form gebildet: 
Name der Körperschaft ; Sammelgegenstand ; 'Sammlung'

Für Listenfunktionen kann permutiert werden.

Titel: $\quad \neg$ Die $\neg$ Münzsammlung der Universität Gießen / von Hans Georg Gundel. - 1984

SWW Gießen / Universität ; Münze ; Geschichte ; Sammlung (34125)

Gehört eine Sammlung zum üblichen Bestand einer Körperschaft, so wird in der Grundkette das Schlagwort 'Sammlung' weggelassen.

Bei derartigen Sammlungen und bei Teilen davon entfallen in der Schlagwortkette bei der Körperschaft i. d. R. Zwischenstufen wie 'Handschriftenabteilung', 'Gemäldesammlung' (als Körperschaftsname), 'Papyrussammlung' u. ä. als pleonastisch. Ungenauigkeiten werden in Kauf genommen.

SWW Berlin / Staatsbibliothek; Handschrift ; Katalog (3124)

nicht: Berlin / Staatsbibliothek / Handschriftenabteilung ; Handschrift ; Katalog

Abteilungen bleiben jedoch erhalten, wenn die Sammlung nicht zum üblichen Bestand dieser Körperschaft gehört (vgl. § 609,2).

SWW Industrie- und Handelskammer Frankfurt, Main / Bibliothek ; Katalog

Bei Dom- und Kirchenschätzen wird der Name des Ortes bzw. der Kirche mit dem entsprechenden Sachschlagwort verknüpft. Für Listenfunktionen kann permutiert werden.

SWW Aachen; Domschatz

SWW Quedlinburg / Stiftskirche ; Kirchenschatz (312)

7. Sind Sammlungen oder Teile davon Gegenstand einer Ausstellung, so werden Grundketten in folgender Form gebildet:

1.Grundkette: $\quad$ Sammler ; 'Sammlung' ; 'Ausstellung' ; Ort $<\mathrm{Jahr}>$

2.Grundkette: $\quad$ Sammelgegenstand ; 'Sammlung'; 'Ausstellung'; Ort $<$ Jahr $>$

Für Listenfunktionen kann permutiert werden.

SWW Armand, Alfred ; Sammlung; Ausstellung ; Hamburg <1982>

SWW Zeichnung; Geschichte 1440-1850 ; Sammlung ; Ausstellung ; Hamburg <1982>

SWW Lowenthal, Edith ; Sammlung; Ausstellung; New York <NY, 1996>

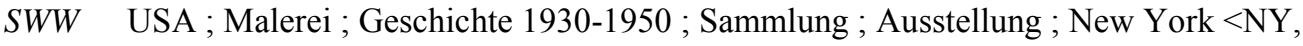
1996>

8. Die Bestimmungen $\S 736,1-7$ gelten analog für Privatbibliotheken, Familienarchive, Nachlässe u. ä. 


\section{Audiovisuelle Materialien}

\section{§ 737 Audiovisuelle Materialien}

1. Zu den audiovisuellen Materialien zählen:

- bildliche Darstellungen (Fotos, Kunstblätter, Plakate usw.),

- bildliche Darstellungen zur Projektion (Dias, Diastreifen, Arbeitstransparente, Arbeitstransparentstreifen usw.),

- Tonträger (Schallplatten, Tonbänder, Tonkassetten, AudioCDs usw.) (zu Musiktonträgern vgl. § 744),

- Bildtonträger (Filme, Videokassetten, Bildplatten, Tonbildreihen usw.),

- Spiele (und vergleichbare Gegenstände),

- Kombinationen mehrerer audiovisueller Materialarten und sonstige Materialien,

- Audiovisuelle Materialien in Mikroform.

Anm.: Mikroformen von Texten gelten nicht als audiovisuelles Material.

2. Für audiovisuelle Materialien werden die gleichen Regeln angewandt wie für andere Bibliotheksmaterialien, insbesondere die Regeln über die Inhaltsanalyse (§ 4). Neben dem behandelten Thema im engeren Sinn kann auch der Zweck des Dokuments erschlossen werden, etwa seine Verwendung in einem bestimmten Kontext. Die Art des Datenträgers wird durch ein Formschlagwort gekennzeichnet (vgl. Anl. 6), ggf. zusätzlich zur Form der Darstellung. Das Formschlagwort 'Audiovisuelles Material' wird vergeben, wenn mindestens zwei audiovisuelle Materialien vorliegen.

Das Formschlagwort 'Bildliche Darstellung' wird verwendet, soweit nicht einer der Unterbegriffe ('Bildnis', 'Dia', 'Graphik', 'Kalender', 'Karikatur', 'Photographie', 'Plakat', 'Tafel') einschlägig ist. Es bezeichnet auch bildliche Darstellungen zur Projektion; daneben kann es auch in einer Schlagwortkette mit Formschlagwörtern für elektronische Publikationen verwendet werden. Der dargestellte Gegenstand wird durch Schlagwörter ohne den $\mathrm{Zu}$ satz $<$ Motiv $>$ wiedergegeben.

Das Formschlagwort 'Tonträger' wird verwendet, soweit nicht einer der Unterbegriffe ('CD', 'Schallplatte', 'Tonbildreihe', 'Tonkassette') einschlägig ist. Der Inhalt des Tonträgers (Musik, Sprache, Geräusche usw.) wird durch einschlägige Sachschlagwörter ausgedrückt. Der Zusatz $<$ Motiv $>$ entfällt dabei, außer bei musikalischen Motiven.

Titel: Hitler spricht [Tonträger]. - Schallplatte. - 1980

SWW g Deutschland ; z Geschichte 1933-1945 ; f Quelle ; f Schallplatte

Titel: $\quad$ Highlights der deutschen TV-Werbung : Folge 1, ,süß und salzig“, die besten Spots aus der Genussmittelbranche 1956-1996. - 1996 [Videokassette]

SWW g Deutschland ; s Werbespot ; s Genussmittelindustrie ; z Geschichte 1956-1996 ; f Videokassette

Titel: Entwicklungszusammenarbeit am Beispiel Tansanias / Landesinstitut für Lehrerfortbildung ...

$\neg$ Ein $\neg$ Medienpaket. - 1996. - 34 S. + 12 Dias

Videokassette. Dokumentation einer Studienreise. - 1996

SWW g Tansania; s Landeskunde ; f Lehrmittel ; f Audiovisuelles Material

Die beiden audiovisuellen Medien werden unter dem Oberbegriff zusammengefasst. Das Buch wird nicht eigens erschlossen, da es geringen Umfang hat. 
Titel: $\quad \neg$ The $\neg$ riddle of the Dead Sea scrolls [Bildtonträger]

Mitschnitt einer dokumentarischen Fernsehsendung auf Video; die Entstehung als Fernsehsendung wird bei der Erschließung nicht berücksichtigt.

SWW t Qumrantexte; f Videokassette

Titel: $\quad \neg$ Das $\neg$ Deutsche Exilarchiv in Frankfurt am Main [Tonträger] / Deutschlandfunk Mitschnitt einer Hörfunksendung; dies wird bei der Erschließung nicht berücksichtigt.

SWW c Frankfurt <Main> / Deutsches Exilarchiv 1933-1945 ; f Tonkassette

Titel: $\quad$ Zillis - Evangelium in Bildern : die romanische Bilderdecke in Zillis / Graubünden neu gedeutet / Huldrych Blanke. - 1994

[Buch]. - 159 S. : zahlr. Ill.

Diaserie. - 168 Dias

SWW g Zillis-Reischen / Sankt Martin; s Deckenmalerei ; f Bildband

SWW g Zillis-Reischen / Sankt Martin ; s Deckenmalerei ; f Dia

Die beiden Teile sind selbständig benutzbar; sie werden daher getrennt erschlossen.

Aber:

Titel: $\quad$ Fachsprache Deutsch Betriebswirtschaft [Medienkombination] / Lothar Jung. - 1993

Lese- und Arbeitsbuch. - 159 S.

Aufnahme der Hörtexte. - 1 Tonkassette

SWW g Deutsch; s Wirtschaftssprache ; f Lehrmittel

Sofern die Tonkassette nicht eigenständig benutzbar ist, wird nur das Buch erschlossen.

3. Die Erschließung von (Spiel-)Filmen und vergleichbaren Fernsehsendungen beschränkt sich i.d.R. auf Dokumente, die einen bestimmten, als Problem, Ereignis oder mit einem Namen benennbaren Gegenstand behandeln.

Titel: $\quad$ Gone with the wind [Bildtonträger]

SWW s Sezessionskrieg <1861-1865> ; f Film 16 mm

Titel: Holocaust [Bildtonträger]

SWW s Judenvernichtung; f Videokassette

4. (Spiel-)Filme und Fernsehsendungen können bei einer lokalen Anwendung dieses Regelwerks mit Form- und Gattungsbegriffen oder mit Bezeichnungen für künstlerische Strömungen erschlossen werden (vgl. § 5,5).

Anm.: Zur Erschließung von Hörspielen vgl. §§ 762,9,c; 766.

Titel: $\quad \neg$ Der $\neg$ Förster vom Silberwald [Bildtonträger] : österreichischer Spielfilm von 1954

SWW s Heimatfilm; f Videokassette

Titel: $\quad$ Schrei wenn Du kannst [Bildtonträger] / Regie: Claude Chabrol. - 1959

SWW s Nouvelle vague; f Film $35 \mathrm{~mm}$

5. (Spiel-)Filme und Fernsehsendungen können bei einer lokalen Anwendung dieses Regelwerks durch Schlagwörter für Entstehungsgebiet, die Gattungsbezeichnung 'Film' bzw. 'Fernsehsendung', ein Zeitschlagwort sowie das Formschlagwort für den Datenträger erschlossen werden (vgl. § 5,3).

Titel: $\quad \neg$ Der $\neg$ Förster vom Silberwald [Bildtonträger]: österreichischer Spielfilm von 1954

SWW g Österreich ; s Film ; z Geschichte 1954 ; f Videokassette

6. Zur Erschließung von Musiktonträgern vgl. § 744. 


\section{Elektronische Publikationen}

\section{§ 737a Elektronische Publikationen}

1. $\mathrm{Zu}$ den elektronischen Publikationen zählen alle Publikationen, bei denen Daten in maschinenlesbarer Form vorliegen, unabhängig vom Typ, vom Inhalt oder von der Funktion der Datei bzw. Dateien (z.B. Programme, Texte, Graphiken, Audio- oder Videosequenzen, Datenbanken). Sie können in einer festen physischen Form vorliegen, z.B. auf Diskette oder CDROM, oder in immaterieller Form als Online-Publikation auf einem lokalen Rechner oder auf einem fremden Rechner, zu dem ein definierter Zugang besteht.

Wie weit eine Bibliothek Publikationen erschließt, die auf fremden Rechnern liegen, hängt von lokalen Bedürfnissen ab.

2. Unabhängig vom Typ (Programmdatei, Datendatei), von der Funktion oder - bei mehreren Dateien - vom Inhalt der einzelnen Datei erfolgt die Erschließung elektronischer Publikationen nach den gleichen Regeln wie für andere Bibliotheksmaterialien, insbesondere die Regeln über die Inhaltsanalyse (§ 4). Beschlagwortet wird i.d.R. der wesentliche Inhalt der gesamten elektronischen Publikation.

Titel: Duden. Das Bildwörterbuch [Computerdatei] : die Gegenstände und ihre Benennung ; 27500 Begriffe aus allen Bereichen des Lebens werden aus detailgenauen Bildtafeln durch direkte Bildzuordnung erklärt; optimiertes 32-Bit-Programm für Windows und Apple Macintosh, moderne und ergonomische Benutzeroberfläche, erweiterte Suchmöglichkeiten, persönliches Arbeiten mit Leuchtstiftfunktion ; schreibungstolerante Suche von Stichwörtern, Volltextsuche, Benutzerwörterbücher, persönliche Textzusammenstellung, Verknüpfung mit allen installierten Titeln der PC-Bibliothek, Netzwerkfähigkeit auf Anfrage. - Version 2.0. - 1998. - 1 CD-ROM : farb. ; $12 \mathrm{~cm}$, in Behältnis 23 × $16 \times 3 \mathrm{~cm}+$ Beil. (16 S. : Ill.)

SW: $\quad$ g Deutsch ; f Bildwörterbuch ; f CD-ROM

Neben dem behandelten Thema im engeren Sinn kann auch der Zweck der Publikation erschlossen werden, wie ihre Verwendung in einem bestimmten Kontext (z. B. Hilfs- oder Zusatzprogramme für ein anderes Programm oder für Dateien, die als Bildschirmschoner verwendet werden können).

Der Titel einer elektronischen Publikation wird nur dann Schlagwort, wenn dazu Sekundärliteratur vorliegt.

Die Systemvoraussetzungen werden i.d.R. nicht berücksichtigt.

Bei entsprechenden Inhalten werden analog die Bestimmungen über die fakultative ErschlieBung mit Gattungsbegriffen $(\S 5,3-7)$ angewandt.

Die Art des Datenträgers wird durch ein Formschlagwort gekennzeichnet (vgl. Anl. 6), ggf. zusätzlich zur Form der Darstellung. Das Formschlagwort 'Elektronische Publikation' wird vergeben, wenn der Datenträger nicht in der Liste der Formschlagwörter vertreten ist oder wenn mindestens zwei Datenträger vorliegen.

Titel: Transistor-Lexikon [Computerdatei] : die Datenbank mit den wichtigsten Informationen und technischen Daten von mehreren tausend Transistoren. - 1995. - 1 CD-ROM + Textbeil. (1B1.)

SWW s Transistor; f Datensammlung; f CD-ROM 
Titel: $\quad$ Langenscheidts Wörterbuch-Computer Englisch : Alpha 40 ; rund 40000 Wörter: Memofunktion; blitzschnelles Finden. - 1988 - 1 Taschenrechner + Bedienungsanleitung (64 S.)

SWW g Englisch ; f Wörterbuch ; g Deutsch ; f Elektronische Publikation

3. Ist bei einer Kombination von Programm- und Datendateien eindeutig erkennbar, dass der Anteil der Programmdatei(en) überwiegt, so wird nur dieser erschlossen $(\S 737 \mathrm{a}, 4)$. Überwiegt der Anteil der Datendatei(en), so ist nur dieser zu beschlagworten (§ 737a,5). Sind beide Anteile etwa gleichwertig, so werden sie als zwei getrennte Gegenstände erschlossen.

Ist die elektronische Publikation mit einem Druckwerk oder mit audiovisuellem Material verbunden, so werden i.d.R. die Materialien als getrennte Gegenstände behandelt. Dies gilt unabhängig davon, ob die Materialien in der Titelaufnahme als einteilig oder als mehrteilig angesehen werden (vgl. RAK-NBM $\S 3 b$ ). Bei mehrteiligen Aufnahmen werden aber Schlagwortketten beim Gesamtwerk erfasst.

Ist jedoch das Druckwerk nur eine Anleitung (Bedienungs- bzw. Installationsanleitung) oder eine Begleitdokumentation, die keine eigenständige, über den Inhalt der elektronischen Publikation hinausgehende Information enthält, so entfällt die Erschließung des Druckwerks.

Ist umgekehrt die elektronische Publikation inhaltlich unselbständiges Begleitmaterial, enthält also z.B. nur die im Buch beschriebenen Beispiele und Musterlösungen, so entfällt die Erschließung der elektronischen Publikation. Ebenso entfällt die Erschließung bei Demound Testversionen sowie anderen zeitlich bzw. funktionell stark begrenzten Versionen von Software-Vollversionen.

a) Getrennte Erschließung der elektronischen Publikation und des Druckwerks (bzw. des audiovisuellen Werks)

Titel: $\quad$ Homebanking [Medienkombination] / Michael Altenhövel. - 1994

[Buch]. - $159 \mathrm{~S}$.

Diskette. - MS-Money 2.0b Vollversion

Das Buch behandelt das Thema allgemein; auf der Diskette ist dagegen ein spezielles Programm enthalten. Für die unterschiedlichen Inhalte werden zwei Schlagwortketten gebildet.

SWW s Homebanking; f Ratgeber

SWW s Homebanking; f Programm ; f Diskette

Titel: Word für Windows 6.0 [Medienkombination] / Sylvia Böhmer ; Martin Böhmer. 1997

[Buch]. - $882 \mathrm{~S}$.

CD-ROM Gesamter Buchtext als Electronic-Publishing-Text auf der CD-ROM

Es handelt sich um eine Einführung in das Programm, das selbst nicht enthalten ist. Beide Teile sind inhaltlich völlig identisch und können getrennt voneinander benutzt werden. Beide Medien werden getrennt erschlossen.

SW $\quad$ s WORD für WINDOWS 6.0

SWW $\quad$ s WORD für WINDOWS $6.0 ; \mathrm{fCD}-\mathrm{ROM}$

Titel: WordPerfect für IBM-PCs und PC-Netzwerke [Computerdatei] : Textverarbeitungssoftware. - Version 5.1, deutsch. - 1990. - 7 und/oder 13 Disketten + Arbeitsbuch (IX, 484 S.), Nachschlagen 1 und 2 (IX, 972 S., 16 Bl.), WordPerfect leicht gemacht $(20 \mathrm{~S}$.

Das Werk besteht aus dem Textverarbeitungsprogramm und einer umfangreichen Bedienungsanleitung. Diese ist in gleicher Weise zu benutzen wie eine getrennt erschienene Einführung (Sekundärliteratur). Buch und Programm werden daher getrennt erschlossen.

SWW s Textverarbeitung; f Programm; f Diskette

SW $\quad$ s WordPerfect 5.1 
Titel: Marburger Index [Medienkombination] : Kunst in Deutschland [teilw.: Inventar der Kunst in Deutschland] / Hrsg.: Bildarchiv Foto Marburg

Mikroficheausgabe. - ca. 9150 Mikrofiche

Datenbank 1996. - 1 CD-ROM

Es handelte sich zunächst (1977-1990) um eine Sammlung von Photographien von Kunstwerken auf Mikrofiche, die später durch ein gedrucktes Register und ab 1996 durch eine CDROM-Ausgabe erschlossen wurden. (Das Verhältnis beider Produkte wird vom Verlag nicht klar dargelegt.) Da beide Medien mit einem Formschlagwort erschlossen werden, werden zwei Schlagwortketten gebildet.

SWW g Deutschland; s Kunst ; z Geschichte ; f Bildliche Darstellung ; f Mikroform

SWW g Deutschland; s Kunst ; z Geschichte ; f Bildliche Darstellung ; f CD-ROM

b) Erschließung nur der elektronischen Publikation

Titel: Meyers Lexikon Informatik [Computerdatei] : ein Sachlexikon für Studium und Praxis. - 1996. - 1 CD-ROM + Dokumentation (4 S.)

Die Dokumentation enthält lediglich eine Anleitung zum Benutzen der CD-ROM, daher wird nur die elektronische Publikation erschlossen.

SWW s Informatik ; f Wörterbuch ; f CD-ROM

Titel: Aufgabentrainer lineare Algebra [Computerdatei] : computerunterstützte Weiterbildung unter Windows / Gabriele Piehler ; Heinz Peter Reidmacher. - 1995. - 3 Disketten + Begleittext (36 S.)

Der Begleittext enthält keine Aufgaben, sondern nur eine Anleitung zur Bedienung. Erschlossen werden daher nur die Disketten.

SWW s Lineare Algebra; f Aufgabensammlung; f Diskette

c) Erschließung nur des Druckwerks

Titel: $\quad$ 2D- und 3D-Konstruktionen mit AutoCAD 13 / Gabriele Poppe. - 1996. - 408 S. + Diskette

Die Diskette enthält keinen eigenständigen Inhalt, sondern lediglich die schon im Buch enthaltenen Beispiele. Daher wird nur das Buch erschlossen.

SW S AutoCAD 13.0

Titel: Aufgabensammlung Kältetechnik : Aufgaben und Lösungen mit Begleitdiskette. 1995. - 129 S. + Begleitdiskette

Die Diskette umfasst nur einen Teil der Lösungen und kann daher bei der Erschließung übergangen werden.

SWW s Kältetechnik ; f Aufgabensammlung

4. Besteht die elektronische Publikation aus Programmdateien (ausführbaren Dateien), wird der Dateityp i.d.R. durch das Formschlagwort 'Programm' ausgedrückt.

Handelt es sich um ein Programm mit Produktnamen oder um mehrere Programme mit einem gemeinsamen Namen, so wird es / werden sie mit dem einschlägigen Sachschlagwort und dem Formschlagwort 'Programm' erschlossen.

Zwischen den verschiedenen Typen bzw. Vertriebskonzepten von Programmen (z.B. Hilfs-, Dienst- oder Anwendungsprogramme, Shareware, Freeware oder Public Domain, Versionen für bestimmte Betriebssysteme usw.) wird im Form- und im Sachschlagwort nicht unterschieden. Jedoch werden funktionell stark eingeschränkte Versionen (z.B. Demoware, Crippleware) oder Software, die nur bis zu einem bestimmten Datum verwendet oder nur eine bestimmte Anzahl von Malen aufgerufen werden kann (Expireware) nicht erschlossen.

Anm.: Die Bewertung hängt von den Bedürfnissen der einzelnen Bibliothek und von den technischen Möglichkeiten bei der Erschließung ab. 
Titel: Word 6.0 [Computerdatei]

Das Textverarbeitungsprogramm liegt auf Diskette vor.

SWW s Textverarbeitung; f Programm ; f Diskette

Titel: Schach-Box [Computerdatei]

$\neg \mathrm{Die} \neg$ Top-Schachprogramme Check Check und Chessfriend als Vollversionen und dazu: die besten Shareware-Schachprogramme : viele utilities ... - 1994. - 1 CD-

ROM.

$\neg$ Die $\neg$ umfassende Sammlung zum Thema Schach : ca. 50 Shareware, Public-

Domain-Schachprogramme ... - 1996. - 2 CD-ROMs

SWW s Computerschach ; f Programm ; f CD-ROM

Titel: $\quad$ Erste-Hilfe-Kasten Windows NT 4 [Computerdatei] : Tools für Administratoren und Programmierer ; System- und Desktop-Utilities ; Programme für DFÜ und Internet ; Software für Audio und Video / Andreas F. Golla. - 1996. - 1 CD-ROM + Textbeil. (6 S.)

SWW s Windows NT 4.x ; f Programm ; f CD-ROM

Windows NT steht hier nicht für den Inhalt, sondern für den Zweck der Programme: systemnahe Anwendersoftware, die unter dem Betriebssystem Windows NT eingesetzt wird.

Titel: Homebox [Computerdatei] : das große More-Fun-Paket für Ihren PC ; mit allem was das PC-Leben so richtig schön macht: 44918 Icons, Multimediaprogramme, Editoren, Player, 93 Bildschirmschoner, 624 SoundDateien ..., 430 Hintergrundbilder für den Windows Desktop ... - 1995. - 1 CD-ROM.

kein Schlagwort, da ganz heterogener Inhalt

Sekundärliteratur zu Programmen ist wie folgt zu beschlagworten:

- bei einzelnen Programmen: Name des Programms unter Beachtung der Regelung in $\S 306 a, 10$,

(Das Anwendungsgebiet von Programmen wird i.d.R. nur als Oberbegriff bzw. mehrgliedriger Oberbegriff in der SWD erfasst.)

- bei mehreren Programmen zu einem bestimmten Thema: Thema ; s Programm (oder ein anderes passendes Schlagwort),

- bei mehreren Programmen zur Ergänzung eines Programms:

Name des Hauptprogramms ; s Programm

(oder ein anderes passendes Schlagwort).

Titel: $\quad$ Word 6.0 professionell nutzen / Peter Rinearson. - 1991

SW S WORD 6.0

Datensatz der SWD:

SW WORD 6.0

MO Textverarbeitung; Programm

Inhalt: Vergleich von Programmen für Schachcomputer

SWW s Computerschach; s Programm

Inhalt: Verzeichnis von Hilfsprogrammen für Windows NT 4

SWW s Windows NT 4x; s Programm; f Verzeichnis

5. Bei Datendateien (nicht ausführbaren Dateien, die nur Daten im weitesten Sinn enthalten; z.B. Texte, Graphiken, Audio- und Videosequenzen, Datenbanken sowie Multimediaanwendungen) wird der Dateityp i.d.R. nur indirekt durch Verknüpfung von Schlagwörtern für den Dateiinhalt, häufig in Verbindung mit Formschlagwörtern wie 'Bibliographie', 'Bildliche Darstellung', 'Datensammlung', 'Beispielsammlung' usw. ausgedrückt. 
a) Datenbanken

Titel: PsycLit [Computerdatei] : summarizes the world's serial and book literature in psychology and related disciplines. - CD-ROM-Ausg. - 1986

CD-ROM-Version der Psychological abstracts, lokal auf Festplatte überspielt. Gliedert sich in die Dateien Journal articles 1974-1990, Journal articles 1991-3/97, Chapters and books 1/873/97. Diese Differenzierung wird in der Sacherschließung übergangen.

$S W W$ s Psychologie ; f Bibliographie ; fCD-ROM

Titel: Vademecum deutscher Lehr- und Forschungsstätten [Computerdatei]

Online-Datenbank bei einem Host. Zugang durch Pauschalvertrag mit Passwort; inhaltlich mit der Druckausgabe bzw. CD-ROM identisch.

SWW g Deutschland ; s Forschungseinrichtung ; f Adressbuch ; f Online-Publikation

Titel: Beilstein Crossfire [Computerdatei]

Inhouse-Datenbank; Datenlieferung über Magnetband

SWW s Organische Chemie ; f Datensammlung ; f Online-Publikation

b) Texte

Titel: English poetry [Computerdatei] : the English poetry full text database. - 1994-1995

Enthält englische Gedichte des 5. bis 20. Jahrhunderts. Die Ausgaben, nach denen digitalisiert wurde, sind zitiert, jedoch nicht insgesamt abgebildet; Textdateien.

SWW g Englisch; s Lyrik; f Anthologie ; f CD-ROM

Titel: Art theorists of the Italian Renaissance [Computerdatei] / ed. board: Deborah Howard ... - 2 CD-ROMs.

Enthält ca. 40 Werke des 15. und 16. Jahrhunderts im Original sowie in italienischer und englischer Übersetzung (sofern erschienen), ohne editorische Anmerkungen; Image-Dateien.

SWW g Italien ; s Ästhetik ; z Geschichte 1400-1600 ; f Quelle ; f CD-ROM

SWW s Renaissance ; s Ästhetik ; g Italien ; f Quelle ; f CD-ROM

Titel: Frauenbewegung und Prostitution [Computerdatei] / Petra Schmackpfeffer. http: //www.bis.uni-oldenburg.de/bisverlag/schfra89/schfra89.htm

Die Online-Publikation unterscheidet sich inhaltlich nicht von der Druckausgabe desselben Werks, sondern nur durch die andere Aufbereitung.

SWW g Deutschland ; s Prostitution ; s Frauenbewegung ; z Geschichte ; f OnlinePublikation

Titel: $\quad \neg$ Die $\neg$ schwarze Spinne [Computerdatei] / Jeremias Gotthelf. - 1997. - 1 CD-ROM

$S W W \quad \mathrm{p}$ Gotthelf, Jeremias / $\mathrm{t} \neg$ Die $\neg$ schwarze Spinne ; f CD-ROM

Enthält den Text (mit Druck- und Editierfunktion usw.) sowie den vorgelesenen Text. Im Hinblick auf die gegenüber der Druckausgabe wesentlich intensivere Erschließung ist die Erschließung im Sachkatalog gerechtfertigt (unabhängig von der Formalkatalogisierung; elektronische Publikationen erhalten die Haupteintragung unter dem Sachtitel).

Titel: Letterbox [Computerdatei] : 200 Musterbriefe für die private und geschäftliche Korrespondenz. - 1996

SWW s Geschäftsbrief; f Beispielsammlung ; f CD-ROM

c) Bilder, Computergraphik, Video

Titel: Boeder-Photo-CD: Asia [Computerdatei] / photos by Leika ... and Robert Meinecke. 1994

SWW g Asien ; f Bildliche Darstellung ; f CD-ROM 
Titel: Ich wünsch' Dir was [Computerdatei] : Glückwünsche zu allen Gelegenheiten ; [über 200 Grafiken, Cartoons und Cliparts ; alle fertigen Beispiele auf CD] / Peter Albrecht. - 1996

SWW s Glückwunschkarte ; f Beispielsammlung ; f CD-ROM

Titel: Wolken und Himmel [Computerdatei] : Handbuch mit ausführlichen Anleitungen für Montage und Anpassung; Gestaltungsmaterial auf CD-ROM mit 88 Bilddateien ... / Hans D. Baumann. - 1996. - 1 CD-ROM + Handbuch (32 S.)

$S W W \quad$ s Wolke ; f Bildliche Darstellung ; f CD-ROM

SWW s Himmel; s Bildverarbeitung; f CD-ROM

Die erste Schlagwortkette steht für die Bilddateien, die zweite für die Anleitung zum Umgang mit diesen.

d) Audio

Titel: Jingle-Parade [Computerdatei] : 98 universell einsetzbare Erkennungsmelodien aus dem High-End-Studio ; ideal für digitale Grußbotschaften, Videos und Präsentationen

SWW s Jingle ; f Beispielsammlung ; f CD-ROM

Titel: WavePool [Computerdatei] : hochwertige Sounds für Ihre Multimedia-Anwendungen; Mensch, Tiere, Verkehr, Musikinstrumente ... ; über 2500 lizenzfreie Sounddateien. 1994. - 1 CD-ROM

SWW $\quad$ s Sound $<$ Multimedia $>$; f Beispielsammlung ; f CD-ROM

Titel: Quintet in A Major, D 667 „The trout“ [Computerdatei] / Franz Schubert Enthält neben der Musik Kommentar, Bibliographie, ein musikalisches Konzentrationsspiel und 10 Forellenrezepte. Daher wird das Werk wie Sekundärliteratur erschlossen.

SWW p Schubert, Franz / t Quintett, Violine Viola Violoncello Kontrabass Klavier D 667 ; fCD-ROM

e) Multimediaanwendungen

Im Gegensatz zu elektronischen Publikationen mit nur einer Dateiart werden bei Multimediaanwendungen die jeweiligen kombinierten Darstellungsmedien nicht einzeln erschlossen. Das Schlagwort 'Multimedia' entfällt als pleonastisch. Hypertext- und Hypermedia-Elemente werden i.d.R. nicht berücksichtigt.

Titel: $\quad$ Knaurs Lexikon von A bis Z [Computerdatei] : nachschlagen mit allen Sinnen ; neu: der Lexikon-Klassiker jetzt mit Bildern, Videos und Ton ; ... rund 2000 farbige Abbildungen, Grafiken, Übersichten, Tabellen, Schaubilder, ca. 60 Minuten Videosequenzen, ca. 30 Minuten Musikbeispiele, ... Hyperlinks ... - 1996. - 1 CD-ROM

SWW f Enzyklopädie; fCD-ROM

Titel: Aerobic [Computerdatei] : Mixed-Mode-CD für Computer und Stereoanlage ... ; interaktives Trainingsprogramm ; Videokurse im Vollbildmodus; Anleitungen mit Zeichnungen ausdruckbar / Nadja Boulares. - 1995. - 1 CD-ROM

Multimediaanwendung. Trotz der besonderen technischen Voraussetzungen ist es beim behandelten Thema selbstverständlich, dass Musik enthalten ist.

SWW s Aerobic; f Anleitung; f CD-ROM

Titel: Zauber klassischer Musik [Computerdatei] : große Komponisten und ihre Werke. 1997. - 1 CD-ROM : farb., mit Ton und Videosequenzen

Es handelt sich um ein Nachschlagewerk. Über ein vergleichbares gedrucktes Werk hinaus enthält es v.a. insgesamt 4 Stunden Klangbeispiele. Dabei handelt es sich jedoch nur um jeweils kurze Sequenzen, die eine eigenständige Erschließung nicht rechtfertigen. Dass alle Formen von Dateien benutzt werden, ist bei einem Werk dieser Art heute Standard. Multimedia entfällt daher als pleonastisch.

SWW s Klassische Musik ; f Wörterbuch ; f CD-ROM 
f) Sonstiges

Titel: $\neg$ Die $\neg$ Generalkarte [Computerdatei] : electronic map ; Deutschland, vollständig auf CD-ROM mit komplettem Ortsregister (130 000 Namen) und weiteren Informationen). - 1993. - 1 CD-ROM, 2 Disketten + Benutzerhandbuch

SWW g Deutschland; f Karte; f CD-ROM

SWW g Deutschland; f Ortsverzeichnis; fCD-ROM

SWW g Deutschland ; f Stadtplan ; f CD-ROM

6. Elektronische Publikationen mit thematisch nicht erschließbaren Spielfilmen, Texten der schönen Literatur, Kinder- und Jugendliteratur, Audiosequenzen, Graphiken usw. können analog nach § 5,3-7 erschlossen werden.

Titel: Baba Jaga und die Zaubergänse [Computerdatei]. - 1 CD-ROM

SWW s Märchenfilm; s Trickfilm; f CD-ROM

Titel: Quintet in A-Major, D 667 „The trout“ [Computerdatei] / Franz Schubert

SWW s Forelle $<$ Motiv>; s Quintett, Violine Viola Violoncello Kontrabass Klavier; f Tonträger ; f CD-ROM

Titel: $\quad \neg$ Die $\neg$ schwarze Spinne [Computerdatei] / Jeremias Gotthelf. - 1997. - 1 CD-ROM

SWW g Deutsch ; s Novelle ; z Geschichte 1842 ; f CD-ROM 



\section{$\S 738$ entfällt}

\section{Musikalische Werke}

\section{§ 739 Grundregeln}

1. Titel musikalischer Werke werden nur dann Schlagwort, wenn Sekundärliteratur dazu vorliegt, nicht jedoch bei Musikdrucken, Musikhandschriften, Musiktonträgern und Musikbildtonträgern. In der SWD erhalten sie den Indikator t.

2. Soweit im Folgenden nichts anderes festgelegt ist, gelten die $\S \S 707-711$ analog. Der Einheitssachtitel wird nach RAK-Musik $\S \S$ M 504-515 bestimmt, bis auf formale Abweichungen, die in den folgenden Paragraphen geregelt sind.

Anm.: Regeln für die alphabetische Katalogisierung von Musikdrucken, Musiktonträgern und Musik-Bildtonträgern : RAK-Musik. - 1997.

Zu Einheitssachtiteln werden bestimmt

a) individuelle Bezeichnungen (Originalsachtitel; vgl. RAK-Musik § M 505);

b) in der wissenschaftlichen Tradition gebrauchte feststehende Bezeichnungen (Konventionalsachtitel; vgl. RAK-Musik § M 506);

c) musikalische Form- und Gattungsbegriffe mit zusätzlichen musikspezifischen formalen Angaben (Formalsachtitel; vgl. RAK-Musik §§ M 507-509).

3. Für die Ansetzung der Titel ist primär die „Einheitssachtiteldatei des Deutschen Musikarchivs“" als Quelle heranzuziehen; die formale Strukturierung folgt den $\S \S 740-743$.

\section{§ 740 Originalsachtitel}

1. Musikalische Werke werden mit ihrem Einheitssachtitel (Originaltitel) angesetzt, wenn dieser aus einer individuellen Bezeichnung besteht (vgl. RAK-Musik § M 505) und erhalten den Indikator t. Bei Verwendung des Einheitssachtitels werden deutsche Übersetzungstitel bzw. andere Titelformulierungen als Synonyme erfasst (vgl. § 709,1).

$\begin{array}{ll}\text { SW } & \text { Berlioz, Hector / Symphonie fantastique } \\ \text { SW } & \text { Musorgskij, Modest P. / Kartinki s vystavki } \\ \text { BF } & \text { Mussorgski, Modest P. / Bilder einer Ausstellung } \\ \text { SW } & \text { Schubert, Franz / Winterreise }\end{array}$

Opuszählung, Zählung nach einem Werkverzeichnis, Gattung, Besetzung, Werkgruppenzählung oder Tonart werden weggelassen, wenn das betreffende musikalische Werk durch den individuellen Werktitel eindeutig gekennzeichnet ist.

Besetzungsangaben gelten jedoch dann als Bestandteil der individuellen Bezeichnung, wenn der Sachtitel aus „einem Begriff (besteht), der wie ein Form- und Gattungsbegriff verwendet wird, und nur einer Besetzungsangabe“ (RAK-Musik § M 505,1).

SW Bartók, Béla / Musik für Saiteninstrumente, Schlagzeug und Celesta

Als individuelle Benennungen gelten auch Originalsachtitel, die aus einem Form- oder Gattungsbegriff mit zusätzlichen individualisierenden Angaben bestehen. 
SW Hindemith, Paul / Symphonie Mathis der Maler

2. Bibliotheken, die RAK-ÖB-A anwenden, können einen im Deutschen gebräuchlichen Sachtitel als Einheitssachtitel verwenden. Dafür wird in der SWD eine ÖB-Alternativform angesetzt (vgl. § 709,3).

$\begin{array}{ll}\text { SW } & \text { Debussy, Claude / Prélude à l'après-midi d'un faune } \\ \text { ÖB } & \text { Debussy, Claude / } \neg \text { Der } \neg \text { Nachmittag eines Fauns } \\ \text { SW } & \text { Mozart, Wolfgang Amadeus / } \neg \text { Le } \neg \text { nozze di Figaro } \\ \text { ÖB } & \text { Mozart, Wolfgang Amadeus / } \neg \mathrm{Die} \neg \text { Hochzeit des Figaro }\end{array}$

3. Bei einem textierten musikalischen Werk wird der Textanfang zum Einheitssachtitel bestimmt, wenn das Werk keinen individuellen Sachtitel hat und kein Formalsachtitel gemäß RAK-Musik § 507 gebildet werden kann (vgl. auch RAK-Musik § 505,3).

SW Beethoven, Ludwig $\neg$ van $\neg /$ Ah! Perfido

Analog RAK-Musik § M 508 wird jedoch bei Einzelwerken, die innerhalb des Gesamtwerkes eines Komponisten zu einer Werkgruppe mit einer eigenen Nummerierung gehören, nach $\S 741$ verfahren.

SW Bach, Johann Sebastian / Kantate BWV 80

$B F \quad$ Bach, Johann Sebastian $/ \neg$ Ein $\neg$ feste Burg ist unser Gott

\section{§ 740a Konventionalsachtitel}

Ist nicht der Originalsachtitel, sondern ein anderer, in der wissenschaftlichen Tradition verwendeter Sachtitel gebräuchlicher, so wird dieser zum Einheitssachtitel bestimmt. (vgl. RAK-Musik § M 506). Zu später hinzugefügten Zitiertiteln vgl. § 742.

$\begin{array}{ll}\text { SW } & \text { Bach, Johann Sebastian / Matthäuspassion } \\ \text { BF } & \text { Bach, Johann Sebastian / Große Passionsmusik nach dem Evangelium Matthaei }\end{array}$

\section{§ 741 Formalsachtitel}

1. Besteht der Titel eines Einzelwerkes aus der Bezeichnung für die musikalische Form und Gattung sowie weiteren formalen musikspezifischen Angaben (wie Besetzung, Tonart, Zählung), so wird ein Formalsachtitel nach RAK-Musik $§$ M 507 gebildet. Die musikalischen Form- und Gattungsbegriffe werden i.d.R. abweichend von RAK-Musik § M 507,3 im Singular angesetzt.

Entsprechend RAK-Musik § M 507,4 werden den Form- und Gattungsbezeichnungen zur Unterscheidung ergänzende Angaben - soweit möglich in der unten angegebenen Reihenfolge - hinzugefügt. Bei Vorliegen von Opuszahl, Werkverzeichnis und Werkgruppenzählung kann von der nicht gewählten Form verwiesen werden. Abweichend von RAK-Musik steht lediglich vor der Angabe der Besetzung ein Komma mit Spatium.

a) Gattungsbezeichnung

b) Besetzung

Die Ordnung der Instrumentenbezeichnungen erfolgt entsprechend RAK-Musik. Abweichend von Anlage M 4a RAK-Musik werden für die Instrumente, Instrumentengruppen und Vokalensembles keine Abkürzungen verwendet. 
Für die Reihenfolge der Besetzungsangabe gilt

ba) bei konzertanten Werken:

Soloinstrument(e)

Ensemble (Chor, Orchester)

bb) bei Kammermusikwerken:

Blasinstrument(e)

Streichinstrument(e)

Zupfinstrument(e)

Schlaginstrument(e)

Tasteninstrument(e)

Basso continuo

c) Zählung eines gebräuchlichen Werkverzeichnisses

SW Schubert, Franz / Sinfonie D 849

SW Mozart, Wolfgang Amadeus / Non temer, amato bene KV 490

SW Mozart, Wolfgang Amadeus / Non temer, amato bene KV 505

SW Mozart, Wolfgang Amadeus / Sinfonie KV 16a

d) Opuszählung, abweichend von RAK-Musik ohne Spatium nach dem Komma, das einer Opuszahl für mehrere Werke folgt

SW Beethoven, Ludwig $\neg$ van $\neg$ / Sonate, Klavier op. 30,1

SW $\quad$ Beethoven, Ludwig $\neg$ van $\neg$ / Quartett, Violine 1,2 Viola Violoncello op. 59

$B F \quad$ Beethoven, Ludwig $\neg$ van $\neg /$ Streichquartett op. 59

e) Werkgruppenzählung

SW Mahler, Gustav / Sinfonie Nr. 9

f) Angabe der Tonart

SW Stamitz, Carl / Konzert, Oboe Orchester B-Dur

SW Poulenc, Francis / Messe G-Dur

g) Entstehungsjahr, abweichend von RAK-Musik als Homonymenzusatz in Winkelklammern

SW Ives, Charles / Improvisationen $<1938>$

2. Wenn mehrere Musikwerke bzw. eine Werkgruppe oder das Gesamtwerk eines Komponisten in einem Dokument behandelt werden, wird abweichend von RAK-Musik kein Formalsachtitel nach $\S 741,1$ bestimmt, sondern es wird der Personenname mit einem Kompositum aus Gattung und Besetzung verknüpft. Käme als zusammenfassende Bezeichnung das Schlagwort 'Musik' in Frage, wird nur der Personenname verwendet.

Abweichend von RAK-Musik $\S$ M 509 a) und b) wird für Gesamt- und Teilausgaben der Werke eines Komponisten (Sammlungen) kein Formalsachtitel mit 'Werke' etc. als Einheitssachtitel bestimmt. 
Titel: Beethoven : formale Strategien der späten Quartette / Ulrich Siegele. - 1990

SWW Beethoven, Ludwig $\neg$ van $\neg$; Streichquartett ; Geschichte 1822-1826

nicht: Beethoven, Ludwig $\rightarrow$ van $\neg$ / Quartette , Violine 1,2 Viola Violoncello; Geschichte 18221826

Titel: $\quad$ Schubert-Handbuch / hrsg. von Walther Dürr ... - 1997

SW Schubert, Franz

\section{$\S 742$ Zitiertitel}

Gebräuchliche Titel, die nicht zur Ansetzung herangezogen werden, da es sich um später hinzugefügte Zitiertitel bzw. nachträglich beigefügte volkstümliche Bezeichnungen handelt, werden als Synonyme erfasst (vgl. auch RAK-Musik § M 506,1,Anm. 2).

$\begin{array}{ll}\text { SW } & \text { Beethoven, Ludwig } \neg \text { van } \neg \text { / Sonate, Klavier op. } 57 \\ \text { BF } & \text { Beethoven, Ludwig } \neg \text { van } \neg / \text { Appassionata } \\ \text { SW } & \text { Mozart, Wolfgang Amadeus / Sinfonie KV 551 } \\ \text { BF } & \text { Mozart, Wolfgang Amadeus / Jupiter-Sinfonie }\end{array}$

\section{§ 743 Komponist, Textdichter, Interpret}

Vokalwerke werden als mehrgliedriges Schlagwort mit dem Komponisten und dem Werktitel angesetzt (vgl. RAK-Musik $\S$ M 614). Ist im vorliegenden Dokument der Text gleichgewichtig oder überwiegend behandelt, so wird zusätzlich ein mehrgliedriges Schlagwort mit dem Textautor und dem Werktitel (abweichend von RAK-Musik) angesetzt. Wird nur der Text behandelt, so erfolgt die Ansetzung mit dem Autor und dem Werktitel. Das musikalische Werk mit einem zusätzlichen passenden Sachschlagwort kann als Synonym erfasst werden.

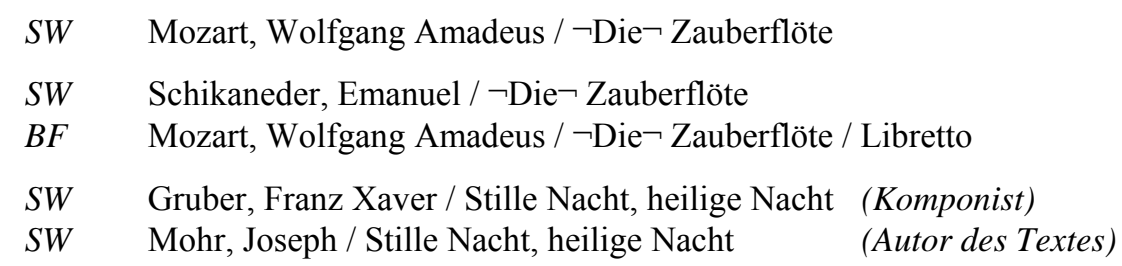

Interpreten der Jazz-, Rock-, Pop- und anderer interpretengebundener Musik werden nach RAKMusik § M 697,1 (Alternativbestimmung) als mehrgliedriges Schlagwort mit dem Werktitel als zweitem Glied angesetzt. Der Werktitel wird als Synonym erfasst.

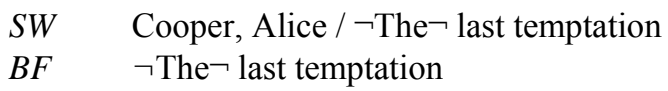

Komponisten der Musik zu einem Film oder Musical erhalten abweichend von RAK-Musik $\S$ M 697,2a,3a eine mehrgliedrige Ansetzung mit dem Werktitel.

$\begin{array}{ll}\text { SW } & \text { Steiner, Max / Gone with the wind } \\ \text { BF } & \text { Gone with the wind / Filmmusik }\end{array}$

Komponisten der Musik zu einem Ballett erhalten nach RAK-Musik § M 697,4a eine mehrgliedrige Ansetzung mit dem Werktitel.

SW Čajkovskij, Petr I. / Lebedinoe ozero

ÖB Tschaikowski, Pjotr I. / Schwanensee 
Moderne Tanztheaterproduktionen sind mit dem Werktitel anzusetzen. Die Namen beteiligter Personen (z.B. Choreographen, Komponisten) werden in Verbindung mit dem Werktitel als Synonyme erfasst.

\author{
SW $\quad$ Parade $<$ Ballett $>$ \\ $B F \quad$ Satie, Erik / Parade $<$ Ballett $>$ \\ Massine, Léonide / Parade $<$ Ballett $>$ \\ Cocteau, Jean / Parade $<$ Ballett $>$
}

\title{
§ 743a Einheitssachtitel für Teile musikalischer Werke
}

1. Teile eines musikalischen Einzelwerkes werden i.d.R. unselbständig angesetzt und gemäß $\S 711$ nach Schrägstrich (und nicht gemäß RAK-Musik § M 512 in Winkelklammern) hinzugefügt. Der unselbständige spezifische Titel des Teiles kann als Synonym erfasst werden. Unselbständige Teile mit unspezifischem Titel können mit dem jeweiligen Werk verknüpft werden.
SW Mozart, Wolfgang Amadeus / $\neg$ Le $\neg$ nozze di Figaro / Non più andrai
BF Mozart, Wolfgang Amadeus / Non più andrai
Mozart, Wolfgang Amadeus / Nun vergiss leises Flehen
SW $\quad$ Mozart, Wolfgang Amadeus / $\neg$ Le $\neg$ nozze di Figaro ; Ouvertüre
SW Haydn, Joseph / Sinfonie H 1,40 ; Satz 4

Bei mehreren Teilen eines musikalischen Einzelwerkes wird (abweichend von RAK-Musik $\S$ M 512,2) der Einheitssachtitel nicht um das weitere Schlagwort 'Ausw.' ergänzt. Handelt es sich bei diesen um Individualnamen, so kann jeder Titel einzeln angesetzt und es können bis zu fünf Schlagwörter pro Dokument verwendet werden.

$$
\begin{aligned}
& \text { SW } \quad \text { Haydn, Joseph / } \neg \text { Die } \neg \text { Jahreszeiten / Komm, holder Lenz } \\
& \text { SW Haydn, Joseph / } \neg \text { Die } \neg \text { Jahreszeiten / Hier steht der Wandrer nun } \\
& \text { SW Haydn, Joseph / } \neg \mathrm{Die} \neg \text { Jahreszeiten / Schon eilet froh der Ackermann } \\
& \text { nicht: Haydn, Joseph / } \neg \text { Die } \neg \text { Jahreszeiten / Ausw. }
\end{aligned}
$$

2. Ein einzelner Teil eines Zyklus erhält jedoch einen eigenen Einheitssachtitel, wenn der Teil ein umfangreiches Werk mit eigener, feststehender Bezeichnung ist, von dem wiederum Teile einzeln veröffentlicht werden können (vgl. auch RAK-Musik § M 513). Die Ansetzung erfolgt mit dem Titel des Teiles. Das Gesamtwerk mit dem angefügten Titel des Teiles wird als Synonym erfasst.

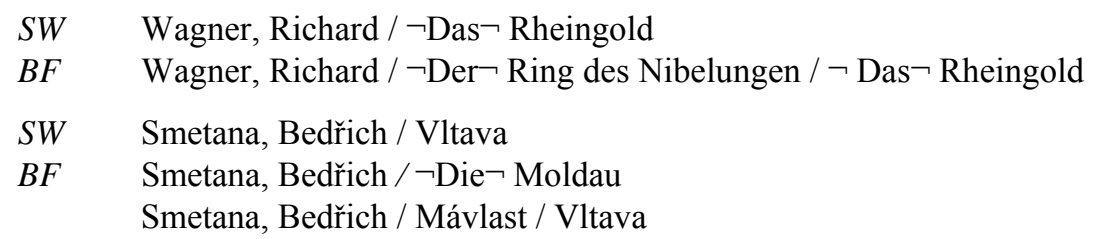

3. Für zwei oder mehr Teile aus einem Zyklus, die jeweils abgeschlossene Kompositionen bilden und eigene feststehende Titel haben, wird abweichend von RAK-Musik $§$ M 513,2 dem Einheitssachtitel des Zyklus nicht als weiteres Schlagwort die Abkürzung 'Ausw.' hinzugefügt, sondern es wird je eine Ansetzungsform gebildet.

$$
\begin{aligned}
& \text { SW Distler, Hugo / Das ist je gewisslich wahr } \\
& \text { nicht: Distler, Hugo / Geistliche Chormusik / Ausw. }
\end{aligned}
$$


Inhalt: Die vier Jahreszeiten von Vivaldi

SW Vivaldi, Antonio / $\neg \mathrm{Il} \neg$ cimento dell'armonia e dell'inventione / Konzert R 269

$B F \quad$ Vivaldi, Antonio / $\neg \mathrm{La} \neg$ primavera

Vivaldi, Antonio / Quattro stagioni / $\neg$ La $\neg$ primavera

Vivaldi, Antonio / $\neg$ Der $\neg$ Frühling

Vivaldi, Antonio / Vier Jahreszeiten / $\neg$ Der $\neg$ Frühling

SW Vivaldi, Antonio / $\neg \mathrm{Il} \neg$ cimento dell'armonia e dell'inventione / Konzert R 315

BF $\quad$ Vivaldi, Antonio / $\neg$ L' $\neg$ estate

Vivaldi, Antonio / Quattro stagioni / $\neg$ L' $\neg$ estate

Vivaldi, Antonio / $\neg$ Der $\neg$ Sommer

Vivaldi, Antonio / Vier Jahreszeiten / $\neg$ Der $\neg$ Sommer

SW Vivaldi, Antonio / $\neg \mathrm{Il} \neg$ cimento dell'armonia e dell'inventione / Konzert R 293

BF $\quad$ Vivaldi, Antonio / $\neg$ L' $\neg$ autunno

Vivaldi, Antonio / Quattro stagioni / $\neg$ L' $\neg$ autunno

Vivaldi, Antonio / $\neg$ Der $\neg$ Herbst

Vivaldi, Antonio / Vier Jahreszeiten / $\neg$ Der $\neg$ Herbst

SW $\quad$ Vivaldi, Antonio / $\neg$ Il $\neg$ cimento dell'armonia e dell'inventione / Konzert R 297

BF $\quad$ Vivaldi, Antonio / $\neg$ L' $\neg$ inverno

Vivaldi, Antonio / Quattro stagioni / $\neg$ L' $\neg$ inverno

Vivaldi, Antonio / $\neg$ Der $\neg$ Winter

Vivaldi, Antonio / Vier Jahreszeiten / $\neg$ Der $\neg$ Winter

\section{§ 744 Musikdrucke, Musiktonträger und Musikvideos}

1. Musikdrucke, Wiedergaben musikalischer Werke auf Tonträgern und Musikvideos können bei einer lokalen Anwendung des Regelwerks nach folgenden Aspekten erschlossen werden (vgl. § 5,6):

- Thematisch erschließbare sachliche Inhalte (Motiv, Anlass)

- Form und Gattung

- Besetzung

- Provenienz

- Zeit

- Präsentation (Ausgabeform, z.B. Klavierauszug)

- Realisation (Formbegriff, z.B. Musikdruck, Tonträger, Videokassette)

Einen Entwurf dazu bildet: „Regeln für den Schlagwortkatalog (RSWK)/Musikalien und Musiktonträger. - Entwurf. - Berlin: Deutsches Bibliotheksinstitut, 1991.“

2. Abweichend von diesem Entwurf sind folgende Formschlagwörter zugelassen:

- Musikdruck

- Tonträger

$-\mathrm{CD}$

- DVD-Audio

- DVD-Video

- Schallplatte

- Tonkassette

- Elektronische Publikation

mit Unterbegriffen (vgl. Anl. 6). 
3. Abweichend von $\S 750$ dieses Entwurfs ist eine Berücksichtigung von Provenienz und Zeit bei einer Erschließung nach $\S 5,3$ in allen Fällen möglich. Es wird empfohlen, dafür eigene Schlagwortketten neben denen mit Motiv/Anlass, Form/Gattung und Besetzung zu bilden.

Titel: Schumann, Robert: [Gedichte op. 37] 12 Gedichte aus F. Rückerts Liebesfrühling : op. 37

SWW g Deutschland ; s Lied ; z Geschichte 1840 ; f Musikdruck

daneben:

SWW $\quad$ s Liebe $<$ Motiv $>$; s Lied ; s Gesang $<$ Solo $>$, Klavier ; f Musikdruck

§§ 745 - 752 vgl. Regeln für den Schlagwortkatalog (RSWK), Musikalien und Musiktonträger : Entwurf. - Berlin: Dt. Bibliotheksinst., 1991

\section{$\S \S 753$ - 759 entfallen}

\section{Schöne Literatur}

\section{§ 760 Aufnahmeprinzipien für den Schlagwortkatalog}

Gemäß § 3,2 kann schöne Literatur in den Schlagwortkatalog aufgenommen werden.

Die Aufnahme beschränkt sich auf

a) thematisch erschließbare Werke (vgl. § 4,6),

b) Anthologien.

Zunächst ist zu prüfen, ob die Darstellung so kenntnisreich, umfassend und informativ ist, dass ein Nachweis im Schlagwortkatalog sinnvoll erscheint. Dabei ist den Benutzerinteressen Rechnung zu tragen. Der literarische Wert und das Genre eines Dokuments bleiben unberücksichtigt, ebenso i.d.R. Einzelaspekte. Bei Anthologien wird die literarische Gattung erschlossen.

SWW Französisch; Märchen; Anthologie

Darüber hinaus ist die Erschließung der literarischen Gattung oder literarischer Strömungen nur bei lokaler Anwendung möglich (vgl. § 5,4).

\section{§ 761 Schlagwortformen und Schlagwortkategorien}

Sämtliche nach RSWK vorgesehenen Schlagwortformen und -kategorien können auch zur Indexierung schöner Literatur verwendet werden. Der Zusatz $<$ Motiv $>$ wird bei der Beschlagwortung der schönen Literatur nicht verwendet (vgl. § 705,8,a).

SWW Einsamkeit; Lyrik; Anthologie

SWW Körperbehinderung ; Belletristische Darstellung 


\section{§ 762 Einzelne Schlagwortkategorien}

Anm.: Im Folgenden sind Permutationsmuster nach $\S 15$ angegeben.

1. Personenschlagwörter (Ansetzung gemäß $§ 101 \mathrm{ff}$.)

Für Dokumente mit sachlicher Bedeutung für Leben und Werk nachweisbarer historischer oder zeitgenössischer Personen wird das Personenschlagwort verwendet, ebenso für Familien, biblische, mythologische und literarische Gestalten.

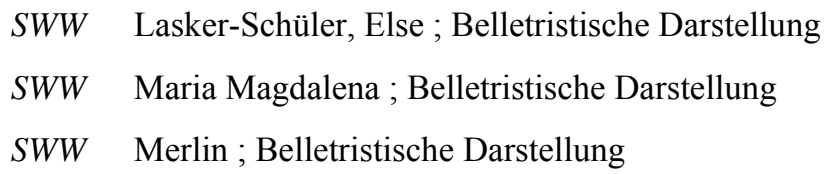

Auch die Beziehung einer Person zu anderen Personen oder einem Sachthema oder ein geographischer bzw. historischer Bezug wird ggf. berücksichtigt.

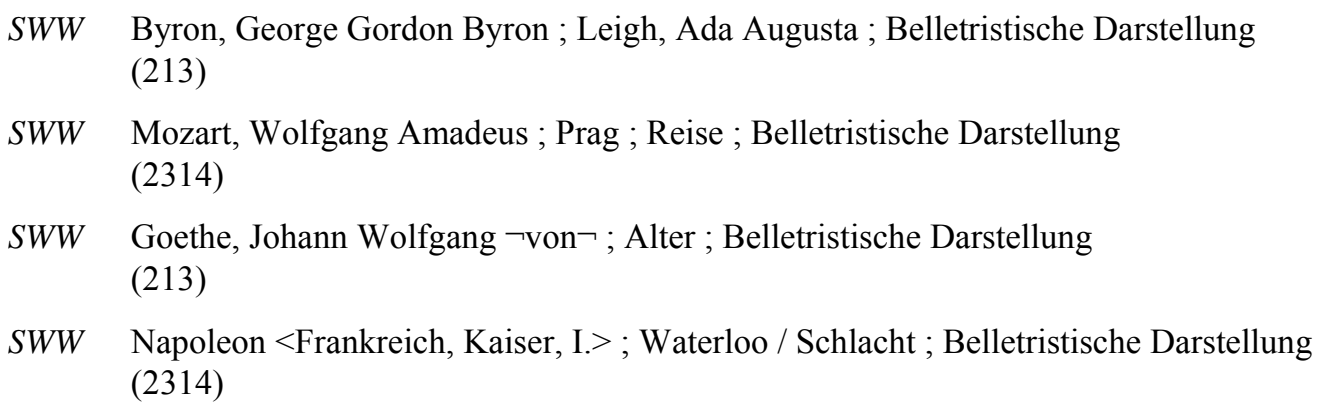

2. Geographische/ethnographische Schlagwörter (Ansetzung gemäß §§ 201ff.)

Für Dokumente, die über die Besonderheiten eines Geographikums oder Ethnographikums informieren, wird das entsprechende geographische oder ethnographische Schlagwort verwendet.

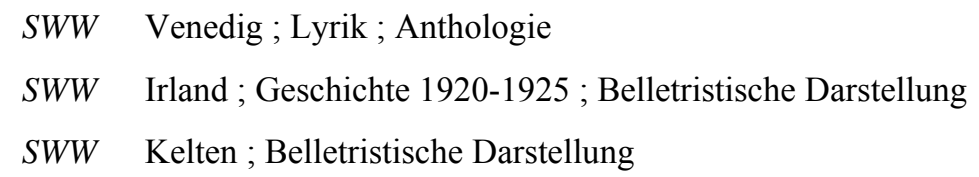

Nicht aufgenommen werden Dokumente, bei denen der Ort der Handlung zwar bestimmt werden kann, die aber keine Informationen über das Geographikum enthalten. Sehr spezielle, schwer nachweisbare oder möglicherweise fiktive geographische/ethnographische Schlagwörter werden vermieden (vgl. § 8,2).

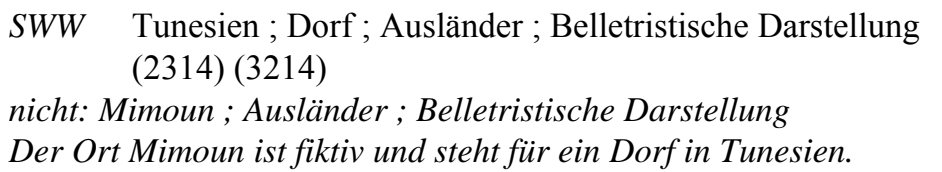

Bei nachweisbaren, sehr speziellen Geographika/Ethnographika, die für den Benutzer von Interesse sein könnten, sind zwei Grundketten mit dem spezifischen und dem übergeordneten Schlagwort möglich (vgl. auch § 13,4,e).

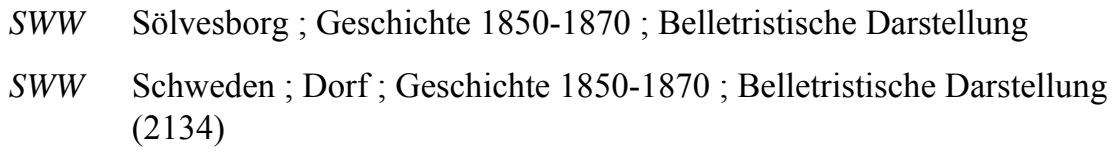


Ist ein spezifischer geographischer/ethnographischer Name allgemein bekannt, so wird auf die zweite Grundkette mit einem übergeordneten Schlagwort verzichtet.

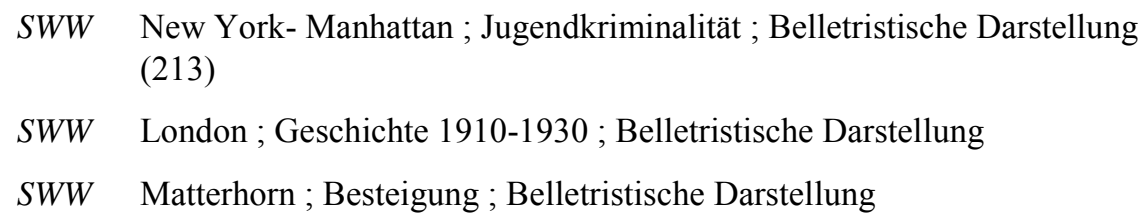

3. Sachschlagwörter (Ansetzung gemäß $\S \S 301 \mathrm{ff}$.)

Alle in der SWD enthaltenen Sachschlagwörter können auch für die Beschlagwortung der schönen Literatur verwendet werden. Auf sehr allgemeine Begriffe, die häufig Thema der schönen Literatur sind, sollte verzichtet werden, wenn sie nicht im Kontext der Schlagwortkette präzisiert werden können.

SWW Liebe ; Kurzgeschichte; Anthologie

SWW Weibliche Körperbehinderte ; Liebesbeziehung ; Belletristische Darstellung (213)

nicht: Liebe ; Belletristische Darstellung

Das Sachschlagwort wird entsprechend dem dargestellten Sachverhalt so spezifisch wie möglich gewählt.

SWW Leukämie ; Belletristische Darstellung

wenn diese Krankheit im Dokument behandelt wird

nicht: Krebs <Medizin> ; Belletristische Darstellung

Enthält die Darstellung über diesen begrenzten Sachverhalt hinaus noch weitergehende, allgemeinere Informationen, kann ein übergeordneter Begriff in einer weiteren Grundkette berücksichtigt werden.

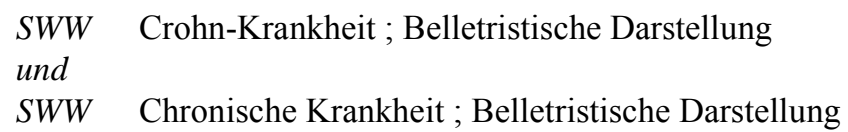

4. Zeitschlagwörter und andere Zeitaspekte (Ansetzung gemäß §§ 401ff.)

Zeitangaben werden auch bei der Erschließung der schönen Literatur verwendet, wenn die Darstellung historisch von Bedeutung ist. Dabei ist die zeitliche Eingrenzung häufig schwieriger als bei der Sachliteratur. Ggf. muss die Zeitangabe annäherungsweise bestimmt bzw. auf- oder abgerundet werden.

SWW Arzt ; Geschichte 1021-1050 ; Belletristische Darstellung

SWW Venedig; Ghetto ; Geschichte 1600 ; Belletristische Darstellung (2134)

Es handelt sich um eine Erzählung, die in einem historisch nur annäherungsweise bestimmbaren, aber sehr kurzen Zeitraum spielt.

Verbale Epochenbezeichnungen werden nur für Anthologien in Verbindung mit literarischen Gattungsbezeichnungen verwendet. Es werden entsprechend $\S 410$ zwei Grundketten gebildet.

SWW Barock; Lyrik; Deutsch; Anthologie

SWW Deutsch ; Lyrik ; Geschichte 1600-1720 ; Anthologie 
Die Epochenbezeichnungen 'Weimarer Republik' und 'Drittes Reich' können auch in Verbindung mit dem Formschlagwort 'Belletristische Darstellung' verwendet werden.

SWW Hamburg ; Geschichte 1933-1945 ; Belletristische Darstellung

SWW Drittes Reich; Hamburg ; Belletristische Darstellung

Bezeichnungen historischer Einzelereignisse werden auch bei der Erschließung schöner Literatur verwendet.

SWW Siebzehnter Juni ; Belletristische Darstellung

SWW Spanischer Bürgerkrieg; Politische Lyrik; Anthologie

(213)

Sind neben einem historischen Einzelereignis auch die beteiligten historischen Personen Gegenstand der Darstellung, so können mehrere Ketten gebildet werden.

$S W W \quad$ Dreißigjähriger Krieg; Theaterstück

$S W W \quad$ Albrecht $<$ Friedland, Herzog $>$; Theaterstück

Anstelle des Zeitschlagworts 'Prognose' wird bei schöner Literatur, die in der Zukunft spielt, das Sachschlagwort 'Zukunft' verwendet. Auf eine nähere Eingrenzung durch Jahreszahlen wird jedoch verzichtet.

SWW Polizeistaat; Zukunft ; Belletristische Darstellung

5. Körperschaftsnamen (Ansetzung gemäß §§ 601ff.)

Ist eine Körperschaft Gegenstand einer belletristischen Darstellung, so wird das entsprechende Schlagwort verwendet.

SWW Istanbul / Topkapi-Museum ; Belletristische Darstellung

SWW Sozialdemokratische Partei Deutschlands ; Geschichte 1890-1914 ; Belletristische Darstellung

6. Sprach- oder Mundartbezeichnungen (Ansetzung gemäß §§ 701ff.)

Sprach- und Mundartbezeichnungen werden bei der Beschlagwortung von Anthologien verwendet.

SWW Französisch; Lyrik; Anthologie

$S W W \quad$ Frankfurt $<$ Main $>$; Mundartlyrik; Anthologie

SWW Hessisch; Anthologie

Wenn sowohl nicht fiktionale als auch fiktionale Texte enthalten sind.

Einzelne Mundarttexte werden nach ihrem Inhalt erschlossen. Bei lokaler Anwendung können sie mit der Mundartbezeichnung und dem Formschlagwort 'Text' indexiert werden.

SWW Wuppertal ; Mundart ; Text

7. Werke einzelner Autoren, bildender Künstler und Musiker (Ansetzung gemäß $§ \S 707 f f .$, 723ff., 739ff.)

Sind einzelne literarische, wissenschaftliche, künstlerische oder musikalische Werke Gegenstand der Darstellung, so wird der entsprechende Werktitel verwendet.

SWW Ovidius Naso, Publius / Metamorphoses ; Belletristische Darstellung

SWW Barlach, Ernst / Lesender Klosterschüler ; Belletristische Darstellung

SWW Mozart, Wolfgang Amadeus / Don Giovanni ; Belletristische Darstellung 
8. Anonyme Werke, Teile der Bibel, Filme, Hörfunk- und Fernsehsendungen (Ansetzung gemäß § 707ff., 713, 733ff.)

Bearbeitungen von anonymen Werken und von Teilen der Bibel können mit ihrem Titel nachgewiesen werden. Weitere Grundketten mit anderen Schlagwortkategorien sind zulässig.
SWW Nibelungenlied; Belletristische Darstellung
SWW Nibelungen; Belletristische Darstellung
SWW Markusevangelium; Belletristische Darstellung
SWW $\quad$ Markus <Evangelist $>$; Belletristische Darstellung

Ist die Entstehung eines Films oder einer Hörfunk- oder Fernsehsendung Gegenstand der Darstellung, so wird deren Titel verwendet.

SWW Radio days ; Belletristische Darstellung

9. Formschlagwörter

Formschlagwörter werden entsprechend der Anl. 6 verwendet.

a) 'Anthologie' wird für Sammlungen überwiegend belletristischer Texte verwendet (für Texte eines oder mehrerer Autoren). Sie können thematisch zusammengestellt sein.

Die Reihenfolge ist: Thema ; ggf. Gattung ; 'Anthologie'.

$$
\begin{array}{ll}
S W W & \text { Rauchen; Prosa; Anthologie } \\
S W W & \text { New York }<\mathrm{NY}>\text {; Ostjuden; Anthologie }
\end{array}
$$

SWW Benjamin, Walter; Anthologie

Es handelt sich um eine Anthologie mit fiktiven Texten über Walter Benjamin.

Anthologien können aber auch Sammlungen mehrerer Texte einer Gattung sein (nur für Texte mehrerer Autoren).

SWW Sketch; Anthologie

SWW Witz; Anthologie

Zur Verwendung der Sprachbezeichnung bzw. des Geographikums vgl. § 704,a.

Die Reihenfolge ist: Sprache bzw. Geographikum ; Gattung ; ggf. Zeit ; 'Anthologie'.

SWW Neugriechisch; Märchen; Anthologie

sowohl für eine originalsprachige Ausgabe wie für eine Übersetzung in eine andere Sprache

SWW Französisch; Sage; Anthologie

SWW Afrika; Märchen; Anthologie

nicht: Afrikanische Sprachen

SWW Irland ; Märchen; Anthologie

nicht: Englisch und/oder Irisch

b) 'Comic' wird verwendet für Comics mit sachlichem Inhalt.

SWW Polen ; Judenverfolgung; Geschichte 1935-1942 ; Comic

(2134)

SWW Relativitätstheorie; Comic 
c) 'Hörspiel' wird verwendet für Hörspiele mit sachlichem Inhalt.

SWW Vater; Sohn ; Hörspiel

d) 'Text' kann bei lokaler Anwendung für die Beschlagwortung mundartlicher Texte verwendet werden.

SWW Frankfurt $<$ Main $>$ / Mundart ; Text

e) 'Theaterstück' wird verwendet für dramatische Texte.

SWW Fußballfan; Theaterstück

SWW Arzt ; Arzneimittel ; Experiment ; Theaterstück

(2314)

f) 'Belletristische Darstellung' wird für alle erzählenden Gattungen der schönen Literatur verwendet, soweit nicht die Formschlagwörter 'Anthologie', 'Comic', 'Hörspiel', 'Text' oder 'Theaterstück' angebracht sind.

g) Das Formschlagwort 'Humoristische Darstellung' findet bei der schönen Literatur keine Verwendung.

\section{Kinder- und Jugendliteratur}

\section{§ 763 Aufnahmeprinzipien für den Schlagwortkatalog}

Gemäß § 3,2 kann Kinder- und Jugendliteratur in den Schlagwortkatalog aufgenommen werden, soweit ihr Inhalt durch eine oder mehrere Schlagwortketten eindeutig wiedergegeben werden kann. Dies gilt besonders für Kinder- und Jugendsachbücher, deren Inhalt in aller Regel durch die in der SWD enthaltene Terminologie zu erschließen ist.

Erzählende Kinder- und Jugendliteratur sowie Bilderbücher sollten nur in den Schlagwortkatalog aufgenommen werden, wenn sie sachliche Informationen zu den dargestellten Themen bieten oder als Ergänzung zu angebotener Sachliteratur brauchbar sind. Dabei sind Benutzerinteressen und Suchverhalten gerade von Kindern und Jugendlichen zu berücksichtigen.

Eine Erschließung der erzählenden Kinder- und Jugendliteratur durch Gattungsbegriffe ist nur bei Anthologien möglich. Soll die gesamte erzählende Kinder- und Jugendliteratur erschlossen werden, so ist für die Gattungsbezeichnungen ein gesonderter Katalog zu führen. Die Gattungsbezeichnungen sollten der SWD entnommen werden.

Für die Ansetzung und Verwendung von Schlagwörtern bei der Erschließung von Kinder- und Jugendbüchern gelten die allgemeinen Bestimmungen des Regelwerks, soweit nicht im Folgenden Abweichungen festgelegt sind.

\section{§ 764 Schlagwortformen und Schlagwortkategorien}

Sämtliche nach diesem Regelwerk vorgesehenen Schlagwortformen und -kategorien können auch zur Erschließung von Kinder- und Jugendliteratur verwendet werden. Grundlage für die Erschließung ist die SWD. Dem Wortschatz von Kinderbüchern wird dort soweit möglich durch Synonymie-Verweisungen Rechnung getragen (vgl. z. B. § 309).

$\begin{array}{ll}\text { SW } & \text { Rutilismus } \\ \text { BF } & \text { Rothaarigkeit }\end{array}$ 
Der Zusatz $<$ Motiv $>$ wird bei der Beschlagwortung von Kinder- und Jugendliteratur nicht verwendet (vgl. § 705,8,a).

\section{§ 765 Einzelne Schlagwortkategorien}

Anm.: Im Folgenden sind Permutationsmuster nach $\S 15$ angegeben.

1. Personenschlagwörter (Ansetzung gemäß $\S § 101 \mathrm{ff}$.)

Für Kinder- und Jugendbücher über Leben und Werk nachweisbarer historischer oder zeitgenössischer Personen wird das Personenschlagwort verwendet, ebenso für Familien, biblische, mythologische und literarische Gestalten.

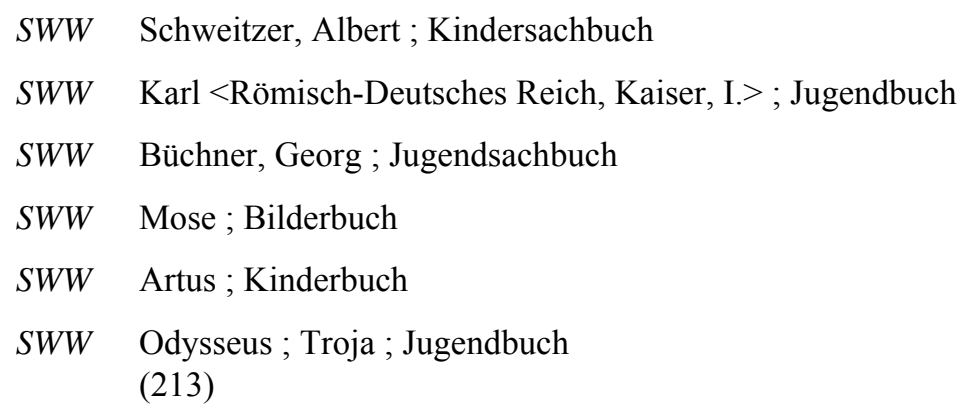

Auch die Beziehung einer Person zu anderen Personen oder einem Sachthema oder ein geographischer/ethnographischer Bezug wird ggf. berücksichtigt.

SWW Varus, Publius Quinctilius ; Teutoburger Wald / Schlacht ; Jugendbuch (2314)

2. Geographische/ethnographische Schlagwörter (Ansetzung gemäß §§ 201ff.)

Für Kinder- und Jugendbücher, die über die Besonderheiten eines Geographikums oder Ethnographikums informieren, wird das entsprechende Schlagwort verwendet.

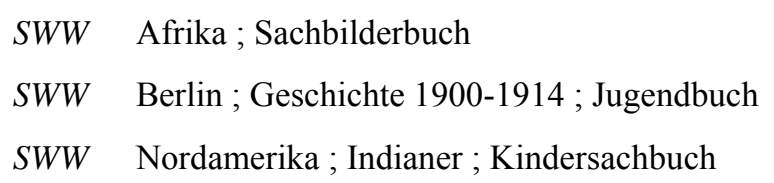

Nicht aufgenommen werden Dokumente, bei denen der Ort der Handlung zwar bestimmt werden kann, aber keine Informationen über das Geographikum enthalten sind. Sehr spezielle, schwer nachweisbare oder möglicherweise fiktive geographische/ethnographische Schlagwörter werden vermieden (vgl. § 8,2).

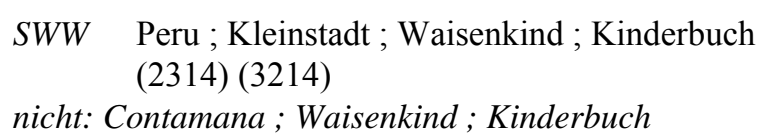

Bei nachweisbaren, sehr speziellen Geographika/Ethnographika, die für den Benutzer von Interesse sein könnten, sind zwei Grundketten mit dem spezifischen und dem übergeordneten Schlagwort möglich (vgl. auch $\S 13,4, \mathrm{e}$ ).

SWW Texel; Seehund; Kinderbuch (213) 
SWW Nordsee ; Seehund ; Kinderbuch

(213)

Ist ein spezifischer geographischer/ethnographischer Name allgemein bekannt, so wird auf die zweite Grundkette mit einem übergeordneten Schlagwort verzichtet.

SWW London; Juden ; Geschichte 1850-1890 ; Jugendbuch

(2134)

3. Sachschlagwörter (Ansetzung gemäß $\S$ 301ff.)

Alle in der SWD enthaltenen Sachschlagwörter können auch für die Beschlagwortung von Kinder- und Jugendbüchern verwendet werden. Dabei ist zu prüfen, inwieweit das nach $\S 6$ vorgeschriebene spezifische Schlagwort für das Suchverhalten von Kindern und Jugendlichen sinnvoll ist. Bei Sachbüchern ist i.d.R. das spezifische Schlagwort vorzuziehen.

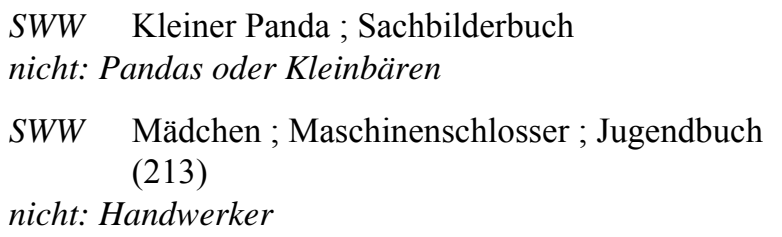

Bei erzählender Kinder- und Jugendliteratur kann das übergeordnete Schlagwort sinnvoller sein.

SWW $\quad$ Mutter ; Krebs $<$ Medizin $>$; Jugendbuch

nicht: Magenkrebs

SWW Dinosaurier; Bilderbuch

nicht: Diplodocus

Wird sowohl das jeweils spezifische Schlagwort als auch der übergeordnete Aspekt für suchrelevant gehalten, so sind zwei Grundketten möglich.

SWW Feldhase; Kinderbuch

SWW Hasen $<$ Familie $>$; Kinderbuch

Für die Indexierung von Bilderbüchern und erzählender Kinderliteratur ist das behandelte Thema maßgeblich, während die Protagonisten (häufig Tiere) und die Intention i.d.R. unberücksichtigt bleiben.

Titel: Post für den Tiger / Janosch. - 1996

SWW Post; Bilderbuch

nicht: Tiger ; Bär ; Bilderbuch

Titel: Ökowelt / Franz Kanehl. - 1993

SWW Umweltschutz; Kindersachbuch

nicht: Umwelterziehung ; Kindersachbuch

In Ausnahmefällen kann auch die Intention eines Buches für die Beschlagwortung herangezogen werden, besonders dann, wenn sich das Thema selbst nicht durch eine oder mehrere Schlagwortketten treffend erfassen lässt.

SWW Friedenserziehung; Kinderbuch 
4. Zeitschlagwörter und andere Zeitaspekte (Ansetzung gemäß §§ 401ff.)

Der zeitliche Aspekt wird auch bei der Erschließung von Kinder- und Jugendbüchern berücksichtigt. Soweit Zeitangaben nicht genau zu ermitteln sind, können sie auch fingiert bzw. auf- oder abgerundet werden.

SWW Burg; Geschichte 1000-1500 ; Sachbilderbuch

SWW Frankfurt $<$ Main $>$; Geschichte 1870-1914; Kindersachbuch

SWW Süddeutschland ; Hexenverfolgung; Geschichte 1627-1629 ; Jugendbuch (2134)

Verbale Epochenbezeichnungen werden nur für Anthologien in Verbindung mit literarischen Gattungsbezeichnungen oder bei Sachbüchern verwendet.

SWW Romantik; Kunstmärchen ; Französisch ; Anthologie ; Kinderbuch

SWW Französisch ; Kunstmärchen ; Geschichte 1810-1840 ; Anthologie ; Kinderbuch (21345)

SWW Sturm und Drang; Schriftsteller; Jugendsachbuch

SWW Deutschland ; Schriftsteller ; Geschichte 1750-1785 ; Jugendsachbuch (2134)

Die Epochenbezeichnungen 'Weimarer Republik' und 'Drittes Reich' werden generell bei der Erschließung von Kinder- und Jugendbüchern verwendet, also auch bei erzählender Literatur.

SWW Weimarer Republik; Arbeiterjugend ; Berlin ; Jugendbuch

SWW Berlin; Arbeiterjugend ; Geschichte 1918-1933; Jugendbuch (2134)

Historische Einzelereignisse können ebenfalls Gegenstand von Kinder- und Jugendbüchern sein.

SWW Französische Revolution ; Kindersachbuch

SWW Deutschland $<$ DDR $>$ / Revolution $<1989>$; Jugendbuch

5. Körperschaftsnamen (Ansetzung gemäß $\S 601 \mathrm{ff}$.)

Ist eine Körperschaft Gegenstand eines Kinder- und Jugendbuchs, so wird das entsprechende Schlagwort verwendet.
SWW Greenpeace e.V.; Jugendsachbuch
SWW München / Deutsches Museum ; Führer ; Kindersachbuch
SWW Vereinigungskirche; Jugendbuch

6. Sprach- und Mundartbezeichnungen (Ansetzung gemäß $\S \S 701 \mathrm{ff}$.)

Sprach- und Mundartbezeichnungen werden bei der Beschlagwortung von Anthologien und für Sprachführer und Wörterbücher für Kinder verwendet.

SWW Hessisch; Kinderreim; Anthologie ; Kinderbuch (2134)

SWW Englisch; Sprachführer; Jugendsachbuch

SWW Französisch; Wörterbuch ; Sachbilderbuch 
Bei lokaler Anwendung können einzelne Mundarttexte mit der Mundartbezeichnung und dem Formschlagwort 'Text' indexiert werden.

SWW Schwäbisch; Text ; Kinderbuch

7. Werke einzelner Autoren, bildender Künstler und Musiker (Ansetzung gemäß §§ 707ff.; 723ff.; 739ff.)

Sind einzelne literarische, wissenschaftliche, künstlerische oder musikalische Werke Gegenstand der Darstellung, so wird der entsprechende Werktitel verwendet.

SWW Mozart, Wolfgang Amadeus / $\neg$ Die $\neg$ Zauberflöte ; Kinderbuch

SWW Leonardo $<$ da Vinci $>$ / Mona Lisa ; Sachbilderbuch

8. $\quad$ Anonyme Werke, Teile der Bibel (Ansetzung gemäß §§ 707ff.; 713)

Bearbeitungen von anonymen Werken und von Teilen der Bibel für Kinder und Jugendliche sowie Bilderbücher zu einzelnen Märchen, Legenden und biblischen Geschichten können mit dem Werktitel nachgewiesen werden.
SWW Gilgamesch-Epos; Jugendbuch
SWW Barmherziger Samariter; Kinderbuch
SWW Wenzellegende; Bilderbuch
SWW $\neg$ Der $\neg$ gestiefelte Kater ; Bilderbuch

Weitere Schlagwortketten mit anderen Schlagwortkategorien sind möglich. Es hängt von der Darstellungsweise und der angesprochenen Altersgruppe ab, ob mehrere Schlagwortkategorien zu berücksichtigen sind oder welcher davon der Vorzug zu geben ist.

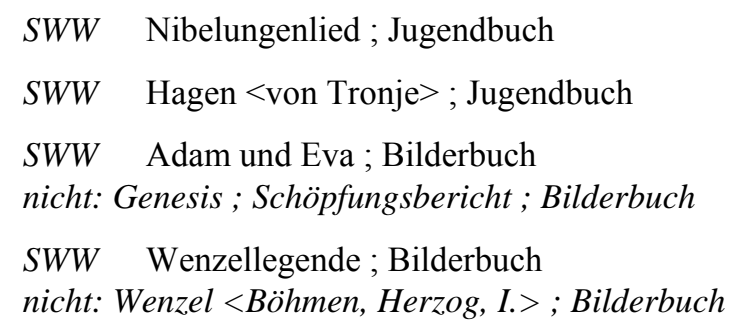

9. Formschlagwörter

Formschlagwörter werden entsprechend der Anl. 6 verwendet.

a) 'Comic' wird gemäß $\S 762,9, \mathrm{~b}$ für alle Comics ohne Unterscheidung von Kindercomics verwendet.

b) 'Bilderbuch' wird für thematisch erschließbare Bilderbücher mit überwiegend erzählendem Charakter verwendet, die sich meist an die Altersgruppe der Vorschulkinder und Leseanfänger wenden, und in denen die Abbildungen mindestens den gleichen Anteil wie der Textteil einnehmen.

c) 'Sachbilderbuch' wird für thematisch erschließbare Bilderbücher mit überwiegend sachlich informierendem Charakter verwendet, die sich meist an die Altersgruppe der Vorschulkinder und Leseanfänger wenden und in denen die Abbildungen mindestens den gleichen Anteil wie der Textteil einnehmen. Bestehen die Illustrationen weitgehend oder ausschließlich aus sachlichen Abbildungen (z.B. Photographien), so werden je nach Altersgruppe die Formschlagwörter 'Kindersachbuch' oder 'Jugendsachbuch' verwendet. 
d) 'Kinderbuch' wird für Bücher für die Altersgruppe bis etwa 12 Jahre mit überwiegend erzählendem Charakter verwendet, die einen bestimmten als Problem, Ereignis oder mit einem Namen benennbaren Gegenstand behandeln.

e) 'Kindersachbuch' wird für Bücher für die Altersgruppe bis etwa 12 Jahre mit überwiegend sachlich informierendem Charakter verwendet.

f) 'Jugendbuch' wird für Bücher für die Altersgruppe der etwa 12-15jährigen mit überwiegend erzählendem Charakter verwendet, die einen bestimmten als Problem, Ereignis oder mit einem Namen benennbaren Gegenstand behandeln. Im Zweifelsfall sind das äußere Erscheinungsbild, die sprachliche Form und die Ausrichtung des Verlags heranzuziehen, um sie von Kinderbüchern und von Literatur für Erwachsene abzugrenzen.

g) 'Jugendsachbuch' wird für Bücher für die Altersgruppe der etwa 12-15jährigen mit überwiegend sachlich informierendem Charakter verwendet. Im Zweifelsfall sind das äußere Erscheinungsbild, die sprachliche Form und die Ausrichtung des Verlags heranzuziehen, um sie von Kinderbüchern und von Literatur für Erwachsene abzugrenzen.

\section{$\S 766$ Verwendung mehrerer Formschlagwörter in einer Schlagwort- kette}

Bei der Erschließung von Kinder- und Jugendliteratur stehen die Formschlagwörter 'Bilderbuch', 'Jugendbuch', 'Jugendsachbuch', 'Kinderbuch', 'Kindersachbuch' und 'Sachbilderbuch' immer als letztes Glied in der Schlagwortkette. Falls die Verwendung eines weiteren Formschlagworts zur eindeutigen Kennzeichnung des vorliegenden Dokuments notwendig ist, kann dieses die vorletzte Stelle in der Schlagwortkette einnehmen.

Zugelassen sind dabei im Bereich Kinder- und Jugendliteratur die Formschlagwörter 'Anthologie' (für Sammlungen von erzählenden Texten und/oder Lyrik für Kinder und Jugendliche) und 'Theaterstück', bzw. 'Hörspiel' (für Theaterstücke und Hörspiele für Kinder und Jugendliche, die thematisch erschlossen werden können).

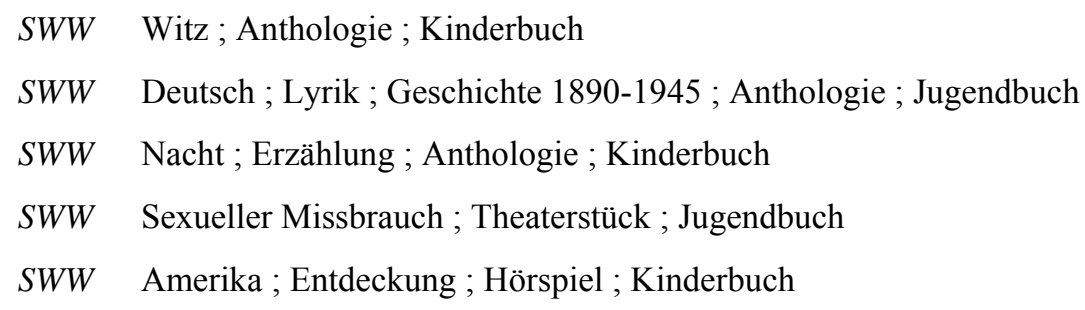

Bei Anthologien, die für Kinder bestimmt sind, ist das Thema bei der Beschlagwortung vorzuziehen, auch wenn es eine literarische Gattungsbezeichnung gibt, die den entsprechenden thematischen Aspekt enthält.

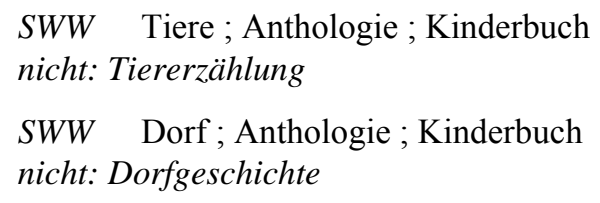

Für Sachbilderbücher, Kindersachbücher und Jugendsachbücher sind eine Reihe von Formschlagwörtern gemäß Anl. 6 als vorletztes Kettenglied möglich. Dies sind insbesondere

- Atlas

- Bestimmungsbuch

- Enzyklopädie （nur als erstes Kettenglied, sonst Wörterbuch) 
- Führer

- Kochbuch (auch als erstes Kettenglied)

- Kunstführer

- Ratgeber

- Sprachführer

- Wörterbuch

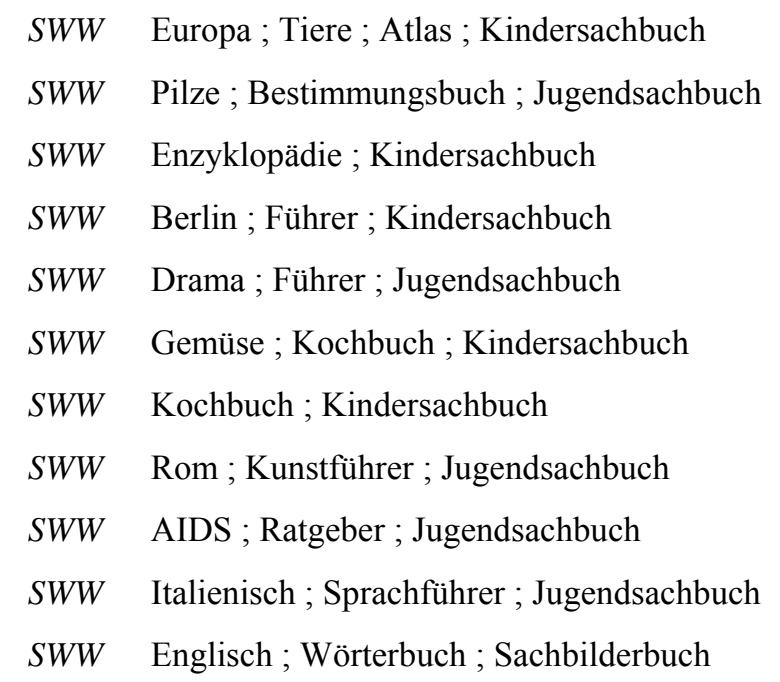

Für Kinder bestimmte Nichtbuchmaterialien ('Audiovisuelles Material', 'CD', 'CD-ROM', 'Diskette', 'Elektronische Publikation', 'Film', 'Schallplatte', 'Tonkassette', 'Tonträger' und 'Videokassette') erhalten das entsprechende Formschlagwort mit dem Zusatz < für Kinder> als letztes Glied in der Schlagwortkette.
SWW Chicago <Ill. > / Art Institute ; Führer ; CD-ROM < für Kinder $>$
SWW Windows 95 ; Diskette $<$ für Kinder $>$
SWW Beethoven, Ludwig $\neg$ van $\urcorner$; Biographie ; Tonträger $<$ für Kinder $>$

\section{Schulbücher und Berufsschulbücher}

\section{§ 767 Aufnahmeprinzipien für den Schlagwortkatalog}

Schulbücher und Lehrmittel für die allgemeinbildenden Schulen sowie Bücher und Materialien für die berufliche Ausbildung in staatlich anerkannten Ausbildungsberufen (im Folgenden vereinfachend Schul- und Berufsschulbücher genannt) können in ihrer Gesamtheit in den Schlagwortkatalog aufgenommen werden, ebenso Aufgabensammlungen und Materialien zur Vorbereitung auf den Unterricht oder auf Klassenarbeiten, Zwischen- und Abschlussprüfungen. Regelungen, die im anschließenden Text für Schulbücher getroffen werden, gelten, soweit im Folgenden keine abweichenden Bestimmungen festgelegt sind, auch für Lehrmittel und Aufgabensammlungen.

Anm.: Bücher und Materialien für andere als die staatlich anerkannten Ausbildungsberufe gelten nicht als Berufsschulbücher im Sinne dieser Regelung. Die Formschlagwörter 'Schulbuch', 'Lehrmittel' und 'Fachkunde' werden hier nicht verwendet. 


\section{§ 768 Unterrichtsfächer, Schularten und Schulstufen}

Anm.: Im Folgenden sind Permutationsmuster nach $\S 15$ angegeben.

1. Schul- und Berufsschulbücher werden mit dem Unterrichtsfach indexiert, für das sie bestimmt sind, nicht mit Begriffen, die den Inhalt des Faches kennzeichnen. Soweit die SWD keine andere Ansetzungsform vorsieht, ist dies ein Kompositum mit dem Grundwort 'unterricht'.

SWW Französischunterricht; Schulbuch

nicht: Französisch; Schulbuch

Aber:

SWW Verkehrserziehung; Grundschule ; Lehrmittel

SWW Wirtschaftslehre; Sekundarstufe 2 ; Schulbuch

Ist ein bestimmtes Thema in einem Unterrichtsfach Gegenstand der Darstellung, so wird es mit berücksichtigt.

SWW Optik; Physikunterricht ; Schulbuch

(213)

Ist in einem Dokument ein Thema für mehrere Unterrichtsfächer dargestellt, so kann für jedes Fach eine Schlagwortkette vergeben werden. Ist ein Thema fächerübergreifend behandelt, so wird das Schlagwort für ein übergeordnetes Unterrichtsfach (z.B. 'Naturwissenschaftlicher Unterricht') oder das in Listenfunktionen hier nicht permutierende Schlagwort 'Unterricht' verwendet.

SWW Gentechnologie; Unterricht; Lehrmittel

zusammenfassend für Sozialkunde-, Biologie-, Religions-, Deutsch- und Geschichtsunterricht

Bei der Behandlung linguistischer oder literarischer Sachverhalte in den sprachlichen Unterrichtsfächern wird die Sprache in Verbindung mit dem entsprechenden Sachschlagwort verwendet, wobei für Listenfunktionen die Listen der nicht permutierenden Schlagwörter in $\S 701,5$,a (linguistische Grundbegriffe) und $\S 703,1$,a (literarische Gattungsbezeichnungen) zu beachten sind. Die Bezeichnung des Unterrichtsfaches wird dann ebenfalls permutiert. Dabei ist darauf zu achten, dass bei der Berücksichtigung des Unterrichtsthemas zusammengehörige Schlagwörter zusammenbleiben.

SWW Latein ; Präposition ; Lateinunterricht ; Lehrmittel (2134) (3124)

SWW Englisch ; Grammatik ; Englischunterricht ; Schulbuch (3124)

keine Eintragung mit SW Grammatik gemäß § 701,5,a und Anl. 5

SWW USA ; Kurzgeschichte ; Englischunterricht; Lehrmittel (2134) (3124)

SWW Deutsch ; Lyrik ; Geschichte 1750-1900 ; Deutschunterricht ; Lehrmittel (41235)

keine Eintragung mit SW Lyrik gemäß § 703,1,a und Anl. 5

2. Zusätzlich zum Fach und/oder Thema des Unterrichts können, soweit zu ermitteln, die Schulart, die Schulstufe und/oder das Schuljahr, für die ein Schul- und Berufsschulbuch bestimmt ist, berücksichtigt werden. Sie erhalten jedoch für Listenfunktionen keine zusätzli- 
che Eintragung, soweit es sich nicht um besondere Schularten (z.B. Sonderschulen) oder Schulstufen (z.B. Orientierungsstufe) handelt.

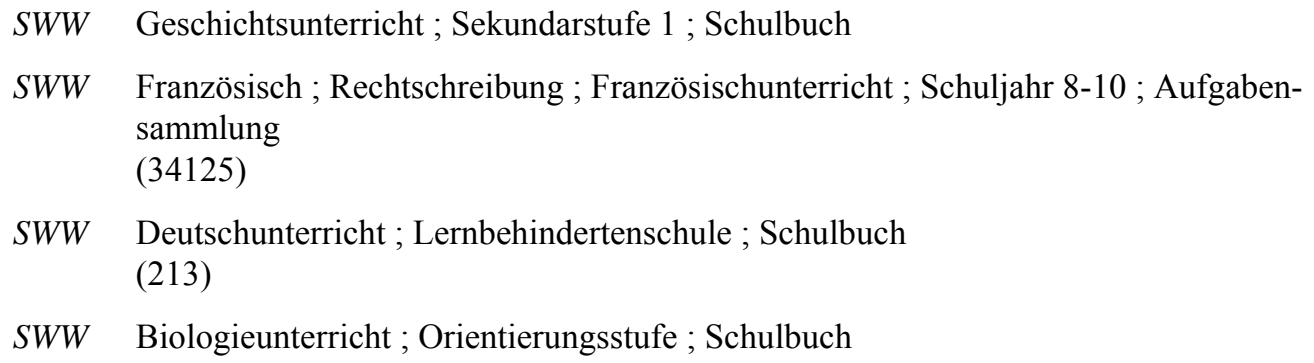

Ist ein Schulbuch für mehrere Schularten geeignet, so wird nach Möglichkeit, z.B. durch Verwendung der entsprechenden Schulstufe, zusammengefasst, statt mehrere Schlagwortketten zu bilden.

SWW Englischunterricht; Sekundarstufe 1; Schulbuch

für ein für Haupt-, Real- und Gesamtschulen geeignetes Schulbuch, auch wenn z.B. das Gymnasium nicht ausdrücklich mit berücksichtigt wird

SWW Kriegsdienstverweigerung ; Sozialkundeunterricht ; Sekundarstufe 2 ; Lehrmittel (2134) (2314)

für ein für Gymnasien und Berufsschulen geeignetes Lehrmittel

3. Für Schul- und Berufsschulbücher, die auch unanbhängig von einem Unterrichtsfach zu benützen sind, können zusätzliche Schlagwortketten vergeben werden.
SWW Geschichtsunterricht; Atlas ; Schulbuch
SWW Weltgeschichte; Atlas
SWW Physikunterricht; Formelsammlung; Schulbuch
SWW Physik; Formelsammlung
SWW Biologieunterricht ; Sekundarstufe 2 ; Lehrmittel
SWW Biologie; Einführung

\section{§ 769 Geographische Aspekte bei Schul- und Berufsschulbüchern}

Schul- und Berufsschulbücher sind häufig nur für ein Bundesland oder einen Staat bestimmt. Dies kann durch die Angabe des Geographikums an vorletzter Position in der Schlagwortkette gekennzeichnet werden. Das geographische Schlagwort wird für Listenfunktionen nicht permutiert.

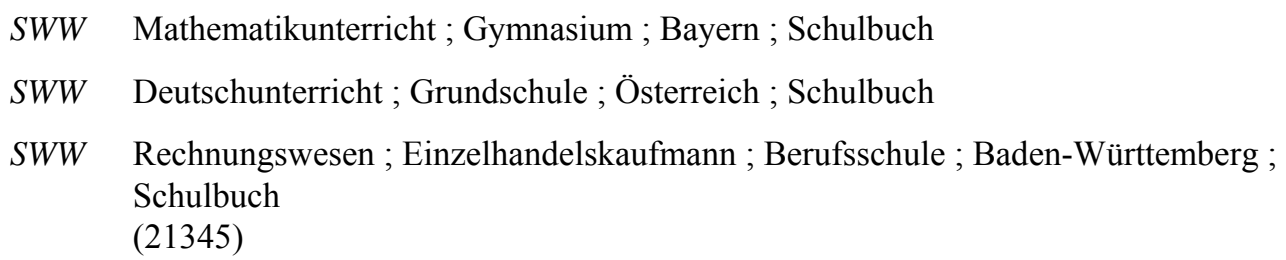

Ist ein Schul- oder Berufsschulbuch laut Impressum für zwei oder mehr Bundesländer zugelassen, so entfällt die Angabe des Bundeslandes.

Behandelt ein Schul- oder Berufsschulbuch auch Sachverhalte, die ein bestimmtes Bundesland, einen Staat oder eine Stadt betreffen, so wird das Geographikum gemäß § 201a berücksichtigt. 
SWW Hessen; Landeskunde; Geographieunterricht ; Schulbuch

(3124)

SWW München ; Geschichte 1918-1945 ; Geschichtsunterricht ; Sekundarstufe 2 ; Lehrmittel

\section{§ 770 Formschlagwörter}

Formschlagwörter werden entsprechend Anl. 6 verwendet.

a) 'Aufgabensammlung' wird für Fragen-, Übungs- und Aufgabensammlungen verwendet, die als Ergänzungen zum Unterricht oder für die Vorbereitung auf eine Prüfung bestimmt sind.

b) 'Fachkunde' wird für Berufsschulbücher verwendet, die das Fachwissen in einem staatlich anerkannten Ausbildungsberuf vollständig darstellen; sie sind i.d.R. über die Berufsausbildung hinaus auch als Handbücher für die berufliche Praxis verwendbar.

c) 'Lehrmittel' wird für Materialien verwendet, die die Schulbücher ergänzen oder ersetzen, geringere Verbindlichkeit für die Unterrichtsgestaltung haben und speziellere Themen für ein oder mehrere Unterrichtsfächer aufbereiten. Sie können sowohl für Schüler wie für Lehrer bestimmt sein. Die Bestimmungen über die Berücksichtigung geographischer Schlagwörter in $\S 769$ gelten auch für Lehrmittel.

d) 'Lesebuch' wird für Schullesebücher und für umfangreiche Textsammlungen für den Deutsch- und Fremdsprachenunterricht verwendet (vgl. § 773,2).

e) 'Schulbuch' wird für Unterrichtswerke verwendet, die für den Gebrauch an allgemeinbildenden und berufsbildenden Schulen zugelassen und für den Schüler bestimmt sind. Einzelne Teile eines mehrbändigen Werks, die für die Hand des Lehrers gedacht sind (Lehrerbände, Lehrerhandreichungen), werden i.d.R. nicht gesondert erschlossen.

f) Für Materialien, die ausschließlich für die Hand des Lehrers bestimmt sind, können außerdem die Formschlagwörter 'Lehrerhandbuch' und 'Unterrichtseinheit' verwendet werden.

Falls die Verwendung eines anderen Formschlagworts zur eindeutigen Kennzeichnung des vorliegenden Dokuments notwendig ist, steht das Formschlagwort 'Schulbuch' oder 'Lehrmittel' an letzter Stelle in der Schlagwortkette.

SWW Deutsch ; Grundwortschatz; Wörterbuch ; Schulbuch (2134)

Bei Nichtbuchmaterialien für Schulunterricht oder Berufsausbildung wie CD-ROMs, Disketten o.ä. steht das Formschlagwort für die physische Form an letzter Stelle in der Schlagwortkette.

\footnotetext{
SWW Physikunterricht; Gymnasium ; Oberstufe ; Aufgabensammlung ; CD-ROM

SWW Buchführung; Einzelhandelskaufmann; Berufsschule; Diskette (2134)
}

\section{§ 771 Schulbücher und Materialien für die Berufsausbildung}

1. Berufsschulbücher werden i.d.R. mit dem für Listenfunktionen nicht permutierenden Schlagwort 'Berufsschule' für die Schulart gekennzeichnet, wenn sie mit einem Ausbildungsberuf, für den sie bestimmt sind, oder mit einem Fach in Verbindung mit einem Ausbildungsberuf oder einem Berufsfeld indexiert werden. 


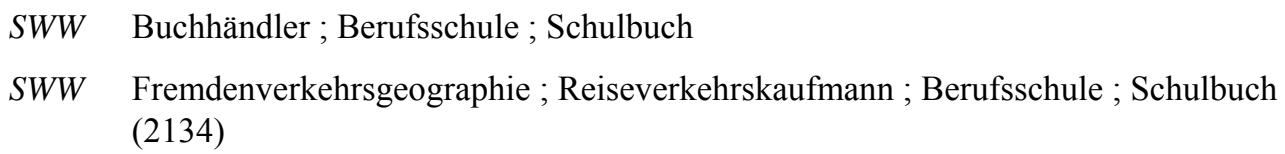

Bei der Erschließung von Schulbüchern für das Berufsgrundbildungsjahr, für ein spezielles Berufsfeld und für das Fach Praktische Fachkunde entfällt das Schlagwort 'Berufsschule'.

SWW Wirtschaftslehre ; Berufsgrundbildungsjahr; Schulbuch (213)

SWW Drehen; Berufsfeld Metalltechnik; Schulbuch (213)

SWW Friseur; Praktische Fachkunde; Schulbuch (213)

Ist ein Fach ohne bestimmte berufliche Ausrichtung, aber in Verbindung mit einer bestimmten berufsbildenden Schulart Gegenstand des Dokuments, so wird das Schlagwort für die Schulart verwendet und für Listenfunktionen permutiert.

SWW Deutschunterricht; Kaufmännische Berufsschule; Schulbuch (213)

Für Schulbücher und Lehrmittel, die für Berufsschulen und andere berufsbildende Schulen (z.B. Berufliche Gymnasien, Berufsfachschulen) geeignet sind, wird zusammenfassend das für Listenfunktionen nicht permutierende Schlagwort 'Berufsbildende Schule' verwendet.

SWW Sozialkundeunterricht; Berufsbildende Schule; Schulbuch

Für Schulbücher, die für allgemeinbildende und berufliche Schulen geeignet sind, wird zusammenfassend die Schulstufe verwendet.

SWW Wirtschaftslehre; Sekundarstufe 2 ; Schulbuch

2. Für die regelgerechte Ansetzung von Berufsbezeichnungen, gelten die in der jeweils neuesten Auflage von „Verzeichnis anerkannter Ausbildungsberufe“, „Beruf aktuell“ und „Blätter zur Berufskunde" genannten Bezeichnungen.

SWW Bäcker; Fachkunde

SWW Chemielaborant; Fachkunde

Ist ein Schulbuch für die weiblichen und männlichen Angehörigen einer Berufsgruppe bestimmt, so wird i.d.R. nur die männliche Form der Berufsbezeichnung verwendet.

SWW Deutschunterricht ; Industriekaufmann ; Berufsschule ; Schulbuch (2134)

Wendet sich das Buch besonders an die weiblichen Auszubildenden oder ist in dem entsprechenden Beruf die weibliche Berufsbezeichnung geläufiger, so wird diese verwendet.

SWW Labormedizin ; Arzthelferin; Berufsschule ; Schulbuch (2134) 


\section{§ 772 Materialien zur Prüfungsvorbereitung}

Dienen Schul- und Berufsschulbücher, Lehrmittel und insbesondere Aufgabensammlungen der Vorbereitung auf eine Prüfung, so wird deren Bezeichnung in Verbindung mit dem entsprechenden Fach oder Thema verwendet.

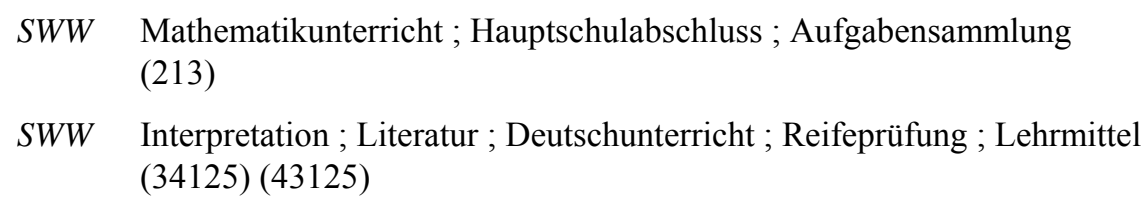

Das Schlagwort 'Abschlussprüfung' in Verbindung mit einem Ausbildungsberuf wird für Listenfunktionen nicht permutiert.

SWW Arzthelferin; Abschlussprüfung; Aufgabensammlung

Die Schulart entfällt i.d.R. im Zusammenhang mit Prüfungsbezeichnungen.

Bei Materialien, die für die Prüfungsvorbereitung in einem bestimmten Staat oder Bundesland bestimmt sind, wird entsprechend $\S 769$ verfahren.

SWW Deutschunterricht; Reifeprüfung ; Baden-Württemberg; Aufgabensammlung (2134)

\section{§ 773 Übungslektüre und Lesebücher}

1. Für den Sprachunterricht bestimmte Lektüretexte werden nicht indexiert. Eine Ausnahme bilden umfangreiche Textsammlungen, die das Formschlagwort 'Lesebuch' erhalten.

Für lektüreergänzende Materialien, Wörterverzeichnisse und Ähnliches wird der Titel (i.d.R. der Name des Autors in Verbindung mit dem Einheitssachtitel oder der Titel des anonymen Werkes) verwendet. (Zur Ansetzung vgl. §§ 707-712.) Mit dem Unterrichtsfach wird verknüpft.

Titel: Erläuterungen zu Schillers Wilhelm Tell für den Schulgebrauch / hrsg. von Wilhelm König. - 1894

SWW Schiller, Friedrich / Wilhelm Tell ; Deutschunterricht ; Lehrmittel (3124)

Inhalt: Wörterverzeichnis zu Albert Camus „La peste“ als Schullektüre

SWW Camus, Albert $/ \neg$ La $\neg$ peste ; Wortschatz ; Französischunterricht ; Lehrmittel (41235)

2. Fibeln werden durch das Schlagwort 'Erstleseunterricht' erschlossen.

SWW Erstleseunterricht; Schulbuch

Bei Fibeln für den Erstleseunterricht im Ausland wird zusätzlich das entsprechende geographische Schlagwort verwendet, bei fremdsprachigen Minderheiten das entsprechende ethnographische Schlagwort.

$$
\begin{aligned}
& \text { SWW Erstleseunterricht ; Dänemark ; Schulbuch } \\
& \text { SWW Erstleseunterricht ; Dänen ; Schleswig-Holstein ; Schulbuch } \\
& \text { für den Erstleseunterricht der dänischen Minderheit in Schleswig-Holstein }
\end{aligned}
$$

Lesebücher werden unter dem Unterrichtsfach in Verbindung mit dem Formschlagwort 'Lesebuch' nachgewiesen. 
SWW Deutschunterricht; Schuljahr 3-4 ; Lesebuch

Als Lesebücher gelten auch umfangreiche Textsammlungen (Anthologien) für den Deutschund Fremdsprachenunterricht.

SWW Latein; Literatur; Lateinunterricht; Lesebuch (3124)

SWW Deutsch ; Lyrik ; Geschichte 1200-1950 ; Deutschunterricht ; Lesebuch (41235) 


\section{Ordnungsregeln}

\section{§ 801 Ordnung der Eintragungen bei Listenfunktionen}

Für Listenfunktionen werden die Ordnungsregeln der RAK übernommen (RAK $\S \S 801 \mathrm{ff}$.), die sinngemäß für alle Schlagwortkategorien bei der Ordnung von Eintragungen im Schlagwortkata$\log$ gelten. 



\section{Anlage 1}

\section{Ansetzung der geistlichen Reichsfürsten 1500-1803}

Zusammenstellung in: Handbuch der deutschen Geschichte / Gebhardt. - 9. Aufl., Ansetzung nach LThK, Köbler und Handbuch der historischen Stätten.

Listen der Bischöfe sind enthalten bei: Grote, Hermann: Stammtafeln. Leipzig: Hahn, 1877. Neudr. Wiesbaden: Fourier, 1983 sowie Gams, Pius Bonifacius: Series episcoporum ecclesiae catholicae 1873-1886. Repr.: Graz: Akad. Dr.- u. Verl.-Anstalt 1957.

\section{Erzdiözesen, Diözesen}

Ihre Erzbischöfe bzw. Bischöfe werden bis zur Säkularisation 1803 bzw. bis zurAuflösung des Reiches nach $\S 108$,8,a wie Herrscher in normierter Form angesetzt.
Augsburg <Diözese $>$
Köln $<$ Diözese $>$
Bamberg <Diözese $>$
Konstanz <Diözese $>$
Basel < Diözese $>$ (bis 1806)
Lübeck < Diözese $>$
Besançon <Diözese > (1674 an Frankreich)
Lüttich < Diözese > (bis 1793)
Brandenburg < Havel, Diözese> (1560 an
Mgf. Brandenburg)
Magdeburg <Diözese> (1648 säkularisiert)
Bremen <Diözese> (1648 säkularisiert)
Brixen $<$ Diözese $>$
Cambrai <Diözese $>$ (bis 1582, dann zu
Frankreich bzw. landständisch)
Cammin <Pommern, Diözese> (1648 säku- larisiert)
Mainz < Diözese >
Meißen <Diözese> (1581 aufgelöst)
Merseburg <Diözese > (1561 säkularisiert)
Metz < Diözese $>$ (1552 zu Frankreich)
Minden <Westfalen, Diözese> (1648 säku- larisiert)
Chur $<$ Diözese $>$ (bis 1806)
Corvey $<$ Diözese $>$ (1792-1803; vorher
Reichsabtei)
Eichstätt $<$ Diözese $>$
Münster <Westfalen, Diözese $>$
Naumburg < Saale, Diözese > (1564 säkulari- siert)
Osnabrück $<$ Diözese $>$
Freising $<$ Diözese $>$
Paderborn <Diözese $>$
Fulda <Diözese > (ab 1752; vorher Reichs-
Passau <Diözese $>$ abtei)
Ratzeburg <Diözese> (1554 an Mecklen- burg)
Halberstadt < Diözese> (1648 säkularisiert)
Havelberg <Diözese > (1548 an Branden- burg)
Regensburg $<$ Diözese $>$
Salzburg $<$ Diözese $>$
Hildesheim < Diözese >
Schwerin < Diözese> (1648 säkularisiert) 
Speyer $<$ Diözese $>$

Straßburg <Diözese > (bis 1803)

Toul <Diözese> (1552 zu Frankreich)

Trient $<$ Diözese $>$

Trier $<$ Diözese $>$
Verden <Aller, Diözese> (1644 säkularisiert)

Verdun < Diözese> (1552 zu Frankreich)

Worms < Diözese $>$

Würzburg <Diözese >

\section{Utrecht $<$ Diözese $>(1648$ zur Niederlande)}

Anm.: Die Diözesen Genf, Lausanne und Sitten sind nicht aufgeführt, da sie ab 1499 Reichsstandschaft nicht mehr wahrnahmen.

Nach 1648 (Westfälischer Friede) wurden Magdeburg, Meissen, Halberstadt, Minden, Bremen, Verden, Schwerin in weltliche Fürstentümer bzw. Herzogtümer umgewandelt und erhielten als solche Sitz und Stimme auf der weltlichen Bank des Reichsfürstenrates.

Als evangelische geistliche Fürstentümer blieben Lübeck und Osnabrück erhalten. Lübeck wechselte 1530 zur Reformation über, blieb aber bis 1803 ein evangelisches geistliches Fürstentum mit Sitz und Stimme im Reichsfürstenrat;

daher: Eberhard <Lübeck, Bischof, II.>

Holle, Eberhard $\neg$ von $\neg B S$ Eberhard $<$ Lübeck, Bischof, II. $>$

(Nach Grote war Eberhard evangelischer Bischof und regierte 1561-1586.)

Der gleiche Sachverhalt trifft zeitweise auch auf das Bistum Verden zu. Martin Weiher wurde als evangelischer Bischof von Cammin 1551 sogar von Rom selbst bestätigt.

Für die Übergangszeit bis zur Regelung durch den Westfälischen Frieden ist daher eine normierte Ansetzung auch der evangelischen geistlichen Bischöfe als Reichsfürsten angebracht.

\section{Nicht dem Reichsfürstenrat angehörige Erzdiözesen und Diözesen}

Ihre Erzbischöfe bzw. Bischöfe werden wie sonstige Personen ihrer Zeit angesetzt.

$\begin{array}{ll}\text { Breslau }<\text { Diözese }> & \text { Leitomischl }<\text { Diözese }> \\ \text { Brünn }<\text { Diözese }> & \text { Leoben }<\text { Diözese }> \\ \text { Budweis }<\text { Diözese }> & \text { Linz }<\text { Diözese }> \\ \text { Chiemsee }<\text { Diözese }> & \text { Ljubljana }<\text { Diözese }> \\ \text { Genf }<\text { Diözese }> & \text { Olmütz }<\text { Diözese }> \\ \text { Graz-Seckau }<\text { Diözese }> & \text { Prag }<\text { Diözese }> \\ \text { Gurk }<\text { Diözese }> & \text { Sankt Pölten }<\text { Diözese }> \\ \text { Königgrätz }<\text { Diözese }> & \text { Schleswig }<\text { Diözese }>(\text { zu Dänemark }) \\ \text { Lavant }<\text { Diözese }> & \text { Sitten }<\text { Diözese }> \\ \text { Lausanne }<\text { Diözese }> & \text { Triest }<\text { Diözese }> \\ \text { Lebus }<\text { Diözese }> & \text { Wien }<\text { Diözese }> \\ \text { Leitmeritz }<\text { Diözese }> & \text { Wiener Neustadt }<\text { Diözese }>\end{array}$

\section{Klöster und Stifte mit Reichsstandschaft}

Ihre Äbte, Pröpste usw. werden wie sonstige Personen ihrer Zeit angesetzt. 


\section{Anlage 2}

Nicht aussagekräftige Sachschlagwörter nach Personenschlagwörtern und Sachschlagwörter, die üblicherweise in Verknüpfung mit Personennamen entfallen (Empfehlende Liste)

\section{Anekdote}

$\mathrm{H}$ In Verknüpfung mit $\mathrm{f}$ Anthologie nach Personennamen nicht permutierend.

Architektur

Ausbildung

Autograph

Bibliothek

Bildnis

H Vgl. auch Anl. 6.

\section{Bildung}

Biographie

H Vgl. auch Anl. 6.

Charakter

Denkmal

H Vgl. § 725,5.

\section{Drama}

H Vgl. § 117,4.

Druckgraphik

Edition

Epik

H Vgl. § 117,4.

Epos

H Vgl. § 117,4.

Erzähltechnik

Erzählung

H Vgl. § 117,4.

Evangelische Theologie $B S$ Theologie

Familienleben
Film

H Mit Ausnahme bei Motiven; vgl. Anl. 6

Forschung

Frau

Freundeskreis

H Vgl. § 117,4.

Gedenkstätte

Genealogie

Geschichtsschreibung

Grab

H Vgl. § 725,5.

Grabmal

H Vgl. § 725,5.

\section{Graphik}

H Vgl. § 117,4 und Anl. 6.

Handschrift <Graphologie>

Heiligenverehrung

Humor

Jubiläum

$\mathrm{H}$ Historisches Einzelereignis nach "Praxisregeln" zu § 415a,2 SW Luther, Martin/ Jubiläum <1993>

Jugend

$\mathrm{H}$ Entfällt, ist immer durch $\mathrm{f}$ Biographie und Lebensdaten zu ersetzen.

Katholische Theologie BS Theologie 


\section{Künstlerisches Werk}

$\mathrm{H}$ Wird nur verwendet, wenn lediglich ein Teil des Werkes Kunst betrifft.

Kult

\section{Kunst}

$\mathrm{H}$ Entfällt i. d. R. in Verbindung mit dem Namen bildender Künstler, vgl. § 116,2,c.

\section{Lehrtätigkeit}

\section{Literarisches Werk}

$\mathrm{H}$ Wird nur verwendet, wenn lediglich ein Teil des Werkes Literatur betrifft.

\section{Literatur}

$\mathrm{H}$ Entfällt in Verbindung mit den Namen einzelner Schriftsteller, vgl. § 116,2,c.

\section{Lyrik}

$$
\text { H vgl. } \S 117,4
$$

\section{Malerei}

$$
\text { H Vgl. § 117,4. }
$$

\section{Mann}

Menschenbild

Musik

H Entfällt i. d. R., vgl. § 116,2,c.

\section{Nachkomme}

\section{Nachlass}

\section{Oper}

$$
\text { H Vgl. § 117,4. }
$$

\section{Philosophie}

$$
\text { H Vgl. § 117,4. }
$$

\section{Plastik}

H Vgl. § 117,4.

\section{Politik}

H Entfällt i. d. R., vgl. § 116,2,c.

\section{Politisches Denken}

Prosa

$$
\text { H Vgl. § 117,4. }
$$

Prosastil BS Sprache

\section{Prozess}

Reformierte Theologie BS Theologie

$$
\begin{aligned}
& \text { Regierung } \\
& \text { Reise } \\
& \text { H Vgl. } \S 117,4 . \\
& \text { A } 4
\end{aligned}
$$

\section{Religion}

Rezeption

Rhetorik

Roman

H Vgl. § 117,4.

Sammlung

H Vgl. § 736 .

\section{Sprache}

H Vgl. § 117,4.

BF Prosastil

Sprachstil

Stil

Sprachstil BS Sprache

Stil $B S$ Sprache

\section{Theologie}

H Vgl. § 117,4.

BF Evangelische Theologie

Katholische Theologie

Reformierte Theologie

Tod

Übersetzung

Umkreis

$\mathrm{H}$ nur für Künstler benutzt

Verehrung

Weltanschauung

Weltbild

Werk

H Entfällt i. d. R., vgl. § 116,2,c.

Ausnahme: Nicht permutierendes Schlagwort in Verbindung mit der Sprachbezeichnung bei Autoren, die in mehreren Sprachen schreiben.

Witz

$\mathrm{H} \quad$ Bei Verknüpfung mit $\mathrm{f}$ Anthologie nach Personennamen nicht permutierend.

\section{Wortschatz}

Zeichnung

H Vgl. § 117,4.

\section{Zeitgenossen}

Zeithintergrund 
Anlage 3 entfällt

\section{Anlage 4}

\section{Bundesstaaten der USA und ihre Abkürzungen in Homonymenzusätzen}

$\begin{array}{llll}\text { Alabama } & <\text { Ala. } & \text { Montana } & <\text { Mont. } \\ \text { Alaska } & <\text { Alas. }> & \text { Nebraska } & <\text { Neb. } \\ \text { Arizona } & <\text { Ariz. }> & \text { Nevada } & <\text { Nev. } \\ \text { Arkansas } & <\text { Ark. }> & \text { New Hampshire } & <\text { NH }> \\ \text { California } & <\text { Calif. }> & \text { New Jersey } & <\text { NJ }> \\ \text { Colorado } & <\text { Colo. }> & \text { New Mexico } & <\text { NM }> \\ \text { Connecticut } & <\text { Conn. }> & \text { New York } & <\text { NY }> \\ \text { Delaware } & <\text { Del. }> & \text { North Carolina } & <\text { NC }> \\ \text { District of Columbia } & <\text { DC }> & \text { North Dakota } & <\text { ND }> \\ \text { Florida } & <\text { Fla. }> & \text { Ohio } & <\text { Ohio }> \\ \text { Georgia } & <\text { Ga. }> & \text { Oklahoma } & <\text { Okla. }> \\ \text { Hawaii } & <\text { Hawaii }> & \text { Oregon } & <\text { Or. }> \\ \text { Idaho } & <\text { Idaho }> & \text { Pennsylvania } & <\text { Pa. }> \\ \text { Illinois } & <\text { Ill. }> & \text { Rhode Island } & <\text { RI }> \\ \text { Indiana } & <\text { Ind. }> & \text { South Carolina } & <\text { SC }> \\ \text { Iowa } & <\text { Iowa }> & \text { South Dakota } & <\text { SD }> \\ \text { Kansas } & <\text { Kan. }> & \text { Tennessee } & <\text { Tenn. }> \\ \text { Kentucky } & <\text { Ky. }> & \text { Texas } & <\text { Tex. }> \\ \text { Louisiana } & <\text { La. }> & \text { Utah } & <\text { Utah }> \\ \text { Maine } & <\text { Me. }> & \text { Vermont } & <\text { Vt. }> \\ \text { Maryland } & <\text { Md. }> & \text { Virginia } & <\text { Va. }> \\ \text { Massachusetts } & <\text { Mass. } & \text { Washington } & <\text { Wash. }> \\ \text { Michigan } & <\text { Mich. }> & \text { West Virginia } & <\text { W Va. }> \\ \text { Minnesota } & <\text { Minn. }> & \text { Wisconsin } & <\text { Wis. }> \\ \text { Mississippi } & <\text { Miss. }> & \text { Wyoming } & <\text { Wyo. }> \\ \text { Missouri } & <\text { Mo. }> & & \\ & & & \end{array}$





\section{Anlage 5}

\section{Sach- und Zeitschlagwörter, die nicht permutiert werden (Empfehlende Liste)}

Akzent

H In Verknüpfung mit Sprachbezeichnungen nicht permutierend, vgl. § 701,5,a.

Allgemeiner Teil

H Ausschließlich nach Fachausdrücken des Rechts.

\section{Analyse}

$\mathrm{H}$ Allgemeinbegriff, möglichst spezifischer indexieren. Mit dem jeweiligen Objekt wird i. d. R. ein Kompositum bzw. eine Adjektiv-Substantiv-Verbindung gebildet; z. B. SW Datenanalyse, SW Musikalische Analyse. Für die Chemie wird SW Chemische Analyse benutzt.

Analyse $<$ Chemie $>$ BS Chemische Analyse

\section{Anatomie}

H In Verknüpfung mit einzelnen Organen oder Lebewesen nicht permutierend; für Pflanzen wird SW Pflanzenanatomie verwendet.

UB Pflanzenanatomie

\section{Architektur}

H In Verknüpfung mit Personennamen nicht permutierend.

\section{Aufbau}

\section{Aufführung}

H Nicht permutierendes Schlagwort in Verknüpfung mit einzelnen Autoren in Verbindung mit Werktitel oder Gattungsbezeichnung oder nach Sprachbezeichnungen in Verbindung mit Ort bzw. Theater und Jahreszahl.

SWW p Halévy, Fromental / $\mathrm{t}$ La $\neg$ juive ; s Aufführung ; g Paris ; z Geschichte 1835

VB Inszenierung

\section{Ausbildung}

H In Verknüpfung mit Personennamen, Personengruppen und Berufen nicht permutierend, sofern nicht SW Berufsausbildung (im Fall von Ausbildungsberufen) oder andere spezifische Schlagwörter in Frage kommen.

\section{Ausgrabung}

H In Verknüpfung mit Geographika nicht permutierend, vgl. § 220,2, für Darstellungen der Ausgrabungsvorgänge sowie üblicherweise in Verbindung mit Bauwerken.

VB Funde

\section{Außenpolitik}

H In Verknüpfung mit einzelnen Staaten und Personen nicht permutierend, vgl. § 220,4. 


\section{Aussprache}

H In Verknüpfung mit Sprachbezeichnungen nicht permutierend, vgl. § 701,5,a.

\section{Auswirkung}

H Für Nachwirkungen und Folgen von Ereignissen aller Art.

VB Rezeption

\section{Autorschaft}

H Für Untersuchungen über die Frage, wer ein Werk verfasst hat, in Verknüpfung mit dem Werktitel nicht permutierend.

\section{Bearbeitung}

$\mathrm{H}$ Nicht permutierend nach Personen und ihrem Werk sowie nach anonymen Werktiteln bei Bearbeitung durch andere Personen. Für die Bearbeitung durch den Autor selbst wird SW Umarbeitung verwendet. In der Technik werden i. d. R. Komposita mit dem bearbeiteten Gegenstand gebildet, z. B. SW Blechbearbeitung.

VB Redaktion Umarbeitung

\section{Begriff}

H Nicht permutierendes Schlagwort bei Konkreta (z. B. Erziehung, Literatur) zur Kennzeichnung von Definitorischem, Begriffsinhaltlichem u. ä. Bei Abstrakta (z. B. Treue, Wahrheit) entfällt das SW Begriff, außer in Verbindung mit Individualnamen, vgl. Praxisregel zu $\S 305,1$,c.

$$
\text { SWW s Erziehung; s Begriff }
$$

\section{Bekämpfung}

H In der Medizin wird i. d. R. SW Prävention bzw. SW Therapie verwendet.

\section{Besonderer Teil}

H Ausschließlich nach Fachausdrücken des Rechts.

\section{Besteigung}

$\mathrm{H} \quad$ In Verknüpfung mit Bergnamen nicht permutierend. Einzelne Besteigungen werden nicht als historisches Einzelereignis behandelt, sondern es wird mit SW Geschichte und Jahreszahl verknüpft; auch für geplante Besteigungen.

SWW g Mount Everest ; s Besteigung ; z Geschichte 1953

\section{Bewertung}

D Allgemein im Sinne der qualitativen und quantitativen Bewertung von Institutionen, Materialien, Gegenständen u. ä.

H Nach Möglichkeit genauer indexieren. In der Psychologie und Pädagogik wird für die subjektive Einschätzung von Handlungen, Eigenschaften bzw. von Personen und Personengruppen SW Beurteilung bevorzugt. Nicht permutierend, wenn im Sinne der qualitativen und quantitativen Bewertung eines Sachverhalts nach bestimmten Kriterien verwendet; SW Bewertung im steuerrechtlichen Sinn wird dagegen permutiert

SWW s Umweltschaden; s Bewertung

\section{Chemische Analyse}

H In Verknüpfung mit dem analysierten Stoff nicht permutierend.

\section{Chemische Synthese}

H In Verknüpfung mit dem synthetisierten Stoff nicht permutierend. 


\section{Chronologie}

$\mathrm{H} \quad$ Als Formschlagwort wird $\mathrm{f}$ Zeittafel verwendet.

\section{Datierung}

\section{Diagnose}

H In Verknüpfung mit einzelnen Krankheiten nicht permutierend.

\section{Drama}

$\mathrm{H}$ In Verknüpfung mit einzelnen Sprachbezeichnungen, Geographika und Personennamen nicht permutierend, vgl. § 703,1.

\section{Druckwerk}

H Benutzt für das Druckerzeugnis; für die Gesamtheit von Hochdrucktechnik und Druckerzeugnis der frühen Druckgeschichte (bis ca. 17.Jh.) wird SW Buchdruck verwendet. Je nach Sachverhalt mit Geographikum oder Sprachbezeichnung verknüpfen.

SWW p Luther, Martin ; s Druckwerk ; c Coburg / Landesbibliothek

SWW s Medizin ; s Druckwerk ; z Geschichte 1600-1700

\section{Echtheit}

H In Verknüpfung mit einzelnen Werken nicht permutierend.

\section{Edition}

D Wissenschaftliche, kritische Herausgabe eines Textes.

$\mathrm{H} \quad$ In Verknüpfung mit Personen und Werktiteln nicht permutierend.

\section{Entdeckung}

H In Verknüpfung mit Geographika nicht permutierend.

\section{Entstehung}

H In Verknüpfung mit einzelnen Gegenständen nicht permutierend, z.B. SWW Sonnensystem ; Entstehung, SWW Schweiz ; Entstehung. Die Schlagwörter s Entwicklung, s Vorgeschichte und z Geschichte werden bevorzugt verwendet.

VB Entwicklung

\section{Entwicklung}

VB Entstehung

\section{Entwurf}

H Nicht permutierendes Schlagwort bei Sekundärliteratur über Entwürfe zu Werken, Regeln, Normen usw. Für Entwürfe der Technik und Architektur können auch f Plan und spezifischere Schlagwörter verwendet werden. In Verknüpfung mit Gesetzestiteln wird mit SW Gesetzentwurf verknüpft. Zu Entwürfen von Verfassungen vgl. § 717.

\section{Epik}

$\mathrm{H}$ In Verknüpfung mit einzelnen Sprachbezeichnungen, Geographika und Personennamen nicht permutierend, vgl. § 703,1.

\section{Epos}

H In Verknüpfung mit einzelnen Sprachbezeichnungen, Geographika und Personennamen nicht permutierend, vgl. § 703,1.

\section{Erforschung}

H Nur in Verknüpfung mit Geographika verwendet. Für wissenschaftliche und länderkundliche Disziplinen gibt es daneben Komposita, z.B. SW Arktisforschung, SW Frankreichforschung.

OB Forschung 


\section{Erzählung}

H In Verknüpfung mit einzelnen Sprachbezeichnungen, Geographika und Personennamen nicht permutierend, vgl. § 703,1.

\section{Etymologie}

H In Verknüpfung mit Sprachbezeichnungen nicht permutierend, vgl. § 701,5,a.

\section{Exegese}

H In Verknüpfung mit Teilen der Bibel und einzelnen biblischen Büchern nicht permutierend.

\section{Exkursion}

H In Verknüpfung mit Geographika bzw. Fachgebieten nicht permutierend; verknüpfe ggf. mit f Führer

$$
\text { SWW g Hessen ; s Geologie ; s Exkursion ; f Führer }
$$

\section{Expedition}

H In Verknüpfung mit Geographika nicht permutierend. Für einzelne Expeditionen wird i.d.R. mit einem Zeitschlagwort mit Jahreszahlen verknüpft.

\section{Fachsprache}

H In Verknüpfung mit einzelnen Sprachbezeichnungen und Fachgebieten nicht permutierend, vgl. §§ 701,4,b; 701,5,a. I.d.R. wird kein Kompositum gebildet.

\section{Film}

H Nicht permutierend nach Werktiteln bei Verfilmungen sowie in Verknüpfung mit Schauspielern, Regisseuren und Drehbuchautoren. Bei bloßer Verknüpfung mit Motiven jedoch permutierend, vgl. § 734; zu f Film vgl. Anl. 6.

$$
\text { SWW t Nibelungenlied; s Film }
$$

\section{Förderungsprogramm}

H In Verknüpfung mit Fachgebieten und Förderungsgegenständen nicht permutierend, vgl. $\S 306 a, 10$.

\section{Forschung}

H Ein Kompositum mit dem Forschungsgegenstand wird i.d.R. nur gebildet, wenn es sich um die Disziplin handelt, z.B. SW Wirtschaftsforschung.

\section{Forschungsprogramm}

H In Verknüpfung mit Fachgebieten und Forschungsgegenständen nicht permutierend, vgl. $\S 306 a, 10$.

\section{Fragment}

H In Verknüpfung mit einzelnen Werken oder Werkgruppen nicht permutierend. Nicht als Formschlagwort benutzt; hier f Quelle oder f Anthologie. Verknüpfung mit Anwendungsbereichen; z.B. SWW Handschrift ; Fragment oder SWW Wachstafel ; Fragment. Entfällt bei der Ansetzung einzelner Handschriften, vgl. § 718.

\section{Fremdsprache}

$\mathrm{H}$ Nach Sprachbezeichnungen nicht permutierend.

\section{Funde}

H Für Interpretation, Klassifizierung, Beschreibung archäologischer Fundgegenstände. Üblicherweise nicht in Verbindung mit Bauwerken benutzt, hier wird SW Ausgrabung verwendet. In Verknüpfung mit Geographika nicht permutierend, vgl. § 220,4. Die Liste der Komposita mit gefundenen Gegenständen ist abgeschlossen; mit weiteren Sachschlagwörtern wird verknüpft. 
VB Ausgrabung

\section{Geistesgeschichte}

H Zeitschlagwort, vgl. § 402,1.

VB Ideengeschichte

\section{Geographie}

H Benutzt als Wissenschaftsfach und für die Geographie einzelner Staaten und Regionen oberhalb der Kreisebene; in Verknüpfung mit diesen Geographika nicht permutierend, vgl. § 220,4. In Verknüpfung mit Städtenamen wird SW Stadtgeographie verwendet.

\section{Geschichte}

H Zeitschlagwort, vgl. § 402,1. Das permutierende Sachschlagwort Geschichte wird nur verwendet, um das Wesen, den Begriff usw. der Geschichte auszudrücken.

\section{Grammatik}

H In Verknüpfung mit Sprachbezeichnungen nicht permutierend, vgl. § 701,5,a.

\section{Heimatkunde}

H Benutzt für Darstellungen zu "Land und Leuten" in Vergangenheit und/oder Gegenwart für Territorien bis zur Ebene des Landkreises; für größere Einheiten wird SW Landeskunde bzw. SW Geographie verwendet. In Verknüpfung mit einzelnen Geographika nicht permutierend, vgl. § 220,4.

\section{Ideengeschichte}

H Zeitschlagwort, vgl. § 402,1.

VB Geistesgeschichte

\section{Innenpolitik}

H In Verknüpfung mit Geographika nicht permutierend, vgl. § 220,4.

\section{Insel}

H In Verknüpfung mit einzelnen Gewässern nicht permutierend; hier werden, soweit sprachlich möglich, Komposita bzw. Adjektiv-Substantiv-Verbindungen gebildet, vgl. § 204,2 (aber z.B. SWW g Indischer Ozean ; s Insel).

\section{Inszenierung}

H In Verknüpfung mit Personen nicht permutierend; i.d.R. mit Namen von Regisseuren bzw. Theatern verknüpft.

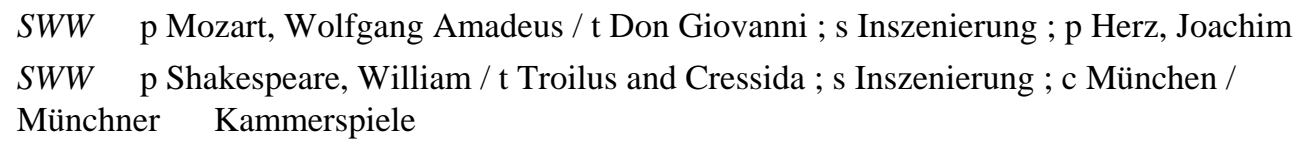

VB Aufführung

\section{Internationaler Vergleich}

$\mathrm{H} \quad$ Nur zu verwenden, wenn Geographika wegen ihrer Anzahl in der Schlagwortkette entfallen müssen, bzw. in Verknüpfung mit einem einzelnen hervorgehobenen Geographikum, das mit vielen anderen Ländern verglichen wird, ohne dass diese durch eine zusammenfassende Bezeichnung wiedergegeben werden können.

\section{Kirchengeschichte}

H Zeitschlagwort, vgl. § 402,1. 


\section{Kontrolle}

H I.d.R. werden Komposita gebildet, die permutiert werden, z.B. SW Trainingskontrolle, aber z.B. SWW Dachbegrünung; Kontrolle.

\section{Kosten}

H In Verknüpfung mit dem kostenverursachenden Gegenstand oder Fachgebiet i.d.R. nicht permutierend z.B. SWW s Dachbegrünung ; s Kosten. Jedoch werden i.d.R. Komposita gebildet, die permutiert werden, z.B. SW s Materialkosten.

\section{Kritik}

H In Verknüpfung mit einzelnen Sachgebieten nicht benutzt für die kritische Darstellung eines bestimmten Sachverhalts, sondern nur für Sekundärliteratur, die sich mit den kritischen Darstellungen eines Themas auseinandersetzt. Darüber hinaus kann bei extrem einseitiger, negativer Darstellung eines Gegenstandes, der normalerweise in Veröffentlichungen positiv bewertet wird, mit dem nicht permutierenden Schlagwort Kritik verknüpft werden.

\section{Küste}

H Soweit sprachlich möglich werden mit Gewässernamen Komposita gebildet, die permutieren; sonst nach Geographika nicht permutierend, vgl. § 204,2.

\section{Kultur}

H In Verknüpfung mit Geographika (vgl. § 220,4) sowie aussagekräftigen Schlagwörtern im Kontext der Kulturgeschichte nicht permutierend.

\section{Kulturbeziehungen}

$\mathrm{H}$ In Verknüpfung mit Geographika nicht permutierend.

\section{Kulturvergleich}

H In Verknüpfung mit dem Vergleichsgegenstand nicht permutierend.

\section{Kunst}

H Nicht permutierend in Verknüpfung mit Geographika, vgl. § 220,4. Entfällt i.d.R. in Verknüpfung mit den Namen einzelner Künstler, vgl. § 116,1.

\section{Landeskunde}

H Benutzt für interdisziplinäre Arbeiten, die über die Geographie hinausgehen, d.h. für Darstellungen zu "Land und Leuten" in Vergangenheit und/oder Gegenwart für Territorien oberhalb der Kreisebene. Für kleinere Einheiten wird SW Heimatkunde verwendet; in Verknüpfung mit Geographika nicht permutierend, vgl. § 220,4.

\section{Lebensbedingungen}

\section{Literatur}

H In Verknüpfung mit einzelnen Sprachbezeichnungen bzw. Geographika nicht permutierendes Schlagwort, vgl. § 703,1. Entfällt i.d.R. in Verknüpfung mit den Namen einzelner Schriftsteller, vgl. § 116,1. Keine Komposita- bzw. Adjektiv-Substantiv-Verbindungen mit einzelnen Wissenschaftsgebieten; diese werden mit SW Fachliteratur bzw. SW Wissenschaftliche Literatur verknüpft.

\section{Lyrik}

H In Verknüpfung mit einzelnen Sprachbezeichnungen, Geographika und Personennamen nicht permutierend, vgl. § 703,1.

\section{Marktübersicht}




\section{Meditation}

H Für Dokumente mit meditativem Inhalt; nicht permutierend in Verknüpfung mit Schlagwörtern, die den Inhalt wiedergeben.

$$
\text { SWW s Liebe; s Christentum; s Meditation }
$$

\section{Messung}

Methode

\section{Modell}

\section{Morphologie}

D Allgemein in Philosophie und Psychologie die Lehre von den Erscheinungsformen (Gestalten).

H Für die Linguistik wird SW Morphologie $<$ Linguistik $>$ benutzt, für die Medizin und die Biologie allgemein SW Morphologie $<$ Biologie $>$.

\section{Morphologie <Biologie>}

H In Verknüpfung mit einzelnen Organen oder Lebewesen nicht permutierend; für Pflanzen benutze SW Pflanzenmorphologie.

UB Pflanzenmorphologie

\section{Morphologie <Linguistik>}

H In Verknüpfung mit Sprachbezeichnungen nicht permutierend, vgl. § 701,5,a.

\section{Mundart}

$\mathrm{H}$ In Verknüpfung mit Geographika und Sprachbezeichnungen nicht permutierend, vgl. $\S \S 220,4 ; 701,5$,a.

\section{Nachweis}

\section{Natur}

H In Verknüpfung mit Geographika nicht permutierend, vgl. § 220,4.

\section{Organisation}

H Für Organisation im Sinne des Organisierens und des Organisiertseins. Nur außerhalb betriebswirtschaftlicher Sachverhalte im Sinn der Regelung von Aufgaben und Tätigkeiten nicht permutierend.

$$
S W W \quad \text { s Kongress ; s Organisation }
$$

\section{Pathologie}

\section{Pflanzen}

H In Verknüpfung mit Geographika nicht permutierend, vgl. § 220,4.

\section{Pflanzenanatomie}

H In Verknüpfung mit einzelnen Pflanzen nicht permutierend.

OB Anatomie

\section{Pflanzenmorphologie}

H In Verknüpfung mit einzelnen Pflanzen nicht permutierend.

OB Morphologie < Biologie $>$

\section{Pflanzenphysiologie}

$\mathrm{H}$ In Verknüpfung mit einzelnen Pflanzen nicht permutierend.

OB Physiologie 


\section{Philosophie}

$\mathrm{H}$ Nicht permutierend in Verknüpfung mit Personennamen und soweit der philosophische Aspekt einer Sache auszudrücken und dies nicht durch eine präzisere Bezeichnung möglich ist, vgl. §322,3,a.

\section{Phonetik}

H In Verknüpfung mit Sprachbezeichnungen nicht permutierend, vgl. § 701,5,a.

\section{Phonologie}

H In Verknüpfung mit Sprachbezeichnungen nicht permutierend, vgl. § 701,5,a.

\section{Physiologie}

UB Pflanzenphysiologie

Tierphysiologie

\section{Politik}

H In Verknüpfung mit Geographika (vgl. § 220,4), Ethnographika und Personennamen nicht permutierend. Mit umfassenden Sachgebieten werden i. d. R. Komposita gebildet. Entfällt i. d. R. in Verknüpfung mit den Namen einzelner Politiker, vgl. § 116,1.

\section{Prävention}

\section{Predigt}

H Für Sekundärliteratur sowie für Predigten und Sammlungen zu einem bestimmten Thema. Bei Predigten zu einem Thema nicht permutierend.

\section{Prognose}

H Zeitschlagwort, vgl. § 401a,4; i. d. R. zur Erfassung von in der Zukunft liegenden Zeiträumen. In den Sozial- und Naturwissenschaften wird i. d. R. kein Kompositum mit dem Prognosegegenstand gebildet; dagegen sind in den Geowissenschaften Komposita mit '-vorhersage' zugelassen.

VB Zukunft

\section{Projekt}

H In Verknüpfung mit Fachgebieten und Projektgegenständen nicht permutierend, vgl. $\S 306 a, 10$.

\section{Prosa}

H In Verknüpfung mit einzelnen Sprachbezeichnungen, Geographika und Personennamen nicht permutierendes Schlagwort, vgl. § 703,1.

\section{Psychologie}

H Nicht permutierend, soweit der psychologische Aspekt einer Sache auszudrücken und dies nicht durch eine präzisere Bezeichnung möglich ist, vgl. § 322,3,a.

\section{Quellenkritik}

\section{Recht}

$\mathrm{H}$ Nicht permutierend, soweit der rechtliche Aspekt einer Sache auszudrücken und dies nicht durch eine präzisere Bezeichnung möglich ist, vgl. § 322,3,a. In Verknüpfung mit Geographika und Ethnographika nicht permutierend, vgl. § 220,4.

\section{Rechtschreibung}

H In Verknüpfung mit Sprachbezeichnungen nicht permutierend, vgl. § 701,5,a.

\section{Rechtsvergleich}

$\mathrm{H}$ Nur verwenden, wenn Geographika wegen ihrer Anzahl in der Schlagwortkette entfallen müssen, bzw. in Verknüpfung mit einem einzelnen hervorgehobenen Geographikum, das mit 
vielen anderen Ländern verglichen wird, ohne dass diese durch eine zusammenfassende Bezeichnung wiedergegeben werden können. Nicht bei Vergleichen zwischen Rechtsnormen im Inland oder von Rechtssystemen.

\section{Redaktion}

H Nicht permutierend in Verknüpfung z. B. mit redaktionsgeschichtlichen Sachverhalten der Bibel.

VB Bearbeitung

\section{Reform}

H Nicht permutierend in Verknüpfung z. B. mit einzelnen Rechtsreformen. Spezifischere Schlagwörter werden bevorzugt verwendet, vgl. § 324,1.

\section{Regelung}

H In Verknüpfung mit dem geregelten Objekt nicht permutierend.

\section{Rezeption}

H In Verknüpfung mit Personen, Werken, Strömungen, Ideen usw. i. d. R. nicht permutierend. Standard der Grundkette: Rezipiertes ; 'Rezeption' ; Rezipient.

$S W W \quad \mathrm{p}$ Nietzsche, Friedrich / $\mathrm{t} \neg$ Der $\neg$ Fall Wagner ; s Rezeption ; $\mathrm{p}$ Mann, Thomas

VB Auswirkung

\section{Roman}

H In Verknüpfung mit Sprachbezeichnungen, Geographika und Personennamen nicht permutierendes Schlagwort, vgl. § 703,1.

\section{Selbstverständnis}

H In Verknüpfung mit Personen, Personengruppen und Berufen nicht permutierend.

\section{Semantik}

H In Verknüpfung mit Sprachbezeichnungen nicht permutierend, vgl. § 701,5,a.

\section{Simulation}

\section{Sozialgeschichte}

H Zeitschlagwort, vgl. § 402,1.

\section{Soziologie}

H Nicht permutierend soweit der soziologische Aspekt einer Sache auszudrücken und dies nicht durch eine präzisere Bezeichnung möglich ist, vgl. § 322,3,a.

\section{Sprache}

H In Verknüpfung mit Personennamen, Geographika und Ethnographika nicht permutierend. Für die stilistischen Merkmale von Sprache benutze SW Sprachstil, außer in Verknüpfung mit Personennamen, vgl. Anl. 2.

\section{Steuerung}

H In Verknüpfung mit dem gesteuerten Objekt nicht permutierend.

\section{Stilistik}

H In Verknüpfung mit Sprachbezeichnungen nicht permutierend, vgl. § 701,5,a.

\section{Struktur}

$\mathrm{H} \quad$ In der Chemie wird SW Chemische Struktur verwendet. 


\section{Studium}

H In Verknüpfung mit fächerübergreifenden Themen, die keinem einzelnen Studium zugeordnet werden können, nicht permutierend. I. d. R. werden jedoch Komposita für Studienfächer gebildet, z. B. SW Physikstudium.

\section{Syntax}

H In Verknüpfung mit Sprachbezeichnungen nicht permutierend, vgl. § 701,5,a.

\section{Symbol}

$\mathrm{H} \quad$ In Verknüpfung mit einzelnen Symbolen nicht permutierend.

\section{Synthese}

H Für die Chemie wird SW Chemische Synthese verwendet.

Synthese $<$ Chemie $>B S$ Chemische Synthese

\section{Systematik}

H Nur in Verknüpfung mit Schlagwörtern aus der Biologie; sonst benutze permutierendes SW Klassifikation.

\section{Textgeschichte}

H Kein Zeit-, sondern Sachschlagwort; Verwendung nach Praxisregel zu § 708,1.

\section{Textkritik}

\section{Theorie}

H Nur zur Erschließung von Sekundärliteratur zu einer bestimmten Theorie oder mehreren Theorien verwendet. Entfällt als Kompositumbestandteil eines Grundwortes, wenn es pleonastisch ist, vgl. § 312,1 .

SWW s Revolution; s Theorie

\section{Therapie}

\section{Tiere}

H In Verknüpfung mit Geographika nicht permutierend, vgl. § 220,4.

\section{Tierphysiologie}

$\mathrm{H} \quad$ In Verknüpfung mit einzelnen Tieren nicht permutierend.

OB Physiologie

\section{Übersetzung}

$\mathrm{H}$ In Verknüpfung mit Personennamen, Werktiteln und Sprachbezeichnungen nicht permutierend.

$$
S W W \quad \mathrm{p} \text { Shakespeare, William / } \mathrm{t} \text { As you like it ; } \mathrm{s} \text { Übersetzung ; g Deutsch }
$$

\section{Umarbeitung}

H Nicht permutierend in Verknüpfung mit Personen und ihrem Werk bei Bearbeitung durch den Autor selbst. Für die Bearbeitung durch andere wird SW Bearbeitung verwendet.

VB Bearbeitung

\section{Unterricht}

H In Verknüpfung mit einem Unterrichtsgebiet nicht permutierend. Spezifische Schlagwörter für Unterrichtsfächer werden bevorzugt verwendet.

$$
\text { SWW s Naturschutz; s Unterricht }
$$

\section{Ursache}




\section{Vorgeschichte}

H Für die zu einem Ereignis führende historische Entwicklung, nicht permutierend in Verknüpfung mit der Bezeichnung des Ereignisses.

SWW s Spanischer Bürgerkrieg; s Vorgeschichte

VB Entstehung

\section{Vorlage}

H In Verknüpfung mit Gattungsbezeichnungen, einzelnen Werken oder Gruppen von Werken nicht permutierend.

$$
\begin{array}{ll}
S W W & \text { s Porzellanmalerei ; s Vorlage } \\
\text { SWW } & \text { p Terentius Afer, Publius ; s Komödie ; s Vorlage }
\end{array}
$$

\section{Vor- und Frühgeschichte}

H Zeitschlagwort, vgl. § 402,1.

\section{Wirtschaft}

H In Verknüpfung mit Geographika nicht permutierend, vgl. § 220,4.

\section{Wortfeld}

$\mathrm{H}$ In Verknüpfung mit einzelnen Wortfeldern nicht permutierend; wird bevorzugt mit einem Wort der deutschen Sprache verknüpft, vgl. § 305,1,c.

\section{Wortfamilie}

H In Verknüpfung mit einzelnen Wortfamilien nicht permutierend, vgl. § 305,1,c.

\section{Wortschatz}

$\mathrm{H} \quad$ In Verknüpfung mit einzelnen Personennamen, Personengruppen und Sprachbezeichnungen nicht permutierend, vgl. § 701,5,a.

$$
\begin{array}{ll}
\text { SWW } & \text { s Kleinkind ; s Wortschatz } \\
\text { SWW } & \text { s Spanisch ; s Wortschatz }
\end{array}
$$

\section{Zeichensetzung}

H In Verknüpfung mit Sprachbezeichnungen nicht permutierend, vgl. § 701,5,a.

\section{Zeitgenossen}

$\mathrm{H}$ In Verknüpfung mit Personennamen, Personengruppen und historischen Einzelereignissen nicht permutierendes Schlagwort für den Ausdruck der Gleichzeitigkeit eines Geschehens.

\section{Zeithintergrund}

H In Verknüpfung mit anderen Schlagwörtern i.d.R. nicht permutierendes Schlagwort für den Ausdruck der Gleichzeitigkeit eines Geschehens.

\section{Zukunft}

H Bei Voraussagen aufgrund statistischer oder sonstiger wissenschaftlicher Methoden wird z Prognose verwendet.

VB Prognose 



\section{Anlage 6}

\section{Liste der Formschlagwörter}

Diese Liste enthält die Formschlagwörter nach $\S 5,1$ und 2 sowie diejenigen, die bei einer lokalen Erschließung nach $\S 5,3-7$ benötigt werden. Ob bestimmte Literaturgattungen von der Erschließung ausgenommen werden, richtet sich nach $\S 3,2$ b und c. Auf die mit * gekennzeichneten Formschlagwörter können unmittelbar Zeitangaben folgen. Der jeweils aktuellste Stand bezüglich Definitionen und Verwendungshinweisen ist der SWD zu entnehmen.

Adressbuch

Altkarte

Anleitung

Anthologie

Antiquariatskatalog

Arbeitstransparent

Atlas

Audiovisuelles Material

Audiovisuelles Material < für Kinder>

Aufgabensammlung

Aufsatzsammlung

Auktionskatalog

Ausstellung

*Autobiographie

Beispielsammlung

Belletristische Darstellung

Bericht

Bestimmungsbuch

*Bibliographie

Bildband

Bilderbuch

Bildliche Darstellung

Bildnis

Bildplatte

Bildwörterbuch

*Biographie

Blindendruck

*Briefsammlung

$\mathrm{CD}$

$\mathrm{CD}<$ für Kinder $>$

CD-ROM

CD-ROM $<$ für Kinder $>$

Checkliste
Comic

Datensammlung

Dia

Diagramm

Diskette

Diskette $<$ für Kinder $>$

Drehbuch

DVD-Audio

DVD-Audio < für Kinder >

DVD-ROM

DVD-ROM < für Kinder $>$

DVD-Video

DVD-Video < für Kinder >

Einblattdruck

Einführung

Elektronische Publikation

Elektronische Publikation < für Kinder $>$

Entscheidungssammlung

Enzyklopädie

Erlebnisbericht

Fachkunde

Fahrplan

Fallsammlung

Fallstudiensammlung

Film

Film $<$ für Kinder $>$

Film $8 \mathrm{~mm}$

Film Super-8

Film $16 \mathrm{~mm}$

Film $35 \mathrm{~mm}$

Film $65 \mathrm{~mm}$

Film $70 \mathrm{~mm}$

Flugblatt 
Formelsammlung

Formularsammlung

Forschungsbericht

Führer

Fundstellenverzeichnis

Genealogische Tafel

Gespräch

Globus

Graphik

Hörspiel

Humoristische Darstellung

Interview

Inventar

Jugendbuch

Jugendsachbuch

Kalender

Karikatur

Karte

*Katalog

Kinderbuch

Kindersachbuch

Kochbuch

Kommentar

Kongress

Konkordanz

Künstlerbuch

Kunstführer

Lehrbuch

Lehrerhandbuch

Lehrmittel

Lehrplan

Lernprogramm

Lesebuch

*Literaturbericht

Medienkombination

Mikroform

Mitgliederverzeichnis

Musikdruck

Nachruf

*Neuerwerbungsliste
Norm

Online-Publikation

Ortsverzeichnis

Patentschrift

Photographie

Plakat

Plan

Praktikum

Predigthilfe

Pressendruck

Pressestimme

Programm

Programmheft

Quelle

Ratgeber

Regest

*Reisebericht

Richtlinie

Rückläufiges Wörterbuch

Sachbilderbuch

Schallplatte

Schallplatte <für Kinder $>$

Schematismus

Schriftenreihe

Schulbuch

Spiel

Sprachatlas

Sprachführer

Stadtplan

*Statistik

Tabelle

Tafel

*Tagebuch

Telefaxverzeichnis

Telefonbuch

Telexverzeichnis

Testmaterial

Text

Theaterstück

Thesaurus 
Tonbildreihe

Tonkassette

Tonkassette <für Kinder>

Tonträger

Tonträger < für Kinder>

Übungssammlung

Umfrage

Unterrichtseinheit

Verkaufskatalog

Verzeichnis

Videokassette
Videokassette < für Kinder>

Vorlesungsverzeichnis

Weltkarte

*Werkverzeichnis

Wörterbuch

Wörterbuch <mehrsprachig >

Zeitschrift

Zeittafel

Zeitung

Zitatensammlung

Abbildungen $<$ Formschlagwort $>$ BS Bildband

Abbildungen $<$ Formschlagwort, Bildliche Darstellung $>$ BS Bildliche Darstellung

Abbildungswerk BS Bildband

Abkürzungsverzeichnis wird zerlegt in s Abkürzung ; f Verzeichnis

Abstracts $<$ Formschlagwort $>$ BS Bibliographie

\section{Adressbuch}

D Verzeichnis, das hauptsächlich dem Nachweis von Adressen dient; unabhängig von der physischen Form. Auch für Adressen in Rechnernetzen. Nicht für Adressbücher mit einer Beschreibung oder Bewertung sowie für Verzeichnisse, die Adressen und weitere Informationen enthalten.

$\mathrm{H}$ Eine Zeitangabe entfällt. Für historische Einwohnerbücher ohne Adressen, benutze $\mathrm{s}$ Einwohner ; z Geschichte mit Jahreszahl ; f Verzeichnis; für Adressbücher mit einer Beschreibung oder Bewertung benutze f Führer; für Verzeichnisse, die Adressen und weitere Informationen enthalten, benutze f Verzeichnis.

BF Anschrift / Verzeichnis

Einwohnerbuch

OB Verzeichnis

VB Führer

Telefaxverzeichnis

Telefonbuch

Telexverzeichnis

Titel: International directory of arts. - 1950 -

Verzeichnis von Institutionen (Museen, Galerien, Verleger usw.) und Personen (Sammler, Restauratoren, Antiquare usw.) in sehr knapper Form. Die Adressen sind die einzig relevante Information.

SWW s Kunst; f Adressbuch

SWW s Kunsthandel ; f Adressbuch

Ahnentafel BS Genealogische Tafel

Akten $<$ Formschlagwort $>$ BS Quelle 
Allgemeinenzyklopädie BS Enzyklopädie

Almanach wird nach $\S 4,4$ i. d .R. nicht beschlagwortet. Für thematisch erschließbare Almanache benutze f Zeitschrift. Denkbar als Gattungsbegriff nach § 5,3.

Alte Karte BS Altkarte

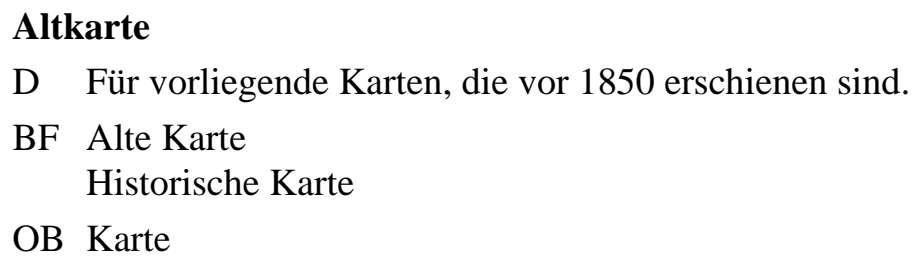

Titel: $\quad$ Plan von Augsburg mit seinen Umgebungen / gestochen von Gg. Mayr u. C. Schleich. - 1839

SWW g Augsburg <Region>; f Altkarte

Amtliche Karte BS Karte

Amtsblatt $<$ Formschlagwort $>$ BS Zeitschrift

\section{Anleitung}

D Für die Einführung in eine spezifisch handwerkliche Tätigkeit sowie in Kunsthandwerk, Zeichnen, Malen, Photographie, soweit diese nicht professionell betrieben werden.

$\mathrm{H}$ Ansonsten benutze f Einführung.

VB Einführung

Ratgeber

$$
\begin{array}{ll}
S W W & \text { s Bootsbau ; f Anleitung } \\
S W W & \text { s Stricken ; f Anleitung } \\
\text { SWW } & \text { s Seidenmalerei ; f Anleitung }
\end{array}
$$

Anonymenlexikon wird zerlegt in

s Anonymes Werk; f Bibliographie

Anschrift / Verzeichnis BS Adressbuch

Ansicht $<$ Formschlagwort $>$ BS Bildliche Darstellung

Ansichten $<$ Formschlagwort $>$ BS Bildband

Ansichtspostkarte $<$ Formschlagwort $>$ BS Bildband

\section{Anthologie}

D Sammlung von überwiegend belletristischen Texten.

H Für andere Sammlungen benutze f Aufsatzsammlung, f Musikdruck (soweit die Noten überwiegen), f Zitatensammlung, f Briefsammlung oder f Quelle.

In der Schlagwortkette wird verknüpft:

1. Sprache bzw. Geographikum ; Gattung ; Zeitschlagwort ; f Anthologie (nur für Texte mehrerer Autoren) oder

2. Motiv ; Gattung ; f Anthologie (für Texte eines oder mehrerer Autoren).

Vgl. §§ 760-762. Beim zugehörigen Schlagwort entfällt der Zusatz $<$ Motiv $>$.

BF Chrestomathie

Lesebuch $<$ Anthologie $>$

Sammlung $<$ Anthologie $>$

Texte $<$ Formschlagwort $>$ 
OB Belletristische Darstellung

UB Zitatensammlung

SWW g Französisch ; s Lyrik ; z Geschichte ; f Anthologie

SWW s Winter; s Lyrik; f Anthologie

Antiquariat / Katalog BS Antiquariatskatalog

\section{Antiquariatskatalog}

D Für vorliegende thematisch eingegrenzte Antiquariatskataloge.

H Die jeweilige Firma entfällt, sofern sie nicht für den Inhalt von besonderer Bedeutung ist.

BF Antiquariat/ Katalog

OB Katalog

Verkaufskatalog

VB Auktionskatalog

Titel: Incunabula / Heribert Tenschert. - 1991. - (Antiquariat Heribert Tenschert: Katalog)

SWW s Inkunabel ; f Antiquariatskatalog

Aphorismus wird als Sachschlagwort behandelt; verknüpfe mit $\mathrm{f}$ Anthologie.

SWW s Ehe ; s Aphorismus; f Anthologie

SWW g Polnisch ; s Aphorismus ; f Anthologie

Arbeitsmittel / Unterricht BS Lehrmittel

\section{Arbeitstransparent}

H Vgl. § 737.

BF Arbeitstransparentstreifen

Folie / Unterricht

Overheadfolie

Transparent / Unterricht

OB Audiovisuelles Material

Lehrmittel

Arbeitstransparentstreifen BS Arbeitstransparent

Architekturführer wird zerlegt in

s Architektur ; f Kunstführer bzw. Name des jeweiligen Bauwerks ; f Führer

Archivinventar wird zerlegt in

Name des jeweiligen Archivs ; f Inventar

Archivrepertorium $<$ Formschlagwort $>$ BS Inventar

\section{Atlas}

D Für alle Arten von Kartenwerken, sowie für Abbildungswerke in der Human- und Tiermedizin sowie der Phytopathologie; auch für elektronische Publikationen.

$\mathrm{H} \quad$ Für Bildatlanten bzw. Bildtafeln bei sonstigen Abbildungswerken benutze $\mathrm{f}$ Bildband oder $\mathrm{f}$ Bestimmungsbuch bzw. es entfällt jegliches Formschlagwort. Das Formschlagwort kann als einziges Schlagwort verwendet werden.

BF Weltatlas

UB Sprachatlas

VB Karte 
Titel: $\quad$ Knaurs großer historischer Weltatlas / hrsg. von Geoffrey Barraclough. - 1982

SWW z Weltgeschichte; f Atlas

Titel: Technologieatlas Deutschland [Computerdatei]

SWW g Deutschland; s Unternehmen ; f Atlas ; f CD-ROM

Audio-CD $<$ Formschlagwort $>$ BS CD

\section{Audiovisuelles Material}

D Für vorliegendes audiovisuelles Material, das nicht unter einen der zugelassenen Unterbegriffe fällt, oder eine Kombination von mindestens zwei audiovisuellen Materialien; nicht für elektronische Publikationen.

H Vgl. § 737.

BF Audiovisuelles Medium <Formschlagwort $>$ AV-Material $<$ Formschlagwort $>$

Bildtonträger $<$ Formschlagwort $>$

Medienkombination < Audiovisuelles Material>

Medienpaket $<$ Audiovisuelles Material $>$

UB Arbeitstransparent

Bildplatte

Dia

Film

Tonbildreihe

Tonträger

Videokassette

\section{Audiovisuelles Material < für Kinder>}

UB Film < für Kinder>

Tonträger $<$ für Kinder $>$

Videokassette $<$ für Kinder $>$

Audiovisuelles Medium < Formschlagwort $>$ BS Audiovisuelles Material

\section{Aufgabensammlung}

D Für Fragen-, Übungs- und Aufgabensammlungen.

H Bei Wissensfragen zum Zweck der Unterhaltung benutze s Quiz. Wird im schulischen Bereich mit dem Unterrichtsfach verknüpft (vgl. §§ 767-773).

BF Examensfragen $<$ Formschlagwort $>$

Gegenstandskatalog

Lösungssammlung

Prüfungsfragen $<$ Formschlagwort $>$

Repetitorium $<$ Formschlagwort, Aufgabensammlung $>$

Übungsaufgaben

Übungsbuch

OB Lehrmittel

UB Übungssammlung

VB Beispielsammlung

Titel: Prüfung Bankkaufleute [Computerdatei] : über 100 Fragen, mit Lösungen und Erfolgsbewertung. - 1993

SWW s Bankkaufmann ; s Abschlussprüfung ; f Aufgabensammlung ; f Diskette 
Titel: $\quad$ Texte zum Hörverstehen und zur Mitschrift / zsgest. von Horst Zindler. - 1987. (Materialien Deutsch als Fremdsprache ; 20)

SWW s Deutschunterricht ; s Ausländer ; f Aufgabensammlung

Aufgabensammlung / Recht VB Fallsammlung

Aufsatz entfällt als Formschlagwort (auch bei der Erschließung unselbständiger Literatur).

\section{Aufsatzsammlung}

D Nur für Sammelwerke mit mehreren Beiträgen eines oder mehrerer Verfasser. Nicht für Kongresse; nicht für Handbücher oder zusammenfassende Darstellungen, deren Teile von mehreren Verfassern stammen; nicht für einen einzelnen Aufsatz.

BF Beiträge $<$ Formschlagwort $>$

Einzelbeiträge

Essays $<$ Formschlagwort $>$

Reader

Sammelwerk $<$ Formschlagwort $>$

Sammlung <Aufsatzsammlung >

Augenzeugenbericht $<$ Formschlagwort $>$ BS Erlebnisbericht

\section{Auktionskatalog}

D Für vorliegende thematisch eingegrenzte Auktionskataloge.

H Die jeweilige Firma entfällt, sofern sie nicht für den Inhalt von besonderer Bedeutung ist.

OB Katalog Verkaufskatalog

VB Antiquariatskatalog

Titel: Jugendstil und angewandte Kunst : 111. Auktion / Galerie Wolfgang Ketterer. - 1986

SWW s Kunsthandwerk ; z Geschichte 1890-1960 ; f Auktionskatalog

Titel: $\quad \neg$ Die $\neg$ Fürstliche Sammlung Thurn und Taxis : Oktober 1993, Regensburg / Sotheby’s London. - 1993

SWW p Thurn und Taxis $<$ Familie $>$; s Sammlung ; f Auktionskatalog

Ausführungsbestimmung entfällt als Formschlagwort.

\section{Ausstellung}

D Für vorliegende Ausstellungskataloge.

$\mathrm{H} \quad$ Wird jedoch nicht vergeben, wenn es sich um Dokumente handelt, die zwar anlässlich einer Ausstellung erschienen sind, aber keinen direkten Bezug dazu haben (also nichts über die Ausstellung aussagen); dann i.d.R. f Aufsatzsammlung. Bei gemischten Dokumenten können auch zwei Ketten vergeben werden. Die Schlagwortkette hat folgende Form (vgl. § 504,3): Thema ; f Ausstellung ; g Ort $<$ Jahr $>$.

BF Ausstellungskatalog $<$ Formschlagwort $>$

OB Katalog

Ausstellungskatalog $<$ Formschlagwort $>$ BS Ausstellung

\section{Autobiographie}

D Für vorliegende Autobiographien einer Person oder Personengruppe, auch für solche in Tagebuchform.

$\mathrm{H}$ Zeitangaben werden nur nach Personennamen zum Formschlagwort hinzugefügt; bei Personengruppen wird z Geschichte mit Jahreszahlen verwendet. 
Für Sammlungen benutze s Autobiographie ; $\mathrm{f}$ Anthologie. Zur Verwendung als Gattungsbegriff vgl. § 5,3 und 4.

BF Erinnerungen $<$ Formschlagwort $>$

Lebenserinnerungen

Memoiren

Selbstbiographie

OB Quelle

VB Biographie

Erlebnisbericht

Tagebuch

Titel: $\quad \neg$ Die $\neg$ gerettete Zunge : Geschichte einer Jugend / Elias Canetti. - 1994

SWW p Canetti, Elias ; f Autobiographie 1905-1921

Titel: $\quad$ Pädagogik in Selbstdarstellungen / hrsg. von Ludwig I. Pongratz. - 1975-1982

SWW g Deutschland ; s Pädagoge ; z Geschichte 1900-1982 ; f Autobiographie

AV-Material < Formschlagwort $>$ BS Audiovisuelles Material

Baudenkmal / Führer benutze

s Architektur ; f Kunstführer

Bauzeichnung $<$ Formschlagwort $>$ BS Plan

Befragung BS Umfrage

Befragung < Interview $>B S$ Interview

\section{Beispielsammlung}

D Für Sammlungen von typischen Einzelfällen zur Veranschaulichung oder als Muster zum Nachmachen; nicht für Beispiele, die einen Gesamteindruck vermitteln sollen.

BF Mustersammlung

Sammlung <Beispielsammlung $>$

VB Aufgabensammlung

Fallstudiensammlung

Formularsammlung

Titel: Letterbox [Computerdatei] : 200 Musterbriefe für die private und geschäftliche

Korrespondenz. - 1996

SWW s Geschäftsbrief ; f Beispielsammlung ; f CD-ROM

Beiträge $<$ Formschlagwort $>B S$ Aufsatzsammlung

\section{Belletristische Darstellung}

D Nur als Formschlagwort verwendet. Für vorliegende thematisch erschließbare Werke der schönen Literatur, soweit nicht einer der zugelassenen Unterbegriffe verwendet wird.

H Vgl. §§ 760-762. Die jeweilige literarische Gattung und der Zusatz <Motiv> beim zugehörigen Schlagwort entfallen. Für belletristische Sammlungen benutze f Anthologie. Zur Erschließung von Werken der schönen Literatur mit Gattungsbegriffen vgl. § 5,3 und 4.

BF Literarische Darstellung

Roman $<$ Formschlagwort $>$ 
UB Anthologie

Comic

Hörspiel

Text

Theaterstück

VB Humoristische Darstellung

Titel: $\quad \neg$ La $\neg$ Révolution en direct / Jean-Louis Donnadieu. - 1988

SWW s Französische Revolution ; f Belletristische Darstellung

Aber:

Titel: $\quad \neg$ Die $\neg$ Französische Revolution als Gegenstand des französischen Theaters : 18901979 / von Erika Demenet. - 1982

SWW g Französisch ; s Drama ; s Französische Revolution <Motiv> ; z Geschichte 18901979

Bergführer wird zerlegt in

s Bergsteigen ; f Führer

\section{Bericht}

D Für den Geschäfts-, Jahres- oder Tätigkeitsbericht einer Körperschaft.

H Die Angabe des behandelten Zeitraumes entfällt.

BF Geschäftsbericht <Formschlagwort $>$

Jahresbericht $<$ Formschlagwort $>$

Tätigkeitsbericht $<$ Formschlagwort $>$

OB Quelle

UB Erlebnisbericht

Forschungsbericht

Literaturbericht

Reisebericht

Inhalt: Bericht der Stadtverwaltung Stuttgart über den Zeitraum 1945-1955

SWW g Stuttgart ; s Stadtverwaltung ; f Bericht

Bestandskatalog BS Katalog

Bestandsverzeichnis < Inventar $>B S$ Inventar

Bestandsverzeichnis $<$ Katalog $>$ BS Katalog

\section{Bestimmungsbuch}

$\mathrm{H} \quad$ Benutzt unabhängig von der physischen Form.

BF Bestimmungsschlüssel

Bestimmungsschlüssel BS Bestimmungsbuch

Bibliobibliographie wird zerlegt in s Bibliographie ; f Bibliographie

\section{Bibliographie}

D Für alle Arten gedruckter Bibliographien und Literaturdatenbanken, nicht für Bibliotheksund Verlagskataloge.

H Der Zeitschriftencharakter wird ggf. nicht ausgedrückt. Der Berichtszeitraum wird angegeben, es sei denn, die Bibliographie berücksichtigt die gesamte Literatur oder die heute noch relevante Literatur unabhängig vom Erscheinungsjahr. Die Zeitangabe wird in diesem Fall 
zum Formschlagwort hinzugefügt. Wenn die Zeitangabe sich dagegen auf den behandelten Gegenstand bezieht, wird z Geschichte mit Jahreszahlen verwendet (vgl. § 503,1). Für Bibliotheks- und Verlagskataloge benutze f Katalog.

BF Abstracts $<$ Formschlagwort $>$

Bibliographische Datenbank $<$ Formschlagwort $>$

Bücherverzeichnis

Dokumentation <im Sinn einer vorliegenden Literaturdokumentation $>$

Literaturdatenbank $<$ Formschlagwort $>$

Literaturdokumentation $<$ Formschlagwort $>$

Literaturverzeichnis

Publikationen $<$ Formschlagwort $>$

Referate $<$ Dokumentation, Formschlagwort $>$

Referateblatt $<$ Formschlagwort $>$

Repertorium <im engeren Sinn>

Veröffentlichungen $<$ Formschlagwort $>$

Werke / Autor $<$ Formschlagwort $>$

Werkverzeichnis / Autor $<$ Formschlagwort $>$

OB Verzeichnis

VB Katalog

Literaturbericht

Neuerwerbungsliste

Titel: Medline express [Computerdatei] / US National Library of Medicine. - 1990. -

(SilverPlatter databases)

SWW s Medizin ; f Bibliographie ; f CD-ROM

Titel: „In der Ferne gegenwärtig“ : Katalog der Goethe-Bibliothek Dorn. - 1986

$S W W \quad$ p Goethe, Johann Wolfgang $\neg$ von $\urcorner$; f Bibliographie

Enthält Schriften von und über Goethe. Gleich beschlagwortet wird, wenn nur Schriften von oder über Goethe enthalten sind.

Titel: Dansk bogfortegnelse / Årskatalog. - 1852 -

SWW g Dänemark; s Druckwerk ; f Bibliographie

SWW s Demographie ; f Bibliographie 1976-1982

Aber:

SWW p Rückert, Friedrich ; f Bibliographie

Umfasst die gesamte relevante Literatur bis zum Erscheinungsjahr des Buchs.

nicht: f Bibliographie 1813-1977

SWW g Italien ; s Vokalmusik ; z Geschichte 1500-1700 ; f Bibliographie

Bibliographische Datenbank <Formschlagwort> BS Bibliographie

Bildatlas BS Bildband

\section{Bildband}

D Für vorliegende Abbildungen in Buchform.

$\mathrm{H}$ Wenn ein Werk sowohl aus Abbildungen wie aus Text besteht, so wird f Bildband benutzt, wenn der Text die Bilder nur erläutert. Das Formschlagwort entfällt, wenn die Abbildungen, z.B. bei kunstgeschichtlichen Werken, nur eine Beigabe zum Text sind, das Schwergewicht also auf dem Text liegt. Im Zweifelsfall wird f Bildband vergeben. Zwei Schlagwortketten ohne und mit Formschlagwort (vgl. § 13,4,a) werden nur gebildet, wenn ein Textband und Tafelband vorliegt. 
Bei Bildbänden von Künstlern wird, wo es möglich ist, die Kunstgattung genannt. Zeitangaben treten zum Zeitschlagwort z Geschichte, nicht zum Formschlagwort. Beim zugehörigen Schlagwort entfällt der Zusatz $<$ Motiv $>$, wenn es sich nicht um Reproduktionen von Kunstwerken handelt.

BF Abbildungen < Formschlagwort $>$

Abbildungswerk

Ansichten < Formschlagwort $>$

Ansichtspostkarte <Formschlagwort $>$

Bildatlas

Bilddokumente

Bilder $<$ Formschlagwort $>$

Bildmaterial $<$ Formschlagwort $>$

Bildsammlung

Illustrationswerk

Photographien $<$ Bildband $>$

UB Comic

Karikatur

VB Bildliche Darstellung

SWW p Hogarth, William ; s Graphik ; f Bildband

Titel: $\quad$ Augsburg in alten Ansichten / [hrsg.] von Josef Mancal. - 1983

SWW g Augsburg ; z Geschichte 1880-1930 ; f Bildband

SWW $\quad$ s Krieg <Motiv> ; s Malerei ; f Bildband

Bilddokumente BS Bildband

Bilddokumente < Bildliche Darstellung $>$ BS Bildliche Darstellung

Bilder $<$ Formschlagwort $>$ BS Bildband

Bilder < Formschlagwort, Bildliche Darstellung $>$ BS Bildliche Darstellung

\section{Bilderbuch}

D Für vorliegende thematisch erschließbare Bilderbücher mit überwiegend erzählendem Charakter. Bücher, die sich vorrangig an die Altersgruppe der Vorschulkinder und Leseanfänger wenden und in denen die Abbildungen mindestens den gleichen Anteil wie der Text einnehmen.

H Vgl. $\S \S$ 763-766. Beim zugehörigen Schlagwort entfällt der Zusatz $<$ Motiv $>$. Zur Verwendung als Gattungsbegriff vgl. jedoch $\S 5,3$ und 4.

OB Kinderbuch

UB Sachbilderbuch

VB Comic

Bildersachbuch BS Sachbilderbuch

\section{Bildliche Darstellung}

D Für vorliegende thematisch erschließbare Bildliche Darstellungen, die nicht unter einen der zugelassenen Unterbegriffe fallen. Benutzt unabhängig von der physischen Form, außer für $\mathrm{f}$ Bildband (Abbildungen in Buchform).

H Beim zugehörigen Schlagwort entfällt der Zusatz <Motiv>, wenn es sich nicht um Reproduktionen von Kunstwerken handelt. 
BF Abbildungen $<$ Formschlagwort, Bildliche Darstellung $>$

Ansicht $<$ Formschlagwort $>$

Bilddokumente $<$ Bildliche Darstellung $>$

Bilder $<$ Formschlagwort, Bildliche Darstellung $>$

Bildmaterial <Formschlagwort, Bildliche Darstellung $>$

Bildsammlung <Bildliche Darstellung $>$

UB Bildnis

Dia

Graphik

Kalender

Karikatur

Photographie

Plakat

Tafel

VB Bildband

SWW g Asien ; f Bildliche Darstellung ; f CD-ROM

Bildmaterial $<$ Formschlagwort $>$ BS Bildband

Bildmaterial <Formschlagwort, Bildliche Darstellung $>$ BS Bildliche Darstellung

\section{Bildnis}

D Für ein vorliegendes einzelnes Bildnis.

H Bei mehreren Bildnissen wird s Bildnis mit $\mathrm{f}$ Bildband verknüpft. Zur Verwendung als Gattungsbegriff vgl. § 5,3 und 4.

BF Porträt

OB Bildliche Darstellung

Titel: Maximiliano Josepho electori duci Bavariae ... / Jeremias Gottlob Rugendas sculp. [ca. 1760]. - Kupferstich, 59 x $38 \mathrm{~cm}$

SWW p Maximilian <Bayern, Kurfürst, III.> f Bildnis ; f Graphik

nicht: p Maximilian <Bayern, Kurfürst, III> ; s Bildnisgraphik

Titel: $\quad$ Bibliothekslandschaft Bayern: Festschrift für Max Pauer zum 65. Geburtstag. - 1989

SWW p Pauer, Max; f Bildnis

Ob dieser Inhalt erschlossen wird, wird im jeweiligen Verbund oder der jeweiligen Bibliothek festgelegt.

Aber:

Titel: $\quad$ Goethe-Bildnisse, 1774-1832. - 1984

SWW p Goethe, Johann Wolfgang $\neg$ von $\neg$; s Bildnis ; f Bildband

\section{Bildplatte}

D Für vorliegende analoge Videoaufzeichnungen, nicht für digitale Aufnahmen.

H Vgl. § 737. Für digitale Aufnahmen benutze f CD-ROM.

BF Laser-Disc

Videoplatte

OB Audiovisuelles Material

Bildplatte < Optische Speicherplatte, Formschlagwort $>$ BS CD-ROM 
Bildquelle wird zerlegt in

f Biographie ; f Bildband oder

f Quelle ; f Bildband

Bildsammlung BS Bildband

Bildsammlung < Bildliche Darstellung> BS Bildliche Darstellung

Bildtonträger $<$ Formschlagwort $>B S$ Audiovisuelles Material

\section{Bildwörterbuch}

D Für ein vorliegendes Wörterbuch, das die Bedeutung von Wörtern durch Bilder veranschaulicht.

OB Wörterbuch

Biobibliographie wird zerlegt in

Jeweiliges Thema ; f Bibliographie

SWW p Shakespeare, William ; f Bibliographie

\section{Biographie}

D 1. Für die vorliegende Biographie einer einzelnen Person, wenn die Lebensbeschreibung überwiegt und für die Darstellung eines einzelnen Lebensabschnitts.

2. Für Sammlungen von Biographien. Die Bezeichnung für die Berufsgruppe wird der für das jeweilige Sachgebiet vorgezogen. Bei umfassenden biographischen Nachschlagewerken entfällt s Historische Persönlichkeit. Kann in diesem Sinn ggf. als einziges Schlagwort benutzt werden.

H Zeitangaben können zum Formschlagwort hinzugefügt werden nach Personennamen, geographischen/ethnographischen Namen und wenn f Biographie als einziges Schlagwort verwendet wird (vgl. § 503,1). Wenn ein Sachschlagwort vergeben wird, wird z Geschichte mit Jahreszahl verwendet.

Für literarische Sammlungen benutze s Biographie ; f Anthologie

BF Biographische Darstellung

Biographisches Nachschlagewerk

Lebensbeschreibung

VB Autobiographie

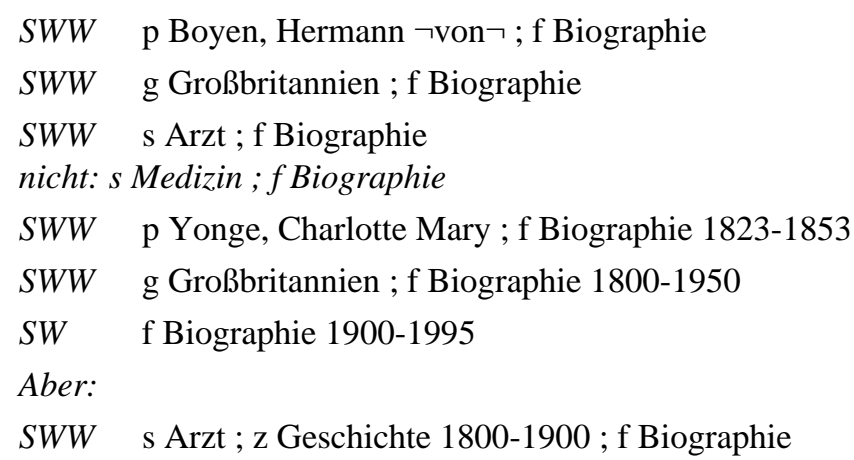

Biographische Darstellung BS Biographie

Biographisches Nachschlagewerk BS Biographie

Blindenbuch BS Blindendruck 


\section{Blindendruck}

D Für vorliegende thematisch erschließbare Druckwerke in Blindenschrift.

H Steht bei Verwendung mehrerer Formschlagwörter als letztes Kettenglied.

BF Blindenbuch

SWW s Physik ; f Kindersachbuch ; f Blindendruck

SWW s Phytotherapie ; f Ratgeber ; f Blindendruck

Branchenverzeichnis wird zerlegt in

s Unternehmen ; f Verzeichnis

\section{Briefsammlung}

$\mathrm{H}$ 1. In Verbindung mit Personennamen: Es wird nicht unterschieden, ob es sich um Briefe von einer oder an eine Person handelt. Beim Briefwechsel zwischen zwei oder mehr Personen werden deren Namen (bis zu sechs) verknüpft, gefolgt von f Briefsammlung. Fakultativ können für Listenfunktionen weitere Ketten mit jeder einzelnen Person gebildet werden. Eine Zeitangabe kann zum Formschlagwort hinzutreten.

2. In Verbindung mit Personengruppen: Bei Briefsammlungen von sieben und mehr Personen wird das Schlagwort für die Personengruppe mit f Briefsammlung verknüpft, ggf. mit dem Zeitschlagwort z Geschichte mit Jahreszahl.

Bei Sammlungen von Briefen als literarische Gattung wird s Brief mit $f$ Anthologie verknüpft. Bei Reisebriefen wird f Reisebericht verwendet.

BF Briefwechsel $<$ Formschlagwort $>$

Korrespondenz $<$ Formschlagwort $>$

OB Quelle

Titel: $\quad$ Briefe aus Italien : 1786-1788 / Johann Wolfgang von Goethe. - 1983

SWW p Goethe, Johann Wolfgang $\neg$ von $\neg$; f Briefsammlung 1786-1788

Titel: $\quad \neg$ Der $\neg$ Briefwechsel zwischen Schiller und Goethe / hrsg. von Emil Staiger . - 1992

SWW p Goethe, Johann Wolfgang $\neg$ von $\neg$; p Schiller, Friedrich ; f Briefsammlung

Eine Zeitangabe wird nicht benötigt, weil der gesamte Briefwechsel zwischen beiden Personen enthalten ist.

fakultativ:

SWW p Goethe, Johann Wolfgang $\neg$ von $\neg$; f Briefsammlung 1794-1805

SWW p Schiller, Friedrich ; f Briefsammlung 1794-1805

Titel: $\quad$ Briefwechsel 1803-1849 / Schelling und Cotta. - 1965

SWW p Cotta, Georg $\neg$ von $\neg$; p Cotta, Johann Friedrich $\neg$ von $\neg$; p Schelling, Friedrich

Wilhelm $\quad \neg$ von $\neg$; f Briefsammlung

fakultativ:

SWW p Cotta, Georg ᄀvon $\neg$; f Briefsammlung 1829-1845

SWW p Cotta, Johann Friedrich $\neg$ von $\neg$; f Briefsammlung 1803-1832

SWW p Schelling, Friedrich Wilhelm $\neg$ von $\neg$; f Briefsammlung 1806-1849

Titel: $\quad \neg$ Das $\neg$ Klassenbuch : Geschichte einer Frauengeneration / Eva Jantzen. - 1997

SWW g Deutschland ; s Frau ; s Alltag ; z Geschichte 1932-1976 ; f Briefsammlung

Aber:

SWW g Deutsch ; s Brief ; z Geschichte ; f Anthologie

Briefwechsel $<$ Formschlagwort $>$ BS Briefsammlung

Bücherverzeichnis BS Bibliographie

Cartoon $<$ Formschlagwort $>B S$ Karikatur 


\section{CD}

D Für vorliegende thematisch erschließbare CDs.

H Vgl. § 737. Zur lokalen Erschließung von Musik nach Form / Gattung, Provenienz und Zeit vgl. § 744 .

BF Audio-CD $<$ Formschlagwort $>$

Compactdisc $<$ Formschlagwort, im engeren Sinn $>$

Musik-CD <Formschlagwort>

OB Tonträger

\section{CD $<$ für Kinder $>$}

OB Tonträger $<$ für Kinder $>$

\section{CD-ROM}

D Für vorliegende thematisch erschließbare elektronische Publikationen auf allen digitalen Formen optischer Speicherplatten (CD-I, Photo-CD, WORM usw.) außer für Tonträger (CD) und alle Arten von DVDs.

H Beschlagwortet wird der Datenträger, wie er erworben wurde, auch wenn die CD-ROM für die Benutzung im Netz installiert oder auf andere Datenträger überspielt wird. Vgl. § 737a. Der Dateityp wird durch ein Formschlagwort (z.B. f Programm, f Bibliographie, f Datensammlung) oder durch ein Sachschlagwort ausgedrückt.

BF Bildplatte <Optische Speicherplatte, Formschlagwort $>$

Compactdisc $<$ Formschlagwort, im weiteren Sinn $>$

Laser optical disc

Optical disc

Optische Platte $<$ Formschlagwort $>$

Optische Speicherplatte $<$ Formschlagwort $>$

Optischer Plattenspeicher $<$ Formschlagwort $>$

OB Elektronische Publikation

UB DVD-Audio

DVD-ROM

DVD-Video

\section{CD-ROM < für Kinder >}

OB Elektronische Publikation < für Kinder>

UB DVD-Audio < für Kinder>

DVD-ROM < für Kinder $>$

DVD-Video < für Kinder>

\section{Checkliste}

BF Prüfliste

Chrestomathie BS Anthologie

Chronologisches Wörterbuch wird als Sachschlagwort verwendet. 


\section{Comic}

D Für vorliegende thematisch erschließbare Comics. Es wird nicht unterschieden, ob es sich um Comics für Kinder, Jugendliche oder Erwachsene handelt.

H Vgl. §§ 760-762. Beim zugehörigen Schlagwort entfällt der Zusatz <Motiv>. Zur Verwendung als Gattungsbegriff vgl. jedoch § 5,3 und 4. Für Anthologien benutze s Comic ; f Anthologie.

OB Belletristische Darstellung

Bildband

Jugendbuch

Kinderbuch

VB Bilderbuch

Karikatur

SWW g Afrika ; s Französin ; s Sklavenhandel ; z Geschichte 1780 ; f Comic

Compact-Cassette BS Tonkassette

Compactdisc $<$ Formschlagwort, im engeren Sinn $>$ BS CD

Compactdisc $<$ Formschlagwort, im weiteren Sinn $>$ BS CD-ROM

Computerdatei $<$ Formschlagwort $>$ BS Elektronische Publikation

Computerdatei im Fernzugriff $<$ Formschlagwort $>$ BS Online-Publikation

Computerprogramm BS Programm

Curriculum $<$ Formschlagwort $>$ BS Lehrplan

Datei $<$ Formschlagwort $>$ BS Elektronische Publikation

Datenbank $<$ Formschlagwort $>$ BS Elektronische Publikation

\section{Datensammlung}

D Für vorliegende Sammlungen von Zahlen und Daten, die weder als $f$ Tabelle noch als $f$ Statistik zu bezeichnen sind; vor allem im naturwissenschaftlich-technischen Bereich.

$\mathrm{H}$ Eine Zeitangabe beim Formschlagwort entfällt. Für historische Daten benutze f Zeittafel.

BF Faktendatenbank $<$ Formschlagwort $>$

OB Verzeichnis

UB Tabelle

VB Statistik

Titel: $\quad$ Dioden : Datenbuch 1980/81. - 1980

SWW s Diode ; f Datensammlung

Inhalt: Beilstein Crossfire

SWW s Organische Chemie ; f Datensammlung ; f Online-Publikation

Deskriptor / Verzeichnis BS Thesaurus 
Dia

D Für vorliegende thematisch erschließbare Diaserien oder ein einzelnes Dia.

H Vgl. § 737. Beim zugehörigen Schlagwort entfällt der Zusatz $<$ Motiv $>$, wenn es sich nicht um Reproduktionen von Kunstwerken handelt.

BF Diapositiv

Diasammlung

Diastreifen

OB Audiovisuelles Material

Bildliche Darstellung

UB Tonbildreihe

\section{Diagramm}

D Für vorliegende graphische Darstellungen, v.a. von Zahlenmaterial.

BF Flussdiagramm $<$ Formschlagwort $>$

VB Plan

Tabelle

Titel: Klimadiagramm-Karten der einzelnen Kontinente und die ökologische Klimagliederung der Erde / Heinrich Walter ... - 1975

SWW s Klima ; f Diagramm

Diapositiv BS Dia

Diasammlung BS Dia

Diastreifen BS Dia

\section{Diskette}

D Für vorliegende thematisch erschließbare elektronische Publikationen auf Diskette.

H Vgl. § 737a. Der Dateityp wird durch ein Formschlagwort (z.B. f Programm, f Bibliographie, f Datensammlung) oder durch ein Sachschlagwort ausgedrückt.

BF Floppydisk

OB Elektronische Publikation

\section{Diskette <für Kinder>}

OB Elektronische Publikation < für Kinder>

Diskographie wird zerlegt in s Tonträger ; f Verzeichnis

Diskussion entfällt als Formschlagwort.

Dokument $<$ Formschlagwort $>$ BS Quelle

Dokumentation <im Sinne einer vorliegenden Literaturdokumentation> BS Bibliographie

Dramatische Darstellung $<$ Formschlagwort $>$ BS Theaterstück

\section{Drehbuch}

D Für ein vorliegendes Drehbuch, wenn das Dokument nur dieses und keine darüber hinausgehenden Materialien enthält; nicht für ein Buch zum Film. Daneben für Sammlungen von Drehbüchern.

BF Filmdrehbuch

Filmmanuskript 
Titel: $\quad$ Non posso dire altro, se non che sono qui = Ich kann nun nichts sagen als ich hier bin. Drehbuch eines Videofilms (Spielfilms) über Goethes Aufenthalt in Rom anlässlich eines Museumsfestes der Casa di Goethe, Rom.

SWW s Non posso dire altro, se non che sono qui ; f Drehbuch

und $\quad \mathrm{p}$ Goethe, Johann Wolfgang $\neg$ von $\neg$; g Rom ; s Reise ; s Film ; f Drehbuch

Titel: $\quad \neg$ Die $\neg$ bleierne Zeit und andere Filmtexte / Margarethe von Trotta. - 1988

SWW p Trotta, Margarethe $\neg$ von $\neg$; s Film; f Drehbuch

\section{DVD-Audio}

D Für vorliegende thematisch erschließbare DVD-Audios.

H Zur lokalen Erschließung von Musik nach Form/Gattung, Provenienz und Zeit vgl. § 744.

OB CD-ROM

Tonträger

DVD-Audio < für Kinder>

OB CD-ROM < für Kinder>

Tonträger $<$ für Kinder $>$

\section{DVD-ROM}

D Für vorliegende thematisch erschließbare DVD-ROMs.

OB CD-ROM

\section{DVD-ROM < für Kinder>}

OB CD-ROM < für Kinder>

\section{DVD-Video}

D Für vorliegende thematisch erschließbare DVD-Videos.

H Zur lokalen Erschließung mit Form- und Gattungsbegriffen, Bezeichnungen für künstlerische Strömungen sowie Entstehungsgebiet vgl. § 737,5. Zur lokalen Erschließung von Musikvideos nach Form/Gattung, Provenienz und Zeit vgl. § 744.

OB CD-ROM

VB Videoskassette

\section{DVD-Video < für Kinder>}

OB CD-ROM < für Kinder $>$

VB Videokassette < für Kinder $>$

\section{Einblattdruck}

D Für einzelne vorliegende thematisch erschließbare Einblattdrucke. Einseitig bedrucktes in sich abgeschlossenes Blatt, vorwiegend aus der Frühzeit des Buchdrucks; zumeist Flugblätter. Nicht für spätere Sammlungen (Reprints, Mikroformen) von Einblattdrucken.

$\mathrm{H} \quad$ Zur Verwendung als Gattungsbegriff vgl. § 5,3 und 4.

OB Quelle

VB Flugblatt

Eindrücke $<$ Formschlagwort $>B S$ Erlebnisbericht 



\section{Einführung}

D Nur für betont didaktische Darstellungen für Anfänger, die nicht als Handbuch oder Lehrbuch geeignet sind, z.B. für Studienführer für ein bestimmtes Studium oder für außerschulisch verwendete Sprachlehrbücher.

H Bei Handbuchcharakter entfällt das Formschlagwort. Für eindeutige Lehr- und Arbeitsbücher, die für die Hand des Studenten gedacht sind, benutze f Lehrbuch, für Sprachübungsbücher benutze f Aufgabensammlung.

BF Lehrbuch $<$ Einführung $>$

Leitfaden

Programmierte Einführung < Formschlagwort $>$

VB Anleitung

Lehrbuch

Ratgeber

Sprachführer

Einleitung als Sachschlagwort verwendet für die biblische Einleitungswissenschaft, sonst benutze f Einführung.

Einwohnerbuch BS Adressbuch

Für historische Einwohnerbücher ohne Adressen benutze s Einwohner ; z Geschichte mit Jahreszahl ; f Verzeichnis.

Einzelbeiträge BS Aufsatzsammlung

Einzelfallstudie $<$ Formschlagwort $>$ BS Fallstudiensammlung

\section{Elektronische Publikation}

D Für vorliegende thematisch erschließbare elektronische Publikationen, die nicht unter einen der zugelassenen Unterbegriffe fallen oder eine Kombination von mindestens zwei verschiedenen Datenträgern.

H Vgl. § 737a. Das Formschlagwort entfällt, wenn eines der zugelassenen Formschlagwörter für den Datenträger benutzt wird. Der Dateityp wird durch ein Formschlagwort (z.B. f Programm, f Bibliographie, f Datensammlung) oder durch Sachschlagwörter ausgedrückt.

BF Computerdatei $<$ Formschlagwort $>$

Datei $<$ Formschlagwort $>$

Datenbank $<$ Formschlagwort $>$

Elektronisches Dokument

Magnetband

Magnetbandkassette

UB CD-ROM

Diskette

Online-Publikation

\section{Elektronische Publikation < für Kinder>}

UB CD-ROM < für Kinder>

Diskette $<$ für Kinder $>$

VB Kinderbuch

Elektronisches Dokument BS Elektronische Publikation 


\section{Entscheidungssammlung}

D Sammlung von Gerichtsentscheidungen.

H Die Zeitangabe beim Formschlagwort entfällt.

BF Gerichtsentscheidung / Sammlung

VB Fallsammlung

Titel: $\quad \neg$ Die $\neg$ Judikate und Sprüche des Obersten Gerichtshofes seit seinem Bestande. - 1950

$S W W \quad$ c Österreich / Oberster Gerichtshof ; f Entscheidungssammlung

Entwurf wird als Sachschlagwort verwendet. Für Entwürfe der Technik und Architektur benutze f Plan.

\section{Enzyklopädie}

D Nur für allgemeine, nicht thematisch beschränkte Nachschlagewerke, unabhängig von Umfang und physischer Form. Auch für allgemeine Nachschlagewerke, die das Wissen nicht in alphabetischer Form bieten.

H Kann als einziges Schlagwort verwendet werden; wird ggf. mit einem Formschlagwort für die physische Form sowie f Kindersachbuch verknüpft. Sprache und Erscheinungsland werden nicht berücksichtigt.

BF Allgemeinenzyklopädie

Konversationslexikon

Lexikon $<$ Formschlagwort, Enzyklopädie $>$

Universalenzyklopädie

Universallexikon

OB Wörterbuch

Titel: Grand Larousse encylopédique : en dix volumes. - 1960-1968

SW f Enzyklopädie

Titel: Herders großes Bilderlexikon [Computerdatei] : multimedial ; ab 5 Jahren. - 1996. $1 \mathrm{CD}-\mathrm{ROM}$

$S W W \quad$ f Enzyklopädie ; fCD-ROM $<$ für Kinder $>$

Erde / Karte BS Weltkarte

Erdkarte $B S$ Weltkarte

Erinnerungen $<$ Formschlagwort $>B S$ Autobiographie

\section{Erlebnisbericht}

D Für vorliegende persönlich gefärbte Augenzeugenberichte.

$\mathrm{H}$ Nicht benutzt in Verbindung mit dem Autor des Erlebnisberichts. Die Verknüpfung mit einem Allgemeinbegriff wird vor der mit der Personengruppe bevorzugt. Eine Zeitangabe entfällt oder wird als z Geschichte mit Jahreszahlen erfasst.

BF Augenzeugenbericht $<$ Formschlagwort $>$ Eindrücke $<$ Formschlagwort $>$

OB Bericht Quelle

VB Autobiographie

Reisebericht

Tagebuch

$S W W \quad$ s Burenkrieg; f Erlebnisbericht

SWW g Russlanddeutsche ; z Geschichte 1920-1976 ; f Erlebnisbericht 
Essays $<$ Formschlagwort $>B S$ Aufsatzsammlung

Examensfragen $<$ Formschlagwort $>B S$ Aufgabensammlung

Exkursion wird als Sachschlagwort behandelt; verknüpfe mit f Führer.

\section{Fachkunde}

D Für Berufsschulbücher, die das Fachwissen in einem staatlich anerkannten Ausbildungsberuf vollständig darstellen. Sind i. d. R. über die Berufsbildung hinaus auch als Handbücher für die berufliche Praxis verwendbar.

H Vgl. §§ 767-773.

OB Schulbuch

$S W W \quad$ s Bäckerhandwerk ; f Fachkunde

$S W W \quad$ s Arzthelferin; f Fachkunde

Fachwörterbuch $<$ Formschlagwort $>B S$ Wörterbuch

\section{Fahrplan}

D Für vorliegende Fahrpläne und deren Reprints.

$\mathrm{H}$ Eine Zeitangabe entfällt.

Titel: $\quad$ Deutsches Kursbuch / Deutsche Reichsbahn, Kursbuchbüro. -1937/38

$S W W \quad$ k Deutsche Reichsbahn ; f Fahrplan

Faktendatenbank $<$ Formschlagwort $>B S$ Datensammlung

\section{Fallsammlung}

D Nur für Sammlungen juristischer Fälle als Lehrmaterial für die Ausbildung.

BF Rechtsfälle $<$ Formschlagwort $>$

Repetitorium $<$ Formschlagwort, Fallsammlung $>$

VB Aufgabensammlung / Recht

Entscheidungssammlung

Titel: $\quad$ Fälle und Erläuterungen zum Sachenrecht für Anfangssemester / Walter Gerhardt. 1986-1996

SWW g Deutschland; s Sachenrecht ; f Fallsammlung

Fallstudie $<$ Formschlagwort $>B S$ Fallstudiensammlung

\section{Fallstudiensammlung}

D Für Fallsammlungen außer den juristischen, aber nur für Auflistungen von Einzelfällen.

H Die Fälle müssen nacheinander vollständig erläutert werden. Nicht benutzt, wenn ein Autor aus Fällen seiner Praxis zur Erläuterung zitiert.

BF Einzelfallstudie $<$ Formschlagwort $>$

Fallstudie $<$ Formschlagwort $>$

VB Beispielsammlung

Fernsprechbuch $B S$ Telefonbuch

Festrede entfällt als Formschlagwort

Festschrift entfällt als Formschlagwort (vgl. § 101a,6).

Fiche $<$ Formschlagwort $>B S$ Mikroform 


\section{Film}

D Für vorliegende thematisch erschließbare Filme; bezeichnet das Material, soweit nicht eines der spezielleren Formschlagwörter verwendet wird.

H Vgl. § 737. Beim zugehörigen Schlagwort entfällt der Zusatz $<$ Motiv $>$. Wenn Filme mit Video aufgezeichnet sind, benutze f Videokassette.

Zur lokalen Erschließung mit Form- und Gattungsbegriffen, Bezeichnungen für künstlerische Strömungen sowie das Entstehungsgebiet vgl. § 737,4 und 5.

OB Audiovisuelles Material

UB Film $8 \mathrm{~mm}$

Film Super-8

Film $16 \mathrm{~mm}$

Film $35 \mathrm{~mm}$

Film $65 \mathrm{~mm}$

Film $70 \mathrm{~mm}$

VB Videokassette

Titel: Ethologie der Graugans [Bildtonträger] / Konrad Lorenz. - ca. 1950. - 1 Film : stumm; $16 \mathrm{~mm}+$ Begleith.

SWW s Graugans ; s Verhaltensforschung; f Film 16 mm

\section{Film < für Kinder $>$}

OB Audiovisuelles Material < für Kinder>

Film 8 mm

OB Film

Film Super-8

OB Film

\section{Film 16 mm}

OB Film

Film 35 mm

OB Film

\section{Film 65 mm}

OB Film

\section{Film 70 mm}

OB Film

Filmdrehbuch BS Drehbuch

Filmmanuskript BS Drehbuch

Filmographie wird zerlegt in s Film ; f Werkverzeichnis

Findbuch $<$ Formschlagwort $>$ BS Inventar

Firmenkatalog BS Verkaufskatalog

Floppydisk BS Diskette 


\section{Flugblatt}

D Für einzelne vorliegende thematisch erschließbare Flugblätter. Kurze Druckschrift, die der Propaganda dient; nicht für spätere Sammlungen (Reprints, Mikroformen) von Flugblättern.

$\mathrm{H} \quad$ Zur Verwendung als Gattungsbegriff vgl. § 5,3 und 4.

OB Quelle

VB Einblattdruck

Flugplan wird als Sachschlagwort behandelt.

Flussdiagramm $<$ Formschlagwort $>$ BS Diagramm

Folie / Unterricht BS Arbeitstransparent

\section{Formelsammlung}

\section{Formularsammlung}

BF Mustersammlung / Formular

VB Beispielsammlung

\section{Forschungsbericht}

D Für vorliegende Forschungsberichte von Institutionen.

H Die Zeitangabe entfällt. Für sachlich bzw. chronologisch geordnete Darstellungen der Sekundärliteratur zu einem Thema benutze f Literaturbericht.

OB Bericht

SWW c Würzburg / Universität ; f Forschungsbericht

Forschungsbericht $<$ Literaturbericht $>B S$ Literaturbericht

Fortschrittsbericht $<$ Formschlagwort $>$ BS Literaturbericht

Fotografie BS Photographie

\section{Führer}

D Benutzt für Reiseführer, Führer zu Institutionen (z.B. Museen), zu einzelnen Bauwerken, zu literarisch-künstlerischen Gattungen und zu Exkursionen sowie für Adressbücher und Verzeichnisse mit Beschreibungen oder Bewertungen.

H Eine Zeitangabe beim Formschlagwort entfällt. Für Reiseführer mit Schwerpunkt auf der Kunst benutze f Kunstführer.

BF Reiseführer $<$ Formschlagwort $>$ Stadtführer

UB Kunstführer Sprachführer

VB Adressbuch Verzeichnis

SWW g London ; f Führer

$S W W$ g Niederlande; s Radwandern ; f Führer

$S W W$ s Oper; f Führer

SWW g Deutschland; s Hotel ; f Führer 


\section{Fundstellenverzeichnis}

D Für vorliegende Verzeichnisse von Fundstellen für Rechtsquellen (Rechtsnormen, Gerichtsentscheidungen) und Rechtsliteratur.

OB Verzeichnis

Titel: $\quad$ Rechtsprechung und Literatur zum Erschließungsrecht des Bundes : Fundstellenverzeichnis / zsgest. von Karl-Heinz Neuhausen ... - 1984

SWW g Deutschland ; s Erschließungsrecht ; f Fundstellenverzeichnis

Gedächtnisschrift im Sinn einer Festschrift entfällt als Formschlagwort (vgl. § 101a,6).

Gedächtnisschrift $<$ Nachruf $>$ BS Nachruf

Gedenkrede $<$ Formschlagwort $>$ BS Nachruf

Gegenstandskatalog BS Aufgabensammlung

Gelegenheitsschrift entfällt als Formschlagwort.

Gemeindeverzeichnis BS Ortsverzeichnis

Genealogie / Tafel BS Genealogische Tafel

\section{Genealogische Tafel}

BF Ahnentafel

Genealogie / Tafel

Stammbaum / Genealogie

Stammtafel

Gerichtsentscheidung / Sammlung BS Entscheidungssammlung

Geschäftsbericht $<$ Formschlagwort $>$ BS Bericht

Geschichtsatlas wird zerlegt in

z Weltgeschichte; f Atlas oder

jeweiliges Geographikum ; z Geschichte ; f Atlas

Geschichtsquelle BS Quelle

Gesetzessammlung wird zerlegt in

s Recht ; f Quelle bzw.

jeweiliges Rechtsgebiet ; f Quelle

\section{Gespräch}

D Nur in Verbindung mit einem Personenschlagwort, wenn kein Sachschlagwort verwendet wird. Im Unterschied zu Interview keine Befragung einer Person durch eine andere.

H Eine Zeitangabe entfällt. Wird ein bestimmtes Thema behandelt, so wird dafür eine weitere Schlagwortkette ohne f Gespräch gebildet. Sind für die Erschließung zwei oder mehr Personen zu berücksichtigen, so werden deren Namen (bis zu sechs) verknüpft, gefolgt von f Gespräch. Fakultativ können für Listenfunktionen weitere Ketten mit jeder einzelnen Person gebildet werden.

VB Interview

Titel: $\quad$ Antonio Calderara in Briefen und Gesprächen / Raimer Jochims. - 1982

SWW p Calderara, Antonio ; f Gespräch

SWW p Calderara, Antonio ; f Briefsammlung 1966-1978

Titel: $\quad$ Vom Werden zum Sein : der große Weisheitslehrer des Ostens im Dialog mit einem der führenden Physiker des Westens / Jiddu Krishnamurti ; David Bohm. - 1987 


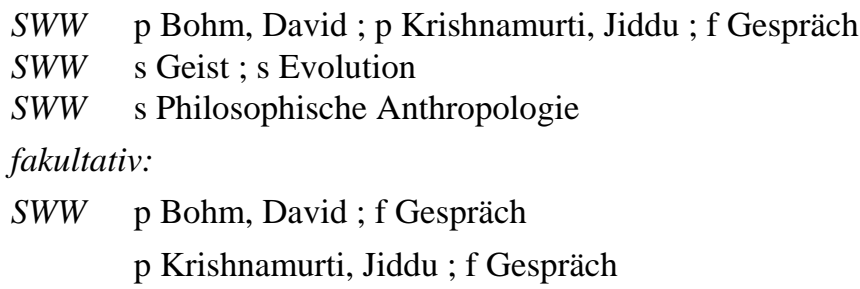

\section{Globus}

$\mathrm{H} \quad$ Wird i.d.R. als einziges Schlagwort verwendet.

VB Karte

Glossar $<$ Formschlagwort $>$ BS Wörterbuch

\section{Graphik}

D Für vorliegende thematisch erschließbare Graphik. Für einzelne graphische Blätter und Folgen von Graphikblättern - sowohl für Original- wie für Reproduktionsgraphik.

Nicht für die Reproduktion von Graphik in Büchern (hier benutze f Bildband), nicht für Pressendrucke, nicht für elektronische Publikationen und audiovisuelle Materialien.

H Beim zugehörigen Schlagwort entfällt der Zusatz <Motiv>. Zur Verwendung als Gattungsbegriff vgl. § 5,3 und 4 .

OB Bildliche Darstellung

UB Plakat

VB Künstlerbuch

Pressendruck

Titel: Plan der Roembrugtige Veltslag van Hochstet [Bildliche Darstellung] / de Vianen. 1704. - Kupferstich $44 \times 47 \mathrm{~cm}$

SWW g Höchstädt $<$ Donau $>$ / Schlacht <1704> ; f Graphik

Titel: $\quad$ Neun Alphabete / mit Holz- und Linolschnitten von H. H. Hübner-Prochotta ...

Graphikmappe, die ähnlich wie beim Buch aufgemacht ist (Buchhülle, Titelblatt), jedoch ansonsten nur aus einer Folge loser Graphikblätter besteht. Daher kein Pressendruck.

SWW s Alphabet; f Graphik

Grundriss entfällt als Formschlagwort oder benutze f Einführung.

Grundzüge entfällt als Formschlagwort oder benutze f Einführung.

Gutachten entfällt als Formschlagwort.

Handbuch entfällt als Formschlagwort.

Handpressendruck BS Pressendruck

Historische Karte BS Altkarte

Historische Quelle BS Quelle

\section{Hörspiel}

D Für vorliegende thematisch erschließbare Hörspiele.

H Vgl. §§ 760-762. Beim zugehörigen Schlagwort entfällt der Zusatz <Motiv>. Bei Hörspielen für Kinder und Jugendliche tritt das Formschlagwort $f$ Hörspiel an die vorletzte Stelle der Schlagwortkette. Zur Verwendung als Gattungsbegriff vgl. § 5,3 und 4. Für eine Sammlung benutze s Hörspiel ; f Anthologie.

Bei Aufnahmen von Hörspielen verknüpft mit dem Formschlagwort für den Datenträger. 
OB Belletristische Darstellung

$$
\begin{aligned}
& \text { SWW } \\
& \text { s Vater ; s Sohn ; f Hörspiel } \\
& \text { SWW }
\end{aligned}
$$

\section{Humoristische Darstellung}

D Für vorliegende thematisch erschließbare nicht belletristische Texte.

$\mathrm{H} \quad$ Beim zugehörigen Schlagwort entfällt der Zusatz $<$ Motiv $>$.

VB Belletristische Darstellung

Karikatur

Illustration wird als Sachschlagwort verwendet.

Illustrationswerk BS Bildband

Index $<$ Formschlagwort $>B S$ Verzeichnis

Index $<$ Formschlagwort, Konkordanz $>$ BS Konkordanz

\section{Interview}

D Für die Niederschrift eines Gesprächs in Form der Befragung einer Person durch eine andere. Auch für Sammlungen von Interviews mit mehreren Personen.

BF Befragung < Interview>

VB Gespräch

Titel: $\quad \neg$ Das $\neg$ Fest des Augenblicks : Gespräche mit Georges Banu / Luc Bondy. - 1997

SWW p Bondy, Luc ; f Interview

Titel: $\quad$ Ich riskiere den Wahnsinn : Gespräche mit Christo ... / André Müller. - 1997

SWW g Deutschland ; s Prominenz ; Interview

\section{Inventar}

D Für vorliegende Bestandsverzeichnisse von Archiven sowie für amtliche Verzeichnisse von Kunstdenkmälern außerhalb von Museen mit Anspruch auf Vollständigkeit.

H Für andere Verzeichnisse im Bereich der Kunst benutze f Verzeichnis, für Museen benutze f Katalog.

BF Archivrepertorium $<$ Formschlagwort $>$

Bestandsverzeichnis $<$ Inventar $>$

Findbuch $<$ Formschlagwort $>$

Kunstwerk / Inventar

Repertorium / Archiv <Formschlagwort $>$

OB Verzeichnis

VB Katalog

Kunstführer

SWW g Niedersachsen ; s Kunst ; f Inventar

Aber:

Titel: Handbuch der deutschen Kunstdenkmäler / Bremen, Niedersachsen. - 1992

SWW g Bremen ; s Kunst ; f Verzeichnis

SWW g Niedersachsen; s Kunst ; f Verzeichnis

Titel: Katalog der Kanzelaltäre in Oberfranken / von Helmuth Meißner. - 1982

SWW g Oberfranken ; s Kanzelaltar ; f Verzeichnis

Titel: Monnaies antiques découvertes au Grand-Duché de Luxembourg. - 1972-1996

SWW g Luxemburg ; s Münzfund ; s Römerzeit ; f Verzeichnis 
Jahrbuch $<$ Formschlagwort $>$ BS Zeitschrift

Jahresbericht $<$ Formschlagwort $>$ BS Bericht

\section{Jugendbuch}

D Bücher für die Altersgruppe der etwa Zwölf- bis Fünfzehnjährigen. Nur für Jugendbücher mit überwiegend erzählendem Charakter, die einen bestimmten, als Problem, Ereignis oder mit einem Namen benennbaren Gegenstand behandeln (§ 4,6). Im Zweifelsfall sind das äußere Erscheinungsbild, die sprachliche Form und die Ausrichtung des Verlags heranzuziehen, um sie von Kinderbüchern und von Literatur für Erwachsene abzugrenzen.

H Vgl. §§ 763-766. Beim zugehörigen Schlagwort entfällt der Zusatz <Motiv>. Zur Verwendung als Gattungsbegriff vgl. § 5,3 und 4.

UB Comic Jugendsachbuch

VB Kinderbuch

\section{Jugendsachbuch}

D Bücher für die Altersgruppe der etwa Zwölf- bis Fünfzehnjährigen mit überwiegend sachlich informierendem Charakter. Im Zweifelsfall sind das äußere Erscheinungsbild, die sprachliche Form und die Ausrichtung des Verlags heranzuziehen, um sie von Kinderbüchern und von Literatur für Erwachsene abzugrenzen.

H Vgl. §§ 763-766; zur Verwendung als Gattungsbegriff vgl. § 5,3 und 4.

OB Jugendbuch

VB Kindersachbuch

\section{Kalender}

D Für vorliegende thematisch erschließbare Kalender mit bildlichen Darstellungen, nicht für Kalender mit dem Charakter eines Jahrbuchs.

H Eine Zeitangabe beim Formschlagwort entfällt. Daneben als Gattungsbegriff nach § 5,3 und 4 denkbar. Für Kalender mit dem Charakter eines Jahrbuchs benutze f Zeitschrift.

OB Bildliche Darstellung

Titel: $\quad$ Naturschutz in Bayern: naturnahe Kleingärten. - 1990

Abreißkalender mit eingehenden Erläuterungen

SWW s Kleingarten ; s Naturnahe Gestaltung ; f Kalender

Titel: $\quad$ Kunstpartner 1997 : Behausung-Heimat

Abreißkalender mit Abbildungen von Werken Regensburger Künstler. Das gemeinsame Thema ist zu vage, um berücksichtigt zu werden.

SWW g Regensburg; s Kunst ; z Geschichte 1996 ; f Kalender

\section{Karikatur}

D Für thematisch erschließbare bildhafte, humoristische Darstellungen.

H Der Zusatz <Motiv> entfällt beim zugehörigen Schlagwort. Zur Verwendung als Gattungsbegriff vgl. § 5,3 und 4 .

BF Cartoon $<$ Formschlagwort $>$

Satire / Kunst

OB Bildband

Bildliche Darstellung

VB Comic

Humoristische Darstellung 


\section{Karte}

D Für vorliegende Karten, außer solchen vor 1850; unabhängig von der physischen Form.

$\mathrm{H} \quad$ Eine Zeitangabe beim Formschlagwort entfällt.

BF Amtliche Karte

Landkarte

Plan $<$ Karte $>$

Straßenkarte $<$ Formschlagwort $>$

Wandkarte $<$ Formschlagwort $>$

UB Altkarte

Stadtplan

Weltkarte

VB Atlas

Globus

Titel: Bodenkarte Bayerns / bearb. und erl. von Franz Münichsdorfer. - 1929

SWW g Bayern; s Boden ; f Karte

Kassette $<$ Tonträger $>$ BS Tonkassette

Kassette $<$ Video $>$ BS Videokassette

\section{Katalog}

D Für das Bestandsverzeichnis einer Sammlung (Bibliothek, Museum usw.) oder einer Gesamtheit von Sammlungen; unabhängig von der physischen Form. Auch für Verlagskataloge.

$\mathrm{H} \quad$ Bei Archivbeständen benutze f Inventar. Für andere Arten der Auflistung benutze $f$ Verzeichnis. f Katalog entfällt bei f Ausstellung.

Wenn ein Bestandskatalog so gewichtig ist, dass er als Bibliographie zum Gegenstand verwendet werden kann, wird zusätzlich eine Schlagwortkette mit dem Formschlagwort f Bibliographie gebildet. Die Zeitangabe wird zum Formschlagwort hinzugefügt, wenn kein Sachschlagwort vergeben wird.

BF Bestandskatalog Bestandsverzeichnis $<$ Katalog $>$

OB Verzeichnis

UB Antiquariatskatalog Auktionskatalog Ausstellung Verkaufskatalog

VB Bibliographie Inventar Neuerwerbungsliste

SWW c Würzburg / Mainfränkisches Museum ; f Katalog

Aber:

Titel: Katalog der Kanzelaltäre in Oberfranken / von Helmuth Meißner. - 1982

SWW g Oberfranken; s Kanzelaltar ; f Verzeichnis

SWW c Erlangen / Universitätsbibliothek ; s Christian Science ; f Katalog

SWW s Christian Science; f Bibliographie

SWW c München / Bayerische Staatsbibliothek ; f Katalog 1501-1840 ; f CD-ROM 
Aber:

SWW c Gießen / Universitätsbibliothek ; s Trivialliteratur ; z Geschichte 1800-1900 ; f Kata$\log$

\section{Kinderbuch}

D Bücher für die Altersgruppe bis etwa zwölf Jahre. Nur für Kinderbücher mit überwiegend erzählendem Charakter, die einen bestimmten, als Problem, Ereignis oder mit einem Namen benennbaren Gegenstand behandeln $(\S 4,6)$. Nicht benutzt für elektronische Publikationen.

H Vgl. §§ 763-766. Beim zugehörigen Schlagwort entfällt der Zusatz <Motiv>. Zur Verwendung als Gattungsbegriff vgl. § 5,3 und 4.

UB Bilderbuch

Comic

Kindersachbuch

VB Elektronische Publikation < für Kinder>

Jugendbuch

\section{Kindersachbuch}

D Bücher für die Altersgruppe bis etwa zwölf Jahre mit überwiegend sachlich informierendem Charakter. Nicht benutzt für elektronische Publikationen.

H Vgl. §§ 763-766; zur Verwendung als Gattungsbegriff vgl. jedoch § 5,3 und 4.

OB Kinderbuch

VB Jugendsachbuch Sachbilderbuch

Kletterführer wird zerlegt in s Klettern ; f Führer

\section{Kochbuch}

D Für eine vorliegende Sammlung von Rezepten aller Art, unabhängig von der physischen Form.

H Kann ggf. als einziges Schlagwort vergeben werden.

BF Kochrezept

Rezept / Kochen

Rezepte / Kochen

Rezeptsammlung / Kochen

Titel: $\quad$ Italienische Küche / Manuela Gasteiger-Klapfer. - 1996

SWW g Italien ; f Kochbuch

Titel: $\quad$ Käserezepte zum Kochen und Backen / Ursula Grüninger. - 1986

SWW s Käse ; f Kochbuch

Kochrezept BS Kochbuch

Kolloquium BS Kongress

\section{Kommentar}

D Nur für juristische, theologische und literarische Kommentare, die eine Quelle im Fortlauf des Textes erläutern.

Kompaktkassette BS Tonkassette 


\section{Kongress}

D Für alle Berichte von Tagungen, Symposien und Kongressen.

H Die Schlagwortkette hat folgende Form (vgl. § 504,3): Thema; f Kongress ; g Ort $<$ Jahr $>$

BF Kolloquium

Kongressbericht $<$ Formschlagwort $>$

Symposium $<$ Kongressbericht $>$

Tagung

Tagungsbericht $<$ Formschlagwort $>$

Vortragssammlung

Kongressbericht $<$ Formschlagwort $>B S$ Kongress

\section{Konkordanz}

BF Index $<$ Formschlagwort, Konkordanz $>$

Personenregister

Register $<$ Formschlagwort, Konkordanz $>$

Werkkonkordanz

Wörterverzeichnis

Wortindex

Konversationslexikon $B S$ Enzyklopädie

Korrespondenz $<$ Formschlagwort $>B S$ Briefsammlung

\section{Künstlerbuch}

D Für vorliegende Künstlerbücher im engeren Sinn (Konzeptbücher, Buchobjekte, Objektbücher).

H Verknüpfe mit dem jeweiligen Künstler. Nicht für Pressendrucke (künstlerisch gestaltete Bücher, Schwergewicht liegt auf der Typographie, Herstellung auf der Handpresse) bzw. für Malerbücher (verbinden einen literarischen Text mit darauf bezüglichen Bildern; Text und Bild stehen gleichberechtigt nebeneinander. Künstler, Drucker, Verleger und ggf. Schriftsteller arbeiten zusammen). Für Graphikmappen, die nicht den Charakter eines Buches haben benutze f Graphik.

VB Graphik

Illustration

Pressendruck

Titel: $\quad$ Euridike / [Anselm Kiefer]. - [1991]. - 19 Blatt : Sand, Asche, verbrannte Zeitungsund Silberpapierfragmente, Haare, Stroh usw. auf Photogr. über Karton

Unikat, nicht mit Druckverfahren hergestellt.

SWW p Kiefer, Anselm; f Künstlerbuch

Titel: Fluxus 1 / George Maciunas. - Besteht aus verschiedenen zusammengeschraubten Blättern, Photos usw. und überwiegend Briefumschlägen, in denen diverse Fluxusgegenstände von verschiedenen Formaten liegen. Als Behälter Holzkasten.

Mehrere Exemplare, die sich unterscheiden.

SWW p Maciunas, George; f Künstlerbuch 
Künstlerlexikon wird zerlegt in s Künstler ; f Biographie

Kunst / Führer BS Kunstführer

\section{Kunstführer}

D Für vorliegende Reise- und Museumsführer mit deutlichem Schwerpunkt auf der Kunst sowie für Architektur.

BF Kunst / Führer

OB Führer

VB Inventar

SWW g Schweden; f Kunstführer

SWW g Chicago <Ill.> ; s Architektur ; z Geschichte 1982-1993 ; f Kunstführer

Kunstwerk / Inventar BS Inventar

Lagerkatalog BS Verkaufskatalog

Landkarte BS Karte

Laser optical disc BS CD-ROM

Laser-Disc BS Bildplatte

Lebensbeschreibung BS Biographie

Lebenserinnerungen BS Autobiographie

\section{Lehrbuch}

D Benutzt für fachlich-wissenschaftlich einführende und studienbegleitende Grundlagenliteratur für die Hand des Studenten und auf Hochschulniveau, d. h. i. d. R. für Anfangssemester bestimmt (Beispiele hierfür z. B. in der Schriftenreihe „Uni-Taschenbücher"). Nicht benutzt für Einführungen in das wissenschaftliche Arbeiten oder für berufspraktische Literatur zur selbständigen Fortbildung, Aktualisierung des Wissensstandes oder Weiterqualifizierung. Nicht benutzt für allgemeinverständliche Darstellungen auch spezieller Sachverhalte zur persönlichen Erweiterung des Bildungshorizonts.

H Unabhängig von der physischen Form benutzt, nicht jedoch für programmierte, interaktive Lehrmittel (benutze f Lernprogramm). Für Sprachlehrbücher bei kurzer, betont didaktischer Darstellung benutze f Einführung, für Darstellungen des Fachwissens für anerkannte Ausbildungsberufe benutze f Fachkunde, für Schulbücher benutze f Schulbuch.

UB Lernprogramm

VB Einführung

Lehrbuch $<$ Einführung $>B S$ Einführung

\section{Lehrerhandbuch}

D Für die Hand des Lehrers bestimmte Ergänzung des Schulbuchs.

H Vgl. §§ 767-773.

VB Schulbuch

Unterrichtseinheit

Lehrmaterial BS Lehrmittel 


\section{Lehrmittel}

D Für Materialien, die Schulbücher ergänzen oder ersetzen, geringere Verbindlichkeit für die Unterrichtsgestaltung haben und spezielle Themen für eines oder mehrere Unterrichtsfächer aufbereiten; analog auch für den außerschulischen Bereich. Sie können sowohl für Lehrer wie für Schüler (Lernende) bestimmt sein.

H Vgl. §§ 767-773; i.d.R. mit dem Unterrichtsfach verknüpft. Nicht für studienbegleitende Literatur, Lehrbücher und Lehrmaterialien zum Selbststudium; nicht für programmierte, interaktive Lehrmittel (benutze f Lernprogramm).

BF Arbeitsmittel / Unterricht

Lehrmaterial

Lernmaterial

Unterrichtsmaterial

Unterrichtsmedium

Unterrichtsmittel

UB Arbeitstransparent

Aufgabensammlung

Lernprogramm

VB Schulbuch

Unterrichtseinheit

\section{Lehrplan}

H Verknüpfe mit geographischem Schlagwort und dem Unterrichtsfach. Eine Zeitangabe entfällt.

BF Curriculum $<$ Formschlagwort $>$

Rahmenrichtlinie <Formschlagwort $>$

Lehrprogramm BS Lernprogramm

Leichenrede $<$ Formschlagwort $>$ BS Nachruf

Leitfaden BS Einführung

Lernmaterial BS Lehrmittel

\section{Lernprogramm}

D Für vorliegende programmierte, interaktive Lehrmittel, v.a. elektronische Publikationen.

H Verknüpfe mit dem Formschlagwort für den Datenträger. Lernprogramme als Teil von Schulbüchern werden nicht gesondert erschlossen.

BF Lehrprogramm

Lernsoftware

Unterrichtsprogramm

OB Lehrbuch

Lehrmittel

Programm

Titel: Historica [Computerdatei] : Weltgeschichte interaktiv erleben. 1 CD-ROM

'Mit dem historischen Altas auf CD gehen Schüler/innen auf eine multimediale Zeitreise durch die Jahrhunderte in Videos, Quellentexten, Tondokumenten'.

SWW z Weltgeschichte ; f Lernprogramm ; f CD-ROM

Lernsoftware BS Lernprogramm 


\section{Lesebuch}

D Für vorliegende Schullesebücher und für umfangreiche Textsammlungen, die für den Deutschunterricht oder Fremdsprachenunterricht bestimmt sind.

H Zur Verwendung vgl. § 773.

BF Schullesebuch

OB Schulbuch

SWW s Deutschunterricht ; s Sekundarstufe 1; f Lesebuch

Lesebuch < Anthologie $>B S$ Anthologie

Lexikon $<$ Formschlagwort $>B S$ Wörterbuch

Lexikon <Formschlagwort, Enzyklopädie $>$ BS Enzyklopädie

Liederbuch wird zerlegt in

s Lied ; f Anthologie

Liste $<$ Formschlagwort $>B S$ Verzeichnis

Literarische Darstellung BS Belletristische Darstellung

\section{Literaturbericht}

D Für sachlich bzw. chronologisch geordnete Darstellungen der Sekundärliteratur zu einem Thema mit ausführlicher Würdigung.

H Der Berichtszeitraum wird angegeben, es sei denn, der Literaturbericht berücksichtigt die gesamte Literatur oder die heute noch relevante Literatur, unabhängig vom Erscheinungsjahr. Die Zeitangabe wird in diesem Fall zum Formschlagwort hinzugefügt. Wenn die Zeitangabe sich dagegen auf den behandelten Gegenstand bezieht, wird z Geschichte mit Jahreszahlen verwendet (vgl. § 503,1).

BF Forschungsbericht $<$ Literaturbericht $>$

Fortschrittsbericht $<$ Formschlagwort $>$

OB Bericht

VB Bibliographie

Literaturdatenbank $<$ Formschlagwort $>$ BS Bibliographie

Literaturdokumentation $<$ Formschlagwort $>$ BS Bibliographie

Literaturverzeichnis BS Bibliographie

Lösungssammlung BS Aufgabensammlung

Luftbild wird als Sachschlagwort benutzt; verknüpfe mit f Bildband, f Atlas oder $\mathrm{f}$ Photographie.

Magnetband $<$ Formschlagwort $>$ BS Elektronische Publikation

Magnetbandkassette $<$ Formschlagwort $>$ BS Elektronische Publikation

Malerbuch $<$ Formschlagwort $>$ BS Pressendruck

Matrikel wird als Sachschlagwort verwendet ; verknüpfe mit f Verzeichnis.

MC BS Tonkassette

\section{Medienkombination}

D Für vorliegende thematisch erschließbare Publikationen aus Printmedien, audiovisuellen Materialien und/oder elektronischen Publikationen. 
H Vgl. § 737; bis zu zwei Medien werden getrennt erschlossen, mehrere audiovisuelle Materialien unter $\mathrm{f}$ Audiovisuelles Material, mehrere elektronische Materialien unter f Elektronische Publikation zusammengefasst. Entfällt bei f Schulbuch.

BF Medienpaket

Medienkombination $<$ Audiovisuelles Material $>$ BS Audiovisuelles Material

Medienpaket BS Medienkombination

Medienpaket < Audiovisuelles Material $>$ BS Audiovisuelles Material

Meditation wird als Sachschlagwort verwendet.

Meinungsumfrage BS Umfrage

Memoiren BS Autobiographie

Messkatalog $<$ Formschlagwort $>B S$ Verkaufskatalog

Mikrofiche $<$ Formschlagwort $>$ BS Mikroform

Mikrofilm $<$ Formschlagwort $>$ BS Mikroform

\section{Mikroform}

D Für vorliegende Ausgaben eines Werks in Mikroform; für alle Arten von Mikroformen.

H Die Erschließung erfolgt in gleicher Weise wie die gedruckter Werke. Für Ausgaben älterer Werke gilt $\S 4,5$.

BF Fiche $<$ Formschlagwort $>$

Mikrofiche $<$ Formschlagwort $>$

Mikrofilm $<$ Formschlagwort $>$

Titel: Journalism history [Mikroform]. - Vol. 1 (1974) -

SWW s Journalismus ; z Geschichte ; f Zeitschrift ; f Mikroform

Titel: Musical world [Mikroform] : a literary and fine art paper. - Vol. 1 - 71

SWW s Musikleben ; z Geschichte 1836-1891 ; f Quelle ; f Mikroform

\section{Mitgliederverzeichnis}

D Für vorliegende Verzeichnisse der Mitglieder einer Körperschaft.

H Bei historischen Zeiträumen wird z Geschichte mit Jahreszahl verwendet.

BF Personenregister / Körperschaft

OB Verzeichnis

SWW c Österreich / Nationalrat ; z Geschichte 1918-1968 ; f Mitgliederverzeichnis

Museumsführer wird zerlegt in:

Name des Museums ; f Führer bzw. Kunstführer oder

Geographikum ; Schlagwort für Museumstyp ; f Führer bzw. Kunstführer

SWW g Bayern; s Eisenbahnmuseum; f Führer

SWW g Hessen; s Kunstgewerbemuseum ; f Kunstführer

Museumskatalog wird zerlegt in:

Name des Museums ; f Kataog

Multimedia entfällt bei vorliegenden elektronischen Publikationen als pleonastisch (vgl. $\S 737 \mathrm{a}, 5, \mathrm{e})$.

MusiCassette BS Tonkassette

Musik-CD $<$ Formschlagwort $>B S \mathrm{CD}$ 


\section{Musikdruck}

D Nur bei lokaler Erschließung für vorliegende thematisch oder nach Form / Gattung, Besetzung, Provenienz, Zeit und Präsentation und Realisation erschließbare Musikdrucke (vgl. § 744).

$\mathrm{H}$ Bei Sammlungen, die auch Texte enthalten, wird je nach dem Charakter der Sammlung f Anthologie oder f Musikdruck verwendet.

Nach $\$$ 746-748, sofern konkret erfassbare sachliche Inhalte vorliegen: Motiv ; Gattung ; Besetzung; Formschlagwort.

SWW g Mexiko <Motiv>; s Konzertstück ; s Blasorchester; f Musikdruck

Nach $\$ \$ 747,748$, sofern keine konkret erfassbaren sachlichen Inhalte vorliegen: Gattung ;

Besetzung ; Formschlagwort.

SWW s Toccata ; s Trio, Trompete 1,2 Orgel ; f Musikdruck

Nach $\$$ 749, 750: Provenienz ; Gattung ; Besetzung ; Zeit ; Formschlagwort. (Für Sammlungen und für Einzelwerke zulässig vgl. \$\$744-752.)

SWW g Norddeutschland ; s Choralbearbeitung; s Orgel ; z Geschichte 1570-1750 ; f Musikdruck

Anm.: $§ \S 745-752$ sind enthalten in „Regeln für den Schlagwortkatalog (RSWK) / Musikalien und Musiktonträger. - Entwurf. - 1991“

Musikkassette $B S$ Tonkassette

Musiktonträger $<$ Formschlagwort $>B S$ Tonträger

Musikvideo $<$ Formschlagwort $>B S$ Videokassette

Mustersammlung $B S$ Beispielsammlung

Mustersammlung / Formular BS Formularsammlung

Mustervertrag wird zerlegt in $\mathrm{s}$ Vertrag ; f Formularsammlung

Nachdruck wird nicht als Formschlagwort verwendet. Zur Beschlagwortung vgl. § 4,5.

\section{Nachruf}

D Nur nach Personennamen bzw. Personengruppen.

H Für Sammlungen benutze s Nachruf ; f Anthologie.

BF Gedächtnisschrift $<$ Nachruf $>$ Gedenkrede $<$ Formschlagwort $>$

Leichenrede $<$ Formschlagwort $>$

Nekrolog

Nachschlagewerk $<$ Formschlagwort $>B S$ Verzeichnis

Nachschlagewerk $<$ Formschlagwort, Wörterbuch $>B S$ Wörterbuch

Nationalbibliographie wird zerlegt in jeweiliger Staat ; s Druckwerk ; f Bibliographie

Nekrolog $B S$ Nachruf

\section{Neuerwerbungsliste}

D Für vorliegende Verzeichnisse der Neuerwerbungen von Museen, Bibliotheken usw.

$\mathrm{H}$ Zeitangaben können dem Formschlagwort hinzugefügt werden. 
VB Katalog

Bibliographie

SWW c Bonn / Universitätsbibliothek ; s Romanistik ; f Neuerwerbungsliste

Norm

D Für vorliegende Normen (im Sinn der Normung), Standards usw.; sowohl für einzelne Normen wie für Sammlungen; nicht für Rechtsnormen.

H Verknüpfe ggf. mit dem Geltungsbereich.

VB Richtlinie

Titel: Erstellung und Weiterentwicklung von Thesauri : DIN 1463. - 1987

SWW g Deutschland; s Thesaurus ; f Norm

Titel: Wasserversorgung : Normen. - 1985-1997

Enthält deutsche und für Deutschland relevante internationale Normen.

SWW g Deutschland ; s Wasserversorgung ; f Norm

Aber:

Titel: Technik der optischen Projektion : Kommentar zu DIN 19045 / Wolfgang Grau. -

1994

SWW s Projektion <Optik> ; t DIN 19045

Euvrekatalog BS Werkverzeichnis

Euvreverzeichnis BS Werkverzeichnis

Online-Datenbank < Formschlagwort $>$ BS Online-Publikation

Online-Dokument BS Online-Publikation

\section{Online-Publikation}

D Für vorliegende thematisch erschließbare Online-Publikationen.

H Vgl. § 737a. Der Dateityp wird durch ein Formschlagwort (z.B. f Programm, f Bibliographie, f Datensammlung) oder durch ein Sachschlagwort ausgedrückt.

BF Computerdatei im Fernzugriff $<$ Formschlagwort $>$

Online-Datenbank $<$ Formschlagwort $>$

Online-Dokument

OB Elektronische Publikation

Opernführer wird zerlegt in

s Oper ; f Führer

Optical disc BS CD-ROM

Optische Platte $<$ Formschlagwort $>$ BS CD-ROM

Optische Speicherplatte $<$ Formschlagwort $>$ BS CD-ROM

Optischer Plattenspeicher $<$ Formschlagwort $>$ BS CD-ROM

Ortslexikon wird zerlegt in

Geographikum ; s Ort (oder s Stadt) ; f Wörterbuch oder

s Ortsname ; f Wörterbuch oder

s Ort ; z Geschichte ; f Wörterbuch oder

s Historische Stätte; f Wörterbuch oder

benutze f Ortsverzeichnis

Ortsname / Verzeichnis BS Ortsverzeichnis 
Ortsplan BS Stadtplan

\section{Ortsverzeichnis}

D Für vorliegende Ortsverzeichnisse mit knappen statistischen oder geographischen Informationen.

H Für Nachschlagewerke mit ausführlichen Informationen benutze s Ort ; f Wörterbuch, für historische Verzeichnisse benutze s Ort ; z Geschichte ; f Wörterbuch oder s Historische Stätte ; f Wörterbuch; für philologische Nachschlagewerke benutze s Ortsname ; f Wörterbuch.

BF Gemeindeverzeichnis

Ortsname / Verzeichnis

OB Verzeichnis

Titel: Neues schweizerisches Ortslexikon. - 1983

SWW g Schweiz; f Ortsverzeichnis

Titel: Topographisch-statistisches Handbuch des Königreichs Bayern nebst alphabetischem Ortslexikon / Josef Heyberger. - 1867

Das Schwergewicht liegt auf einem Verzeichnis der Orte, die nach Landgerichten geordnet sind; kurze statistische Angaben. Der erste Teil fasst dies nur nach übergeordneten Einheiten zusammen. Das Erscheinungsjahr wird nicht berücksichtigt.

SWW g Bayern; f Ortsverzeichnis

Titel: Niedersächsische Orte bis zum Ende des ersten Jahrtausends in schriftlichen Quellen / von Kirstin Casemir ... - 1995

SWW g Niedersachsen ; z Geschichte 800-1100 ; f Ortsverzeichnis

und g Niedersachsen ; s Ort ; z Geschichte 800-1100 ; f Wörterbuch

und g Niedersachsen ; s Ortsname ; z Geschichte 800-1100 ; f Wörterbuch

Aber:

Titel: $\quad$ Landkreis Ebersberg / bearb. von Karl Puchner. - 1951. - (Historisches Ortsnamenbuch von Bayern : Oberbayern ; 1)

SWW g Ebersberg <Kreis> ; s Ortsname ; f Wörterbuch

und $\quad \mathrm{g}$ Ebersberg $<$ Kreis $>$; s Ort ; z Geschichte ; f Wörterbuch

Dargestellt ist die Entwicklung der Ortsnamen und die Geschichte der betreffenden Orte im Abriss.

Overheadfolie BS Arbeitstransparent

Patent $<$ Formschlagwort $>$ BS Patentschrift

\section{Patentschrift}

BF Patent $<$ Formschlagwort $>$

Personalbibliographie wird zerlegt in

Jeweiliges Thema ; f Bibliographie,

SWW g Deutschland ; s Schriftsteller ; f Bibliographie

Personenregister BS Konkordanz

oder zerlegt in s Person ; f Verzeichnis

Personenregister / Körperschaft BS Mitgliederverzeichnis

Photo-CD $<$ Formschlagwort $>$ BS CD-ROM 


\section{Photographie}

D Für eine vorliegende thematisch erschließbare Photographie und für Serien von Photographien. Bezeichnet das Material; nicht für Reproduktionen.

$\mathrm{H} \quad$ Beim zugehörigen Schlagwort entfällt der Zusatz $<$ Motiv $>$. Zur Verwendung als Gattungsbegriff vgl. § 5,3 und 4. Für Reproduktionen von Photographien benutze f Bildband.

BF Fotografie

Photographische Aufnahme

OB Bildliche Darstellung

Titel: $\quad$ Volkskundliche und kulturgeschichtliche Photographien aus den Jahren 1934-1985

[Bildliche Darstellung] / Erika Groth-Schmachtenberger

Photographien in Schubern. Titel fingiert. Der Bestand gliedert sich in einzelne thematische

Serien, die getrennt erschlossen werden.

SWW g Alpen; s Wallfahrt ; z Geschichte 1934-1962 ; f Photographie

usw.

Photographien $<$ Bildband $>B S$ Bildband

Photographische Aufnahme BS Photographie

\section{Plakat}

D Für ein vorliegendes thematisch erschließbares Plakat oder eine Folge von Plakaten.

$\mathrm{H}$ Bei Reproduktionen verknüpfe s Plakat und f Bildband. Beim zugehörigen Schlagwort entfällt der Zusatz $<$ Motiv $>$. Zur Verwendung als Gattungsbegriff vgl. § 5,3 und 4.

OB Bildliche Darstellung

OB Graphik

Titel: $\quad \neg$ The $\neg$ Zugspitze [Bildliche Darstellung] : the queen of the Bavarian Alps, Germany. ca. 1930 . $-100 \times 63 \mathrm{~cm}$

SWW g Zugspitze ; f Plakat

Plan

D Für vorliegende graphische Darstellungen ; z. B. Technische Zeichnungen, Bauzeichnungen, Gartenpläne usw.

H Für vorliegende Pläne im Sinn der Planung benutze s Planung oder s Entwurf. Für vorliegende Karten auch in größerem Maßstab benutze f Karte, für graphische Darstellungen von Zahlenmaterial benutze f Diagramm.

BF Bauzeichnung $<$ Formschlagwort $>$

Technische Zeichnung $<$ Formschlagwort $>$

VB Diagramm

Titel: $\quad$ SMS Emden : (1909 bis 1914); Baupläne des kleinen Kreuzers / Peter Huff. - 1996

SWW $\quad$ s Emden $<$ Schiff, 1908-1914> ; f Plan

Plan $<$ Karte $>$ BS Karte

Plan $<$ Stadtplan $>B S$ Stadtplan

Porträt $B S$ Bildnis

Praktikum

D Anleitung zu praktischen Übungen für Studierende naturwissenschaftlicher Fächer. 
Predigt wird als Sachschlagwort (für die Methode der Darstellung) behandelt; i. d. R. nicht permutierend (vgl. Anl. 5). Benutzt für einzelne Predigten und für Sammlungen zu einem Thema.

\section{Predigthilfe}

Predigtsammlung wird als Sachschlagwort behandelt (auch bei vorliegenden thematisch nicht eingegrenzten Sammlungen).

Pressebericht $<$ Formschlagwort $>B S$ Pressestimme

Pressedienst $<$ Formschlagwort $>B S$ Pressestimme

\section{Pressendruck}

D Für vorliegende auf Handpressen bzw. von Privatpressen hergestellte Druckschriften; i. d. R. künstlerische Drucke für bibliophile Sammler. Auch für Malerbücher (Text und Bild stehen gleichberechtigt nebeneinander; Künstler, Drucker, Verleger und ggf. Schriftsteller arbeiten zusammen).

H Verknüpfe mit dem jeweiligen Künstler oder Verlag. Für Graphikmappen, die nicht den Charakter eines Buches haben, benutze f Graphik.

BF Handpressendruck

Malerbuch $<$ Formschlagwort $>$

VB Graphik

s Illustration

Künstlerbuch

Titel: $\quad$ Dionysos Dithyramben / Friedrich Nietzsche. Ausstattung Henry van der Velde.

Leipzig: Insel-Verlag 1914

SWW p VanDeVelde, Henry; f Pressendruck

k Insel-Verlag Anton Kippenberg <Leipzig $>$; f Pressendruck

Aber:

Titel: $\neg$ Die $\neg$ wunderbaren Abenteuer des Tartarin von Tarascon / Alphonse Daudet ;

Zeichnungen von Emil Preetorius. - Dachau: Einhornverl., 1922

Kein Pressendruck. - Die Zeichnungen sind reproduziert; Illustration zum Text.

SWW p Daudet, Alphonse / $\neg$ Les $\neg$ aventures prodigieuses de Tartarin de Tarascon ;

s Illustration ; p Preetorius, Emil

Pressespiegel BS Pressestimme

\section{Pressestimme}

D Sammlung von Beiträgen zu einem Thema aus einer oder mehreren Zeitungen.

BF Pressebericht $<$ Formschlagwort $>$

Pressedienst $<$ Formschlagwort $>$

Pressespiegel

OB Quelle

\section{Programm}

D Für vorliegende thematisch erschließbare (Computer-)Programme. 
H Vgl. § 737a. Verknüpfe mit dem jeweiligen Datenträger.

BF Computerprogramm

Rechenprogramm

Software $<$ Formschlagwort $>$

UB Lernprogramm

Programm im Sinn von Schulprogramm entfällt.

Programm einer Partei benutze s Parteiprogramm.

Programm $<$ Veranstaltung, Formschlagwort $>B S$ Programmheft

\section{Programmheft}

D Für vorliegende Programme von Theateraufführungen oder anderen Veranstaltungen.

H Verknüpfe mit dem Titel des Stücks, s Aufführung, dem Namen des Theaters und dem Zeitschlagwort.

BF Programm < Veranstaltung, Formschlagwort $>$

Theaterprogramm

Titel: Botho Strauß, Ithaka : Schauspiel nach den Heimkehr-Gesängen der Odyssee / Münchner Kammerspiele, Schauspielhaus

SWW p Strauß, Botho / t Ithaka ; s Aufführung ; c München / Münchner Kammerspiele ; z Geschichte 1996 ; f Programmheft

Programmierte Einführung $<$ Formschlagwort $>B S$ Einführung

Protokoll <Formschlagwort> BS Quelle

Prüfliste BS Checkliste

Prüfungsfragen $<$ Formschlagwort $>B S$ Aufgabensammlung

Pseudonymenlexikon wird zerlegt in s Pseudonym ; f Bibliographie (wenn Titel aufgeführt sind) oder

s Pseudonym ; f Verzeichnis (wenn nur Namen aufgeführt sind)

Publikationen $<$ Formschlagwort $>B S$ Bibliographie

\section{Quelle}

D Für alle Arten von Quellenmaterial, sowohl aus dem historisch-politischen und juristischen als auch aus dem literarischen, künstlerischen oder biographischen Bereich.

BF Akten $<$ Formschlagwort $>$

Dokument $<$ Formschlagwort $>$

Geschichtsquelle

Historische Quelle

Protokoll <Formschlagwort>

Quellensammlung

Sammlung <Quelle>

UB Autobiographie

Bericht

Briefsammlung

Einblattdruck

Erlebnisbericht

Flugblatt 
Pressestimme

Regest

Reisebericht

Tagebuch

Titel: $\quad$ Corpus inscriptionum Graecarum. - Repr. - Bd 1-4. - 1977

SWW g Griechisch ; s Inschrift ; f Quelle

Quellensammlung BS Quelle

Quiz wird als Sachschlagwort verwendet.

Radwanderführer wird zerlegt in

s Radwandern ; f Führer

Rahmenrichtlinie $<$ Formschlagwort $>$ BS Lehrplan

\section{Ratgeber}

D Praxisbezogene Einführung für Laien, soweit nicht als $\mathrm{f}$ Anleitung zu bezeichnen.

$\mathrm{H}$ Für Einführungen in ein Studium benutze $f$ Einführung, für solche in spezifisch handwerkliche Tätigkeiten benutze f Anleitung.

VB Einführung

Anleitung

SWW s Einkommensteuererklärung ; f Ratgeber

Reader BS Aufsatzsammlung

Reallexikon $<$ Formschlagwort $>$ BS Wörterbuch

Rechenprogramm BS Programm

Rechtsfälle $<$ Formschlagwort $>$ BS Fallsammlung

Rechtsprechungsübersicht wird zerlegt in

s Rechtsprechung ; f Fundstellenverzeichnis

Rede entfällt als Formschlagwort.

Referate $<$ Dokumentation, Formschlagwort $>$ BS Bibliographie

Referateblatt $<$ Formschlagwort $>$ BS Bibliographie

Regelsammlung entfällt bei Spielanleitungen, z.B. für Kartenspiele, als pleonastisch. Im Sport benutze s Wettkampfbestimmung bzw. s Spielregel (bei Sportspielen).

\section{Regest}

D Für vorliegende Regesten (knappe Zusammenfassungen des Inhalts einer Urkunde).

OB Quelle

Regionalbibliographie wird zerlegt in

Name der Region ; s Landeskunde ; f Bibliographie

Register $<$ Formschlagwort $>$ BS Verzeichnis

Register $<$ Formschlagwort, Konkordanz $>$ BS Konkordanz

\section{Reisebericht}

D Für vorliegende Berichte über eine oder mehrere Reisen. 
H Die Form als Tagebuch wird ggf. nicht berücksichtigt. Für die literarische Gattung benutze s Reiseliteratur, s Reiseroman usw. Bei historischen Reiseberichten werden bei Bedarf Zeitangaben zum Formschlagwort hinzugefügt.

BF Reisebeschreibung

Reisebriefe

Reisereportage

Reisetagebuch

OB Bericht

Quelle

VB Erlebnisbericht

Tagebuch

Titel: Vom Schreibtisch zum Äquator : afrikanische Reisen / Leo Frobenius. - 1982

SWW g Afrika; f Reisebericht 1904-1914

Reisebeschreibung BS Reisebericht

Reisebriefe BS Reisebericht

Reiseführer $<$ Formschlagwort $>$ BS Führer

Reisereportage BS Reisebericht

Reisetagebuch BS Reisebericht

Repertorium <im engeren Sinn> BS Bibliographie

Repertorium <im weiteren Sinn> BS Verzeichnis

Repertorium / Archiv $<$ Formschlagwort $>$ BS Inventar

Repetitorium < Formschlagwort, Aufgabensammlung $>$ BS Aufgabensammlung oder entfällt als Formschlagwort.

Repetitorium <Formschlagwort, Fallsammlung $>$ BS Fallsammlung

Report entfällt als Formschlagwort.

Reprint wird nicht als Formschlagwort verwendet. Zur Beschlagwortung vgl. § 4,5.

Rezept / Kochen BS Kochbuch

Rezepte / Kochen BS Kochbuch

Rezeptsammlung / Kochen BS Kochbuch

\section{Richtlinie}

D Für alle Sammlungen von Vorschriften, Regeln und Standards, die nicht Gesetzescharakter haben.

H Richtlinien der Europäischen Union werden nach § 715,11 mit dem Titel angesetzt bzw. (sofern mehrere) als Sachschlagwort behandelt.

BF Vorschrift

VB Norm

Titel: $\quad$ Führung des Liegenschaftskatasters / Niedersächsische Vermessungs- und Katasterverwaltung. - 1983

SWW g Niedersachsen ; s Kataster ; f Richtlinie 
Titel: Zusätzliche technische Vorschriften und Richtlinien für den Bau bituminöser Fahrbahndecken / Der Bundesminister für Verkehr, Abt. Straßenbau. - 1984

SWW s Fahrbahndecke ; s Bituminöser Stoff ; f Richtlinie

Richtwert wird als Sachschlagwort verwendet; verknüpfe mit f Datensammlung.

Roman $<$ Formschlagwort $>$ BS Belletristische Darstellung

Romanführer wird zerlegt in

s Roman ; f Führer

\section{Rückläufiges Wörterbuch}

OB Wörterbuch

\section{Sachbilderbuch}

D Bücher mit überwiegend sachlich informierendem Charakter, die sich vorrangig an die Altersgruppe der Vorschulkinder und Leseanfänger wenden und in denen die Abbildungen mindestens den gleichen Anteil wie der Text einnehmen.

H Vgl. § 763-766. Bestehen die Illustrationen weitgehend oder ausschließlich aus sachlichen Abbildungen (z.B. Photographien), so werden je nach Altersgruppe f Kindersachbuch oder f Jugendsachbuch verwendet.

BF Bildersachbuch

OB Bilderbuch s Sachbuch

VB Kindersachbuch

Sachregister $<$ Formschlagwort $>$ BS Verzeichnis

Sachwörterbuch $<$ Formschlagwort $>$ BS Wörterbuch

Sammelwerk $<$ Formschlagwort $>$ BS Aufsatzsammlung

Sammlung <Anthologie $>B S$ Anthologie

Sammlung <Aufsatzsammlung> BS Aufsatzsammlung

Sammlung <Beispielsammlung > BS Beispielsammlung

Sammlung <Quelle $>$ BS Quelle

Satellitenbild wird als Sachschlagwort benutzt; verknüpfe mit $\mathrm{f}$ Bildband, $\mathrm{f}$ Atlas oder $\mathrm{f}$ Photographie.

Satire für vorliegende Satiren benutze f Belletristische Darstellung oder f Humoristische Darstellung.

Satire / Kunst BS Karikatur

\section{Schallplatte}

D Für vorliegende thematisch erschließbare Schallplatten.

H Vgl. § 737. Zur lokalen Erschließung von Musik nach Form / Gattung, Provenienz und Zeit vgl. § 744 .

OB Tonträger

Schallplatte <für Kinder>

OB Tonträger < für Kinder> 
Schauspiel $<$ Formschlagwort $>$ BS Theaterstück

Schauspielführer wird zerlegt in

s Drama ; f Führer

Schautafel BS Tafel

\section{Schematismus}

D Verzeichnis der Pfarreien, Klöster, Geistlichen usw. einer Diözese oder eines Ordens.

$\mathrm{H}$ Eine Zeitangabe entfällt.

OB Verzeichnis

\section{Schriftenreihe}

Schriftstellerlexikon wird zerlegt in s Schriftsteller ; f Biographie

\section{Schulbuch}

D Unterrichtswerk, das für den Gebrauch an allgemeinbildenden und berufsbildendenSchulen zugelassen und für die Hand des Schülers bestimmt ist, unabhängig von der physischen Form.

H Zur Verwendung vgl. §§ 767-773. Wird mit dem Unterrichtsfach verknüpft. Einzelne Teile eines mehrbändigen Werks, die für die Hand des Lehrers bestimmt sind (Lehrerbände, Lehrerhandreichungen) oder Teile die in anderer physischer Form vorliegen, werden i.d.R. nicht gesondert beschlagwortet. f Medienkombination entfällt.

UB Fachkunde

Lesebuch

VB Lehrerhandbuch

Lehrmittel

Titel: $\quad$ Learning English. Password Green. - 1995-1996

Schulbuch für Gymnasien. Besteht aus gedruckten Materialien (Schülerbuch, Workbook usw.), audiovisuellen Materialien (CD, Tonkassette, Bildfolie) für Schüler oder Lehrer sowie

Lernsoftware (Diskette, CD-ROM) für Schüler oder Lehrer.

$S W W \quad$ s Englischunterricht ; s Gymnasium ; f Schulbuch

Schullesebuch BS Lesebuch

Selbstbiographie BS Autobiographie

Skiführer wird zerlegt in

s Skisport ; f Führer oder

s Skilauf ; f Führer oder

s Tourenskilauf ; f Führer oder

s Skilanglauf ; f Führer

Software $<$ Formschlagwort $>$ BS Programm

\section{Spiel}

D Für vorliegende thematisch erschließbare Spiele; auch für Computerspiele, nicht für Planspiele.

H Zur Verwendung als Gattungsbegriff vgl. § 5,3 und 4.

Titel: $\quad$ Ene mene ... Müll : ein Würfelspiel für 2-4 Kinder ... -1982

SWW s Abfallbeseitigung; f Spiel 
Titel: $\quad$ Dow Jones

Spiel auch für Erwachsene

SWW s Börsenspekulation ; f Spiel

Spielanleitung, z.B. bei Kartenspielen, entfällt als pleonastisch.

\section{Sprachatlas}

H Soweit möglich mit der Sprach- bzw. Mundartbezeichnung verknüpft; mit dem Geographikum nur, wenn mehrere Sprachen oder Mundarten oder ein räumlich eingeschränkter Teil einer Mundart enthalten sind.

OB Atlas

Titel: $\quad$ Sorbischer Sprachatlas. - 1965-1996

SWW g Sorbisch; f Sprachatlas

Titel: $\quad$ Atlas linguistique et ethnographique du Centre / Pierrette Dubuisson. - 1971-1982

SWW g Zentralfrankreich ; f Sprachatlas

\section{Sprachführer}

D Sprachhilfe für Reisende.

H Verknüpft mit der Zielsprache, nicht der Sprache des Dokuments.

OB Führer

VB Einführung

Sprachlehrbuch wird zerlegt in

Name der Sprache ; f Einführung

Stadtatlas BS Stadtplan

Stadtführer BS Führer

\section{Stadtplan}

D Für vorliegende Stadtpläne; auch für kleinere Orte und Stadtregionen sowie für Sammlungen von Stadtplänen; auch für elektronische Publikationen und audiovisuelle Materialien.

BF Ortsplan

Plan $<$ Stadtplan $>$

Stadtatlas

OB Karte

Stammbaum / Genealogie BS Genealogische Tafel

Stammtafel BS Genealogische Tafel

\section{Statistik}

D Für vorliegendes statistisches Material, unabhängig von der physischen Form.

H I.d.R. wird eine Zeitangabe zum Formschlagwort hinzugefügt.

BF Statistisches Material

VB Datensammlung

SWW s Wirtschaftswachstum ; f Statistik 1945-1980

Statistisches Material BS Statistik

Straßenkarte $<$ Formschlagwort $>$ BS Karte 
Studienführer wird als Formschlagwort nicht verwendet

- für allgemeine Studienführer der Hochschulen benutze f Führer,

SWW c Würzburg / Universität ; f Führer

- für Einführungen in ein Fach benutze f Einführung.

SWW s Germanistikstudium ; f Einführung

Stundenbild BS Unterrichtseinheit

Symposium $<$ Kongressbericht $>$ BS Kongress

\section{Tabelle}

D Tabellarisch angeordnete Zahlen und Daten.

OB Datensammlung

VB Diagramm

Titel: Große Sendertabelle ... / Ulrich Freyer. - 1995

SWW s Rundfunksender; s Frequenz; f Tabelle

Titel: $\quad$ Mehrwertsteuer-Tabelle ... - 1992

SWW g Deutschland; s Mehrwertsteuer; f Tabelle

Tätigkeitsbericht $<$ Formschlagwort $>B S$ Bericht

\section{Tafel}

D Nur für Wandtafeln und für Schaubilder, die nicht durch $f$ Diagramm oder $f$ Verzeichnis wiederzugeben sind.

H Beim zugehörigen Schlagwort entfällt der Zusatz $<$ Motiv $>$.

BF Schautafel

Wandtafel

OB Bildliche Darstellung

Titel: $\quad$ Wandtafel der Fußreflexzonen ... / E. Sedlacek. - [1984]. - 1 Tafel ; 58 x 99 cm

SWW s Fuß; s Reflexzone ; f Tafel

Titel: Optisches Staatsrecht : allgemeine Staatslehre und deutsches Staatsrecht dargestellt in 54 Schaubildern / von E. Dieter Bösche. - 1987

SWW g Deutschland; s Staatsrecht; f Tafel

SWW s Staatslehre; f Tafel

Aber:

Titel: $\quad$ Signaltafeln : alle Tag- und Nachtsignale, Sicht- und Schallsignale für die Berufs- und Sportschiffahrt. - 1994. - 9 Bl., überwiegend Ill.

SWW s Schifffahrt ; s Signal ; f Verzeichnis

\section{Tagebuch}

D Nur in Verbindung mit Personen bzw. Personengruppen.

$\mathrm{H}$ Eine Zeitangabe wird nur nach Personennamen zum Formschlagwort hinzugefügt; sonst wird das Zeitschlagwort z Geschichte mit Jahreszahl verwendet.

In Verbindung mit Allgemeinbegriffen oder Geographika benutze $f$ Quelle oder $f$ Erlebnisbericht, für Sammlungen s Tagebuch ; f Anthologie.

Zur Verwendung als Gattungsbegriff vgl. § 5,3 und 4.

OB Quelle 
VB Autobiographie Erlebnisbericht

Reisebericht

Titel: Tagebuch aus dem London des 17. Jahrhunderts / Samuel Pepys. - 1997

SWW p Pepys, Samuel ; f Tagebuch 1660-1669

daneben für das gleiche Werk:

SWW g London; z Geschichte 1660-1669 ; f Erlebnisbericht

Tagung BS Kongress

Tagungsbericht BS Kongress

Technische Zeichnung $<$ Formschlagwort $>$ BS Plan

Telefax / Verzeichnis BS Telefaxverzeichnis

Telefaxbuch BS Telefaxverzeichnis

\section{Telefaxverzeichnis}

BF Telefax / Verzeichnis

Telefaxbuch

OB Verzeichnis

VB Adressbuch

\section{Telefonbuch}

D Benutzt unabhängig von der physischen Form.

BF Fernsprechbuch

OB Verzeichnis

VB Adressbuch

\section{Telexverzeichnis}

OB Verzeichnis

VB Adressbuch

\section{Testmaterial}

D Für vorliegende Materialien eines einzelnen Tests oder mehrerer Tests.

Titel: $\quad \neg$ Das $\neg$ Freiburger Persönlichkeitsinventar : FPI / Jochen Fahrenberg ... - Rev. Fassung FPI-R und teilw. geänderte Fassung FPI-A 1. - 1994. - 95 S. : graph. Darst. + Testmaterial

SWW $\quad$ s FPI ; f Testmaterial

Zur Ansetzung des Tests vgl. \& 714.

Titel: Neue Intelligenztests : ein umfassendes Test- und Übungsprogramm / Marc Wittmann ... - 1997

Es handelt sich um Materialien aus mehreren Tests.

SWW s Intelligenztest; f Testmaterial

\section{Text}

D Nur bei lokaler Anwendung für die Erschließung mundartlicher Texte $(\S 762,9)$ sowie für Erschließung schöner Literatur, von Kinder- und Jugendliteratur sowie von Altbeständen mit Gattungsbegriffen (vgl. § 5,3-4 und 7).

OB Belletristische Darstellung 


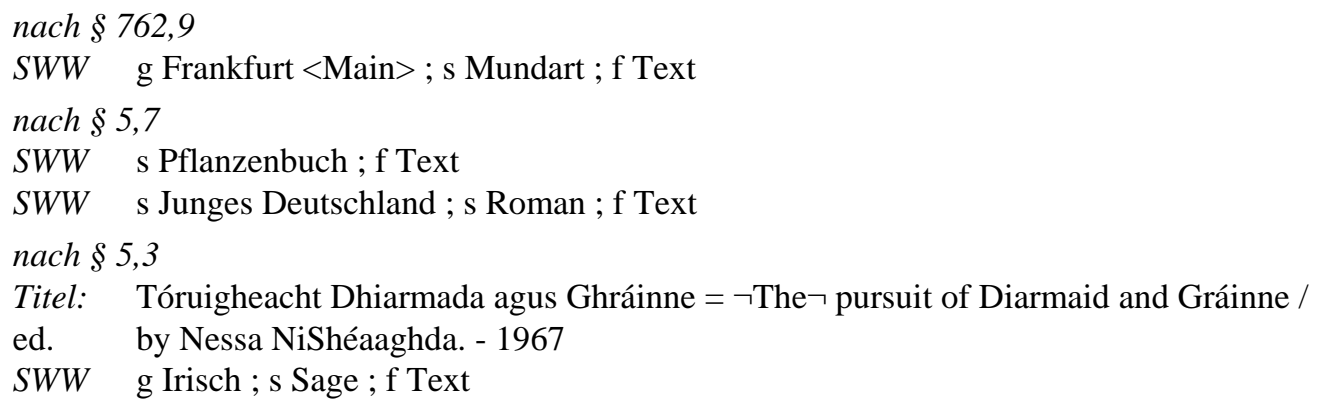

Texte $<$ Formschlagwort $>$ BS Anthologie

Theaterprogramm BS Programmheft

\section{Theaterstück}

D Für vorliegende thematisch erschließbare Dramen.

H Vgl. §§ 760-762. Beim zugehörigen Schlagwort entfällt der Zusatz <Motiv>. Bei Kinderund Jugendtheaterstücken tritt $\mathrm{f}$ Theaterstück an die vorletzte Stelle der Schlagwortkette.

Für eine Sammlung von Theaterstücken benutze s Drama ; f Anthologie. Zur Erschließung mit dem Gattungsbegriff s Drama vgl. jedoch § 5,3 und 4.

BF Dramatische Darstellung <Formschlagwort $>$

Schauspiel $<$ Formschlagwort $>$

OB Belletristische Darstellung

Titel: $\quad \neg$ Das $\neg$ Schultütenmonster : drei Einschulungsstücke / Texte von Heide-M. Kasper. 1994

SWW s Schulanfang ; f Theaterstück ; f Kinderbuch

Thematischer Katalog <Formschlagwort> BS Werkverzeichnis

\section{Thesaurus}

D Für vorliegende Thesauri.

H Für unstrukturierte Schlagwortlisten benutze s Schlagwort ; f Verzeichnis.

BF Deskriptor / Verzeichnis

OB Verzeichnis

Tonband $<$ Formschlagwort $>B S$ Tonträger

Tonbandkassette BS Tonkassette

\section{Tonbildreihe}

H Vgl. § 737.

BF Tonbildschau

OB Audiovisuelles Material

Dia

Tonträger

Tonbildschau BS Tonbildreihe

\section{Tonkassette}

D Für vorliegende thematisch erschließbare Tonkassetten.

H Vgl. § 737. Zur lokalen Erschließung von Musik nach Form / Gattung, Provenienz und Zeit vgl. § 744 . 
BF Compact-Cassette

Kassette <Tonträger $>$

Kompaktkassette

$\mathrm{MC}$

MusiCassette

Musikkassette

Tonbandkassette

OB Tonträger

\section{Tonkassette < für Kinder>}

OB Tonträger < für Kinder>

\section{Tonträger}

D Für vorliegende thematisch erschließbare Tonträger, die nicht unter einen der zugelassenen Unterbegriffe fallen.

H Vgl. § 737. Zur lokalen Erschließung von Musik nach Form / Gattung, Provenienz und Zeit vgl. § 744. Entgegen $§ 752$ des Entwurfs „RSWK Musik“ 1991 sind Unterbegriffe als Formschlagwort zugelassen.

BF Musiktonträger $<$ Formschlagwort $>$

Tonband <Formschlagwort $>$

OB Audiovisuelles Material

UB CD

DVD-Audio

Schallplatte

Tonbildreihe

Tonkassette

Titel: Hitler spricht [Tonträger]. - 1980. - 1 Schallplatte : 33 UpM ; 30 cm

SWW g Deutschland ; z Geschichte 1933-1945; f Quelle ; f Schallplatte

Bei lokaler Erschließung nach RSWK Musik:

SWW s Braut $<$ Motiv> ; s Oper ; f Tonkassette

\section{Tonträger $<$ für Kinder $>$}

OB Audiovisuelles Material < für Kinder>

UB CD < für Kinder >

DVD-Audio < für Kinder>

Schallplatte $<$ für Kinder $>$

Tonkassette <für Kinder>

Transparent / Unterricht BS Arbeitstransparent

Übungsaufgaben BS Aufgabensammlung

Übungsbuch BS Aufgabensammlung

\section{Übungssammlung}

D Nur für den Bereich des Sports sowie für körperliche Übungen, z.B. in der Krankengymnastik oder im Hatha-Joga. Nicht jedoch für Entspannungs- oder Denkübungen; hierfür benutze f Beispielsammlung.

OB Aufgabensammlung

\section{Umfrage}

D Für eine vorliegende Veröffentlichung von Umfrageergebnissen. Entfällt bei empirischen Untersuchungen, denen Umfrageergebnisse zugrunde liegen. 
BF Befragung

Meinungsumfrage

Titel: What do UK librarians dislike about their jobs / Linda Stewart. - 1982

SWW g Großbritannien ; s Bibliothekar ; s Berufszufriedenheit ; f Umfrage

Universalenzyklopädie BS Enzyklopädie

Universallexikon BS Enzyklopädie

Unterrichtsbeispiel BS Unterrichtseinheit

\section{Unterrichtseinheit}

D Didaktische Handreichung, die den Lehrstoff in Form vollständiger Unterrichtseinheiten darbietet.

H Vgl. §§ 767-773.

BF Stundenbild Unterrichtsbeispiel Unterrichtsmodell

VB Lehrerhandbuch Lehrmittel

Unterrichtsmaterial BS Lehrmittel

Unterrichtsmedium BS Lehrmittel

Unterrichtsmittel BS Lehrmittel

Unterrichtsmodell BS Unterrichtseinheit

Unterrichtsprogramm BS Lernprogramm

Urkunde wird als Sachschlagwort benutzt. Bei Sammlungen verknüpfe mit f Quelle bzw. f Regest.

\section{Verkaufskatalog}

D Katalog oder Liste zum Kauf bestimmter Produkte. Für Verlags- oder Buchhandelskatalog benutze f Katalog.

H Die jeweilige Firma entfällt, sofern sie nicht für den Inhalt von besonderer Bedeutung ist. Bei Reprints von Verkaufskatalogen tritt ggf. die Zeitangabe zum Sachschlagwort.

BF Firmenkatalog

Lagerkatalog

Messkatalog <Formschlagwort $>$

OB Katalog

UB Antiquariatskatalog

Auktionskatalog

Titel: $\quad$ Kunst der Antike : Katalog / Galerie Günter Puhze, Freiburg, Breisgau. - 1977

SWW s Altertum ; s Kunst ; f Verkaufskatalog

SWW s Kunst ; z Geschichte 3000 v. Chr.-500 ; f Verkaufskatalog

Aber:

Titel: $\quad$ Preise und Abbildungen von Gebrüder Gabler GmbH, Fingerhutfabrik, Schorndorf. Nachdr. des Originalkatalogs von 1910. - 1988

SWW k Gebrüder Gabler ; s Fingerhut ; z Geschichte 1910 ; f Verkaufskatalog

Veröffentlichungen $<$ Formschlagwort $>B S$ Bibliographie 
Vertragssammlung wird zerlegt in jeweiliges Sachgebiet ; f Quelle

SWW s Handelsvertrag; f Quelle

\section{Verzeichnis}

D Für vorliegende Verzeichnisse mit kurzgefassten Informationen.

H Eine Zeitangabe tritt ggf. zum Sachschlagwort. Für Verzeichnisse mit detaillierteren Informationen benutze $f$ Wörterbuch. Für Verzeichnisse mit einer Beschreibung oder Bewertung benutze f Führer. Für Verzeichnisse von Anbietern in Rechnernetzen benutze f Adressbuch.

BF Index $<$ Formschlagwort $>$

Liste $<$ Formschlagwort $>$

Nachschlagewerk $<$ Formschlagwort $>$

Register $<$ Formschlagwort $>$

Repertorium <im weiteren Sinn $>$

Sachregister $<$ Formschlagwort $>$

UB Adressbuch

Bibliographie

Datensammlung

Fundstellenverzeichnis

Inventar

Katalog

Mitgliederverzeichnis

Ortsverzeichnis

Schematismus

Telefaxverzeichnis

Telefonbuch

Telexverzeichnis

Thesaurus

Vorlesungsverzeichnis

Werkverzeichnis

Zitatensammlung

VB Führer

Videoband $<$ Formschlagwort $>$ BS Videokassette

Videoclip $<$ Formschlagwort $>$ BS Videokassette

\section{Videokassette}

D Für vorliegende thematisch erschließbare Videokassetten.

H Vgl. §§ 737; 744. Das Formschlagwort f Film entfällt i.d.R. Beim zugehörigen Schlagwort entfällt der Zusatz $<$ Motiv $>$.

Zur lokalen Erschließung mit Form- und Gattungsbegriffen, Bezeichnungen für künstlerische Strömungen sowie Entstehungsgebiet vgl. § 737,5. Zur lokalen Erschließung von Musikvideos nach Form / Gattung, Provenienz und Zeit vgl. § 744.

BF Kassette $<$ Video $>$

Musikvideo $<$ Formschlagwort $>$

Videoband $<$ Formschlagwort $>$

Videoclip <Formschlagwort $>$

OB Audiovisuelles Material 
VB DVD-Video

Film

Titel: $\quad \neg$ Der $\neg$ Odolkönig : die Geschichte einer Weltmarke / ein Film von Christian Frey und Detlev Meyer. - 1 Videokassette

SWW s Odol ; z Geschichte ; f Videokassette

Bei lokaler Erschließung nach $\S 5,5$ :

Titel: $\quad \neg$ Der $\neg$ Förster vom Silberwald [Bildtonträger] : österreichischer Spielfilm von 1954. 1 Videokassette

SWW s Heimatfilm ; f Videokassette

Bei lokaler Erschließung nach RSWK-Musik:

Titel: Aida [Bildtonträger] / Giuseppe Verdi. The Metropolitan Opera

SWW s Oper; f Videokassette

Titel: Young Elvis [Bildtonträger] : 20 Tracks

SWW s Rock 'n' Roll ; f Videokassette

\section{Videokassette < für Kinder>}

OB Audiovisuelles Material < für Kinder>

VB DVD-Video < für Kinder>

Videoplatte BS Bildplatte

Vorlagensammlung wird zerlegt in s Vorlage ; f Beispielsammlung

Vorlesung entfällt als Formschlagwort.

\section{Vorlesungsverzeichnis}

H Verknüpfe mit der jeweiligen Hochschule.

OB Verzeichnis

Vorschrift BS Richtlinie

Vortrag entfällt als Formschlagwort.

Vortragssammlung BS Kongress

Wanderführer wird zerlegt in s Wandern ; f Führer

Wanderkarte wird zerlegt in s Wandern ; f Karte

Wandkarte < Formschlagwort $>$ BS Karte

Wandtafel BS Tafel

Weltatlas BS Atlas

\section{Weltkarte}

D Abbildung der gesamten Erdoberfläche in einer Karte oder einem Kartenwerk. Benutzt nur sofern kein Sachschlagwort vergeben wird.

H Verknüpfe ggf. mit f Altkarte.

BF Erde / Karte

Erdkarte

OB Karte

Werk entfällt als Formschlagwort (vgl. § 116,1). 
Werke $<$ Formschlagwort $>$ BS Werkverzeichnis

Werke / Autor $<$ Formschlagwort $>$ BS Bibliographie

Werkkatalog BS Werkverzeichnis

Werkkonkordanz BS Konkordanz

\section{Werkverzeichnis}

D Vollständiges Verzeichnis des Werks (des Lebenswerks oder eines Teils) von bildenden und darstellenden Künstlern (Interpreten, Regisseuren, Schauspielern usw.) sowie von Komponisten. Sowohl für einzelne Personen wie für Personengruppen.

H Die Schlagwörter s Kunst und s Musik als Bezeichnung für das Werk entfallen als pleonastisch. Bei anderen Werkverzeichnissen benutze f Bibliographie. Wenn das Werkverzeichnis nur eine bestimmte Epoche umfasst, wird eine Zeitangabe zum Formschlagwort hinzugefügt.

BF Euvrekatalog

Euvreverzeichnis

Thematischer Katalog <Formschlagwort>

Werke $<$ Formschlagwort $>$

Werkkatalog

OB Verzeichnis

SWW p Hitchcock, Alfred ; s Film ; f Werkverzeichnis

Werkverzeichnis / Autor $<$ Formschlagwort $>$ BS Bibliographie

\section{Wörterbuch}

D Für vorliegende Sachwörterbücher (Lexika) und Sprachwörterbücher, unabhängig von der physischen Form.

H Zur Reihenfolge in der Schlagwortkette bei Sprachwörterbüchern vgl. § 702. Im schulischen Bereich wird mit dem Unterrichtsfach verknüpft. Für biographische Lexika benutze f Biographie.

BF Fachwörterbuch $<$ Formschlagwort $>$

Glossar $<$ Formschlagwort $>$

Lexikon $<$ Formschlagwort $>$

Nachschlagewerk $<$ Formschlagwort, Wörterbuch $>$

Reallexikon $<$ Formschlagwort $>$

Sachwörterbuch $<$ Formschlagwort $>$

UB Bildwörterbuch

Enzyklopädie

Rückläufiges Wörterbuch

Titel: Dictionary of psychology / I. P. Chaplin. - 1985

SWW s Psychologie ; f Wörterbuch

Sachwörterbuch; die Sprache wird nicht berücksichtigt.

Titel: $\quad$ Deutsch-chinesisches Wörterbuch ... - 1985

SWW g Chinesisch ; f Wörterbuch ; g Deutsch

Titel: Dictionnaire de la prononciation / Alain Lerond. - 1980

SWW g Französisch ; s Aussprache ; f Wörterbuch

Titel: Dictionary of science and technology / Thomas C. Collocott ... - 1983

SWW g Englisch; f Wörterbuch ; s Technik

SWW g Englisch ; f Wörterbuch ; s Naturwissenschaften

fachlich begrenztes einsprachiges (Sprach)Wörterbuch 


\section{Wörterbuch <mehrsprachig>}

D Für vorliegende zwei- und mehrsprachige fachliche Sprachwörterbücher sowie drei- und mehrsprachige allgemeine Sprachwörterbücher.

H Zur Reihenfolge in der Schlagwortkette vgl. $\S \S 702,2, \mathrm{c} ; 702,3, \mathrm{~b}$ und c.

Wörterverzeichnis $B S$ Konkordanz

Wortindex $B S$ Konkordanz

\section{Zeitschrift}

D Für vorliegende thematisch erschließbare Zeitschriften und zeitschriftenartige Reihen (in der Definition von RAK, unabhängig von der physischen Form).

H Entfällt, wenn ein anderes Formschlagwort für die Art der Darstellung verwendet wird, z. B. f Adressbuch, f Bericht, f Bibliographie, f Forschungsbericht, f Katalog, f Literaturbericht, f Telefonbuch. Zur Verwendung als Gattungsbegriff vgl. jedoch $\S 5,3$ und 4.

BF Amtsblatt $<$ Formschlagwort $>$

Jahrbuch $<$ Formschlagwort $>$

Titel: Electronic journal of probability [Computerdatei]. - Vol. 1 - . - 1996 http://math.washington.edu/ ejpecp/

$S W W \quad$ s Wahrscheinlichkeitsrechnung ; f Zeitschrift ; f Online-Publikation

Zeitschriftenverzeichnis wird zerlegt in jeweiliges Sachgebiet; s Zeitschrift ; f Bibliographie bzw. jeweiliges Sachgebiet ; s Zeitschrift ; f Katalog

\section{Zeittafel}

H Steht i. d. R. nach z Geschichte (ggf. mit Jahreszahl).

$S W W \quad \mathrm{~g}$ Deutsch; s Literatur ; $\mathrm{z}$ Geschichte ; $\mathrm{f}$ Zeittafel

Aber:

$S W W \quad \mathrm{p}$ Goethe, Johann Wolfgang $\neg$ von $\urcorner$; f Biographie ; f Zeittafel

\section{Zeitung}

$\mathrm{H}$ Zeitungen werden mit dem Erscheinungsort und $\mathrm{f}$ Zeitung erschlossen.

Titel: Erlanger Tagblatt. - 1858 -

$S W W \quad$ g Erlangen; f Zeitung

Zitat / Anthologie BS Zitatensammlung

Zitat / Verzeichnis BS Zitatensammlung

\section{Zitatensammlung}

H Kann als einziges Schlagwort verwendet werden.

BF Zitat/Anthologie

Zitat / Verzeichnis

OB Anthologie

Verzeichnis

Titel: $\quad \neg$ The $\neg$ dictionary of Australian quotations / ed. by Stephen Murray-Smith. - 1984

SWW g Australien; f Zitatensammlung

Titel: $\quad$ Parlamentarisches Schimpfbuch / Gunter Pursch (Hrsg.). - 1980-1986

$S W W \quad$ c Deutschland $<$ Bundesrepublik $>$ / Bundestag; f Zitatensammlung 



\section{Anlage 7 entfällt}

Anlage 8 entfältt

\section{Anlage 9 Zeitcode der UDK (Universelle Dezimalklassifikation)}

Es handelt sich hierbei um verkürzte Jahreszahlen, die bis 1000 v. Chr. einstellig, zwischen 1000 v. Chr. und 1800 n. Chr. zweistellig und nach 1800 i. d. R. dreistellig angegeben werden. Zeiträume v. Chr. sind durch v gekennzeichnet (vgl. auch § 418,5).

\begin{tabular}{|c|c|c|c|}
\hline \multicolumn{2}{|c|}{ - 3000 v. Chr. v3 } & $1301-1400$ & 13 \\
\hline $3000-2000$ & $\mathrm{v} 2$ & $1401-1500$ & 14 \\
\hline $2000-1000$ & $\mathrm{v} 1$ & $1501-1600$ & 15 \\
\hline \multirow{2}{*}{\multicolumn{2}{|c|}{$\begin{array}{l}\text { Erweiterung auf Jahrhunderte durch } 2 \text {. Stelle } \\
\text { ab } 1000 \text { v. Chr. }\end{array}$}} & $1601-1700$ & 16 \\
\hline & & $1701-1800$ & 17 \\
\hline 1000 - 901 v. Chr. & v09 & \multirow{2}{*}{\multicolumn{2}{|c|}{$\begin{array}{l}\text { Erweiterung auf Dekaden durch } 3 \text {. Stelle ab } \\
\text { dem 19. Jahrhundert }\end{array}$}} \\
\hline 900 - 801 v. Chr. & v08 & & \\
\hline $800-701$ v. Chr. & v07 & $1801-1810$ & 180 \\
\hline 700 - 601 v. Chr. & v06 & $1811-1820$ & 181 \\
\hline $600-501$ v. Chr. & v05 & $1821-1830$ & 182 \\
\hline $500-401$ v. Chr. & v04 & $1831-1840$ & 183 \\
\hline $400-301$ v. Chr. & v03 & $1841-1850$ & 184 \\
\hline 300 - 201 v. Chr. & v02 & $1851-1860$ & 185 \\
\hline 200 - 101 v. Chr. & v01 & $1861-1870$ & 186 \\
\hline 100 - 1 v. Chr. & $\mathrm{v} 00$ & $1871-1880$ & 187 \\
\hline 1- 100 n. Chr. & 00 & $1881-1890$ & 188 \\
\hline $101-200$ & 01 & $1891-1900$ & 189 \\
\hline $201-300$ & 02 & $1901-1910$ & 190 \\
\hline $301-400$ & 03 & $1911-1920$ & 191 \\
\hline $401-500$ & 04 & $1921-1930$ & 192 \\
\hline $501-600$ & 05 & $1931-1940$ & 193 \\
\hline $601-700$ & 06 & $1941-1950$ & 194 \\
\hline $701-800$ & 07 & $1951-1960$ & 195 \\
\hline $801-900$ & 08 & $1961-1970$ & 196 \\
\hline $901-1000$ & 09 & $1971-1980$ & 197 \\
\hline $1001-1100$ & 10 & $1981-1990$ & 198 \\
\hline $1101-1200$ & 11 & $1991-2000$ & 199 \\
\hline $1201-1300$ & 12 & $2001-$ & 200 \\
\hline
\end{tabular}





\section{Anlage 10 Konkordanz zu den Gattungsbegriffen des VD 17}

Im „Verzeichnis der Drucke des 17. Jahrhunderts“ wird zur sachlichen Erschließung eine Liste von Gattungsbegriffen, weiten Sachschlagwörtern und Formschlagwörtern verwendet. Wenn diese Daten in Kataloge mit Beschlagwortung nach RSWK überführt werden sollen, ist eine Umsetzung in Schlagwortketten erforderlich, um im Retrieval konsistente Ergebnisse zu ermöglichen. Es wird empfohlen, diese Ketten nach § 4,5 zu bilden. Dabei sollte jeweils das Erscheinungsdatum des Buchs eingefügt werden.

Anm.: Zugrunde gelegt ist die Liste der Gattungsbegriffe mit Stand vom Januar 1997.

s Akustik ; z Geschichte ; f Quelle

s Alchemie ; z Geschichte ; f Quelle

s Altertumswissenschaft ; z Geschichte ;

f Quelle

H Im VD 17: Altertumskunde

s Amtsdrucksache ; z Geschichte ; f Quelle H Im VD 17: Amtsdruckschrift

s Anatomie ; z Geschichte ; f Quelle

s Archäologie ; z Geschichte ; f Quelle

s Architektur ; z Geschichte ; f Quelle

s Ars moriendi ; z Geschichte ; f Quelle

s Arzneibuch ; z Geschichte ; f Quelle

s Astrologie ; z Geschichte ; f Quelle

s Astronomie; z Geschichte ; f Quelle

s Atlas ; z Geschichte ; f Quelle

s Auktionskatalog; z Geschichte; f Quelle

s Autobiographie ; z Geschichte ; f Quelle

s Befestigung ; z Geschichte ; f Quelle H Im VD 17: Festungsbau

s Beichtspiegel ; z Geschichte ; f Quelle

s Bergbau ; z Geschichte ; f Quelle

s Bibelausgabe ; z Geschichte ; f Quelle

H Im VD 17: Bibel

s Bibliographie ; z Geschichte ; f Quelle

s Bibliothekskatalog ; z Geschichte ;

f Quelle s Bilderlyrik ; z Geschichte ; f Quelle

H Im VD 17: Figurengedicht

s Bildnis ; z Geschichte ; f Quelle

H Im VD 17: Porträtwerk

s Biographie ; z Geschichte ; f Quelle

s Botanik ; z Geschichte ; f Quelle

s Brief ; z Geschichte ; f Quelle

H Im VD 17: Brief oder Briefsammlung

s Briefsteller ; z Geschichte ; f Quelle

s Buch ; s Anzeige ; z Geschichte ; f Quelle H Im VD 17: Bücheranzeige

s Buchhandel ; s Katalog ; z Geschichte ; f Quelle

s Chemie ; z Geschichte ; f Quelle

s Chirurgie ; z Geschichte ; quelle

s Chronik ; z Geschichte ; f Quelle

s Dissertation ; z Geschichte ; f Quelle

$\mathrm{H}$ Verknüpft mit dem jeweiligen Fachgebiet:

Theologie, Philosophie, Recht, Medizin (im VD 17: theol., phil., jur., med.) Im VD 17: Dissertation oder Dissertationensammlung

s Drama ; z Geschichte ; f Quelle

s Einblattdruck ; z Geschichte ; f Quelle

s Emblemliteratur ; z Geschichte ; f Quelle

H Im VD 17: Emblembuch

s Enzyklopädie ; z Geschichte ; f Quelle 
s Fest ; z Geschichte ; f Quelle

H Im VD 17: Festbeschreibung

s Fibel ; z Geschichte ; f Quelle

s Flugschrift ; z Geschichte ; f Quelle

s Frauenliteratur ; z Geschichte ; f Quelle

s Fürstenspiegel ; z Geschichte ; f Quelle

s Gartenbau ; z Geschichte ; f Quelle

s Gebet ; z Geschichte ; f Quelle

s Gebetbuch ; z Geschichte ; f Quelle

s Geld ; z Geschichte ; f Quelle

H Im VD 17: Geldwesen

s Gelegenheitsschrift ; z Geschichte ;

f Quelle

H Verknüpfe mit dem jeweiligen Anlass; z.B. s Geburt ; s Gelegenheitsschrift ; z Geschichte ; f Quelle

s Genealogie ; z Geschichte ; f Quelle

s Geographie ; z Geschichte ; f Quelle

s Geologie ; z Geschichte ; f Quelle

s Geometrie ; z Geschichte ; f Quelle

s Gesangbuch ; z Geschichte ; f Quelle

s Gesellschaftsschrift ; z Geschichte ;

f Quelle

s Gesetz ; z Geschichte ; f Quelle

H Im VD 17: Gesetzessammlung

s Grammatik ; z Geschichte ; f Quelle

s Gynäkologie ; z Geschichte ; f Quelle

s Handlesekunst ; z Geschichte ; f Quelle

H Im VD 17: Chiromantie

s Hausväterliteratur ; z Geschichte ; f Quelle

s Hirtendichtung ; z Geschichte ; f Quelle

H Im VD 17: Schäferdichtung

s Hochschulschrift ; z Geschichte ; f Quelle

s Itinerar ; z Geschichte ; f Quelle

s Jagdbuch ; z Geschichte ; f Quelle

H Im VD 17: Jagdliteratur

s Jesuitenliteratur ; z Geschichte ; f Quelle H Im VD 17: Jesuiten; Ordensliteratur s Judaika ; z Geschichte ; f Quelle

H Im VD 17: Judaicum

s Jugendbuch ; z Geschichte ; f Quelle

s Kalender ; z Geschichte ; f Quelle

s Katechismus ; z Geschichte ; f Quelle

s Kirchenlied ; z Geschichte ; f Quelle

s Kochbuch ; z Geschichte ; f Quelle

s Kommentar ; z Geschichte ; f Quelle

$\mathrm{H}$ Verknüpfe mit dem jeweiligen Fachgebiet:

Geschichte, Politik, Recht, Theologie Im VD 17: hist., jur., pol., theol.

s Kurzepik ; z Geschichte ; f Anthologie H Im VD 17: Erzählsammlung

s Landwirtschaft ; z Geschichte ; f Quelle

s Legende ; z Geschichte ; f Quelle

s Leichenpredigt ; z Geschichte ; f Quelle

H Im VD 17: Leichenpredigt oder Leichenpredigtsammlung

s Libretto ; z Geschichte ; f Quelle

s Lied ; z Geschichte ; f Quelle

H Im VD 17: Lied

s Lied ; z Geschichte ; f Anthologie

H Im VD 17: Liedersammlung

s Lyrik ; z Geschichte ; f Quelle

H Im VD 17: Gedicht

s Lyrik ; z Geschichte ; f Anthologie

H Im VD 17: Gedichtsammlung

s Magnetismus ; z Geschichte ; f Quelle

s Mathematik ; z Geschichte ; f Quelle

s Matrikel ; z Geschichte ; f Quelle

s Mechanik ; z Geschichte ; f Quelle

s Medizin ; z Geschichte ; f Quelle

s Messkatalog ; z Geschichte ; f Quelle

H Im VD 17: Meßkatalog

s Messrelation ; z Geschichte ; f Quelle

H Im VD 17: Meßrelation

s Militär ; z Geschichte ; f Quelle

H Im VD 17: Kriegskunde 
s Mineralogie ; z Geschichte ; f Quelle

s Musik ; z Geschichte ; f Quelle

H Im VD 17: Musikbuch

s Musterbuch ; z Geschichte ; f Quelle

s Optik ; z Geschichte ; f Quelle

s Ordensliteratur ; z Geschichte ; f Quelle

H Verknüpfe mit dem jeweiligen Orden;

z.B. $k$ Benediktiner ; s Ordensliteratur

s Pädagogik ; z Geschichte ; f Quelle

s Perioche ; z Geschichte ; f Quelle

s Pflanzenbuch ; z Geschichte ; f Quelle

s Physik ; z Geschichte ; f Quelle

s Physiognomik; z Geschichte ; f Quelle

H Im VD 17: Physiognomie

s Poetik ; z Geschichte ; f Quelle

s Praktik ; z Geschichte ; f Quelle

s Predigt ; z Geschichte ; f Quelle

s Predigtsammlung; z Geschichte ; f Quelle

s Rechenbuch ; z Geschichte ; f Quelle

s Rede ; z Geschichte ; f Quelle

s Regest ; z Geschichte ; f Quelle

H Im VD 17: Regesten

s Reisebericht ; z Geschichte ; f Quelle

H Im VD 17: Reisebeschreibung

s Rhetorik ; z Geschichte ; f Quelle

s Roman ; z Geschichte ; f Quelle

s Sage ; z Geschichte ; f Quelle

s Satire ; z Geschichte ; f Quelle

s Schreibmeisterbuch ; z Geschichte ;

f Quelle

s Schulbuch ; z Geschichte ; f Quelle

s Schule ; z Geschichte ; f Quelle

H Im VD 17: Schulschrift s Schwank ; z Geschichte ; f Quelle

s Spiel ; z Geschichte ; f Quelle

s Sprachführer ; z Geschichte ; f Quelle

s Sprichwort ; z Geschichte ; f Anthologie

H Im VD 17: Sprichwortsammlung

s Streitschrift ; z Geschichte ; f Quelle

$\mathrm{H}$ Verknüpfe mit dem jeweiligen Fachgebiet; z.B. Politik, Recht, Theologie Im VD 17: polit., jur., theol.

s Theaterzettel ; z Geschichte ; f Quelle

s Tierbuch ; z Geschichte ; f Quelle

s Tiermedizin ; z Geschichte ; f Quelle

s Tischzucht ; z Geschichte ; f Quelle

s Topographie ; z Geschichte ; f Quelle

s Totentanz ; z Geschichte ; f Quelle

s Urkunde ; z Geschichte ; f Quelle

H Im VD 17: Urkundenbuch

s Verordnung ; z Geschichte ; f Quelle

s Verserzählung ; z Geschichte ; f Quelle

s Völkerrechtlicher Vertrag ; z Geschichte ;

f Quelle

H Im VD 17: Vertrag

s Volksbuch ; z Geschichte ; f Quelle

s Vorlesung ; z Geschichte ; f Quelle

s Vorlesungsverzeichnis ; z Geschichte ;

f Quelle

s Wappenbuch ; z Geschichte ; f Quelle

s Wörterbuch ; z Geschichte ; f Quelle

H Im VD 17: Lexikon und Wörterbuch

s Zeitschrift ; z Geschichte ; f Quelle

s Zeitung ; z Geschichte ; f Quelle

s Zitatensammlung ; z Geschichte ; f Quelle

H Im VD 17: Zitatesammlung

s Zoologie ; z Geschichte ; f Quelle 



\section{Beispielregister}

Dieses Register umfaßt alle einzelnen, der SWD entsprechenden Schlagwörter (nicht Schlagwortketten) aus den Beispielen der einzelnen Paragraphen, auch die im laufenden Text genannten, nicht jedoch die nur in Erläuterungen zu Beispielen oder in Hinweisen in Datensätzen wiedergegebenen Schlagwörter.

Neben den im Register als solche gekennzeichneten ÖB-Alternativformen sind aus den Beispielsätzen auch die in den Feldern $\mathrm{OB}, \mathrm{MO}, \mathrm{VB}$ und $\mathrm{CF} / \mathrm{CS}$ zitierten Schlagwörter aufgenommen. Außerdem wurden die Anlagen 1, 2, 5, 6 und 10 ausgewertet.

Bei gleichlautendem Form- und Sachschlagwort ist i. d. R. das Formschlagwort gemeint; falls beides vorkommt, ist das Sachschlagwort eigens gekennzeichnet.

Um das Register nicht unnötig aufzublähen, sind die Einträge unter 'Geschichte' (auch mit Jahreszahlen) auf Nachweise der Stellen beschränkt, wo sich substantielle Aussagen zum Zeitschlagwort finden.

Verwiesen wird auf die jeweils unterste gezählte Hierarchiestufe der Abschnitte bzw. auf die Anlagen als Ganze; mehrfaches Vorkommen in einem Abschnitt oder in einer Anlage ist nicht berücksichtigt.

Aachen 736,6

ab 706,2

ABC-Waffen 302,3

Abendzeitung $<$ München $>710,3$

Abendzeitung $<$ Nürnberg $>710,3$

Aberglaube 702,4

Abfallbeseitigung 324,1; Anl. 6

Abkürzung Anl. 6

Absatz 10,2

Absatz $<$ Text $>10,2$

Abschlussprüfung 772; Anl. 6

Absurder Roman 704,a

Abwärme 322,1

Accent grave 308,2

Acht-Bit-Mikroprozessor 314,2,d

Adam und Eva 765,8

Adel 13,4,a; 201a,6

Adela $<$ von Pfalzel $>13,4$, a

Adenauer, Konrad 116,2,d

Admiral 306,5

Admiral $<$ Schmetterling $>306,5$

Adressbuch 503,2; 737a,5,a; Anl. 6

Adsorption 322,1

Adverbiale 701,5,a

AEG-Aktiengesellschaft / Turbinenhalle

Berlin 730,1,d
Äquator 201,1,d; 210,1

Aerobic 737a,5,e

Äußere Hebriden 205,2

Afrika 201,1,b; 306a,10; 503,1,a; 701,1,d; 701,1,e; 703,2,a; 705,9; 762,9,a; 765,2; Anl. 6

Afrikaans 701,1,a

Afrikanische Sprachen 701,1,d

Agasias $<$ Sohn des Dositheos $>$ / Borghesischer Fechter 727,1

Aggsbach Dorf / Kloster 720

Ägypten 206,2; 705,3,b

Ägypten <Altertum> 206,2

AIDS 313,2,b; 317,2,a; 766

Aigeira / Theater 730,1,b

Aischylos 108,4,b

Aix-les-Bains 202b,3

Aktivkohle 322,1

Akustik Anl. 10

Akzent 701,5,a; Anl. 5

$\neg$ el- $\neg$ Alamain 202a, 1

Albee, Edward / Who's afraid of Virginia Woolf 710,4

Albrecht $<$ Friedland, Herzog $>762,4$

Alchemie Anl. 10

Alexander $<$ Makedonien, König, III. $>$ 10,3 
Alexander $<$ Makedonien, König, III. $>$ /

Feldzug $<334$ v. Chr.-324 v. Chr. $>$ $415 \mathrm{a}, 2$

Alexander $<$ Russland, Zar, I. $>108,7$,a

Alexander Magnus $<$ Mittellatein $>712,3$,b

Alexander Magnus $<$ Serbisch $>712,3, b$

Alexanderdichtung 705,3,a

Alexanderreich 415a,2

Alexandriner 704,a

Alkane 306a, 8

Alkene 303,2,c

Alkohol 303,4

Alkohole 303,4

Alkoholismus 117,4; 317,2,a

Allergie 315,1

Allgemein bildende höhere Schule 201a,3; 311,2

Allgemeine Geschäftsbedingungen 303,2,a

Allgemeiner Deutscher Arbeiterverein 401a,3,b

Allgemeiner Teil Anl. 5

Alltag 13,4,c; 324,3; Anl. 6

Alltagskultur 212a,2

Almanach Anl. 6

Alpen Anl. 6

Alphabet Anl. 6

Alphastrahlung 314,2,c

Alphonsus $<$ Mondkrater $>201,3$

Altenarbeit 12,2,b; 12,3,a

Altenbild 734,4

Altenglisch 18,3

Alter 315,2,c; 762,1

Altertum 408a,3,a; Anl. 6

Altertumswissenschaft Anl. 10

Altes Testament 713,1

Altfranzösisch 18,$3 ; 324,3 ; 703,1, b ; 704$,a

Altgermanistik 708,10

Althochdeutsch 712,6

Altindisch 706,2

Altirisch 706,2

Altkarte Anl. 6

Altkirchenslawisch 718,1

Alto Adige $<$ Zeitung $>710,2$

Altomünster / Kloster 618,3

Altomünsterer Passionsspiel 712,6

Altsächsisch 701,3,a

Amalie $<$ Preußen, Prinzessin $>108,7, b$

Amarna 206,1

Amarnazeit 408; 409,1
Amerika 766; Anl. 6

Amerikanisches Englisch 701,1,e

Aminosäuren 6,2; 322,3,c

Ammann, Jost 705,1

Amoral 315,2,a

Amorpher Zustand 7,2

Ampicillin 306a,8

Amtsdrucksache Anl. 10

AN.TAH.SUM-Fest 306a,7

Analyse Anl. 5

Analysis 304,3

Anatomie 324,4; 501; Anl. 5; Anl. 10

Ancona / Stadtverfassung <1566 $>715,10$

Anden 205,3

Andenstaaten 201,1,g; 211,1,a

Anekdote 703,1,a; Anl. 2

Angeln 212b,3,b

Angeln $<$ Landschaft $>212 b, 3, b$

Angeln $<$ Volk $>212 \mathrm{~b}, 3, \mathrm{~b}$

Angestellter 303a,3

Anglistik 704,b

Ankara / Millî Folklor Enstitüsü 603,5

Anlaut 706,2

Anleitung 737a,5,e; Anl. 6

Anna selbdritt 705,5

Annandale-on-Hudson $<\mathrm{NY}>203,3$, a

Anonymes Werk Anl. 6

Anthologie 5,1; 324,4; 408a,1,b; 705,8,a; 718,$1 ; 737 \mathrm{a}, 5, \mathrm{~b} ; 760 ; 761 ; 762,2 ; 762,3$; 762,4; 762,6; 762,9,a; 765,4; 765,6; 766;

Anl. 6; Anl. 10

Anthracenderivate 8,2

Anthroposophie 101a,1

Antifaschismus 705,6

Antike 408a,1,a; 408a,3,a; 409,3; 410,1; 410,2

Antikernkraftbewegung 6,1

Antikominternpakt 716

Antikommunismus 12,5,b

Antillen 701,1,e

Antiquariatskatalog 503,2; Anl. 6

Apachen 212b,2,a

Aphorismus Anl. 6

Apokryphen 303,2,e

Apothekenrecht 4,3

Aquarell 116,1; 117,4

Aquarienfische 303,2,b

Aquarium 312

Araber 212 
Arabisch 14,2; 701,1,f; 702,2,b

'Arafāt, Yāsir 110,1

Arbeiter 12,5,b

Arbeiterbewegung 13,4,c; 201a,3; 406,2;

Arbeiterin 12,5,b

Arbeiterjugend 765,4

Arbeiterliteratur 13,4,c

Arbeitnehmer 305,2,e; 317,2,a

Arbeitsbedingungen 303,2,a

Arbeitsloser 317,1

Arbeitslosigkeit 317,1; 317,2,a; 705,8,a

Arbeitstransparent Anl. 6

Archäologie Anl. 10

Archidiakonat 203,4

Architektur 12,4,b; 408a,3,b; 724; 730,1,c;

730,1,d; Anl. 2; Anl. 5; Anl. 6; Anl. 10

Architekturphotographie 504,3; 736,5

Arctic Red River $<$ Region $>204 a, 1$

Argentinien 201a,3; 306a,7; 415a,2;

701,1,e; 703,2,b; 703,2,c: 735,1

Argentinien / Brasilien / Krieg <1825-1828>

$415 \mathrm{a}, 2$

Ariovist 108,4,c

Aristoteles 111a; 116,2,c; 708,4

Aristoteles / De arte poetica 116,3

Aristoteles / De mundo 708,4

Aristoteles / Metaphysica 101a,2

Aristotelismus 111a

Arkadien $<$ Motiv $>705,1$

Arktis 205,3

Armand, Alfred 736,3; 736,7

Armee im Lande $<$ Polen $>$ / Poleska Dywizja

Piechoty $<30>616,4$

Arnim, Bettina $\neg$ von $\urcorner 111 \mathrm{a}$

Arnsberg < Bezirk $>203,4$

Arrondissement 203,4

Ars moriendi Anl. 10

Arsenik 17,3,a

Arteriae bronchiales 303,2,d

Artikulationsstörung 12,3,c

Artois 701,2,a

Artus 765,1

Arzneibuch Anl. 10

Arzneimittel 304,4; 762,9,e

Arzneimittelrecht 4,3

Arzt 762,4; 762,9,e; Anl. 6

Arzthelferin 771,2; 772; Anl. 6

Ärztliche Behandlungspflicht 504,3

Ärztlicher Kunstfehler 304,5
Arztrecht 324,1

Asien 305,2,e; 737a,5,c; Anl. 6

Associated Press 603,3

Association of South-East Asian Nations 211,2

Ästhetik 737a,5,b

Astrologie Anl. 10

Astronomie 309; Anl. 10

Atemwege 303,2,a

Athen / Parthenon 730,1,a

Atlantis 201,1,e

Atlantischer Ozean 201,1,b

Atlas 503,2; 505; 766; 768,3; Anl. 6;

Anl. 10

auctoritas $<$ Wort $>302,2$, a

Audiovisuelles Material 737,2; Anl. 6

Audiovisuelles Material < für Kinder > 766; Anl. 6

Aufbau Anl. 5

Aufführung 13,4,b; 322,3,c; Anl. 5; Anl. 6

Aufgabensammlung 737a,3,b; 737a,3,c; 768,2; 770,a; 772; Anl. 6

Aufsatzsammlung 4,2; 13,1; 13,4,a; 13,4,d; 101a,6; 324,4; 403,6; 408a,3,b; 705,9; Anl. 6

Augsburg 4,5; 503,3; Anl. 6

Augsburg / Dom 731,3

Augsburg / Rathaus 101a,3

Augsburg / Staats- und Stadtbibliothek / Etymachietraktat / Handschrift /

2. Cod. 160 718,2,a

Augsburg / Staats- und Stadtbibliothek / 2. Cod. 160 718,2,a

Augsburg $<$ Diözese $>$ Anl. 1

Augsburg $<$ Diözese $>$ / Seelsorgeamt $619,1, \mathrm{c}$

Augsburg $<$ Region $>$ Anl. 6

Augustus $<$ Römisches Reich, Kaiser $>$ $108,7, \mathrm{a}$

Auktionskatalog 503,2; Anl. 6; Anl. 10

Aurangabad $<$ Bihar $>203,3$,a

Aurangabad $<$ Maharashtra $>203,3$, a

Ausbildung Anl. 2; Anl. 5

Ausgrabung 220,4,b; Anl. 5

Ausland 212a,1,c

Ausländer 324,2; 706,2; 762,2; Anl. 6

Ausländerfeindlichkeit 705,8,a; 705,8,b

Ausländischer Arbeitnehmer 310,1

Auslandsinvestition 211,2 
Ausreißer 303a,3

Ausreißerin 303a,3

Außenhandel 306,7; 502

Außenhandelsstatistik 502

Außenministerium 614,5

Außenpolitik 13,4,c; 101a,4; 220,4,b; 305,2,e; 403,6; 720; Anl. 5

Außenseiter 308,1

Außenwirtschaftspolitik 220,4,b

Außereuropäische Länder 201,1,g

Außerstreitverfahren 311,2

Aussprache 324,2; 701,5,a; Anl. 5; Anl. 6

Ausstellung 504,3; 735; Anl. 6

Ausstellung ; Hamburg <1982> 735,2; 736,7

Ausstellung ; Kassel $<1993>735,1$

Ausstellung ; Köln $<1982>504,3$

Ausstellung; Magdeburg <1996> 735,2

Ausstellung; München $<1978>735,2$

Ausstellung ; München <1979> 735,4

Ausstellung ; Münster $<$ Westfalen, 1979 $>$ 735,3

Ausstellung ; New York $<$ NY, 1996> 736,7

Ausstellung; Stuttgart $<1995>735,1$

Ausstellung; Villingen-Schwenningen $<1982>736,2$

Ausstellung; Washington $<$ DC, 1981 $>$

Ausstellung; Wien $<1996>408 \mathrm{a}, 1, \mathrm{c}$

Australien 703,2,b; Anl. 6

Auswirkung Anl. 5

Auszubildender 12,5,b

Autobahn 210,2

Autobahn 93 17,2,c

Autobahnbrücke 210,4

Autobiographie 503a; Anl. 6; Anl. 10

Autobiographie 1905-1921 Anl. 6

AutoCAD 13.0 737a,3,c

Autogenes Training 504,1

Autograph Anl. 2

Automation 322,2

Autonome Region 203,4

Autorensystem 12,4,a

Autorschaft Anl. 5

Awaren 212a,1,a

Babenhausen $<$ Hessen $>$ / Stadtarchiv Babenhausen / Musikhandschrift / Cod. $\mathrm{XII} / 5 / 6 / 4 \quad 718,2, \mathrm{~b}$
Bach, Johann Sebastian / Kantate BWV 80 740,3

Bach, Johann Sebastian / Matthäuspassion 740a

Baden-Württemberg 401a,2,b; 715,6; 769; 772

Bäcker 771,2

Bäckerhandwerk Anl. 6

Bahnhof 730,1,b

Bairisch 701,3,b

Bakterien 322,5

Balabanoff, Angelica 13,4,e

Balassa-Kodex 718,1

Balkansprachen 701,1,d

Baltikum 6,1

Bamberg <Diözese $>$ Anl. 1

Bamberger Apokalypse 718,1

Bangladesch 207,2

Banja Luka 202a,4

Bank of England 730,1,d

Bankgebäude 730,1,d

Bankkaufmann Anl. 6

Bantusprachen 701,1,c

Bar Kochba 108,4,c

Bargello 727,2

Bariumverbindungen 13,6;314,3

Barlach, Ernst / Lesender Klosterschüler 762,7

Barmherziger Samariter 765,8

Barock 13,1; 408; 408a, 1,a; 409,2; 762,4

Bartók, Béla / Musik für Saiteninstrumente, Schlagzeug und Celesta 740,1

Basalt 303,2,c

Basel / Hauptbahnhof 730,1,b

Basel <Diözese $>$ Anl. 1

Basler Missionsgesellschaft 606,1,a

Bauchspeicheldrüse 12,2,c

Bauchspeicheldrüsenkrebs 12,2,c

Baudelaire, Charles / Réversibilité 711,1,a

Bauernroman 705,3,a

Bauhaus 408a,5,b

Bauhaus $<$ Musikgruppe $>612,2$

Bauland 203,5

Bauland $<$ Baden-Württemberg $>$ 203,5

Baumann, Gerhard 106,4

Baumschulpflanzen 303,2,b

Baumtest 12,3,d

Baur, Alfred 736,2

Bayerische Alpen 205,3 
Bayerische Motoren-Werke 306a,4

Bayerische Vereinsbank / Filiale Augsburg $730,1, \mathrm{~d}$

Bayern 4,5; 203,3,c; 210,3; 212b,3,a; 324,3; 401a,2,a; 506,2; 769; Anl. 6

Bayern / Bauordnung 715,1

Bayern / Landrecht $<1618>715,10$

Bayern / Staatsministerium für Unterricht und Kultus 614,3,c

Bayern $<$ Volk $>212 \mathrm{~b}, 3$,a

Bayern $<$ Volksgruppe $>212 \mathrm{~b}, 3, \mathrm{c}$

Bayern, Pilar $\neg$ von $\neg 108,7, \mathrm{c}$

Bayes-Verfahren 305,2

Bayreuther Blätter 708,10

be $305,1, \mathrm{c}$

Beamter 305,1,a

Bearbeitung Anl. 5

Beaver Creek $<$ Colorado $>203,3$,a

Becken $<$ Geologie $>$ 209a,5

Beckett, Samuel 18,2; 18,3

Beckett, Samuel / Mal vu mal dit 18,3

Bedarfsplanung 304,3

Bedrohte Pflanzen 303,2,b

Bedrohte Tiere 304,2,d; 315,1,c; 324,2

Beeinflussung 14,4

Beethoven, Ludwig $\neg$ van $\neg 741,2 ; 766$

Beethoven, Ludwig $\neg$ van $\neg$ / Ah! Perfido 740,3

Beethoven, Ludwig $\neg$ van $\neg$ / Messe op. 123 8,4

Beethoven, Ludwig $\neg$ van $\neg$ / Quartett, Violine 1,2 Viola Violoncello op. 59 741,1,d

Beethoven, Ludwig $\neg$ van $\neg$ / Sonate, Klavier op. 30,1 741,1,d

Beethoven, Ludwig $\neg$ van $\neg$ / Sonate, Klavier op. $57 \quad 742$

Befestigung Anl. 10

Behinderung 317,2,a

Behnisch und Partner 602,8

Behnisch, Günter 602,8

Beichtspiegel Anl. 10

Bein 12,3,b

Beispielsammlung 737a,5,b; 737a,5,c; 737a,5,d; Anl. 6

Bekämpfung Anl. 5

Belfort 730,1,b

Belgien 602,9

Belgrad / Institut Mathématique 603,4
Belletristische Darstellung 4,6; 5,1; 705,8,a; 761; 762,1-9; Anl. 6

Bellotto, Bernardo 705,9

Benediktiner 618,3

Benediktiner / Bayerische Kongregation 618,3

Ben-Gûryôn, Dāwid 110,2

Benjamin, Walter 762,9,a

Benutzung 315,2,a

Beratung 308,1

Berchtesgaden 418,1

Berchtesgadener Land 203,3,c

Berg 203,5; 303,4

Berg $<$ Starnberg $>203,5$

Bergama 207,5

Bergbau Anl. 10

Berge $<$ Bergbau $>303,4$

Bergen $<$ Limburg, Niederlande $>10,3$

Bergmann, Gerhard 106,4

Bergmannssprache 701,4,a

Bergsteigen Anl. 6

Bergwerk 408a,3,a

Bericht 503,2; Anl. 6

Berichterstattung 705,8,b

Berlin 202,1; 703,1,a; 765,2; 765,4; 766

Berlin / Akademie der Künste / Sektion für Dichtkunst 609,2,a

Berlin / Deutsches Theater 605,6

Berlin / Reichstagsgebäude 730,1,a

Berlin / Staatliche Museen / Antikensammlung 725,5

Berlin / Staatsbibliothek 736,6

Berlin / Staatsbibliothek / Berliner Weltgerichtsspiel / Handschrift / Ms. germ. fol. $722718,2, \mathrm{a}$

Berlin / Stadtschloss 730,3

Berlin 2000 Olympia GmbH 17,2,g

Berlin-Charlottenburg / Schloss 730,1,b

Berliner Missionswerk der Evangelischen Kirche in Berlin-Brandenburg 602,6

Berlin-Grunewald / Jagdschloss 209,5

Berlin-Reinickendorf 201,1,a

Berlin-Spandau 730,1,b

Berlioz, Hector / Symphonie fantastique 740,1

Bern $<$ Kanton $>201,1$,a

Bernsteinhandel 19,1

Bernwardssäule 728,a

Beruf $<$ Motiv $>705,1$

Berufsausbildung 317,2,a; 715,1

Berufsbild 705,3,b 
Berufsbildende Schule 771,1

Berufsfeld Metalltechnik 771,1

Berufsgrundbildungsjahr 771,1

Berufsschule 769; 770; 771,1; 771,2

Berufswahl 317,2,a

Berufszufriedenheit Anl. 6

Besançon <Diözese > Anl. 1

Beschäftigungspolitik 13,3

Besonderer Teil Anl. 5

Bestattung 315,1,c

Besteigung 762,2; Anl. 5

Bestimmungsbuch 13,4,b; 766; Anl. 6

Beteigeuze 314,1

Beton 7,5; 8,5; 304,3

Betriebssystem 306a,6

Betsaida 201,1,a

Beuys, Joseph 736,4

Bewältigung 19,3; 308,1

Bewegliche Sache 311,2

Bewertung 322,3,c; Anl. 5

Beziehung 14,4

Bezirk 203,4

Bhagavadgītā 711,1,a

Biafrakonflikt 416

Bibel 705,5; 708,11; 713,2; 718,1; 735,1

Bibelausgabe 735,1; Anl. 10

Bibliographie 4,7; 13,1; 13,4,a; 101a,6; 501; 502; 503,1,a; 506,2; 737a,5,a; Anl. 6; Anl. 10; (Sachschlagwort) Anl. 6

Bibliographie 1900-1945 506,2

Bibliographie 1900-1985 13,4,d

Bibliographie 1912-1979 116,2,e

Bibliographie 1938-1960 503,1,a

Bibliographie 1945-1974 406,2

Bibliographie 1976-1982 Anl. 6

Bibliothek 9,4; 13,4,a; 312; Anl. 2

Bibliothekar Anl. 6

Bibliotheksbau 730,1,c

Bibliothekskatalog Anl. 10

Bibliotheksverband 602,9

Bielefeld 201a,4

Bilbao / Academia de la Lengua Vasca 604

Bildband 5,3; 8,2; 13,4,d; 116,2,b; 201a,6; 501; 503,3; 504,1; 705,1; 705,7,a; 723; 737,2; Anl. 6

Bilderbuch 765,1; 765,3; 765,8; 765,9,b; 766; Anl. 6

Bilderlyrik Anl. 10

Bilderstreit 416
Bildliche Darstellung 737,2; 737a,3,a; 737a,5,c; Anl. 6

Bildnis 737,2; Anl. 6; (Sachschlagwort) Anl. 2; Anl. 6; Anl. 10

Bildplatte Anl. 6

Bildteppich 5,3

Bildung 312; Anl. 2

Bildungsgang 322,5

Bildungswesen 312

Bildverarbeitung 737a,5,c

Bildwörterbuch 737a,2; Anl. 6

Binnenschifffahrt 305,2,e; 324,3

Biographie 4,5; 116,2,e; 503,1,a; 503a; 506,2; 704,a; 766; Anl. 2; Anl. 6; Anl. 10

Biographie 1800-1950 Anl. 6

Biographie 1823-1853 Anl. 6

Biographie 1840-1860 17,2,a

Biographie 1888-1898 116,2,e

Biographie 1900-1995 505

Biographie 1900-1995 Anl. 6

Biologie 768,3

Biologieunterricht 768,2; 768,3

Bischof 619,2

Bismarck $<$ Familie $>107,1$

Bismarck, Otto $\neg$ von $\neg 116,1 ; 622$

Bit 313,2,b

Bithynien 206,1

Bituminöser Stoff Anl. 6

Black Muslims 306a,6

Blaschkewitz, Johannes Chrysostomus $108,8, \mathrm{~b}$

Blasorchester Anl. 6

Blaubart 705,5

Blauer Reiter 408a,5,b; 601,2

Blei-235-Target 314,2,i

$\neg$ Die $\neg$ bleierne Zeit 733,1

Blenheim Palace 730,2

Blindendruck Anl. 6

Blutgefäß 322,1

BMW <Marke> 306a, 4

Boccaccio, Giovanni / $\neg$ Il $\neg$ Decamerone / Proemio 711,3

Bocholt $<$ Borken, Borken $>$ 203,2

Boden 305,2,g; Anl. 6

Bodennutzung 201a,4

Bodensee 324,3

Bodensee-Gebiet 204a, 1

Boeing 737 306a,3

Börsenspekulation Anl. 6 
Böse Schwiegermutter 705,4

Böse Winzer 713,3

Boff, Leonardo 115a,2

Bohm, David Anl. 6

Bondy, Luc Anl. 6

Boner, Alice 736,2

Bonn / Helmholtz-Gymnasium 605,7

Bonn / Universitätsbibliothek Anl. 6

Bonn / Werbe- und Verkehrsamt 614,3,c

Bonn-Godesberg 202a,4; 209,1,a

Book of Kells 718,1

$\neg$ Das $\neg$ Boot $<$ Film $>733,1$

Bootsbau Anl. 6

Bor 304,2,d

Bosch, Hieronymus / Versuchung des heiligen Antonius 725,4

Botanik Anl. 10

Boyen, Hermann $\neg$ von $\neg$ 506,2; Anl. 6

Brandenburg < Havel, Diözese $>$ Anl. 1

Brandenburg-Ansbach $<$ Markgrafschaft $>$ 617,2

Brandleitetunnel 210,4

Brasilien 212a,1,c; 415a,2

Braut $<$ Motiv $>$ Anl. 6

Break-even-Analyse 302,4

Brecht, Bertolt / $\neg$ Die $\neg$ Ausnahme und die Regel 13,4,b

Brecht, Bertolt / $\neg$ Die $\neg$ Horatier und die Kuriatier 13,4,b

Bremen Anl. 6

Bremen / Kunstverein Bremen 18,2

Bremen $<$ Diözese $>$ Anl. 1

Brennerautobahn 210,1;210,4

Breslau $<$ Diözese $>$ Anl. 1

Brest-Litowsk / Friede 415

Brief Anl. 6; Anl. 10

Briefsammlung Anl. 6

Briefsammlung 1786-1788 503,1,b; Anl. 6

Briefsammlung 1803-1832 Anl. 6

Briefsammlung 1806-1849 Anl. 6

Briefsammlung 1829-1845 Anl. 6

Briefsammlung 1966-1978 Anl. 6

Briefsteller Anl. 10

Brigade Ehrhardt 616,4

Britisch-Somaliland 207,4

Brixen $<$ Diözese $>$ Anl. 1

Brixen $<$ Hochstift $>618,1$

Bronzezeit 408a,4; 418,3

Brown, Charles B. 105,1
Bruckner, Anton 410,2

Bruder 705,4

Bruder Lustig 705,5

Bruder und Schwester 705,4

Brücke 10,2: 612,2

Brücke $<$ Graphentheorie $>10,2$

Brücke $<$ Künstlervereinigung $>10,2 ; 612,2$

Brücke $<$ Teppich $>10,2$

Brücke $<$ Zahnmedizin $>10,2$

Bruegel, Pieter $<$ der Ältere $>/ \neg$ Der $\neg$ Turmbau zu Babel 705,8,c; 725,4

Brünn $<$ Diözese $>$ Anl. 1

Buch 13,4,a

Buch; Anzeige Anl. 10

Buchan, Bertha $\neg$ von $\neg 18,1$

Buchführung 770

Buchhändler 317,2,a; 771,1

Buchhandel; Katalog Anl. 10

Buchmalerei 736,2

Budapest / Margareteninsel 209,4

Buddhistische Gemeinschaft Österreichs 617,2

Budweis $<$ Diözese $>$ Anl. 1

Büchner, Georg 765,1

Büchner, Georg / Dantons Tod 101a,2; 708,3

Büchner, Georg / Woyzeck / Autograph / Weimar / Goethe-und-Schiller-Archiv / 10/3,1 718,2,a

Bugenhagen, Johannes 103,1

Bultmann, Rudolf 101a,1

Bund Evangelisch-Freikirchlicher Gemeinden in Deutschland 617,2

Bundesärztekammer / Literaturpreis 306a,5

Bundesland 201a,3

Bundesstraße 210,2

Bundesstraße 27 210,2

Bundestagswahl 305,2; 305,2,f

Bundesverband Deutscher Banken 606,1,a

Buren 212

Burenkrieg 415a,1,a; Anl. 6

Burg 12,8; 765,4

Burgos / Huelgas / Bibliothek 718,2,b

Burgruine 730,1,b

Buschmänner 212

Butler, Samuel $<$ Schriftsteller, 1612-1680 $>$ $106,3, \mathrm{c}$

Butler, Samuel $<$ Schriftsteller, 1835-1902> $17,2, \mathrm{a} ; 106,3, \mathrm{c}$ 
Byron, George Gordon Byron 762,1

Byzantinisches Reich 418,3

Byzanz 207,5

Cabo Blanco $<$ Mallorca $>202,1$

Čajkovskij, Petr I. 602,3

Čajkovskij, Petr I. / Lebedinoe ozero 743

Calcados $<$ Dep. $>203,3, \mathrm{c}$

Calderara, Antonio Anl. 6

Camarthen $<$ County $>$ 207,4

Cambio 16 17,2,e

Cambrai $<$ Diözese $>$ Anl. 1

Cammin $<$ Pommern, Diözese $>$ Anl. 1

Campingplatz 302,4

Camus, Albert 115a,2

Camus, Albert $/ \neg$ La $\neg$ peste 773,1

Canetti, Elias Anl. 6

Captatio Benevolentiae 302,2,b

Carcinogenität 302,1

Č'arenc', Egišse 110,4

Cardiff / University of Wales 603,2

Cardigan $<$ County $>207,4$

Carotin $<$ alpha- $>314,2$, b

Carotine 314,2,b

Cassa di Risparmio di Ravenna 602,6

Castellón de la Plana 202a,2

Catawba-Sprache 18,$2 ; 18,3$

Causa 305,1,c

causa $<$ Wort $>305,1, \mathrm{c}$

CD 5,3; 737,2; Anl. 6

$\mathrm{CD}<$ für Kinder $>766$; Anl. 6

CDC 6600 306a,3

CD-ROM 4,7; 504,1; 737,2; 737a,3-6; 770; Anl. 6

CD-ROM $<$ für Kinder $>766$; Anl. 6

Čebyšev-Ungleichung 305,2,d

Čechov, Anton P. 109,1

Celle $<$ Kreis $>203,3, \mathrm{c}$

Central Plains 205,2

Cham $<$ Oberpfalz $>$ / Gymnasium Cham 611,2

Cham $<$ Oberpfalz $>$ / Joseph-vonFraunhoferGymnasium 611,2

Cham $<$ Oberpfalz $>$ / Robert-SchumanGymnasium 611,2

Cham $<$ Oberpfalz, Kreis $>203,3, \mathrm{c}$

Champex 209,2

Chanson de Roland 324,3; 712,4

Chapbook 6,2

Charakter Anl. 2
Charles $<$ Wales, Prinz $>108,7, b$

Checkliste Anl. 6

Chemie 4,3; Anl. 10

Chemielaborant 771,2

Chemische Analyse Anl. 5

Chemische Synthese 322,3,c; Anl. 5

Chemische Waffe 317,1

Chemischer Krieg 317,1

Chicago <Ill. $>203$,3,a; Anl. 6

Chicago $<$ Ill. $>$ / Art Institute 766

Chicago $<$ Ill. $>$ / Field Museum of Natural History 611,1

Chicago-Schule $<$ Architektur $>305,2$,e

Chicanos 703,4

Chiemsee $<$ Diözese $>$ Anl. 1

China 220,4,b; 306a,6; 306a, 7; 406,4; $408 \mathrm{a}, 2, \mathrm{~b}$

China / Bürgerkrieg <1945-1949> 415a,2

Chinaseide 305,2,e

Chinesisch Anl. 6

Chinesische Medizin 305,2,e

Chinesische Schrift 704,b

Choralbearbeitung Anl. 6

Chorgestühl 728,b

Christ $12,5, b ; 312$

Christentum 12,5,b; 312; 324,4; 410,1; Anl. 5

Christian Science Anl. 6

Christlich-Demokratische Union Deutschlands / Landesverband Hessen 606,2

Christliche Kunst 304,2,d

Christusdarstellung 705,3,a

Chronische Krankheit 762,3

Chronologie Anl. 5

Chur $<$ Diözese $>$ Anl. 1

Cicero, Marcus Tullius / De re publica / Somnium Scipionis 711,2

Cicero, Marcus Tullius 108,4,a

Ciudad Bolivar 202a,3

Claudel, Paul 705,6

Claudius $<$ Römisches Reich, Kaiser, I. $>$ $101 \mathrm{a}, 4$

Clausewitz, Carl $\neg$ von $\neg 312$

Clusterverbindungen 304,2,d

Coburg / Landesbibliothek Anl. 5

Codex Hammurapi 715,10

Codex iuris canonici 715,12

Col de l'Iseran 204,1

Comburg / Stiftskirche 728,c 
Comic 762,9,b; 765,9,a; Anl. 6; (Sachschlagwort) 705,$1 ; 705,7, \mathrm{~b}$

Commedia dell'arte $322,3, \mathrm{c}$

Computerschach $737 \mathrm{a}, 4$

Computervirus 304,4

Comunione e Liberazione 13,5

Confédération Générale du Travail 602,2

Confederation of Health Service Employees 611,2

Conques / Sainte-Foy 725,5

Container 308,2

Contra rehin 712,6

Control Data Corporation 306a,3

Convention on international financing leasing 716

Cooper, Alice / $\neg$ The $\neg$ last temptation 743

Copper-Eskimo 213a

Corvey / Kloster 719

Côte d'Azur 201,1,b

Cotta, Georg $\neg$ von $\neg$ Anl. 6

Cotta, Johann Friedrich $\neg$ von $\neg$ Anl. 6

County 203,4

Coventry / University of Warwick 605,4

Cranach, Lucas $<$ der Ältere $>106,2$,d

Cranach, Lucas $<$ der Jüngere $>106,2$,d

Crohn-Krankheit 762,3

C-Stern-Algebra 314,2,g

Cuprate 13,6;314,3

Curtis, Eduard S. 116,2,a

Cytologie 302,1

Dänemark 202,5; 773,2; Anl. 6

Dänen 773,2

Daimler-Benz-Aktiengesellschaft 13,3; $606,1, \mathrm{~b}$

Daniel $<$ Buch $>713,1$

Daniel $<$ Prophet $>106,2$,a

Dansk Etnografisk Forening 603,3

Daressalam / Universität / Faculty of Engineering $609,2, b$

Darmstadt / Deutsche Akademie für Sprache und Dichtung 18,3

Darmstadt $<$ Bezirk $>203,3$,c

Darstellung 14,4

Darwin, Charles 13,1

Daten 303,2,a

Datensammlung 503,2; 737a,2; 737a,5,a; Anl. 6

Datenverarbeitung 317,2,b

Datierung Anl. 5
Daudet, Alphonse / $\neg$ Les $\neg$ aventures prodigieuses de Tartarin de Tarascon Anl. 6

Dauerversuch 201a,4

DB2 $17,2, \mathrm{c}$

DDT 313,2,a

De Gasperi, Alcide 102,2

Debussy, Claude / $\neg$ Der $\neg$ Nachmittag eines Fauns (ÖB-Alternative) 740,2

Debussy, Claude / Prélude à l'après-midi d'un faune 740,2

Decarboxylasen 303,2,c

Deckenmalerei 737,2

Dekalog 17,1

Dekanat 203,4

Della Scala $<$ Familie $>725,5$

Democrazia Cristiana 606,2

Demographie Anl. 6

Demosthenes / Orationes 712,2

Denkmal 725,5; Anl. 2

Dependenzgrammatik 706,2

Deportation 14,2

Deutsch 13,1; 305,1,c; 317,2,b; 322,4; 324,$2 ; 403,1 ; 403,6 ; 408 \mathrm{a}, 1, \mathrm{c} ; 418,1$; 418,4,b; 418,4,c; 418,5,a; 418,5,c; 701,1,a; 701,1,e; 701,3,a; 701,5,a; 702,1; 702,2,a; 702,2,b; 702,3,a; 703,1,a; 703,2,a; 704,a; 705,1; 705,3,b; 705,5; 705,7,a; $705,7, \mathrm{~b} ; 705,9 ; 706,2 ; 737,2 ; 737 \mathrm{a}, 2$; 737a,6; 762,4; 766; 768,1; 770; 773,2; Anl. 5; Anl. 6

Deutschbalten 212a,1,b

Deutsch-dänischer Krieg $<1864>415 \mathrm{a}, 2$

Deutsche 212a,1,c; 212a,2; 305,2,e

Deutsche Angestellten-Gewerkschaft $606,1, a$

Deutsche Bank 622

Deutsche Bucht 201,1,b

Deutsche Bundesbank 201a,3

Deutsche Chronik <Zeitschrift, Augsburg $>$ $708,8, \mathrm{~b}$

Deutsche Demokratische Partei 12,2,b; $12,4, a ; 620 \mathrm{a}$

Deutsche Elektrotechnische Kommission 610

Deutsche Gesellschaft für Betriebswirtschaft / Arbeitsausschuss Fertigungswirtschaft $609,2, \mathrm{~b}$

Deutsche Reichsbahn 503,2; 612,1; Anl. 6 
Deutsche Reichsbahn $<$ Deutschland, DDR $>$ 612,1

Deutsche Staatspartei 620a

Deutsche Turnerschaft 611,2

Deutsche Zentrumspartei 622

Deutscher Alpenverein / Sektion Tübingen 606,2

Deutscher Bahaibund 617,2

Deutscher Bund / Bundesheer 616,1

Deutscher Einwanderer 212a,3

Deutscher Orden / Ballei Thüringen 618,3

Deutscher Turnerbund 611,2

Deutscher Urlauber 305,2,e

Deutscher Verein für das Höhere Mädchenschulwesen 20,8

Deutsches Soldatenjahrbuch 708,8,a

Deutsch-französischer Krieg <1870-1871> 219,2; 415a, 1 ,a

Deutschland 5,3; 6,1; 12,4,a; 13,4,c; 14,4; $17,2, a ; 18,2 ; 201 \mathrm{a}, 3 ; 201 \mathrm{a}, 5202,5 ; 211,2$; $212 \mathrm{a}, 5 ; 218,2 ; 219,2 ; 303,1 ; 324,4$; 403,2; 403,6; 406,2; 406,4; 408a, 2,a; 408a, 2,b; 410,2; 415a, 1,a; 501; 503,1,a; 504,1; 616,2; 620a; 702,4; 704,a; 704,b; 705,8,a; 705,8,b; 705,9; 708,10; 715,1; 715,2; 715,8; 720; 733,5; 735,2; 737,2; 737a,3,a; 737a,5,a; 737a,5,b; 737a,5,f; 744,3; 765,4; Anl. 6

Deutschland / Armee $<8>616,2$

Deutschland / Botschaft $<$ Tschechische Republik $>614,2$

Deutschland / Bundesausbildungsförderungsgesetz 715,3

Deutschland / Bundesministerium für Wirtschaftliche Zusammenarbeit und Entwicklung 614,5

Deutschland / Bundesverfassungsgericht 614,2

Deutschland / Bundeswehr 616,1

Deutschland / Gesetz über befristete Arbeitsverträge mit wissenschaftlichem Personal an Hochschulen und Forschungseinrichtungen 715,1

Deutschland / Grundgesetz 717

Deutschland / Immerwährender Reichstag 418,3

Deutschland / Innenministerium 614,5

Deutschland / Presse- und Informationsamt 614,4
Deutschland / Reichsheer 616,1

Deutschland / Reichshofratsordnung $<1559>715,10$

Deutschland / Reichshofratsordnung $<1654>17,2$, a

Deutschland / Reichstag 614,3,c

Deutschland / Reichswehr 616,1

Deutschland / Städtebauförderungsgesetz 715,2

Deutschland / Strafgesetzbuch 715,9

Deutschland / Tierseuchengesetz 715,9

Deutschland / Verfassung <1919> 717

Deutschland / Viehseuchengesetz 715,9

Deutschland / Wehrmacht 616,1

Deutschland $<$ Bundesrepublik $>6,1 ; 13,4$,c; $212 \mathrm{a}, 5 ; 401 \mathrm{a}, 4 ; 622 ; 715,2 ; 734,4$

Deutschland $<$ Bundesrepublik $>$ / Bundestag Anl. 6

Deutschland $<$ Bundesrepublik $>$ / Bundeswehr 616,1

Deutschland $<$ Bundesrepublik, Motiv $>$ $705,7, \mathrm{~b}$

Deutschland $<$ DDR $>$ / Nationale Volksarmee 616,1

Deutschland $<$ DDR $>$ / Revolution $<1989>$ 765,4

Deutschlandbild 705,3,b

Deutsch-Luxemburgischer Naturpark 209a,3

Deutschunterricht 324,$2 ; 706,2 ; 708,11$; 768,$1 ; 769 ; 771,1 ; 771,2 ; 772 ; 773,1$; 773,2; Anl. 6

Deutungstest 714

Dia 502; 737,2; Anl. 6

Diät $315,1, \mathrm{c}$

Diagnose Anl. 5

Diagramm Anl. 6

Dialektologie 322,3,c

Dialog 703,1,a

Dianetik 4,2

Diario de Zaragoza 708,10

Diebstahl 312

Dieselmotor 12,3,d; 302,4

Digitonin 306a, 8

Digne 210,2

Diktatur des Proletariats 305,2

DIN 19045 Anl. 6

Dinosaurier 4,6; 765,3

Diode Anl. 6 
Diözese 203,4

Diskette 737a,3,a; 737a,3,b; 737a,4; 770; Anl. 6

Diskette $<$ für Kinder $>$ 766; Anl. 6

Diskriminierung 317,2,a

Dissertation Anl. 10

Distler, Hugo / Das ist je gewisslich wahr $743 \mathrm{a}, 3$

Distrikt 203,4

Dix, Otto 705,1

DNS 313,2,a

Dolce stil nuovo 308,2

Dom 10,3; 201a,6

Dominikanische Republik 705,3,b

Domschatz 736,6

Donatello 727,2

Donau 202,5

Donaueschingen / Fürstlich-Fürstenbergische Sammlungen 736,1

Doolittle, Hilda 102,2

Doppelbesteuerungsabkommen 716

Dorf 762,2; 766

Dornach / Goetheanum 730,1,d

Dortmund / Evangelischer Kirchbautag $<1973>607,4$

Dostoevskij, Fedor M. 105,2

Dostoevskij, Fedor M. / Prestuplenie i nakazanie 709,3

Dostojewski, Fjodor M. / Schuld und Sühne (ÖB-Alternative) 709,3

Doyle, Arthur Conan 116,1

Drama $116,2, c ; 117,4 ; 203,5 ; 312 ; 403,6$; 502; 703,1,a; 703,2,a; 705,3,b; 766;

Anl. 2; Anl. 5; Anl. 6; Anl. 10

Drama $<$ Ostmakedonien $>203,5$

Dream of the rood 709,3

Drehbuch Anl. 6

Drehen 771,1

Drei Könige 305,1,b

Drei-Fünf-Halbleiter 314,2,d

Dreißigjähriger Krieg 13.4.c; 17,1; 401a, 2,a; 762,4

Dresden / Rüstkammer 609,1,a

Dresden / Schloss Albrechtsberg 209,5

Dresden / Zwinger 418,3

Dresden $<$ Motiv $>705,9$

Dresden-Loschwitz 724

Drittes Reich 324,4; 408a,2,b; 762,4; 765,4

Drittes Reich $<$ Motiv $>705,1$
Drittmittelforschung 304,5

Druckgraphik 410,2; 705,9; Anl. 2

Druckmaschine 324,2

Druckrohr 322,2

Druckwerk Anl. 5; Anl. 6

Drusen / Aufstand <1925-1926> 18,2

Dschabal Musa 204,1

Duales System Deutschland GmbH 201a,4

Dublin / Chester Beatty Library / Papyrus 16 718,3

Düppeler Schanzen / Erstürmung 8,4; $415 \mathrm{a}, 2$

Dürer, Albrecht / Friedrich der Weise 8,4; 725,4

Dürer, Albrecht 116,1;116,2,c

Dürrnberg $<$ Hallein $>8,3$

Düsseldorf / Deutsche Oper am Rhein $605,5, \mathrm{a}$

Düsseldorf / Hafen 730,1,b

Düsseldorfer Malerschule 408a,5,b

Duisburg / Deutsche Oper am Rhein $605,5, \mathrm{a}$

Duisburg / Stadtrecht $<1518>715,10$

Dulles, John Foster 101a,4

Dumpingpreis 302,4

Durankulak 202,2

Dyfed 207,4

E. S. $<$ Meister $>101,1 ; 104$

Ebersberg $<$ Kreis $>$ Anl. 6

Echnaton $<$ Ägypten, Pharao $>108,7$,a

Echtheit Anl. 5

Edition Anl. 2; Anl. 5

Effi Briest $<$ Film, 1974> 733,4

Ehe Anl. 6

$\neg$ Die $\neg$ Ehe der Maria Braun 11,3; 101a,3; 733,3

Ehefrau 305,2,e

Ehemann 305,2,e

Eherecht 220,4,b

Eheschließung 307,2,b

Ehevermittlung 307,2,b

Ehre $<$ Motiv $>116,2, \mathrm{c}$

Ehrendorf 209,2

Ei 305,1,c; 315,2,b

ei $<$ Phonem $>305,1, \mathrm{c}$

Eichendorff, Joseph $\neg$ von $\neg 13,3 ; 324,3$

Eichstätt / Diözesanarchiv Eichstätt 609,1,b

Eichstätt $<$ Diözese $>$ Anl. 1 
Eichstätt / Dom 725,5

Eidgenössischer Turnverein 603,1

Eifelium 408a,4

Eifersucht 305,1,c

Einblattdruck Anl. 6; Anl. 10

Einer wird gewinnen 733,1

Einführung 4,3; 501; 504,1; 768,3; Anl. 6

Einkommensteuererklärung Anl. 6

Einkristall 322,3,b

Einleitung Anl. 6

Ein-Maschinen-Reihenfolgeproblem 302,4

Einsamkeit 761

Einstellung $<$ Arbeitsrecht $>7,2$

Einstellung $<$ Prozessrech $>>7,2$

Einstellung 14,$4 ; 212 \mathrm{a}, 2 ; 317,2$,a

Einundzwanzig-Zentimeter-Linie 17,1; $314,2, d$

Einwanderer 305,2 ,e

Einwohner 212a,3; Anl. 6

Einzelhandelskaufmann 769; 770

Einzeller 4,7

Einzugsgebiet 202,5

Eisen 304,2,d

Eisenbahnlinie 210,3;210,4

Eisenbahntunnel 210,4

Eisendisulfid 314,1

Eisenerz 315,1

Eisenlegierung 7,2

Ekklesiologie 117,4

El Palmar de Troya 202b,4

Elberfeld 207,4

Eldorado 201,1,e

Elegie 410,2

Elektrizität 408a,1,b

Elektronik 702,3,b

Elektronische Publikation 737a,2; Anl. 6

Elektronische Publikation < für Kinder> 766; Anl. 6

Elektronisches Musikinstrument 306a,6

Eleonore $<$ von Aquitanien $>108,7, b$

Elisabethanisches Zeitalter 12,8 Pauschalvw.

Elisabeth-Psalter 718,1

Eltern 305,2 ,e; 322,1; 324,2

Eltern $<$ Motiv $>705,7, a$

Elternarbeit 324,2

Emblemliteratur Anl. 10

Emser Depesche 415a,1,a

Emslandlinie 210,2
Enden $<$ Schiff, 1908-1914> Anl. 6

Endorf $<$ Oberbayern, Pfarrei $>618,1$

Endothia parasitica $12,5, \mathrm{~b}$

Engel $<$ Motiv $>705,5$

England 101a,5; 403,5

England / Bill of rights 715,10

Englisch 14,2; 305,1,c; 317,2,b; 401a,3,a; 701,1,e; 701,4,a; 701,4,b; 701,5,a; 702,1; 702,2,a; 702,2,b; 702,2,c; 702,3,b; 702,3,c; 703,1,a; 703,2,a; 705,6; 737a,2; 737a,5,b; 765,6; 766; 768,1; Anl. 6

Englisches Sprachgebiet 201,1,f

Englischunterricht 306a,10; 504,1; 768,1; 768,2; Anl. 6

Entdeckung 766; Anl. 5; Anl. 6

Ente Nazionale Idrocarburi 603,3

Entlastung $<$ Psychologie $>306,3$

Entlastung $<$ Raumordnung $>306,3$

Entlastung $<$ Recht $>306,3$

Entlastung $<$ Technik $>306,3$

Entmythologisierung 101a,1

Entscheidungssammlung 503,2; Anl. 6

Entstehung Anl. 5

Entwicklung Anl. 5

Entwicklungsländer 201,1,g; 201a,2; $211,1, \mathrm{~b} ; 303,2, \mathrm{e}$

Entwicklungsplanung 218,2

Entwicklungstest 12,3,d

Entwurf Anl. 5

Enzyklopädie 505; 737a,5,e; 766; Anl. 6; Anl. 10

Enzym 303,2,c

Eozän 209a,5

Epik 703,1,a; Anl. 2; Anl. 5

Episkopalkirche 602,9

Epos 5,4; 18,3; 703,1,a; Anl. 2; Anl. 5

Erbach $<$ Odenwaldkreis $>203,3$,a

Erdbeben 415a,1,b

Erdölmarkt 304,2,d

Erfolgshonorar 318

Erforschung Anl. 5

Erfurt 210,4

Erlangen Anl. 6

Erlangen / Universitätsbibliothek Anl. 6

Erlangen $<$ Kirchenkreis $>618,1$

Erlebnisbericht 212a,3; 503,2; 503a; Anl. 6

Ernährung 317,2,a

Erotik $<$ Motiv $>705,9$

Erschließungsrecht Anl. 6 
Erste Kroatische Sparkasse 603,2

Erstleseunterricht 773,2

Erwachsenenbildung 324,1

Erwachsener 317,2,a

Erwartung 322,2

Erzähltechnik Anl. 2

Erzählung 703,1,a; 703,2,a; 766; Anl. 2; Anl. 5

Erzbischof 619,2

Erziehung 315,3; Anl. 2; Anl. 5

Eskimo 213a

Essay 5,1

ETA 6,2

E.-T.-A.-Hoffmann.Gesellschaft 12,5,e; 602,8

Ethylen $322,3, b$

Etsch 201,1,b

Etymologie 701,5,a; Anl. 5

Europa 201a,6; 303,1; 403,1; 408a,3,b; 503,2; 766

Europabrücke 210,4

Europäische Gemeinschaften / Fernsehrichtlinie 715,1

Europäische Union 211,2

Europäische Union / Fernsehrichtlinie 715,11

Evangeliar 718,1

Evangelische Kirche 4,2; 324,2; 617,2

Evangelische Kirche im Rheinland / Mitarbeitervertretungsgesetz 715,12

Evangelische Kirche in Deutschland / Kirchenamt $619,1, \mathrm{c}$

Evangelische Kirche in Deutschland 617,2

Evangelische Landeskirche in Baden / Kirchenbauamt $619,1, \mathrm{c}$

Evangelisch-Reformierte Landeskirche des Kantons Bern 617,2

Evolution Anl. 6

Evolutionstheorie 13,1

Exegese Anl. 5

Existentialismus $115 \mathrm{a}, 2$

Exkursion Anl. 5; Anl. 6

Exodus $<$ Altenglisches Epos $>18,3$

Expedition Anl. 5

Experiment $762,9, \mathrm{e}$

Eyck, Hubert $\neg$ van $\neg$ / Genter Altar 727,1

Eyck, Jan $\neg$ van $\neg /$ Genter Altar 727,1

Fablel 18,$3 ; 703,1, b$
Fachkunde 767; 770,b; 771,2; Anl. 6

Fachsprache 7,5; 701,4,b; 701,4,c; 701,5,a; Anl. 5

Fahrbahndecke Anl. 6

Fahrenheit $451 \quad 17,2$,e

Fahrnis 311,2

Fahrplan 503,2; Anl. 6

Faisal $<$ Saudi-Arabien, König $>108,7, a$

Fallsammlung Anl. 6

Fallstudiensammlung Anl. 6

Familie 305,2,e

Familienleben Anl. 2

Fanghzi 306a,7

Farbentest $12,3, \mathrm{c}$

Farbpyramidentest $12,3, \mathrm{c}$

Fastnacht 311,1

Faunenregion 209a,4

Faust $<$ Film, 1926 $>733,1 ; 733,4$

Faust $<$ Film, 1960 $>733,1$

Faust $<$ Theaterstück $>712,3, \mathrm{~b}$

Faust $<$ Volksbuch $>712,3, \mathrm{~b}$

Feindschaft 705,4

Feldberg $<$ Schwarzwald, Berg $>$ 203,2

Feldhase 765,3

Femme fatale 705,5

Fernsehsendung 733,5; 734,1; 734,2; 734,3; 734,$4 ; 737,5$

Fernsehspiel 704,a

Fernstraße 210,2

Fernwanderweg 210,2

Fest 306a,7; Anl. 10

Festbetrag 304,4

Festung 730,1,b

Fettsäuren 322,5

Feuerbohne 6,2

Fibel Anl. 10

Fibel $<$ Gewandnadel $>305,2$

Fibrinogendegradationsprodukt $12,2, \mathrm{~d}$

Ficoronische Ziste 727,3

Fides $<$ Heilige $>725,5$

Fieseler-Storch 306a,3

Film Anl. 6; (Sachschlagwort) 5,3; 12,6,a; 306,$7 ; 705,1 ; 705,10 ; 733,4 ; 733,5$; 734,$1 ; 734,2 ; 734,3 ; 734,4 ; 737,5 ;$ Anl. 2 ; Anl. 5; Anl. 6

Film $8 \mathrm{~mm}$ Anl. 6

Film 16 mm 4,7; 737,3; Anl. 6

Film 35 mm 5,3; 5,5; 705,8,a; 737,4; Anl. 6

Film 65 mm Anl. 6 
Film $70 \mathrm{~mm}$ Anl. 6

Film Super-8 Anl. 6

Film < für Kinder> 766; Anl. 6

Fin de siècle 409,1

Finanzministerium 614,5

Fingerhut Anl. 6

Finnisch 701,5,a; 706,2

Finnland 220,4,b

Fische 303,2,b; 304,2,d

Fiskalpolitik 308,1

Fitness $12,5, \mathrm{~b}$

Flamenco $12,4, \mathrm{a}$

Flavier 107,2

Fleischer 311,1

Florenz / Biblioteca Medicea-Laurenziana $730,1, \mathrm{c}$

Florenz / Santa Croce 727,2

Florian $<$ Heiliger $>108,4$, a

Flüchtiger Stoff 304,2,d

Flüchtling 305,2 ,e

Flüssiger Zustand 322,3,b

Flugblatt Anl. 6; (Sachschlagwort) 704,a

Flughafen München-Riem 730,1,b

Flugplan Anl. 6

Flugschrift Anl. 10

Förderungsprogramm 306a,10; Anl. 5

Förderunterricht 317,2,a

Fokolar-Bewegung 13,5

Fondation Maeght 606,1,a

Fontane, Theodor 17,2,a; 734,3

Fontane, Theodor / Effi Briest 418,3

Forces Françaises de l'Intérieur / Corps Franc du Sidobre 616,4

Forchheim $<$ Oberfranken $>210,3$

Forelle $<$ Motiv $>737 \mathrm{a}, 6$

Formelsammlung 768,3; Anl. 6

Formularsammlung Anl. 6

Forschung 304,5; Anl. 2; Anl. 5

Forschungsbericht Anl. 6

Forschungseinrichtung 737a,5,a

Forschungsprogramm 306a,10; Anl. 5

Forstenrieder Park 209,6

Forstwirtschaft 305,2,c

Fort Knox $<$ Ky. $>202 \mathrm{a}, 3$

FORTRAN IV 17,3,b

Fortschrittliche Volkspartei 620a

Fossile Fische 303,2,b

FPI Anl. 6

Fragment Anl. 5
Frankenbund / Gruppe Bamberg 609,2,b

Frankenschnellweg 201,1,d

Frankfurt $<$ Main $>212 \mathrm{a}, 3 ; 701,2, \mathrm{~b} ; 762,6$; 762,9,d; 765,4; Anl. 6

Frankfurt $<$ Main $>$ / Deutsches Exilarchiv 1933-1945 737,2

Frankfurt $<$ Main $>$ / Evangelische Bethlehemgemeinde 618,2

Frankfurt $<$ Main $>$ / Frankfurter Buchmesse 607,3

Frankfurt $<$ Main $>$ / Frankfurter Buchmesse $<1994>607,3$

Frankfurt $<$ Main $>$ / Frankfurter Buchmesse $<1996>607,2$

Frankfurt $<$ Main $>$ / Jüdische Gemeinde 618,2

Frankfurt $<$ Main $>$ / Max-Planck-Institut für Hirnforschung 609,1,c

Frankfurt $<$ Main $>$ / Pädagogische Arbeitsstelle $<$ Deutscher Volkshochschulverband $>612,1$

Frankfurt $<$ Main $>$ / Pädagogische Arbeitsstelle $<$ Hessischer Landesverband für Erwachsenenbildung $>612,1$

Frankfurt $<$ Main $>$ / Universität 605,4

Frankfurter Verkehrs- und Tarifverbund $606,1, \mathrm{~b}$

Frankfurter Würstchen 305,2,e

Frankokanadier 212a,1,ba

Frankokanadisch 701,1,e

Frankophones Afrika 201,1,f

Frankreich 5,$3 ; 13,3 ; 14,2 ; 201,1, a ; 202,5$; $212 b, 2, b ; 318,1 ; 324,3 ; 410,2 ; 602,2$; 620a; 704,a; 715,7; 716

Frankreich / Außenministerium / Archiv / Fonds Bourbon 718,3

Frankreich / Nationalversammlung 614,2

Frankreich / Verfassung $<1958>17,2$,a

Frankreich $<$ Motiv $>705,3, \mathrm{~b}$

Frankreichbild 305,2,e; 705,3,b

Franz $<$ Münster, Bischof $>108,8$,a

Franz $<$ von Assisi $>102,2$

Franziskaner 618,3

Franziskanerinnen von der Heiligen Familie 618,3

Französin 212b,2,b; Anl. 6

Französisch 4,5; 7,5; 324,2; 701,1,e; 701,2,c; 701,5,b; 702,2,b; 702,3,b; 702,3,c; 703,1,a; 703,2,a; 703,2,b; 704,a; 
705,9; 706,2; 712,6; 760; 762,6; 762,9,a; 765,$4 ; 765,6 ; 768,2 ;$ Anl. 6

Französische Revolution 14,4; 116,2,c; 403,3; 415; 765,4; Anl. 6

Französische Revolution $<$ Motiv $>$ Anl. 6 Französischer Jura 209a,2

Französischunterricht 768,$1 ; 768,2 ; 773,1$

Franzosen 212a,1,c; 212b,2,b

Frau 8,2; Anl. 2; Anl. 6

Frau $<$ Motiv $>312$

Frauenbewegung 737a,5,b

Frauenliteratur Anl. 10

Freiburg $<$ Breisgau, Diözese $>618,1$

Freie Demokratische Partei 12,2,d

Freierprobe 705,5

Freihandel 218,2

Freising $<$ Diözese $>$ Anl. 1

Freisinnig-Demokratische Partei der

Schweiz 12,2,d

Freiwillige Gerichtsbarkeit 311,2

Freizeitverhalten 212a,2

Fremdenfeindlichkeit 733,5

Fremdenverkehr 309; 317,2,a

Fremdenverkehrsgeographie 501; 771,1

Fremdsein in Deutschland 733,5

Fremdsprache 706,2; Anl. 5

Fremdwort 305,2,g; 702,1; 702,1

Frequenz Anl. 6

Freskomalerei 728,b

Freundeskreis 117,4; Anl. 2

Friede $415 \mathrm{a}, 2$

Friede $<$ Motiv $>705,9$

Friedenserziehung 765,3

Friedhof 730,1,b

Friedrich $<$ Preußen, König, II. $>106,2$,b

Friedrich, Caspar David 117,4

Friedrich Karl <Mainz, Erzbischof $>108,8$,a

Friedrich Pustet $<$ Firma $>$ 606,1,b

Friesisch $701,3, \mathrm{c}$

Friseur 771,1

Frühling 705,8,a

Frühneuhochdeutsch 701,3,a

Fugger $<$ Familie $>101,1$

Führer 201a,5; 201a,6; 303,1; 503,2; 765,5; 766; Anl.5; Anl. 6

Führungskräfte der Druckindustrie und Informationsverarbeitung e. V. 602,5

Fünf 305,1,b

Fürsorge 310,2
Fürstenspiegel Anl. 10

Fürstentum 203,4

Fulda 203,3,b

Fulda $<$ Diözese $>$ Anl. 1

Fulda $<$ Fluss $>203,3, b$

Funde 220,4,b; Anl. 5

Fundstellenverzeichnis Anl. 6

Fuß Anl. 6

Fußball 12,5,c; 406,2

Fußballfan 12,5,c; 322,1: 762,9,e

Fußballweltmeisterschaft $<1978>607,6$

Fußboden 324,2

Fußbodenheizung 324,2

Gälische Sprachen 706,2

Gagern $<$ Familie $>622$

Galeere 4,5

Galois-Darstellung 305,2,d

Garching $<$ München $>$ / Max-Planck-Institut für Plasmaphysik 601a,1

Garmisch 209,1,c

Garmisch-Partenkirchen 209,1,c

Garmisch-Partenkirchen / Mariae Himmelfahrt 209,5

Gartenbau Anl. 10

Gartentulpe 306a,9

Gaschromatographie 322,5

Gatchina 202,3

Gau 203,4

Gaucho-Literatur 306a,7

Gaunersprache 701,5,a

Gebet 324,4; 704,a; Anl. 10

Gebetbuch Anl. 10

Gebirgswald 324,1

Gebrüder Gabler Anl. 6

Gedenkstätte Anl. 2

Gefängnis 307,3

Gefangener $<$ Motiv $>705,7$,a

Gehirn 12,6,a

Geiger-Müller-Zählrohr 302,4

Geist Anl. 6

Geistesgeschichte 402,1; 403,1; 406,2; 406,3; Anl. 5

Geistesgeschichte 1648-1756 403,1

Geistesgeschichte 1790-1830 403,1

Geistesgeschichte 2000 v. Chr.-300 v. Chr. 403,1

Geisteswissenschaften 303,2,f

Geld Anl. 10 
Geldmengenpolitik 201a,3

Geldmengenziel 201a,3

Geldtheorie 4,5

Gelegenheitsschrift Anl. 10

Gelsenkirchen-Schalke 209,1,a

Gemeinsamer Ausschuss des Deutschen Bundestages und des Bundesrates nach Artikel 77 des Grundgesetzes 610

Gemischtwirtschaftliche Betriebsweise 306,9

Gemma Augustea 727,3

Gemüse 766

Gen 306a,8

Genealogie 13,4,a; Anl. 2; Anl. 10

Genealogische Tafel Anl. 6

Generationskonflikt $<$ Motiv $>705,1$

Genetik 401a,2,c

Genf $<$ Diözese $>$ Anl. 1

Genfer Konventionen $<1949>716$

geniezen 305,1,c

Gentechnologie 322,3,a; 768,1

Genua 4,5

Genussmittelindustrie 737,2

Geographie 220,4,b; Anl. 5; Anl. 10

Geographieunterricht 14,1; 769

Geographischer Name 704,a

Geological Society of China 606,1 ,a

Geologie 4,5; Anl. 5; Anl. 10

Geometrie Anl. 10

Georg-Büchner-Preis 12,4,a; 306a,5

George, Stefan 305,2,d

George-Kreis 305,2,d

Gepatschferner 209a,2

Gerichtsbezirk 203,4

Gerlach, Walther 116,2,e

Germanische Sprachen 701,1,c

Germanisches Becken 201,1,c

Germanistikstudium Anl. 6

Gernrode $<$ Quedlinburg $>$ / Stiftskirche 731,3

Gerste 315,2,b

Gerstensorte 304,2,d

Gesamtschule 306a,10

Gesang $<$ Solo $>$, Klavier 744,3

Gesangbuch Anl. 10

Geschäftsbrief 737a,5,b; Anl. 6

Geschichte (Zeitschlagwort) 6,1; 401a,2,a; 402,3; 405,2; 405a; 406,2; 406,3;

705,7,b; 720; Anl. 10 und öfter

Geschichte (Sachschlagwort) 15,7; 405,1
Geschichte Anfänge-1594 418,1

Geschichte Anfänge-1695 403,5

Geschichte Anfänge-1919 401a,2,c

Geschichte 800 v. Chr.-500 408a,3,a

Geschichte 647 v. Chr.-546 v. Chr. 403,4

Geschichte 334 v. Chr.-324 v. Chr. 415a,2

Geschichte 500-1500 408a,3,b

Geschichte 777-1500 503,3

Geschichte 1000-1500 765,4

Geschichte 1021-1050 762,4

Geschichte 1024-1250 6,1

Geschichte 1380 5,3

Geschichte 1480-1554 4,5

Geschichte 1500-1600 401; 501

Geschichte 1500-1970 408a,3,b

Geschichte 1510 4,5

Geschichte 1517-1585 503,1,a

Geschichte 1583 4,5

Geschichte 1600-1720 13,1

Geschichte 1600-1800 13,1

Geschichte 1618-1648 13,4,c

Geschichte 1700-1800 13,4,e

Geschichte 1731 5,3

Geschichte 1750-1815 401a,2,b

Geschichte 1770 4,5

Geschichte 1815- 403,6

Geschichte 1840 744,3

Geschichte 1842 737a,6

Geschichte 1912-1926 116,2,d

Geschichte 1915-1955 17,2,a

Geschichte 1939 401a,2,c

Geschichte 1945-1994 401a,3,a

Geschichte 1950-1960 116,2,d

Geschichte 1954 737,5

Geschichte 1959 5,3

Geschichte 1993 5,3

Geschichtsschreibung 14,4;219,2; 306a,7; 322,5; 406,4; 704,a; Anl. 2

Geschichtsunterricht 322,2; 405,2; 768,2; 768,3; 769

Geschichtswissenschaft 405,1

Geschlechtsunterschied 316,4

Gesellschaft 305,1,a; 306,5; 401a,4

Gesellschaft $<$ Recht $>306,5$

Gesellschaft Deutscher Chemiker 601,1

Gesellschaft für Salzburger Landeskunde / Mitteilungen der Gesellschaft für Salzburger Landeskunde 708,5

Gesellschaftsschrift Anl. 10 
Gesetz Anl. 10

Gespräch 503,2; Anl. 6

$\neg$ Der $\neg$ gestiefelte Kater 765,8

Gesundheit 312

Gesundheitswesen 312

Getränkehandel 304,5

Gewalttätigkeit 322,1

Gewerkschaft 602,2

Ghana 201a,2

Ghetto $730,1, \mathrm{~b} ; 762,4$

Gießen / Universität 736,6

Gießen / Universitätsbibliothek 503,3; Anl. 6

Gilgamesch-Epos 765,8

Gipsabguss 735,2

GISELA $<$ Datenbanksystem $>306,8$

Glaube $<$ Motiv $>705,1$

Gletscher 209a,2

Gletscherleiche 8,5

Globus Anl. 6

Glücksspiel 304,4

Glückwunschkarte $737 \mathrm{a}, 5, \mathrm{c}$

GmbH 302,3

Gnade $<$ Motiv $>116,2, \mathrm{c}$

Gobi 201,1,b

Godesberg 209,1,a

Godesberger Grundsatzprogramm 708,6

Göteburg / Universität 605,4

Goethe, Johann Wolfgang $\neg$ von $\neg 116,2$,b; $116,2, \mathrm{c} ; 416 ; 418,3 ; 503,1, \mathrm{~b} ; 705,6$; 762,1; Anl. 6

Goethe, Johann Wolfgang $\neg$ von $\neg$ / Faust 13,$1 ; 708,11$

Goethe, Johann Wolfgang $\neg$ von $\neg$ / Faust I $17,3, \mathrm{~b}$

Goethe, Johann Wolfgang $\neg$ von $\neg$ / Faust I / Walpurgisnacht 711,1 , a

Goethe, Johann Wolfgang $\neg$ von $\neg$ / Faust II, Akt 5 711,2

Götter 116,2,c

Göttingen / Akademie der Wissenschaften 605,2

Göttingen / Universität $<$ Motiv $>705,2$

Göttingische gelehrte Anzeigen 708,7

Gogh, Vincent $\neg$ van $\neg 724$

Goldenes Rössl 725,4

Golf von Neapel 204,1

Gone with the wind 418,$3 ; 733,2 ; 733,4$; 733,5

Goten $212 ; 212 b, 2, a$
Gotik 409,3; 410,2

Gotisch $305,1, \mathrm{c}$

gotisch $<$ Wort $>305,1, \mathrm{c}$

Gotthelf, Jeremias / $\neg$ Die $\neg$ schwarze Spinne $737 \mathrm{a}, 5, \mathrm{~b}$

Gouvernement 203,4

Goya y Lucientes, Francisco José $\neg$ de $\neg$ /

Desastres de la guerra 725,3

Grab 725,5; Anl. 2

Grabmal 725,5; Anl. 2

Grabrelief 725,5

Grässel, Hans 736,5

Grafschaft 203,4

Grafschaft Hoya $<$ Kreis $>202 \mathrm{a}, 3$

Grammatik 401a,2,c; 701,5,a; 768,1; Anl. 5; Anl. 10

Grant, Ulysses S. / Feldzug <1862-1863> 101a,2

Graphik Anl. 6; (Sachschlagwort) 116,2,a; 737,2; Anl. 2

Graugans Anl. 6

Graz / Universität 405,1

Graz-Seckau <Diözese $>$ Anl. 1

Great Plains 205,2

Greenpeace e. V. 765,5

Green-River-Formation 201,1,c; 209a,5

Gregor $<$ Papst, I. $>108,9$, a

Gregorianischer Kalender 4,5

Greifswald 5,1

Greifswald / Universitätsbibliothek 609,1,b

Greyerzer Land 203,3,c

Griechenland 5,1;206,2

Griechenland $<$ Altertum $>206,2 ; 408 \mathrm{a}, 3$,a; 735,2

Griechisch 305,1,c; 324,3; 410,2; 701,3,a; 704,b; Anl. 6

Grieshaber, HAP 736,4

Grieshaber, HAP / Totentanz von Basel 723

Grimm, Jacob 107,3

Grimm, Wilhelm 107,3

Großbritannien 4,$2 ; 210,1 ; 220,4, b ; 403,6$; 406,2; 406,4; 408a,2,a; 415a, 1,a; 416; 418,1; 616,2; 716; 735,4; Anl. 6

Großbritannien / Department of Employment and Productivity 614,2

Großbritannien / East Kent Regiment 616,2

Großbritannien / Innenministerium 614,5

Großbritannien / Unterhaus 622

Großer Schneeberg 201,1,b 
Großer Sklavensee $<$ Region $>$ 204a, 1

Großer Waldgärtner 306a,9

Großmacht 211,1,b

Gruber, Franz Xaver / Stille Nacht, heilige Nacht 743

Grundmorphem 706,2

Grundriss Anl. 6

Grundschule 768,1; 769

Grundwortschatz 770

Gruppenarbeit 13,4,c

Gruppentherapie 12,3,b

Gruppo 63318

Guaraní-Sprache 701,1,c

Gudbrandsdal 703,2,b

gueule 324,2

Guillaume $<$ de Lorris $>$ / Roman de la rose 708,3

Guinea 203,1

Guinea $<$ Landschaft $>203,1$

Gupta-Kunst 306a,7

Gurk $<$ Diözese $>$ Anl. 1

GUS 207,3

Gustav Adolf $<$ Schweden, König, II. $>$ $108,7, \mathrm{a}$

Gutachten Anl. 6

$\neg$ Das $\neg$ Gute 305,1,a

Gymnasiast 322,5

Gymnasium 311,2; 769; 770; Anl. 6

Gynäkologie Anl. 10

H-II-Gebiet 17,2,b

Hämoglobin 309

Haferflocken 303,3

Hagen $<$ von Tronje $>765,8$

Hahn $<$ Familie, Sylt $>107,1$

Hahn $<$ Familie, Theologe $>107,1$

Halévy, Fromental / $\neg$ La $\neg$ juive Anl. 5

Halberstadt $<$ Diözese $>$ Anl. 1

Halbunziale 704,b

Halifax $<$ Nova Scotia $>203,3$,a

Halifax $<$ York $>203,3$,a

Hals-Nasen-Ohren-Heilkunde 302,4; $305,2, \mathrm{c}$

Hamburg 501; 762,4

Hamburg / Amt für Marktwesen 614,4

Hamburg / Arbeitsamt Hamburg 615,2

Hamburg / Behörde für Wirtschaft und Verkehr 614,5

Hamburg / Hafenstraße 209,4
Hamburg / Hamburger Sportverein 605,3

Hamburg / Kirchengemeinde Sankt Nikolai 618,2

Hamburg / Meteorologisches Observatorium 605,2

Hamburg / Universität der Bundeswehr 605,4

Hameln / Stift 618,3

Hamilton, Emma 115a,1

Hamilton, William $<$ Diplomat $>115 \mathrm{a}, 1$

Hamilton-Gleichungen 303,5

Handbuch Anl. 6

Handel 19,$1 ; 305,2, \mathrm{e}$

Handelsvertrag 716; Anl. 6

Handlesekunst Anl. 10

Handschrift 704,b; 718,1; 735,1; 736,6

Handschrift $<$ Graphologie $>$ Anl. 2

Handschriftenkatalogisierung 324,1

Handwerkskammer für Mittelfranken 606,2

Hannover 203,3,c

Hannover / Maschsee 209,4

Hannover / Niedersächsisches Institut für Radioökologie 602,4

Hannover $<$ Bezirk $>203,3$,c

Hannover $<$ Kreis $>203,3$,c

Hannover $<$ Staat $>203,3, \mathrm{c}$

Hannsmann, Margarete 736,4

Hanse 418,3

Harmonie 306,7

Harmonie $<$ Musik $>306,7$

Hartlöten 322,2

Hartmann $<$ von Aue $>$ / Iwein / Handschrift A $718,2, \mathrm{a}$

Harz 205,1,e

Harz $<$ Südwest $>205,1$, a; 205,1,e

Hasen $<$ Familie $>765,3$

Hauptsatz der Thermodynamik 2 17,2,d

Hauptschulabschluss 772

Haus 322,4

Hausbuchmeister 104

Hauser, Kaspar 705,5

Hausform 201a,5

Hauslabjoch 8,5

Hausmusik 13,4,a

Havelberg $<$ Diözese $>$ Anl. 1

HAWIK 8,2

Haydn, Joseph / $\neg$ Die $\neg$ Jahreszeiten / Hier steht der Wandrer nun 743a,1 
Haydn, Joseph / $\neg$ Die $\neg$ Jahreszeiten /

Komm, holder Lenz 743a,1

Haydn, Joseph / $\neg$ Die $\neg$ Jahreszeiten / Schon eilet froh der Ackermann 743a,1

Haydn, Joseph / Sinfonie H 1,40 743a,1

Hebräisch 305,1,c

Hebriden 205,2

Heckenrose 303,2,b

Heer 616,$1 ; 616,2$

Hegel, Georg Wilhelm Friedrich 105,1; $305,2, \mathrm{~d}$

Hegelianismus 305,2,d

Heidelberg / Universitätsbibliothek / Armenbibel / Cod. Pal. germ. 148 718,2,b

Heidelberger Liederhandschriften 718,1

$\neg$ Das $\neg$ Heilige 305,1,a

Heiligenverehrung Anl. 2

Heilsgeschichte 405,3

Heimatfilm 5,5; 737,3; Anl. 6

Heimatkunde 220,4,b; Anl. 5

Heimatroman 12,6,a

Heinrich < bei Rhein, Pfalzgraf, II.> 725,5

Heinrich $<$ Sachsen, Herzog, III. $>108,7$,a

Heinrich $<$ von Morungen $>101,1$

Heiratsanzeige $307,2, \mathrm{~b}$

Heiratsschwindler $307,2, \mathrm{~b}$

heit 305.1.c

Hekla-Gebiet 204a,1

Heldenepos 324,3

Helgoland 201,1,b

Helium 322,3,b

Helium-3-Reaktion 314,2,i

Hellenismus 409,1; 410,1

Hellenistische Staaten 409,1

Hemingway, Ernest 117,4; 705,6

Hemingway, Ernest / For whom the bell tolls 709,3

Hemingway, Ernest / Wem die Stunde schlägt (ÖB-Alternative) 709,3

Hennebergisch-Fränkischer Geschichtsverein 611,2

Hepatitis 305,1,a

Hermes 108,4,a

Herrenhaus 612,2

Herrschaft 203,4

Herstellung 304,2,d

Herz 12,3,d

Herz, Joachim Anl. 5

Herzmuskel 12,3,d
Herzogtum 203,4

Herzogtum Lauenburg $<$ Kreis $>202 \mathrm{a}, 3$

Hessen 209a,3; 209a,5; 210,3; 769; Anl. 5

Hessisch 701,2,a; 762,6; 765,6

Hessische Elektrizitäts-Aktiengesellschaft 602,5

Hethiter 306a.7

Hexenprozess 8,2

Hexenverfolgung 765,4

$\mathrm{Hi}-\mathrm{Fi}$ 302,3; 313,2,b

Hildesheim $<$ Diözese $>$ Anl. 1

Hildesheimer Silberfund 725,4

Hilfsverb 305,1,c

Himmel 737a,5,c

Hindemith, Paul / Symphonie Mathis der Maler 740,1

Hindi 702,2,c

Hippokrates $<$ Zeitschrift $>710,2$

Hirtendichtung 705,6; Anl. 10

Hispanistik 317,2,b

Hispanoamerika 703,2,c

Historische Geographie 220,4,b

Historische Stätte Anl. 6

Historischer Roman 12,6,a; 703,1,a; 705,7,a

Hobbes, Thomas 13,4,e

Hochmoor 209a,3

Hochpreußisch 701,3,c

Hochsauerlandkreis 203,3,c

Hochschulschrift Anl. 10

Hochschulsport 315,2,b

Hochstift 203,4

Hochtemperaturreaktor 313,1

Hochtemperatursupraleiter 13,$6 ; 305,2$

Höchstadt $<$ Aisch $>210,3$

Höchstädt $<$ Donau $>$ / Schlacht $<1704>$ Anl. 6

Höfische Literatur 703,1,a

Hölderlin, Friedrich 4,6; 13,4,e; 14,4

Hörfunksendung 734,1; 734,4

Hörspiel 762,9,c; 766; Anl. 6

Hof $<$ Motiv $>117,4$

Hoffmann, Ernst T. A. 12,5,e; 602,8

Hoffmann, Heinrich $<$ Schriftsteller $>106,4$

Hoffmann von Fallersleben, August Heinrich 106,4

Hofgastein 202a,4

Hofmeister 310,3

Hogarth, William Anl. 6

Hohenloher Ebene 204,1 
Hohenzollern $<$ Burg $>107,2$

Hohenzollern $<$ Familie $>107,2$

Holl, Maria 8,2

Holmes, Sherlock 101,1; 110a

Holocaust $<$ Fernsehsendung $>733,5$

Holz 324,2

Holz, Arno / $\neg$ Die $\neg$ Familie Selicke 708,3

Holzschale 306,5

Holzschnitt 705,1

Homebanking 737a,3,a

Homer (ÖB-Alternative) $108,4, b$

Homerus 108,4,b; 324,3

Homerus / Ilias 1,1-47 711,3

Homerus / Ilias 20-21 711,2

Homerus / Odyssea 705,5

Homotopiegruppe 2 305, 1 ,b

Honorar 318

Honorierungssystem 318

Hopf-Verzweigung 305,2,d

Horatius Flaccus, Quintus 108,4,a

Horta de San Juan 202,2

Hostoun 202,4

Hotel Anl. 6

Hotelfachfrau 303a, 1

Hoya $<$ Grafschaft $>202 \mathrm{a}, 3$

HP LaserJet IV 6,3

HPPLC 313,2,d

Hügelland von Aschanti 204,1

Hühnerei 315,2,b

Hugenotten 303,2,e

Human potential movement 601,2

Humanismus 409,3

Humanistisches Gymnasium 12,5,b; 322,5

Humor 13,4,a; Anl. 2

Humoristische Darstellung 762,9,g; Anl. 6

Hund $305,1, \mathrm{a}$

Hunnen 212; 418,3

Hwangho 202,2

Hygiene 4,3

Ibárruri, Dolores Gómez 13,4,e

IBM Deutschland Informationssysteme $\mathrm{GmbH} 18,2$

IBM 306a, 4

Ibo 602,$4 ; 701,1, \mathrm{c}$

Ibo-Sprache 701,1,c

Ideengeschichte 402,1; 406,2; Anl. 5

Identifikation 322,5

Ignacio $<$ de Loyola $>116,2, \mathrm{c}$
Illustration 736,4; Anl. 6

Immunität $<$ Medizin $>306,3$

Immunität $<$ Recht $>306,3 ; 306,5$

In dubio pro reo $302,2, \mathrm{~b}$

Incipit 704,a

Indian Library Association 602,9

Indianer 116,2,a; 306a,6; 705,7,a; 765,2

Indianer $<$ Motiv $>705,7, a$

Indien 306a, 7; 602,9; 701,1,e; 703,2,a;

703,$3 ; 736,2$

Indien $<$ Nord $>306 \mathrm{a}, 7$

Indischer Ozean $<$ Region $>211,1$,a

Industrialisierung 4,2

Industrie 622

Industrie- und Handelskammer 305,2,c

Industrie- und Handelskammer Frankfurt, Main / Bibliothek 736,6

Industriebau 730,1,d

Industriepark 730,1,b

Industriestaaten $211,1, \mathrm{~b}$

Informatik 317,2,b; 737a,3,b

Information Retrieval 302,2,b

Informationssystem 304,4

Informationsverarbeitung 18,1

Ingenieurwissenschaften $303,2, \mathrm{f}$

Inhaltserschließung 101a,6

Inkareich 206,1

Inkareich $<$ Motiv $>705,7, \mathrm{~b}$

Inkunabel 309; Anl. 6

Innenarchitekt $12,5, \mathrm{~b}$

Innenarchitektur $12,5, \mathrm{~b}$

Innenministerium 614,5

Innenpolitik 220,4,b; Anl. 5

Inschrift 704,b; Anl. 6

Insekten $13,4, \mathrm{~b}$

Insel Anl. 5

Insel-Bücherei 708,9,b

Insel-Verlag Anton Kippenberg < Leipzig $>$

Anl. 6

Inszenierung 13,4,b; Anl. 5

Intellektueller 311,1

Intelligenzquotient 313,1

Intelligenztest 8,2; Anl. 6

Intensivstation $12,3, \mathrm{~d}$

Interaktion $13,4, \mathrm{c}$

Interessenverband 305,2,a

Interleukine 303,2,c

Internationale Architektenunion 604 
Internationale Atomenergie-Organisation 602,4

Internationaler Bauorden 602,4

Internationaler Gerichtshof 603,2

Internationaler Vergleich Anl. 5

Internierter 305,2,e

Interpersonale Wahrnehmung 13,4,c

Interpretation 772

Interview Anl. 6

Inventar 622; Anl. 6

Iran 204,$2 ; 206,2$

Iran <Altertum $>206,2 ; 403,4 ; 415 \mathrm{a}, 2$

Irisch Anl. 6

Irland 704,b; 762,2; 762,9,a

Irmina $<$ von Oeren $>13,4, a$

Irokesen 212a, $1, \mathrm{a}$

Ironie 705,6

Islam 306a,6

Islamische Presse 19,1

Israel 7,$5 ; 206,2$

Israel $<$ Altertum $>206,2$

Istanbul 207,5

Istanbul / Topkapi-Museum 762,5

Istanbul / Universität Istanbul 605,4

Isthmus von Korinth 204,1

Italien 8,$5 ; 116,2, b ; 212 b, 2, b ; 318 ; 403,2$; 622; 737a,5,b; Anl. 6

Italien / Strafprozessordnung 715,5

Italiener 212b,2,b

Italienisch 116,3; 318; 408a,1,b; 766

Italienischer Jugendlicher 305,2,e

Italienisch-Somaliland 207,4

Itinerar Anl. 10

Ives, Charles / Improvisationen <1938>

$741,1, \mathrm{~g}$

Izdatel'stvo Pedagogika 601,1

Jack $<$ the Ripper $>104$

Jacobi-Polynome 303,2,a

Jägersprache 701,4,a; 704,a

Jagd 705,6

Jagdbuch Anl. 10

Japan 736,2

Japanese Society for Bacteriology 603,4

Jean $<$ Berry, Herzog, II. $>$ / Belles heures 8,4

Jean $<$ Berry, Herzog, II. $>/ \neg$ Les $\neg$ très riches heures 718,1

Jean $<$ de Meung $>$ / Roman de la rose 708,3

Jesuiten 101,$2 ; 116,2, \mathrm{c}$
Jesuitenliteratur Anl. 10

Jingle $737 a, 5, c$

Jive 106,5

Jive $<$ Tanz $>106,5$

Johannes $<$ Papst, XXIII. $>108,9$,a

Johannesevangelium 713,1

Johannesevangelium 1,1-18 17,2,f

Journalismus Anl. 6

Joyce, James 116,2,e

Ju 88 306a,3

Jubiläum Anl. 2

Judaika Anl. 10

Juden 765,2

Judenbild 705,3,b

Judenspanisch 701,1,a

Judenverfolgung 305,2,e; 762,9,b

Judenvernichtung 733,$5 ; 737,3$

Judenviertel 730,1,b

Jude $\tau$ 203,4

Jüdischer Friedhof 730,1,b

Jugend 306,5; 317,2,a; 324,4; 712,3,b; Anl. 2

Jugend <Zeitschrift, München, 1896.1940>

306,$5 ; 712,3, \mathrm{~b}$

Jugendbuch 212a,5; 705,8,a; 765,1-5;

765,8; 765,9,f; 766; Anl. 6; Anl. 10

Jugendkriminalität 324,$2 ; 762,2$

Jugendlicher 305,2,e

Jugendliteratur 305,2,c

Jugendsachbuch $505 ; 765,4 ; 765,5 ; 765,6$;

$765,9, \mathrm{~g} ; 766$; Anl. 6

Jugendsprache $701,4, a ; 702,2, b$

Jugendstil 409,1

Julier $<$ Familie $>107,2$

Julier $<$ Pass $>107,2$

Junge 305,2 ,e

Junges Deutschland 5,1; 5,4; Anl. 6

Jupiter 12,5 , a

Juridiska Föreningen i Finland 604

Justizministerium 614,5

Justizvollzugsanstalt 307,3

K $217,2, \mathrm{c}$

Kältetechnik 737a,3,c

Käse Anl. 6

Kaiser $<$ Motiv $>705,7$,a

Kaiserchronik 712,3; 712,5

Kalender 503,2; 737,2; Anl. 6; Anl. 10

Kammermusik 403,5

Kanada 205,$3 ; 212 a, 3 ; 218,2$ 
Kanada / Mounted Police 614,3,c

Kanadaforschung 304,4

Kanon 306,7

Kanon $<$ Hymnodie $>306,7$

Kanon $<$ Musik $>306,7$

Kant, Immanuel / Kritik der reinen Vernunft 8,4

Kant, Immanuel / Kritik der reinen Vernunft $<1781>710,1$

Kant, Immanuel / Kritik der reinen Vernunft $<1787>17,2, a ; 710,1$

Kant, Immanuel / Kritik der Urteilskraft 709,1

Kantate 5,3

Kanton 203,4

Kanzelaltar Anl. 6

Kardinaltugend 303,3

Karikatur 737,2; Anl. 6

Karl $<$ Römisch-Deutsches Reich, Kaiser, I. $>$ 765,1

Karneval 311,1

Karolinger 13,4,a; 107,2

Karte 503,2; 737a,5,f; Anl. 6; (Sachschlagwort) $305,2, \mathrm{~g} ; 306,6$

Kasachisch 704,b

Kaspisches Meer 204,2

Kassel / Universitätsbibliothek, Landesbibliothek und Murhardsche Bibliothek / Hildebrandslied / Handschrift / Ms. theol. 54718,2 ,a

Kassel / Universitätsbibliothek, Landesbibliothek und Murhardsche Bibliothek / 2. Ms. theol. 54 718,2,a

Kastell 730,1,b

Katalog 503,1,a; 503,3; 504,1; 736,6; Anl. 6

Katalog 1501-1840 Anl. 6

Katalonien 415a,4

Kataster Anl. 6

Katechismus Anl. 10

Katharina <England, Königin, 1401-1437> $108,7, \mathrm{~b}$

Katholik 317,2,a

Katholische Universität 602,9

Katholische Zeitung 304,2,d

Katholisches Krankenhaus 304,2,d

Katholizismus 705,6

Katze $<$ Motiv $>705,9$

Kauf auf Probe 305,2

Kaufmännische Berufsschule 771,1
Kaukasische Sprachen 701,3,c

Kelten 762,2

Kentucky $<$ Ost $>205,1$,a

Kernkraftwerk 322,1

Keynes, John Maynard 219,1

Keynessche Theorie 4,5; 409,3

Khanat 203,4

Kibbuz 18,2; 201a,3

Kiefer, Anselm Anl. 6

Kienzle, Hellmut 736,2

Kind 303,$1 ; 305,2, \mathrm{e} ; 317,2, \mathrm{a} ; 322,1 ; 324,2$; 733,5

Kind $<3$ Jahre $>17,2$,d

Kind $<$ Motiv $>705,7$,a

Kinder- und Hausmärchen 708,7; 708,9,a

Kinderbuch 4,6; 765,1; 765,2; 765,4; 765,6; 765,7; 765,8; 765,9,d; 766; Anl. 6

Kindergarten 304,3

Kinderkrankenhaus 304,2,d

Kinderkrankenschwester 324,2

Kinderkrankheit 304,4

Kinderliteratur 305,2,c

Kinderpsychologie 324,$1 ; 324,2$

Kinderreim 765,6

Kindersachbuch 765,1-5; 765,9,e; 766; Anl. 6

King, Martin Luther 105,2

Kirchberg $<$ Niedenstein $>212 \mathrm{a}, 3$

Kirchengeschichte 401; 401a,2,a; 402,1; 405,2; 406,2; 406,3: Anl. 5

Kirchengeschichte 1500-1965 406,3

Kirchengeschichte $<$ Fach $>405,2$

Kirchenkreis 203,4

Kirchenlied Anl. 10

Kirchenprovinz 203,4

Kirchenschatz 736,6

Kirchenstaat 206,1

Kirchenväter 303,2,e

Kirchschlag $<$ Bucklige Welt $>202,2$

Klassenarbeit 307,3

Klassifikation 601a,1

Klassische Musik 737a,5,e

Kleine Spiele 303,2,a

Kleiner Panda 765,3

Kleingarten Anl. 6

Kleinkind 324,1; Anl. 5

Kleinstaat 201,2;211,1,b

Kleinstadt 765,2

Kleist, Heinrich $\neg$ von $\neg 5,1$

Klemens $<$ Papst, VII., Gegenpapst $>108,9$,a 
Klettern Anl. 6

Klima Anl. 6

Klingemann, Ernst August Friedrich / Nachtwachen 708,4

Klipper 302,1

Kloster 12,4,b; 203,4

Klosterneuburg / Stift 724

Kluth, Rolf 101a,6

Kniegelenkverletzung 324,1; 324,2

Knoten $<$ Mathematik $>305,2$

Koalitionskriege 303,2,e

Koblenz / Bundesarchiv 622

Kochbuch 766; Anl. 6; Anl. 10

Köln 12,2,b; 408a,4

Köln / Dom 723

Köln $<$ Diözese $>$ 619,2; Anl. 1

Könige $<$ Buch, I $>713,1$

Königgrätz $<$ Diözese $>$ Anl. 1

Königreich 203,4

Königsberg 202,4

Körperbehinderung 761

Körperliche Züchtigung $<$ Motiv $>705,4$

Körpersprache 316,4

Kohlendioxid 17,1

Kohlenwasserstoffe 303,2,c; 304,2,d; 306a, 8

Kolin / Schlacht 8,4

Kollege 13,4,c

Kollontaj, Aleksandra M. 13,4,e

Kolonialroman 705,9

Kolonie 303,1

Komitat 203,4

kommen 302,2 ,a

Kommentar Anl. 6; Anl. 10

Kommunismus 4,5; 12,5,b

Kommunistische Partei Frankreichs 13,3; 324,3

Komödie 703,1,a; Anl. 5

Kompositum 706,2

Komsomol 602,4

Kondition $12,5, \mathrm{~b}$

Konferenz 415a,2

Konfuzianismus 306,7

Kong, Qiu 110,3

Kongress 504,3; Anl. 6; (Sachschlagwort) Anl. 5

Kongress ; Coburg <1981 $>$ 408a,2,a

Kongress ; Dortmund $<1992>601 \mathrm{a}, 1$

Kongress ; Konstanz $<1984>$ 408a,1,a
Kongress ; Linz $<1987>410,2$

Kongress ; Münster $<$ Westfalen, 1981 $>$ 504,3

Konjunkturtheorie 4,5

Konkordanz Anl. 6

Konkordat 716

Konrad <von Parzham $>108,8, b$

Konstantinopel 207,5

Konstantin-Vita 711,1,b

Konstanz $<$ Diözese $>$ Anl. 1

Kontrolle Anl. 5

Konversationsanalyse 306,7

Konzertstück Anl. 6

Konzil 415a,2

Kopenhagen 201,1,a

Kopfschmerz 303,1

Korrosion 7,5; 8,5; 304,3

Kosten Anl. 5

Kostenträgererfolgsrechnung 305,2,b

Krähen 306a,9

Kraftfahrtversicherung 307,3

Kraftfahrzeugbeleuchtung 304,4

Krakau / Jagellonische Bibliothek / Ms. slav. fol. 29 718,2,a

Krakau / Jagellonische Bibliothek / Neues Testament / Niedersorbisch / Handschrift / Ms. slav. fol. 29 718,2,a

Krankenhaus 12,3,d

Krankenhausabfall 324,1

Krankenhausarzt 324,1

Krankenpflege 4,3

Krebs $<$ Medizin $>765,3$

Kreuzgang 12,4,b

Krieg 312; 415a,2

Krieg $<$ Motiv $>116,2$,a; 705,1; Anl. 6

Kriegsdienstverweigerung 768,2

Kriegsgefangener 305,2,e

Kriegsschuldfrage 4,2

Kriminalroman 116,1

Krise 9,4

Krishnamurti, Jiddu Anl. 6

Kritik 14,4; Anl. 5

Kritische Waffengänge 708,9,b

Krone $<$ Münze $>$ 201a,6

Krüger-Nationalpark 209a,3

Kruzifix 727,2

K-Theorie 302,4

Kuba 705,10

Kubismus 408a,1,a; 410,2 
Künstler 4,5; Anl. 6

Künstlerbuch Anl. 6

Künstlerisches Werk Anl. 2

Künstlerschule 305,2,d

Küste 204,2; Anl. 5

Kulenkampff, Hans-Joachim 734,1

Kult Anl. 2

Kultur 201a,6; 220,4,b; 402,3; 403,2; 408a,2,a; Anl. 5

Kulturbeziehungen Anl. 5

Kulturkonflikt 212a,5

Kulturvergleich Anl. 5

Kungsleden 210,2

Kunst 4,5; 116,1; 201a,5; 220,4,b; 306,7; 306a, 7; 405,2; 408a, 1,c; 410,2; 735,1; 737a,3,a; Anl. 2; Anl. 5; Anl. 6

Kunstführer 766; Anl. 6

Kunstgeschichte $<$ Fach $>405,2$

Kunsthandel Anl. 6

Kunsthandwerk Anl. 6

Kunstmärchen 315,2,b; 765,4

Kunststoff 303,2,c

Kupfer 322,3,b

Kurfürstentum 203,4

Kurpark 730,1,b

Kurzepik Anl. 10

Kurzgeschichte 703,2,a; 762,3; 768,1

La Ruta Maya 210,2

Labormedizin 771,2

Labour Party 612,1; 622

Labour Party $<$ Irland $>612,1$

Labour Party $<$ Neuseeland $>612,1$

Lachen 13,4,a

Lackarbeit 736,2

$\neg$ The $\neg$ ladder $<$ Zeitschrift $>710,2$

Ländlicher Raum 8,2

Längsschnittuntersuchung 322,5

Lärmschutz 324,2

Lagos plan of action 306a, 10

Lahn 202,5

Lambda-Kalkül 314,2,c

Lancelot du Lac 712,3,b

Land 203,4

Landesgrenze 210,3

Landeskunde 5,1; 13,4,d; 220,4,b; 504,1; 737,2; 769; Anl. 5; Anl. 6

Landschaftsverband 203,4

Landwirtschaft 305,2,c; Anl. 10
Landwirtschaftsministerium 614,5

Lanfranco $<$ da Milano $>106,2$,a

Langobarden 220,4,b

Langvokal 706,2

Lanzelot $712,3, \mathrm{~b}$

Lanzelot $<$ Mittelhochdeutsch, Prosa $>$ $712,3, \mathrm{~b}$

Laotisch $701,1, \mathrm{f}$

Laplace-Operator 314,1

Laptewsee 202,3

Larsson, Carl 117,4

Laryngaltheorie $701,5, \mathrm{~b}$

Laserdrucker 6,3

Lasker-Schüler, Else 762,1

Latein $305,1, \mathrm{c} ; 401 \mathrm{a}, 2, \mathrm{c} ; 410,2 ; 701,1, \mathrm{~b}$; $704, b ; 718,1 ; 768,1 ; 773,2$

Lateinschule $12,5, \mathrm{~b}$

Lateinunterricht 768,$1 ; 773,2$

Lauenburg $<$ Herzogtum $>202 a, 3$

Lausanne $<$ Diözese $>$ Anl. 1

Lausitz 205,2

Lavant $<$ Diözese $>$ Anl. 1

Le Havre 202a,1

Lebensbedingungen Anl. 5

Lebensmittelrecht 715,6

Lebus $<$ Diözese $>$ Anl. 1

Legasthenie 317,2,a

Legende Anl. 10

Lehnwort 701,5,a

Lehrbuch Anl. 6

Lehrer 13,4,c; 14,4; 305,2,e; 316,4

Lehrerhandbuch 770,f; Anl. 6

Lehrerin 303a, $1 ; 316,4$

Lehrerkollegium 13,4,c

Lehrfilm 12,6,a

Lehrling $12,5, \mathrm{~b}$

Lehrmittel 6,$3 ; 708,11 ; 737,2 ; 767-769$; 770,c; 772; 773,1; Anl. 6

Lehrplan 503,2; Anl. 6

Lehrtätigkeit Anl. 2

Leichenpredigt Anl. 10

Leigh, Ada Augusta 762,1

Leipzig 601,2

Leipzig / Leipziger Frühjahrsmesse < 1983> 601,2

Leipzig / Universität 720

Leipzig / Sächsische Akademie der Wissenschaften / Historische Kommission 611,1

Leipzig / Völkerschlacht 418,3 
Leipzig $<$ Region $>204 a, 2$

Leistungsdifferenzierung 306a, 10

Leistungsmessung 7,3

Leitmeritz $<$ Diözese $>$ Anl. 1

Leitomischl $<$ Diözese $>$ Anl. 1

Lektor $<$ Hochschule $>306,4$

Lektor $<$ Liturgie $>306,4$

LEKTOR $<$ Programmiersprache $>306,4$

Lektor $<$ Verlag $>306,4$

Leo $<$ Papst, I. $>17,3$, a

Leoben $<$ Diözese $>$ Anl. 1

León, Luis $\neg$ de $\neg 108,8, b$

Leonardo $<$ da Vinci $>$ / Felsengrottenmadonna 727,1

Leonardo <da Vinci $>$ / Mona Lisa 101a,2; $723 ; 727,1 ; 765,7$

Lermooser Tunnel 210,1

Lernbehindertenschule 310,$1 ; 768,2$

Lernen $12,5, \mathrm{~b} ; 305,1, \mathrm{a}$

Lernprogramm Anl. 6

Lernpsychologie 7,2

Lerntechnik 12,5,b

Les Grandes- Jorasses 202a, 1

Lesebuch 770,d; 773,1; 773,2; Anl. 6

Lesen 305,1 , a

Leser 6,2

Lettre de Cachet 302,2,b

Leukämie 762,3

Levante 305,2 ,e

Libanon $13,4, \mathrm{~b}$

Libretto Anl. 10

Liebe 762,3; Anl. 5

Liebe $<$ Motiv $>705,1 ; 744,3$

Liebesbeziehung 762,3

Lied 704,a; 744,3; Anl. 6; Anl. 10

Liederbuch 718,1

Liederhandschrift 718,1

Ligue Internationale contre le Racisme et l'Antisémitisme 602,7

Lineare Algebra 737a,3,b

Lineare partielle Differentialgleichung $305,2, \mathrm{~b}$

Linz $<$ Diözese $>$ Anl. 1

Lipide 303,2,c

Lippe 203,5

Lippe $<$ Fluss $>203,5$

Lippe $<$ Kreis $>203,5$

Lippe $<$ Staat $>203,5$
Lissabon / Laboratorio Nacional de Engenharia Civil 603,3

Literarische Revue 708,8,a

Literarische Zeitschrift 704,a

Literarisches Werk Anl. 2

Literatur 13,1; 13,4,a; 13,4,c; 116,1; 306,7; 306a, 7; 317,2,b; 318; 408a,1,b; 408a, 1,c; 418,1; 418,4,c; 418,5,c; 703,1,a; 703,2,b; 703,2,c; 703,3; 703,4; 705,3,b; 705,5; 705,7,a; 705,7,b; 772; 773,2; Anl. 2;

Anl. 5

Literaturbericht 503,1,a; Anl. 6

Literaturbericht 1900-1985 13,4,d

Literaturkritik 704 ,a

Literaturpreis 12,4,a; 306a,5

Literaturtheorie 706,2

Literaturwissenschaft $317,2, \mathrm{~b}$

Ljubljana 12,2,c

Ljubljana / Naturkundemuseum 12,2,c

Ljubljana $<$ Diözese $>$ Anl. 1

Lochamer-Liederbuch 718,1

Löten 305,1,a

Löwen / Katholieke Universiteit 602,9

Logograph 303,5

Lombardus, Marcus / Disputation zwischen einem Juden und einem Christen / Handschrift / München / Bayerische Staatsbibliothek / Cgm 972 718,2,a

London 203,1; 705,8,a; 762,2; 765,2; Anl. 6

London / Britisches Museum 603,2

London / British Library 20,8

London / National Gallery 727,1

London / Royal Society / Bibliothek $609,2, \mathrm{~b}$

London / Tate Gallery 605,2

London $<$ Ontario $>203,1$

London $<$ Tex. $>203,1$

London-Wimbledon 207,4

London-Wimbledon / All England Lawn Tennis Championships 605,7

Lorentz-Gruppe 302,4

Los Angeles $<$ Calif. $>$ 203,3,a

Los Angeles- Hollywood 209,3

Lotte $<$ Literarische Gestalt $>110 \mathrm{a}$

Louisiade-Archipel 209a,2

Lowenthal, Edith 736,7

Lucanus, Marcus Annaeus / Pharsalia 116,2,c

Ludwig <Mailand, Herzog $>108,7$,a

Lübeck $<$ Diözese $>$ Anl. 1 
Lüftlmalerei 116,1

Lüttich $<$ Diözese $>$ Anl. 1

Lützowsches Freikorps 616,4

Luftbild Anl. 6

Luftwaffe 616,1

Lullus, Raimundus 108,5

Lunge 322,1

Lungenkrebs 322,3,c

Luther, Martin 13,4,d; 115a,2; 116,2,b; 117,4; 725,5; Anl. 5

Luther, Martin / Jubiläum < 1993> Anl. 2

Luther, Martin / Thesenanschlag 415; 416

Luther-Bibel 713,2

Lutherische Kirche 303,1

Luxemburg 203,3,c; 209a,3; Anl. 6

Luxemburg $<$ Distrikt $>203,3$,c

Luxemburg $<$ Provinz $>203,3, \mathrm{c}$

Luxemburg $<$ Stadt $>203,3$,c

Luxemburg, Rosa 13,4,e

Luzern $<$ Kanton $>10,3 ; 203,3, c$

Lyonnais 7,5

Lyrik 13,3; 116,2,d; 324,3; 703,1,a; 703,2,a; 703,2,b; 705,8,a; 705,9; 712,6; 718,1; 7371,5,b; 761; 762,2; 762,4; 762,6; 766; 768,1; 773,2; Anl. 2; Anl. 5; Anl. 6; Anl. 10

Lysipp $<$ von Sikyon $>108,4, c$

Maas-Mosel-Gebiet 13,4,a

Maastrichter Vertrag 716

Maciunas, George Anl. 6

Mädchen 305,2,e; 765,3

Männerbild 705,3,b

Märchen 315,2,b; 703,1,a; 703,2,b; 703,4; 705,$5 ; 760 ; 762,9, \mathrm{a}$

Märchendrama 117,4

Märchenfilm 737a,6

Magdeburg / Kulturhistorisches Mudeum 735,2

Magdeburg <Diözese > Anl. 1

Maginotlinie 210,1

Magnetische Kernresonanz 313,3

Magnetismus Anl. 10

Mahfūz, Nağīb 110,1

Mahler, Gustav / Sinfonie Nr. 9 741,1,e

$\neg$ Der $\neg$ Maikäfer $<$ Zeitschrift $>710,2$

Main-Taunus-Kreis 201,1,a; 203,3,c

Mainz 202,2
Mainz $<$ Diözese $>$ Anl. 1

Mainzer Becken 209a,5

Makedonien 203,3,c

Makedonien $<$ Altertum $>10,3 ; 206,2$; $415 \mathrm{a}, 2$

Makedonien $<$ Griechenland $>$ 203,3,c

Makedonien $<$ Landschaft $>203,3, \mathrm{c}$

Malerei 406,3; 408a,1,a; 705,1; 705,3,b; 705,5; 705,7,a; 705,9; 735,4; 736,5; 736,7; Anl. 2; Anl. 6

Malteser-Hilfsdienst Memmingen 606,2

Management 324,2

Mandschurisch 701,1,a

Manessische Handschrift 718,1

Manierismus 408a,5,a

Mann Anl. 2

Mann $<$ Motiv $>705,3, b$

Mann, Heinrich / Professor Unrat 734,2

Mann, Thomas Anl. 5

Mao, Zedong 110,3

Mare Australe <Mars $>10,3$

Maria Laach / Klosterkirche 725,5

Maria Magdalena 762,1

Maria Plain / Wallfahrtskirche 731,3

Mariazell / Wallfahrtskirche 731,5

Marienbad 202,4

Mariendichtung 705,3,a

Marienverehrung 305,2,d

Marine 616,1

Marketing 322,3,c; 702,1

Markgräfler Land $<$ Nord $>205,1$,a

Markgrafschaft 203,4

Markov-Kette 305,2,d

Markt Sankt Florian 202a,3

Marktübersicht Anl. 5

Markus $<$ Evangelist $>108,6 ; 762,8$

Markusevangelium 762,8

Marmantheorie 306a,7

Marmorplastik 705,5

Marple, Jane 110a

Married with children 733,1

Mars $<$ Planet $>10,3$

Martianus $<$ Capella $>108,4$,a

Marx, Erich 736,4

Marx, Karl 106,3,e

Marx, Karl $<$ Komponist $>106,3$,a

Marx, Karl <Künstler $>106,3$,a

Marx-Aveling, Eleanor 13,4,e

Marxismus 4,2 
Maschinenbau 701,4,b

Maschinenlärm 324,2

Maschinenschlosser 765,3

Massai 218,2

Massenmedien 6,3; 307,2,d: 705,8,b

Matabeleland 205,1,d

Materialfluss 304,4

Mathe-Master 12,4,a

Mathematik Anl. 10

Mathematikunterricht $12,4, a ; 18,1 ; 304,3$; $769 ; 772$

Matrikel 720; Anl. 6; Anl. 10

Matterhorn 762,2

Maximilian <Bayern, Kurfürst, III.> Anl. 6

Maximum-Likelihood-Schätzung 302,4

Max-Niemeyer-Verlag $<$ Halle, Saale $>612,1$

Max-Niemeyer-Verlag < Tübingen> 612,1

Maxwellsche Gleichungen 303.2,a

mâze 302,2,a

Mechanik Anl. 10

Mecklenburgisch 701,2,c

Medici, Lorenzo $\neg$ de' $\neg$ / Gebetbuch / München / Bayerische Staatsbibliothek / Clm $23639718,2, \mathrm{~b}$

Medienkombination Anl. 6

Medienkonsum 6,3

Meditation Anl. 5; Anl. 6

Medizin 306a,7; 702,3,a; Anl. 5; Anl. 6; Anl. 10

Medizinische Ethik 305,2

Medizinische Radiologie 4,3

Meer 307,2,b

Mehrwertanteil 311,2

Mehrwertsteuer Anl. 6

Meißen $<$ Diözese $>$ Anl. 1

Meißener Porzellan 306a,4; 305,2,e

Meister des Antoine de Roche 718,2,b

Meister des Bartholomäusaltars / Bartholomäusaltar 727,1

Memmingen 701,2,c

Menander 108,4,b

Menge 312

Mengenlehre 312

Mensch 324,4

Menschenbild 312; Anl. 2

Merinoschaf 306a,9

Merkmal 18,1

Merkur 108,4,a

Merlin 762,1
Merseburg $<$ Diözese $>$ Anl. 1

Mescalero 212b,2,a

Mesmerismus $<$ Motiv $>705,9$

Messe $<$ Wirtschaft $>601,2$

Messkatalog Anl. 10

Messrelation Anl. 10

Messung Anl. 5

Metall 303,2,c

Metallischer Werkstoff 304,3

Metallseife 303,5

Metapher 116,3

Methode 322,3,c; Anl. 5

Methode der kleinsten Quadrate 302,2,b

Metten / Kloster 8,4

Metz 306a,4

Metz <Diözese $>$ Anl. 1

Metz $<$ Marke $>306 a, 4$

Mexiko 203,3,c

Mexiko $<$ Land $>203,3$,c

Mexiko $<$ Motiv $>$ Anl. 6

Mexiko $<$ Stadt $>203,3$,c

Michelangelo $<$ Buonarroti $>$ / $\neg$ Das $\neg$ Jüngste

Gericht 728,a

Microteaching 308,2

MIDI $<$ Musikelektronik $>$ 306a,6

Migration 322,3,c

Mikroform 737a,3,a; Anl. 6

Mikroprozessor 68000 306a,3

Militär 616,1; Anl. 10

Militärpolitik 218,2

Miller, Arthur / Death of a salesman 13,4,b

Minden $<$ Westfalen $>$ / Dom 727,4

Minden $<$ Westfalen, Diözese $>$ Anl. 1

Mineralischer Rohstoff 19,5

Mineralogie Anl. 10

Mingdynastie 408a,2,b

Minumum-Maximum-Prinzip 302,4

Mischverfassung 305,2,a

Missionar $<$ Motiv $>705,9$

Mitgliederverzeichnis Anl. 6

Mitgliedsstaaten 211,2

Mittelalter 408a,3,b

Mittelenglisch 712,6

Mittelfränkisch 701,3,c

Mittelhochdeutsch 305,1,c; 418,3; 703,1,a; 718,1

Mittellandkanal 210,1

Mittelmeerküste 202,5

Mittelmeerraum 13,4,b 
Mittelpersisch 701,3,a

Mittelrhein 205,2

MMPI 714

Mode 403,2

Modell 306a,10; Anl. 5

Modern Dance 302,2,b

Mönch < vom Main> 106,2,c

Mörike, Eduard 312

Möttuls saga 712,6

Mohr, Joseph / Stille Nacht, heilige Nacht 743

Molkereifachfrau 303a,3

Molkereifachmann 303a,3

Mond $<$ Motiv $>705,9$

Mondsee 204,1

Monet, Claude / Seerosen 723

Money 2.0 b 737a,3,a

Monika $<$ Heilige $>108,4$,a

Monitor $<$ Fernsehsendung $>733,1$

Monreale / Dom 728,c

Montage $<$ Künste $>306,7$

Montage 306,7

Monte Rosa 204,1

Montpellier / Société Archéologique de Montpellier 605,2

Moral 315,2,a

Morphologie 306,7; Anl. 5

Morphologie $<$ Biologie $>306,7$; Anl. 5

Morphologie $<$ Linguistik $>306,7 ; 701,5, a$; 706,2; Anl. 5

Morphonologie 706,2

Mors-Salzstock 209a,6

Morte Arthur $<$ Alliterierendes Gedicht $>$ $712,3, \mathrm{~b}$

Morte Arthur $<$ Strophisches Gedicht $>712,3, \mathrm{~b}$

Mosaik 728,c

Mose 765,1

Moskau / Metro 730,1,b

Mount Everest 204,1; Anl. 5

Mozart, Wolfgang Amadeus 101,1; 705,7,a; 734,$3 ; 762,1$

Mozart, Wolfgang Amadeus / Don Giovanni 762,7; Anl. 5

Mozart, Wolfgang Amadeus / $\neg$ Die $\neg$ Hochzeit des Figaro (ÖB-Alternative) 740,2

Mozart, Wolfgang Amadeus / Non temer, amato bene KV 490 741,1,c

Mozart, Wolfgang Amadeus / Non temer, amato bene KV 505 741,1,c
Mozart, Wolfgang Amadeus / $\neg$ Le $\neg$ nozze di Figaro 740,2; 743a, 1

Mozart, Wolfgang Amadeus / $\neg$ Le $\neg$ nozze di Figaro / Non più andrai $743 a, 1$

Mozart, Wolfgang Amadeus / Sinfonie KV 16 a $741,1, c$

Mozart, Wolfgang Amadeus / Sinfonie KV 551742

Mozart, Wolfgang Amadeus / $\neg$ Die $\neg$ Zauberflöte $743 ; 765,7$

München 10,2; 736,5; 769

München / Bayerische Staatsbibliothek 601,$1 ; 602,1 ; 735,2$

München / Bayerische Staatsbibliothek / Clm 17142 718,3; Anl. 6

München / Deutsches Museum 765,5

München / Münchner Kammerspiele Anl. 5; Anl. 6

München / Olympische Spiele <1972> 607,6

München / Sankt Johann Nepomuk 731,1; 731,5

München / Sankt Leonhard <Pfarrei $>$ 618,2

München / Sankt Michael 209,5

München / Sankt Michael <Pfarrei $>$ 605,7; 618,2

München / Sozialwissenschaftliches Institut 616,3

München $<$ Berka, Weimar $>10,2$

Münchener Rückversicherungs-Gesellschaft $606,1, \mathrm{~b}$

München-Freising < Diözese > / Domkapitel $619,1, \mathrm{c}$

München-Maxvorstadt 209,1,a

München-Perlach / Sankt Michael $<$ Pfarrei $>$ 605,$7 ; 618,2$

München-Perlach / Sankt Michael 209,5

Münster $<$ Westfalen, Diözese $>10,4$; Anl. 1

Münze 101a,4; 736,6

Münzfund Anl. 6

Muhammad $<$ Osmanisches Reich, Sultan, VI. $>108,7, \mathrm{a}$

Multimedia Anl. 6

Mundart 7,5; 220,4,b; 501; 701,2,a; 701,2,b; 701,2,c; 701,3,c; 701,5,a; 703,1,a; 703,2,b; 762,6; 762,9,d; Anl. 5; Anl. 6

Mundartlyrik 762,6

Museum Anl. 6 
Musik 116,1; 401a,3,a; 408a,1,a; 409,2; 410,2; Anl. 2; Anl. 10

Musikalien 303,2,a

Musikdruck 5,6; 744,3; Anl. 6

Musikerziehung 305,2

Musikhandschrift 324,1; 504,1; 718,2,b

Musikhören 306,7

Musikinstrument 8,5

Musikleben Anl. 6

Musikzeitschrift 708,10

Musizierender Engel 705,5

Muskel 12,3,d

Musorgskij, Modest P. / Kartinki s vystavki 740,1

Mussorgski, Modest P. / Bilder einer Ausstellung (ÖB-Alternative) 740,1

Musterbuch Anl. 10

Mutter 765,3

Nachdruck Anl. 6

Nachfragetheorie 306,7

Nachkomme Anl. 2

Nachlass Anl. 2

Nachruf Anl. 6

Nacht 766

Nachweis Anl. 5

Nahrungsmittelhilfe 416

Nantes / Archives Départementales de Loire-Atlantique / Série Fi 718,3

Napoleon $<$ Frankreich, Kaiser, I.> 705,5; 734,$4 ; 762,1$

National and Local Government Officers' Association 611,2

National Union of Public Employees 611,2

Nationalpark 209a,3

Nationalsozialismus 322,$2 ; 324,4$

NATO 602,4

Natur 220,4,b; Anl. 5

Naturlyrik 116,1

Naturnahe Gestaltung Anl. 6

Naturpark 209a,3; 303,1

Naturphilosophie 116,2,c

Naturschutz Anl. 5

Naturschutzgebiet 209a,3

Naturschutzrecht 715,6

Naturwissenschaften 324,4; Anl. 6

Naturwissenschaftlicher Unterricht 768,1

Naumburg <Saale, <Diözese $>$ Anl. 1

Nebraska 201,1,a
Nee, $\ldots<$ Watchman $>106,2, \mathrm{c}$

Nefiracetam 306a, 8

Negev 201a,3

Neidhart / Lieder 712,2

Nelson, Horatio 115a, 1

Neocatechumenate 13,5

Neokeynesianismus 409,3

Neolithikum 408a,4

Neotropische Region 201,1,c; 209a,4

Neuburg $<$ Donau $>$ / Sankt Ursula 731,5

Neuburg-Schrobenhausen $<$ Kreis $>202 b, 5$

Neue Makroökonomie 409,3

Neuerwerbung 735,2

Neuerwerbungsliste 503,2; Anl. 6

Neues Testament 306,7

Neugotik 408a,5,a

Neugriechisch 701,3,a; 762,9,a

Neuhebräisch 701,3,a

Neulatein 701,3,a

Neuroleptikum 303,2,c

Neustadt $<$ Rübenberg $>202 b, 2$

Neustadt $<$ Waldnaab, Kreis $>203,2$

Neutralität 218,2

Neuzeit 408a,3,b

New York $<$ NY $>704$,a; 762,9,a

New York $<$ NY $>$ / Freiheitsstatue 730,1,a

New York $<\mathrm{NY}>$ / Metropolitan Museum of Art / Bibliothek 603,3

New York $<\mathrm{NY}>$ / School of Education $<$ Fordham University $>612,1$

New York $<\mathrm{NY}>$ / School of Education $<$ New York University $>612,1$

New York- Manhattan 203,3,a: 209.1.a; 762,2

New York cops (ÖB-Alternative) 733,2

Newcastle-under-Lyme 202b,3

Newman, John Henry 108,8,b

Newport $<$ Gwent $>203$, 1

Newport $<$ Wight $>203,1$

n-Halbleiter 314,2,b

Nibelungen 762,8

Nibelungenlied 418,$3 ; 708,7 ; 762,8 ; 765,8$; Anl. 5

Nibelungenlied / Handschrift C 8,4; 718,2,a

Nichtdirektive Gesprächsführung 13,4,c

Nichteisenmetall 303,2,c

Nichtsesshafter 19,2

Niederdeutsch 703,1,a

Niederlande 704,a; Anl. 6 
Niedersachsen Anl. 6

Niedersachsen / Abfallgesetz 715,1

Niedersachsen / Landesplanungsgesetz 715,1

Niederwalddenkmal 730,2

Nietzsche, Friedrich / $\neg$ Der $\neg$ Fall Wagner Anl. 5

Nikolaus $<$ von Dresden $>$ / Tabule novi et veteris coloris / Böhmisch / Göttingen / Niedersächsische Staats- und Landesbibliothek / Ms. theol. 182 718,2,a

NIR 602,4

Nitrophenol $<2->17,2, \mathrm{~b}$

Niveaulinie 19,1

Nizäa / Konzil <787> 416

NMR-Spektroskopie 313,3

Nördlingen 8,2

Noetherscher Ring 305,2,d

Nomos 203,4

Nootropikum 306a,8

Nord $<$ Frankreich, Dep. $>203,5$

Nordamerika 116,2,a; 765,2

Norddeutschland 205,1,e; Anl. 6

Nordfriesisch 701,3,c

Nordfriesische Inseln 204,2

Nordische Staaten 13,1

Nordischer Rat 603,2

Nordschwarzwald 205,1,c

Nordsee 765,2

Nordseeküste 204,2

Nordterritorium $<$ Australien $>203,5$

Nordwestdeutschland 205,1,e

Norm 306a,6; Anl. 6

Normandie 703,2,b

Norwegisch 703,2,b

Notengebung 306,6

Nouveau roman 308,2

Nouvelle vague 5,$5 ; 737,4$

Novalis $12,2, \mathrm{a} ; 103,2$

Novelle 703,3; 737a,6

Novozybkov 202,3

Nowosibirsk 202,3

Nürnberg 324,3

Nürnberg / $\neg$ Das $\neg$ Narrenschiff 730,1,a

Nürnberg / Bundesanstalt für Arbeit 615,2

Nürnberg / Burg 8,4; 730,3

Nuntiatur $<$ Polen $>619,3$

Nuntiatur $<$ Warschau $>619,3$

Nuraghenkultur 13,3
Nutzpflanzen 201a,4

NYPD blue 733,2

Oberamt 203,4

Oberboden 307,2,c

Oberfranken Anl. 6

Oberlausitz 205,2

Oberschenkel 12,3,b

Oberschlesien 702,1

Oberstufe 770

Objektivität 322,3,b

Oblast 203,4

Obst $12,3, \mathrm{f}$

Obstbau 12,3,f

Oder-Neiße-Linie 201,1,d; 210,1

Odol Anl. 6

Odysseus 765,1

OECD 211,$2 ; 611,2$

Ödipus 110a

OEEC 611,2

Öffentliche Meinung 13,4,e

Öffentlicher Personennahverkehr 305,2,b

Österreich 201a,3; 202,5; 211,2; 212a,2; 311,$2 ; 317,2$,a; 701,1,e; 703,2,a; 703,2,b; 737,$5 ; 769$

Österreich / Bundesamt für Agrarbiologie 611,1

Österreich / Bundesheer 616,1

Österreich / Bundes-Verfassungsgesetz 717

Österreich / Einkommensteuergesetz 8,4

Österreich / Nationalrat Anl. 6

Österreich / Oberster Gerichtshof Anl. 6

Österreichische Niederlande 202,6

Österreichischer Gewerkschaftsbund 603,1

Ötztaler Alpen 209a,2

Offener Unterricht 308,1

Offshore-Banking 302,4

Oktoberrevolution 322,5; 401a,3,b; 415a,1,a

Oldenburg $<$ Oldenburg $>202 \mathrm{~b}, 5$

Oldenburg < Oldenburg, Bezirk $>202 b, 5$

Oldenburg < Oldenburg, Kreis $>202 b, 5$

Oldenburg $<$ Staat $>202 b, 5$

Oldenburg $<$ Staat $>$ / Kirchenordnung $<1725>715,10$

Olive 306,5

Olive $<$ Anatomie $>306,5$

Oliveira, Raimundo Falcão $\neg$ de $\neg$ 102,2

Olmütz $<$ Diözese $>$ Anl. 1

Olympische Spiele 607,5 
Online-Katalog 601a,1

Online-Publikation 737a,5,a; 737a,5,b; Anl. 6

OPEC 211,2

Opel 306a,4

Oper 401a,2,c; 705,1; 734,3; Anl. 2; Anl. 6

Oper $<$ Motiv $>705,7$, a

Optik 5,2; 768,1; Anl. 10

Optische Eigenschaft 13,6

Ordensliteratur Anl. 10

Organisation Anl. 5

Organische Chemie 737a,5,a; Anl. 6

Organische Verbindungen 322,1

Orgel Anl. 6

Orientierungsstufe 768,2

Orpheus 101,1

Ort 203,4; Anl. 6

Ortsname 702,1; Anl. 6

Ortsverzeichnis 737a,5,f; Anl. 6

$\mathrm{OS} / 2 \quad 17,2, \mathrm{c}$

Oseberg 209,3

Osebergfund 727,3

Osmanisches Reich 207,3;213a

Osnabrück $<$ Diözese $>$ Anl. 1

Osnabrück $<$ Diözese $>$ / Kirchenbote für das

Bistum Osnabrück 708,5

Ostblock 13,4,c; 202,6

Ostchinesisches Meer 205,1,b

Ostermann, Dagmar <1920-> 106,3,c

Osteuropa 202,6

Ostjuden 762,9,a

Ostkaukasische Sprachen 701,3,c

Ostniederdeutsch 701,2,c

Ostprovinz $<$ Sambia $>203,5$

Ostseeraum 211,1,a

Ostverträge 13,4,c; 303,2,e

Ost-West-Konflikt 302,4

Oswald $<$ von Wolkenstein $>108,5$

Ottawa 203,3,a; 212b,3,b

Ottawa $<$ Kan. $>203,3$,a

Ottawa $<$ Volk $>212$ b,3,b

Otto $<$ Römisch-Deutsches Reich, Kaiser, I. $>$ 10,4

Otto $<$ Römisch-Deutsches Reich, Kaiser,

III.> / Evangeliar / München / Bayerische

Staatsbibliothek / Clm 4453 718,2,b

Otto $<$ von Freising $>108,5$

Ottomotor 12,3,d

Ouvertüre 743a,1
Ovidius Naso, Publius / Metamorphoses 762,7

$\neg$ The $\neg$ owl and the nightingale 712,6

Paderborn $<$ Diözese $>$ Anl. 1

Padua / $\neg$ Il $\neg$ Santo $<$ Kirche $>727,2$

Pädagoge Anl. 6

Pädagogik 315,3; Anl. 10

Pädagogische Einrichtung 315,3

Pädagogische Soziologie 324,1

Paläarktis 201,1,c

Palästinenser 7,5

Palas 730,3

Palissot de Montenoy, Charles 102,2

Palladianismus 12,5,e

Palladio, Andrea 12,5,e

Pamir $<$ Schiff $>$ 306a, 6

Pannonische Legenden 711,1,b

Papierherstellung 304,2,d

Parade $<$ Ballett $>743$

Parcevals saga $12,4, \mathrm{a}$

Paris Anl. 5

Paris / Eiffelturm $<$ Motiv $>705,2$

Paris / Louvre 727,1

Paris / Musée des Arts Décoratifs 605,2

Paris / Théatre National de l'Odéon 620a

Paris / Val-de-Grâce 731,5

Paris $<$ Salzburg, Erzbischof $>106,2, b$

Pariser Kommune 705,8,a

Paris-Montmartre 209,3

Parlamentswahl 324,3

Parodie 705,6

Partei 4,5; 9,4; 12,4,a; 408a,2,b; 620a

Parteiprogramm Anl. 6

Partenkirchen 209,1,c

Parther 212

Partielle Differentialgleichung 305,2

Partito Popolare Italiano <1919-1926> 612,1

Partito Popolare Italiano <1994-> 612,1

Parzen 101,1

Passau <Diözese > 619,2; Anl. 1

Passé simple 701,5,b

Passionsspiel 712,6

Pastoraltheologie $<$ Zeitschrift $>710,2$

Patentschrift Anl. 6

Pathologie Anl. 5

Patient 322,2

Patriarchat 203,4

Pauer, Max Anl. 6 
Paul, Jean 103,2

Paulus $<$ Apostel $>108,6$

Paulus $<$ Apostel $>$ / Römerbrief 713,1

Peking / Volkstheater 13,4,b

Pembroke $<$ County $>207,4$

Pepys, Samuel Anl. 6

Perec, Icchok Leib 110,2

Pergamon 207,5

Perikles 108,4,c

Perioche Anl. 10

Perle 303,3

Perm / A. M. Gorkii State University 605,4

Peronismus 201a,3

Perpendicular style 408

Persönlichkeitstest 12,3,c; 12,3,d; 714

Person Anl. 6

Perth $<$ Schottland $>203,3$,a

Perth $<$ Westaustralien $>203,3$,a

Peru 205,3; 765,2

Pfarrei 203,4

Pferd $303,2, b$

Pferd $<$ Gattung $>303,2$,b

Pferde $<$ Familie $>303,2, \mathrm{~b}$

Pflanzen 220,4,b; 303,2,b; Anl. 5

Pflanzenanatomie Anl. 5

Pflanzenbuch 5,7; Anl. 6; Anl. 10

Pflanzenmorphologie Anl. 5

Pflanzenphysiologie Anl. 5

Pfleggericht 203,4

Philologie 704,b

Philosophie 4,5; 305,1,a; 306,7; 322,3,a; Anl. 2; Anl. 5

Philosophische Anthropologie 705,6; Anl. 6

Phonetik 305,1,c; 322,4; 701,5,a; Anl. 5

Phonologie 305,1,c; 322,4; 701,5,a; Anl. 5

Photographie 737,2; Anl. 6; (Sachschlagwort) $116,2, a ; 302,1$

Photorealismus 408a,5,b

Physik 4,3; 768,3; Anl. 6; Anl. 10

Physikunterricht 5,2; 768,1; 768,3; 770

Physiognomik Anl. 10

Physiologie Anl. 5

Phytotherapie Anl. 6

Piaget, Jean 501

Picasso, Pablo 116,2,a

Pietismus $13,4, \mathrm{e}$

Pietroasa 209,3

Pikardisch 701,2,c

Pilze 766
Pimen $<$ Moskau und ganz Russland, Patriarch $>108,9, b$

PIMS 306a, 10

Piz Palü 204,1

pk-Werk 302,4

PL 1 17,3,b

Plakat 737,2; Anl. 6

Plan Anl. 6

Planungsregion 203,4

Plastik 304,2,d; 410,2; 735,2; Anl. 2

Poetik 116,3; Anl. 10

Polarroute 210,1

Polen 212b,3,a; 762,9,b

Polen $<$ Südwest $>202,6$

Polen $<$ Volk $>212$ b,3,a

Polen $<$ Volksgruppe $>212 \mathrm{~b}, 3, \mathrm{c}$

Political correctness 308,2

Politik 116,1; 220,4,b; Anl. 2; Anl. 5

Politische Ethik 622

Politische Lyrik 706,2; 762,4

Politische Reform 306a,6

Politische Willensbildung 7,2

Politischer Unterricht 6,3

Politisches Denken Anl. 2

Politisches Programm 306a,10

Politisches System 6,1; 13,4,b; 13,5

Polizeistaat 762,4

Polizist 317,2,a

Polnisch 305,1,c; 702,1; Anl. 6

Polymere 303,2,c

Polynesien 402,2

Porz $<$ Rhein $>209,2$

Porzellan 408a,2,b

Porzellanmalerei Anl. 5

Post 765,3

Potifar 108,6

Poulenc, Francis / Messe G-Dur 741,1,f

Pound, Ezra / $\neg$ The $\neg$ cantos $7 \quad 711,2$

Präfektur 203,4

Präferenz 306,7

Präfix $305,1, c ; 706,2$

Prägung 316,4

Präkolumbianische Zeit 408a,4

Präposition 305,1,c; 768,1

Präraffaeliten 303,2,e

Präsidentenwahl 415a.1.b

Praetorius, Mattheus / Deliciae Prussicae oder Preussische Schaubühne / Wilna / 
Lithuanian Academy of Sciences / Bibliothek / f. 129, N 1338/1-2 718,2,a

Prävention 322,3,c; 324,2; Anl. 5

Prag 762,1

Prag / Karls-Universität / Archiv 609,2,b

Prag <Diözese $>$ Anl. 1

Praktik Anl. 10

Praktikum Anl. 6

Praktische Fachkunde 771,1

Praseodymverbindungen 13,6

Predigt Anl. 5; Anl. 6; Anl. 10

Predigthilfe Anl. 6

Predigtsammlung Anl. 6; Anl. 10

Preetorius, Emil Anl. 6

Přerov nad Labem 202b,4

Presse 406,4; 705,3,b

Pressendruck Anl. 6

Pressestimme Anl. 6

Prestige 317,2,a

Preußen 612,2; 716

Preußen / Gesindeordnung 715,10

Preußen / Herrenhaus <Körperschaft $>$ 612,2

Preußen / Verfassung $<1848>717$

Preußen, Louis Ferdinand $\neg$ von $\neg<1907$ 1994> 108,7,c

Preußisch 701,3,c

Prince Edward Island 111,2

Privatlehrer 310,3

Proband $12,6, b ; 19,2$

Prognose 322,3,b; 401a,4; 406,2; 762,4; Anl. 5

Prognose 1986-2030 401a,4

Prognose 1998-2000 17,2,a

Prognose 2000-2005 401

Programm 737a,3,a; 737a,4; Anl. 6; (Sachschlagwort) 306a,6; 737a,4

Programmheft Anl. 6

Projekt 211,2; 306a,10; Anl. 5

Projektion $<$ Linguistik $>306,5$

Projektion $<$ Mathematik $>306,5$

Projektion $<$ Optik $>306,5$; Anl. 6

Projektion $<$ Psychologie $>306,5$

Prominenz Anl. 6

Prooemium 711,3

Propstei 203,4

Prosa 703,1,a; 705,9; 762,9,a; Anl. 2; Anl. 5

Prosodie 706,2

Prostitution 737a,5,b
Protestant Episcopal Church in the United States of America 602,9

Protestantismus 317,2 ,a

Protestbewegung 306a,6

Protobantu 701,3,a

Proton-Proton-Wechselwirkung 314,2,i

Proust, Marcel / A la recherche du temps perdu / $\neg$ Le $\neg$ temps retrouvé 711,1 ,a

Provinz 203,4

Prozess Anl. 2

Psalmen 50 711,2

Psalter 718,1

Pseudonym Anl. 6

Psychiatrische Klinik 324,2

Psychisch Kranker 317,2,a

Psychische Belastung 12,2,b

Psychische Krankheit 322,2

Psychische Störung 317,2,a

Psychologie 4,7; 702,4; 737a,5,a; Anl. 5; Anl. 6

Psychologische Beratung 12,5,b

Psychosoziale Versorgung 317,2,a

Psychotherapie 12,3,b; 12,5,b; 317,2,a

Publik <Zeitung $>708.8, \mathrm{c}$

Publik-Forum 708,8,c

Publikum 12,5,c

Publikumszeitschrift 304,4

Punische Kriege 415a,3

Punischer Krieg <218 v. Chr.-201 v. Chr. $>$ 415a, 1 , a

Punt 418,3

Puškin, Aleksandr S. 602,8

Pustertal 201,1,b

Pythagoreischer Lehrsatz 314,1

Quarzit 303,2,c

Quedlinburg / Stiftskirche 736,6

Quelle 4,5; 14,4; 401a,2,c; 403,6; 406,3; 503,3; 503a; 715,6; 715,7; 720; 737,2; $737 \mathrm{a}, 5, \mathrm{~b} ;$ Anl. 6

Quellenkritik 322,5; Anl. 5

Quintett, Violine Viola Violoncello Kontrabass Klavier 737a,6

Quiz Anl. 6

Qumrantexte 733,5; 737,2

Rabenvögel 306a,9

Radar 302,3

Radierung 705,9 
Radio days 762,8

Radio-Essay $<$ Hörfunksendung $>733,1$

Radioimmunoassay 12,2,d

Radiokarbonmethode 314,1

Radleuchter 728,c

Radwandern 201a,6; Anl. 6

Raffaello $<$ Sanzio $>305,2$,d

Raimund, Ferdinand 117,4

Rainer $<$ Österreich, Erzherzog $>108,7, b$

Rallye Monte Carlo <1982> 607,6

Rapallovertrag 415a,1,a

Ratgeber 737a,3,a; 766; Anl. 6

Ratzeburg $<$ Diözese $>$ Anl. 1

Rauchen 762,9,a

Raum differenzierbarer Funktionen 314,3

Realismus 408a,1,c

Rechenbuch Anl. 10

Rechnungswesen 769

Recht 220,4,b; 322,3,a; 408a,2,b: 715,7; Anl. 5; Anl. 6

Rechtschreibung 701,5,a; 768,2; Anl. 5

Rechts-links-Shunt 302,4

Rechtsprechung Anl. 6

Rechtstheorie 7,2

Rechtsvergleich Anl. 5

Red Power 306a,6

Redaktion Anl. 5

Rede Anl. 6; Anl. 10

Reduplizierendes Verb 706,2

Referateblatt 502

Reflexzone Anl. 6

Reform Anl. 5

Reformatio in peius 308,2

Regelung Anl. 5

Regenbogenschüsselchen 212a,4

Regensburg Anl. 6

Regensburg / Sankt Emmeram / Kloster 618,3

Regensburg $<$ Diözese $>$ Anl. 1

Regest Anl. 6; Anl. 10

Regierung Anl. 2

Region 203,4

Regionalstruktur 14,4

Reifeprüfung 772

Reim 703,1,b

Reise 762,1; Anl. 2; Anl. 6

Reisebericht 503,1,a; Anl. 6; Anl. 10

Reisebericht 1880-1885 503,1,a

Reisebericht 1904-1914 Anl. 6
Reiseverkehrskaufmann 771,1

Reiter $<$ Motiv $>725,5$

Reiterstandbild 705,3,a

Relativitätstheorie $762,9, \mathrm{~b}$

Religiöse Toleranz 4,5

Religiöse Volkskunst 736,5

Religion Anl. 2

Remarque, Erich Maria / Im Westen nichts Neues $705,8, \mathrm{c}$

Rembrandt $<$ Harmensz van Rijn $>$ / Hundertguldenblatt 725,3

Renaissance 409,3; 410,1; 410,2; 737a,5,b

Rentner 317,2,a

Report Anl. 6

Republik 203,4

Ressourcen 303,2,a

Restaurierung 8,5

Retabel 727,4

Revolution 415a,2; Anl. 5

Revolutionärin 13,4 ,e

Rezeption 13,1; 14,4; 408a, 1,a; 410,1;

418,1; Anl. 2; Anl. 5

Rhede $<$ Borken $>202 \mathrm{~b}, 2$

Rhein 205,2; 305,2,e

Rheinland 703,2,b

Rheinlande 401a,2,b

Rheinland-Pfalz 209a,3; 209a,5

Rhein-Main-Gebiet 204,2

Rheinschiene Mitte 210,1

Rheintal <Motiv $>705,7$,a

Rhetorik Anl. 2; Anl. 10

Rhetorische Figur 704,a

Rheumaklinik 12,3,d

Rhinitis 309

Ria $12,2, \mathrm{~d}$

Richtlinie 715,1; Anl. 6

Richtwert Anl. 6

Riddara sögur 712,6

$\neg$ The $\neg$ riddle of the Dead Sea scrolls 733,5

Riehen $<$ Basel $>$ / Fondation Beyeler 736,1

Riesengebirge 204,1

$\neg$ ar- $\neg$ Rijad 202a,1

Rilke, Rainer Maria 116,2,d

Rindenkrebs 12,5,b

Rio de la Plata 202a,2

Rio Grande do Sul 202a,2

Ritschenhausen 210,4

Ritter 312

Rittersaal 730,3 
Rock'n' Roll Anl. 6

Rockefeller Foundation / International Health Division 609,2,a

Rodin, Auguste 705,9

Römerzeit 408a,4; 705,5; Anl. 6

Römisches Recht 305,2,e; 311,2; 408a,3,b

Römisches Reich / Zwölftafelgesetz 715,10

Römisches Reich <Motiv> 705,7,a; 705,7,b

Römisches Reich 101a,4; 206,1; 408a,2,a; 408a,3,a; 725,5

Rohrverbindung 322,2

Rolandslied (ÖB-Alternative) 712,4

Rollentausch 705,4

Rom 4,5; 766; Anl. 6

Rom / Peterskirche 418,3

Rom / Piazza Navona 209,4

Rom / San Giovanni in Laterano 731,1

Rom / Tempel des Apollo Palatinus 725,4

Rom / Tempel des Vespasian 725,4; 725,5

Rom / Vatikanische Bibliothek / Cod. Ottob. lat. 3029736,5

Rom $<$ Motiv $>705,1$

Rom- Castel Fusano / Villa Chigi 209,5

Roma $<$ Göttin $>212 b, 3, b$

Roma $<$ Volk $>212 b, 3, b$

Roman 5,3; 5,4; 12,6,a; 116,2,c; 403,2; 418,4,b; 418,5,a; 703,1,a; 703,2,b; 705,1; 705,5; 705,7,a; 734,3; 734,4; Anl. 2;

Anl. 5; Anl. 6; Anl. 10

Romanik 418,3

Romanistik Anl. 6

Romantheorie 704,a

Romantik 410,2; 705,9; 735,2; 765,4

Rorschach-Test 714

Rose 303,2,b

Rosen im Herbst 733,4

Rosengewächse 303,2,b

Rosenpflanzen 303,2,b

Rostow $<$ Don $>202 \mathrm{~b}, 3$

Rota 619,1,c

Rotes Moor 209a,3

Rothenburg <Tauber $>202 \mathrm{~b}, 2$

Rothenburg $<$ Tauber $>$ / Verein Alt-Rothenburg 605,2

Rotkäppchen $711,1, \mathrm{a}$

Rougemont $<$ Doubs $>203,2$

Route Napoléon 210,2

Ruderfußkrebse 309

Rückert, Friedrich Anl. 6
Rückläufiges Wörterbuch Anl. 6

Rühmann, Heinz 734,1

Ruhrgebiet $<$ Motiv $>734,4$

Ruhrgebiet 705,8 ,a

Rund um die Berolina 733,1

Rundfunksender Anl. 6

Runkelstein 730,2

Russell Sage Foundation 603,3

Russen $212 ; 212 b, 1$

Russisch 305,1,c; 701,1,a; 703,1,a

Russland 207,3; 415a,1,a

Russland $<$ Sowjetrepublik $>207,3$

Russlanddeutsche Anl. 6

Rutilismus 764

s $305,1, \mathrm{c}$

Saarbrücken / Oberlandesgericht Saarbrücken 615,2

Sachbilderbuch 765,$2 ; 765,3 ; 765,6 ; 765,7$; 765,9,c; 766; Anl. 6

Sachenrecht Anl. 6

Sachsen / Statistisches Landesamt 614,2

Sachtext 706,2

Säure $303,2, c$

Saga $12,4, a$

Sage 762,9,a; Anl. 6; Anl. 10

Saint-Denis 724

Saint-Exupéry, Antoine $\neg$ de $\neg$ 117,4

Salmen, Walter 13,4,a

Salomon und Markolf $<$ Spielmannsepos $>$ $712,3, \mathrm{a}$

Salomon und Markolf $<$ Spruchdichtung $>$ $712,3, \mathrm{a}$

Saloniki / Acheiropoietos-Basilika 731,2

SALT II 716

Salz 303,2,c

Salzburg 207,1

Salzburg / Salzburger Festspiele 601,1

Salzburg < Diözese $>$ Anl. 1

Salzlagerstätte 209a,6

Sambia 207,2

Sammlung 736,1-7; Anl. 2; Anl. 6

Samtgemeinde 203,4

San Francisco $<$ Calif. $>415 a, 1, b$

San Marino 202a,3

Sandwüste 209a,2

Sankt Gallen 202a,3

Sankt Galler Klosterplan 727,3

Sankt Petersburg 207,1 
Sankt Petersburg / Russische Akademie der Wissenschaften / Bibliothek 605,5,b

Sankt Pölten $<$ Diözese $>$ Anl. 1

Sans Pareil $<$ Firma $>612,2$

Santiago de Chile 202b,4

São Paulo 202a,3

Saponine 306a, 8

Sardinien 408a,3,a

Sartre, Jean-Paul 105,1; 115a,2

Satellitenbild Anl. 6

Satire 703,2,b; Anl. 10

Satz 4 305,1,b; 743a, 1

Scala $<$ Familie $>725,5$

Scener ur ett äktenskap 733,1; 733,3

Schaf 306a, 9

Schale $<$ Gefäß $>306,5$

Schalke $<$ Gelsenkirchen $>209,1$, a

Schallplatte 737,2; Anl.6

Schallplatte <für Kinder $>$ 766; Anl. 6

Schankara 110,5

Schauerroman 5,4

Schauspielerin 305,2,e

Schedel, Hartmann / Weltchronik 709,2

Schelf 307,3

Schelling, Friedrich Wilhelm $\neg$ von $\neg$ Anl. 6

Schematismus 503,2; Anl. 6

Schicksal 305,1,c

Schiffbau 4,5

Schifffahrt 402,2; Anl. 6

Schiffsuntergang 324,3

Schikaneder, Emanuel / $\neg$ Die $\neg$ Zauberflöte 743

Schiller, Friedrich 117,4; Anl. 6

Schiller, Friedrich / Wilhelm Tell 773,1

Schlacht 415a,2

Schlaf, Johannes / $\neg$ Die $\neg$ Familie Selicke 708,3

Schlaraffenland 201,1,e

Schlesien 202,6

Schlesisch 701,2,a

Schleswig <Diözese > Anl. 1

Schleswig-Holstein 773,2

Schlöndorff, Volker 734,1

Schlosspark $730,1, \mathrm{~b}$

Schmetterlinge 201a,6

Schnabelkanne 8,3

Schnaittach / Jüdisches Museum Franken $605,5, \mathrm{~b}$

Schneebergbahn 210,2
Schnittstelle 306a,6

Schottel, Justus Georg / Ausführlich Arbeit von der teutschen Haubtsprache 709,1

Schreiben 315,3; 317,1

Schreibmeisterbuch Anl. 10

Schrift 315,3; 317,1; 704,b

Schriftenreihe 501; Anl. 6

Schriftsprache 315,3

Schriftsteller 704,a; 765,4; Anl. 6

Schriftstellergruppe 318

$\neg$ Der $\neg$ Schritt vom Wege 733,4

Schubert, Franz 741,2

Schubert, Franz / Quintett, Violine Viola Violoncello Kontrabass Klavier D 667 $737 \mathrm{a}, 5, \mathrm{~d}$

Schubert, Franz / Sinfonie D 849 741,1,c

Schubert, Franz / Winterreise 740,1

Schüler 305,2,e

Schülerbeurteilung 14,3

Schülerin 303a, 1

Schülerurteil 14,3

Schützenhof $<$ Preetz $>612,1$

Schuhabsatz 10,2

Schulanfang Anl. 6

Schulaufsicht 14,4

Schulbuch 5,$2 ; 504,1 ; 767-769 ; 770$,e; 771,1-2; 773,2; Anl. 6; Anl. 10

Schule 19,3; 211,2; Anl. 10

Schule $<$ Motiv $>705,1 ; 705,9 ; 705,10$

Schuljahr 1 17,2,d

Schuljahr 3-4 773,2

Schuljahr 8-10 768,2

Schulklasse 306,6

Schulleistung 7,3

Schulpolitik 13,3;324,3

Schulschwierigkeit 315,2,c

Schwäbisch 701,2,c; 765,6

Schwäbisch Gmünd 503,3

Schwangerschaftsabbruch 4,$2 ; 715,8$

Schwank Anl. 10

Schwarze 212

Schweden 13,4,c; 218,2; 762,2;

Anl. 6

Schweden / Reichstag 614,2

Schwedisch 13,4,c; 704,b

Schwefel 304,2,d

Schwein 315,2,b

Schweißer 715,1

Schweitzer, Albert 765,1 
Schweiz 13,4,b; 18,2; 306a,10; 311,2; 701,1,d; 703,2,a; 703,3; Anl. 6

Schweiz / Armee 616,1

Schweiz $<$ Motiv $>705,7$,a

Schweizerdeutsch 701,2,a

Schwellenländer 211,1,b

Schwerbehinderter 317,1

Schwerbehinderung 317,1

Schwere Krankheit 324,2

Schwerin $<$ Diözese $>$ Anl. 1

Schwermetallbelastung 201a,4

Schwester 705,4

Schygulla, Hanna 733,3

Sciencefiction 302,$4 ; 308,2$

Scientology 4,2

Scilitanische Märtyrer 101,2

Seehund 765,2

Segelschulschiff 306a,6

Seidenmalerei Anl. 6

Seine-Gebiet 204a,1

Sekte 306a,6

Sekundarstufe 1 768,2; Anl. 6

Sekundarstufe 2 305,1,b; 322,2; 768,1-3; $769 ; 771,1$

Selbstanalyse 4,2

Selbstbild 705,3,b

Selbstbildnis $116,2, \mathrm{c}$

Selbsttäuschung 12,3,e

Selbstverständnis Anl. 5

Self-consistent Field 302,2,b

Semantik 701,5,a; 706,2; Anl. 5

Seneca, Lucius Annaeus $<$ Philosophus $>105,2$

Seneca, Lucius Annaeus $<$ Philosophus $>$ / Medea 711,1,b

Senegal 703,2,b

Serbischer Psalter 718,1

Sesto al Règhena 202b,4

Sexualdelikt 733,5

Sexueller Missbrauch 766

Sezessionskrieg < 1861-1865> 733,5; 737,3

Shakespeare, William 116,2,c; 705,1; Anl. 6

Shakespeare, William / As you like it Anl. 5

Shakespeare, William / King Lear 709,2

Shakespeare, William / Measure for measure $116,2, \mathrm{c}$

Shakespeare, William / Troilus and Cressida Anl. 5
Shaw, George Bernard 312

Shaw, George Bernard / Pygmalion 734,2

Sicherheitspolitik 211,2;622

Sieben Weltwunder 305,1,b

Siebzehnter Juli 762,4

Siedlung Heinzelspitze 202a,3

Siedlungsgeographie 201a,5

Siegen / Nikolaikirche 728,c

Sierra Nevada $<$ Andalusien $>203,3$,a

Sierra Nevada $<$ USA $>203,3, a$

Sigma-Hyperon 314,2,c

Sigmarszell / Musikverein Sigmarszell 605,3

Signal Anl. 6

Simon $<$ Magus $>106,2$,a

Simulation Anl. 5

Sinaikloster 618,3

Sinn 312

Sinti 703,4

Sioux 18,2

Sisteron 210,2

Sitten $<$ Diözese $>$ Anl. 1

Sjöberg, Erik 103,1

Sketch 762,9 ,a

Skilanglauf Anl. 6

Skilauf Anl. 6

Skisport Anl. 6

Sklavenhandel Anl. 6

Slovenská Spoločnost' Antropologická 603,5

Slowenien / Verfassung < Entwurf, 1991 > 717

Slowenisch 703,2,a; 703,2,b

šm 305,1,c

Smetana, Bedřich / Vltava 743a,2

Soapopera 705,1

Society of Cypriote Studies 603,4

Sölvesborg 762,2

Sohn 762,9,c; Anl. 6

Soldat 305,2 ,e

Soldatensprache 702,2 ,a

Solženicyn, Aleksandr I. 116,2,b

Somalia 207,4

Song Gaozong $<$ China, Kaiser $>110,3$

Sonnleitner $<$ Familienname $>107,1$

Sorben 212a, $1, \mathrm{~b}$

Sorbisch Anl. 6

Souffleuse 303a,1

Sound $<$ Multimedia $>737 \mathrm{a}, 5, \mathrm{~d}$ 
Sowjetunion 207,$3 ; 305,2$,e; 415a,1,a

Sowjetunion / KGB 116,2,b

Sozialarbeit $12,3, \mathrm{a}$

Sozialdemokratische Partei Deutschlands $622 ; 762,5$

Sozialdemokratische Partei Deutschlands / Ortsverein Itzehoe 606,2

Sozialdemokratische Partei Deutschlands / Ortsverein Nördlingen 611,1

Sozialdemokratische Partei Deutschlands / Parteitag $<1982>607,7$

Soziale Klasse 306,6

Soziale Situation 212a,5

Sozialgeschichte 402,1; 405a; 406,2; 406,3; Anl. 5

Sozialgeschichte 1517-1585 17,2,a

Sozialgeschichte 1800-1988 401a,2,b

Sozialgeschichte 1890-1970 406,2

Sozialgeschichte $<$ Fach $>405,2$

Sozialhilfe 310,2

Sozialismus $13,4, \mathrm{e}$

Sozialistische Staaten 201,1,g; 211,1,b

Sozialkundeunterricht 768,2; 771,1

Sozialphilosophie 4,2

Sozialwissenschaften 303,$5 ; 322,3, \mathrm{c}$

Soziologie 4,5; 322,3,a; Anl. 5

Spätantike 408a,3,a; 409,3

Spätlatein 701,3,a

Spagnulo, Giuseppe 602,8

Spaichingen 209,4

Spanien 218,$1 ; 324,3 ; 402,2 ; 402,3 ; 708,10$; 715,6

Spanien / Cortes 324,3

Spanier 14,2

Spanisch 317,2,b; 701,1,e; 702,1; 702,3,c; 705,7,b; Anl. 5

Spanische Niederlande 202,6

Spanischer Bürgerkrieg 415a,4; 762,4; Anl. 5

Spannungsabhängigkeit 315,2 ,a

Spartacus 108,4,a

Spectator $<$ Zeitschrift, London, 1711-1714> 710,3

Spectator $<$ Zeitschrift, London, 1828-> 710,3

Spessart 701,2,a

Speyer $<$ Diözese $>$ Anl. 1

Spiel Anl. 6; Anl. 10

Spielkarte 306,6
Spielregel Anl. 6

Spinnentiere 13,4,b

Spirituosenhandel 304,5

Sport 12,5,b; 317,2,a; 702,3,c

Sportlehrer 14,3

Sportunterricht 14,3

Sportverletzung 324,1;324,2

Sportwissenschaft 12,5,b

Sprachatlas 502; Anl. 6

Sprache 117,4; 701,1,d; Anl. 2; Anl. 5

Sprachführer 765,6; 766; Anl. 6; Anl. 10

Sprachliche Universalien 305,2,a

Sprachnorm 315,2,c

Sprachstörung 12,3,c

Sprichwort 703,2,b; Anl. 10

Staat 203,$4 ; 312 ; 324,4$

Staatenimmunität 306,5

Staatsgrenze 14,$4 ; 202,5$

Staatslehre Anl. 6

Staatsrecht Anl. 6

Stadion $730,1, \mathrm{~b}$

Stadt 203,4; 324,3; Anl. 6

Stadthalle 730,1,b

Stadtmauer 730,1,b

Stadtpark 730,1,b

Stadtplan 737a,5,f; Anl. 6

Stadtrat 612,2

Stadtstreicher 311,1

Stadtverkehr 324,3

Stadtverwaltung 503,2; Anl. 6

Stadtwald 209,4

Städel, Johann Friedrich 736,5

Stände 303,4

Stahl 304,2,d

Stalingrad 207,5

Stalingrad / Schlacht 418,5,b

Stamitz, Carl / Konzert, Oboe Orchester

B-Dur 741,1,f

Stammeln $12,3, \mathrm{c}$

Stand 303,4

Standardsprache 701,1,e

Statistik 5,1; 305,2,g; 502; 503,1,a; Anl. 6

Statistik 1945-1980 Anl. 6

Statuette 725,5

Stein, Edith $108,8, \mathrm{~b}$

Steiner, Max / Gone with the wind 743

Steinobst $12,3, \mathrm{f}$

Steinobstanbau 12,3,f

Stereotyp 705,3,b 
Steuerung Anl. 5

Sticken 305,1,a

Stickerei $305,1, \mathrm{a}$

Stift 203,4

Stilistik 701,5,a; 706,2; Anl. 5

Stillleben 735,3

Stochastisches Modell 322,3,c

Stockhausen, Karlheinz 105,1

Strafe 7,2

Strafrecht 715,8

Strahlenschutzgesetz 715,4

Straßburg / Münster / Engelspfeiler 8,4; 730,3

Straßburg $<$ Diözese $>$ Anl. 1

Straßenverkehr 315,1,c

Strategisches Management 306a,10

Strausberg / Sozialwissenschaftliches Institut 611,$1 ; 616,3$

Strauß, Botho / Ithaka Anl. 6

Streichquartett 741,2

Streitschrift Anl. 10

Streptococcus 19,4; 306a,9

Stricken Anl. 6

Struktur Anl. 5

Student 305,2,e; 317,2,a

Studienführer Anl. 6

Studium 315,2,b; Anl. 5

Stundenbuch 718,$1 ; 718,2, \mathrm{~b}$

Sturm und Drang 765,4

Stuttgart 503,2; Anl. 6

Stuttgart / Staatliche Akademie der Bildenden Künste / Klasse Spagnulo 602,8

Stuttgart / Universität $<1781-1794>612,1$

SU-3-Symmetrie 17,2 ,b; 314,2, e

Substantiv $305,1, \mathrm{c} ; 322,4 ; 324,2 ; 706,2$

Sudan-Arabisch 701,1,e; 701,1,f

Südafrika $415 \mathrm{a}, 1, \mathrm{a}$

Südafrika $<$ Staat $>5,3 ; 209 a, 3$

Süddeutschland 765,4

Südlicher Bug 205,1,b

Südlicher Oberrhein $<$ Planungsregion $>$ $201,1, \mathrm{a}$

Südostasienwissenschaften 305,2 ,e

Südtirol 205,1,b

Suffix 305,1,c

Superintendentur 203,4

Supervisor 306,8

SUPERVISOR < Expertensystem> 306,8

Surrealismus 408a,5,a
Sveti Stefan 202a,3

Swift, Jonathan / Gulliver's travels 705,6

Symbol Anl. 5

Synode 415a,2

Syntax 701,5,a; 706,2; Anl. 5

Synthese Anl. 5

Syrien 18,2

Syrlin, Jörg <der Ältere> 728,b

Systematik Anl. 5

Tabelle Anl. 6

Tacitus, Cornelius 105,2

Täuschung 12,3,e

Tafel 737,2; Anl. 6

Tagebuch 503a; Anl. 6

Tagebuch 1660-1669 Anl. 6

Tagula 209a,2

Takla Makan 209a,2

Taler 201a,6

Tamil 701,1,b

Tangdynastie 408a,2,b

Tannenberg / Schlacht $<1410$, Motiv $>$ 705,2

Tansania 218,$2 ; 737,2$

T'aqaišvili, Ek'vit'ime 110,4

Tarimbecken 204,2; 209a,2

Taufschüssel 728,c

Taxi 310,1

Technik Anl. 6

Telefaxverzeichnis 503,2; Anl. 6

Telefonbuch 503,2; Anl. 6

telein 324,3

Telexverzeichnis 503,2; Anl. 6

telos 305,1,c

Telugu 701,1,c

Telugu-Sprache 701,1,c

Tennenbach / Kloster 618,3

Tennesseetal 204,2

Tennis 324,2

Terahertzbereich 13,6

Terentius Afer, Publius Anl. 5

Teresa $<$ de Jesús $>108,8, b$

Territorium 203,4

Tertiär $408 \mathrm{a}, 4$

Test 12,3,c

Testmaterial Anl. 6

Tethysmeer 201,1,c

Teutoburger Wald / Schlacht 765,1

Texaco Inc. 602,5 
Texel 765,2

Text 5,$3 ; 5,4 ; 5,7 ; 762,6 ; 762,9, d ; 765,6$; Anl. 6

Textgeschichte 13,1; 405,3; Anl. 5

Textkritik Anl. 5

Textverarbeitung 306a,6; 737a,3,a; 737a,4

Thackeray, William Makepeace 117,4

Thailändisch 701,1,a

Thaisprachen $701,1, \mathrm{f}$

Theater 305.2.g; 620a; 704,a

Theaterstück 502; 705,8,a; 762,4; 762,9,e; 766; Anl. 6

Theaterzeitschrift 305,2,g

Theaterzettel Anl. 10

Thema 14,4

Theodōrakēs, Mikēs 109,1

Theologie 117,4; 322,3,a; Anl. 2

Theologie der Befreiung 115a,2

Theorie 13,4,e; 322,3,c; Anl. 5

Therapie 322,2; Anl. 5

Thermodynamische Eigenschaft 322,3,b

Thesaurus Anl. 6; (Sachschlagwort) Anl. 6

Thomas < von Aquin $>106,2$,a

Thurn und Taxis $<$ Familie $>$ Anl. 6

Thymus 312

Tiepolo, Giovanni Battista 728,b

Tierbuch Anl. 10

Tiere 220,4,b; 766; Anl. 5

Tiere $<$ Motiv $>324,3$

Tiermedizin Anl. 10

Tierphysiologie Anl. 5

Tipi 212a,4

Tirol und Fridebant $<$ Epik $>712,3, \mathrm{~b}$

Tirol und Fridebant $<$ Lehrgedicht $>712,3, \mathrm{~b}$

Tirol und Fridebant $<$ Rätsel $>712,3, \mathrm{~b}$

Tischzucht Anl. 10

Toccata 5,6; Anl. 6

Tod Anl. 2

Tölz-Wolfratshausen $<$ Kreis $>$ 203,3,c

Tolstoj $<$ Familie $>107,1$

Tonale-Linie 201,1,d

Tonbildreihe 5,1;737,2; Anl. 6

Tonkassette 737,2; Anl. 6

Tonkassette $<$ für Kinder $>766$; Anl. 6

Tonträger $501 ; 504,1 ; 737,2 ; 737 \mathrm{a}, 6$;

Anl. 6; (Sachschlagwort) Anl. 6

Tonträger <für Kinder $>$ 766; Anl. 6

Topographie Anl. 10

tor $<$ Morphem $>305,1, \mathrm{c}$
Tor $305,1, \mathrm{c}$

Torschok / Puschkin-Museum 602,8

Tote Hand 310,3

Totentanz Anl. 10

Toul <Diözese $>$ Anl. 1

Tour de France $<1980>607,6$

Tourenskilauf Anl. 6

Traditionsbuch 719

Training 19,3

Trainingsprogramm 12,6,b

Trans-Arabian Pipeline 210,1

Transistor $737 \mathrm{a}, 2$

Transplantation 315,2,b

Traun 203,3,b

Traun $<$ Bayern, Fluss $>203,3, b$

Traun $<$ Österreich, Fluss $>$ 203,3,b

Traunstein 203,3,b

Traunstein / Chiemgau-Gymnasium 611,1

Traunstein / Landgericht Traunstein 615,2

Traunstein $<$ Berg $>203,3, b$

Trekking 19,3

$\neg$ Le $\neg$ trésor des contes 712,6

Trichlorethane 315,4

Trickfilm 737a,6

Trient $<$ Diözese $>$ Anl. 1

Trier $730,1, \mathrm{~b}$

Triest $<$ Diözese $>$ Anl. 1

Trio, Trompete 1,2 Orgel 5,6; Anl. 6

Tristan und Isolde 101,1

Tristan-Akkord 101a,1

Trivialliteratur 503,3; Anl. 6

Trockental 201,2

Troja 206,$1 ; 765,1$

Trollflöjten 733,4

Tropische Pflanzen 305,2,e

Troposphäre 201,3

Trotta, Margarethe $\neg$ von $\neg$ Anl. 6

Tschaikowski, Pjotr I. / Schwanensee (ÖBAlternative) 743

Tschaikowsky-Gesellschaft 602,3

Tschechische Republik / Zivilgesetzbuch 715,9

Tschechoslowakei / Zivilgesetzbuch 715,9

Türkei 8,2; 13,4,d; 207,3; 212a,2; 213a; 504,1

Türkin 212a,5; 303a,1

Türkischer Schüler 305,2,e

Türkisches Mädchen 212a,5

Tulpe 306a,9 
Tunesien 762,2

Tunguska 205,2

Tympanon 730,3

Typ C 18,1

Übereinkommen über einen Verhaltenskodex für Linienkonferenzen 716

Übersetzung 713,2; Anl. 2; Anl. 5

Übungsprogramm $12,6, \mathrm{~b}$

Übungssammlung Anl. 6

Uhr 736,2

UKW-Antenne 302,4

Ulan 303,1

Ulfilas 713,2

Ulm / Münster 10,3; 728,b

'Umar Haiyām 110,1

Umarbeitung Anl. 5

Umformen 305,1,a

Umfrage 212a,2; Anl. 6

Umkreis 305,2,d; Anl. 2

Umlandverband 203,4

Umschulung 317,2,a

Umwelt 306a, 10

Umweltchemikalie 306a, 10

Umwelterziehung 211,2

Umweltpolitik 307,2,d

Umweltschaden 317,2,a; Anl. 5

Umweltschutz 765,3

UNESCO 602,4

Ungarisch 718,1

Ungarn / Central Statistical Office 603,4

Ungarn / Justizministerium 614,5

Ungeborenes 305,1,a

Union des Démocrates pour la République $606,1, \mathrm{a}$

UNISON 611,2

Universität 602,$9 ; 605,4$

UNIX 306a,6

Untere Tunguska 205,2

Untergrundbahn 730,1,b

Unternehmen Anl. 6

Unterricht 768,1; Anl. 5

Unterrichtseinheit 770,f; Anl. 6

Unterrichtsfilm 12,6,a

Unterrichtsstil 316,4

Uralische Sprachen 701,1,c

Uran-235 17,2,b; 314,2,f

Uran-235-Target 314,2,f

Urdu 702,2,c
Urkunde Anl. 6; Anl. 10

Urlauber 305,2,e

Ursache Anl. 5

Urslawisch 701,3,a; 706,2

USA 14,$1 ; 101 \mathrm{a}, 4 ; 209 \mathrm{a}, 5 ; 218,2 ; 305,2$,e; 322,$5 ; 403,2 ; 415 \mathrm{a}, 1, \mathrm{~b} ; 602,9 ; 616,2$; 703,2,b; 703,2,c; 703,4; 705,1; 716; 734,4; 736,$7 ; 768,1$

USA / Age discrimination in employment act 715,5

USA / Engineer Combat Battalion $<51>$ 616,2

USA / Kongress 622

USA / Landwirtschaftsministerium / Bureau of Statistics 614,4

USA / Oberster Gerichtshof 601,1; 614,2

USA / Südstaaten 201,1,g; 203,5

USA / Wirtschaftsministerium / Bureau of Statistics 614,4

Utopie 306,7

Utrecht $<$ Diözese $>$ Anl. 1

uts 706,2

V.24-Schnittstelle 314,2,e

Valence $<$ Drôme $>203,3$,a

Valla, Lorenzo 108,5

Valmy / Kanonade 416

Valromey 209a,2

Valton, Prosper 736,3

VanDeVelde, Henry Anl. 6

Van-Diemen-Golf 111,2; 202a,1

Varus, Publius Quinctilius 765,1

Vater 762,9,c; Anl. 6

Vatikanisches Konzil <1962-1965> 607,8

Vecellio, Tiziano $<$ Künstler, 1477-1576> / Spanien schützt die Religion 725,4

Vedute 705,9

Venedig 305,2,e; 762,2; 762,4

Venedig / Dogenpalast 725,3

Venus 106,$5 ; 306,4$

Venus $<$ Planet $>106,5 ; 201,3 ; 306,4$

Venus $<$ Raumsonde $>306,4$

Venus von Willendorf 727,3

ver $302,2, \mathrm{a}$

Verb 305,1,c; 324,3; 701,1,e; 706,2

Verband der Deutschen Buchdrucker 602,4

Verband Deutscher Lehrer im Ausland 603,1

Verbandsgemeinde 203,4 
Verbrennungsmotor $12,3, \mathrm{~d}$

Verbrüderungsbuch 719

Verbundträger 304,2,d

Verden $<$ Aller, Diözese $>$ Anl. 1

Verdun $<$ Diözese $>$ Anl. 1

Verehrung Anl. 2

Verein 1000 Jahre Kronach 17,2,g

Verein der Diplom-Bibliothekare an Wissenschaftlichen Bibliotheken 602,4

Verein Deutscher Bibliothekare 602,5

Verein Deutscher Ingenieure 602,7

Verein Deutscher Ingenieure / VDINachrichten 708,5

Verein für Sachsen-Meiningische Geschichte und Landeskunde 611,2

Vereinigungskirche 765,5

Vereinte Nationen / Charta 708,5

Vereinte Nationen / UNICITRAL-Modellgesetz über die Beschaffung von Gütern, Bau- und Dienstleistungen 715,11

Verfassung 211,2

$\neg$ Die $\neg$ verfeindeten Brüder 705,4

Vergütung 318

Verhaltensforschung Anl. 6

Verhältnis 14,4

Verkaufskatalog Anl. 6

Verkehrserziehung 768,1

Verkehrslärm 315,2,b

Verkehrsplanung 324,3

Verlag Die Runde 602,5

Vernersches Gesetz 13,3; 305,2,d

Verona 725,5

Verordnung Anl. 10

Verordnungsermächtigung 311,2

Verserzählung Anl. 10

Versetzung < Arbeitsrecht $>306,3$

Versetzung $<$ Beamtenrecht $>306,3$

Versetzung $<$ Kristallographie $>306,3$

Versetzung $<$ Pädagogik $>306,3$

Versicherungsleistung 304,4

Versicherungswirtschaft 201a,2

$\neg$ Das $\neg$ Versprechen $<$ Film, 1983 $>$ 733,1; 733,5

$\neg$ Das $\neg$ Versprechen $<$ Film, 1995 $>733,1$

Versuchsperson 12,6,b

Verteidigungsministerium 614,5

Vertrag Anl. 6

Verwaltungsgemeinschaft 203,4

Verzeichnis 212a,3; 704,a; 737a,4; Anl. 6
Vézelay / Sainte Madeleine 730,3

Victoriasee 201,1,b

Videokassette 5,5; 737,2-5; Anl. 6

Videokassette $<$ für Kinder $>$ 766; Anl. 6

Viertaktmotor $12,3, \mathrm{~d}$

Viktoria $<$ Großbritannien, Königin $>108,7$,a

Villingen $<$ Schwarzwald $>$ / Franziskaner-

kirche 209,5

Vitamin A1 314,2,f

Vitamin B12 314,2,a

Vitamin-B12-Mangel 314,2,a

Vivaldi, Antonio / $\neg$ Il $\neg$ cimento dell'armonia e dell'inventione / Konzert R 269 $743 \mathrm{a}, 3$

Vivaldi, Antonio / $\neg$ Il $\neg$ cimento dell'armonia e dell'inventione / Konzert R 293 $743 \mathrm{a}, 3$

Vivaldi, Antonio / $\neg$ Il $\neg$ cimento dell'armonia e dell'inventione / Konzert R 297 $743 \mathrm{a}, 3$

Vivaldi, Antonio / $\neg$ Il $\neg$ cimento dell'armonia e dell'inventione / Konzert R 315 $743 \mathrm{a}, 3$

Vögel 303,2,b; 324,2

Völkerrechtlicher Vertrag Anl. 10

Völkerwanderungszeit 408a,4

Vogelfluglinie 210,1

Vogelkrankheit 324,2

Vogelzug 303,2,b

Vokal 701,5,a; 706,2

Vokalmusik Anl. 6

Volkach / Sankt Maria im Weingarten 731,6

Volksbefreiungsarmee $<$ Jugoslawien $>$ /

Divizija $<4>616,4$

Volksbuch Anl. 10

Volksliteratur 712,6

Volksschule 14,4

Volkstanz 12,4,a

Vom Winde verweht (ÖB-Alternative) 733,2

Vor- und Frühgeschichte 402,1; 402,2; 406,2; Anl. 5

Vorau / Stiftsbibliothek / Evangeliar / Cod. $346718,2, \mathrm{~b}$

Vorderhirn 12,6,a

Vorgeschichte 219,2; 405,3; Anl. 5

Vorlage Anl. 5; Anl. 6

Vorlesung Anl. 6; Anl. 10

Vorlesungsverzeichnis Anl. 6; Anl. 10

Vortrag Anl. 6 
Vorwort 711,3

Wagner, Richard 101a,1

Wagner, Richard / $\neg$ Die $\neg$ Meistersinger von Nürnberg 101a,2

Wagner, Richard / $\neg$ Das $\neg$ Rheingold 743a,2

Wahlverfahren $<$ Psychologie $>12,3$,c

Wahrsagen 408a,3,a

Wahrscheinlichkeitsrechnung Anl. 6

Waisenkind 705,8,a; 765,2

Waldgärtner 306a, 9

Waldorf-Astoria Hotel 606,2

Waldschaden 306a,10

Waldtiere 324,1

Walhalla 730,2

Wallfahrt Anl. 6

Wallonisch 701,2,a

Wandern Anl. 6

Wappenbuch Anl. 10

Warschau / Krakowskie Przedmiescie $201,1, \mathrm{~d}$

Wasserversorgung Anl. 6

Wasserwerk Mannheim 606,1,b

Waterloo / Schlacht 762,1

Weibliche Abgeordnete 303a,2

Weibliche Angestellte 303a,3

Weibliche Körperbehinderte 762,3

Weibliches Mitglied 303a,20

Weimar / Stadtrat 612,2

Weimarer Republik 408a,2,b; 762,4; 765,4

Wein 8,5

Weinbau 7,5; 701,4,c

Weinhold, Gertrud 736,5

Weisheitsliteratur 322,3,a

Weiss, Peter 705,6

Weißkrainer Land 703,2,b

Weizenkeim 303,3

Weltanschauung Anl. 2

Weltbild 705,3,b; Anl. 2

Weltgeschichte 402,1; 406,3; 768,3; Anl. 6

Weltgeschichte 1880-1918 408a,2,a

Weltgeschichte 1945-1987 406,3

Weltgesundheitsorganisation 603,2

Weltkarte Anl. 6

Weltkrieg <1914-1918> 4,5

Weltkrieg $<1939-1945>4,2 ; 17,2$,a; 418,3; 418,4,b; 418,5,a; 418,5,b

Weltkrieg $<1939,1945$, Motiv $>10,4$

Weltwirtschaft 17,2,a
Weltwirtschaftskrise $<1929-1932>415 a, 1$,a

Wenzellegende 765,8

Werbespot 737,2

Werk 116,1; 116,2,c; Anl. 2; Anl. 6

Werkverzeichnis Anl. 6

Westalpen 205,1,b

Westeuropa 13,5

Westfassade $730,1, \mathrm{~b}$

Westgoten 212b,1;212b,2,a

Westmitteldeutsch 701,3,c

Wettkampfbestimmung Anl. 6

Weyarn / Sankt Peter und Paul 504,1

Who's afraid of Virginia Woolf 710,4

Wiblingen / Kloster 605,6

Widerstand 322,2

Wien 17,2,a; 408a,1,c

Wien / Graphische Sammlung Albertina $622 ; 735,2$

Wien / Heeresversorgungsschule 616,3

Wien / Universitäts-Frauenklinik $<2>602,5$

Wien $<$ Diözese $>$ Anl. 1

Wiener Kongress $415 ; 607,8$

Wiener Neustadt $<$ Diözese $>$ Anl. 1

Wiesbaden / Lutherkirche 731,2

Wiesbaden / Stadtrat 8,4;614,2

Wikinger 212a,1,a

Wildenburg $<$ Amorbach $>730,2$

Wilhelm Gustloff $<$ Schiff $>324,3$

Willibald $<$ Heiliger $>725,5$

Wimbledon 207,4

Winchester / New Minster / Kloster 719

Winchester-Bibel 713,2

Windenschwärmer 306a,9

Windows 95766

Windows NT 4.x 737a,4

Winter Anl. 6

Wintergerste 304,2,d

Wintringen / Kapelle 731,4

Winzersprache 7,$5 ; 701,4, \mathrm{c}$

Wirkung 6,3

Wirtschaft 220,4,b; 305,2,g; 405a; Anl. 5

Wirtschaftliche Integration 306a, 10

Wirtschafts- und Rechtslehre 305,2,c

Wirtschaftsbeziehungen 211,2

Wirtschaftsentwicklung 401a,4

Wirtschaftslehre 768,$1 ; 771,1 ; 771,2$

Wirtschaftsministerium 614,5

Wirtschaftspolitik 219,1

Wirtschaftssprache 737,2 
Wirtschaftsstatistik 305,2,g

Wirtschaftstheorie 4,2

Wirtschaftswachstum 5,1; Anl. 6

Wissenschaftliche Schule 305,2,d

Wissenschaftlicher Film 12,6,a

Wissensrepräsentation 19,3

Wittelsbacher 107,2

Wittenberg 725,5

Witz 762,9,a; 766; Anl. 2

Wochenzeitung 315,2,b

Woiwodschaft 203,4

Wolframate $303,2, \mathrm{c}$

Wolga 202,1

Wolgast / Petrikirche 731,2

Wolgograd 207,5

Wolhynisches Fieber 302,1

Wolke 737a,5,c

word 306,8

WORD $<$ Programm $>306,8 ; 306 a, 3 ; 306 a, 6$

WORD 5.0 306a,3

WORD $6.0737 \mathrm{a}, 4$

Word für Windows $6.0 \quad 504,1 ; 737 \mathrm{a}, 3, \mathrm{a}$

WordPerfect 5.1 737a,3,a

Worms / Reichstag 116,2,b

Worms / Synode $<868>415 \mathrm{a}, 2$

Worms $<$ Diözese $>$ Anl. 1

Wörterbuch 4,5; 13,4,a; 14,2; 305,2,g; 317,2,b; 405,1; 408a,3,b; 504,1; 504,2; 702,1; 702,2,a; 702,2,b; 702,3,a; 702,3,b; 702,4; 704,a; 737a,2; 737a,3,b; 737a,5,e; 765,6; 766; 770; Anl. 6; Anl. 10

Wörterbuch $<$ mehrsprachig $>702,2$,c; 702,3,b; 702,3,c; Anl. 6

Wortfamilie 305,1,c; Anl. 5

Wortfeld 305,1,c; Anl. 5

Wortschatz 4,5; 701,1,e; 701,5,a; 704,a; 773,1; Anl. 2; Anl. 5

Wortstamm 305,1,c

Württemberg 13,4,e

Würzburg / Mainfränkisches Museum Anl. 6

Würzburg / Marktplatz 730,1,b

Würzburg / Residenz 728,b; 730,1,b

Würzburg / Universität Anl. 6

Würzburg $<$ Diözese $>$ Anl. 1

Wüste 201,2

Wunder 708,11

Wunderlich, Rudolf $<$ Widerstandskämpfer $>$ $106,3, \mathrm{~b}$
Wuppertal 762,6

Wuppertal-Elberfeld 207,4

Wurmlingen $<$ Rottenburg, Neckar $>$ / Kapelle 731,6

$\mathbf{X}<$ Doktor $>106,2, \mathrm{c}$

Yangwu-Bewegung 306a,6

Yonge, Charlotte Mary Anl. 6

Yttriumverbindungen 13,6;314,3

Yunus Emre 110,1

Yuzawa $<$ Akita $>203,3$, a

Yuzawa $<$ Niigata $>203,3$,a

Zahnarzt 317,2,a

Zahnradbahn 210,2

Zauberspruch 712,6

ZDF 606,1,b

Zeichensetzung 701,5,a; Anl. 5

Zeichentest 12,3,d

Zeichnung 117,$4 ; 622 ; 705,9 ; 735,2 ; 736,3$; 736,7; Anl. 2

Zeitgenossen Anl. 2; Anl. 5

Zeitgeschichte $<$ Fach $>405,2$

Zeithintergrund Anl. 2; Anl. 5

Zeitschrift 5,1; Anl. 6; (Sachschlagwort) 305,2,g; 708,10; Anl. 10

Zeitschrift für deutsches Altertum und deutsche Literatur 708,10

Zeittafel Anl. 6

Zeitung Anl. 6; (Sachschlagwort) 18,2; 315,2,b; 708,10; Anl. 10

Zeitungssprache $701,5, \mathrm{~b}$

Zell $<$ Luzern $>10,3$

Zeno $<$ Citieus $>108,4, b$

Zensur 306,6

Zentralafrikanische Republik 207,2

Zentralfrankreich Anl. 6

Zeus 12,5,a; 705,5

Zhuangzi 110,3

Zillis-Reischen / Sankt Martin 737,2

Zinsstruktur 201a,3

Zitadelle 730,1,b

Zitatensammlung Anl. 6; Anl. 10

Zola, Émile / Germinal 711,1,a

Zürcher Bibel 713,2

$\neg$ Der $\neg$ Zürcher Oberländer 18,2

Zürich / Buddhistische Gemeinschaft 618,2

Zürich / Technische Hochschule 605,4 
Zugewinn 311,2

Zugspitze 202,1; Anl. 6

Zugvögel 303,2,b

Zukunft 762,4

Zulu-Sprache 5,3

Zungen-R 302,4

Zwangsvollstreckung 311,2

Zwanzigster Juli 17,1; 403,3

Zweireichelehre 115a,2

Zweitaktmotor 12,3,d

Zweiter Bildungsweg 305,1,b

Zwilling 303,1

Zwischenhirn 12,6,a 



\section{Sachregister}

Die Zahlen beziehen sich auf die Paragraphen

\footnotetext{
Abkürzung

- Homonymenzusatz 306,8

- Körperschaftsname 602,4

- - Rechtschreibung 602,4

- Kunstwort 313,2,b

- Psychologischer Test 714

- Rechtsnorm 715,3

- Sachschlagwort 313

- - Kompositum 313,3

- - Rechtschreibung 302,3

- Synonymie-Verweisung 12,2,b

- USA

- - Bundesstaat Anl. 4
}

Abstraktionsrelation

- Hierarchische Verweisung 12,3,b

Adelsfamilie 107,2

Adelshaus 730,1,b

\section{Adjektiv}

s. a. Substantiviertes Adjektiv

- Geographisches Schlagwort 202a,1.2; 202b,2

- Körperschaftsname

- - Rechtschreibung 602,7

Adjektiv-Substantiv-Verbindung

- Geomorphologische Bezeichnung 204

- Inversion 305,2

- Sachschlagwort 302,2,b; 305,2

\section{Ältere Literatur}

- Erscheinungsjahr 5,7

- Erschließung

- - Gattungsbegriff Anl. 10

- Formschlagwort 5,7

- Jahresangabe 401a,2,c

- Lokale Anwendung 5,7

- Terminologie 4,5

- Zusätzliche Erschließung 3,2,h; 5,7
Aktuelle Bezeichnung
- Sachschlagwort 310
- Zeitcode 418,1
- Zeitschlagwort 401a,3,a

Akzent 16,3

- Synonymie-Verweisung 16,6

Allgemeinbegriff

- Epochenbezeichnung 410,2

- Historisches Einzelereignis 415a,2

- Individualname 13,3; 306a,10

- Sachschlagwort 304

- Schlagwortform 8

- Schlagwortkette

- - Pleonasmus 324,3

Allgemeines Sprachwörterbuch 702,2

- Formschlagwort 702,2,a.c

Allgemeinsprache 9,3; 309

Almanach 4,4

Alphabet

s. a. Griechisches Alphabet

s. a. Kyrillisches Alphabet

s. a. Nichtlateinisches Alphabet

\section{Altertum}

- Einheitssachtitel 712

- - Deutscher Titel 712,4

- Homonymenzusatz 206,2

- Personenname 108,4

- Verwendung 408a,3,a

\section{Altes Buch}

s. Ältere Literatur

Analoge Ansetzung

- Sachschlagwort 304,2,d

Anatomie 303,2,d

Anonymer Werktitel

- Nicht ortsgebundenes Kunstwerk 727,3.4

\section{Anonymes Werk}

s. a. Sachtitelwerk

- Ansetzung 708,4.7

- Definition 707,5

- Hierarchische Verweisung 712,6

- Jugendliteratur 765,8 
- Kinderliteratur 765,8

- Mittelalter 712,3

- - Bearbeiter 712,3,c

- - Homonymenzusatz 712,3,b

- - Nachschlagewerk 712,3,a

- Schöne Literatur 762,8

\section{Ansetzung}

s. a. Schlagwortansetzung

Anthologie 760

\section{Antike}

- Verwendung 408a,3,a

Antike Literatur

- Verwendung 410,2

\section{Antonym}

s. Gegensatzpaar

\section{Arabisch}

- Geographisches Schlagwort 202a,1

- Personenname 110,1

Archivalien 718-720

Archivalienfonds 718,3

Art der Darstellung

- Formschlagwort 5,1

Artikel

- Geographisches Schlagwort 202a,1.2; 202b,2

Artikel <Recht $>715,8$

Arzneimittelname 306a,8

Assoziative Verweisung 12,5

- Bedeutungswandel 310,2

- Ortsgebundene Körperschaft 605,5,a

- Personenname 12,5,e

- Rechtsnorm 715,9

- Verzicht 12,6

\section{Audiovisuelle Materialien}

- Ansetzung 737,1

- Definition 737,1

- Formschlagwort 4,7; 504,1; 737,2; Anl. 6

- Zusätzliche Erschließung 3,2,d.f.g; 5,3.5.6

\section{Aufbewahrungsort}

- Kunstwerk 724

- Nicht ortsgebundenes Kunstwerk 727,2-4

- Schriftdenkmal 718-719

\section{Aufsatz}

- Festschrift 3,2,a

- Sammelwerk 3,2,a

- Zeitschrift 3,2,a

\section{Ausstattungsgegenstand}

- Bauwerk 728

Ausstellung 504,3; 607,1; 735

- Sammlung 736,7

Australien

- Bundesstaat

- - Homonymenzusatz 203,3,a

\section{Autor}
s. Verfasser

\section{AV-Medien}

s. Audiovisuelle Materialien

Bad

- Geographisches Schlagwort 202a,4

Bauplastik 730,3

Bauwerk 723-731

s. a. Nicht ortsgebundenes Kunstwerk

s. a. Ortsgebundenes Kunstwerk

- Ansetzung 725; 730

- Außerhalb eines Ortes 730,2

- Ausstattungsgegenstand 728

- Definition 723; 730,1

- Nicht ortsgebundene Körperschaft 730,1,d

- Ortsgebundene Körperschaft 730,1,c

- Ortsteil 209,4-6

- Synonymie-Verweisung 725,3-5; 730,1,a; 730,2; 731,3.5.6

\section{Bauwerksteil 730,3}

\section{Bearbeiter}

- Anonymes Werk

- - Mittelalter 712,3,c

- Synonymie-Verweisung 712,3,c

Bedeutungswandel

- Assoziative Verweisung 310,2

- Sachschlagwort 310,2.3

\section{Begleitmaterial}

- Elektronische Publikation 737a,3

\section{Begriff}
s. a. Naturwissenschaftlicher Begriff
s. a. Rhetorischer Begriff
s. a. Sprachwissenschaftlicher Begriff
s. a. Stilistischer Begriff
s. a. Technischer Begriff
s. a. Verwandter Begriff
- Definition 2,5
- Schlagwort 7,1-3

Begriffszerlegung 9,3

- Sachschlagwort 304,3

- Schlagwortform 8,5 


\section{Beiname}

- Homonymenzusatz 106,2,a.c; 108,5

\section{Belletristik}

s. Schöne Literatur

Bemerkung 19

- Definition 19,2

- Quellenangabe 19,1

- Redaktionelle Bemerkung 19,4

- Verweisung 19,5

- Verwendungshinweis 19,3

Benutze Kombination

- Synonymie-Verweisung 12,2,b

- Verweisung 8,5

\section{Benutze Synonym}

- Synonymie-Verweisung 12,2,a

Benutzt für

- Synonymie-Verweisung 12,2,a

Berufsausbildung 771

Berufsgruppe

s. Personengruppe

Berufsschulbuch

s. Schulbuch

\section{Besetzung}

- Musikalisches Werk 741,1,b

\section{Bezeichnung}

s. a. Aktuelle Bezeichnung

s. a. Biochemische Bezeichnung

s. a. Chemische Bezeichnung

s. a. Fremdsprachige Bezeichnung

s. a. Veraltete Bezeichnung

- Definition 2,6

- Wahl 9,3

\section{Beziehung}

- Definition 2,10

\section{BF $<$ Symbol>}

s. Benutzt für

Bibel 713

Bibelausgabe 713,2

Biblische Person

- Ansetzung 108,6

\section{Biblisches Buch}

- Ansetzung 713

Bindestrich

- Geographisches Schlagwort 202b,5

- Sachschlagwort 302,4

\section{Biochemische Bezeichnung}

s. unter Chemische Bezeichnung

Bischof Anl. 1

Bistum

s. Diözese

\section{Brauchtum}

- Hierarchische Verweisung 306a,7

BS <Symbol>

s. Benutze Synonym

Buchstabe

- Linguistische Untersuchung 305,1,c

- Sachschlagwort 305,1,c; 314

Burg 730,1,b

CF früher <Symbol>

s. Chronologische Form; früher

CF später <Symbol>

s. Chronologische Form; später

Chemische Bezeichnung

- Ansetzung 303,2,c; 314

- Homonymenzusatz 314,2,b

- Ordnung 314,2 b

- Zahl 17,2,b; 17,3,a; 314

- Strukturisomer

- - Quasisynonym 315,4

Chinesisch

- Personenname 110,3

Chinesische Dynastie

- Epochenbezeichnung 408a,2,b

Christentum

- Pleonasmus 324,4

Chronologische Form; früher

- Chronologische Verweisung 12,7

Chronologische Form; später

- Chronologische Verweisung 12,7

Chronologische Verweisung 12,7

- Körperschaftsname 611

- Rechtsnorm 715,9

Codierung

- Ethnographisches Schlagwort 213a

- Geographisches Schlagwort 213a

- Körperschaftsname 620a

- Personenschlagwort 111a

- Sachschlagwort 318

- Schlagwortnormdatei 18

- Zeitschlagwort 405a; 418 


\section{D $<$ Symbol $>$}

s. Definition

\section{Datei}

- Elektronische Publikation 737a,5

\section{Datensatz}

- Ethnographisches Schlagwort 213a

- Formschlagwort 503a

- Geographisches Schlagwort 213a

- Körperschaftsname 620a

- Personenschlagwort 111a

- Sachschlagwort 318

- Zeitschlagwort 405a

Definition

- Bemerkung 19,2

Dekanat 618,1

Denkmal 725,5

Deutscher Titel

- Fernsehsendung 733,2

- Film 733,2

- - RAK-ÖB-A 733,2

- Literarisches Werk 709,3; 712,4

- Musikalisches Werk 740,2

- ÖB-Alternativform 712,4

- Rechtsnorm 715,5

- Synonymie-Verweisung 12,2,b

- Wissenschaftliches Werk 712,4

\section{Deutschland}

- Lokale Anwendung

- - Listenfunktion 13,3; 201a,5

- Pleonasmus 13,3; 715,2

- Rechtsmaterie 715,2

Deutschsprachige Rechtsnorm 715,1-4

Diakritisches Zeichen 16,3

- Synonymie-Verweisung 16,6

\section{Dialekt}

s. Mundart

Diözese 618,1

- Homonymenzusatz Anl. 1

\section{Dokument}

- Definition 2,3

- Erscheinungsjahr 3,2,c

- Erschließung 3,1

- Inhaltsanalyse 4; 7,1

\section{Dynastie}

s. a. Chinesische Dynastie

s. a. Herrscherfamilie

\section{Ehrenzeichen}

- Individualname 306a,2

Eigenname

s. Individualname

\section{Einheitssachtitel}

- Altertum 709,1

- Deutscher Titel 709,3; 712,4

- Frühe Neuzeit 712

- Mittelalter 712

- Musikalisches Werk 739,2; 740

- Rechtschreibung 709,1

- Zitiertitel 709,2

\section{Eintragung}

- Definition 2,13

Einwohner 212a,3

Elektronische Publikation 737 a

- Ansetzung 737a,2

- Audiovisuelle Materialien 737a,3

- Begleitmaterial 737a,3

- Datei 737a,5

- Definition 737a,1

- Druckwerk 737a,3

- Formschlagwort 4,7

- Medienkombination 737a,3

- Multimedia 737a,5,e

- Zusätzliche Erschließung 3,2,d.f; 5,3

Entwicklungsachse 210,1

Enzyklopädie 505

Epochenbezeichnung 408-410

- Allgemeinbegriff 410,2

- Ansetzung 409

- Chinesische Dynastie 408a,2,b

- Ethnographisches Schlagwort 219,3

- Geographisches Schlagwort 219,3; 410,1

- Geologie 408a,4

- Indikator 11,2

- Jahresangabe 408a

- Kompositum 409,3

- Kulturepoche 408a,1

- Permutation 410,3

- Personenschlagwort 410,2

- Politische Geschichte 408a,2

- Reihenfolge 410,1

- Schlagwortkette 410

- Verwendung 408a

- Vor- und Frühgeschichte 408a,4

Erbauungsliteratur 4,4 
Erscheinungsjahr

- Ältere Literatur 5,7

- Dokument 3,2,c

\section{Erscheinungsweise}

- Formschlagwort 5,1

Erzbischof Anl. 1

Erzdiözese Anl. 1

\section{Ethnische Gruppe 212}

Ethnographisches Schlagwort 212-212b

- Adjektiv-Substantiv-Verbindung 305,2,e

- Ansetzung 212b

- Codierung 213a

- Datensatz 213a

- Definition 212

- Epochenbezeichnung 219,3

- Formschlagwort 219,1

- Geographisches Schlagwort 212a,2

- Hierarchische Verweisung 212b,2,a

- Historisches Einzelereignis 415a,2

- Indikator 11,2

- Jugendliteratur 765,2

- Kinderliteratur 765,2

- Ländercode 18,2

- Literarische Gattung 703,4

- Literatur 703,4

- Nachschlagewerk 212b,1

- Permutation 15,10,d; 220

- Personenschlagwort 116,2,b; 117,3

- Pleonasmus 13,3

- Präkombiniertes Schlagwort 213

- Reihenfolge 15,4.5.10,d

- Sachschlagwort 212a,4; 220,4,b

- Schöne Literatur 762,2

- Vergleich 218,1;219,2

- Verwendung 212a

- Weibliche Form 212a,5; 212b,2,b

- Zeitschlagwort 219,1

\section{Europa}

- Pleonasmus 13,3

Fachlexikon 702,4

Fachliches Sprachwörterbuch 702,3

- Formschlagwort 702,3

Fachsprache 9,3; 701,4,b

- Gebräuchliche Bezeichnung 309

- Mundart 704

- Sprache 704

Familie 107

- Homonymenzusatz 107,1

\section{Fernsehsendung}

s. a. Mehrere Fernsehsendungen

- Ansetzung 733

- Behandelter Gegenstand 733,5

- Beteiligte Person 733,3

- Deutscher Titel 733,2

- Form 737,4

- Gattung 737,4

- Hierarchische Verweisung 733,5

- Homonymenzusatz 733,1

- Literarische Vorlage 733,4

- Motiv 705,8,a

- Synonymie-Verweisung 733,1.3.4

- Zusätzliche Erschließung 5,5; 737,5

Fest $415 a, 1, b$

Festschrift

- Aufsatz 3,2,a

- Personenschlagwort 101a,6

Fiktive geographische Einheit 201,1,e

Film

s. a. Mehrere Filme

- Ansetzung 733

- Behandelter Gegenstand 733,5

- Beteiligte Person 733,3

- Deutscher Titel 733,2

- Form 737,4

- Gattung 737,4

- Hierarchische Verweisung 733,5

- Homonymenzusatz 733,1

- Inhalt 737

- Literarische Vorlage 733,4

- Lokale Anwendung 5,3; 737,5

- - Gattung 737,4

- Motiv 705,8,a

- ÖB-Alternativform 733,2

- RAK-ÖB-A

- - Deutscher Titel 733,2

- Regisseur

- - Synonymie-Verweisung 733,3

- Synonymie-Verweisung 733,1.3.4

- Zusätzliche Erschließung 5,5; 737,5

Firma 306a,3.4; 606,1,b

Förderungsprogramm

- Individualname 306a,10

Form

- Fernsehsendung 737,4

- Film 737,4

\section{Formel}

s. a. Reaktionsformel

- Ansetzung 314 
- Griechisches Alphabet 314,2,c

- Nichtlateinisches Schriftzeichen 314

- Sonderzeichen 314

- Zahl 17,2,b; 314

Formschlagwort 501-506

- Allgemeines Sprachwörterbuch 702,2,a.c

- Ältere Literatur 5,7

- Ansetzung 502; Anl. 6

- Art der Darstellung 5,1

- Audiovisuelle Materialien 4,7; 504,1; 737,2; Anl. 6

- Datensatz 503a

- Definition 501

- Elektronische Publikation 4,7

- Erscheinungsweise 5,1

- Ethnographisches Schlagwort 219,1

- Fachliches Sprachwörterbuch 702,3

- Geographisches Schlagwort 219,1

- Geschichte 503,1

- Jahresangabe 17,2,a; 403,7,b; 503,1

- Jugendliteratur 4,6; 765,9; 766

- Kinderliteratur 4,6; 765,9; 766

- Kompositum 305,2,g

- Lokale Anwendung

- - Listenfunktion 506,2

- Materialkategorie 504,1; Anl. 6

- Niveau der Darstellung 5,1

- Permutation 15,10,a; 506

- Personenschlagwort 116,2,e; 117,5; 503,1,b

- Physische Form 5,1

- Reihenfolge 15,8.10,a

- Schlagwortkette 504; 505

- Schöne Literatur 4,6; 762,9

- Schulbuch 770

- Verwendung Anl. 6

- Zeitschlagwort 503

- Zusätzliche Erschließung 5

Forschungsprogramm

- Individualname 306a,10

Fortlaufendes Sammelwerk

- Assoziative Verweisung 708,8,c

- Hierarchische Verweisung 708,10

- Titeländerung 708,8

\section{Frankreich}

- Ort

- - Zusatz 202b,3

Fremdsprachige Bezeichnung

- Gebräuchliche Bezeichnung 308

Fremdsprachige Rechtsnorm 715,5

\section{Frühe Neuzeit}

- Einheitssachtitel 712

- - Deutscher Titel 712,4

Frühgeschichte

s. Vor- und Frühgeschichte

Fürstenname 108,7.8,a

\section{Gattung}

s. a. Kunstgattung

s. a. Literarische Gattung

- Fernsehsendung 737,4

- Film 737,4

- Musikalisches Werk 741

- Zusätzliche Erschließung 5

Gattungsbegriff

- Ältere Literatur

- - Erschließung Anl. 10

- Lokale Anwendung 5,3-5

- VD 17 Anl. 10

Gebiet

- Geographisches Schlagwort 204a

Gebietskörperschaft

- Behandlung 613,2

- Definition 613,1

- Homonymenzusatz 203,3,c.4

- Namensänderung 207,4

- Nicht zentrales Organ 615

- - Ansetzung 615,2

- - Definition 615,1

- Organ

- Abteilung 614,2.3

- Ansetzung 614,2-4

- - Definition 614,1

- - Zwischenstufen 614,4

- Statusänderung 203,3,c; 207,3

- Verschiedene Ausdehnung 203,3,c

Gebräuchliche Bezeichnung

- Sachschlagwort 304

- Schlagwortform 8,5; 9,3; 307,2,a

\section{Gegensatzpaar}

- Sachschlagwort 315,2,a

\section{Gegenstand}

- Anzahl 13,4

- Definition 2,4

- Formaspekt 13,4,d

- Schlagwortkette 7,1; 13,1.4,a.6; 14,1

- Verschiedener Aspekt 13,4,c

- Verwandter Begriff 12,5,d

Geistesgeschichte 402,1; 406,2.3

Geistlicher Würdenträger 108,8; Anl. 1 
Gemeinsame Körperschaftsdatei (GKD)

- Geographisches Schlagwort 202,2

- Körperschaftsname 602

Gen 306a,8

\section{Geographische Einheit}

s. a. Fiktive geographische Einheit

s. a. Kleinräumiges Geographikum

- Namensänderung 207

\section{Geographische Gattungsbezeichnung 201,2}

Geographisches Schlagwort 201-211

s. a. Historisches geographisches Schlagwort

s. a. Mehrgliedriges geographisches Schlagwort

s. a. Unspezifisches geographisches Schlagwort

- Adjektiv 202a,1.2; 202b,2

- Ansetzung 202-211

- Arabisch 202a,1

- Artikel 202a,1.2; 202b,2

- Bad 202a,4

- Bauwerk 209,4-6

- Bindestrich 202b,5

- Codierung 213a

- Datensatz 213a

- Definition 201

- Epochenbezeichnung 219,3; 410,1

- Ersatz 202,5

- Ethnographisches Schlagwort 212a,2

- Formschlagwort 219,1

- Gebiet 204a

- Gemeinsame Körperschaftsdatei (GKD) 202,2

- Geomorphologische Bezeichnung 204

- Hebräisch 202a,1

- Homonymenzusatz 202b,5; 203; 209,1,a

- Indikator 11,2

- Jugendliteratur 765,2

- Kinderliteratur 765,2

- Kompositum 204a

- - Küste 204,2

- - Tal 204,2

- Körperschaftsname 201a,3

- Ländercode 18,2

- Literatur 703,2

- Mehrere Homonymenzusätze 203,2

- Nachschlagewerk 202,1

- Nichtlateinisches Alphabet 202,3

- Ortsgebundenes Kunstwerk 209,5; 730,1

- Permutation 15,10,d; 220

- Personenname 202,3; 202a,1

- Personenschlagwort 116,2,; 117,3

- Pleonasmus 13,3

- Präfix 202a,1.2
- Reihenfolge 15,4.5.10,d

- Sachschlagwort 201a,3; 219,1

- - Permutation 220,4,b

- Sankt 202a,3

- Schlagwortkette 217-220

- Schöne Literatur 762,2

- Schulbuch 769

- Sprache 701,1,e; 704,a

- Synonymie-Verweisung 202,2-4; 202b,2-5

- Teileinheit 205

- Überschneidungsgebiet 205,3

- Untersuchungsbereich 201a,4

- Unterteilung 205

- Vergleich 218,1;219,2

- Verwandter Begriff 202,6

- Verwandtschaftsbezeichnung 202a,1

- Verwendung 201a

- Zeitschlagwort 219,1

Geologie

- Epochenbezeichnung 408a,4

Geologische Bezeichnung 201,1,c; 209a

Geomorphologische Bezeichnung

- Adjektiv-Substantiv-Verbindung 204

- Geographisches Schlagwort 204

- Homonymenzusatz 204,1

- Kompositum 204

Gesamtdarstellung

s. a. Aktuelle Darstellung

s. a. Historische Gesamtdarstellung

Gesamtwerk 3,3

Gesangbuch 4,4

Geschichte

- Formschlagwort 503,1

- Gesamtdarstellung 401a,2

- Historische Gesamtdarstellung 401a,2

- Indikator 11,2

- Jahresangabe 403

- Kompositum 402,1.3; 405

- - Homonymenzusatz 405,2

- Sachschlagwort 405,1.3

Geschwister 107,3

Gesetz

s. Rechtsnorm

Gesteinsname 303,2,c

Gewerbebetrieb 606,1,b

Gliedstaat 201,1,a

- Namensänderung 207,3,4 
Grab, Grabmal 725,5

Grenze 201,1,d; 210

Griechisches Alphabet

- Formel 314,2,c

- Personenname 109

Groß- und Kleinschreibung

- Sachschlagwort 302,2

\section{Großbritannien}

- Ort

- - Zusatz 202b,3

Grube 209a,6

\section{Grundbegriffe 2}

Grundkette

- Definition 13,2

- Reihenfolge 15

- Sachschlagwort 321

H $<$ Symbol $>$

s. Verwendungshinweis

Hafen 730,1,b

Handschrift 704,b; 718-720

s. a. Schriftdenkmal

Handschriftenfonds 718,3

Hebräisch

- Geographisches Schlagwort 202a,1

- Personenname 110,2

Heiliger 108,8

Herkunftsort

- Nicht ortsgebundenes Kunstwerk 727,4

Herrscher 108,7

- Homonymenzusatz 106,2,b

- Verwendung 101a,4

- Zählung 17,3,a; 108,7

Herrscherfamilie 107,2

\section{Hierarchische Verweisung}

s. a. Mehrgliedriger Oberbegriff

s. a. Oberbegriff

- Anonymes Werk 712,6

- Bauwerk 725,3-5

- Brauchtum 306a,7

- Definition 12,3,a

- Ethnographisches Schlagwort 212b,2,a

- Fernsehsendung 733,5

- Film 733,5

- Fortlaufendes Sammelwerk 708,10

- Historisches Einzelereignis 415a,1,a

- Hörfunksendung 733,5
- Individualname 306a,6.7

- Körperschaftsname 602,9

- Kunstgattung 306a,7

- Kunstwerk 725,3-5

- Literaturgattung 306a,7

- Mehrgliedriger Oberbegriff 12,4

- Mundart 701,2,c

- Quasisynonym 315,2

- Rechtsnorm 715,4

- Sprache 701,1,f; 701,3,c

- Stilrichtung 306a,7

\section{Himmelskörper 201,3}

Himmelsrichtung 205,1

Hinweissatz 7,5; 12,5,c

- Schriftdenkmal 722,1.2

- Verwandter Begriff

- - Verwendung 317,2,a

Historische Gesamtdarstellung

- Geschichte 401a,2

Historische Rechtsnorm 715,9.10

Historisches Einzelereignis

- Allgemeinbegriff 415a,2

- Ansetzung 415a

- Definition 415

- Ethnographisches Schlagwort 415a,2

- Geographisches Schlagwort 415a,2

- Hierarchische Verweisung 415a,1,a

- Homonymenzusatz 415a,1,a

- Indikator 11,2; 415

- Individualname 415a,1,a

- Jahresangabe 17,2,ab; 401a,3,c

- Körperschaftsname 601,2; 607,1

- Permutation 416

- Personenschlagwort 101a,2; 116,2,b.c; 415a,2

- Plural 303,2,e; 415a,3

- Sachschlagwort 415a,2

- Schlagwortkette 416

- Synonymie-Verweisung 415a,1,a

Historisches geographisches Schlagwort 201,1,a; 206-207

- Homonymenzusatz 206,2

- Nachschlagewerk 206,1

- Namensänderung 207

Hochschule 605,4

Hochstift 618,1

Hörfunksendung

- Ansetzung 733

- Behandelter Gegenstand 733,5

- Form 737,4 
- Gattung 737,4

- Hierarchische Verweisung 733,5

- Homonymenzusatz 733,1

- Motiv 705,8,a

\section{Homonym}

s. unter Homonymenzusatz

\section{Homonymenzusatz}

- Abkürzung 306,8

- Altertum 206,2

- Anonymes Werk

- - Mittelalter 712,3,b

- Ansetzung 10

- Beiname 106,2,a.c; 108,5

- Biblisches Buch 713

- Chemische Bezeichnung 314,2,b

- Definition 10,1

- Diözese Anl. 1

- Ethnographisches Schlagwort 212b,3

- Familie 107,1

- Fernsehsendung 733,1

- Film 733,1

- Gebietskörperschaft 203,3,c.4

- Geographisches Schlagwort 202b,5; 203

- Geomorphologische Bezeichnung 204,1

- Geschichte

- - Kompositum 405,2

- Herrscher 106,2,b

- Historisches Einzelereignis 415a,1,a

- Historisches geographisches Schlagwort 206,2

- Hörfunksendung 733,1

- Individualname 306,4

- Jahresangabe 17,2,ab; 710; 716; 717

- Körperschaftsname 612

- Kreis 203,3,c

- Mehrere Homonymenzusätze 10,4; 203,2

- Motiv 705

- - Mehrgliedriges Schlagwort 705,2

- Ort 203; 209,1,a

- - Australien 203,3,a

- - Indien 203,3,a

- - Japan 203,3,a

- - Kanada 203,3,a

- - USA 203,3,a; Anl. 4

- Personenschlagwort 106; 108,4-9

- Polysem 306,1.2

- Rechtsnorm 305,2; 306

- Sachtitelwerk 710

- Stadt 203,3,b

- Synonymie-Verweisung 12,2,d

- Unspezifisches geographisches Schlagwort 203,5

- Urheberwerk 710,1

- Veranstaltung 607,3.4
- Verfasserwerk 710,1

- Verfassung 717

- Vertrag 716

- Verwaltungseinheit 203,4

- Volk 212b,3,a.b

- Volksstamm 212b,3,b

- Volksgruppe 212b,3,c

- Wegfall 10,2

Ideengeschichte 402,1; 406,2

Indexierung (Datenverarbeitung) 20

Indien

- Bundesstaat

- - Homonymenzusatz 203,3,a

Indikator

- Epochenbezeichnung 11,2

- Ethnographisches Schlagwort 11,2

- Formschlagwort 11,2

- Geographisches Schlagwort 11,2

- Geschichte 11,2

- Grundsätzliches 2,8

- Historisches Einzelereignis 11,2; 415

- Körperschaft 11,2

- Körperschaftsname 601,3

- Personenschlagwort 11,2; 101,1

- Prognose 11,2

- Sachschlagwort 11,2

- Sachtitelwerk 11,2

- Schlagwortkategorie 11,2

- Sprache 11,2; 701,1,a

- Urheberwerk 11,2

- Verfasserwerk 11,2

- Verweisung 11,3

- Werk 708,2.11

- Werktitel 11,2

- Zeitschlagwort 11,2

Individualname

- Allgemeinbegriff 13,3; 306a,10

- Ehrenzeichen 306a,2

- Förderungsprogramm 306a,10

- Forschungsprogramm 306a,10

- Geographisches Schlagwort 209,5

- Hierarchische Verweisung 12,3,c; 306a,6.7

- Historisches Einzelereignis 415a,1,a

- Künstlervereinigung 306a,2

- Militärische Körperschaft 616,4

- Pleonasmus 324

- Politische Bewegung 306a,2

- Produktgruppe 306a,4

- Projekt 306a,10

- Sachschlagwort 306a

- Schlagwortform 8

- Schriftdenkmal 
- - Sekundärliteratur 718,a

- Schriftstellergruppe 306a,2

- Sekte 306a,2

- Wegstrecke 210,2

- Zahl 17,2,c; 17,3,b

Inhaltsanalyse 4

- Weltanschauung 4,2

- Zielgruppe 4,3

Inhaltserschließung

- Definition 2,1

Inkunabel $718-720$

Innergebietliche Neuordnung

- Namensänderung 207,4

Inschrift 704,b

Internationale Körperschaft 211,2; $601 \mathrm{ff}$.

- Rechtsnorm 715,11

Jahresangabe

- Epochenbezeichnung 408a

- Formschlagwort 17,2,a; 403,7,b; 503,1

- Geschichte 401a

- Historisches Einzelereignis 17,2,ab; 401a,3,c; 415a,1,a

- Homonymenzusatz 17,2,ab; 415a,1,a; 710; 716; 717

- Musikalisches Werk 741,1,g

- Personenschlagwort 17,2,ab; 106,3,c

- Rechtsnorm 715,10

- Verfassung 17,2,ab; 717

- Vertrag 17,2,ab; 716

- Zahl 17,2,a

- Zeitcode 418,3

- Zeitschlagwort 17,2; 401-403

Japan

- Präfektur

- - Homonymenzusatz 203,3,a

\section{Japanisch}

- Personenname 110,3

Jugendliteratur 763-765

- Anonymes Werk 765,8

- Erschließung 763

- Ethnographisches Schlagwort 765,2

- Formschlagwort 4,6; 765,9; 766

- Geographisches Schlagwort 765,2

- Körperschaftsname 765,5

- Kunstwerk 765,7

- Mehrere Formschlagwörter 766

- Musikalisches Werk 765,7

- Personenschlagwort 765,1

- Sachschlagwort 765,3
- Schlagwortform 764

- Schlagwortkategorie 764

- Sprache 765,6

- Wissenschaftliche Bibliothek 3,2,e

- Zeitschlagwort 765,4

- Zusätzliche Erschließung 3,2,f; 5,3.4

Kalender 4,4

Kanada

- Provinz

- - Homonymenzusatz 203,3,a

Katastrophe 415a,1,b

Kinderliteratur 763-765

- Anonymes Werk 765,8

- Erschließung 763

- Ethnographisches Schlagwort 765,2

- Formschlagwort 4,6; 765,9; 766

- Geographisches Schlagwort 765,2

- Körperschaftsname 765,5

- Kunstwerk 765,7

- Mehrere Formschlagwörter 766

- Musikalisches Werk 765,7

- Personenschlagwort 765,1

- Sachschlagwort 765,3

- Schlagwortform 764

- Schlagwortkategorie 764

- Sprache 765,6

- Wissenschaftliche Bibliothek 3,2,e

- Zeitschlagwort 765,4

- Zusätzliche Erschließung 3,2,f; 5,3.4

Kirche

- Rechtsnorm 715,12

Kirchenbau 730,1,b; 731,6

- Außerhalb eines Ortes 731,6

Kirchengemeinde 618,2

Kirchengeschichte 402,1; 406,3

Kirchenkreis 618,1

Kirchenordnung 715,10

Klassifikatorische Erschließung 1,2; 2,1,b; 6,3

Kleinräumiges Geographikum 209,4-6

Kloster 618,3

Körperschaft

s. a. Gebietskörperschaft

s. a. Nicht ortsgebundene Körperschaft

s. a. Ortsgebundene Körperschaft

s. a. Untergeordnete Körperschaft

- Definition 601

- Indikator 11,2 
- Namensänderung 611

- Sammlung 736,5.6

- Teilung 611,2

- Veranstaltung 607

- Zusammenschluss 611,2

Körperschaftsname 601-622

- Abkürzung 602,4

- - Rechtschreibung 602,4

- Adjektiv

- - Rechtschreibung 602,7

- Ansetzung 602-620

- Chronologische Verweisung 611

- Codierung 620a

- Datensatz 620a

- Gemeinsame Körperschaftsdatei (GKD) 602

- Geographisches Schlagwort 201a,3; 605

- Hierarchische Verweisung 602,9

- Historisches Einzelereignis 601,2; 607,1

- Homonymenzusatz 612

- Indikator 601,3

- Jugendliteratur 765,5

- Juristische Wendung 602,5

- Kinderliteratur 765,5

- Kompositum 305,2,f

- Ländercode 18,2

- Mehrere Sprachen 604

- Nachschlagewerk 603

- Nichtlateinisches Alphabet 602,3

- Offizieller Name

- Mehrere Sprachen 604

- Ort 602,6; 605,3

- Ortsteil 602,6; 605,3.7

- Permutation 622

- Personenschlagwort 116,2,b.c; 602,8

- Präkombiniertes Schlagwort 305,2,f; 620

- Rechtschreibung 602

- Schlagwortkette 622

- Schöne Literatur 762,5

- Schriftdenkmal

- - Sekundärliteratur 719

- Sprachencode 18,3

- Sprachenreihenfolge 603-604

- Synonymie-Verweisung 602,2; 609,2,b.5; 614,2; 615,2

- Veranstaltung 607,7

- Verwendung 601a

\section{Komponist}

- Musikalisches Werk 741,2

- Vokalwerk 743

\section{Kompositum}

- Epochenbezeichnung 409,3

- Geographisches Schlagwort 204a

- Geomorphologische Bezeichnung 204
- Geschichte 402,1.3; 405

- - Homonymenzusatz 405,2

- Motiv 705,3

- Sachschlagwort 307,2,b; 314,2

- - Abkürzung 313,3

- - Pleonasmus 312

- - Rechtschreibung 302,2,b.4

Kongress 504,3; 607,1

Konventionalsachtitel $740 \mathrm{a}$

Kreis

- Homonymenzusatz 203,3,c

Künstlername

- Ansetzung 724

Künstlerschule 408a,5,b; 601,2

Künstlervereinigung 408a,5,b; 601,2

- Individualname 306a,2

Küste

- Kompositum

- - Geographisches Schlagwort 204,2

Kunstgattung

- Hierarchische Verweisung 306a,7

- Personenschlagwort 116,1.2,a

Kunsthandwerkliches Produkt 306a,4

Kunstrichtung 408a,5,a

Kunststil 408a,5,a

Kunstwerk 723-731

s. a. Bauwerk

s. a. Mosaik

s. a. Nicht ortsgebundenes Kunstwerk

s. a. Ortsgebundenes Kunstwerk

- Abbildung

- - Zusätzliche Erschließung 3,2,d; 5,3

- Ansetzung 725

- Aufbewahrungsort 724

- Definition 707,1; 723

- Herkunftsort 724

- Hierarchische Verweisung 725,4

- Jugendliteratur 765,7

- Kinderliteratur 765,7

- Person 725,4

- Personengruppe 725,4

- Schöne Literatur 762,7

- Synonymie-Verweisung 725,3-5

- Unspezifischer Werktitel 725,5

\section{Kunstwort}

- Abkürzung 313,2,b 
Kurztitel

- Rechtsnorm 715,1.3

Kyrillisches Alphabet

- Personenname 109

Ländercode

- Schlagwortnormdatei 18,2

Ländergruppe 201,1,g; 211

- Plural 303,2,e

Lagerstätte 209a,6

Landrecht 715,10

LC <Symbol>

s. Ländercode

Lebensabschnitt $116,2, \mathrm{~d}$

Lebensweisheit 4,4

Lehrmittel

- Zusätzliche Erschließung 5,2

\section{Lexikon}

s. a. Enzyklopädie

s. a. Fachlexikon

s. a. Wörterbuch

\section{Linguistische Untersuchung}

- Buchstabe 305,1,c

- Morphem 305,1,c

- Phonem 305,1,c

- Schlagwortkette 322,4

- Wort 305,1,c

Linguistischer Terminus

s. Sprachwissenschaftlicher Begriff

Listenfunktion

- Definition 2,13

- Lokale Anwendung

- - Deutschland 13,3; 201a,5

- - Formschlagwort 506,2

\section{Listenkatalog 1,5}

Literarische Gattung 703,1,a

- Ethnographisches Schlagwort 703,4

- Mehrsprachige Region 703,3

- Mundart 704

- Personenschlagwort 116,1

- Sprache 704

Literarische Gestalt 101,1; 110a

- Altertum 108,4,a

Literarisches Werk

- Ansetzung 708

- Definition 707,1
- Schriftdenkmal

- - Sekundärliteratur 718

Literatur 703

s. a. Jugendliteratur

s. a. Kinderliteratur

s. a. Minder wichtige Literatur

s. a. Schöne Literatur

- Ethnographisches Schlagwort 703,4

- Geographisches Schlagwort 703,2

- Mehrsprachige Region 703,3

- Verbreitungsgebiet 703,2

Literaturgattung

- Hierarchische Verweisung 306a,7

Lokale Anwendung 1,1; 760

- Ältere Literatur 5,7

- Deutschland 715,2

- - Listenfunktion 13,3; 201a,5

- Film 737,5

- - Gattung 737,4

- Formschlagwort

- - Listenfunktion 506,2

- Gattungsbegriff 5,3-5

- Mundartliteratur 762,6; 765,6

- Musikalisches Werk 5,6; 744,1

- Rechtsnormen 715,8

Manuskript 718-720

Markenname

s. Produktname

Maschinelle Indexierung 1,3; 2,1,a

Materialkategorie

- Formschlagwort 504,1; Anl. 6

Mathematischer Begriff 314

Medienkombination

- Elektronische Publikation 737a,3

Meditative Literatur 4,4

Mehrbändiges Werk 3,3

Mehrere Fernsehsendungen 734

Mehrere Filme 734

Mehrere Sachschlagwörter 322

Mehrgliedriger Oberbegriff 12,4

s. a. Hierarchische Verweisung

Mehrgliedriges geographisches Schlagwort 209,4.5; 209a,3

Mehrgliedriges Schlagwort 8,4

- Ländercode 18,2 
- Personenschlagwort 101a,2

- Synonymie-Verweisung 12,2,c

Mehrsprachige Region

- Literarische Gattung 703,3

- Literatur 703,3

- Sprache 701,1,d

Mehrsprachiges Wörterbuch 702,2,c; 702,3,b.c

Mensch 324,4

Metropolitenname 108,9,b

Militärische Körperschaft 616

- Individualname 616,4

- Synonymie-Verweisung 616,3

Minder wichtige Literatur 3,2,b

\section{Minderheit}

s. a. Ethnische Gruppe

s. a. Nationale Minderheit

Ministerium 614,5

Mittelalter

- Anonymes Werk 712,3

- Bearbeiter 712,3,c

- Einheitssachtitel 712

- - Deutscher Titel 712,4

- Personenname 108,5

- Verwendung 408a,3,b

MO <Symbol>

s. Mehrgliedriger Oberbegriff

Monogrammist 104

Morphem

- Linguistische Untersuchung 305,1,c

Mosaik 728

Motiv 705

- Fernsehsendung 705,8,a

- Film 705,8,a

- Homonymenzusatz 705,1

- - Mehrgliedriges Schlagwort 705,2

- Kompositum 705,3

- Medienbericht 705,8,b

- Personenschlagwort 705,5-7

- Sachschlagwort 705,4

- Schlagwortkette 705,9.10

- Schöne Literatur 705,8

- Zeitschlagwort 705,7,b

MU <Symbol>

s. Unterbegriff zu mehrgliedrigem Oberbegriff
Multimedia

- Elektronische Publikation 737a,5,e

Mundart 701,2

- Geographisch bestimmte Form 701,3,c

- Handschrift 704,b

- Hierarchische Verweisung 701,2,c

- Inschrift 704,b

- Literarische Gattung 704

- Philologie 704,b

- Pleonasmus 701,5,b; 703,1,b

- Rhetorischer Begriff 704,a

- Schrift 704,b

- Sondersprache 704,a

- Sprachstufe 701,3,b

- Sprachwissenschaftlicher Begriff 701,5,a; 704,a

- Stilistischer Begriff 704,a

Mundartliteratur

- Lokale Anwendung 762,6; 765,6

Musikalisches Werk 739-744

s. a. Vokalwerk

- Besetzung 741,1,b.2

- Definition 707,1

- Deutscher Titel 740,2

- Einheitssachtitel 739,2; 740

- Gattung 741

- Jahresangabe 741,1,g

- Jugendliteratur 765,7

- Kinderliteratur 765,7

- Komponist 741,; 743

- Konventionalsachtitel 740a

- Lokale Anwendung 5,6; 744,1

- Opus 741,1,d

- Schöne Literatur 762,7

- Teil 743a

- Text 740,3

- Tonart 741,1,f

- Werkgruppe 741,1,e

- Werkverzeichnis 741,1,c

- Zitiertitel 742

Musikdruck

- Zusätzliche Erschließung 3,2,d.g; 5,3.6; 744

Musiktonträger

- Zusätzliche Erschließung 3,2,d.g; 5,3.6; 744

Musikvideo

- Zusätzliche Erschließung 3,2,d.g; 5,3.6; 744

Mythologische Gestalt 101,1; 110a

- Altertum 108,4,a

Nachdruck 4,5 
Nachschlagewerk

- Anonymes Werk

- - Mittelalter 712,3,a

- Biblische Person 713,1

- Ethnographisches Schlagwort 212b,1

- Geographisches Schlagwort 202,1-4

- Historisches geographisches Schlagwort 206,1

- Körperschaftsname 603

- Personenschlagwort 108,2.4-7; 110,4.5

- Pseudonym 103,2

- Rechtschreibung 16,2

- Schlagwortwahl 9,3

\section{Namensänderung}

- Gebietskörperschaft 207,4

- Geographische Einheit 207

- Gliedstaat 207,3.4

- Historisches geographisches Schlagwort 207

- Innergebietliche Neuordnung 207,4

- Körperschaft 611

- Ort 207

- Staat 207,3.4

Nationale Minderheit 212; 212a,1,b

Nationalpark 209a,3

Natürliche Sprache 9,3

Naturpark 209a,3

Naturräumliche Einheit 201,1,b; 202,5; 209a

Naturwissenschaftlicher Begriff 314

Navigieren 20,9

Neuauflage 4,5

Neuzeit

- Verwendung 408a,3,b

Nicht aussagekräftiger Wortteil 9,4

Nicht aussagekräftiges Schlagwort

- Permutation 325,2,b

- Personenschlagwort Anl. 2

- Sachschlagwort 322,3,c; Anl. 2; Anl. 5

Nicht ortsgebundene Körperschaft 606

- Ansetzung 606,2

- Bauwerk 730,1,d

- Definition 606,1

- Synonymie-Verweisung 606,2

Nicht ortsgebundenes Kunstwerk 727-728

- Anonymer Werktitel 727,3.4; 728,c

- Ansetzung 727-728

- Aufbewahrungsort 727,2-4; 728,a.b

- Definition 723; 727
- Herkunftsort 727,4

- Unspezifischer Werktitel 727,2.4; 728,b

Nicht zentrales Organ

- Körperschaft 615

- Ansetzung 615,2

- - Definition 615,1

\section{Nichtlateinisches Alphabet}

s. a. Griechisches Alphabet

s. a. Kyrillisches Alphabet

- Geographischer Name 202,3

- Körperschaftsname 602,3

- Personenname 110

- Transliteration 16,3

Nichtlateinisches Schriftzeichen

- Formel 314

Niveau der Darstellung

- Formschlagwort 5,1

\section{Notation}

- Schlagwortnormdatei 18,1

Notname 104

Nuntiatur 619,3

OB <Symbol>

s. Oberbegriff

Oberbegriff

s. a. Hierarchische Verweisung

s. a. Mehrgliedriger Oberbegriff

- Hierarchische Verweisung 12,3

- Schlagwortkette 13,5

\section{ÖB-Alternativform}

- Deutscher Titel 712,4

- Film 733,2

- Personenschlagwort 110,6

Online-Katalog

- Schlagwortrecherche 20

Online-Publikation 737a

Opus

- Musikalisches Werk 741,1,d

Ordensgemeinschaft $618,3.4$

Ordensmitglied 108,8

Ordnung der Eintragungen 801

- Chemische Bezeichnung 314,2,b

\section{Organ}

s. a. Nicht zentrales Organ

- Gebietskörperschaft 614

- - Abteilung 614,2.3

- - Ansetzung 614,2-5 
- - Definition 614,1

- - Zwischenstufen 614,4

- Religionsgemeinschaft 619

Ort

- Australien

- - Homonymenzusatz 203,3,a

- Doppelort 209,1,c

- Frankreich

- - Zusatz 202b,3

- Großbritannien

- - Zusatz 202b,3

- Homonymenzusatz 203; 209,1

- Indien

- - Homonymenzusatz 203,3,a

- Japan

- - Homonymenzusatz 203,3,a

- Kanada

- - Homonymenzusatz 203,3,a

- Körperschaftsname 602,6; 605,3

- Namensänderung 207

- Ortsgebundene Körperschaft 602,6

- Russland

- - Zusatz 202b,3

- USA

- - Homonymenzusatz 203,3,a; Anl. 4

- Zusatz 202b

Ortsgebundene Körperschaft 605

- Aktueller Ortsname 605,6

- Ansetzung 605,2

- Assoziative Verweisung 605,5,a

- Bauwerk 730,1,c

- Definition 605,1

- Hauptsitz 605,5,a

- Nebensitz 605,5,a

- Ort 602,6

- Ortsteil 602,6

- Synonymie-Verweisung 605,2.4

- Unterordnung 605,5,b

Ortsgebundenes Kunstwerk 730

- Ansetzung 730

- Außerhalb eines Ortes 730,2

- Definition 730,1

- Freistehendes Kunstwerk 730,1

- Geographisches Schlagwort 209,5

- Unspezifischer Werktitel

- - Sachschlagwort 730,1,b

\section{Ortsteil}

- Bauwerk 209,4

- Deutschland 209,2

- Körperschaftsname 602,6; 605,3.7

- Name 209
- Ortsgebundene Körperschaft 602,6

- Synonymie-Verweisung 209

Papstname 108,9,a

Paragraph 715,8

Parteitag 607,7

Partitive Relation

- Hierarchische Verweisung 12,3,b

Patriarchenname 108,9,b

Perikope 713,3

Periodische Veranstaltung 607,4-8

Permutation 15

- Definition 2,13

- Epochenbezeichnung 410,3

- Ethnographisches Schlagwort 15,10,d; 220

- Formschlagwort 15,10,a; 506

- Geographisches Schlagwort 15,10,d; 220

- Historisches Einzelereignis 416

- Körperschaftsname 622

- Nicht aussagekräftiges Schlagwort 325,2,b

- Personenschlagwort 15,10,d; 117

- Sachschlagwort 15,10,c; 325; Anl. 5

- Sprache 15,10,d

- Zeitschlagwort 15,10,b; 406,6; Anl. 5

Persönlicher Name 108,5.7-9

Persönlichkeitsschutz 103,3

Person

- Kunstwerk 725,4

- Sammlung 736

- - Werke einer Person 736,4

Personengruppe 101,1.2

- Kunstwerk 725,4

- Plural 303,2,e

- Sachschlagwort 317,2,a

- - Weibliche Form 303a

Personenname

- Altertum 108,4

- Arabisch 110,1

- Assoziative Verweisung 12,5,e

- Chinesisch 110,3

- Geographisches Schlagwort 202,3; 202a,1

- Griechisches Alphabet 109

- Hebräisch 110,2

- Japanisch 110,3

- Körperschaftsname 602,8 
- Kyrillisches Alphabet 109

- Mittelalter 108,5

- Nichtlateinisches Alphabet 110

- Sachschlagwort 302,4; Anl. 2

- Zeitraum 101a,5

\section{Personennamendatei 7,4}

Personenschlagwort 101-117

s. a. Adelsfamilie

s. a. Biblische Person

s. a. Familie

s. a. Fürstenname

s. a. Geistlicher Würdenträger

s. a. Geschwister

s. a. Heiliger

s. a. Herrscher

s. a. Künstlername

s. a. Literarische Gestalt

s. a. Metropolitenname

s. a. Monogrammist

s. a. Mythologische Gestalt

s. a. Notname

s. a. Papstname

s. a. Patriarchenname

s. a. Pseudonym

s. a. Seliger

- Ansetzung 102-111

- Codierung 111a

- Datensatz 111a

- Definition 101

- Epochenbezeichnung 410,2

- Ethnographisches Schlagwort 116,2,b; 117,3

- Festschrift 101a,6

- Formschlagwort 116,2,e; 117,5

- Geographisches Schlagwort 116,2,b; 117,3

- Historisches Einzelereignis 101a,2; 116,2,b.c; 415a,2

- Homonymenzusatz 106; 108,4-9

- Indikator 11,2; 101,1

- Jahresangabe 17,2,ab; 106,3,c

- Jugendliteratur 765,1

- Kinderliteratur 765,1

- Kompositum

- - Rechtschreibung 302,4

- Körperschaftsname 116,2,b.c; 602,8

- Kunstgattung 116,1.2,a

- Ländercode 18,2

- Literarische Gattung 116,1

- Mehrere Personenschlagwörter 115a

- Mehrgliedriges Schlagwort 101a,2

- Motiv 705,5-7

- Nachschlagewerk 108,2.4-7; 110,4.5

- Nicht aussagekräftiges Schlagwort Anl. 2

- ÖB-Alternativform 110,6
- Permutation 15,10,d; 117

- Pleonasmus 101a,1

- Präkombiniertes Schlagwort 111

- RAK-ÖB-A 110,6

- Rechtschreibung 102; 109-110

- Reihenfolge 15,3.5.10,d

- Sachschlagwort 116,2,c

- Schlagwortkette 117

- Schöne Literatur 762,1

- Schriftdenkmal 718

- Sprache 116,2,b

- Sprachencode 18,3

- Synonymie-Verweisung 101a,3; 102,2; 106,4; 108,3

- Tätigkeit 106,3

- Vergleich 115a,1; 116,3

- Verwendung 101a

- Werktitel 116,2,b

- Zeitschlagwort 116,2,d; 117,5

Pfarrei 618,1.2

Pflanzengeographische Region 201,1,c; 209a

Pflanzenname 303,2,b; 306a,9

- Quasisynonym 315,2,b

\section{Philologie}

- Mundart 704,b

- Sprache 704,b

\section{Phonem}

- Linguistische Untersuchung 305,1,c

\section{Physische Form}

- Formschlagwort 5,1

Pleonasmus 9,4

- Christentum 324,4

- Deutschland 715,2

- Deutschland <Bundesrepublik> 715,2

- Mensch 324,4

- Mundart 701,5,b; 703,1,b

- Personenschlagwort 101a,1

- Rechtsnorm 715,2

- Sachschlagwort

- - Kompositum 312; 324,1

- Schlagwortkette 324; 703,1,b.2,b

- Staat 324,4

Plural

- Ethnographisches Schlagwort 212b,1

- Historisches Einzelereignis 303,2,e; 415a,3

- Ländergruppe 201,1,g; 303,2,e

- Personengruppe 303,2,e

- Sachschlagwort 303,2

- Sprachgruppe 303,2,e; 701,1,c

- Staatengruppe 201,1,g; 303,2,e 
- Synonymie-Verweisung 303,5

- Textgruppe 303,2,e

- Wissenschaftsfach 303,2,f

Pluraliatantum 303,2,a s. a. Quasipluraliatantum

\section{Politiker}

- Verwendung 101a,4

Politische Bewegung

- Individualname 306a,2

Polydimensionalität

- Hierarchische Verweisung 12,3,d

Polyhierarchie

- Hierarchische Verweisung 12,3,d

Polysem 10,1; 306,1.2

Präfix

- Geographisches Schlagwort 202a,1.2

Präkombiniertes Schlagwort

s. a. Adjektiv-Substantiv-Verbindung s. a. Kompositum

- Ethnographisches Schlagwort 213

- Geographisches Schlagwort 213

- Körperschaftsname 305,2,f; 620

- Personenschlagwort 111

- Sachschlagwort 302,2,b; 305,2

- Schlagwortform 8,5

- Synonymie-Verweisung 12,2,c; 304,5

Präposition

- Geographisches Schlagwort 202a,1.2

Preis <Auszeichnung> 306a,2.5

Produktgruppe

- Individualname 306a,4

Produktname 306a,2-4

Prognose

- Indikator 11,2

- Sachschlagwort 405,1

- Zeitschlagwort 401a,4

Programm

- Elektronische Publikation 737a,4

Projekt

- Individualname 306a,10

Propstei 618,1

Prüfungsvorbereitung 772

Pseudonym 103

- Nachschlagewerk 103,2

- Synonymie-Verweisung 103,2
Psychologischer Test

- Abkürzung 714

- Ansetzung 714

- Synonymie-Verweisung 714

Q < Symbol>

s. Quellenangabe

Quasipluraliatantum 303,2,a

Quasisynonym

- Hierarchische Verweisung 315,2

- Pflanzenname 315,2,b

- Sachschlagwort 315

- Strukturisomer

- - Chemische Verbindung 315,4

- Synonymie-Verweisung 12,2,b

- Tiername 315,2,b

- Unterbegriff 315,2

- Verschiedene Begriffskategorien 315,2,c

- Verwandter Begriff 315,3

Quellenangabe

- Bemerkung 19,1

R <Symbol>

s. Redaktionelle Bemerkung

RAK 1,4

- Personenschlagwort 102

RAK-ÖB-A

- Deutscher Titel 712,4

- Film

- - Deutscher Titel 733,2

- Personenschlagwort 110,6

Rasse 212

Rathaus 730,1,b

Reaktionsformel 314,2,i

Rechtschreibung

- Allgemeines 16

- Einheitssachtitel 709,1

- Ethnographisches Schlagwort 212b,1

- Körperschaftsname 602

- - Abkürzung 602,4

- - Adjektiv 602,7

- Nachschlagewerk 16,2

- Personenschlagwort 102; 109-110

- - Kompositum 302,4

- Sachschlagwort 302

- - Abkürzung 302,3

- - Kompositum 302,1.4

Rechtsmaterie 715-717

Rechtsnorm

s. a. Deutschsprachige Rechtsnorm 
s. a. Fremdsprachige Rechtsnorm

s. a. Historische Rechtsnorm

- Abkürzung 715,3

- Artikel 715,8

- Assoziative Verweisung 715,9

- Chronologische Verweisung 715,9

- Definition 715,1

- Deutscher Titel 715,5

- Hierarchische Verweisung 715,4

- Homonymenzusatz 715,10

- Internationale Körperschaft 715,11

- Jahresangabe 715,10

- Kirche 715,12

- Kurztitel 715,1.3

- Paragraph 715,8

- Pleonasmus 715,2

- Sachschlagwort 715,4-8

- Sammlung 715,6.7

- Synonymie-Verweisung 715,1.3.5.8

- Titeländerung 715,9

- Verweisung 715,8.9

- Zitiertitel 715,1.3

\section{Rechtssprache}

- Regional unterschiedlicher Sprachgebrauch 311,2

- Schlagwortwahl 307,3

\section{Redaktionelle Bemerkung}

- Bemerkung 19,4

\section{Region}

s. a. Mehrsprachige Region

- Geographisches Schlagwort 204a

Regional unterschiedlicher Sprachgebrauch 311

- Rechtssprache 311,2

- Verwaltungssprache 311,2

\section{Regisseur}

- Film 733,3

\section{Reihenfolge}

- Epochenbezeichnung 410,1

- Ethnographisches Schlagwort 15,4.5.10,d

- Formschlagwort 15,8.10,a

- Geographisches Schlagwort 15,4.5.10,d

- Personenschlagwort 15,3.5.10,d

- Sachschlagwort 15,5.6.10,c

- Schlagwortkategorie 11,1

- Sprache 15,10,d

- Zeitschlagwort 15,7.10,b

\section{Relation}

- Definition 2,10
Religionsgemeinschaft 617-619

- Ansetzung 617,2

- Definition 617,1

- Lokale Einheit 618,2.3

- Organ 619

- Personelle Einheit 618,4

- Regionale Einheit 618,1

Reprint 4,5

- Jahresangabe 401a,2,c

\section{Retrieval}

s. Schlagwortrecherche

\section{Rhetorischer Begriff}

- Mundart 704,a

- Sprache 704,a

Römische Zahl 314

- Ansetzung 314

Russland

- Ort

- - Zusatz 202b,3

Sacherschließung

- Definition 2,1

- VD 17 Anl. 10

Sachschlagwort 301-325

s. a. Mehrere Sachschlagwörter

- Abkürzung 313

- - Rechtschreibung 302,3

- Adjektiv-Substantiv-Verbindung 305,2

- Aktuelle Bezeichnung 310

- Allgemeinbegriff 304

- Analoge Ansetzung 304,2,d

- Ansetzung 302-318

- Bedeutungswandel 310,2.3

- Begriffszerlegung 304,3

- Bindestrich 302,4

- Buchstabe 305,1,c; 314

- Codierung 318

- Datensatz 318

- Definition 301

- Ethnographisches Schlagwort 212a,4; 219,1

- - Permutation 220,4,b

- Formschlagwort 305,2,g

- Gebräuchliche Bezeichnung 304

- Geographisches Schlagwort 201a,3; 219,1

- - Permutation 220,4,b

- Groß- und Kleinschreibung 302,2

- Hierarchische Verweisung 12,3,c

- Historisches Einzelereignis 415a,2

- Homonym 306

- Homonymenzusatz 305,2; 306

- Indikator 11,2

- Individualname 302,1; 305,2,e; 306,4.8; 306a 
- Jugendliteratur 765,3

- Kinderliteratur 765,3

- Kompositum 305,2; 307,2,b; 314,2

- - Abkürzung 313,3

- - Bindestrich 302,4

- - Pleonasmus 312

- - Rechtschreibung 302,2,b.4

- Ländercode 18,2

- Nicht aussagekräftiges Schlagwort 322,3,c; Anl. 2; Anl. 5

- Permutation 15,10,c; 325; Anl. 5

- Personengruppe 317,2,a

- Personenname 302,4; Anl. 2

- Personenschlagwort 116,2,c

- Plural 303

- Präkombinierte Bezeichnung

- - Pleonasmus 324,1

- Präkombiniertes Schlagwort 302,2,b; 305,2

- - Personenname 305,2,d

- Quasisynonym 315

- Rechtschreibung 302

- Rechtsnorm 715,4-8

- Reihenfolge 15,5.6.10,c

- Sachschlagwort 322

- - Mehrere Sachschlagwörter 322

- Schlagwortkette 321-325

- Schlagwortwahl 304; 307

- Schöne Literatur 762,3

- Schriftdenkmal

- - Sekundärliteratur 718; 719

- Singular 303

- Sonderzeichen 314

- Sprache 701,1,e.5

- Sprachencode 18,3

- Synonymie-Verweisung 307

- Unspezifischer Werktitel

- - Nicht ortsgebundenes Kunstwerk 727,4

- - Ortsgebundenes Kunstwerk 730,1,b

- Veraltete Bezeichnung 310

- Verschiedene Begriffskategorien 317

- Verwandter Begriff 316-317

- Weibliche Form 303a

- Wissenschaftsfach 317,2,b

- Wortart 305

- Wortfolge 305,2

- Zählung 10,5; 17,2,d; 305,1,b; 306a,3

\section{Sachtitel}

s. a. Anonymer Werktitel

s. a. Deutscher Titel

s. a. Einheitssachtitel

s. a. Konventionalsachtitel

s. a. Kurztitel

s. a. Unspezifischer Werktitel

s. a. Zitiertitel
- Synonymie-Verweisung 708,9; 712,5

- Verfasserwerk 708,9

Sachtitelwerk

- Ansetzung 708,2.7

- Definition 707,4

- Homonymenzusatz 710

- Indikator 11,2

Sammelwerk

- Aufsatz 3,2,a

Sammlung

- Ansetzung 736,2-8

- Ausstellung 736,7

- Definition 736,1

- Körperschaft 736,1; 736,5.6

- Mehrere Besitzer 736,3

- Person 736

- - Werke einer Person 736,4

- Synonymie-Verweisung 736,5

Sankt

- Geographisches Schlagwort 202a,3

SC $<$ Symbol>

s. Sprachencode

Schlagwort

- Begriff 7,1-3

- Definition 2,7

- Reihenfolge 15

- Schlagwortkette 7

Schlagwortansetzung 9

- Grundsätzliches 2,9

Schlagwortfolge

s. Schlagwortkette

Schlagwortform 8

- Allgemeinbegriff 8

- Gebräuchliche Bezeichnung 8,5; 9,3; 307,2,a

- Individualname 8

- Präkombiniertes Schlagwort 8,5

Schlagwortgebung

- Grundprinzipien 6

Schlagwortkatalog

- Definition 2,12

- Fakultativ zu erschließende Dokumente 3

Schlagwortkatalogisierung

- Definition 2,2

- Grundprinzipien 6

Schlagwortkategorie 11

- Definition 2,8

- Indikator 11,2

- Reihenfolge 11,1; 15 
Schlagwortkette 13-15

s. a. Grundkette

- Allgemeinbegriff 324,3

- Anzahl 13,1.4,a

- Begriff 7,3

- Beziehungen 14

- Definition 2,2; 13,1

- Epochenbezeichnung 410

- Ethnographisches Schlagwort 217-220

- Formschlagwort 504; 505

- Gegenstand 7,1; 13,1.4,a.6; 14,1

- Geographisches Schlagwort 217-220

- Grundsätzliches 2,2,b

- Historisches Einzelereignis 416

- Körperschaftsname 622

- Mehrdeutigkeit 14

- Motiv 705,9.10

- Personenschlagwort 115-117

- Pleonasmus 7,3; 324

- Sachschlagwort 321-325

- Schlagwort 7

- Sprache 13,3; 706

- Untersuchungsmethode 322,5

- Vergleich 13,4,b; 15,9.10,d.e

- Verwandter Begriff 316,4

- Weibliche Form 316,4

- Zeitschlagwort 406

Schlagwortnormdatei 1,$1 ; 2,2 ; 7,4.5$ s. a. Datensatz

- Codierung 18

- Ländercode 18,2

- Notation 18,1

- Schlagwortrecherche 20

- Sprachencode 18,3

- Verwandter Begriff 12,5,c

- Verweisung 20,9

- Zeitcode 18,4

\section{Schlagwortrecherche}

- Online-Katalog 20

- Schlagwortnormdatei 20

\section{Schlagwortsatz}

s. Datensatz

\section{Schlagwortsprache 2,2; 9,3}

\section{Schlagwortverknüpfung}

s. Schlagwortkette

\section{Schlagwortwahl 9}

- Nachschlagewerk 9,3

- Rechtssprache 307,3

- Sachschlagwort 304; 305,2,a; 307

- Verwaltungssprache 307,3

Schloss 730,1,b
Schöne Literatur 760-762

- Anonymes Werk 762,8

- Erschließung 760,1

- Ethnographisches Schlagwort 762,2

- Formschlagwort 4,6; 762,9

- Geographisches Schlagwort 762,2

- Körperschaftsname 762,5

- Kunstwerk 762,7

- Musikalisches Werk 762,7

- Personenschlagwort 762,1

- Sachschlagwort 762,3

- Schlagwortform 761

- Schlagwortkategorie 761

- Sprache 762,6

- Wissenschaftliche Bibliothek 3,2,e

- Zeitschlagwort 762,4

- Zusätzliche Erschließung 3,2,d.f; 5,3.4

\section{Schreibvariante}

- Synonymie-Verweisung 12,2,b

\section{Schrift}

- Mundart 704,b

- Sprache 704,b

Schriftdenkmal 718-720

- Hinweissatz 719

- Primärliteratur 720

- Sekundärliteratur

- - Ansetzung 718

- - Aufbewahrungsort 718

- - Individualname 718,1

- - Körperschaftsname 719

- - Literarisches Werk 718,2,a

- - Personenschlagwort 718; 719

- - Sachschlagwort 718,2,b; 719

- - Signatur 718; 719

- - Verweisung 718; 719

\section{Schriftenreihe}

- Gesamtaufnahme 3,4

- Stücktitel 3,4

\section{Schriftstellergruppe}

- Individualname 306a,2

Schulbuch 767-773

- Berufsausbildung 771

- Erschließung 767

- Formalschlagwort 770

- Geographisches Schlagwort 769

- Schulart 768,2

- Schulstufe 768,2

- Unterrichtsfach 768,1

- Zusätzliche Erschließung 5,2

\section{Sekte}

- Individualname 306a,2 
Seliger 108,8

\section{Signatur}

- Schriftdenkmal

- - Sekundärliteratur 718; 719

Singular

- Sachschlagwort 303

Sondersprache 701,4 ,a

- Mundart 704,a

- Sprache 704,a

Sonderzeichen 17

- Formel 314

- Sachschlagwort 314

Sozialgeschichte 402,$1 ; 406,2.3$

Sportlicher Wettbewerb 607,1

\section{Sprache}

s. a. Fachsprache

s. a. Sondersprache

s. a. Umgangssprache

- Ansetzung 701

- Fachsprache 704

- Geographisches Schlagwort 701,1,c.e; 704,a

- Handschrift 704,b

- Hierarchische Verweisung 701,1,f.3,c

- Indikator 11,2; 701,1,a

- Inschrift 704,b

- Jugendliteratur 765,6

- Kinderliteratur 765,6

- Ländercode 18,2

- Literarische Gattung 704

- Mehrsprachige Region 701,1,d

- Permutation 15,10,d

- Personenschlagwort 116,2,b

- Philologie 704,b

- Pleonasmus 13,3; 701,5,b; 703,1,b.2,b

- Reihenfolge 15,10,d

- Rhetorischer Begriff 704,a

- Sachschlagwort 701,1,e.5

- Schlagwortkette 13,3; 706

- Schöne Literatur 762,6

- Schrift 704,b

- Sondersprache 704,a

- Sprachencode 18,3

- Sprachwissenschaftlicher Begriff 701,5,a; 704,a

- Stilistischer Begriff 704,a

- Synonymie-Verweisung 703,2,c

- Verbreitungsgebiet 701,1,e

Sprachencode

- Schlagwortnormdatei 18,3
Sprachenreihenfolge

- Körperschaftsname 603-604

Sprachgebiet 201,1,f

Sprachgebrauch

- Synonymie-Verweisung 12,2,b

Sprachgruppe

- Plural 701,1,c

Sprachstufe 701,3,a

- Mundart 701,3,b

Sprachunterricht

- Text 773

Sprachwissenschaftlicher Begriff

- Mundart 701,5,a; 704,a

- Sprache 701,5,a; 704,a

Staat

- Namensänderung 207,3.4

- Pleonasmus 324,4

Staatengruppe 201,1,g; 211

- Plural 201,1,g

Stadt

- Homonymenzusatz 203,3,b

Stadtrecht 715,10

Stadtverfassung 715,10

Stamm 212

Steitkräfte 616,1

Stift 618,3

Stilistischer Begriff

- Mundart 704,a

- Sprache 704,a

Stilrichtung

- Hierarchische Verweisung 306a,7

Straßenname 730,1,b

Stratigraphische Einheit 209a

Streik 415a,1,b

Streitschrift 4,4

Strukturisomer

- Chemische Verbindung

- - Quasisynonym 315,4

Substantiviertes Adjektiv 305,1

Substantiviertes Verb 305,1

Superintendentur 618,1 
Symbol

- Formel 314

\section{Synonym}

s. a. Quasisynonym

- Definition 12,2,a, Anm.

\section{Synonymie-Verweisung}

- Bauwerk 730,1,a.2; 731,3.5.6

- Bearbeiter 712,3,c

- Definition 12,2,a

- Fernsehsendung 733,1.3.4

- Film 733,1.3.4

- Geographisches Schlagwort 202,2; 202b,2-5

- Historisches Einzelereignis 415a,1,a

- Homonymenzusatz 12,2,d

- Körperschaftsname 602,2; 609,2,b.5; 614,2; 615,2

- Militärische Körperschaft 616,3

- Nicht ortsgebundene Körperschaft 606,2

- Ortsgebundene Körperschaft 605,2.4

- Ortsteil 209

- Personenschlagwort 101a,3; 102,2; 106,4; 108,3

- Plural 303,5

- Präkombiniertes Schlagwort 304,5

- Pseudonym 103,2

- Psychologischer Test 714

- Rechtsnorm 715,1.3.5.8

- Regisseur

- - Film 733,3

- Sachschlagwort 307

- Sachtitel 708,9; 712,5

- Sammlung 736,5

- Sprache 703,2,c

- Titeländerung 708,8

\section{Syntaktische Indexierung 2,2,b}

Tal

- Kompositum

- - Geographisches Schlagwort 204,2

Technischer Begriff 314

Teil

- Musikalisches Werk 743a

- Werk 711

Test

s. a. Psychologischer Test

Text

- Musikalisches Werk 740,3

- Vokalwerk 743

Tiergeographische Region 201,1,c; 209a
Tiername 303,2,b; 306a,9

- Quasisynonym 315,2,b

Titel

s. a. Sachtitel

s. a. Werktitel

Titeländerung

- Fortlaufendes Sammelwerk 708,8

- Rechtsnorm 715,9

Tonart

- Musikalisches Werk 741,1,f

Tonträger

s. a. Musiktonträger

- Inhalt 737,2

Transliteration

- Nichtlateinisches Alphabet 16,3

Transposition 2,13; 15,2

UB $<$ Symbol $>$

s. Unterbegriff

\section{UDK-Code}

- Zeitcode 418,2.5; Anl. 9

Umgangssprache

- Gebräuchliche Bezeichnung 309

Universelle Dezimalklassifikation s. UDK

Universität 605,4

Unspezifischer Werktitel

- Kunstwerk 725,5

- Nicht ortsgebundenes Kunstwerk 727,2

- Ortsgebundenes Kunstwerk 730,1,b

- - Sachschlagwort 730,1,b

Unspezifisches geographisches Schlagwort

- Homonymenzusatz 203,5

\section{Unterbegriff}

- Hierarchische Verweisung 12,3

- Quasisynonym 315,2

Unterbegriff zu mehrgliedrigem Oberbegriff

- Hierarchische Verweisung 12,4

Untergeordnete Körperschaft

- Ansetzung 609

- Definition 608

- Mehrere Körperschaften 610

Unterschiedlicher Sprachgebrauch

s. a. Regional unterschiedlicher Sprachgebrauch 


\section{Untersuchungsbereich}

- Geographisches Schlagwort 201a,4

Untersuchungsmethode

- Schlagwortkette 322,5

\section{Urgeschichte}

s. Vor- und Frühgeschichte

\section{Urheberwerk}

- Ansetzung 708,5.6

- Definition 707,3

- Homonymenzusatz 710,1

- Indikator 11,2

- Sachtitel 708,6

USA

- Bundesstaat

- - Abkürzung Anl. 4

- - Homonymenzusatz 203,3,a; Anl. 4

VB $<$ Symbol $>$

s. Verwandter Begriff

VD 17

- Gattungsbegriff Anl. 10

Veraltete Bezeichnung

- Sachschlagwort 310

\section{Veranstaltung}

s. a. Parteitag

s. a. Periodische Veranstaltung

- Ansetzung 607,2-8

- Definition 607,1

- Homonymenzusatz 607,3.4

- Körperschaft 607

- Körperschaftsname 607,7

- Mehrere Orte 607,6

\section{Verb}

s. a. Substantiviertes Verb

Verbale Inhaltserschließung 2,1,a

Verfasser

- Vokalwerk 743

Verfasserwerk

- Ansetzung 708,2.3.11

- Definition 707,2

- Homonymenzusatz 710,1

- Indikator 11,2

Verfassung 717

- Homonymenzusatz 717

- Jahresangabe 17,2,ab; 717

\section{Vergleich}

- Ethnographisches Schlagwort 218,1; 219,2

- Geographisches Schlagwort 218,1; 219,2
- Personenschlagwort 115a,1; 116,3

- Schlagwortkette 13,4,b; 15,9.10,d.e

Verkehrsweg

s. Wegstrecke

Verknüpfung

s. Schlagwortkette

Verordnung

s. Rechtsnorm

Verschiedene Begriffskategorien

- Quasisynonym 315,2,c

Vertrag 716

- Homonymenzusatz 716

- Jahresangabe 17,2,ab; 716

Verwaltungseinheit

- Homonymenzusatz 203,4

Verwaltungssprache

- Regional unterschiedlicher Sprachgebrauch 311,2

- Schlagwortwahl 307,3

Verwandter Begriff

- Assoziative Verweisung 12,5

- Gegenstand 12,5,d

- Geographisches Schlagwort 202,6

- Hinweissatz

- - Verwendung 317,2,a

- Quasisynonym 315,3

- Sachschlagwort 316-317

- Schlagwortkette 316,4

- Schlagwortnormdatei 12,5,c

Verwandtschaftsbezeichnung

- Geographisches Schlagwort 202a,1

Verweisung 12

s. a. Assoziative Verweisung

s. a. Chronologische Verweisung

s. a. Hierarchische Verweisung

s. a. Synonymie-Verweisung

- Bemerkung 19,5

- Benutze Kombination 8,5

- Definition 2,11; 12,1

- Indikator 11,3

- Rechtsnorm 715,8.9

- Schlagwortnormdatei 20,9

- Schriftdenkmal 718; 719

Verwendungshinweis

- Bemerkung 19,3

Verzeichnis der Drucke des 17. Jhs. s. VD 17 
Vokalwerk

- Ansetzung 743

- Komponist 743

- Text 743

- Verfasser 743

Volk 212

- Homonymenzusatz 212b,3,a.b

Volksgruppe

- Homonymenzusatz 212b,3,c

\section{Volksstamm}

s. Stamm

Vor- und Frühgeschichte 402,1.2

- Epochenbezeichnung 408a,4

- Schlagwortkette 406,2

Vorläufige Ansetzung 9,1

Vorname 105

Vw $<$ Symbol $>$

s. Verweisung

Wahl 415a,1,b

Wandmalerei 728

Wegstrecke 201,1,d; 210

- Individualname 210,2

\section{Weibliche Form}

- Ethnographisches Schlagwort 212a,5; 212b,2,b

- Sachschlagwort 303a

- Schlagwortkette 316,4

Weltall 201,3

\section{Weltanschauung}

- Inhaltsanalyse 4,2

Weltgeschichte 402,1; 406,3

\section{Werk}

s. a. Anonymes Werk

s. a. Fortlaufendes Sammelwerk

s. a. Kunstwerk

s. a. Literarisches Werk

s. a. Mehrbändiges Werk

s. a. Urheberwerk

s. a. Verfasserwerk

s. a. Werktitel

s. a. Wissenschaftliches Werk

- Definition 707-714

- Teil 711

- Zählung 17,2,e.f.3,b; 711,2.3

Werkabschnitt 116,2,d

\section{Werkgruppe}

- Musikalisches Werk 741,1,e

- Teil 711

Werktitel 116,2,c

s. a. Sachtitel

- Indikator 11,2

- Personenschlagwort 116,2,b

- Sprachencode 18,3

Werkverzeichnis

- Musikalisches Werk 741,1,e

Wettbewerb

s. a. Sportlicher Wettbewerb

- Ansetzung 306a,2.5

Wissenschaftliches Werk

- Ansetzung 708

- Definition 707,1

Wissenschaftsfach

- Plural 303,2,f

- Sachschlagwort 317,2,b

Wörterbuch 702

s. a. Allgemeines Sprachwörterbuch

s. a. Fachlexikon

s. a. Fachliches Sprachwörterbuch

- Formschlagwort 504,2

\section{Wort}

- Linguistische Untersuchung 305,1,c

Wortart

- Sachschlagwort 305

Wortfolge

- Sachschlagwort 305,2

Zählung

- Herrscher 17,3,a; 108,7.9

- Sachschlagwort 10,5; 17,2,d; 305,1,b; 306a,3

- Werk 17,2,e.f.3,b; 711,2.3

- Zahl 17,2,d

Zahl 17

s. a. Römische Zahl

- Chemische Bezeichnung 17,2,b.3,a; 314

- Formel 17,2,b; 314

- Individualname 17,2,c.3,b

- Jahresangabe 17,2,a.d

Zahlwort 305,1,b; 314,2,d

ZC $<$ Symbol $>$

s. Zeitcode

Zeichen

s. a. Sonderzeichen

Zeichenvorrat 16,3 


\section{Zeitangabe}

s. Jahresangabe

Zeitcode 418

- Aktuelle Darstellung 418,1

- Jahresangabe 418,3

- Schlagwortnormdatei 18,4

- Titeldaten 418,4.5

- UDK-Code 418,2.5; Anl. 9

\section{Zeitraum}

- Ansetzung 403

- Personenname 101a,5

Zeitschlagwort 401-406

s. a. Epochenbezeichnung

s. a. Geschichte

s. a. Historisches Einzelereignis

s. a. Prognose

- Aktuelle Darstellung 401a,3,a

- Ansetzung 402-405

- Codierung 405a; 418

- Datensatz 405a

- Definition 401

- Ethnographisches Schlagwort 219,1

- Formschlagwort 503

- Geographisches Schlagwort 219,1

- Indikator 11,2

- Jahresangabe 17,2; 401-403

- Jugendliteratur 765,4

- Kinderliteratur 765,4

- Permutation 15,10,b; 406,6; Anl. 5

- Personenschlagwort 116,2,d; 117,5

- Prognose 401a,4

- Reihenfolge 15,7.10,b

- Schlagwortkette 406

- Schöne Literatur 762,4

- Verwendung 401a

\section{Zeitschrift}

- Stücktitel 3,5

\section{Zeitschriftenartige Reihe}

- Stücktitel 3,5

Zeitung

- Stücktitel 3,5

\section{Zerlegungskontrolle}

s. Begriffszerlegung

\section{Zettelkatalog 1,5}

\section{Zielgruppe}

- Inhaltsanalyse 4,3

\section{Ziffer}

s. Zahl

\section{Zitiertitel}

- Einheitssachtitel 709,2

- Musikalisches Werk 742

- Rechtsnorm 715,1.3

Zusatz

- Ort 202b 
